\title{
Technical Reference Book For The Energy Economic Data Base Program EEDB
}

Published: December 1986
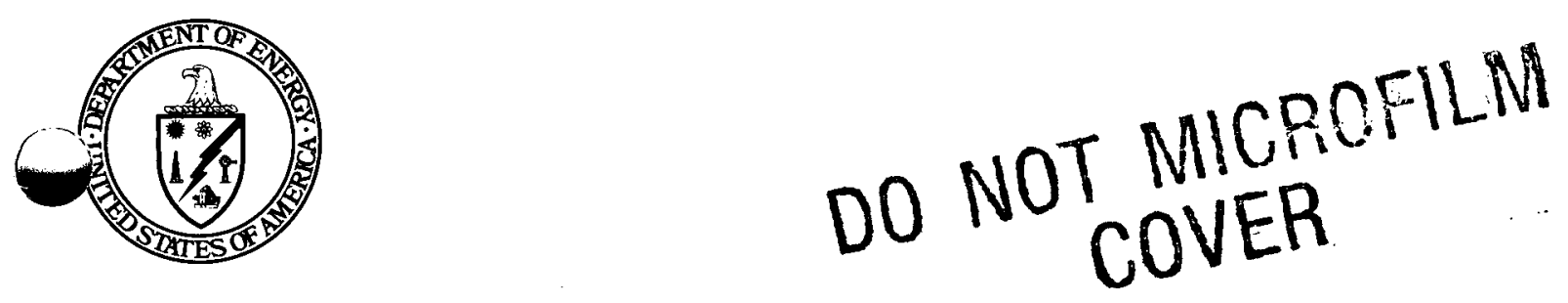

Prepared for:

U.S. Department of Energy

Assistant Secretary for Nuclear Energy

Office of Program Support

Plans and Evaluation Division 


\section{DISCLAIMER}

This report was prepared as an account of work sponsored by an agency of the United States Government. Neither the United States Government nor any agency Thereof, nor any of their employees, makes any warranty, express or implied, or assumes any legal liability or responsibility for the accuracy, completeness, or usefulness of any information, apparatus, product, or process disclosed, or represents that its use would not infringe privately owned rights. Reference herein to any specific commercial product, process, or service by trade name, trademark, manufacturer, or otherwise does not necessarily constitute or imply its endorsement, recommendation, or favoring by the United States Government or any agency thereof. The views and opinions of authors expressed herein do not necessarily state or reflect those of the United States Government or any agency thereof. 


\section{DISCLAIMER}

Portions of this document may be illegible in electronic image products. Images are produced from the best available original document. 


\section{DO NOT MICROFILMT COVER}

This report has been reproduced directly from the best available copy.

Available from the National Technical Information Service, U. S. Department of Commerce, Springfield, Virginia 22161.

\section{Price: Printed Copy A17}

Microfiche A01

Codes are used for pricing all publications. The code is determined by the number of pages in the publication. Information pertaining to the pricing codes can be found in the current issues of the following publications, which are generally available in most libraries: Energy Research Abstracts, (ERA): Government Reports Announcements and Index (GRA and 1); Scientific and Technical Abstract Reports (STAR); and publication, NTIS-PR-360 available from (NTIS) at the above address. 


\section{Technical Reference Book For The Energy Economic Data Base Program EEDB}

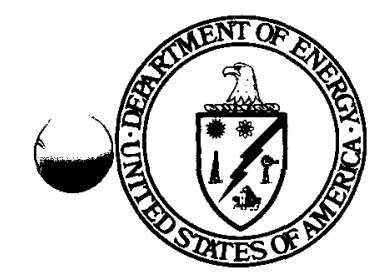

\section{DISCLAIMER}

This report was prepared as an account of work sponsored by an agency of the United States Government. Neither the United States Government nor any agency thereof, nor any of their employees, makes any warranty, express or implied, or assumes any legal liability or responsibility for the accuracy, completeness, or usefulness of any information, apparatus, product, or process disclosed, or represents that its use would not infringe privately owned rights. Reference herein to any specific commercial product, process, or service by trade name, trademark, manufacturer, or otherwise does not necessarily constitute or imply its endorsement, recommendation, or favoring by the United States Government or any agency thereof. The views and opinions of authors expressed herein do not necessarily state or reflect those of the United States Government or any agency thereof.

Prepared for:

U.S. Department of Energy

Assistant Secretary for Nuclear Energy

Office of Program Support

Plans and Evaluation Division

Washington, D.C. 20545

Prepared by:

United Engineers \& Constructors Inc.

Philadelphia, PA 19101

Under the Direction of

Oak Ridge National Laboratory

Under Contract No.: DE-AC05-840R21400

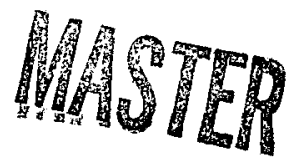


TABLE OF CONTENTS

\section{ENERGY ECONOMIC DATA BASE (EEDB) PROGRAM \\ TECHNICAL REFERENCE BOOK \\ PHASE VIII UPDATE (1986)}

Legal Notice

List of Principal Contributors

1

List of Tables

List of Figures

11

111

iv

$\underline{\text { Page }}$

1-1

1-1

$1-1$

1-3

1.3 Organization of the Technical Reference Book

$2-1$

$2-1$

$2-4$

$2-8$

$3-1$

System Design Description for the 1144 MWe

Pressurized Water Reactor Nuclear Power Generating

Station (EEDB Program Technical Data Mode1 A3 - PWR)

3.1 Introduction

3.2 Design Criteria and Key Parameters

$3-1$

$3 \rightarrow 9$

$3-105$

3.4 Engineering Drawings

3.5 Design/Construction Schedule

\section{0}

System Design Description for the 1311 MWe

4-1

Large Scale Prototype Breeder Nuclear Power

Generating Station (EEDB Program Technical Data Model A5 - LSPB)

4.1 Introduction

4.2 Design Criteria and Key Parameters

4-1

4.3 System Design Descriptions

4.4 Engineering Drawings

4.5 Design/Construction Schedule 
TABLE OF CONTENTS (cont' $d$ )

\author{
ENERGY ECONOMIC DATA BASE (EEDB) PROGRAM \\ TECHNICAL REFERENCE BOOK \\ PHASE VIII UPDATE (1986)
}

Section

Title

Page

5.0

System Design Description for the 488 MWe High

Sulfur Coal Fossil Power Generating Station (EEDB

Program Technical Data Model C5 - HS5

5.1 Introduction 5-1

5.2 Design Criteria and Key Parameters. 5-1

5.3 System Design Descriptions $5-8$

5.4 Engineering Drawings 5-88

5.5 Design/Construction Schedule 5-98

6.0 References, Definitions and Glossary 6-1

6.1 References and Bibliography 6-1

6.2 Definitions

6.3 Glossary of Acronyms and Abbreviations 6-6

\title{
Appendices
}

A-1 Description of Standard Hypothetical A-1-1

Middletown Site for Nuclear Power Plants

Al.1 General A-1-2

Al.2 Topography and General Site Characteristics A-1-2

Al.3 Site Access A-1-2

Al.4 Population Denstty and Land Use A-1-3

A1.5 Nearby Facilities A $-1-3$

Al.6 Meteorology and C1imatology A-1-3

A1.7 Hydrology A $-1-5$

A1.8 Geology and Seismology A-1-6

Al.9 Sewage and Radioactive Waste Disposal A-1-6

A-2 Description of Standard Hypothetical A-2-1

Middletown Site for Coal-Fired Power Plants

A2.1 General A-2-2

A2.2 Topography and General Site Characteristics A-2-2

A2.3 Site Access A-2-2

A2.4 Population Density and Land Use A-2-3

A2.5 Nearby Facilities A-2-3

A2.6 Meteorology and C1imatology A-2-3

A2.7 Hydrology A-2-5

A2.8 Geology and Seismology A-2 -6

A2.9 Sewage and Liquid Effluents A-2-6 


\author{
LEGAL NOTICE \\ ENERGY ECONOMIC DATA BASE (EEDB) PROGRAM \\ TECHNICAL REFERENCE BOOK \\ PHASE VIII UPDATE (1986)
}

This report was prepared under the funding of the U.S. Department of Energy (Oak Ridge National Laboratory) Subcontract No. 43X-86004V. Neither the United States Government or any agency thereof, nor any person acting on behalf of the United States Government:

a. makes any warranty or representation, expressed or implied with respect to the accuracy, completeness, or usefulness of the information contained in this report, or that the use of any information, apparatus, method or process disclosed in this report may not infringe privately owned rights; or

b. assumes any liabilities with respect to the use of, or for damage resulting from the use of, any information, apparatus, method, or process disclosed in this report.

As used in the above "person acting on behalf of the United States Government" Includes any employee or contractor thereof or any employee of such contractor to the extent that such employee prepares, disseminates, or provides access to, any information pursuant to his employment or contract with the United States Government, or his employment with such contractor. 


\section{ENERGY ECONOMIC DATA BASE (EEDB) PROGRAM \\ TECHNICAL REFERENCE BOOK \\ PHASE VIII UPDATE (1986)}

J. H. Crowley, Manager

Advanced Engineering Department

*R. E. Allen, Program Project Manager

Energy Economic Data Base Program

*R. G. Benedict
M. S. Cooper
E. B. Donner
W. E. Dahme

R. J. Gramatges

A. J. Karalis

R. T. Lowthert

*B. J. Menaker

M. D. Miller

*H. E. Painter

C. Murawczyk

N. J. Russo

J. F. Smith

* Principal Authors 
ENERGY ECONOMIC DATA BASE (EEDB) PROGRAM TECHNICAL REFERENCE BOOK

PHASE VIII UPDATE (1986)

Table

Number

Title

Page

$1-1$

Technical and Capital Cost Data Models

$1-4$

Base Data Studies and Reports

Technical Data Model Update History

$1-6$

$1-3$

Nuclear and Comparison Power Generating Stations

$1-9$

for the Phase VIII Update (1986)

$3-1$

Pressurized Water Reactor

$3-2$

Nuclear Power Generating Station (PWR)

Technical Data Model Base Parameter Summary

3-2

1144 MWe Pressurized Water Reactor

$3-82$

Nuclear Power Generating Station (PWR)

Design Ambient. Conditions for Electric Equipment

$4-1$

Large Scale Prototype Breeder

$4-3$

Nuclear Power Generating Station (LSPB)

Technical Data Model Base Parameter Summary

4-2

1311 MWe Large Scale Prototype Breeder

$4-72$

Nuclear Power Generating Station (LSPB)

Design Ambient Conditions for Electric Equipment

$5-1$

488 MWe High Sulfur Coal

$5-2$

Fossil Power Generating Station (HS5)

Comparison Plant Technical Data Model

Base Parameter Summary

5-2 488 MWe High Sulfur Coal

$5-68$

Fossil Power Generating Station (HS5)

Design Ambient Conditions for Electric Equipment

$5-3$

488 MWe High Sulfur Coal

5-97

Fossil Power Generating Station (HS5)

Flue Gas Desulfurization System Flows

Al-1

Accident Meteorology for a Ground Level Release

$A-1-7$

A1-2

Accident Meteorology for an Elevated Release

$A-1-8$ 


\section{ENERGY ECONOMIC DATA BASE (EEDB) PROGRAM \\ TECHNICAL REFERENCE BOOK \\ PHASE VIII UPDATE (1986)}

Figure

Number

Title

Page

3.1 Plot Plan - 1144 MWe PWR NPGS -

$3-106$

Middletown Hypothetical Site

3.2 General Arrangement -

Plan at E1. 19'-0" (Ground F1.) -

1144 MWe PWR NPGS -

Middletown Hypothetical site

3.3 General Arrangement -

Plan at E1. 73'-0" (Oper. Fl.) -

1144 MWe PWR NPGS -

Middletown Hypothetical Site

3.4 General Arrangement -

Sections "A-A" and "B-B" Elevations -

$3-109$

1144 MWe PWR NPGS -

Middletown Hypothetical Site

3.5 Steam Heat Balance Diagram -

1144 MWe PWR NPGS -

Middletown Hypothetical Site

3.6

Single Unit 1144 MWe Pressurized Water Reactor

Preconstruction Permit Licensing Process Flow Diagram

3.7

Single Unit 1144 MWe Pressurized Water Reactor

Nuclear Power Generating Station (PWR) -

Licensing Milestone Schedule

3.8 Single Unit 1144 MWe Pressurized Water Reactor

Nuclear Power Generating Station (PWR) -

Engineering \& Construction Milestone Schedule

4.1 Plot Plan - 1311 MWe LSPB NPGS -

Middletown Hypothetical Site

4.2 General Arrangement -

Plan at E1. 19'-0" (Ground F1.) -

1311 MWe LSPB NPGS -

Middletown Hypothetical Site 
ENERGY ECONOMIC DATA BASE (EEDB) PROGRAM TECHNICAL REFERENCE BOOK

PHASE VIII UPDATE (1986)

Figure

Number

Title

Page

4.3

General Arrangement -

Plan at E1. 88'-9" (Oper. F1.) -

1311 MWe LSPB NPGS -

Middletown Hypothetical Site

4.4

General Arrangement -

Section "A-A" Elevation -

1311 MWe LSPB NPGS -

Middletown Hypothetical Site

4.5

Steam Heat Balance Diagram -

4-101

1311 MWe LSPB NPGS -

Middletown Hypothetical Site

4.6

Single Unit 1311 MWe

4-107

Large Scale Prototype Breeder

Nuclear Power Generating Station (LSPB)

Preconstruction Permit Licensing

Flow Diagram

4.7

Single Unit 1311 MWe

Large Scale Prototype Breeder

Nuclear Power Generating Station (LSPB)

Licensing Milestone Schedule

4.8

Single Unit 1311 MWe

$4-111$

Large Scale Prototype Breeder

Nuclear Power Generating Station (LSPB)

Engineering and Construction Milestone

Schedule

5.1

Plot Plan - 488 MWe HSC FPGS -

Middletown Hypothetical site

5.2

General Arrangement -

Plan at E1. 19'-0" (Ground F1.) -

Boiler \& Turbine Area -

488 MWe HSC FPGS -

Middletown Hypothetical Site 
ENERGY ECONOMIC DATA BASE (EEDB) PROGRAM

TECHNICAL REFERENCE BOOK

PHASE VIII UPDATE (1986)

Figure Number

$5.4 \quad$ General Arrangement -

Section "A-A" Elevation 488 MWe HSC FPGS -

Middletown Hypothetical Site

5.5 Steam Heat Balance Diagram

488 MWe HSC FPGS -

Middletown Hypothetical site

5.6 Flow Diagram - Balanced Draft System 488 MWe HSC FPGS -

Middletown Hypothetical Site

Flow Diagram - Coal Handling System -

488 MWe HSC FPGS -

Middletown Hypothetical Site

5.8 Flow Diagram - Flue Gas Desulfurization

System - 488 MWe HSC FPGS -

Middletown Hypothetical Site

States with Power Plant Site Certification Authorities and/or Those Requiring a State EIS/EA

488 MWe High Sulfur Coal-Fired

5.11488 MWe High Sulfur Coa1-Fired

Power Generating Station (HS5)

Licensing Activity and Chronology Diagram

Power Plant Permitting Stage

(Group 1 and Group 2 States) 
LIST OF FIGURES (cont'd)

ENERGY ECONOMIC DATA BASE (EEDB) PROGRAM

TECHNICAL REFERENCE BOOK

PHASE VIII UPDATE (1986)

Figure

Number

Title

Page

5.12

Single Un1t 488 MWe High Sulfur

$5-105$

Coal-Fired Power Generating Station (HS5)

Licensing Milestone Schedule

5.13

Single Unit 488 MWe High Sulfur

$5-108$

Coal-Fired Power Generating Station (HS5)

Engineering \& Construction Milestone Schedule

Al.1

Temperature Duration Curves; Middletown, U.S.A.

$A-1-9$

A2.1

Temperature Duration Curves; Middletown, U.S.A.

$A-2-7$ 


\section{SECTION 1}

\subsection{INTRODUCTION}

The Energy Economic Data Base (EEDB) Program is sponsored by the U.S. Department of Energy (DOE) for the purpose of developing current technical and cost information for nuclear and comparison electric power generating stations. The objective, history, structure and usage of the program are discussed in the EEDB Program Reference Book. ${ }^{1}$ The data base was first assembled in 1978 from an initial update of the technical/cost data models developed for the predecessor studies 1isted in Table 1-1. Eight updates of the data base have been performed between 1978 and 1986, in which various technical/cost data models have been updated, added, superceded or discontinued. Table 1-2 provides a summary of the evolution of the EEDB Program.

Current technical and cost information are obtained through periodic updates of the technical details and associated costs of the data models contained in the EEDB. The EEDB Phase VIII Update (1986) of this Technical Reference Book describes the technical detail that supports the updated cost estimates given in the EEDB Program Phase VIII Update (1986) Report.2

\subsection{TECHNICAL DATA MODELS}

The EEDB contains a variety of nuclear and coal-fired power plant technical data models, as described in the Program Reference Book. 1 Each of the technical data models is a complete and detailed conceptual design for a single unit, commercial, steam electric, power generating station located on a standard hypothetical "Middletown" site. A complete description of this hypothetical site is given in Appendices $\mathrm{A}-1$ and $\mathrm{A}-2$ for the nuclear and comparison power plants respectively.

During the Eighth Update (1986), the PWR, LSPB and HS5 technical and cost data models tabulated in Table 1-3 were updated. In addition, the LSPB cost data model level of detail was expanded. The PWR and HS5 data models are supported by the Base Data Studies tabulated in Table 1-1. The LSPB data model is supported by information developed by the Consolidated Management of fice for the LMFBR of the Electric Power Research Institute (EPRI/CoMO) for the Department of Energy. 3

This Eighth Update Technical Reference Book contains the results of the PWR, LSPB and HS5 effort described above, as it has been updated and expanded from the Seventh Update Technical Reference Book. 4

\subsection{DATA BASE REPORTS}

For the Eighth Update (1986), the EEDB Program Report is divided into two parts. 


\title{
This Volume: $\quad$ Energy Economic Data Base Program Technical Reference Book Phase VIII Update (1986) \\ Companion Volume: Energy Economic Data Base Program Phase VIII Update (1986) Report
}

These volumes are supplemented and amplified by three volumes prepared for previous updates.

\author{
Energy Economic Data Base Program \\ Reference Book ${ }^{1}$ (Phase V Update) \\ Energy Economic Data Base Program \\ Phase VII Update (1984) Report 5 \\ Energy Economic Data Base Program \\ Phase VI Update (1983) Report 6
}

The purpose of this Technical Reference Book is to provide the current technical design bases for each of the technical data models updated in the Eighth Update (1986). It contains a set of detailed system design descriptions for these technical data models, which are supplemented with engineering drawings and design/construction milestone schedules. The system design descriptions reflect regulatory and industry practice and experience for nuclear and coal-fired power generating stations that are under construction on January 1, 1986. It is intended that the Technical Reference Book be periodically updated. Significant technical changes will be recorded and described in the Technical Reference Book updates or in those Update Reports published in the intervening years between Technical Reference Book revisions.

The purpose of the Program Reference Book (Phase V Update) and the Phase VI (1983) and Phase VII (1984) Update Reports is to provide the historical development of the EEDB through the Seventh Update. These documents contain important descriptive and tutorial information concerning the structure and use of the EEDB. They also contain reports of work done to support various aspects of the first seven updates, ${ }^{5-1}$ together with significant reference data developed during those updates.

The purpose of the Eighth Update Report is to present the results of the current update, including a detalled description of technical and cost changes made to the Seventh Update. The succeeding Update Reports, for a particular technical reference date, together with the Program Reference Book and the Technical Reference Book, document the entire data base through the reference date of the last Update Report. It is intended that a new Update Report be published for each update, using a standard format for easy cross referencing. 


\subsection{ORGANIZATION OF THE TECHNICAL REFERENCE BOOK}

This Technical Reference Book contains six sections and two appendices. Sections 1 and 2 provide introductory and explanatory information on the use of the Technical Reference Book.

Sections 3 through 5 present the system design descriptions and engineering drawings for the technical data models 1isted in Table 1-3. Each system design description includes a key parameter tabulation, plot plan, grade floor plan, operating floor plan, cross-section, heat balance diagram and milestone schedule.

Section 6 provides a list of references cited in the Technical Reference Book. This section also contains a glossary of acronyms and abbreviations repeated for convenience from the current Update Report.

Appendices A-1 and A-2 provide descriptions of the hypothetical "Middletown" site for the nuclear and comparison power generating stations. 
TABLE $1-1$

ENERGY ECONOMIC DATA BASE

TECHNICAL AND CAPITAL COST DATA MODELS BASE DATA STUDIES AND REPORTS NUCLEAR POWER GENERATING STATIONS

EEDB Data Mode1 Number Designator

A1

BWR

$\stackrel{\mathfrak{1}}{\mathfrak{L}}$

HTGR-SC

A3

PWR

A4

PHWR

A5

LMFBR

B1

HTGR-PS

Base Data Study or Report

Commercial Electric Power Cost Studies - Capital Cost Boiling Water Reactor (BWR) Plant (NUREG-0242, COO-2477-6) 12 a

The HTGR (High Temperature Gas Cooled Reactor-Steam Cycle) for Electric Power Generation - Design and Cost Evaluation

(Gas Cooled Reactor Associates - GCRA/AE/78-1) 13

Commercial Electric Power Cost Studies - Capital Cost Pressurized Water Reactor (PWR) Plant

(NUREG-0241, COO-2477-5) $12 \mathrm{~b}$

Conceptual Design of a Large HWR (Pressurized Heavy Water Reactor) for U.S. Siting

(Combustion Engineering, Inc. - CEND-379) 14

NSSS Capital Costs for a Mature LMFBR (Liquid Metal Fast Breeder Reactor) Industry and Addendum

(Combustion Engineering, Inc. - CE-FBR-78-532 \& CE-ADD-80-310) 15,16

1170 MWt HTGR (High Temperature Gas Cooled Reactor - Process Steam) Steamer Cogeneration Plant - Design and Cost Study (DOE/ET-34222-T1) 17 
TABLE 1-1

ENERGY ECONOMIC DATA BASE

TECHNICAL AND CAPITAL COST DATA MODELS BASE DATA STUDIES AND REPORTS COMPARISON POWER GENERATING STATIONS

EEDB Data Mode1

Number Designator

C1

$\mathrm{C} 2$

芯

Base Data Study or Report

Commercial Electric Power Cost Studies - Capital Cost -
High and Low Sulfur Coal Plants - 1200 MWe (Nominal)

(NUREG-0243, COO-2477-7) $12 \mathrm{c}$

Commercial Electric Power Cost Studies - Capital Cost -

Low and High Sulfur Coal Plants - 800 MWe (Nominal)

(NUREG-0244, COO-2477-8) $12 \mathrm{~d}$

$\begin{array}{ll}\text { C3 } & \text { LS12 } \\ \text { C4 } & \text { LS8 } \\ \text { D1 } & \text { CGCC } \\ \text { D2 } & \text { LS5/HS5 } \\ & \\ \text { D3 } & \text { LS5-D/H/ } \\ & \text { HS5-D } / H\end{array}$

Same as EEDB Data Model C1

Same as EEDB Data Mode1 C2

Study of Electric Plant Applications for Low Btu Gasification of Coal for Electric Power Generation (FE-1545-TK59) 18

An Assessment of New Coal-Fueled (Low Sulfur Coal P1ant), Cogeneration Power Plants for Electricity Production and Hot Water District Heating (ORNL/TM-6830/P8) 19

$\mathrm{HS} 5-\mathrm{D} / \mathrm{H}$

Same as EEDB Data Mode1 D2

HS = High Sulfur Coal 
TABLE $1-2$

ENERGY ECONOMIC DATA BASE

TECHNICAL DATA MODEL UPDATE HISTORY

NUCLEAR POWER GENERATING STATIONS

Plant Type

Boiling Water Reactor Plant (BWR)

High Temperature Gas Cooled Reactor Plant (HTGR)

High Temperature Gas Cooled Reactor Plant ๖

Pressurized Water Reactor Plant (PWR)

Pressurized Heavy Water Reactor Plant (PHWR)

Pressurized Heavy Water Reactor Plant (PHWR)

Gas Cooled Fast Reactor Plant (GCFR)(e)

High Temperature Gas Cooled Reactor Plant - Process Steam (HTGR-PS)

Liquid Metal Fast Breeder Reactor Plant (LMFBR)

Large Scale Prototype Breeder Plant (LSPB)

\begin{tabular}{|c|c|c|c|c|c|c|c|c|}
\hline \multirow[b]{2}{*}{$\begin{array}{c}\text { Net } \\
\text { Capacity } \\
\text { (MWe) }\end{array}$} & \multicolumn{8}{|c|}{ EEDB Data Model (a) Number } \\
\hline & $\begin{array}{l}\text { Initial } \\
\text { Update } \\
\text { (1978) } \\
\end{array}$ & $\begin{array}{c}\text { 2nd } \\
\text { Update } \\
(1979) \\
\end{array}$ & $\begin{array}{c}\text { 3rd } \\
\text { Update } \\
(1980) \\
\end{array}$ & $\begin{array}{c}4 \text { th } \\
\text { Update } \\
(1981) \\
\end{array}$ & $\begin{array}{l}5 \text { th } \\
\text { Update } \\
(1982) \\
\end{array}$ & $\begin{array}{c}6 \text { th } \\
\text { Update } \\
(1983) \\
\end{array}$ & $\begin{array}{c}7 \text { th } \\
\text { Update } \\
\text { (1984) } \\
\end{array}$ & $\begin{array}{c}8 \mathrm{th} \\
\text { Update } \\
\text { (1986) } \\
\end{array}$ \\
\hline 1190 & Al & Al & Al & Al & A1 & Al & -- & -- \\
\hline 1330 & A2 & A2 & -- & -- & -- & -- & -- & -- \\
\hline 858 & -- & -- & $\mathrm{A} 2(\mathrm{~b})$ & $\mathrm{A} 2$ & $\mathrm{~A} 2(\mathrm{c})$ & -- & -- & -- \\
\hline 1139 & A3 & A3 & A3 & A3 & A3 & A3 & $\mathrm{A} 3$ & -- \\
\hline 1144 & - & - & - & - & - & -- & - & $A 3(d)$ \\
\hline 1162 & A4 & A4 & - & -- & -- & -- & -- & - \\
\hline 1260 & - & -- & $\mathrm{A} 4(\mathrm{~b})$ & A4 & $\mathrm{A} 4(\mathrm{c})$ & - & - & -- \\
\hline 917 & B1 & B1 & -- & -- & -- & - & -- & -- \\
\hline 150 & - & -- & $\mathrm{B} 1(\mathrm{~b})$ & BI & B1 & -- & -- & - \\
\hline 1390 & B2 & - & - & -- & -- & -- & -- & -- \\
\hline 1457 & - & $A 5(b)$ & A5 & A5 & A5 & A5 & -- & $-\rightarrow$ \\
\hline 1320 & -- & -- & $\rightarrow$ & -- & - & - & B3 (b) & - \\
\hline 1311 & -- & - & -- & -- & - & - & -- & $A 5(d)(f)$ \\
\hline
\end{tabular}

For notes see Sheet 3 of 3 
TABLE $\quad 1-2$

ENERGY ECONOMIC DATA BASE

TECHNICAL DATA MODEL UPDATE HISTORY COMPARISON POWER GENERATING STATIONS

\begin{tabular}{|c|c|c|c|c|c|c|c|c|c|}
\hline \multirow[b]{2}{*}{ Plant Type } & \multirow[b]{2}{*}{$\begin{array}{c}\text { Net } \\
\text { Capacity } \\
\text { (MWe) } \\
\end{array}$} & \multicolumn{8}{|c|}{ EEDB Data Model (a) Number } \\
\hline & & $\begin{array}{l}\text { Initial } \\
\text { Update } \\
\text { (1978) } \\
\end{array}$ & $\begin{array}{c}\text { 2nd } \\
\text { Update } \\
\text { (1979) } \\
\end{array}$ & $\begin{array}{c}\text { 3rd } \\
\text { Update } \\
(1980) \\
\end{array}$ & $\begin{array}{c}4 \text { th } \\
\text { Update } \\
(1981) \\
\end{array}$ & $\begin{array}{c}5 \text { th } \\
\text { Update } \\
(1982) \\
\end{array}$ & $\begin{array}{c}6 \mathrm{th} \\
\text { Update } \\
(1983) \\
\end{array}$ & $\begin{array}{l}7 \text { th } \\
\text { Update } \\
\text { (1984) } \\
\end{array}$ & $\begin{array}{c}8 \mathrm{th} \\
\text { Update } \\
\text { (1986) } \\
\end{array}$ \\
\hline Comparison High Sulfur Coal Plant (HS12) & 1232 & $\mathrm{Cl}$ & $\mathrm{Cl}$ & C1 & -- & -- & -- & -- & -- \\
\hline & 1240 & -- & -- & -- & $\mathrm{Cl}$ & -- & -- & -- & -- \\
\hline Comparison High Sulfur Coal Plant (HS8) & 795 & $\mathrm{C} 2$ & $\mathrm{C} 2$ & $\mathrm{C} 2$ & C2 & $\mathrm{C} 2$ & -- & -- & -- \\
\hline 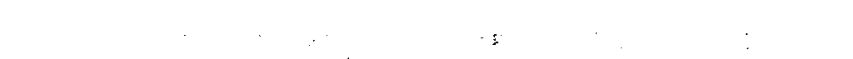 & 791 & -- & -- & -- & -- & -- & $\mathrm{C} 2(\mathrm{~b})$ & -- & -- \\
\hline Comparison Low Sulfur Coal Plant (LS12) & 1243 & C3 & C3 & $\mathrm{C} 3(\mathrm{~g})$ & -- & -- & -- & -- & -- \\
\hline$\cdot \cdot+\cdots$ & 1244 & -- & -- & -- & C3(b) & -- & -- & -- & -- \\
\hline Comparison Low Sulfur Coal Plant (LS8) & 802 & C4 & C4 & $\mathrm{C} 4(\mathrm{~g})$ & -- & -- & -- & -- & -- \\
\hline & 795 & -- & -- & -- & $\mathrm{C} 4(\mathrm{~b})$ & -- & -- & -- & -- \\
\hline $\begin{array}{l}\text { Comparison Coal Gasification Combined } \\
\text { Cycle Plant (CGCC) }\end{array}$ & 630 & D1 & D1 & D1 & D1 & - & -- & -- & -- \\
\hline Comparison Low Sulfur Coal Plant (LS5) & 480 & -- & -- & -- & D2 & -- & -- & -- & -- \\
\hline Comparison High Sulfur Coal Plant (HS5) & 480 & -- & -- & - & -- & $\mathrm{D} 2(\mathrm{~b})$ & -- & -- & -- \\
\hline & 486 & - & -- & -- & -- & -- & $\mathrm{C5}(\mathrm{b})$ & C5 & -- \\
\hline & 488 & -- & -- & -- & -- & -- & -- & -- & $\operatorname{c5}(\mathrm{d})$ \\
\hline $\begin{array}{l}\text { Comparison Low Sulfur District Heating } \\
\text { Cogeneration Coal Plant (LS5-D/H) }\end{array}$ & 360 & -- & -- & -- & D3 & -- & -- & -- & -- \\
\hline $\begin{array}{l}\text { Comparison High Sulfur District Heating } \\
\text { Cogeneration Coal Plant (HS5-D/H) }\end{array}$ & 360 & -- & -- & -- & -- & D3 (b) & -- & -- & -- \\
\hline
\end{tabular}


TABLE $1-2$

ENERGY ECONOMIC DATA BASE

TECHNICAL DATA MODEL UPDATE HISTORY

NOTES

\footnotetext{
(a) $\quad A=$ Detailed Data Model, Detailed Level Update

B = Summary Data Mode1, Summary Level Update

$C=$ Detailed Data Model, Detailed Level Update

D = Summary Data Model, Summary Level Update
}

(b) Indicates replacement of preceding data model

(c) Summary Level Update of Detailed Data Model

(d) Mechanical draft cooling towers replaced with natural draft cooling towers causing capacity change

(e) GCFR data model was deleted from the data base in the Third Update (1980)

(f) Data model refined to fully conform to EEDB ground rules and site conditions

(g) Added flue gas cleaning to technical data model 
TABLE $1-3$

ENERGY ECONOMIC DATA BASE

NUCLEAR AND COMPARISON POWER GENERATING STATIONS

FOR THE PHASE VIII UPDATE (1986)

EEDB Data Model

Number Designator

A3

PWR

A5

LSPB

HS5
Plant Type

Pressurized Water React or Plant

Large Scale Prototype Breeder Plant

Comparison High Sulfur Coal Plant
Net

Capacity

1144 MWe

1311 MWe

488 MWe 


\section{SECTION 2}

\subsection{RULES AND PROCEDURES}

The EEDB has been designed so that technical and cost comparisons of selected power generation alternatives may be made on a comprehensive and consistent basis. A standardized level of technical detail and a uniform cost/technical accounting system have been developed to assure consistency and comparability among the various data models, as well as visibility of their technical design features components.

Bottom line cost comparisons are based on the detailed and unfform system/ equipment lists that have been developed for each technical data model. These lists are based on specific structure/system design descriptions, supporting engineering drawings and standardized milestone schedules that describe a technical data model's conceptual design. Quantities of equipment and commodities, their installation manhours and related engineering and fleld supervision manhours are developed from these data for each update of the technical data models. The bottom line costs are calculated by applying current unit costs, commodity and equipment installation rates and labor rates to these quantities.

In order to assure consistency and accountability of cost estimates, certain rules and procedures have been followed to control the preparation and updating of the technical data models' structure/system design descriptions.

\subsection{ASSUMPTIONS AND GROUND RULES}

The pressurized water reactor nuclear power generating station (PWR) and the 488 MWe high sulfur coal fossil power generating station (HS5) are considered to be the lead technical data models for nuclear and comparison power plants respectively. This ground rule has been adopted for two reasons: 1) a major use of the EEDB is to provide current cost input for nuclear/coal comparisons; and 2) information on current design practice and actual field experience is most readily obtainable for the types of units represented by these data models. Complete structure/system design descriptions are given for the PWR, LSPB and HSS technical data models in Sections 3,4 and 5 respectively of this Technical Reference Book.

When the terms safety-related and non-safety-related are used in the structure/system design descriptions in this Technical Reference Book, they refer to the function of the structure, system or equipment relative to safety. For example, the PWR reactor coolant pump is placed in the non-safety-related category, even though the pump casing is a part of the primary pressure boundary. The function of this pump is to circulate reactor coolant between the core and the steam generator during normal operation or during decay heat removal if it is available. These are not safety functions; consequently, the pump is not designed to fulfill these functions during design basis events. However, in order to fulf $\$ 11$ its function, the pump must be provided with a 
safety-class casing in order to maintain the integrity of the primary pressure boundary, because the function of the pressure boundary is safetyrelated.

General assumptions and ground rules for the structure/system design descriptions have been established as follows:

a. The conceptual designs are based upon a full complement of licensing requirements, design criteria and construction practice current for units under construction on January $1,1986$.

b. Safety classifications, seismic categories and design codes promulgated in national standards are utilized in the design of structures and systems and in the application and selection of materials and equipment.

c. Technical data models are developed for a complete single unit station.

d. The design and useful lives of the nuclear and fossil power plants are as follows:

$\frac{\text { Power Plant Life (Years) }}{\text { Nuclear }}$

$\begin{array}{lll}\text { Design Life } & 40 & 30 \\ \text { Useful Life } & 30 & 30\end{array}$

e. Each technical data model conceptual design is constrained to accommodate the geological, meteorological and labor productivity parameters of the hypothetical "Middletown" site.

f. Where design objectives nay be met through several equivalent application approaches, a common approach is selected for use in each technical data model, unless intrinsic concept differences dictate a different approach for one of the data models. Some deviations from this approach exist with the LSPB data model, because it is adapted from the EPRI/CoMo design originally developed to different ground rules.

g. Common structural design features are:

1) Containment buildings are of the reinforced concrete, steel plate lined type, or of the free standing steel containment type with reinforced concrete shield building. 
2) Boiler houses are completely enclosed.

3) Turbine buildings are completely enclosed and house isolated "high-tuned" reinforced concrete turbine pedestals.

4) Selsmic Category I buildings and structures have reinforced concrete mats founded on rock, and reinforced concrete walls, floor slabs and roofs with insulated or uninsulated built-up roofing.

5) Non-Seismic Category I buildings and structures have reinforced concrete spread footings or reinforced concrete footings founded on rock, and steel framed superstructures with insulated or uninsulated siding (exterior walls), metal partitions or masonry walls (interior walls) and insulated or uninsulated built-up roofing.

6) Intermediate floor slabs are cast-in-place concrete over metal deck supported on steel framing.

h. Common mechanical design features are:

1) Turbine-generator units are tandem-compound (preferred) or cross-compound machines of domestic (preferred) or foreign manufacture.

2) Draft systems, coal handling systems and flue gas desulfurization systems for the coal-fired power plants are simflar in design, except for capacity requirements.

3) The design of the main heat rejection systems are based upon the use of natural draft wet cooling towers for data models updated in the Phase VIII and later updates; earlier data models are based on the use of mechanical draft wet cooling towers.

4) The nuclear power plant ultimate heat sink designs are based on the use of mechanical draft wet cooling towers or afr blast heat exchangers.

i. Common electrical/instrumentation-and-control design features are:

1) The switchyard and the generator step-up transformer are not included in the system design descriptions, because of wide variations in preference, practice and grid interconnection requirements. (The switchyard is 
shown on the plot plans and milestone schedules for completeness.)

2) Independent grid interconnections are provided at different voltage levels as follows:

\begin{tabular}{l} 
Number of \\
Grid Interconnections \\
\hline $500 \mathrm{kV} \quad 230 \mathrm{kV} \quad 115 \mathrm{kV}$
\end{tabular}

Units Larger than 500 MWe 2

Units $500 \mathrm{MWe}$ and Smaller

0 $2 \quad 2$

(The higher voltage level is for the connection to the generator step-up transformer. The lower voltage level is for the connection to the reserve auxiliary transformer.)

3) Diese1-generator units are utilized for standby (nuclear power plants) or emergency (fossil power plants) power supplies. The LSPB data model uses gas turbine generator units per the original EPRI/CoMO design.

4) All field wiring to the control room is brought directly to the panels in the control room.

5) Computers are utilized for plant surveillance (nuclear power plants), or for plant surveillance and control (fossil power plants).

j. No allowance for spare parts or replacement equipment is made in quantities of material and equipment.

\subsection{DESIGN AND REGULATORY CRITERIA}

Unique concept design criteria are given in the preamble to each of the structure/system design descriptions. General design and regulatory criteria that are applicable to all concepts are given in this section.

\subsubsection{Design Criteria}

General criteria that apply to both nuclear and fossil power plants may be found in the various standards published by the American Nuclear Society (ANS), American Institute of Chemical Engineers (AIChE), American Society of Civil Engineers (ASCE), American Society of Mechanical Engineers (ASME), Institute of Electrical and Electronic Engineers (IEEE), the Instrument Society of America (ISA) and others. These organizations have promulgated 
over 5,000 standards which are applicable to nuclear and fossil power plants. of these, approximately 200 are exclusively applicable to nuclear power plants. Of particular importance for both the nuclear and fossil power plants is the ASME Boiler and Pressure Vessel Code. The criteria in these standards record standard or accepted practice for proper system design and equipment application relative to nuclear safety, system efficiency, required technical parameters, standard capacities and sizes, equipment and component 11fe, pre- and post-operational testing, and operating personnel safety.

Standards written specifically for nuclear power plants have a major impact on the design of structures, systems and equipment and on the quantities of commodities, equipment and manhours required to design and construct these plants.

Structural quantities of commodities and manhours for nuclear power plants are severely impacted by the design criteria followed in current practice. Loads considered in the design of the containment structures described in the nuclear power plant system design descriptions are as follows:

a. Dead Loads - Permanent gravity loads including concrete, structural steel, equipment, piping, cable trays and hydrostatic pressure. (The ground water level was assumed at $\mathrm{E} 1+10 \mathrm{ft}-0 \mathrm{in}$. Bouyancy from ground water was considered in building stability and base mat design.)

b. Live Loads - Loads wh1ch vary with intensity and/or occurrence. (During normal operation the live loads considered were a snow load of 80 psf, lateral soll pressures, and contents of vessels. Live loads from cranes, wet concrete on liner plates and major equipment transport loads occurring during construction were also considered.)

c. Operational Thermal Loads - Thermal effects and loads during normal operating or shut-down conditions. (Outside temperatures were varied from $-10^{\circ} \mathrm{F}$ to $90^{\circ} \mathrm{F}$.)

d. Operational pipe Reactions - Piping reactions during normal operation or shut-down conditions.

e. Pressure Variation - Differential pressure loads resulting from pressure variation either inside or outside the containment.

f. Wind Load - Wind pressures resulting from a basic design wind speed of $110 \mathrm{mph}$ at a height of 30 feet above grade (recurrence period 100 years). 
g. Operating Basis Earthquake (OBE) - The earthquake that could reasonably be expected to affect the plant site during the operating life of the plant. (The vertical and horizontal design response spectra are obtained from USNRC Regulatory Guide 1.60 , scaled for a peak horizontal ground acceleration of $0.125 \mathrm{~g}$.)

h. Safe Shut-down Earthquake (SSE) - The earthquake based upon an evaluation of the maximum earthquake potential in the plant region. (The effects were considered in a similar manner to that described for the OBE, except that the design response spectra are scaled for a peak horizontal ground acceleration of $0.25 \mathrm{~g}$. )

i. Tornado Loads - Tornado effects including wind pressure, differential pressure loads due to rapid atmospheric pressure change and tornado generated missile impact effects. (A maximum tangential wind velocity of $290 \mathrm{mph}$, a translational velocity of $70 \mathrm{mph}$ and a pressure drop of $3 \mathrm{psi}$ at a rate of $2 \mathrm{psi} / \mathrm{sec}$ were used in the design. Tornado missiles considered include a wood plank, wood pole, steel rod, steel pipe, and an automobile, in accordance with the USNRC Standard Review Plan.

j. Flood Loads - No flooding of the site was considered because the plant site lies ten feet above the 100 year maximum water level of the North River (refer to Appendix A).

k. Accident Pressure Load - The maximum design pressure equivalent to the maximum calculated internal pressure associated with a Design Basis Accident with an appropriate margin to account for uncertainties in the load definition.

1. Accident Temperature Load - Thermal effects and loads generated by the Design Basis Accident.

m. Accident Pipe Reactions - Pipe reaction loads due to thermal conditions generated by the Design Basis Accident.

n. Pipe Break Loads - The local effects of a ruptured high energy pipe including jet reaction forces, jet impingement loads and missile impact forces.

- Safety Relief Valve Discharge Loads - Hydrodynamic loads resulting from safety relief valve activation (BWR plants only). 
Structures having a safety-related function are required to be designed to withstand the effects of the Safe Shut-down Earthquake and remain functional. These structures, which are identified in the preamble to Account 21 in each nuclear power plant system design description, are designated as Seismic Category I structures and are designed for loads similar to those described for the reactor containment building. These structures must assure:

a. The integrity of the reactor coolant pressure boundary.

b. The capability to shut-down the reactor and maintain it in a safe shut-down condition.

c. The capability to prevent or mitigate the consequences of accidents which could result in potential off-site radiation exposures comparable to the guideline exposures of 10CFR100.

Mechanical and electrical quantities of equipment and manhours for nuclear power plants are also impacted by the design criteria followed in current practice for safety-related systems.

Safety-related mechanical equipment, components and interconnecting piping systems are designed to the stress limitations imposed by the ANS "Conditions of Design" and the ASME Boiler and Pressure Vessel Code - Section III. Application of these criteria require field fit-ups to manufacturing class tolerances for equipment/piping supports and seismic restraints. Reliability of mechanical systems/equipment is achieved by invoking stringent material selection and qualification and certification procedures, coupled with specific conservative design requirements such as stress limitations.

Safety-related electrical equipment, components and systems are designed on a probability of fallure basis. This requires safety-related systems and equipment to be redundant, that is duplicated to the extent that either system, equipment or component may fulfill its safety function, regardless of the state of operation or failure of its counterpart. In addition, all safety-related electric equipment and components, including their redundant counterparts, must be qualified by test, analysis or a combination of testing and analysis to be capable of performing the safety functions for which they were designed under the accident conditions upon which the design is predicated.

The structure/system design descriptions reflect the requirements currently invoked from the industry standards. The design features and the resulting quantities of commodities, equipment and manhours in these descriptions are reflective of current practice.

\subsubsection{Regulatory Criteria}

The safety-related structures, systems, components, and equipment in nuclear power plants must meet the requirements of Parts $20,50,51,71,73$ and 100 
of Title 10 of the Code of Federal Regulations, in particular the Appendices of Part 50 (design requirements) and Part 100 (site/seismic criteria). This is accomplished by following the interpretations of these requirements found in the NRC regulatory guide series, the Standard Review Plans (NUREG-0800), hundreds of accumulated NRC office of Inspection and Enforcement Bulletins, Circulars and Notices and daily notices of interpretation problems and resolutions published by various owner and other industry groups.

Appendix A to 10CFR50 requires that safety related systems be designed to specific General Design Criteria which include consideration of quality standards and that Quality Assurance programs be implemented to assure that they meet this criteria in a manner commensurate to the importance of the safety function to be performed. Appendix B to 10CFR50 gives detailed requirements for Quality Assurance Programs. While implementation of these requirements have had little impact on quantities of commodities and equipment, Quality Assurance practices have had an impact on the unit prices and quantities of manhours (craft, engineering and field supervision) associated with the installation, fabrication, erection and inspection of these items.

In addition to these regulatory impacts, quantities of commodities, equipment and manhours for the nuclear power plants have been impacted by a number of other factors over the last several years, as discussed in the EEDB Phase $V$ (1982) Update Report.7 The nuclear power plant system design descriptions found in this Technical Reference Book reflect current industry practice relative to the response to these factors, including interpretation of regulatory requirements.

The regulatory impact on the coal-fired power plants is significantly more straightforward than for the nuclear power plants. The major regulatory impact for coal-fired power plants is in the environmental area and relates to control of water and gaseous discharges. In particular, control of $\mathrm{SO}_{2}$ emissions is required to conform to the 1979 New Source Performance Standards (NSPS). The coa1-fired power plant system design descriptions found in the Technical Reference Book employ flue gas desulfurization, dust suppression and waste water control technologies that meet current requirements. Closedcycle cooling has been considered in the coal-fired power plant model.

\subsection{CODE-OF-ACCOUNTS SYSTEM}

From a technical viewpoint, all steam electric power generating stations have the same basic systems and structures. For ease of comparison of design parameters and overall cost, these basic systems and structures are given unique code-of-accounts numbers, as discussed in the Program Reference Book, 1 that are identical for all types or sizes of electric power generating stations at the two-digit or three-digit level of detail. The basic accounts are described in the following paragraphs. 


\subsubsection{Direct Cost Accounts}

The direct cost accounts include the commodities (e.g. concrete, piping, wiring), components, equipment and their installation manhours that comprise the structures and systems of a power plant. These accounts describe the structures, reactor or boiler plant, turbine plant, electric plant, miscellaneous plant and main condenser heat rejection system. The general content of the two-digit accounts is given below for all power plants. Specific structure and system content at the three-digit level of detail for the PWR, LSPB and HS5 are given in the form of system design descriptions in Sections 3 through 5 respectively.

\section{Structures and Improvements (Account 21)}

This account includes the on-site surface buildings and structures and subsurface foundations and tunnels, that house and support all equipment, components, piping, ducting, and wiring. Also included in this account are site improvements, such as excavation, grading, roadways and railroads. In particular, substructure and superstructure details, architectural features and treatment of floors, walls, roofs, doors and glazing may be found in this account. The sub-accounts also include equipment and piping for the heating, ventilating and air conditioning systems, piping for the roof, floor and sanitary drains, and equipment for the lighting and service power (120 volt ac) systems for that structure.

Nuclear power plants have two basic classes of on-site structures. Certain structures support and protect safety-related equipment and assist in the prevention of significant release of radioactivity to the environment. These critical structures are designed to withstand a Design Basis Earthquake at the Middletown site. They are given the designation of Seismic Category I. The other class of structures is designated as Non-Seismic Category I. These structures house and support equipment not essential to the prevention of significant release of radiation and are similar to on-site structures for fossil power plants.

The account does not include the foundations for individual plant machinery or the buildings and foundations for the flue gas desulfurization and heat rejection systems. Equipment foundations are described in the appropriate equipment account, while the flue gas desulfurization and heat rejection system buildings are included in the Flue Gas Desulfurization Structures (Account 225 for the fossil power plants only) and the Main Condenser Heat Rejection System Structures (Account 261) accounts, respectively.

Reactor or Boiler Plant Equipment (Account 22)

This account includes the equipment that liberates thermal energy from a fuel and uses the resulting heat to generate steam. For each reactor or boiler, support equipment is included to control the plant output, store an inventory of fuel, pretreat the fuel before actual burning (in the case of fossil power plants) and store and treat the residue or waste products. 
For a nuclear power plant, this equipment includes the reactor safety systems, the fuel storage systems, and the radioactive waste handing systems. For a fossil power plant, this equipment includes the draft system, the flue gas desulfurization system and associated structures, the coal handing system and various waste handling systems. In both cases, the account includes the interconnecting piping systems, structural supports for equipment, and the necessary instrumentation and control systems.

Turbine Plant Equipment (Account 23)

The turbine plant includes the power conversion system equipment that produces electric power from the steam generated by the reactor or boiler plants. All of the EEDB technical models use a conventional steam-turbine generator unit, although the configuration varies from plant to plant. An elevated foundation/pedestal supports the steam turbines and electric generator. The condenser is located directly below the low pressure steam turbine.

This account includes the turbine-generator unit, the condenser, the systems to purify and return the condensate to the reactor or boiler plant (condensate and feedwater systems) and the elevated turbine-generator pedestal. The account also includes the main vapor piping system, auxiliary support systems, interconnecting piping systems, structural supports for equipment, and the necessary instrumentation and control systems.

Electric Plant Equipment (Account 24)

The electric plant includes the systems and equipment required to deliver the generated electric power to the utility's step-up transformer and off-site transmission system, provide auxiliary electric power for all power plant equipment and auxiliaries, and provide standby power for safety systems for nuclear power plants or emergency backup power for selected systems for fossil power plants. The major sub-accounts are those for the cable and raceways for all power, control and instrumentation systems.

Although building lighting and service power equipment are included in Account 21 , the equipment for the distribution of power to these systems is included in this account.

This account also includes structural supports for equipment, the generator control system equipment and the plant grounding, lightning protection, freeze protection and cathodic protection equipment. For nuclear power plants, the most critical electric systems are designated "class 1E." These are systems that are essential to the prevention of significant release of radioactivity to the environment.

Misce11aneous P1ant Equipment (Account 25)

This account contains the auxiliary mechanical and electric equipment required for normal power plant start-up, operation and maintenance. This includes the transportation and lift equipment (cranes), equipment in the air, water and 
steam service system, the auxiliary boiler, the fire detection and protection systems, the communication system, the non-radioactive waste water treatment system, various plant monitoring systems, and miscellaneous furnishings and fixtures.

The account also includes the necessary interconnecting piping systems and structural supports for equipment.

Main Condenser Heat Rejection System (Account 26)

This account includes the equipment and associated structures that dispose of the heat rejected by the power plant and provide make-up water to the power plant. The systems are designed to dissipate the "excess" heat and provide the make-up water in such a way that harmful effects to the environment are minimized.

The current power plants described by the EEDB technical data models use a closed, circulating water cooling system with wet natural draft cooling towers to dissipate the waste heat. The largest source of waste heat, usually accounting for 90 percent of the total, is the main steam-turbine condenser.

The account also includes structures, equipment and interconnecting piping systems for obtaining and pretreating the plant make-up water.

\subsubsection{Indirect Cost Accounts}

The indirect cost accounts include those construction support activities required to design and build the structures and systems described in the direct cost accounts. At the two-digit account level of detail, the indirect cost accounts are identical for each power plant type. They describe the construction services, engineering and home office services, and field supervision and field office services. Unlike the direct costs, the indirect cost accounts are also identical for each power plant type at the three-digit account level of detail. Therefore, three digit indirect cost accounts are given below in the form of brief system design descriptions instead of being repeated in Sections 3 through 5 for each type of power plant.

\section{Construction Services (Account 91)}

Temporary Construction Facilities (Account 911)

This sub-account includes temporary structures and facilities, janitorial services, maintenance of temporary facilities, guards and security, roads, parking lots, laydown areas, and temporary electrical, heat, air, steam and water systems, general cleanup, and related items and activities.

Construction Tools and Equipment (Account 912)

Construction tools and equipment include rental and/or purchase of construction equipment, small tools and consumables (fuel, lubricants, etc.), as well as maintenance of construction equipment. 
Payroll Insurance and Taxes (Account 913)

These expenses include insurance and taxes related to craft labor, such as Social security taxes and state unemployment taxes, workmen's compensation insurance and public liability and property damage insurance.

Permits, Insurance and Local Taxes (Account 914)

These expenses could include builders all-risk insurance, local fees and permits, state and local taxes and nuclear liability insurance. Currently in EEDB estimates, builders all-risk insurance is the only cost included in this account. Payments to federal, state and local governments for taxes, fees and permits should be included in owner's costs.

Engineering and Home Office Services (Account 92)

Home Office Services (Account 921)

This sub-account includes engineering and design (both home of fice and field) and home office support, including procurement and expediting activities, estimating and cost control, engineering planning and scheduling, reproduction services, and expenses associated with performance of the above functions (i.e., telephone, postage, computer use, travel, etc.). The costs for the engineering, design and home office services include salaries of personnel, direct payroll-related costs (DPC), overhead loading, expenses and related fees.

Home Office Quality Assurance (Account 922) (Nuclear Power Plants)

This account includes the services of home office quality assurance engineers and staff personnel engaged in work on the project. Services include reviews, audits, vendor surveillance, etc. as required for design and construction of the nuclear safety-related portion of the facility. Costs for these services include salaries, DPC, overhead loading and expenses (e.g., travel) for these individuals.

Home Office Construction Management (Account 923)

These services include those of the construction manager and his assistants. Services of construction planning and scheduling, construction methods, labor relations, and safety and security personnel are utilized as required. Costs for these services include salaries, DPC, overhead loading and expenses.

Field Supervision and Field office Services (Account 93)

(Note: Field Engineering is included in Account 92.) 
Field Office Expenses (Account 931)

These expenses include costs associated, with purchase and/or rental of furniture and equipment (including reproduction), communication charges, postage, stationery, other office supplies, first aid and medical expenses.

Field Job Supervision (Account 932)

This management function includes the resident construction superintendent and his assistants, craft labor supervisors, field accounting, payroll and administrative personnel, field construction schedulers, field purchasing personnel, warehousemen, survey parties, stenographers and clertcal personnel. Costs of these services include salaries, DPC, overhead loading, relocation costs of key personnel, and fees.

\section{Field Quality Assurance/Quality Control (Account 933)}

These services include those of personnel located at the job site engaged in equipment inspection, required documentation of safety-related equipment (nuclear power plants only), inspection of construction activities and construction training meetings. Costs included are salaries, DPC, and overhead loading.

\section{Plant Startup and Test (Account 934)}

These services are associated with preparation of start-up and plant operation manuals and test procedures, direction and supervision of testing of equipment and systems as the plant nears completion and direction of start-up of the facility. Costs of these services include salaries, DPC, overhead loading, and miscellaneous related expenses. Costs of any craft labor required for start-up and testing activities are included in the appropriate Direct cost line 1 tems.

\subsubsection{System Design Descriptions}

In the system design descriptions that follow, the text is organized in accordance with the direct cost two-digit accounts described above. Discussions are further sub-divided within each two-digit account to a three-digit account level of detail. A listing of the three-digit account breakdown is provided in the introductory text provided for each two-digit system design description account discussion. The two-digit account level, as described above, is at the plant level. The three-digit account level is at the major structure or system level. 


\section{SECTION 3}

3.0 SYSTEM DESIGN DESCRIPTION FOR THE 1144 MWe

PRESSURIZED WATER REACTOR NUCLEAR POWER GENERATING STATION

(EEDB PROGRAM TECHNICAL DATA MODEL A3 - PWR)

\subsection{INTRODUCTION}

Section 3 describes the design of the EEDB Program 1144 MWe pressurized water reactor nuclear power plant technical data model, as of the technical and regulation date of January 1, 1986.

In the 1144 MWe pressurized water reactor nuclear power plant, the reactor coolant water is heated at a pressure of 2250 psia inside the nuclear reactor by the fission process. The heated water is pumped through a primary piping system or "loop" to a steam generator.

In the steam generators, approximately $15.2 \times 10^{6} 1 \mathrm{~b} / \mathrm{hr}$ of steam is heated to its final saturated conditions, nominally 1000 psia, $544^{\circ} \mathrm{F}$. A second independent piping loop feeds the saturated steam to the steam turbine and steam reheaters and returns feedwater to the steam generators.

Both fresh (new) and spent (used) fuel for the nuclear reactor, up to 1.33 cores, are stored in on-site facilities. Radioactive and other waste products are treated and stored on-site and disposed of of f-site.

General key parameters are given for the PWR in Table 3-1, Items 1 through 13. Engineering drawings are presented in Figures 3.1 through 3.5 , which may be found in Section 3.4. A milestone licensing/design/construction schedule and discussion are given in Section 3.5 and Figures 3.6 through 3.8 .

\subsection{DESIGN CRITERIA AND KEY PARAMETERS}

The plant technical design is based upon the Westinghouse Reference Safety Analysis Report (RESAR-3S) 20 , the princlpal technical features corresponding to the Public Service Company of New Hampshire Seabrook Station, circa July, 1976, and industry experience. RESAR-3S describes the Westinghouse standardized fourloop single unit nuclear steam supply system (NSSS) for a pressurized water reactor.

This design basis has been modified and updated for each update of the EEDB Program, in order to reflect current industry practice, experience and response to regulations for that update. Therefore, the January 1, 1986 design basls is no longer completely representative of the older Seabrook Station or RESAR-3S.

Table 3-1 summarizes the key technical parameters for the PWR. These base parameters, together with the text, engineering drawings and milestone schedules of the following sections, provide the system design descriptions for the PWR technical data model. 
TABLE 3-1

ENERGY ECONOMIC DATA BASE

PHASE VIII UPDATE

PRESSURIZED WATER REACTOR NUCLEAR POWER GENERATING STATION (PWR)

TECHNICAL DATA MODEL BASE PARAMETER SUMMARY

GENERAL

1. Site

2. Operation

3. Technical Data Model Reference Date

4. Plant Life (years)

5. Number of Units

6. Thermal Power (MWt)

a. Rated (Core)

b. Nuclear Steam Supply System(1)

7. Net Plant Heat Rate (Btu/kWh) (2)

8. Net Plant Effictency (\%)(2)

9. Net Power to $\mathrm{GSU}^{(3)}$ (MWe)

10. Water Table (Feet above mean river leve1)

11. 100 Year Flood (Feet above mean river leve1)

12. External Missiles

\section{LICENSING}

13. Codes \& Standards Reference Date
Middletown, USA

Base Load

January 1, 1986

30

Single

3,417

3,431

10,192

33.48

1144

10

8

Tornadoes Only

January 1, 1986

(1) Includes React or Coolant Pumping Power

(2) Based on Rated Thermal Power

(3) Generator Step-up Transformer 


\section{TABLE $3-1$}

\section{ENERGY ECONOMIC DATA BASE}

PHASE VIII UPDATE

PRESSURIZED WATER REACTOR NUCLEAR POWER GENERATING STATION (PWR)

TECHNICAL DATA MODEL BASE PARAMETER SUMMARY

\section{CIVIL/STRUCTURAL}

14. Containment

$$
\text { a. Type }
$$

b. Overall Height ( $f t$ )

c. Inside Diameter ( $f t$ )

d. Free Volume $\left(10^{6} \mathrm{cu} \mathrm{ft}\right)$

e. Design Pressure (psig)

15. Turbine Building

16. Turbine Pedesta1

17. Fuel Storage (Number of Cores)

18. Flooding Provisions

19. Seismic SSE/OBE (g)

20. Foundations (Type)
a. Se1smic Category I
b. Non-Seismic Category I

21. Grade Elevation (Feet above mean river level)

\section{MECHANICAL}

22. Reactor

a. Type

b. Vessel Inside Diameter/Height (in/in)
Reinforced Concrete with Steel Plate Liner

219

140

2.8

52

Enclosed

High Tuned

$4 / 3$

No Special Provisions

$0.25 / 0.125$

Mat

Spread Footings

18

Cylindrical Carbon Steel Pressure Vessel with Stainless Steel Cladding, Hemispherical Bottom Head and Removable Hemispherical Upper Head

$173 / 516$ 
TABLE $3-1$

ENERGY ECONOMIC DATA BASE

PHASE VIII UPDATE

PRESSURIZED WATER REACTOR NUCLEAR POWER GENERATING STATION (PWR) TECHNICAL DATA MODEL BASE PARAMETER SUMMARY

MECHANICAL (Cont'd)

c. Number Fuel Assemblies

193

d. Initial Core

$\mathrm{UO}_{2}$

e. Enrichment (\%)

3

f. Refueling Method

- Horizontal Tube Fuel Transfer System Between Fuel Pool and Reactor Vesse1

- Rail Mounted Refueling Platform with Telescoping Grapple over Fuel Pool

23. Primary Fluid Type/Wt ( $\left.10^{5} 1 \mathrm{bs}\right)$

Light Water $/ 5.70$

24. Moderator

Light Water

25. Reactor Coolant Conditions at Reactor Outlet
a. Temperature $\left({ }^{\circ} \mathrm{F}\right)$
618
b. Pressure (psia)
2,250
c. Flow $\left(10^{6} 1 \mathrm{~b} / \mathrm{h}\right)$
140.6

26. Reactor Coolant/Recirculation Loops
a. Number of Loops/Number of Pumps per Loop
b. Drive Type/hp
Four/One
Electric Motor/7000 (hot)
Electric Motor/9000 (cold)

\section{Steam Generators}
a. Number per Coolant Loop
1
b. Type
Vertical U-Tube with Integral Steam Drums 
TABLE $3-1$

\section{ENERGY ECONOMIC DATA BASE}

PHASE VIII UPDATE

PRESSURIZED WATER REACTOR NUCLEAR POWER GENERATING STATION (PWR)

TECHNICAL DATA MODEL BASE PARAMETER SUMMARY

MECHANICAL (Cont'd)

c. Classification (Section III, ASME B\&PVC)

d. Tota1 Heat Transfer Surface (SF) 220,600

e. Total Steam Flow at Rated Load $\quad 15.2$ $\left(10^{6} 1 \mathrm{~b} / \mathrm{h}\right)$

f. Outlet Steam Pressure at Rated 1,000 Load (psia)

28. Turbine-Generator
a. Configuration
Tandem-Compound, 6-F1ow
b. Speed $(r / m i n)$
1,800
c. Last Stage Blade Length (in)
43

29. Main Steam Conditions at High Pressure Turbine Inlet (Rated Load)
a. Pressure (psia)
975
b. Temperature $\left({ }^{\circ} \mathrm{F}\right)$
544
c. Flow $\left(10^{6} 1 \mathrm{~b} / \mathrm{hr}\right)$
13.7

30. Gross Turbine-Generator Output at 2.5 Inches $\mathrm{HgA}$ (MWe)

31. Condensers
a. Type
Single Pressure
b. Shells/Divisions per Shell
$3 / 1$
c. Arrangement
Transverse
d. Number of Passes
Two
e. Water Box
Split
f. Pressure (in-HgA)
2.5 
TABLE $3-1$

ENERGY ECONOMIC DATA BASE

PHASE VIII UPDATE

PRESSURIZED WATER REACTOR NUCLEAR POWER GENERATING STATION (PWR)

TECHNICAL DATA MODEL BASE PARAMETER SUMMARY

MECHANICAL (Cont'd)

g. Total Heat Transfer Surface (SF) 1,225,050

32. Cooling Tower
a. Type
Natural Draft Wet Evaporative
b. Number/Total Flow - Norma1 (gpm)
$2 / 717,000$

33. Cooling Tower Conditions
a. Approach $\left({ }^{\circ} \mathrm{F}\right)$
14
b. Range $\left({ }^{\circ} \mathrm{F}\right)$
22
c. Wet Bulb $\left({ }^{\circ} \mathrm{F}\right)$
74

34. U1timate Heat Sink

2-100\% Mechanical Wet Evaporative Cooling Towers

35. Feedwater Pumps
a. Main (Number/Drive)
2/Turbine
b. Other (Number/Service/Drive)
1/Emergency/Turbine
1/Emergency/Motor

36. Feedwater Heaters
a. Open Stages (Number)
None
b. High Pressure Closed Stages (Number/Number Trains)
$1 / 2$
c. Low Pressure Closed Stages (Number/Number Trains)
$4 / 3,1 / 2$
37. Stages of Reheat (Number/Type)
One/Steam

\section{ELECTRICAL}

38. Connection to off-site Power (Number $/ \mathrm{kV}$ )

$2 / 500,2 / 230$ 
TABLE 3-1

ENERGY ECONOMIC DATA BASE

PHASE VIII UPDATE

PRESSURIZED WATER REACTOR NUCLEAR POWER GENERATING STATION (PWR)

TECHNICAL DATA MODEL BASE PARAMETER SUMMARY

ELECTRICAL (Cont'd)

39. Generator
a. Rating (MVA)
1,390
b. Voltage $(\mathrm{kV})$
25
c. Power Factor
0.9
d. $\mathrm{H}_{2}$ Pressure (psig)
75

40. Generator Disconnect
a. Type
Load Break Switch
b. Rating (kV)
36

41. Auxiliary Power System

$\begin{array}{lll}\text { a. Medium Voltage System A (kV) } & 13.8\end{array}$

b. Medium Voltage System B (kV) 4.16

c. Low Voltage System (V) 480

d. Direct Current Systems (v) 250/125

42. Unit Auxiliary Transformer 90

Nameplate Rating(4) (MVA)

43. Reserve Auxiliary Transformer 90

Nameplate Rating(4) (MVA)

44. Diese1-Generator Unit
a. Type/Number
Medium Speed/2
b. Voltage $(\mathrm{kV})$
$4 \cdot 16$
c. Rating (kW/PF)
$6083 / 0.8$

(4) Total of all transformers at top class of cooling rating 


\section{TABLE $3-1$}

\section{ENERGY ECONOMIC DATA BASE}

PHASE VIII UPDATE

PRESSURIZED WATER REACTOR NUCLEAR POWER GENERATING STATION (PWR) TECHNICAL DATA MODEL BASE PARAMETER SUMMARY

ELECTRICAL (Cont'd)

45. Control Room Wiring

46. Multiplexing of BOP Cables

47. Instrumentation
Wired Directly to Panels in Control Room

None

Independent Sensors for Computer Input 


\subsection{SYSTEM DESIGN DESCRIPTIONS}

The material presented in this section is organized as follows:

\section{Code of}

Accounts

Title of Account

Page

21

Structures and Improvements

$3-10$

22

Reactor Plant Equipment

$3-29$

23

Turbine Plant Equipment

$3-60$

24

Electric Plant Equipment

$3-78$

25

Miscellaneous Plant Equipment

$3-90$

26

Main Condenser Heat Rejection System

$3-99$ 
Civil/Structural key parameters are given in Items 10 through 12 and 14 through 21 of Table 3-1. Plant configuration in the form of a Plot Plan and General Arrangement drawings is given in Figures 3.1 through 3.4. The table and figures supplement and amplify the following discussion of Account 21 .

The primary structure in the plant is the reactor containment building which is Seismic Category $I$ and consists of a steel lined reinforced concrete cylinder with a hemispherical dome and a flat reinforced concrete foundation. The continuous welded plate liner is attached to the inside face of the concrete to ensure a high degree of leak-tightness. The reactor containment building houses the reactor and its associated coolant system, provides biological shielding and prevents significant release of radiation to the environment, in case of abnormal events in the reactor coolant system. The interior concrete of the reactor containment supports the reactor plant components and equipment.

The containment and other Seismic Category I structures house all safety related equipment essential for safe plant operation, shut-down and control. Construction of these structures generally includes a reinforced concrete foundation mat, exterior walls, interior walls, floor slabs and roof slabs. The exterior walls are designed to resist horizontal loads and behave as shear walls. The interior slabs and roof slabs are supported on heavy structural steel framing.

The major Seismic Category I structures include:

Reactor Containment Building (Account 212) - Houses the Nuclear Steam Supply System (NSSS) and its associated coolant system, provides biological shielding and prevents significant release of radiation in case of abnormal events in the reactor coolant system. The interior concrete of the reactor containment supports the reactor plant components and equipment, provides biological shielding and protects the steel liner from postulated pipe break effects in the reactor coolant system.

Primary Auxiliary Building and Tunnels (Account 215) - Houses auxiliary nuclear equipment such as heat exchangers, pumps, demineralizers, filters, tanks, ventilation equipment and residual heat removal equipment.

Waste Process Building (Account 216) - Houses 1iquid, solid and gaseous radioactive waste processing and boron recovery equipment.

Fue1 Storage Building (Account 217) - Houses new and spent fuel, associated pool cooling and cleaning systems, and decontamination and shipping areas.

Control Room and Diesel-Generator Building (Account 218A) - The north portion of the structure, comprising the diesel-generator building, houses the emergency diesel-generator units, their associated equipment and the diesel engine fuel oil storage tanks. The south portion of the structure, comprising the 
PWR ACCOUNT 21

control room building, houses the necessary instrumentation and control equipment essential for plant operation under normal and abnormal conditions.

Emergency Feedwater Pump Building (Account 218E) and Electrical Tunne1 (Account 218G) - Houses emergency feedwater pumps, demineralized water make-up pumps, and the electrical cables and raceways running between the reactor containment building and the control room and diesel-generator building.

Radiological Control Access (RCA) Manway Tunnels (Account 218F) - Provide access to various main plant structures from the administration and service building.

Main Steam and Feedwater Pipe Enclosures (Account 218J) - Houses the Seismic Category I sections of the main steam and feedwater piping external to the reactor containment building.

Ultimate Heat Sink Structure (Account 218T) - Houses the cooling towers and associated equipment necessary to provide emergency service water to the plant.

The major Non-Seismic Category I structures house equipment and components not required for plant safety or safe shut-down. In general, these structures consist of structural steel framing, metal siding and concrete channel plank roofing. They bear on reinforced concrete spread footings or reinforced concrete footings founded on the rock underlying the site. The Non-Seismic Category I structures are designed and located such that their failure will not cause loss of function of a Seismic Category I structure.

The major Non-Seismic Category I structures include:

Turbine Room and Heater Bay (Account 213) - Houses the turbine-generator, condensers and associated equipment, feedwater heaters, feedwater pumps, condensate pumps, condensate polishing and demineralizing equipment, other auxiliary equipment, and electrical switchgear rooms;

Security Building (Account 214) - Provides a controlled means of access to the plant and houses the center for monitoring and controlling access to selected critical areas within the plant.

Administration and Service Building (Account 218B) - Houses the general offices, conference rooms, storage areas, auxiliary boilers, water treatment equipment and various laboratories and shops.

Technical Support Center (Account 218L) - Houses the necessary monitoring, control and communication equipment required for on-site response to emergency conditions.

Fire Pump House (Account 218D)

Non-Essential Switchgear Building (Account 218H) 
PWR ACCOUNT 21

Waste Water Treatment Building (Account 218S)

The following additional major Non-Seismic Category I structures are included under Account 261 - Structures (Main Condenser Heat Rejection System):

Make-up Water Intake Structure

Circulating Water Pump House

Make-up Water Pretreatment Building

Interconnecting piping systems are provided for Building Services systems such as rainwater conductor and sewage systems. They comprise the piping, fittings, valves, hangers and supports, and other components required for a complete system. Materials and wall thicknesses are chosen based on the service conditions and operational requirements of each system. The factors generally considered include: temperature, pressure, corrosion resistance, abrasion resistance, fluid purity requirements and cost. Carbon steel is used for steam (below $750^{\circ} \mathrm{F}$ ), clean water, air, oil, and other services without special requirements. Other materials used include cast iron for sanitary drains and some below grade service, copper for potable water, galvanized steel for yard drains, and polyvinyl-chloride (PVC) and fiberglass reinforced plastic (FRP) for corrosive services.

The following pages provide detailed descriptions of the major and minor Seismic Category I and Non-Seismic Category I structures, ordered numerically by account number. 
ACCOUNT 211 Yardwork

The plant location is the hypothetical site of Middletown, USA. This site is defined in Appendix A-1 of this Technical Reference Book. The plant configuration is shown in the Plot Plan given in Figure 3.1 .

The datum plane for site and yard elevations is mean river level. Main plant finish grade is 18 feet above mean river level. Soil overburden is estimated to be eight feet thick. Limestone rock with no underground cavities and satisfactory for supporting plant structures is located below the overburden.

Site preparation consists of clearing, grubbing, and stripping of top soil for all structures, roads, rallroads, parking areas, materials handing areas and construction facilities. Rough grading quantities include the general cut and fill for the main plant structures and fine grading with landscaping.

Earth excavation, rock excavation, backfill, concrete fill and dewatering for the main plant structures are included with the structure associated yardwork. This includes all excavation work for the main nuclear and turbine plant areas. Excavation work for structures not included within the main excavation are included with the structural work for each of the individual buildings. The cut and fill work also includes hauling, dumping, stockpiling, placing and compacting. For those portions of structures below rock, concrete fill is used under and adjacent to the structure. In cases where rock elevations vary or where Seismic Category I base mats or footings are above rock, concrete fill is used to assure that building loads are carried to competent rock. Earth fill is separated into select and Category I fill adjacent to Seismic Category I structures, select and Non-Category I fill adjacent to Non-Seismic Category I structures and general area fill in the main plant area. In general, the main plant excavation is a large open cut with deeper cuts provided to accommodate the reactor containment building, reactor cavity pit and the residual heat removal equipment vault.

Structural and fill concrete are produced by an on-site concrete batch plant. Excavated material is used on site for general fill whenever possible. Spoil areas and storage areas are utilized for excavated material not used for fill or for top soil. Erosion and sedimentation control of those areas is practiced in accordance with EPA requirements. Temporary settling basins are provided to collect all runoff during construction prior to discharge into the North River.

The transformer area, above ground oil storage tanks and other oil or chemical storage and handling areas are designed to contain spills and collect surface water runoff. This runoff, together with the turbine building floor drains and other plant dirty drains, is routed by underground piping to the holding pond or to the waste water treatment building for treatment, as required, before discharge into the North River. 
The yard drainage system consists of interceptor ditches (paved and unpaved) and storm drains with catch basins to carry of $\mathrm{f}$ storm water from developed areas. Water courses that are intercepted near the plant are diverted by ditches into existing stream beds or storm drains. Culverts carry stream flow under the railroad and roads. The yard surface water drainage is directed to the North River via the existing water courses wherever possible. Building roof drainage is directed to the yard drainage system.

The sanitary sewage system, piping and toilet facilities for permanent plant requirements are provided based on 35 gallons per day per person and a permanent work force of 300 people, for a treatment rate of 10,500 gallons per day. This system is a package type activated sludge sewage treatment plant, including final chlorination, to meet secondary treatment effluent standards.

Highway access is provided to the site by five miles of secondary roads connecting to a state highway. These roads are in good condition and need no additional improvements. An on-site asphalt road, paved in accordance with the standard thicknesses for public highways, is provided around the main plant structures. Service roads are arranged to provide access to truck sized doors in the plant and to all buildings requiring servicing or maintenance by vehicles. In addition, parking areas, concrete curbs and walks are provided. Temporary construction roads with minimum thickness paving and unpaved roads for materials handling equipment are provided.

Rallroad access to the site is provided by constructing a single track railroad spur which intersects the $B \& M$ Railroad. The length of the spur from the main line to the plant site is five miles. The spur approaches the site from the east. During construction, 500 to 600 cars of construction materials are delivered including the transformers and generator stator. These items are the heaviest loads anticipated to be delivered by rail and require special cars. Additional spurs are provided to the southeast end of the turbine building and the south end of the fuel storage building. All roadbed, trackage and railroad structures are designed in accordance with the latest railroad standards.

In addition to the above items, fencing, a main gate guard house, and roadway and yard lighting are provided with the yardwork.

\section{ACCOUNT 212 Reactor Containment Building}

The reactor containment building, which houses the NSSS and associated equipment, is a Seismic Category I reinforced concrete cylindrical structure with a hemispherical dome. It is designed to a maximum calculated internal design pressure of 52 psig. The containment has a flat reinforced concrete foundation keyed into the rock by the depression for the reactor cavity pit. The reinforced concrete foundation is 151 feet in diameter and ten feet thick, founded approximately 60 feet below finished grade which is 52 feet below the top of rock. The reactor cavity pit extends an additional 23 feet below the bottom of the reinforced concrete foundation. The cylindrical portion of the containment has an inside diameter of 140 feet and a wall thickness of 4.5 
PWR ACCOUNT 21

feet. It measures 149 feet from the top of the foundation mat to the springline of the dome. The dome portion has an inside spherical radius of 70 feet and a thickness of 3.5 feet. The inside height from the top of the mat to the underside of the dome is 215 feet.

A continuously welded steel plate liner, $3 / 8$ of an inch thick on the cylinder wal1, $1 / 2$ of an inch thick on the dome and $1 / 4$ of an inch thick on the foundation mat, is anchored to the inside face of the concrete. The liner functions as a leak-tight membrane to prevent significant fission product release in the event of an accident. The bottom liner plate is supported on top of the foundation mat and is protected by a four feet thick reinforced concrete slab which supports internal equipment loads and forms the floor of the containment.

A combination equipment hatch and personnel air lock is provided in the containment wall at the level of the operating floor. It is used to move equipment into the containment during construction and for removal and replacement of equipment during plant operation. A personnel lock is provided for access at a lower floor level of the containment. Piping, electrical cable, fuel transfer and duct penetrations are also provided through the wall at various locations. They are designed to remain gastight during all conditions for which the containment is designed.

The containment floor supports all primary equipment, primary equipment supports, supports for other components and equipment located in the containment and the interior containment structures. Al1 containment interior structures are independent of the containment cylinder wall. The major containment interior structures include the following:

a. Primary Shield Wall - A six feet thick circular reinforced concrete wall enclosing and supporting the reactor pressure vesse1.

b. Secondary Shield Wall - A four feet thick octagon shaped reinforced concrete wall enclosing the reactor coolant piping, steam generators, reactor coolant pumps and their supports.

c. Refueling Cavity/Refueling Canal - Reinforced concrete walls and floors covered with a continuous seam welded stainless steel liner, through which new and spent fuel elements are transported during refueling.

d. Operating Floor Slab and Crane Support Beams - A three feet thick reinforced concrete slab spanning between the crane support structure beams. The beams are supported on a series of reinforced concrete columns. The crane rails at the extremities of the operating floor slab support a gantry type polar crane used for placement and maintenance of major equipment in the containment. 
Other reinforced concrete internal structures are the pressurizer shield wall, control rod missile shield and interior walls, hatches, block-outs, and slabs for equipment compartments.

The annulus between the secondary shield wall and the containment wall houses accumulator tanks, the pressurizer relief tank, instrumentation racks, heat exchangers, cooling units, filter systems and miscellaneous equipment for auxiliary systems. The primary system is housed within the secondary shield wall which isolates the system and postulated accidents from the auxiliary systems in the containment structure and provides necessary shielding. Structural steel is utilized to support floors in the annulus at the operating level and intermediate levels to provide means of travel and access to the various components and equipment.

In addition to housing the NSSS and providing a leak tight structure, the containment serves as a biological shield which protects the environment from the effects of normal plant operation and abnormal events. It also protects the housed systems from the effects of various natural phenomena that are postulated to occur at the plant site.

The containment building heating, ventilating and air conditioning (HVAC) systems maintain a containment atmosphere suitable for equipment operation and provide a means for removing fisston products prior to entry, during refueling and following a design basis accident (DBA).

During normal operations, suitable temperatures are maintained by the containment recirculation cooling system. This system is comprised of six fan coil units, each rated at 20 percent of the maximum design heat load. Two 100 percent capacity water chillers, located in the primary auxiliary building, provide water at $40^{\circ} \mathrm{F}$ to the fan coil units in the containment.

Prior to entry into the containment, fission products are reduced to acceptable levels by the containment recirculating filter system and pre-entry purge system. The pre-entry purge system supplies fresh air at 15,000 cfm and exhausts the containment atmosphere through prefilters and HEPA-charcoal-HEPA filters. Prior to use of the pre-entry system, the radiation in the containment atmosphere is reduced to a satisfactory level by recycle through the recirculating filter system. The recirculating filter system, a fully redundant safety related system, is equipped with prefilters and HEPA-charcoal-HEPA filters and has a capacity of $4,000 \mathrm{cfm}$. The recirculating filter system also functions during post-LOCA conditions, along with the combustible gas control system described in Account 223, to reduce the fission products prior to venting the containment for hydrogen control.

The gross volume of the containment is 3,000,000 cubic feet and the net volume is 2,750,000 cubic feet. 
PWR ACCOUNT 21

ACCOUNT 213 Turbine Room and Heater Bay

The turbine building (including heater bay) is a Non-Seismic Category I structure, located east of the containment structure. The turbine room is a three story (elevations 19 feet, 48 feet and 73 feet) steel framed structure 135 feet wide, 325 feet long and 130 feet high. The heater bay is a two story (elevations 19 feet and 48 feet) steel framed structure 65 feet wide, 325 feet long and 77 feet high. The combined building volume is approximately $7,330,000$ cubic feet.

The building is supported on reinforced concrete footings on rock. The reinforced concrete ground floor is located at grade. The mezzanine and operating floors are cast-in-place concrete on metal deck supported on steel framing. The roof is concrete channel plank covered with a roofing membrane and supported on steel framing. The exterior walls are insulated metal siding, and the interior walls are concrete block or metal partitions. The turbine pedestal is described under Account 231.

The building houses the turbine-generator unit, its condensers and associated equipment, feedwater heaters, feedwater pumps, condensate pumps, condensate polishing and demineralizing equipment, turbine lube oil equipment, other auxiliary equipment, and electrical switchgear rooms. The feedwater heaters are located in the heater bay.

A rail car bay is located at the southeast end of the building for transport of generator and turbine parts. An overhead traveling crane located at the top of the building serves this bay as well as the full turbine hall operating floor area. The heater bay is also served by an overhead trave1ing crane located at the top of the building. This crane serves the heater bay portion of the rail car bay as well as the full heater bay mezzanine floor (elevation $48 \mathrm{feet}$ ) area. All floors are connected by several stairways and a passenger elevator.

The turbine hall and heater bay are cooled by power roof ventilators and heated by steam unit heaters located throughout the building.

\section{ACCOUNT 214 Security Building}

The security building is a single story windowless, reinforced concrete Non-Seismic Category I structure located east of the administration and service building and north of the technical support center building with a reinforced concrete base slab located at grade. The building is 53 feet wide, 63 feet long and 20 feet high with a total interior volume of approximately 56,700 cubic feet.

The exterior walls, interior walls and floor slab of the security building are reinforced concrete. Exterior walls are a minimum of two feet thick. The roof slab is reinforced concrete covered with bullt-up roofing. Public areas are provided with suspended acoustical ceilings. 
PWR ACCOUNT 21

The security bullding heating, ventilating and air-conditioning (HVAC) system maintalns environmental conditions within prescribed comfort zones. Heating and air conditioning is provided by $f$ an cooler/heating units. Supply air to the building is heated by hot water coils in the fan heating units. Hot water and chilled water for the fan cooler/heating units are supplied from the administration and services building hot and chilled water systems. Security building HVAC systems are non-safety-related systems.

The security building provides a controlled means of access to the plant to prevent industrial sabotage or the theft of nuclear materials. All personnel must pass through this building and be checked by the associated security systems for ingress and egress to sensitive plant structures/areas or areas where radioactive materials are stored. The plant security system is monitored and operated from this building. Additionally, facilities are provided to administrate and operate the plant security force.

ACCOUNT 215 Primary Auxiliary Building and Tunnels (Including Residual Heat Removal Equipment Vault)

The primary auxiliary building is a reinforced concrete Seismic Category I structure located north of the containment structure and supported on a four feet thick reinforced concrete foundation. The building is asymmetrical, having changes in elevation of the base mat at various locations in the building. Nominally the base mat is founded on rock 30 feet below grade. Portions of the building are founded deeper or shallower than the above; however, in all cases support is provided by rock. The major portion of the building is 79 feet wide, 145 feet long and three stories or 91 feet high. Some portions of the building have a raised roof for mechanical equipment location. The portion of the building housing the safety-related pumps (the residual heat removal equipment vault) is an attached section founded on rock 85 feet below grade. The height of the safeguards vault is 90.5 feet. The volume of the primary auxiliary bullding and safeguards vault is approximately $1,140,000$ cubic feet.

The exterior walls, interior walls and floor slabs of the primary auxiliary building are reinforced concrete. The exterior walls are a minimum of two feet thick. The floor slabs are cast-in-place concrete over metal deck and supported on steel framing. The roof slab is reinforced concrete covered with built-up roofing.

The 79 feet by 145 feet portion of the building has two intermediate reinforced concrete floors which house miscellaneous auxiliary nuclear equipment, such as heat exchangers, pumps, demineralizers, filters, tanks and ventilation equipment. Below grade reinforced concrete pipe tunnels connect the building to the containment, waste treatment building and fuel storage building. The safeguards vault section is subdivided into compartments and houses containment spray pumps, residual heat removal pumps and heat exchangers. 
PWR ACCOUNT 21

The primary auxiliary building is ventilated by outside air supplied at $250,000 \mathrm{cfm}$. During the winter months heating is provided by duct coils and unit heaters supplied from the building hot water heating system. Approximately $60,000 \mathrm{cfm}$ of the supply air is directed from the primary auxiliary building to the fuel storage building for area ventilation and eventual exhaust. The primary auxiliary bullding exhaust is divided into non-contaminated and potentially contaminated systems. The non-contaminated exhaust is sent directly to the plant vent without filtration and is rated at 120,000 cfm. Potentially contaminated areas of the building are exhausted separately through prefilters and a HEPA-charcoal-HEPA filter bank in the atmospheric cleanup system. The atmospheric cleanup exhaust system is rated at $76,000 \mathrm{cfm}$.

ACCOUNT 216 Waste Process Bullding (Including Tank Farm)

The waste process building is a partially reinforced concrete Seismic Category I structure with some wall and roof sections of other materials in the NonSeismic Category I portions of the building. It is located north of the primary auxiliary building and supported on a four feet thick reinforced concrete foundation. The building is asymmetrical, having changes in elevation of the base mat at various locations in the building. Nominally, the base mat is founded on rock 55 feet below grade. Portions of the building are founded shallower than the above. However, except for the tank farm portion which is founded at grade, support is provided by rock in all cases.

The waste process building is approximately 80 feet wide, 150 feet long and four stories or 120 feet high. Some portions of the bullding have a raised roof for mechanical equipment location. The tank farm portion of the bullding is approximately 57 feet wide by 128.5 feet long and is attached to the south side of the building adjacent to the primary auxiliary bullding. The height of the tank farm building is 65 feet. The volume of the waste processing bullding is approximately $1,350,000$ cubic feet and the volume of the tank farm portion is approximately 450,000 cubic feet.

For the major portion of the waste processing building, the exterior walls, interfor walls, and floor slabs, are reinforced concrete. These exterior walls are a minimum of two feet thick. The floor slabs are cast-in-place concrete over metal deck and supported on steel framing. The roof slab of this portion of the building is reinforced concrete, covered with built-up roofing. Portions of the building have insulated metal siding and metal roof decks covered with insulation and built-up roofing. Steel framing is used in these portions of the buflding instead of reinforced concrete. Seismic Category I requirements are invoked where necessary to protect selected components.

The tank farm portion of the building is constructed of structural steel framing with insulated metal siding and insulated built-up roofing on metal roof deck supported on structural steel. A 20 feet high reinforced concrete dike/wa11 surrounds the refueling water storage tank. 
A reinforced concrete truck loading facility is attached to the west wall of the building for shipping drums or contalners. Below grade pipe tunnels connect the waste process building to the primary auxiliary building. The building contains radioactive liquid, gaseous, and solid waste processing and boron recovery equipment. The tank farm portion of the building houses the make-up water storage tank and the refueling water storage tank.

The waste process building is ventilated by outside air supplied at 120,000 cfm. During the winter months the supply air is heated by steam coils in the supply air units and a hot water unit heater located in the boron waste compartment. Air is exhausted from the bullding through prefilters and HEPA-charcoal-HEPA filtration units to reduce the level of radioactive materials that might be present, and discharged to the plant vent.

\section{ACCOUNT 217 Fuel Storage Building}

The fuel storage bullding is a reinforced concrete Seismic Category I structure located west of the containment structure and supported on a four feet thick reinforced concrete foundation. The building is asymmetrical, having changes in elevation of the base mat at varlous locations in the building. The spent fuel pit is founded on rock 40 feet below grade. Portions of the building are located above this elevation but are supported on rock, except for the cask shipping area which is supported on grade. The building is 97.5 feet wide, 98 feet long and 104 feet high. The volume of the building is approximately 630,000 cubic feet.

The spent fuel storage area is constructed of thick reinforced concrete walls and floor. They are lined on the inside surfaces with continuous seam welded stainless steel plates for leak-tightness. The building exterior walls, interior walls, and floor slabs are reinforced concrete. The exterior walls are a minimum of two feet thick. The floor slabs are cast-in-place concrete over metal deck and supported on steel framing. The roof slab of the fuel storage building is reinforced concrete covered with built-up roofing.

The bullding contains the new fuel storage area, spent fuel storage area, cask storage area, cask decontamination and shipping areas and spent fuel pool cooling and cleaning systems. New and spent fuel are stored in stainless steel racks located in pools of borated water. The 125 ton bridge crane and auxiliary hoists handle the spent fuel casks and new fuel bundles. A crane that runs on rails supported on the operating floor handles the fuel assemb1ies.

The fuel storage building is ventilated by outside air supplied from the primary auxiliary bullding supply system at approximately 60,000 cfm. During the winter months heating is provided by hot water fan coll unit heaters located throughout the building. Air is exhausted from the building through prefilters and HEPA-charcoa1-HEPA exhaust filtration units, to reduce the level of radioactive materials that might be present, and directed to the primary auxiliary bullding exhaust system for discharge to the plant vent. 
PWR ACCOUNT 21

ACCOUNT 218A Control Room and Diesel-Generator Building

The control room and diesel-generator building is a reinforced concrete Seismic Category I structure located east of the primary auxiliary and waste process buildings with a four feet thick reinforced concrete base slab located at grade. Al1 load carrying walls and columns are founded on rock below grade. The overall dimensions of the building are 90 feet wide and 231 feet long. The south portion of the structure, comprising the control room and essential switchgear building, is $90 \mathrm{feet}$ wide, 138 feet long and four stories or 103 feet high. The north portion of the structure, comprising the dieselgenerator and fuel oil storage building, is 90 feet wide, 93 feet long and two stories or 58.5 feet high. The seven day diesel fuel oil storage tanks are located below the north end of the diesel-generator building in a 90 feet by 60 feet room, with a reinforced concrete foundation founded on rock 40 feet below grade. The volume of the control room and essential switchgear building is approximately $1,180,000$ cubic feet. The volume of the combined dieselgenerator and fuel oil storage tank building is approximately 610,000 cubic feet.

The exterior walls, interior walls and floor slabs are reinforced concrete. The exterior walls are a minimum of two feet thick. A reinforced concrete wall separates the redundant diesel-generator units and supports the second floor. The roof of the diesel-generator building and the intermediate floors and roof of the control room building are supported on reinforced concrete columns. All floor slabs are cast-in-place concrete over metal deck and supported on steel framing. The roof slabs of both the control room and diesel-generator buildings are reinforced concrete covered with insulation and built-up roofing. The diese1-generator building houses the diesel-generator units, air intakes for the diesel-generator units, building ventilation equipment, and the diesel engine fuel oil storage tanks. The control room building houses electrical switchgear, motor-generator sets and battery rooms on the first floor. The second and fourth floors are utilized for cable spreading. The main control and computer rooms are located on the third floor. The "over and under" cable spreading areas for the control room permit each electrical division to have an independent cable spreading area, separated by three hour fire walls from the spreading area of the other division.

The control room building HVAC system provides the equipment and redundancy necessary to maintain an operating environment in the control room and the emergency switchgear, battery, and cable spreading areas during all normal and emergency conditions. The control room is also provided with redundant environmental control systems that ensure habitability for extended periods of time following postulated design basis"äccidents. These control room habitability systems are considered to be part of the station engineered safety features (ESF) and consist of redundant emergency air intakes and recirculation charcoal filtration units. Additionally, food supplies, water and other necessities for prolonged isolation in the control room are provided in appropriate storage areas. 
Each diesel-generator compartment in the building is provided with its own ventilation system for use when the diesels are in operation, and a standby heating system for equipment protection under winter conditions. Independent diesel engine combustion air intake structures are provided at the top of the diesel-generator portion of the building. Each space houses an intake air filter and inlet air silencer for one of the redundant diesel-generator units. Heating for other general building areas is provided by a non-safety related hot water heating system serving heating coil units and duct reheat coils throughout the building. Those safety related areas that require heating during shut-down under winter conditions are equipped with electrical space heaters to provide protection to the equipment.

\section{ACCOUNT 218B Administration and Service Building}

The administration and service building is a Non-Seismic Category I structure located north of the turbine building and heater bay. The building is a two story steel frame structure 176 feet wide, 270 feet long and 38 feet high. The building volume is approximately 1,500,000 cubic feet.

This building is supported on reinforced concrete spread footings. The reinforced concrete ground floor is located at grade. The intermediate floor is reinforced concrete supported on metal deck on steel framing. The roof is concrete channel plank covered with insulation and built-up roofing and supported on steel framing. The exterior walls are insulated metal siding and the interior walls are either concrete block or metal partitions. The south wall is common with the heater bay. Most areas are provided with suspended acoustical ceilings.

The building houses the auxiliary boilers, equipment rooms, service shops, storage areas, locker and change rooms, showers, toilet rooms, lunch room, laboratories, general offices and conference rooms.

The administration and service building HVAC systems maintain environmental conditions of normally occupied spaces within the prescribed comfort zone and ensure that temperatures and humidity in other areas are suitable for material storage and equipment operation. Heating and air conditioning is provided by fan cooler/heating units located throughout the building. Supply air is provided by a multi-zone air handling unit and the fan cooler/ heating units. Return air fans exhaust air to the air handling units or atmosphere as required. Supply air to the building is heated as necessary by steam preheaters in the air handling units and hot water coils in the fan cooler/heating units. Hot water and chilled water for the fan cooler/ heating units are supplied from a central hot water heating system and a central chilled water system. Steam for preheating supply air to the air handling unit is supplied by the auxiliary boiler system. Local wall or ceiling fans exhaust air as required from toilet rooms, locker rooms and laboratory fume hoods. All HVAC systems associated with the administration and services building are non-safety related systems. 
PWR ACCOUNT 21

ACCOUNT 218D Fire Pump House Including Foundations For Two Fire Protection Tanks

The fire pump house is a Non-Seismic Category I structure located southeast of the main plant structures, east of the fuel oil storage tank and south of the switchyard. The two Non-Seismic Category I fire protection water tanks are located south of the fire pump house.

The fire pump house is a single story steel frame structure 28 feet wide, 84 feet long and 17 feet high. Two halls eight feet wide and eight feet high enclose the piping between the main structure and the two fire protection water tanks. The building has an approximate volume of 42,000 cubic feet. The building houses switchgear, the fire pumps and the pumps and heat exchanger sets used for freeze protection of the storage tanks.

The bullding is supported on reinforced concrete spread footings. The floor is reinforced concrete supported on grade, and contains trenches for some of the piping and an eight feet by ten feet by eight feet deep pit in the northwest corner where the heating and freeze protection systems steam piping enters from underground. The exterior walls are insulated metal siding. The roof is metal deck covered with insulation and bullt-up roofing supported on steel framing.

The fire pump house is ventilated by roof fans. Heating is provided by steam unit heaters.

Each fire protection tank foundation is a reinforced concrete ring wall 18 inches thick with the mean diameter equal to the tank diameter. The top of the ring wall is six inches above grade, and the bottom is four feet below grade. Tank anchor bolts are set in the ring wall. A compacted sand bed is provided inside the ring wall to support the tank floor.

ACCOUNT 218E Emergency Feedwater Pump Building and ACCOUNT 218G Electrical Tunnel

The emergency feedwater pump building is a reinforced concrete Seismic Category I structure located east of the containment structure and above the electrical cable tunnel. The building extends from the roof of the electrical tunnel seven feet above grade to 27 feet above grade. The portions of the building extending beyond the electrical tunnel are supported on reinforced concrete walls founded on rock... The containment serves as the west wall of the building. The building is approximately 33 feet wide and 80 feet long. The volume is approximately 66,000 cubic feet.

The electrical cable tunnel is a reinforced concrete box type Seismic Category I structure located beneath the emergency feedwater pump house. It is a two-story high structure where it joins the containment. The cable tunnel is divided into two parts by a longitudinal reinforced concrete Seismic Category I wall. This permits safety-related redundant electrical division cables to be separated by a three hour fire wall. The tunnel is approximately 52 feet wide and extends from seven feet above grade to 50 feet below grade 
and is founded on rock. The top slab is the floor of the emergency feedwater pump building. In the area away from the containment, tunnel dimensions, configurations and elevations vary, but are nominally 19 feet in width.

The exterior walls, interior walls, floor slab and roof slab of the emergency feedwater pump building are reinforced concrete. The exterior walls are a minimum of two feet thick. The portion of the floor slab which forms the roof of the electrical tunnel is cast-in-place concrete over metal deck and supported on steel framing. The roof slab of the emergency feedwater pump building is reinforced concrete covered with built-up roofing. The roof is supported on reinforced concrete columns on the west side adjacent to the containment.

The emergency feedwater pump building is ventilated by roof fans. During the winter months, heating is provided by steam heater units.

The emergency feedwater pump bullding contains the emergency feedwater pumps, demineralized water make-up pumps, valve stations and an auxiliary control panel. The electrical tunnel contains cable runs from the containment to the control building and the containment electrical penetration area.

ACCOUNT 218F Radiological Control Access (RCA) Manway Tunne1s

The manway tunnels are reinforced concrete box type Seismic Category I structures, which are founded at various elevations. Where they extend beneath a bullding, the bottom floor of the bullding forms the roof of the tunnel. In other areas the roof is cast-1n-place concrete over metal deck and supported on steel framing. The clear dimensions of the tunnels are eight feet square.

The tunnels provide controlled access to various main plant structures from the administration and service building.

ACCOUNT 218H Non-Essential Switchgear Building

The non-essential switchgear building is a Non-Seismic Category I structure located east of the control buflding and west of the administration and service building. The building is a single story steel frame structure 39 feet wide, 98 feet long and 16 feet high with an approximate volume of 61,000 cubic feet. The bullding is supported on reinforced concrete footings on rock. The reinforced concrete ground floor is located at grade. The roof is concrete channel plank covered with built-up roofing and supported on steel framing. The exterior walls are insulated metal siding and masonry. The east and west walls are common with the administration and service building and control building respectively. The south wall is common with the turbine building heater bay.

The non-essential switchgear bullding is ventilated with roof fans and wall fans. In the winter months, heating is provided by electric space heaters. 
PWR ACCOUNT 21

The building houses most of the non-safety-related electrical switchgear and load centers.

ACCOUNT 218J Main Steam and Feedwater Pipe Enclosures

The main steam and feedwater pipe enclosure areas are reinforced concrete Seismic Category I structures located on the south and north sides of the containment structure. The floors are located 17 feet below grade with the walls extending to competent rock for support except in the portion of the north tunnel near the containment where the roof of the mechanical penetration area forms the floor of the enclosure. The mechanical penetration area is 39 feet high and founded on rock 56 feet below grade. The enclosures are each 18 feet wide ( 20 feet wide on the north side), 115 feet long and 59 feet high, with a total volume of approximately 245,000 cubic feet. The mechanical penetration area is approximately 25 feet wide and 90 feet 1 ong and is also a reinforced concrete Seismic Category I structure.

The exterior walls, interior wall slabs and roof slab are reinforced concrete. The exterior walls are a minimum of two feet thick. The roof of the mechanical area which forms the floor of the north enclosure is cast-in-place concrete over metal deck and supported on steel framing. The roof of the enclosures is reinforced concrete supported on reinforced concrete beams and covered with insulation and built-up roofing.

Each enclosure is ventilated with outside air from a ducted supply fan at a rate of $11,000 \mathrm{cfm}$.

The enclosures support and protect the Seismic Category I portion of the main steam and feedwater piping between the containment and the turbine building.

ACCOUNT 218K Pipe Tunnels

The pipe tunnels are water-sealed reinforced concrete box type structures. Where the pipe in the tunnel is Seismic Category I, the tunnel is designed to be Seismic Category $I$. The tunnels are founded at various elevations. Where they extend beneath a building, the bottom floor of the building is the roof of the tunne1. In other areas, the roof is cast-in-place concrete over metal deck and supported on steel framing. The clear dimensions of the tunne1 are eight feet wide by ten feet high. The tunnels provide protection for piping runs between various buildings.

ACCOUNT 218L Technical Support Center

The technical support center is a windowless reinforced concrete Non-Seismic Category I structure located east of the administration and service building and south of the security building with a reinforced concrete base slab located at grade. The building is 50 feet wide, 80 feet long and 20 feet high with a total volume of approximately 68,000 cubic feet. 
PWR ACCOUNT 21

The exterior walls, interior walls and floor slab are reinforced concrete. The exterior walls are a minimum of two feet thick. The roof slab of the technical support center is reinforced concrete covered with built-up roofing. Most areas are provided with suspended acoustical ceilings. The monitoring display area is provided with a raised floor system.

The technical support center HVAC system maintains environmental conditions within normal comfort zones. Heating and air conditioning is provided by fan cooler/heating units. Supply alr to the building is heated by hot water colls in the fan heating units. Hot water and chilled water for the fan cooler/heating units are supplied from the administrative and services building hot and chilled water systems. Technical support center HVAC systems are non-safety-related systems.

The technical support center houses the necessary instrumentation, control and communication facilities to monitor, control and coordinate site emergencies. The technical support center meets the criteria promulgated in NUREG-0696 "Functional Criteria for Emergency Response Facilities."

ACCOUNT 218P Containment Equipment Hatch Missile Shield

The containment equipment hatch missile shield is a reinforced concrete Seismlc Category I structure located adjacent to the containment structure in the southwest quadrant. The reinforced concrete floor is located at grade at the elevation of the equipment hatch floor. Three of the four walls are supported on a reinforced concrete footing founded on rock. The fourth wall is the containment structure. The structure is ten feet wide, 34 feet long and 40 feet high. The volume is approximately 14,000 cubic feet.

The walls, floor slab and roof slab are reinforced concrete. The exterior walls are a minimum of two feet thick. The wall in front of the equipment hatch is removable. The roof and floor slabs are supported from the walls by reinforced concrete beams. The roof slab is water sealed.

The missile shield provides an entrance enclosure and protects the steel equipment hatch from tornado generated missiles.

ACCOUNT $218 \mathrm{~S}$ Waste Water Treatment Building

The waste water treatment building is located west of the main plant structures. It is a one story prefabricated steel Non-Seismic Category I structure 25 feet wide, 80 feet long and 20 feet high. The building volume is approximately 40,000 cubic feet.

The building is supported on reinforced concrete spread footings. The reinforced concrete ground floor is located at grade. The roof is standing seam metal deck supported by steel framing. The exterior walls are insulated metal siding. Partial interior partitions to separate various equipment are reinforced concrete. 
The building houses a control area, storage area, pumps, tanks and other waste water treatment equipment. Large items, such as the batch holding tank, are located adjacent to the building.

Two waste water holding basins are located close to the waste water treatment building. Both are constructed of reinforced concrete, 100 feet long by 70 feet wide, with the bottoms ten feet below grade and the tops of the walls two feet above grade. The basins are side by side, with one common wall. The pumps for emptying the basins are supported on structural steel at one end of the basin. The steel also supports grating around the pumps to provide access.

Heating is provided by electric unit heaters. The building is ventilated by drawing outside air through wall louvers and exhausting through power roof ventilators.

\section{ACCOUNT 218T Ultimate Heat Sink Structure}

The ultimate heat sink is a Seismic Category I reinforced concrete structure located west of the main plant structures and supported on a four feet thick reinforced concrete foundation. The base mat is founded on rock 31 feet below grade. The building is 50 feet wide, 270 feet long and 128.5 feet high. The building volume is approximately $1,480,000$ cubic feet.

The exterior and interior walls, floor slabs and roof slab are reinforced concrete. The exterior walls are a minimum of two feet thick. The intermediate floor slabs are cast-in-place concrete over metal deck and supported on steel framing. The roof slab is reinforced concrete covered with built-up roofing.

The upper portion of the two middle bays contain two cooling tower cells. The upper portion of the bays north and south of the tower bays are each two story mechanical and electrical equipment rooms. They contain the pumps which transport the service water through underground pipes to the main plant buildings. The bottom portion of the end and middle bays form a basin which provides 30 days of service water to the plant in the event that the Non-Seismic Category I main cooling towers are not operable.

The mechanical and electrical equipment rooms are ventilated with outside air. During the winter months heating is provided by electric unit heaters.

\section{ACCOUNT 218V Contro1 Room Emergency Air Intake Structures}

The control room emergency air intake structures are two Seismic Category I reinforced concrete structures located approximately 500 feet northeast and southwest of the control building. Each box-like structure is ten feet square and seven feet deep inside. The internal volume is 700 cublc feet. The bottom slab is three feet thick and is founded on rock ten feet below grade. Walls are two feet thick. Each top slab is two feet thick, 18 feet square and forms the floor of the security area around the air intake pipe. A 
manhole in the top slab allows access to the radiation monitors and other equipment inside the structure. A seven feet high security fence is located around the perimeter of each slab.

Each afr intake structure is capable of providing air required to ensure habitability of the control room for abnormal occurrences during plant operation. 


\section{ACCOUNT 22 REACTOR PLANT EQUIPMENT}

Mechanical key parameters related to the reactor plant are given in Items 22 through 27 and 34 of Table 3-1. Reactor Plant equipment configuration in the form of General Arrangement drawings is given in Figures 3.2 through 3.4. The table and figures supplement and amplify the following discussion of Account 22 .

The reactor plant equipment produces and supplies saturated steam to the turbine-generator unit, which converts the thermal energy to electric energy. The NSSS is a standard Westinghouse PWR system and includes the reactor pressure vessel and internals, control rod system, reactor core cooling system, pressurizing system, residual heat removal system, safety injection system, containment spray system, combustible gas control system, radioactive waste system, chemical and volume control system, fuel handling and storage system, and associated instrumentation and controls for these systems.

The Balance of Reactor Plant (BORP) systems include the inert gas system, reactor water make-up system, coolant treatment and recycle system, fluid leak detection system, nuclear service water system, primary component cooling water system, and associated instrumentation and control for these systems.

Interconnecting piping systems are included with each NSSS and balance of reactor plant auxiliary system. They comprise the piping, fittings, valves, containment piping penetrations, steam traps, strainers, specialties, hangers and supports, pipe whip and seismic restraints, insulation and other components required for a complete system. Materials and wall thicknesses are chosen based on the service conditions and operational requirements of each system. The factors generally considered include: temperature, pressure, corrosion resistance, abrasion resistance, fluid purity requirements and cost. Carbon steel is used for steam (below $750^{\circ} \mathrm{F}$ ), clean water, air, oil and other services without special requirements. Other materials used include stainless steel and stainless steel tubing.

The piping systems are designed for American Nuclear Society Safety Class 1, 2 or $3(\mathrm{SC} 1, \mathrm{SC} 2, \mathrm{SC} 3)$ or Non-Nuclear Safety (NNS). Safety-related piping systems that are not part of the primary coolant boundry, such as for the emergency core cooling and auxiliary cooling systems, are designed for SC2 or SC3. Non-safety-related piping systems that do not interface with safety class systems are designed for NNS.

The paragraphs given below provide brief technical descriptions of the reactor plant equipment accounts, in order to afford guidance to the more detailed descriptions of the pages that follow.

Account 221 Reactor Equipment (reactor vessel, reactor core, rod cluster control assemblies, and control rod drive mechanisms) 
Account 222 Main Heat Transfer and Transport System (reactor coolant pumps, steam generators, primary piping, pressurizer, pressurizer relief tank, and safety and relief valves)

Account 223 Safeguards System (residual heat removal system, safety injection system, containment spray system, and combustible gas control system)

Account 224 Radwaste Processing System (1iquid waste, steam generator blowdown processing, gas waste and solid waste systems)

Account 225 Fuel Handling and Storage System (new fuel storage, spent fuel storage, new and spent fuel handling, and spent fuel pool cooling and purification equipment and systems)

Account 226 Other Reactor Plant Equipment $\left(\mathrm{H}_{2} / \mathrm{N}_{2}\right.$ gas supply system, reactor make-up water system, chemical and volume control system, boron recycle system, fluid leak detection system, nuclear service water system, primary component cooling water system, maintenance equipment and sampling system)

Account 227 Reactor Plant Instrumentation and Control (bench-board, panels and racks, process computer, monitoring systems, plant control systems and associated instruments) 
ACCOUNT 221 Reactor Equipment

Reactor equipment includes the reactor vessel, fuel core, control rod clusters and their drive mechanisms, and various internal support mechanisms. The reactor vessel serves to contain the light water moderator coolant. The coolant flows through the fuel core where it picks up heat and transports it to the external steam generators for the production of steam.

\section{Reactor Vessel}

The reactor pressure vessel is a vertical cylindrical stainless steel clad carbon steel vessel, with a welded hemispherical bottom head and a removable flanged and gasketed hemispherical upper head. The vessel contains the core, core supporting structures, control rods and other parts directly associated with the core. The vessel has inlet and outlet nozzles located in a horizontal plane just below the reactor vessel flange but above the top of the core.

The reactor core is enclosed by a shroud that forms an annulus with the inner wall of the reactor vessel. Coolant enters the vessel through the inlet nozzles and flows downward through the annulus to the bottom of the reactor. Then the coolant flow is directed upward through the core. Thermal energy from the nuclear fission reaction heats, but does not boil, the pressurized water in the core. The heated water is directed to the reactor vessel outlet nozzles. It is then pumped through the four primary water loops to the steam generators and returned to the inlet nozzles.

\section{Reactor Core}

The core is approximately cylindrical in shape and consists of fuel assemblies containing the fissionable material. The fuel is in the form of slightly enriched uranium dioxide pellets which are enclosed in Zircaloy-4 tubes. The tubes (rods) are then combined to form the fuel assemblies. Pressurized water flowing upward through the core acts as moderator, coolant, and a solvent for the boric acid (chemical) "shim."

The reactor core is of the multi-region type. Fuel assemblies having the highest enrichment are placed on the periphery of the core; those with lower enrichments are mixed in the central region of the core in a pattern that yields the most uniform power distributions. At the time of refueling, the central region fuel assemblies having the lowest enrichments are removed and outer region fuel assemblies are shifted inward in accordance with a selected reload pattern. Fresh fuel is then added at the core periphery. This method ensures the desired power distribution and results in the optimum power output for the entire core.

Reactor control is provided by neutron-absorbing control rod clusters that enter the reactor vesse1 through the upper head and by a neutron absorber (boric acid) dissolved in the reactor coolant. The control rod clusters are used to follow load changes, to provide reactor trip capability, and to furnish control for slight deviations in reactivity due to temperature. 
In the event of a reactor trip, the control rods fall into the core by gravity. The concentration of the boric acid is varied during the life of the core to compensate for changes in reactivity that occur with fuel depletion, as well as to compensate for the reactivity associated with the xenon transients arising from power level changes.

\section{Rod Cluster Control Assemblies}

The control elements of a rod cluster control assembly consist of cylindrical neutron absorber rods, having approximately the same dimensions as a fuel rod and connected at the top by a spider-like bracket to form rod clusters. Each rod cluster element incorporates rods of silver-indium-cadmium absorber material extending the full length of the core. Stainless steel tubes encapsulate the absorber material, isolating it from the reactor coolant. Rod cluster controls provide operational reactivity control and can shut the reactor down at all times, even if the most reactive rod were prevented from entering the core.

Control Rod Drive Mechanisms

The control rod clusters are positioned by latch-type magnetic jack drive mechanisms mounted on the reactor vessel head.

The drive mechanism consists of five major components: 1) pressure housing, 2) operating coil stack, 3) internal latch assembly, 4) position indicator coil stack, and 5) control rod cluster drive shaft.

A11 moving components of the mechanism are contained in a stainless steel pressure housing attached to a head adapter. The adapter is welded to the reactor vessel and constitutes, in effect, an integral part of the vessel. The housing is completely free of mechanical seals and of penetrations for hydraulic and electric lines.

\section{ACCOUNT 222 Main Heat Transfer and Transport System}

The reactor coolant system (RCS) consists of four similar heat transfer loops connected in parallel to the reactor pressure vessel. Each loop contains a reactor coolant pump, steam generator and associated piping and valves. In addition, the system includes a pressurizer, a pressurizer relief tank, interconnecting piping and instrumentation necessary for operational control. All of the above components are located in the containment building.

During operation, the RCS transfers the heat generated in the core to the steam generators where steam is produced to drive the turbine-generator unit. Borated demineralized water is circulated in the RCS at a flow rate and temperature consistent with controlling the reactor core thermal-hydraulic performance. The water also acts as a neutron moderator and reflector, and as a solvent for the neutron absorber used in chemical "shim" control. 
Reactor Coolant Pumps

The reactor coolant pumps are identical single-speed centrifugal units driven by air-cooled, three-phase induction motors. The shaft is vertical with the motor mounted above the pump. A fly-wheel on the shaft above the motor provides additional inertia to extend pump coast-down. Coolant enters at the bottom of the pump and is discharged from the side.

\section{Steam Generators}

The steam generators are identical vertical shell and "U"-tube evaporators with integral moisture separating equipment. The heated reactor primary coolant flows through the inverted "U"-tubes, entering and leaving through the nozzles located in the hemispherical bottom head of the steam generator. Steam is generated in the secondary loop water on the shell side at 1000 psia. The generated steam flows upward through the integral moisture separators and steam drum to the outlet nozzle at the top of the steam generator.

$\underline{\text { Primary Piping }}$

The reactor primary coolant loop piping is specified in sizes consistent with system requirements. The inside diameter of the hot leg primary piping from the reactor vessel outlet to the steam generator inlet is 29 inches. The inside diameter of the cold leg return 1 ine to the reactor vessel from the reactor coolant pump discharge is 27-1/2 inches. The inside diameter of the primary piping between the steam generator outlet and the reactor coolant pump suction is increased to 31 inches to reduce pressure drop and improve flow conditions to the pump suction.

\section{Pressurizer}

The conditions in the reactor coolant system are controlled by the use of a single pressurizer, where water and steam are maintained in equilibrium by electrical heaters or water sprays. Steam is formed by the heaters or condensed by the pressurizer sprays, to minimize pressure variations caused by contraction and expansion of the reactor coolant inventory.

The pressurizer is a vertical, cylindrical vessel with hemispherical top and bottom heads. Electrical heaters are installed through the bottom head of the vessel while the spray nozzle, relief and safety valve connections are located in the top head of the vessel.

\section{Pressurizer Relief Tank}

The pressurizer relief tank is a horizontal, cylindrical vessel with hemispherical ends. Steam from the pressurizer safety and relief valves is discharged into the pressurizer relief tank through a sparger pipe below the relief tank water level. The steam introduced into the tank is condensed and cooled by mixing it with water that is near ambient temperature. 


\section{Safety and Rellef Valves}

The pressurizer safety valves are of the totally enclosed pop-type. The valves are spring-loaded, self-activated with back-pressure compensation. The power operated relief valves (PORV) limit system pressure for large power mismatches. They are operated automatically or by remote manual control. Remotely operated block valves are provided to isolate the inlet to the PORV if excessive leakage occurs.

\section{ACCOUNT 223 Safeguards System}

The safeguards system is provided to mitigate the consequences of postulated accidents. The system consists of the residual heat removal (RHR) system, safety injection system (SIS), containment spray system (CSS), and combustible gas control (CGC) system. Other engineered safety features are discussed under other accounts. The containment recirculating filter system and the control room habitability system are discussed under Accounts 212 and 218A respectively. The primary component cooling water system and the nuclear service water system are discussed under Account 226.

\section{Residual Heat Removal (RHR) System}

In compliance with General Design Criteria 34 and 35 of Appendix A to 10CFR50, the primary function of the residual heat removal system is to transfer fission product decay heat energy from the core and RCS during plant shut-down and refueling operations. The system is also employed in conjunction with the safety injection system for emergency core cooling under postulated pipe rupture accident conditions. The system may also be used to transfer refueling water between the refueling cavity and the refueling water storage tank at the beginning and end of refueling operations.

The RHR system consists of two trains that are completely independent and redundant to each other with respect to safeguards activities.

Under the normal residual heat removal mode, the system is capable of:

a. Cooling the reactor coolant from $350^{\circ} \mathrm{F}$ to $140^{\circ} \mathrm{F}$ within 20

hours after shut-down with both pumps and both heat

exchangers in operation.

b. Maintaining reactor coolant temperature as refueling progresses with only one pump and one heat exchanger.

c. Draining the refueling cavity to the refueling water storage tank (RWST) with one residual heat removal pump, without the transfer being on the critical path for refueling.

Under the safeguards heat removal mode, for a postulated large loss-ofcoolant-accident (LOCA), the system is capable of: 
a. Injecting sufficient water into the reactor coolant system from the refueling water storage tank to maintain short term core flooding and cooling.

b. Cooling sufficient containment sump water and recirculating it into the RCS to maintain long term core flooding and cooling.

The RHR system heat exchangers are cooled by the primary component cooling water system, which is described under Account 226.

Safety Injection System (SIS)

The safety injection system supplies borated water to the RCS to limit fuel rod cladding temperature during a postulated LOCA. In the event of a postulated steam line break, the system supplies a highly concentrated boric acid solution to provide rapid shut-down.

The SIS has three modes of operation: Injection phase (passive and active), cold leg recirculation, and hot leg recirculation.

During the passive injection phase, accumulator tanks (one per loop) rapidly inject borated water, stored at approximately $650 \mathrm{psig}$, into the cold legs of the reactor coolant system. The contents of the accumulators are discharged automatically if depressurization of the RCS causes a reversal of the pressure differential across the accumulator check valves.

The active injection phase is handled in two ways: a low-head operation for injection of borated water into the RCS for large potential breaks, which results in rapid blowdown and depressurization; and a high-head operation for injection into the RCS for small potential breaks, which results in slow blowdown and depressurization.

Following a postulated LOCA, emergency coolant flow is maintained to the RCS cold legs after the RWST is emptied by recirculating water from the containment sump via the RHR system pumps. After approximately 24 hours of cold leg recirculation, the recirculation flow is shifted to the RCS hot legs. Transfer from the injection phase to the cold leg recirculation phase is automatic. Transfer from cold leg recirculation to hot leg recirculation is remote manual.

The multiple paths in the accumulator subsystem are completely independent and redundant to each other with respect to safeguards activites. The safety injection subsystem consists of two trains that are completely independent and redundant to each other with respect to safeguard activities.

\section{Containment Spray System (CSS)}

In the event of a postulated LOCA, the containment spray system is capable of: 
a. Serving as an active containment heat removal system in conjunction with the RHR system to limit the containment pressure to values below the design pressure, in compliance with General Design Criterion 38 of Appendix A to 10CFR50.

b. Removing sufficient containment airborne iodine to limit external doses to values below those set by 10CFR100, in compliance with General Design Criterion 41 of Appendix A to 10CFR50.

The combined energy removal rate provided by the CSS and RHR System, in its safeguards mode, is sufficient to reduce containment pressure such that leakage is reduced to one-half of the design leakage within 24 hours after a postulated LOCA.

The CSS system first functions on water from the RWST and then on water recycled from the containment sump. Activation of the injection phase of the CSS is automatic. Activation of the recirculation phase of the CSS is automatic, but operator action is required to isolate the depleted RWST.

The cSS consists of two independent, redundant trains with the exception of the common RWST and spray additive tank.

The RWST is designed to supply the safety injection, the charging, the residual heat removal and the containment spray pumps for at least 20 minutes during the injection phase of a design basis accident or to supply the refueling water. The CSS heat exchangers are cooled by the primary component cooling water system, which is described under Account 226.

\section{Combustible Gas Control (CGC) System}

The combustible gas control system provides concentration control of hydrogen in the containment atmosphere following a postulated LOCA. The system is capable of removing sufficient hydrogen from the containment atmosphere following a postulated LOCA to assure that hydrogen concentration in the containment does not exceed four percent by volume.

The system consists of one recombiner package with redundant active components. The active components are completely independent and redundant to each other and are powered from redundant Class $\mathrm{lE}$ buses.

In the postulated event of complete hydrogen recombiner system failure or unavailability, the containment atmosphere hydrogen concentration is contro1led by feed and bleed procedures using the compressed air and exhaust filter systems.

The hydrogen recombiner is located inside the containment. The associated controls are in the main control room. The system is manually started after a postulated LOCA and functions with no further operator action. 
The concept of radioactive waste processing for the plant is based on an examination of all potential pathways of radioactive release to the environment. The transport of radioactivity from the primary coolant system to various parts of the plant during normal operation is traced and evaluated in order to determine the performance of each process interposed between the source of radioactivity: and the subsequent pathways to the environment. Necessary processing and treatment equipment is provided to keep the release of radioactivity to the environment as low as is reasonably achievable and in compliance with 10CFR20 and Appendix I of 10CFR50.

There are three radwaste systems: The radioactive liquid waste system, the radioactive gas waste system, and the radioactive solid waste system. All potentially radioactive liquids, gases and solids are collected and processed according to physical and chemical properties, and the radioactive concentrations. Care is taken in the design to minimize the mechanical leakage paths in these systems in order to limit unprocessed leakage.

\section{Liquid Waste System}

The radioactive liquid waste system is designed to collect and process potentially radioactive liquid wastes for recycle or for release to the environment.

Radioactive liquid wastes are segregated into six streams, namely, non-aerated reactor coolant (normally processed in the boron recovery system), aerated equipment drains, miscellaneous waste (floor drains, decontamination waste, etc.), detergent waste, regenerant waste, and hot laboratory chemical waste. Each stream is independently processed with treatment components selected based on the chemical/radiochemical composition and the uftimate disposition of the stream.

Two collection tanks are provided for each major (miscellaneous waste, detergent waste and regenerant waste) input stream with automatic valves on their respective inlet lines. The valves are interlocked so that one or the other is always in the open position, permitting complete isolation of a collection tank prior to processing. This design eliminates the potential of a collection tank's contents belng contaminated by uncontrolled inputs after sampling or chemical adjustment. The isolation capability is also provided for the major input stream test tanks; however, isolation is done manually. Two 100 percent capacity pumps are provided with each set of major input stream collection tanks and test tanks. Piping and valving is provided such that each pump associated with a set of tanks may take suction from either tank or may recirculate to either tank.

Collection tank capacity for all drainage streams are based on accommodating 30 days of average daily input plus one anticipated transient plus 20 percent contingency plus an added ten percent overall margin of design. Other collection tanks are sized based on operating requirements and operating experience for the particular waste stream. Tank pumps are designed 
to recirculate two complete tank volumes within an eight hour period in order to assure adequate mixing for sampling, analysis and chemical adjustment prior to process or transfer of the tank contents. Dual components and strategic interconnections between treatment streams are provided in order to provide operational flexibility.

Two mixed bed demineralizers are provided in the miscellaneous waste stream. These demineralizers are utilized for either series or parallel operation depending on the radiochemical composition of the process stream. When aligned in series, the decontamination factor (DF) for the demineralizers is $10^{3}$. When used in parallel, one demineralizer is utilized as a spare and the demineralizer $D F$ is $10^{2}$. In order to protect these demineralizers, two 100 percent capacity reverse osmosis units are provided to pretreat the water. These components are effective in removing organics and trace amounts of ofl which may be present in the miscellaneous waste system. A DF of 10 is credited to this component.

The liquid waste system is capable of processed water recycle. All water used for system make-up is deaerated utilizing a vacuum degasifier. The main source of detergent wastes is the rad-laundry. The processed water originating from this facility is reused in the laundry. Processed water is also used for decontamination operations. In the event that the processed water quality in a test tank is sub-standard, the capability exists for reprocessing the liquid.

Process parameters are monitored and the treatment system flow is controlled from the radioactive waste management control room located in the radioactive waste processing building. If it is ever necessary to discharge liquid to the environment, it is monitored for compliance with the requirements of 10CFR50, Appendix I and 10CFR20.

Steam Generator Blowdown Processing System

Secondary side water chemistry control specifications require continuous blowdown from each steam generator to achieve optimum effectiveness from the steam generator chemistry control program.

The steam generator blowdown processing system is designed to accommodate blowdown under a wide range of conditions. A minimum blowdown rate of five gpm per generator is required for chemistry control purposes. Assuming steam generator primary to secondary side leakage of $0.1 \mathrm{gpm}$ coincident with fuel defects of 0.5 percent, it is possible to have continuous blowdown through the ion exchangers, provided the resin is periodically renewed. Under other conditions of steam generator in-leakage, a continuous blowdown rate of 12.5 gpm maximum per generator is provided to maintain proper chemistry control in the steam generator. The design basis of the processing portion of the blowdown processing system is $50 \mathrm{gpm}$ total, permitting $12.5 \mathrm{gpm}$ continuous blowdown from each steam generator. To facilitate the removal of any accumulated solids from the tube sheet, the system is designed to accommodate, through the bypass portion of the system, a blowdown rate of $50 \mathrm{gpm}$ per steam generator or 200 gpm total. 
PWR ACCOUNT 22

Although processed system effluent is normally recycled to the main condenser, the system is designed to permit continuous release of processed steam generator blowdown fluid diluted with condenser circulating cooling water, provided the concentrations of radionuclides do not exceed the allowable limits.

As this system performs no function related to safe shut-down of the plant, a11 components downstream of the blowdown processing system isolation valve are classified as non-nuclear safety (NNS) class. Piping and valving inside and outside the containment up to the blowdown processing system isolation valve are classified American Nuclear Society Safety Class 2 .

The reactor unit has four steam generators and each generator has its own blowdown and sample lines. Flash tanks and pumps are provided for each steam generator, in order to balance the steam flow rates from the generators. Each flow of blowdown fluid is individually flow rate controlled before the blowdown lines are manifolded outside of the containment barrier.

Fluid from the steam generator manifold enters under pressure into a shell and tube heat exchanger. In the exchanger, the fluid temperature is reduced by plant service cooling water which is controlled to maintain a constant blowdown fluid exit temperature. The pressure is then reduced across a pressure control valve, and the blowdown fluid is directed through an inlet filter, a radiation monitor and into a surge tank. From the surge tank the fluid is pumped to the discharge line through a second radiation monitor by the discharge pumps. The rate of discharge is controlled by level instrumentation in the surge tank so that tank level is maintained nearly constant.

Normally, when the radioactivity of the blowdown fluid is below plant operating limits, the blowdown fluid follows the path described above, and receives no processing except filtering and cooling. Major steam generator leakage may cause the activity of the secondary side to be above a predetermined $11 \mathrm{mit}$. In this event, automatic isolation of the system is provided when the radiation monitor located upstream of the surge tank triggers an alarm in the control room and trips closed the control valve downstream of the heat exchanger. As the surge tank level decreases, the control valve throttles down the discharge flow, and a low surge tank level switch shuts of $f$ the pumps.

In the event the first radiation monitor fails to detect the activity, a redundant monitor, located. on the discharge side of the surge tank, trips closed a valve isolating the system. In this case, with the pumps deadheaded, mini-flow lines protect the pumps. The surge tank level increases until a high level switch trips closed the control valve downstream of the heat exchanger, thereby terminating blowdown. Operator action can also shut of $f$ the pumps.

The processing portion of the system consists of two cation demineralizers and two mixed bed demineralizers, connected in series, a filter and instrumentation that provides process related information used to assess system performance. After processing, the fluid normally is recycled to the main condenser, but can be discharged through the discharge line when required. 
The processing system is designed to operate continuously provided the resin beds are periodically renewed. Resin bed exhaustion is signaled by alarms on $\mathrm{pH}$ meters located between each pair of series connected demineralizers, and between the cation and mixed bed demineralizers. A pH change indicates breakthrough of the upstream bed, but the fresh downstream bed continues to process the flow. Process is then diverted through the downstream bed, spent resin is transferred to the solid waste system, and new resin is charged to the demineralizer. This fresh demineralizer is then valved back on line as the new downstream bed.

Gas Waste System

The radioactive gas waste system is designed to provide storage for shortlived isotope decay and controlled release to the environment of fission product gases removed from the volume control tank, the boron recycle evaporator, the reactor coolant drain tank and the reactor vessel.

The system continuously accepts inputs from the various gas waste sources. Since the major input to the system is from the volume control tank which contains significant amounts of hydrogen, a means for hydrogen removal is incorporated into the system design. This serves two functions, namely the reduction of the quantity of gas that must be stored and the elimination of a potentially explosive constituent from the process stream.

The system provides sufficient holdup of the gas to allow the short-lived isotopes to decay so that the only major dose contributor released to the environment is $\mathrm{Kr}_{85}$. Releases from the system are performed on a controlled basis so that environmental discharges are made when favorable meteorological conditions exist. In addition, all releases are monitored for compliance with the requi rements of 10 CFR 20 and 10CFR50 Appendix $I$.

Four gas decay tanks are provided. These tanks are used in the following manner: one tank filling, one tank decaying, one tank releasing, and one tank on standby.

Two recombiner and two gas compressor packages are provided. In both cases, one unit is normally used with the other on a standby basis.

The process is monitored and controlled from the radioactive waste management control room located in the radioactive waste processing building.

\section{Solid Waste System}

The radioactive solid waste system is designed to collect, process and store, for eventual off-site disposal, the radioactive solid wastes generated by reactor plant operation and maintenance. Radioactive inputs to the system are spent demineralizer resins, evaporator and process concentrates, expended filter cartridges and other miscellaneous solid waste and refuse. 
PWR ACCOUNT 22

It is advantageous to minimize the volume of solid radioactive material for off-site disposal, since the costs associated with their shipment and burial are continuously increasing. This activity is accomplished in the volume reduction system. Water recovered from the volume reduction process is processed in the liquid waste system and recycled within the plant.

Two collection tanks are provided for the accumulation of evaporator and process concentrates. This permits the isolation of a given tank for processing while the other tank is aligned for continued concentrates input. Two redundant concentrate tank pumps are provided. Each pump is designed to recirculate two complete tank volumes within an eight hour period in order to assure adequate mixing for sampling, analysis and chemical adjustment prior to processing.

A single spent resin storage tank and spent resin transfer pump are provided. In addition, a resin sluicing system consisting of two redundant sluice pumps and sluice filters is provided. The sluice system uses water from the spent resin storage tank to sluice resin from the various demineralizer vessels to the spent resin storage tank.

Evaporator and process concentrates, spent resins and hot laboratory waste concentrates are processed through the volume reduction system, where they are dewatered and intimately mixed with asphalt. The mixture is then poured into suitable containers. Radioactive filter cartridges are remotely removed from the filter vessels. They are transported to the solid waste handling area and placed inside the containers along with the asphalt mixture. Following solidification, the containers are "topped off" for off-site disposal.

Miscellaneous dry wastes such as rags and paper are accumulated during plant operation, compacted by a hydraulic compactor to reduce their volume, and packaged in suitable containers for off-site disposal.

Storage is provided for both filled and empty containers. The hot storage area is serviced by suitable remote handling equipment with visual monitoring provided. In addition, the design incorporates an area for decontamination of containers prior to loading on a truck for off-site shipment.

All wastes are solidifed, packaged and shipped off-site in accordance with 10CFR73 and 49CFR172.

\section{ACCOUNT 225 Fuel Handling and Storage System}

The fuel handling and storage system is required to process and inspect new fuel shipped to the site, perform refuelings of the reactor, store spent fuel, and prepare shipments of spent fuel for off-site processing.

\section{New Fuel Storage}

The new fuel storage facilities are located adjacent to the spent fuel pool in the fuel storage building. The storage vault is a rectangular concrete 
room containing the new fuel storage racks which securely hold the new fuel in a vertical position. Space is provided for handling and storage of 75 new fuel assemblies which is equal to a one-third core load plus ten spare assemblies.

\section{Spent Fuel Storage}

The spent fuel storage pool is designed to accommodate $1-1 / 3$ cores (258 fuel assemblies) plus 22 additional spare spaces. The spent fuel assemblies are stored in racks located at the bottom of the spent fuel pool. The spent fuel pool is a water-filled cavity constructed of reinforced concrete, with stainless steel lined interior surfaces. Center-to-center rack spacing is 21 inches, which assumes $k_{\text {eff }} \leq 0.90$, even if the fuel is immersed in unborated water.

A minimum of 10.5 feet of water above the highest fuel element position is provided to permit fuel handling without exceeding $2.5 \mathrm{mr} / \mathrm{hr}$ at the fuel handiing bridge. The concrete walls provide adequate radiation protection from irradiated fuel assemblies.

New and Spent Fuel Handling

New fuel assemblies are received by truck or rail, removed one at a time from their shipping containers and placed in new fuel racks in the new fuel area by the fuel storage building crane. Alternatively, they may be placed directly into available fuel storage racks in the spent fuel pool. In this case they are placed in the new fuel elevator by the fuel storage building crane, lowered into the fuel storage area by the new fuel elevator and stored in the fuel storage racks.

Fuel is moved between the reactor vessel and the refueling canal via the reactor vessel refueling cavity by the refueling machine. The refueling cavity and the refueling canal are flooded with water from the refueling water storage tank during shut-down for refueling. After the reactor head is raised, this water is pumped into the reactor vessel by the RHR system and overflows into the refueling cavity and refueling canal. A rod cluster control changing fixture is located in the refueling canal for transferring control elements from one fuel assembly to another.

The fuel transfer system is used to move fuel assemblies between the refueling canal in the containment building and the spent fuel pool in the fuel storage building. After a fuel assembly is placed in the fuel transfer system fuel container, the lifting arm pivots the fuel assembly to the horizontal position for passage through the fuel transfer tube. After the transfer car transports the fuel assembly through the transfer tube, the lifting arm at that end of the tube pivots the assembly to a vertical position so that the assembly can be lifted out of the fuel container. In the fuel storage building, fuel assemblies are moved about by the fuel handling machine. 
PWR ACCOUNT 22

Spent Fuel Pool Cooling and Purification Equipment and Systems

The spent fuel pool cooling and purification system removes the decay heat generated by the fuel elements stored in the spent fuel pool. It also maintains the purity and optical clarity of the spent fuel pool water. In addition, after reactor refueling, the system purifies the water in the reactor vessel cavity and returns the water to the refueling water storage tank.

Two separate and redundant spent fuel pool cooling loops are provided to preclude loss of cooling by failure of a pipe, valve or other loop component. Either spent fuel cooling loop is capable of maintaining the pool temperature at $125^{\circ} \mathrm{F}$ or below when there is one-third of a core of spent fuel in the pool. When there is $1-1 / 3$ cores of spent fuel in the pool, one cooling loop will maintain the pool temperature at $175^{\circ} \mathrm{F}$ while both loops will maintain the temperature at $125^{\circ} \mathrm{F}$.

Two separate and redundant spent fuel pool purification system loops are provided to match the fuel pool cooling system configuration. Either loop can process a volume equal to one-third of the fuel pool inventory per day. The system only operates when the pool water temperature does not exceed $130^{\circ} \mathrm{F}$.

All liquid connections at the spent fuel pool are at an elevation such that no pipe failure would drain the pool to the extent that spent fuel is exposed. The cooling and purification loops are capable of cross-connection if necessary.

ACCOUNT 226 Other Reactor P1ant Equi pment

This section discusses the remainder of the reactor plant equipment, such as the $\mathrm{H}_{2} / \mathrm{N}_{2}$ gas supply system, reactor make-up water system, chemical and volume control system, boron recycle system, fluid leak detection system, nuclear service water system, primary component cooling water system, maintenance equipment and sampling system.

\section{$\mathrm{H}_{2} / \mathrm{N}_{2}$ Gas Supply System}

This system provides nitrogen and hydrogen from commercial cylinders to nuclear components as necessary for operation and testing. The depletion of cylinders is indicated in the control room so that they may be replaced.

The system pressurizes the accumulators to 650 psig with nitrogen, provides nitrogen blanketing in the various tanks, and supplies hydrogen to the hydrogen recombiners for equipment testing. The system also provides and maintains a hydrogen concentration in the primary coolant through the volume control tank. This system has no safeguard functions.

\section{Reactor Make-up Water System}

The reactor make-up water system provides for the storage and distribution of 
reactor grade water. It also provides the storage capacity for recycled water from the boron recycle system and the liquid waste processing system. Since the water contains tritium, its use is restricted.

The system serves no safeguard functions, and is designed as American Nuclear Society Non-Nuclear Safety, Non-Seismic Category I, except for the containment penetration and isolation valves. The capacity of the reactor make-up water storage tank is 112,000 gallons. The tank is located indoors where a temperature of at least $50^{\circ} \mathrm{F}$ is maintained. The tank is provided with an internal diaphragm to exclude exposure to air. Demineralized make-up water is supplied from the demineralized water storage tank.

The reactor make-up water system includes two 100 percent capacity reactor make-up water pumps. The system provides water to the recycle evaporation packages, spent resin storage tank, waste evaporator package, chemical mixing tank, pressurizer relief tank, reactor coolant pump standpipes, boric acid batching tank, boric acid blender, boron thermal regeneration demineralizers, recycle demineralizers, spent fuel pool, resin fill tank, spray additive tank, and evaporator bottom holding tank. The design flow rate of $150 \mathrm{gpm}$ is based on the supply requirement for emergency cooling of the pressurizer relief tank.

Chemical and Volume Control System (CVCS)

The chemical and volume control system is designed to maintain required water inventory in the reactor coolant system and seal water injection flow to the reactor coolant pumps. The system also controls reactor coolant water chemistry conditions, activity level and soluble chemical neutron absorber concentration; shares emergency core cooling functions; and provides means for filling, draining and pressure testing of the RCS.

During power operation, a continuous "feed-and-bleed" operation is maintained to and from the RCS. Letdown water leaves the RCS and flows through the shell side of the regenerative heat exchanger where it gives up its heat to make-up water being returned to the RCS. The letdown water then flows through orifices where its pressure is reduced, through the letdown heat exchanger, and through a low-pressure letdown valve where a second pressure reduction occurs. After passing through a mixed bed demineralizer, where ionic impurities are removed, the water flows through the reactor coolant filter, and into the volume control tank via a spray nozzle. Alternate paths downstream of the mixed bed demineralizers are used to direct the letdown flow to the boron thermal regeneration system (BTRS) or the boron recycle system (BRS). The vapor space in the volume control tank contains hydrogen which dissolves in the coolant. Any fission gases present are removed from the system by venting of the volume control tank continuously, intermittently, or prior to plant shut-down. Continuous purging of the volume control tank considerably reduces the activity level of the primary coolant. 
The charging pumps take the coolant from the volume control tank and direct it along two parallel paths: 1) to the RCS through the tube side of the regenerative heat exchanger, and 2) to the seals of the reactor coolant pumps. The streams directed to the seals divide with some water flowing into the RCS and the remainder leaving the pumps as controlled seal leakage. From the pumps, the controlled leakage water goes to the seal water heat exchanger and then returns to the volume control tank for another circuit. If the normal letdown and charging path through the regenerative heat exchanger is not operable, water is injected into the RCS through the reactor coolant pump seals, and returned to the volume control tank through the excess letdown heat exchanger and seal water heat exchanger.

Surges from the RCS accumulate in the volume control tank unless a high water level in the tank causes flow to be diverted to the boron recycle or waste processing systems.

An alternate flow path downstream from the purification demineralizers directs letdown coolant through the thermal regeneration demineralizers to effect boron concentration changes during load following operations. A throttling valve in the letdown line is used to direct the flow through the demineralizers.

\section{Boron Recycle System (BRS)}

The boron recycle system receives and recycles reactor coolant effluent for reuse of the boric acid and make-up water. The system processes the reactor coolant effluent by means of demineralization and gas stripping, and uses evaporation to separate and recover the boric acid and make-up water.

When water is directed to the BRS, the flow passes first through the recycle evaporator feed demineralizers and filters and then into the recycle holdup tanks. The recycle evaporator feed pumps are used to transfer liquid from one recycle holdup tank to the other if desired.. When sufficient water is accumulated to warrant evaporator operation, the recycle evaporator feed pumps take suction from the selected recycle holdup tank. The fluid is directed through the recycle evaporator, where dissolved gases: (i.e. hydrogen, fission gases, etc.) are removed in the stripping. column before it enters the evaporator she11. These gases are directed to the gaseous waste processing system.

The distillate from the evaporator package flows to the test tanks. A radiation monitor is installed in the ine from the distillate cooler to the test tanks. On detection of high activity, the distillate is returned to the recycle holdup tank.

Prior to pumping water from the test tanks to the reactor make-up water storage tank, the contents are thoroughly mixed by the test tank pumps operating in a recirculation mode. If further cleanup is required, the contents are directed through the recycle demineralizers and filters and returned to the test tanks. Excess water is discharged to the environment. 
The evaporator concentrates the boric acid solution until a four percent by weight solution is obtained. The accumulated batch is normally transferred directly to the boric acid tanks in the CVCS through the recycle evaporator concentrates filter. Before transferring the boric acid from the evaporator to the boric acid tanks, it is analyzed and returned to the recycle holdup tanks for reprocessing, if it does not meet the required chemical standards.

Connections are provided so that the recycle evaporator can be used as a waste evaporator, if required.

All portions of the BRS which contain concentrated boric acid solution are located within a heated area in order to maintain solution temperatures at $\geq 65^{\circ} \mathrm{F}$. This is $10^{\circ} \mathrm{F}$ above the solubility limit for the nominal four percent by weight boric acid solution. If a portion of the system which normally contains concentrated boric acid solution is not located in a heated area, it is provided with some other means (e.g. heat tracing) to maintain solution temperature $\geq 65^{\circ} \mathrm{F}$.

\section{Fluid Leak Detection System}

Fluid leaks are detected by monitoring sump levels, airborne particles and gas radiation. The system monitors the reactor containment atmosphere, spaces containing components for recirculation of loss-of-coolant-accident (LOCA) fluids, and potential effluent discharge paths for radioactivity that may be released from normal operation, including anticipated operational occurrences, and from postulated accidents. The fluid leak detection system is designed in compliance with General Design Criterion 64 of Appendix A to 10CFR50.

\section{Nuclear Service Water (NSW) System}

The nuclear service water system transfers surplus heat loads from various sources in the primary and the secondary parts of the reactor plant to the environment. During normal operation, this heat load is transferred via the main cooling tower complex. During loss of off-site power or a postulated LOCA, two dedicated mechanical draft cooling tower cells dissipate the energy to the surrounding air. These towers are called the ultimate heat sink (UHS). The NSW system and UHS consist of two completely independent and redundant flow trains. Either loop is capable of transferring 100 percent of the required heat load during all normal or postulated accident conditions. Unavailability or loss of either loop necessitates plant shut-down.

Normal flow through the system is provided by the balance-of-plant (BOP) service water system (refer to Account 252). A loss of off-site power or a postulated LOCA results in isolation of the non-safety-related portions of the NSW system, including the connections with the BOP service water system. The UHS cooling towers and NSW system pumps are automatically started. Following such a postulated accident, the system can function for 30 days without requiring water make-up to the towers by using water stored in the UHS cooling tower basin. 
PWR ACCOUNT 22

The UHS, including the cooling towers, and the safety-related portions of the NSW system are al1 designed to nuclear safety class, Seismic Category I requi rements.

Primary Component Cooling Water (PCCW) System

The primary component cooling water system transfers the heat generated by various components in the reactor plant, including those performing safetyrelated functions, to the nuclear service water system under all modes of plant operations, including operation following a LOCA or main steam line break (MSLB). The PCCW system also serves as an intermediate fluid barrier between the nuclear service water system and the reactor coolant pressure boundary. Two completely independent and redundant flow loops are provided to serve safety-related components and other reactor plant equipment. Unavailability or loss of either loop necessitates plant shut-down. During normal operations, the two loops have approximately equal heat transfer requi rements.

The two 100 percent capacity pumps in each loop facilitate plant operations and maintenance. Only one pump in a loop can be powered by the corresponding emergency diese1-generator unit at any given time. In the event of a postulated LOCA or MSLB, the non-safety-related portions of the PCCW system are isolated.

The safety-related portions of the PCCW system are all designed to nuclear safety class, Seismic Category I requirements.

\section{Maintenance Equipment}

The maintenance equipment includes remote handling tools, radioactive maintenance facility, portable shielding, tools and equipment for the reactor vesse1, fuel core tools and fixtures, decontamination facility, laundry equipment and hot change area facility.

\section{Sampling System}

The sampling system provides representative liquid and gas samples for chemical and radio-chemical analyses to evaluate the water chemistry of the reactor coolant and liquids from the steam generator, chemical and volume control system, residual heat removal system, and pressurizer.

Two sample lines are connected to the pressurizer, one at the steam end and one at the liquid end. Each line is cooled by two heat exchangers in series, capable of cooling a flow of $0.75 \mathrm{gpm}$ to about $100^{\circ} \mathrm{F}$. Delay coils are not required on the pressurizer sample lines because the pressurizer is assumed to contain a relatively stagnant volume with a sufficient residence time to permit decay of any $\mathrm{N}_{16}$ content to a safe level. Each pressurizer sample line has a capillary tube of sufficient length and size to limit flows to 1.5 gpm with all valves in the line fully open. 
PWR ACCOUNT 22

The reactor coolant sample lines have coils of sufficient length and size to ensure that it takes the reactor coolant sample of $0.8 \mathrm{gpm}$ at least 45 seconds to flow from the point of sample to the containment wall. This allows shortlived isotopes, primarily $\mathrm{N}_{16}(7.4$ seconds half-life) to decay sufficiently to permit handling of the sample.

\section{ACCOUNT 227 Reactor Plant Instrumentation and Control}

The reactor plant instrumentation and control system provides monitoring and protection for plant, personnel and equipment and enables the operator to start up, operate, and shut down the reactor.

\section{Main Contro1 Board}

The overall design of the main control board is primarily dictated by the requirements of the reactor plant. The main control board is a Class $1 \mathrm{E}$, hardwired, walk-in, "U"-shaped, duplex control board, designed in accordance with appropriate IEEE nuclear standards. It contains a combination of Class $1 \mathrm{E}$ and Non-Class $1 E$ control and information devices necessary for remote operation of the unit. Arrangement of the controls within the main control board is system oriented. Within systems it is train and/or loop oriented. Instrument configurations and arrangements follow human engineering factors guidelines.

Overall arrangements, besides providing for physical separation requirements, are coordinated to assure safe and efficient operation. The front panels of the main control board contain the controls and information displays for the engineered safety features, reactivity control, turbine, turbine auxiliaries, cooling water systems, ultimate heat sink, generator, generator auxiliaries and electrical auxiliary power distribution systems. The rear panels of the main control board contain controls and instrumentation for miscellaneous support systems such as read-outs for the area radiation monitors.

The use of combustible materials within the main control board is prohibited. Each component is clearly identified with a distinctively colored permanent tag. Colored nameplates are employed on exterior surfaces of the main control board to identify component function.

The main control board is composed of three sections: the NSSS control board, the turbine plant control board, and the main generator and auxiliary electric power system control board. The NSSS control board is discussed under this account description. The turbine plant control board is discussed under Account 236. The main generator and auxiliary electric power system control board is discussed under Account 243.

\section{NSSS Control Board}

The nuclear steam supply system (NSSS) control board is a part of the main control board described above. Necessary devices and control logic for remote operation of the steam generating unit (NSSS) and its auxiliaries are mounted on and in this control board. 
PWR ACCOUNT 22

Reactor and auxiliary process systems and components which are monitored and controlled from this board are tabulated below:

a. Safety Related Systems and Components

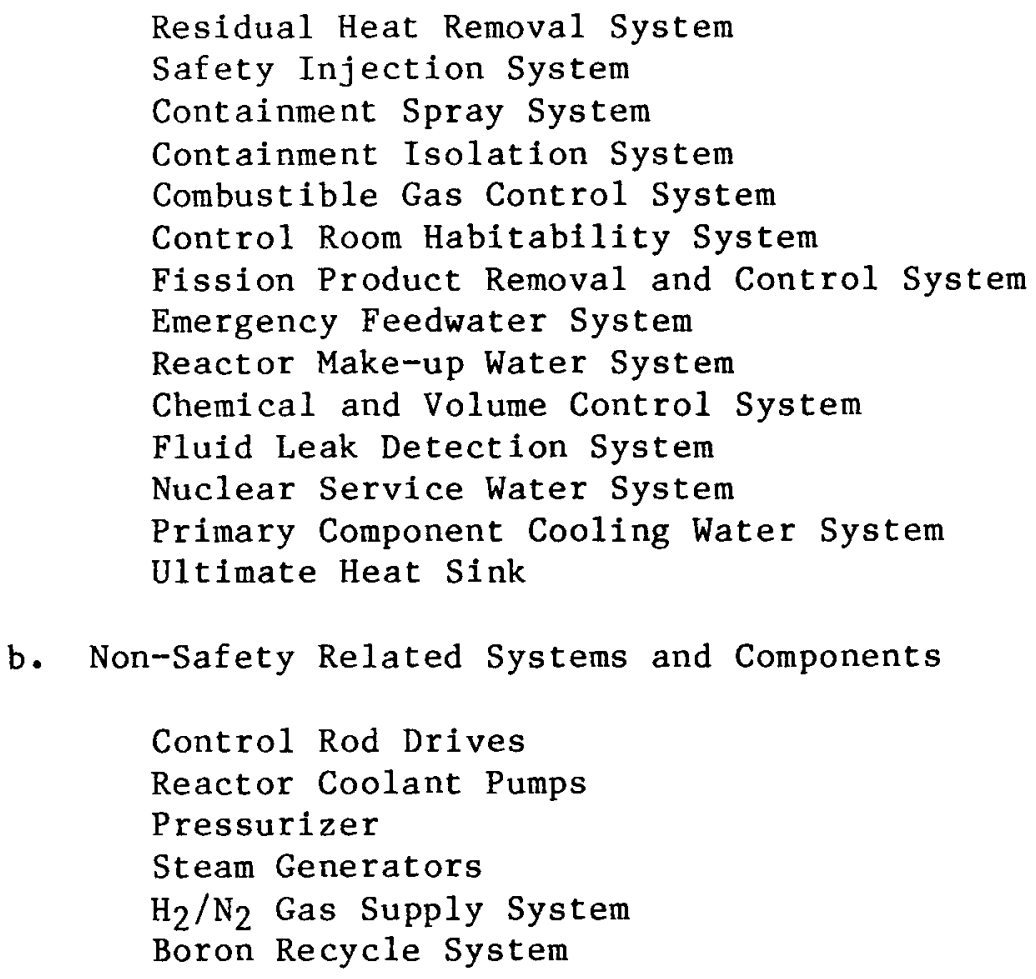

Instrumentation and control systems associated with the NSSS control board are tabulated below:

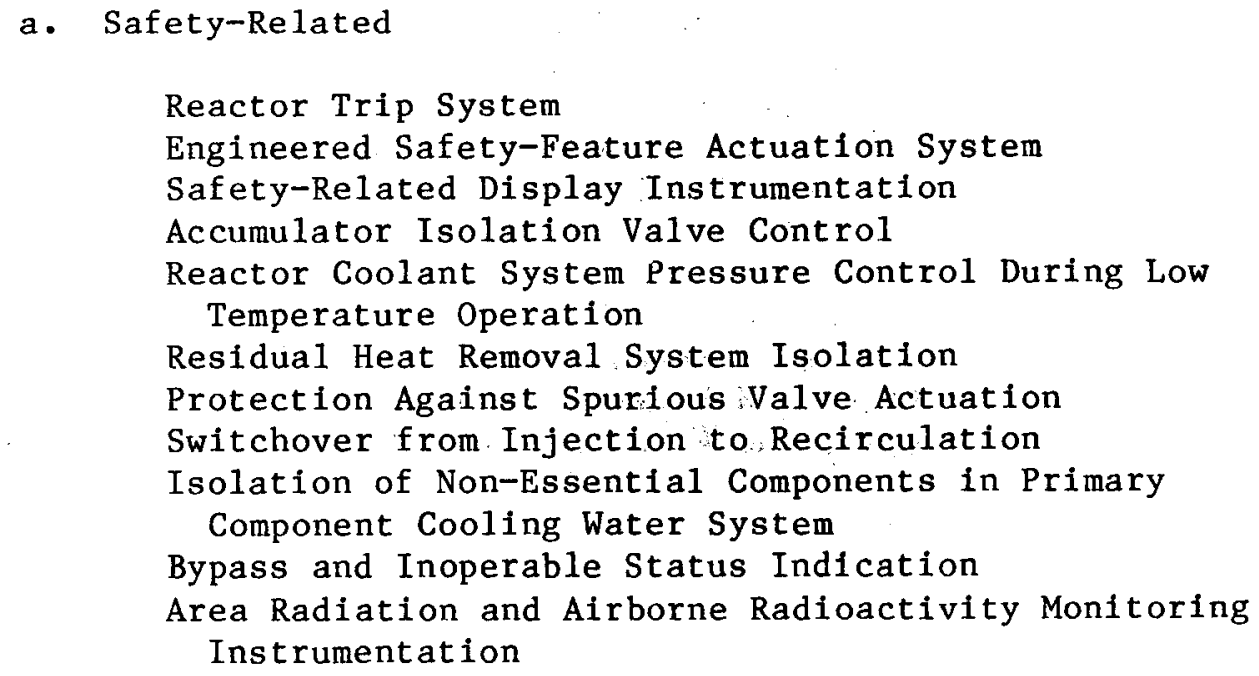


b. Not Required for Safety

\author{
Reactor Control System \\ Rod Position Control System \\ Plant Control System Interlocks \\ Pressurizer Pressure Control \\ Pressurizer Water Level Control \\ Steam Generator Water Level Control \\ Steam Dump Control \\ Incore Instrumentation
}

Safe Shutdown Control

The main control room is the primary station for safe shut-down control of the plant and is designed to be available at all times. Controls required for bringing the plant to hot or cold shut-down and for maintaining the shut-down condition are located in the main control room. In the event that the main control room becomes uninhabitable, the plant may be brought to and maintained in a safe shut-down condition using alternate control provisions outside the main control room.

The instrumentation and controls tabulated below, which are utilized to achieve and maintain a safe shut-down, are available in the event an evacuation of the control room is required.

a. General Considerations

- both the turbine and the reactor are tripped, locally

or at the main control room;

- all automatic systems continue functioning; and

- controls for equipment having dual independent motor controls outside the control room (which duplicate manual functions inside the control room) are provided with a selector switch which transfers control from the main control room to a local station.

b. Monitoring Indicators

\author{
Water Level and Pressure for Each Steam Generator \\ Pressurizer Water Level and Pressure \\ Reactor Coolant Pumps 1 and 4 Hot and Cold Leg \\ Temperature \\ Intermediate Range Neutron Flux \\ Volume Control Tank Level \\ Primary Component Cooling Water Loop Temperature \\ Emergency Feedwater Flow
}


c. Control of Pumps and Fans

Reactor Coolant Pumps

Emergency Feedwater Pumps

Charging and Boric Acid Transfer Pumps

Boration Capability

Residual Heat Removal Pumps

Primary Component Cooling Water Pumps

Service Water Pumps

Service Water Cooling Tower Pumps and Fans

Containment Cooling Units

Control Room Ventilation

Controlled Steam Release and Feedwater Supply

d. Control of Emergency Diese1-Generator Units and Auxiliaries

e. Control of Valves and Heaters

Charging Flow Control Valves

Modulating Letdown Valves

Emergency Feedwater Control Valves

Main Steam Atmospheric Relief Valves

Main Steam Isolation and Bypass Valves

Pressurizer Heaters

Pressurizer Auxiliary Spray Valves

Pressurizer Relief Valves

Reactor Coolant Pump Seal Return Valves

Reactor Coolant Pump Seal Injection Valves

Excess Letdown Isolation Valves

Charging Flow Isolation Valves

Accumulator Tank Isolation Valves

Emergency Boration Valve

Cooling Tower Discharge and Test Valves

Service Water Intake/Discharge Valves

Primary Component Cooling Water Temperature Contro1

Valves

Containment Structure Cooling Valves

Heating, Ventilating and Air Conditioning (HVAC) Panels

These panels provide monttoring and control of the HVAC systems for buildings which house the reactor plant systems. Typical HVAC systems controlled from these panels are the control building air handling system, containment air handling system, containment purge systems, diesel-generator unit air handling system and fuel storage building air handling system.

Radwaste Panels and Racks

The complete waste management system consists essentially of three subsystems: liquid waste system, gaseous waste system and solid waste system. 
Overall control of the complete system is exercised from radwaste panels in a local control room located near the waste management facility in the waste process building. For the liquid waste system, the panels control the collection, processing and directing of the processed waste either for re-use or discharge from the site. For the gaseous portion of the system, the panels monitor the removal of gaseous fission products from the reactor coolant letdown and the primary drain tank.

The radwaste panels also carry indicating lights to show the status of various sump pumps and equipment. The radwaste system alarm signals are reported through a common annunciator in the main control room.

Racks are provided for mounting local instruments. For the solid waste system, solidification, handling and drumming for shipment and storage are performed through local panels near the equipment.

Logic Pane1s and Cabinets

These panels and cabinets provide mounting space for analog devices, such as function generators, bistable modules, summers, dividers, analog controllers and selectors. Typical process control loops, which have analog devices in these panels and cabinets are: control rod reference signals, steam dump control, feedwater turbine speed control, pressurizer pressure and level control, boric acid blend control, volume control tank level control and steam generator level control.

\section{Instrument Racks}

Open type instrument racks are provided to mount local instruments such as pressure transmitters, manifolds, pressure switches, and other pneumatic instruments that connect directly with the process pipes. Each rack has a rigid structure, suitably braced, to withstand stress incidental to shipping, installation and operation without warping or twisting. Instruments, electrical devices and conduits on the racks are placed out of the paths of condensation, or water drains from testing or calibrating instruments. Sufficient clearance is provided for maintenance or replacement of the instrumentation without interruption of service to adjacent devices. There is provision to collect the drains when an instrument is removed. Suitable engraved plastic nameplates are provided for each instrument.

\section{Process Computer}

The process computer system is designed to provide real time, on-line data acquisition, alarm monitoring, data manipulation, and performance calculation functions while providing data display to the plant operators. Sequence of events and post trip review functions, as well as normal alarm recording data, group logs and periodic logs provide additional historical recording functions. 
The system combines state-of-the-art computer hardware with color CRTs to assemble and display plant performance data and plant status information.

The safe operation of the plant is not dependent on the availability of the process computer system, nor does the process computer perform a control function. The design objectives of the computer are summarized below:

a. Reduce the amount of information that an operator must monitor

b. Reduce the size of the main control board

c. Improve the operator's perception, decision making, and response time

d. Provide dynamic alarm indications

e. Provide graphic display of system parameters and process trends

f. Provide graphic comparison of design limits and actual performance

g. Provide core performance and fuel management data

h. Provide turbine plant performance calculations and displays.

\section{Radiological Monitoring and Data Management System}

The radiological data management system is designed to assure compliance with the applicable NRC and licensing requirements, by providing information concerning the radiological environment of the plant. The system enables the health physicist and plant operating personnel to maintain complete awareness, in real-time, of plant radiation levels. Permanent records are automatically produced for regulatory requirements. The system consists of the following sub-systems :

\section{a. Process Radiation Monitoring System \\ b. Effluent Radiation Monitoring System \\ c. Area Radiation Monitoring System \\ d. Data Acquisition and Processing System}

Each monitor channel is complete with detector, preamplifier, digital buffer, microprocessor with alarm outputs, and readout modules. The data acquisition and processing system is a computer-based system that collects the available information from field-mounted detectors, performs the necessary calculations and displays the results on the CRT as required. The system assists in the generation of required NRC reports. 
PWR ACCOUNT 22

\section{Neutron Monitoring System}

The neutron monitoring system consists of:
a. Out-of-core flux detectors
b. Fixed in-core thermocouples
c. Movable in-core flux detectors

The out-of-core detectors protect the reactor core by monitoring the neutron flux and generating appropriate trips and alarms for various phases of reactor operating and shut-down conditions. They also provide a secondary control function by indicating reactor status during start-up and power operation. The out-of-core detectors are located in vertical instrument wells adjacent to the four corners of the core cross section. There are three groups of detectors: source range, intermediate range and power range detectors.

The in-core instrumentation provides information on the neutron flux distribution and fuel assembly outlet temperatures at selected core locations.

The thermocouples are positioned at preselected locations to measure fuel assembly coolant outlet temperature for use in monitoring the core radial power sharing and coolant enthalpy distribution. The movable in-core flux detectors can traverse the entire length of selected fuel assemblies, thus providing a three dimensional map of the neutron flux distribution.

Instrumentation for Following the Course of an Accident

Instrumentation to assess plant and environs conditions during and following an accident are provided to give indications of critical plant variables. Necessary indications are those required by the plant operator during accident conditions to:

a. Determine the overall status of the plant

b. Initiate and accomplish safe plant shut-down

c. Determine whether reactor trip, engineered safety features and manually initiated safety systems are functioning properly

d. Determine the potential for causing a gross breach of the barriers to radioactivity release

e. Assess the operation of plant systems

f. Provide information regarding the release of radioactive material 
These indications also provide material evidence for post-accident investigation into the causes and consequences of the event. The required instrumentation is selected or designed to be capable of surveying postulated accident environments in which they are located for the time their function is required.

The following variables are monitored in the control room or at remote locations, as necessary:

a. Type B Variables

Reactivity Control

Core Cooling Parameters

Maintaining Reactor Coolant System Integrity

Maintaining Containment Integrity

b. Type C Variables

Fuel Cladding Parameters

Reactor Coolant Pressure Boundary Parameters

Containment Parameters

c. Type D Variables

Residual Heat Removal System Parameters

Safety Injection System Parameters

Primary Coolant System Parameters

Steam Generator Parameters

Emergency Feedwater System Parameters

Containment Cooling System Parameters

Chemical and Volume Control System Parameters

Radwaste System Parameters

Ventilation System Status

Power Supply Parameters

d. Type E Variables

Containment Radiation Leve 1

Area Radiation Level

Airborne Radioactive Materials Released from Plant

Environs Radiation and Radioactivity

Meteorology

Accident Sampling Capability

Reactor Diagnostic System

The reactor diagnostic system consists of:
a. Loose parts monitoring
b. Vibration monitoring 
c. Neutron noise threshold monitoring

d. Data handling and analysis

Loose parts monitoring is accomplished with an array of strategically located accelerometers mounted external to major reactor components. The system is designed to alarm the presence of unusual noises in the reactor coolant system and to assist in determining the location and energy level of these noises. The information is used to decide the feasibility of continuing plant operation if an abnormal condition occurs.

Vibration monitoring is accomplished by monitoring the acoustic signals and vibration generated by rotating parts. Permanently mounted accelerometers and non-contact probes are used to monitor and alarm excessive vibration of reactor coolant pumps and motors. A portable system is provided for periodic monitoring of all other accessible rotating equipment in both the primary and secondary plant. The vibration monitor provides a warning of impending equipment failure and helps measure vibration frequency trends useful for preventive maintenance and outage planning.

Neutron noise threshold monitoring is accomplished by monitoring signals from power range neutron detectors. An adjustable threshold detector provides an alarm for large cyclical variations in neutron flux on each of the detector channels. Periodic signatures conducted by plant staff using data analysis equipment are used to verify the structural integrity of reactor internals.

Input signals from system sensors are available for audio interpretation by the maintenance personnel and for audio comparison against prerecorded baseline information. Recording permits retention of selected audio signals for subsequent playback to help interpret and analyze data.

\section{Containment Atmospheric Monitoring System}

The containment atmospheric monitoring system monitors the hydrogen content, gamma radiation levels and fission products in the containment atmosphere. Alarms are provided for high radiation level conditions. Permanent records of the measurements are provided on control room recorders.

Containment Leakage Monitoring

The containment leakage monitoring system measures the containment overall integrated leakage rate at required periodic intervals. The system measures and records the absolute pressure, the dewpoint temperature, and the dry-bulb temperature. Sensors having high accuracy and resolution and good repeatability are utilized, since changes in the measured parameters are small. A data acquisition system is provided to compute the containment leakage based on the measured inputs. 
Failed Fue1 Detection System

The failed fuel detector is a gamma activity monitoring device. It monitors reactor coolant for fission product gamma activity as a means for detecting leaks in the fuel rod cladding. Output from the radiation channels are recorded to provide trends, and alarmed to alert operations personnel to abnormal radiation levels. Sampling and radiochemical analysis of reactor coolant water is used to verify the fission product activity.

\section{Reactor Power Control System}

The reactor power control system is designed to follow load changes as they are made on the turbine. The system automatically adjusts the power level of the reactor to match the power demanded by the turbine. The turbine load determines a reference temperature which corresponds to the reactor power level required to meet the turbine demand. For large and rapid variations, the turbine load signal is also compared to a nuclear power (flux) signal, resulting in a signal which corresponds to the rate at which the load is decreasing or increasing. The rate signal and the reference temperature signal are compared to the auctioneered average temperature generated in the reactor. This comparison results in an error signal proportional to the reactor power increase or decrease required. This error signal is inputted to the rod control system which performs the load change in the reactor.

\section{Reactor Protection System}

The reactor protection system receives signals from nuclear instrumentation and process instrumentation bistables, control board pushbuttons, and fieldmounted devices, and combines these signals according to prescribed logic to produce actuation signals for reactor trip and engineered safeguards operation. By tripping the reactor whenever the limit of an operating region is approached, the system automatically keeps the reactor operating within a safe region. The safe operating region is defined by several considerations such as mechanical/hydraulic limitations on equipment, and heat transfer phenomena. Therefore, the protection system keeps surveillance on process variables which are directly related to equipment mechanical limitations, such as pressure, pressurizer water level (to prevent water discharge through safety valves, and uncovering heaters), and also on variables which directly affect the heat transfer capability of the reactor (e.g., flow and reactor coolant temperatures). Typical causes of reactor trips are listed below:
a. Nuclear overpower
b. Core therma1 overpower
c. Pressurizer low pressure, high pressure and high water leve1

d. Reactor coolant system low flow 
e. Low feedwater level

f. Low-low steam generator water level

g. Turbine trip

h. Safety injection signal actuation

i. Manual trip

Engineered Safety Features Actuation System (ESFAS)

The engineered safety features actuation system monitors selected plant parameters to determine whether predetermined safety limits are being exceeded. When safety limits are surpassed, ESFAS combines the signals into logic matrices that are indicative of primary or secondary system boundary ruptures. Once the logic combination is completed, ESFAS sends actuation signals to those engineered safety features whose aggregate function provides the best response for the accident. The specific functions which rely on the ESFAS for initiation are listed below:

\section{a. Reactor trip}

b. Proper sequencing of loads on the Class $1 \mathrm{E}$ (engineered safety features) buses

c. Containment isolation and cooling

d. Main steam line isolation

e. Containment isolation

f. Starting the Class $1 \mathrm{E}$ diesel-generator units (standby power supp1y)

g. Isolation of control room air intake ducts

h. Actuation of containment spray

i. High and low pressure injection to the primary coolant system

\section{TMI Instrumentation}

The instrumentation systems described above are enhanced and supplemented with the instrumentation tabulated below, which responds to the "lessons learned" from the Three Mile Island (TMI) Unit 2 event. 
a. Relief and Safety Valve Testing

b. Direct Indication of Valve Position

c. Detection of Inadequate Core Cooling

d. Diverse Containment Isolation

e. Hydrogen Contro1

f. Plant Shielding Review

g. Auto-Initiation of Emergency Feedwater

h. Emergency Feedwater Flow Indication

i. Post-Accident Sampling

j. High-Range Radiation Monitoring

k. Improved Iodine Monitors

1. Transient and Accident Analyses

m. Systems Integrity for High Radioactivity

Reactor Plant Instrument Tubing and Fittings

The scope of supply of instrument tubing begins at the first accessible root valve at the piping and extends to the instrument shut of $f$ valve. Materials and certification of instrument lines which are part of the pressure boundary are in accordance with Instrument Society of America Standards. 
ACCOUNT 23 TURBINE PLANT EQUIPMENT

Mechanical key parameters related to the turbine plant are given in Items 28 through 31 and 35 through 37 of Table 3-1. A steam heat balance is given in Figure 3.5. The table and figure supplement and amplify the following discussion of Account 23 .

The turbine plant equipment includes the steam handling, power conversion and condensate/feedwater machinery of the steam cycle. All turbine plant equipment includes margin in the design to compensate for some wear and performance degradation during the life of the plant.

The thermal energy from the reactor primary coolant loop generates saturated steam at 1000 psia within the steam generator. The main steam piping supplies this steam to the throttle/control valves of the turbine-generator unit and to the inlet of the moisture separator/reheaters. The steam turbine is a tandem-compound six-flow machine which develops the mechanical energy to drive the electric generator at $1800 \mathrm{r} / \mathrm{min}$. Normally, 52 percent of the steam generator outlet flow passes through the turbine and exhausts into the condenser. The remaining 48 percent of the flow is either directed to the steam reheaters, or extracted at various stages from the turbine for the six stages of feedwater heating and the auxiliary steam turbine drives for the steam generator feedwater pumps.

The majority of the main steam flow exhausts from the high pressure turbine and passes through the moisture separator/reheaters. The separator/reheaters remove water droplets and reheat the steam before it enters the three low pressure turbines. This provides a two-fold benefit; excessive water induced erosion of the low pressure turbines is avoided and the turbine cycle efficiency is improved.

A turbine bypass system is provided to pass up to 50 percent of inlet steam flow directly to the condenser. This is necessary if heat must be rejected during start-up, shut-down, or other normal transient conditions.

Condensate is pumped from the condenser hot-wells by three 50 percent capacity condensate pumps through 100 percent flow deep bed polishing demineralizers, the steam packing exhauster condenser and the five stages of low pressure heaters to the suction of the feedwater pumps. Two 50 percent capacity heater drain pumps take the fifth and sixth stage heater drains from the heater drain tank along with liquid from the moisture separator reheater and return them to the cycle at the feedwater pump suction. Two 50 percent capacity turbine driven feedwater pumps supply water to the high pressure feedwater heaters to raise the feedwater temperature to $440^{\circ} \mathrm{F}$ before entering the steam generators. Two emergency feedwater pumps, one motor driven and one turbine driven, are provided. 
PWR ACCOUNT 23

Interconnecting piping systems are included with each turbine plant auxiliary system, either at the three-digit or lower order code-of-accounts level of detail. They comprise the piping, fittings, valves, steam traps, strainers, specialties, hangers and supports, insulation and other components required for a complete system. The piping systems are generally designed as American Nuclear Society Non-Nuclear Safety. In some cases they may be designed as Safety Class 2 or 3 , where they interface with Safety Class piping systems. Materials and wall thicknesses are chosen based on the service conditions and operational requirements of each system. The factors generally considered include: temperature, pressure, corrosion resistance, abrasion resistance, fluid purity requirements and cost. Carbon steel is used for steam (below $750^{\circ} \mathrm{F}$ ), clean water, air, oil and other services without special requirements. other materials used include: stainless steel and stainless steel tubing.

The paragraphs given below provide brief technical descriptions that preview the more detailed descriptions given in the pages that follow.

Account 231 Turbine-Generator (turbomachinery, generator, exciter, stator cooling water system, gas systems, hydrogen seal oil system, electro-hydraulic control system, turbine gland steam sealing system, moisture separator/ reheater, moisture separator/reheater drain system, lubricating oil system, turbine oil storage and conditioning system)

Account 232 Not used

Account 233 Condensing System (condensers, condensate system, condenser gas removal system, turbine bypass system and condensate polishing system)

Account 234 Feedheating System (feedwater heaters, feedwater system and extraction steam system)

Account 235 Other Turbine Plant Equipment (main vapor piping system, turbine building closed cooling water system, demineralized water make-up system, chemical treatment system and neutralization system)

Account 236 Turbine Plant Instrumentation and Control (turbine plant control board, panels; cabinets and racks, and process computer): 
ACCOUNT 231 Turbine-Generator

The turbine-generator produces 1192 MWe at the generator terminals with rated load throttle steam conditions of 975 psia $/ 544^{\circ} \mathrm{F}, 166$ psia $/ 519^{\circ} \mathrm{F}$ reheat, zero percent make-up, 2.5 in-HgA back pressure, turbine driven feedwater pumps, and six stages of feedwater heating. With an estimated 48 MWe station auxiliary load, 1144 MWe is delivered to the generator step-up transformer for off-site transmission.

For brief periods during the summer, when the ambient wet bulb temperature approaches the site maximum of $74^{\circ} \mathrm{F}$, the condenser pressure may rise above 2.5 in-HgA, limiting the turbine-generator performance. During the worst condition, the condenser pressure will not exceed 3.0 in-HgA which causes a reduction in generating capability of less than one percent and a corresponding increase in heat rate. The cumulative total of these periods during which performance is limited is estimated as 800 hours per year.

The turbine is an $1800 \mathrm{r} / \mathrm{min}$ tandem-compound machine with six-flow exhaust and 43 inch last stage blades. It consists of a double flow high pressure section and three double flow low pressure sections. The throttle flow at rated load is $13,729,027$ pounds of steam per hour.

The cold reheat steam exhausts from the high pressure turbine and passes in parallel through four moisture separator/reheaters which are horizontal shell and tube heat exchangers with a high efficiency separator incorporated in the design. Main steam is supplied to the tube side for reheating the steam flow before being admitted through the intercept valves to the low pressure machines. The high pressure condensate from the tube side is piped to the highest pressure feedwater heater, while the drains from the moisture separator are directed to the heater drain tank.

The turbine is provided with a low speed turning gear for rotating the turbine spindle after shut-down. Low speed rotation is required for uniform cooling and thermal contraction of the rotating parts.

The "high-tuned" turbine pedestal is reinforced concrete and is supported on a thick reinforced concrete foundation mat bearing on rock. The turbine pedestal is isolated from the remaining building support loads.

\section{Generator}

The generator has a rating of 1390 MVA with $0.90 \mathrm{PF}, 25,000 \mathrm{~V}, 3$ phase, $60 \mathrm{~Hz}$. It is a totally enclosed $1800 \mathrm{r} / \mathrm{min}$ machine utilizing hydrogen at $75 \mathrm{psig}$ to cool the rotor and stator end turns. The stator is a conductor-cooled type with deionized water as the liquid coolant.

The generator is furnished with the following equipment: cooling system, including hydrogen coolers; terminal bushings; instruments; grounding pads; bearing seals; housing insulation; foundation plates and shims; and special tools. 
PWR ACCOUNT 23

The generator stator is serviced by the following external equipment: a deionized water circulating and cooling unit assembled on a skid, including storage tank, pumps, coolers, deionizer, flow meter, conductivity cells, gauges, piping, valves, filters, instruments, and regulating equipment; and a stator winding cooling control cabinet assembled and combined with the hydrogen cooling control cabinet, including annunciator, generator automatic runback logic and all necessary control devices.

\section{Exciter}

The exciter is of the direct driven alternator and rotating silicon diode rectifier type. It has a 2.5 response ratio and is designed for $1800 \mathrm{r} / \mathrm{min}$. The alternator bearings, the silicon diode rectifier assemblies, and the main generator collector and brush rigging are all enclosed within the exciter housing. The housing is furnished with suitable water-to-air heat exchangers and a closed ventilation circuit for circulating the cooling air.

The excitation switchgear is a metal enclosed integrated unit of standard low voltage design that is located indoors. The function of the excitation switchgear is to connect, rectify and control excitation to the ac alternator exciter from the alternator stator, and to provide voltage regulation by adjustment of the generator field voltage ( $d c$ regulator) or the generator terminal voltage (ac regulator). The excitation switchgear houses the exciter field breaker, the thyristor regulator bridge and the ac and dc regulator $\operatorname{logic}$.

\section{Stator Cooling Water System}

The stator cooling water system provides deionized cooling water to the windings of the generator stator. Coolant deionization reduces electrical conduction losses and ensures good dielectric behavior. Pipes and fittings in contact with deionized water are stainless steel, brass and copper.

The deionized water is pumped from a storage tank by an exciter shaft or motor driven circulating pump through a heat exchanger and filters into the cooling circuit inside the stator conductors and back to the storage tank. If the conductivity of the cooling water exceeds a preset value at the out let of the first filter, some of the flow is diverted through a mixed bed demineralizer which discharges into the storage tank.

\section{Gas Systems}

Hydrogen and carbon dioxide gas systems are provided for controlling the atmosphere within the main generator housing.

Hydrogen gas is utilized to cool the generator rotor and the stator end turns and to reduce rotor windage losses. The hydrogen is circulated within the generator housing under pressure. The heat from electrical and mechanical losses is removed by two shell and tube type coolers located at each end of the generator housing. 
The hydrogen is supplied from a series of hydrogen storage containers which are individually connected to a manifold. The manifold is equipped with a relief valve, generator pressure and bottle pressure regulators with isolation valves, high and low pressure gauges, a pressure switch for hydrogen supply pressure "low" alarm and bottle connectors. A hydrogen control cabinet is provided on which are mounted hydrogen purity gauges, temperature detectors and other devices required to ensure safe and effective operation of the hydrogen control system. Enough hydrogen supply is provided to fill and pressurize the generator once and supply the required make-up for a nominal operating period.

The carbon dioxide system consists of a liquid carbon dioxide storage unit with refrigeration system, vaporizer, relief valves and two pressure reducing valves. Carbon dioxide is used for purging hydrogen from the generator housing during shut-down, and for purging air from the housing before being filled with hydrogen during start-up. Sufficient capacity is provided to purge the system of air twice and of hydrogen once.

Hydrogen Seal 0il System

The hydrogen seal ofl system provides oil to the generator hydrogen seal assemblies to prevent the escape of hydrogen to the outside atmosphere from inside the generator housing.

Oil is pumped from a gas detraining tank, through a filter, to a hydrogen seal assembly located at each end of the generator shaft. Some of the oil passes through the two seal assemblies towards the hydrogen side and comes in contact with the hydrogen inside the generator. This oil absorbs bubbles of hydrogen and is collected in an oil manifold which is connected to the gas detraining tank by piping. Hydrogen diffuses towards the surface of the oil inside the tank. Vacuum pumps dispose of the hydrogen by transferring it to the outside atmosphere.

Electro-Hydraulic Control (EHC) System

The electro-hydraulic control system consists of the speed control unit, the load control unit and the flow control units for the turbine machinery. The speed control unit compares actual turbine speed with a speed reference, or actual acceleration with an acceleration reference, and provides a speed error signal for the load control unit. The load control unit combines the speed error signal with the load reference signal to determine the desired steam flow signals for the stop valves, control valves and intercept valves. Finally, the valve flow control units accurately position the appropriate turbine valves to obtain the desired steam flows through the turbine.

A high pressure fluid system is provided to convert the low power level signals from the EHC circuits to high power level mechanical outputs for positioning the large steam valves. This system consists of a fluid reservoir, two independent pumping systems, fluid coolers, accumulators, a fluid transfer unit and a filter unit. 
Turbine Gland Steam Sealing System

The turbine gland steam sealing system seals the turbine shaft at turbine shell penetrations under all conditions of turbine loading. The sealing system prevents air in-leakage along the shaft (high pressure turbine during start-up and low pressure turbines at all load conditions) and steam outleakage from the high pressure turbine during partial load and full load operation. In addition to sealing the main turbine, the gland steam sealing system seals the steam generator feed pump turbines and the main turbine main steam inlet valves.

Another function of this system is to provide steam for prewarming the turbine internals and rotor while on turning gear prior to start-up.

Each turbine shaft end is provided with a series of labyrinth packings and two glands. The outer glands of each shaft are piped to, and maintained at, a pressure slightly below atmospheric by the steam packing exhauster. Steam leaking outward through the packings and air leaking inward are collected in the outer gland and drawn of $f$ to the steam packing exhauster.

The steam packing exhauster consists of a shell and tube type service condenser with two motor driven air removal blowers. The blowers create a vacuum of three to five inches of water which draws steam and air from the outer gland of each turbine shaft seal into the condenser shell. With condensate as a coolant, the steam is condensed and drained into the main condenser, while the air is removed by blowers to atmosphere.

The inner glands of each shaft are connected by pipes to the seal steam header. The header is maintained at an acceptable pressure by a group of control valves and safety valves which admit supplemental steam when needed from the main steam piping or auxiliary steam piping, and "spill" excess steam to the main condenser.

During start-up, steam.from the auxiliary steam system or main steam system is supplied to the seal steam header and from there to all the inner glands. This steam flows through the labyrinth packings inward toward the turbines and outward to the outer glands. As load increases with a corresponding pressure increase inside the high pressure turbine, flow direction through the inner glands of this turbine reverses. Steam from inside the turbine flows outward to the seal steam header. (This does not occur with the low pressure turbines, which always require external steam to be supplied.) As steam from the high pressure turbine is supplied to the seal steam header, the amount of supplemental steam required decreases.

As the load continues to increase, the quantity of steam being supplied by the high pressure turbine exceeds the quantity required for sealing the low pressure turbines, steam generator feed pump turbines and main turbine valve stems. The excess is "spilled" to the main condenser.

The sealing system operates automatically at all load conditions. 


\section{Moisture Separator/Reheater}

Four moisture separator/reheaters are utilized to recondition the wet steam exhausted from the high pressure turbine, prior to its passage to the low pressure turbines. The moisture is first removed and then the steam is reheated to a superheated state.

Each moisture separator/reheater is a horizontal shell and tube type heat exchanger. Steam directly from the steam generators flows through the tubes. High pressure turbine exhaust steam flows through the shell.

High pressure turbine exhaust steam enters the bottom of the reheater shell and passes through stainless steel chevron plate type moisture separators. The steam flows upward through the "U"-shaped reheater tube bundle, where it is reheated to superheat conditions. Exiting from the top, the steam flows to the low pressure turbines.

\section{Moisture Separator/Reheater Drain System}

The thermal energy required for reheating is supplied from the main steam line upstream of the turbine stop valve to the tube side of the reheater bundle. The bundle drains to separate drain tanks where the non-condensibles are vented to the main condenser through an orifice, and condensate flows to the No. 6 feedwater heater through a control valve which maintains tank level.

Each moisture separator drains to a drain tank and then to the heater drain tank through a similar control valve. Safety valves are provided on each unit for protection against overpressure. These safety valves discharge to the main condenser.

\section{Lubricating 0il System}

The lubricating oil system supplies oil to the main turbine-generator bearings, the thrust bearing wear detector, the overspeed trip reset, and the oil trip. The system equipment includes pumps, oil coolers, a lube oil reservoir, and necessary interconnecting piping and controls.

A main turbine shaft driven centrifugal pump normally supplies the required bearing lubricating oil. During start-up and shut-down, this shaft driven pump is primed by an ac motor driven suction pump. When the unit reaches 95 percent of rated speed, an oil tank booster pump takes over for the motor suction pump. This booster pump is driven by an oil turbine utilizing the discharge from the shaft driven centrifugal pump.

Additional pumps include the ac turning gear oil pump and the dc emergency bearing ofl pump. Both the ac motor driven suction pump and the ac motor driven turning gear oil pump start automatically on low oil pressure. The dc emergency bearing ofl pump is powered by the station batteries and is used as a final back-up source for lubricating oil. 
PWR ACCOUNT 23

The lubricating ofl system reservoir contains a screen for removing foreign materials from the oil drained into the reservoir and the following additional equipment: vapor extractor, air ejector, pressure control orifices and flow check valves, two oil coolers, float-type ofl level indicator with high and low level alarms, and pressure switches with test valves for automatic starting of the turning gear and emergency ( $a c$ and $\mathrm{dc}$ ) motor driven oil pumps.

Turbine 0il Storage and Conditioning System

The turbine oil storage and conditioning system provides storage for new and used turbine lubricating oil, continuous on line purification of the oil in the main turbine reservoir and in the steam generator feed pump turbine reservoirs, and transfer between the reservoirs, storage tanks and trucks. It can also be used for batch cleanup of contaminated ofl during a unit outage.

The storage and transfer portions of this system are common to the main turbine and the steam generator feed pump turbines, but separate purification equipment is provided. The storage and transfer portions of this system include: one clean and one dirty oil storage tank, a transfer pump and interconnecting pipe, fittings and valves. Purification equipment includes: an ac motor driven centrifuge, positive displacement inlet and discharge pumps, electric heater, necessary instruments, transfer switch, feed/stop valve and electric controller with safety interlocks. The purification system for the main turbine has a capacity of 1570 gallons per four of 150 SSU lubricating oil at $100^{\circ} \mathrm{F}$. The electric heater is $80 \mathrm{~kW}$. Equipment for the feed pump turbine drives is proportionately smaller.

During normal plant operation, lube oil from the main turbine reservoir and from the steam generator feed pump turbine reservoirs overflows to the lube oil conditioning unit where water and solids are removed by a centrifuge. The cleaned oil is returned to the reservoirs. This continuous bypass method of operation provides maximum protection against turbine damage due to contaminated oil.

Each of the storage tanks can hold a full inventory of oil to permit batch replacement or batch cleaning of the full inventory during a plant outage.

New oil received by truck can be pumped by the truck's onboard pumps to either the clean or dirty oil storage tank or to the lube oil conditioner, but not directly to the turbine reservoirs: By making all oil to the reservoirs go through the lube oil conditioner, risk of contamination is minimized. Discharge of used oil to trucks is done with the lube oil transfer pump.

During a plant shut-down, it is possible to batch purify oil held in any of the reservoirs, the clean oil storage tank or the dirty oil storage tank and return the purified oil to any of these locations.

The lube oil conditioning unit is capable of reducing the moisture to 0.1 percent by volume reducing solids contamination to 0.02 percent by volume without removing additives or increasing the oil acidity. 


\section{ACCOUNT 233 Condensing System}

The three surface condensers are single stage, two-pass design with divided fabricated steel water boxes and she11. The condensers are designed to handle the total heat rejection from the main turbine and the two auxiliary turbine drives for the feedwater pumps. Each condenser has a condensing surface of 408,350 square feet composed of 30,210 one inch diameter, 22 BWG (Birmingham Wire Gage), SS-304 tubes, 52 feet long. Cooling water flow in each condenser is $230,600 \mathrm{gpm}$ resulting in a tube velocity of seven feet per second and a temperature rise at full load of $22^{\circ} \mathrm{F}$.

Each condenser shell is floor mounted and connected to the turbine exhaust flange by means of a stainless steel expansion joint to accommodate thermal expansion. The three shells are interconnected by means of a pressure equalizing duct.

The tube sheets are bolted to the shell with provisions for thermal expansion of the tubes. The tubes are rolled into the holes in the tube sheets with flared ends to reduce entrance and exit losses.

The shel1 is carbon steel welded construction with $1 / 16$ inch corrosion allowance. The water boxes are fabricated steel construction and are bolted to the condenser she11s. They are designed for easy removal without disturbing the tube sheets. The total hotwe 11 capacity of the three she1ls is 66,000 gallons at normal water level.

The hotwell is designed to deaerate the condensate to limit dissolved oxygen to a maximum of five parts per million at the outlet during normal steady-state operation.

\section{Condensate System}

The condensate pumps are of the vertical "can" type, suitable for the net positive suction head requirements of condenser hotwell service. The pumps develop sufficient head to ensure adequate suction pressure at the steam generator feed pumps after overcoming the pressure drop in the condensate piping, steam packing exhauster condenser, condensate polishing demineralizers, and the low pressure feedwater heaters.

Three half-size motor driven pumps are supplied. The third pump is on standby service or is isolated for maintenance. In addition to the main flow, the condensate pumps supply seal water to various equipment such as the condensate pump seals, heater drain pump seals, and steam generator feedwater pump glands. The condensate pumps also discharge excess condensate to the condensate storage tank and supply water to the turbine exhaust hood sprays. 
PWR ACCOUNT 23

The condensate storage tank is combined with the emergency feedwater tank into a single vessel. The upper portion is condensate storage and the portion below the lowest condensate connection is emergency feedwater storage. An internal floating head minimizes contact between the water and air. The field erected tank is made of stainless steel. It is seismically designed and meets the requirements of American Nuclear Society Safety Class 3 . The foundation is a reinforced concrete mat. The tank is surrounded by a two feet thick reinforced concrete wall to the roof level for missile protection.

\section{Condenser Gas Removal System}

Three half-size mechanical vacuum pumps are supplied for removing non-condensible gases from the three condenser she11s. During start-up, all three pumps are operating, to minimize the evacuation time. When an acceptable vacuum is reached, one pump is placed in the standby mode. Normally, two pumps are required to maintain the condenser vacuum. If the condenser pressure rises, the standby pump starts automatically. To avoid cycling, the standby pump is manual1y stopped.

The vacuum pumps are motor driven rotary two-stage units. The seals for the pumps utilize demineralized water and a closed cooling system integrated with each pump assembly. Circulating water is used for cooling.

\section{Turbine Bypass System}

The turbine bypass system:

- provides a means of controlled heat release from the reactor through the steam generators and main condenser during start-up, hot shut-down, cool-down and reactor physics testing;

- provides a means of limiting the inflow transients to prevent reactor trips during rapid load reductions including load rejections of up to 100 percent electric power;

- provides a bypass of steam to the condenser during transients; and

- provides capability for testing the turbine cycle.

The condensing system is designed to accept up to 50 percent of the main steam flow bypassing the turbine during start-up and transient conditions. For this purpose, two 16 inch main steam headers are provided, each with six 8 inch pipelines and six inch dump valves, which discharge into the main condensers. Each valve is rated to pass 635,000 pounds per hour of steam, and has a maximum capability of $1,210,000$ pounds per hour at 1200 psia design. The control of the turbine bypass valves is coordinated with the turbine controls such that minimum transient disturbance is experienced by the nuclear steam supply system. 
Condensate Polishing System

One complete condensate polishing system is provided that is capable of treating 100 percent of the condensate flow. The condensate polishing system removes both dissolved and suspended impurities from the condensate stream by a combination of filtration and ion exchange. The system consists of six individual high flow rate, deep bed type demineralizers operating in parallel. At maximum flow conditions, five of the demineralizers are in service with the sixth acting as standby. Each demineralizer has a resin charge of 260 cubic feet, consisting of 172 cubic feet of cation resin and 88 cubic feet of anion resin. Each demineralizer is 10.5 feet in diameter, and has a flow rate of $4,200 \mathrm{gpm}$ ( $50 \mathrm{gpm}$ per square foot of flow area). The vessels are steel, lined with rubber, and have stainless steel internals. The vessels are designed for operating conditions of 500 psig at $130^{\circ} \mathrm{F}$.

A mixed bed polishing vessel will normally remain in service until its cycle is terminated, due to either a high accumulation of solids, indicated by excessive pressure drop, or exhaustion of its ion exchange capability, indicated by high effluent conductivity. At the termination of a service cycle, the exhausted resin is sluiced hydraulically from the polishing vessel to the resin separation/cation regeneration vessel. Within this vessel, the resin charge is separated into cation and anion portions. The anion resin is then sluiced to the anion regeneration vessel before chemical regeneration is commenced. Cation resin is regenerated with a dilute solution of sulfuric acid; anton resin is regenerated with a warm dilute solution of sodium hydroxide. To lengthen the service cycle of the resin charge, the system has the optional capability to recycle a dilute ammonia solution between the resin contained in the two external regeneration vessels. Following regeneration, the resins are sluiced to the resin storage vessel where they are remixed and stored.

Provided as part of the condensate polishing system are chemical storage tanks and pumps for acid, caustic and ammonia, a caustic dilution water heater, an air blower, condensate pumps, piping, valves, instrumentation and a control panel designed for semi-automatic operation.

\section{ACCOUNT 234 Feedheating System}

Six stages of feedwater heaters are utilized to heat the feedwater returning to the steam generators. Heaters are placed in series with each stage operating at increasing extraction pressure along the feedwater heater train. Pressures are maintained by various stages of extraction steam from the high pressure and the low pressure turbines. Heating the boiler feedwater in this manner improves the overall cycle efficiency.

A11 heaters are of the closed type having a horizontal "U"-tube arrangement, using stainless steel tubes. Each heater has an integral drain-cooler section with the exception of the fifth stage heater. The drains from Heaters 2 through 4 and 6 cascade to the next lower pressure heater through a control valve that maintains water level within the she11. Drains from Heater 5 are pumped forward into the condensate line between Heater 5 and the steam generator feed pump suction. Drains from Heater 1 cascade to the condenser. 
PWR ACCOUNT 23

Due to the physical size of the heaters required for each stage of feedwater heating, three parallel trains of heaters are utilized for the first four stages, with each individual heater being sized for one-third capacity. The two highest stages of feedwater heaters are in two trains with each heater sized for 50 percent of the flow. The two lowest pressure stage feedwater heaters are installed in the condenser necks below the three low pressure turbines. One of the three trains of both the first and second stage heaters is located in each of the three condenser necks. The individual trains of the remaining four stages of feedwater heaters are located in the heater bay.

Only the highest heater stage is in the discharge of the feedwater pump and subject to full system pressure. The remaining five stages of heaters are subject only to the discharge pressure of the condensate pumps.

To allow for: maintenance, a bypass line and valve are provided for every two stages of feedwater heaters. Although the first two stages may be bypassed, maintenance cannot be performed until the unit is shut down (due to their location in the condenser necks).

\section{Feedwater System}

Feedwater leaves the fifth stage feedwater heater and flows to the steam generator feed pump suction with sufficient pressure to provide adequate NPSH for the pumps. At the discharge of the steam generator feed pumps, the pressure is sufficient to deliver the water through the high pressure feedwater heater to the steam generator inlet, and maintain the required main steam pressure.

The two steam generator feed pumps are multi-stage barrel type centrifugal pumps each driven by a steam turbine to provide water at 1200 psia to the high pressure feedwater heater. Each pump has a 60 percent flow margin ( 80 percent capacity) to prevent reactor trip from the loss of one pump. Each feed pump is designed for a flow rate of $17,200 \mathrm{gpm}(27,350 \mathrm{gpm}$ at 80 percent $)$ developing a total dynamic head of 2,350 feet when operating at a speed of $5,300 \mathrm{r} / \mathrm{min}$. Calculated brake horsepower under these conditions is 10,100 .

The steam generator feed pump drives are each dual-admission, multi-stage, non-extraction, condensing turbines with design ratings of 10,100 horsepower $(16,200$ horsepower at 80 percent) at $5,300 \mathrm{r} / \mathrm{min}$. Normally extrection steam from the main turbine is used to drive this turbine. During low load oper ation, the dual-admission inlet allows use of main steam when the pressure of the extraction steam is too low. For start-up, auxiliary boiler steam is supplied through the low pressure inlet. The turbines exhaust through ducts to the main condenser. To account for pressure drop through the ducts, these auxiliary turbines are designed for a backpressure of 0.5 in-HgA higher than the main turbine.

For emergency conditions, two 100 percent capacity emergency feedwater pumps are provided, rated for a flow of $655 \mathrm{gpm}$ and a total dynamic head of 3,000 feet. One of the emergency pumps is driven by a 700 horsepower, $3600 \mathrm{r} / \mathrm{min}$ 
motor. The other is driven by a multi-stage turbine exhausting to atmosphere, also rated at 700 horsepower, $3600 \mathrm{r} / \mathrm{min}$.

Extraction Steam System

The extraction steam system conveys steam extracted from selected stages of the turbines to:

a. The shell side of the closed feedwater heaters where it condenses heating the feedwater which is in the tubes.

b. The steam generator feed pump drive turbines.

All extraction lines, except the three lowest pressure extractions are provided with motorized shut-off valves and non-return valves to prevent any back flow to the turbine. The lowest pressure extraction is for moisture removal, and discharges directly to the condenser. The second and third lowest pressure extractions supply steam only to the first and second stage feedwater heaters which are located in the condenser necks. Since, in all three cases, the extraction steam pipe never exits from the condenser, installation of any valves is physically impractical.

Extraction flow to the feedwater heaters is controlled only by the rate at which it condenses in the heater shel1. When the steam condenses in the feedwater heaters, the drains are normally cascaded to the shell side of the next lowest pressure heater. A level control valve on the drain line keeps the drain cooler tubes submerged. An alternate drain on each heater shell bypasses the drain cooler section and drains directly to the condenser. These drains are automatically opened in response to a high liquid level in the shel1. The lowest pressure heater drains to the condenser. Heater 5 normally drains to the heater drain tank where its drains are combined with the moisture separator reheater drains for pumping into the feedwater flow to the steam generator feed pump suction.

Extraction flow to the steam generator feed pump turbines is controlled by the feed pump turbine inlet valves, as discussed above.

\section{ACCOUNT 235 Other Turbine Plant Equipment}

This section discusses the remainder of the turbine plant equipment, such as the turbine building closed cooling water system, demineralized water make-up system, chemical treatment system and neutralization system.

Main Vapor Piping System

The main steam system conveys high pressure saturated steam from the steam generators to the high pressure turbine and the moisture separator/reheaters. Carbon steel pipe is used in the main steam system. The system comprises the main steam piping, auxiliary piping, fittings, main steam isolation and relief valves, other necessary valves, containment piping penetrations, steam 
traps and strainers, specialities, hangers, supports, insulation and the SC2 main steam pipe whip and seismic restraints.

Piping, fittings, valves, penetrations, supports and restraints located inside the reactor containment building, or inside the Seismic Category I main steam and feedwater pipe enclosure (upstream of the main steam isolation valve) are American Nuclear Society Safety Class 2 design. Other piping and components are Non-Nuclear Safety design.

Steam from the main steam system is supplied through a pressure reducing valve to the auxiliary steam system when it is available in preference to producing it in the auxiliary boilers.

\section{Turbine Building Closed Cooling Water System}

Cooling of turbine plant and miscellaneous plant auxiliary equipment in the turbine building is accomplished with a closed recirculating cooling water system. Heat is rejected from this system to the main cooling towers through the service water system (refer to Account 252). The cooling water is circulated through the closed system by two 50 percent capacity motor driven pumps. A third pump is provided as a spare. A head/expansion tank assures adequate net positive suction head at the pump suction, and automatic replenishment of any water lost to leaks. It also provides an expansion volume to account for the varying volume of the water between cold fill and full load.

The heat absorbed by the cooling water is transferred to the service water in two 50 percent capacity shell and tube heat exchangers. Counter-flow exchangers are used, with the cooling water exiting the heat exchangers approximately $10^{\circ} \mathrm{F}$ warmer than the entering service water. Cooling water is on the shell side and service water is in the tubes.

Demineralized Water Make-up System

The demineralized water make-up system treats effluent water from the make-up water pretreatment system. This system produces a high quality demineralized water supply that is utilized as make-up to the steam cycle.

The system provides a maximum of 480,000 net gallons of demineralized water per day to storage. It consists of two trains of treatment equipment which utilize a common forced draft degasifier. Each train contains an activated carbon filter, a strong acid cation exchanger, a strong base anion exchanger and a mixed bed polishing vessel. Additional equipment provided as part of the demineralizer system includes bulk acid and caustic storage tanks, day tanks, regenerant pumps, a caustic dilution water heater, pumps, blowers, piping, valves and instrumentation.

Water directed to the demineralizer system is initially treated by the activated carbon filters. These filters are each eight feet in diameter and contain a median bed depth of 2.5 feet. The filters protect the downstream ion exchange resin by removing any chlorine or organics from the water. 
Following activated carbon filtration, the water is treated by strong acid cation exchangers. These vessels are each 8.5 feet in diameter and contain a resin charge of 142 cubic feet. The resin within these vessels is regenerated by a dilute solution of sulfuric acid. Following the strong acid cation exchangers, the water is combined and treated by a single forced draft degasifier 5.5 feet in diameter. The degasifier removes carbon dioxide from the water in order to reduce the anion loading on the downstream strong base anion exchangers.

The water is pumped from the degasifier to the strong base anion exchangers. These vessels are also 8.5 feet in diameter and contain 112 cubic feet of resin. The anion resin is regenerated with a warm dilute solution of sodium hydroxide. Following these vessels are the mixed bed polishing vessels. These vessels are each 7.5 feet in diameter and contain 53 cubic feet of cation resin and 80 cubic feet of anion resin. After treatment by the demineralized water make-up system, the product water is discharged to the demineralized water tank.

A11 of the pressure vessels of the demineralized water make-up system are rubber-1ined and are designed with 100 percent freeboard. Additionally, the system is designed so that each cation and anion exchange vessel is regenerated once per day at maximum flow. The activated carbon filters and the mixed bed exchangers require weekly backwashing and regeneration at maximum flow.

\section{Chemical Treatment System}

The chemical treatment system injects hydrazine and ammonia into the condensate/feedwater system downstream of the condensate polishing unit. The hydrazine chemically scavanges any oxygen not removed in the condenser. The ammonia maintains the condensate in an acceptable alkaline range by increasing its $\mathrm{pH}$ as required.

The hydrazine is recelved and stored as a 35 percent solution in 55 gallon drums and transferred to the solution tank where it is mixed with condensate to form a five percent solution. Filling the solution tank and making the proper solution is controlled manually. Two positive displacement metering pumps (one spare) inject the solution into the condensate piping at a rate of up to ten gallons per hour. Injection rate is automatically varied in proportion to condensate flow. The proportionality ratio is manually adjusted.

Aqueous ammonia is received by truck and stored in a 7000 gallon storage tank (included as part of the condensate polishing system). Two positive displacement metering pumps (one spare) transfer the ammonia directly from the bulk storage tank into the condensate piping, downstream of the condensate polishing unit, at a rate of up to ten gallons per hour. Injection rate is automatically controlled in proportion to condensate conductivity. The ammonia is also used in the regeneration of the condensate polishing demineralizer. 


\section{Neutralization System}

The neutralization system is designed to receive and neutralize the waste water from a complete regeneration cycle of either a condensate polisher or a make-up demineralizer train. The system consists of two sumps, each able to contain up to 60,000 gallons of waste water, which is equivalent to the volume of waste from one condensate polisher regeneration. Consequently, when the waste in one sump is being neutralized, the other is available to collect waste. Additional equipment provided are an air grid mixer in each sump, two 100 percent capacity $1250 \mathrm{cfm}$ air blowers, and four $1000 \mathrm{gpm}$ acid/caustic resistant vertical sump pumps. Two of these pumps are provided per sump so that one pump per sump is considered to be a 100 percent spare. These pumps are used to recirculate the waste in the sump to enhance mixing and to transfer the neutralized waste to the waste water treatment equipment (refer to Account 255) for additional treatment and discharge.

The required acid and/or caustic for neutralization is supplied from the bulk storage tanks in the water treatment area. Positive displacement acid and caustic chemical pumps, identical to the pumps provided for regeneration of the resin of the make-up water treatment system, are provided for delivering chemicals to the neutralization system. Chemical addition is automatically controlled based on $\mathrm{pH}$. Self-neutralization based on mixing of the spent acid and caustic regenerants is utilized to the maximum possible extent.

\section{ACCOUNT 236 Turbine P1ant Instrumentation and Control}

The turbine plant instrumentation and control system provides monitoring and protection for plant, personnel and equipment. It enables the operator to start up, operate and shut down the turbine plant in conjunction with the reactor plant.

Turbine Plant Control Board

The turbine plant control board is a part of the main control board described under Account 227. This portion of the main control board provides monitoring and control of the turbine and auxiliary process systems and components tabulated below:

\author{
Feedwater System \\ Heater Vents and Drains \\ Main Steam System \\ Turbine \\ Extraction Steam System
}

\author{
Condensate System \\ Circulating Water System \\ Service Water System \\ Turbine Supervisory and Control System \\ Instrument and Service Air Systems
}

\section{Turbine Supervisory Pane1}

The turbine supervisory panel is furnished with the main turbine-generator unit and is mounted on the turbine plant section of the main control board. The panel contains the multi-point vibration recorder for shaft vibration, the eccentricity, speed and position recorder, and the multipoint expansion 
and temperature recorder. An indicator is also provided for turbine shaft vibration phase angle.

Electro-Hydraulic Control Cabinet

The electro-hydraulic control cabinet contains the control and indicating equipment required for the start-up, normal operation and testing of the turbine. This cabinet is furnished with the turbine-generator unit and is mounted as a subpanel on the turbine plant section of the main control board.

Typical control functions provided are:

Selection of starting rates: slow, medium or fast

Setting of turbine speed at start-up

Setting of load limit, and loading rate limit

Chest/shell warming

Turbine trip

Selection of operating mode: standby, manual or remote

Selection of load: increase or decrease

Typical indicating functions provided are:

Turbine speed

Percentage of warming rate

Throttle steam pressure, first stage pressure, intermediate pressure

Generator output, MWe

Acceleration, r/min/min

Valve positions for main stop valves, control valves and intermediate valves.

Typical testing functions are provided for:

Thrust bearing wear detector

Backup overspeed trip

Electrical trip

Mechanical overspeed and piston trip

Main stop valves, control valves and intermediate valves.

Turbine Accessory Panels

Turbine accessory panels contain the instrumentation and control devices for various turbine auxiliary systems. These panels are field mounted or control room mounted. Control panels located in the field are furnished for such typical auxiliary systems as generator hydrogen and cooling water control, turning gear motor control, excitation control and reheater protection piping control. These panels are furnished with the main turbine-generator unit. 
Heating, Ventilating and Air Conditioning Panels

These panels provide monitoring and control of the HVAC systems for buildings which house the turbine plant systems. Typical HVAC systems controlled from these panels are the various turbine building air handling systems.

Logic Panels and Cabinets

These panels and cabinets provide mounting space for analog devices, such as function generators, summers, dividers, analog controllers and selectors. Typical turbine plant systems which have analog devices in these panels and cabinets are the condensate and feedwater systems, circulating water system, heater vents and drain system and main steam system.

Instrument Racks

These racks are similar in construction to those described previously under the same heading in the reactor plant instrumentation and control section under Account 227 .

Process Computer

The computer for the turbine plant is the same computer used for the reactor plant. Refer to the reactor plant instrumentation and control section under Account 227 .

Turbine Plant Instrument Tubing and Fittings

The material requirements of the turbine plant instrument tubing and fittings are similar to those for the reactor plant, as described in the reactor plant instrumentation and control section under Account 227. 
PWR ACCOUNT 24

ACCOUNT 24 ELECTRIC PLANT EQUIPMENT

Electrical key parameters related to the electrical plant are given in Items 38 through 47 of Table 3-1. The table supplements and amplifies the following discussion of Account 24.

The electric plant equipment conveys the electric power generated in the plant to the low voltage bushings of the generator step-up transformers (GSU), controls and meters the electric energy, and protects the components through which the power flows. It also conveys electric power from the electric generator, the off-site power system, or the emergency generators to the plant auxiliaries and the plant control, protection and surveillance systems during normal operation, and to the plant protection system and engineered safety features during normal operation, abnormal conditions, and accident conditions.

Continuous ratings of equipment conveying power from the main generator to the GSU are based on valves wide open turbine operation and generator voltage variation of plus or minus five percent.

Continuous ratings of equipment serving plant auxiliaries and systems, as well as interrupting ratings of their protective and disconnecting devices, are based on equipment load tabulations, fault studies and voltage regulation studies. Equipment continuous current ratings are based on the maximum continuous load plus the largest spare auxiliary, and the effects of diversity. Short time intermittent loads are not included.

The electric plant design features are as follows:

a. The plant auxiliary distribution system design is based on a source voltage variation of plus or minus five percent.

b. The main generator, the three single phase generator stepup transformers (GSU) and the two three phase unit auxi1iary transformers (UAT) are interconnected with isolated phase bus.

c. The generator is provided with a load break switch in the mains between the generator and the UAT tap to disconnect the generator from the off-site power system.

d. Two fifty percent three-winding unit auxiliary transformers (UAT), each $24.5 \mathrm{kV}$ to $13.8-4.16 \mathrm{kV}$, are connected to the generator main leads between the generator load break switch and the GSU.

e. Two fifty percent three-winding reserve auxiliary transformers (RAT), each $230 \mathrm{kV}$ to $13.8-4.16 \mathrm{kV}$, are connected to an off-site transmission system. 
f. The Non-Class $1 \mathrm{E}$ medium voltage ac distribution system is nominally $13.8 \mathrm{kV}$ and $4.16 \mathrm{kV}$. Two separate and independent balance-of-plant (BOP) buses are provided for each voltage level. The two $13.8 \mathrm{kV}$ buses are fed from the " $\mathrm{x}$ " windings and the two $4.16 \mathrm{kV}$ buses are fed from the "Y" windings of the UAT's and RAT's.

g. The Class $1 \mathrm{E}$ medium voltage ac distribution system is a nominal $4.16 \mathrm{kV}$. Two separate and independent Class $1 \mathrm{E}$ buses are provided. Each Class $1 \mathrm{E}$ bus is fed from the " $\mathrm{Y}$ " windings of the UAT's and RAT's through a tap in the $4.16 \mathrm{kV}$ buses.

h. The low voltage ac distribution systems are a nominal 480 volts. Nineteen load center transformer/distribution buses are provided for the BOP systems and eight buses are provided for the Class IE systems. The low voltage ac distribution system is divided into two separate and independent groups of buses.

i. Four separate and independent Class $1 \mathrm{E}, 120$ volt nominal, uninterruptible ac instrumentation and control power supplies and distribution buses fed from the Class 1E 480 volt buses are provided.

j. Two separate and independent Non-Class 1E, 120 volt nominal, uninterruptible power supplies fed from the BOP 480 volt buses are provided. One supplies power to BOP instrumentation and control while the other provides power to the plant computer.

k. The Class $1 E$ de distribution and supply systems are nominally 125 volts. Four separate and independent station batteries and distribution buses are provided.

1. The Non-Class IE dc distribution and supply system is nominally $125 / 250$ volts. One center-tapped station battery and distribution system is provided.

m. One Class $1 \mathrm{E} 125$ volt battery charger is provided for each Class $1 \mathrm{E}$ battery. One Non-Class 1E 125 volt battery charger is provided for each of the two 125 volt sections of the $125 / 250$ volt Non-Class $1 \mathrm{E}$ center-tapped battery.

n. Two redundant Class $1 \mathrm{E}, 100$ percent, $6083 \mathrm{kWe}$ dieselgenerator units are provided as the standby power supply for the Class $1 \mathrm{E}$ buses, and are automatically connected to their respective buses when the normal and preferred power supplies are not available. 
Motor starting voltage and frequency and allowable operational variations, at which the required starting and operating torques are developed, are as follows :

a. Continuous operation of ac motors

1) Voltage: \pm 10 percent of rated

2) Frequency: $\ddagger 5$ percent of rated

b. Starting and short time (approximately 30 seconds)

operation of ac motors:

1) Class 1E (Voltage): 75 percent of rated

2) Non-Class 1E (Voltage): 80 percent of rated

c. dc Motors (Vo1tage): 210 to 280 volts

Al1 Class lE loads (those loads essential to prevent significant release of radioactivity to the environment) are furnished with ac or dc power from one of the following: the Class $1 E$ ac buses, the Class $1 E$ uninterruptible instrumentation and control ac power supplies, or the Class $1 \mathrm{E} d \mathrm{c}$ buses.

The normal power supply for the plant electric auxiliaries is from the main generator through the unit auxiliary transformers. The preferred emergency power supply is $\mathrm{from}$ the $230 \mathrm{kV}$ of $\mathrm{f}-\mathrm{site}$ power supply via the reserve auxiliary transformers. The alternate access power supply is from the $500 \mathrm{kV}$ off-site power supply via the generator step-up transformers and the unit auxiliary transformers, when the generator load break switch is open. The standby power supply is from the two Class $1 \mathrm{E}$ diesel-generator units to the corresponding Class IE medium voltage ac buses.

The power and control circuits, including circuit breakers and cabling, to all Class $1 \mathrm{E}$ loads are qualified, channeled and separated to meet Class lE requi rements. Protective devices are coordinated on the basis that protection of the Class $1 E$ systems is the primary goal.

Table 3-2 (refer to page 3-82) presents allowable ranges of temperature and limits for exposure to radiation for electric equipment. Design ambient conditions for spaces housing electric equipment are based on these ranges and limits plus a minimum of five percent for margin.

Physical and electrical separation of equipment and systems is provided to assure the availability of the minimum required equipment during any design basis event. Physical separation of equipment and circuits is done in such a way that the single failure and fire protection criteria are met and that the independence achieved cannot be compromised by adjacent or supporting mechanical and structural systems.

The paragraphs given below provide brief technical descriptions that provide guidance to the more detailed descriptions that follow: 
Account 241 Switchgear (generator load break switch and station service switchgear)

Account 242 Station Service Equipment (station service and start-up transformers, unit substations and auxiliary power sources)

Account 243 Switchboards (control boards and panels and auxiliary power and signal boards)

Account 244 Protective Equipment (general station grounding, lightning protection, cathodic protection, and heat tracing and freeze protection systems)

Account 245 Electric Structures and Wiring Containers (underground duct runs and conduit and cable tray raceways)

Account 246 Power and Control Wiring (main generator bus duct, power wiring, control cable and instrument wire, and containment penetrations) 
TABLE $3-2$

ENERGY ECONOMIC DATA BASE

PHASE VIII UPDATE (1986)

1144 MWe PRESSURIZED WATER REACTOR NUCLEAR POWER GENERATING STATION (PWR) DESIGN AMBIENT CONDITIONS FOR ELECTRIC EQUIPMENT

\begin{tabular}{|c|c|c|c|c|c|c|}
\hline \multicolumn{3}{|c|}{ Limits } & \multicolumn{2}{|c|}{$\begin{array}{c}\text { Ambient } \\
\text { Temperature } \\
\text { Limit } \\
\left({ }^{\circ} \mathrm{F}\right)\end{array}$} & \multicolumn{2}{|c|}{$\begin{array}{l}\text { Ambient } \\
\text { Radiation } \\
\text { Limit } \\
\text { (Rads) }\end{array}$} \\
\hline \multicolumn{2}{|c|}{$\begin{array}{l}\text { Type of } \\
\text { Equipment }\end{array}$} & Limit & Equipment & $\begin{array}{c}\text { Equipment } \\
\text { Space }\end{array}$ & Equipment & $\begin{array}{c}\text { Equi pment } \\
\text { Space }\end{array}$ \\
\hline \multirow{2}{*}{\multicolumn{2}{|c|}{ Battery }} & Maximum & 90 & N/A & $\mathrm{N} / \mathrm{A}$ & $\mathrm{N} / \mathrm{A}$ \\
\hline & & Minimum & 77 & 80 & $\mathrm{~N} / \mathrm{A}$ & N/A \\
\hline \multirow{2}{*}{\multicolumn{2}{|c|}{ Cable }} & Maximum & 104 & 100 & $1 \times 10^{8}$ & $1 \times 10^{7}$ \\
\hline & & Minimum & N/A & N/A & $\mathrm{N} / \mathrm{A}$ & $\mathrm{N} / \mathrm{A}$ \\
\hline \multirow{2}{*}{\multicolumn{2}{|c|}{ A11 Other** }} & Maximum & 104 & 100 & $\mathrm{~N} / \mathrm{A}$ & $\mathrm{N} / \mathrm{A}$ \\
\hline & & Minimum & $40 *$ & $50 *$ & $\mathrm{~N} / \mathrm{A}$ & N/A \\
\hline \multicolumn{7}{|c|}{$\begin{array}{l}\text { * Or above dewpoint temperature, whichever is higher } \\
\text { ** Sensitive relays and other electrical devices are placed in } \\
\text { controlled environment spaces such as the control room, } \\
\text { electronic equipment room, computer room, or battery room, } \\
\text { as applicable. }\end{array}$} \\
\hline
\end{tabular}


ACCOUNT 241 Switchgear

Generator Load Break Switch

A load break switch is provided in the main generator isolated phase bus to disconnect the generator rapidly from the off-site system when no fault is present. This allows quick connection to the alternate access power supply (GSU and UAT). The switch comprises three single-pole, water-cooled, gangoperated, load break switches with a spare single pole and an independent cooling system. The cooling system has redundant active components.

\section{$\underline{\text { Station Service Switchgear }}$}

The medium voltage metal-clad switchgear comprises two Non-Class $1 \mathrm{E} 13.8 \mathrm{kV}$ buses, two Non-Class $1 \mathrm{E} 4.16 \mathrm{kV}$ buses and two Class $1 \mathrm{E} 4.16 \mathrm{kV}$ buses. These buses are divided into two load groups or trains with each train consisting of one of each of the above buses. Each train is supplied by an independent secondary winding of a three winding UAT or a three winding RAT. Motors rated $2500 \mathrm{hp}$ and above are rated $13.2 \mathrm{kV}$ and motors rated $250 \mathrm{hp}$ to $2250 \mathrm{hp}$ are rated $4.0 \mathrm{kV}$.

Transfer schemes are provided for automatically and manually transferring each train between the preferred emergency power supply and the normal power supply. Load shedding schedules are provided for automatically stripping all $\mathrm{Class} 1 \mathrm{E}$ buses whenever there is an of $\mathrm{f}-\mathrm{site}$ power failure. Sequential loading schemes are provided for the Class IE buses to automatically connect selected engineered safety features to those buses after load shedding, and to re-energize the buses from the diesel-generator units.

Overcurrent and differential protection are provided for each, incoming feeder circuit. Overcurrent protection is provided for all feeder circuits. Differential protection, overload protection and zero sequence overcurrent ground protection is provided for all medium voltage motor circuits.

Non-Class $1 \mathrm{E}$ and Class $1 \mathrm{E} 480$ volt motor control centers are provided for power distribution to motors $100 \mathrm{hp}$ and below, lighting loads and miscellaneous loads such as motor-operated valves, resistance heaters, heat tracing and motor space heaters. These motors are rated at 460 volts. Overcurrent protection is provided for all incoming and feeder circuits. Overload protection is provided for all motor circuits.

ACCOUNT 242 Station Service Equipment

Station Service and Start-up Transformers

Two half-size unit auxiliary transformers (UAT) and two half-size reserve auxiliary transformers (RAT) are provided to furnish power to the plant auxiliary power system. Each pair of transformers is sized with sufficient margin to carry the plant auxiliary load under the heaviest load conditions. Transformer impedances are based on limiting fault current availability to 
PWR ACCOUNT 24

switchgear capability considering the required range for voltage regulation. Each transformer is protected with overcurrent and differential protection schemes and sudden internal overpressure devices.

\section{Unit Substations}

Unit substations are provided to transform the medium distribution voltages to the distribution voltage of 480 volts for Non-Class $1 \mathrm{E}$ and Class $1 \mathrm{E}$ low voltage loads. Motors rated $125 \mathrm{hp}$ through $200 \mathrm{hp}$ are connected to the unit substation buses. These motors are rated at 460 volts.

Unit substation transformer impedances are based on matching switchgear capability to fault current availability considering voltage regulation. overcurrent protection is provided for all feeder circuits. Overload protection is provided for all motor circuits.

\section{Auxiliary Power Sources}

The battery systems comprise the plant Non-Class $1 \mathrm{E}$ and Class $1 \mathrm{E}$ batteries and battery chargers. Each Class $1 \mathrm{E} 125$ volt dc bus is supplied from a Class $1 E 125$ volt battery and a Class $1 E 125$ volt battery charger. The Non-Class lE $125 / 250$ volt dc bus is supplied from a Non-Class lE $125 / 250$ volt centertapped battery and two Non-Class $1 \mathrm{E} 125$ volt battery chargers, one for each 125 volt section of the $125 / 250$ volt battery. During normal operation, dc power is supplied from the battery chargers. During emergency operation, dc power is supplied from the batteries. During start-up and shut-down, dc power is supplied from whichever source is available.

Two redundant Class $1 E$ diesel-generator units are provided as the on-site source of emergency ac power to the Class $1 \mathrm{E} 4.16 \mathrm{kV}$ buses. Each diese1generator unit is provided with redundant automatic air starting systems that are initiated when loss of off-site power, loss of power to engineered safety features or reactor trip occurs. The rating for the diesel-generator units is such that each unit has the capability to continuously operate all protection systems and engineered safety features necessary for a safe and orderly shut-down, following a loss of coolant accident concurrent with loss of off-site power. Minimum voltage that can be experienced at the diese1generator units' terminals during motor starting is 80 percent of rated voltage. Rating, configuration and switching of the diesel-generator units are designed to limit their use to that of a standby power supply.

Four Class $I E$ and two Non-Class $1 E$ dual input solid state inverters are provided to serve as uninterruptible power sources for miscellaneous vital and non-vital ac and plant instrumentation loads. The Class $1 \mathrm{E}$ and NonClass lE inverters are supplied with power from their respective Class $1 \mathrm{E}$ and Non-Class $1 E$ ac buses through regulating transformers or directly from their respective Class $1 \mathrm{E}$ and Non-Class $\mathrm{IE}$ station batteries. 
ACCOUNT $243 \quad$ Switchboards

\section{Control Boards}

Sixteen feet of control benchboard are provided in the main control board described under Account 227 for control, monitoring and data acquisition of the main generator and the auxiliary electric power system functions tabulated below:

a. Main Generator

GSU Circuit Breaker

Generator Load Break Switch

Grid/Generator Synchronizing

Excitation (Watts/Vars)

Auxiliary Systems

b. Auxiliary Power Distribution System

(Class $1 E$ and Non-Class $1 E$ )

RAT Primary Switch

$13.8 \mathrm{kV}$ and $4.16 \mathrm{kV}$ Incoming Feeder Circuit Breakers

Load Center Incoming Feeder Circuit Breakers

Batteries

Battery/dc Switchgear Main Circuit Breakers

Diese1-Generator Units

Diese1-Generator Units Remote/Manual Control

Diese1-Generator Unit Circuit Breakers

One electrical system relay panel lineup is provided in the main control room for protection and metering of the main generator, the generator step-up transformers, and the unit and reserve auxiliary transformers. The main generator protection includes high speed differential, ground overcurrent, loss-of-field, negative sequence overcurrent, and distance relays. The generator step-up transformers and the unit auxiliary transformers are protected by individual and overall differential relays, as well as overcurrent relays. The reserve auxiliary transformer is also protected by differential relays.

Technical Support Center and Emergency Operations Facility System Control Pane1s

Separate control panel lineups are located in the technical support center building for providing on-site technical support and interfacing with the off-site support center systems during emergencies. The Technical Support Center system control panel provides monitoring, data acquisition and communications links with the main control room that are necessary for centralized management and control of an on-site emergency. The Emergency Operations Facility system control panel provides essential communications and data links with regulatory, state and local agencies having support or decision making responsibilities relative to the off-site impact of on-site emergencies. 


\section{Auxiliary Power and Signal Boards}

Four Class $\mathrm{IE}$ and two Non-Class $\mathrm{IE}$ ac power distribution panels are provided to distribute ac power from the inverters to the 120 volt or $120 / 240$ volt uninterruptible loads. They are configured as one panel per inverter for both Class $1 \mathrm{E}$ and Non-Class $\mathrm{IE}$ equipment. Overcurrent protection is provided for all circuits.

Four Class $1 \mathrm{E}$ and one Non-Class $1 \mathrm{E}$ de power distribution switchgear lineups are provided to distribute dc power from the station batteries and their associated chargers. There is one lineup per station battery/charger combination. Overcurrent protection is provided for all feeder circuits. A ground detection scheme is provided for each dc bus.

\section{ACCOUNT 244 Protective Equipment}

\section{General Station Grounding System}

The station grounding system provides the means for maintaining an effective ground at equipment and metal structures and for protecting personnel from dangerous potentials.

A complete grounding system is provided for equipment and raceways, consisting of jumpers from each cable tray and conduit to the ground grid, a bare copper wire run in and bonded to each cable tray, a ground bus mounted in each metal enclosure and connected to the ground grid, pigtails from equipment frames to the ground grid and a dedicated instrument grounding system.

A complete yard grounding system is provided as the plant grounding grid, consisting of building ground grids, unit ground grid and interconnections. Materials used include bare stranded copper conductors, copper clad steel ground rods, silicon-bronze connectors for above-ground connections and thermite process welds for below-grade connections.

\section{Lightning Protection System}

Lightning protection schemes are provided for the containment structure and for all Seismic Category I buildings and for the turbine building. Six lightning protection masts complete with air terminals, bases and connections are provided for protection of the containment building and 1iner. Underwriters laboratories approved lightning protection schemes are provided for each Seismic Category I structure and for the turbine building.

\section{Cathodic Protection System}

Cathodic protection is provided to minimize galvanic corrosion of selected buried metal structures and pipes. A complete integrated system is provided, including transformers, rectifiers, sacrificial anodes, coke breeze anode beds, special wire and terminations. 
PWR ACCOUNT 24

Heat Tracing and Freeze Protection System

Electric heat tracing is provided to maintain concentrated boric acid system components and piping above the boric acid precipitation temperature.

Electric heat tracing freeze protection is provided for diesel-generator unit fuel oil piping and selected water piping located outdoors and above-ground.

A complete system is provided consisting of heat tracing wire, thermal cement, insulation, thermostats, control and alarm panels and interconnecting power and control wire and raceways.

\section{ACCOUNT 245 Electric Structures and Wiring Containers}

\section{Underground Duct Runs}

The Class $1 E$ and Non-Class $I E$ underground duct runs provide physical and environmental protection and physical separation for wire and cable routed between buildings. The duct runs' metallic and non-metallic ducts are encased in reinforced and non-reinforced concrete. Reinforced concrete manholes are provided at appropriate places in long duct runs to facilitate cable pulling. Class $1 \mathrm{E}$ duct runs are designed to Seismic Category I requirements and consist of ducts of rigid steel conduit encased in reinforced concrete. Non-Class $1 \mathrm{E}$ duct runs passing under roadways or railroads are encased in reinforced concrete.

Conduit and Cable Tray Raceways

The Class $1 \mathrm{E}$ and Non-Class $1 \mathrm{E}$ conduit and cable trays provide mechanical protection and physical separation and support for wire and cable routed from point to point within structures. The bulk of the raceway capacity is provided by cable trays of various sizes. Raceways are routed in accordance with the same criteria as for cable routing described under Account 246. Fire stops are placed in cable trays wherever they penetrate floors or firewalls, and in other areas where their installation will reduce the hazard of fire propagation. Class IE raceway supports are designed in accordance with Seismic Category I requi rements.

ACCOUNT 246 Power and Control Wiring

Main Generator Bus Duct

Isolated phase bus is provided to interconnect generator terminals, GSU low voltage terminals and UAT high voltage terminals. This bus is rated at $25 \mathrm{kV}, 35,000$ amperes and is force-cooled with redundant active components in the cooling unit. Tap buses to the UAT and to the potential transformers are self cooled. 
Power Wiring, Control Cable and Instrument Wire

The plant wire and cable consists of three-conductor and triplexed singleconductor power cable; multi-conductor control cable; coaxial, triaxial, shielded twisted pair, multi-shielded twisted pair and shielded quadruplex instrument wire; and containment electrical penetrations. Materials for insulation systems (ethylene-propylene rubber insulation with chloro-sulfonated polyethylene jacket) are selected to provide optimum system performance in the areas of physical stability; tensile strength; flexibility; aging characteristics; resistance to abrasion, ozone (where required), water absorption, heat distortion, and solvent extraction; irradiation; self-extinguishing and non-propagating fire characteristics; and resistance to corona effects (where required).

Wires and cables are assigned to load groups, whether safety-related or not, in order to reduce the hazard of non-safety-related cables being inadvertently routed between two redundant load groups. The same cable that is qualified for use in Class $1 \mathrm{E}$ systems is used in Non-Class $1 \mathrm{E}$ systems to reduce the hazard of unqualified cables being inadvertently installed in Class lE systems. In addition to separation by load groups, wire and cable is also separated by energy level to reduce heating and arcing fault problems.

Wire and cable routing is governed by the following:

a. Requirements for the power supply, control network and/or instrumentation signals

b. Requirements for loading

c. Requirements for physical separation of redundant circuits and circuits having different voltage and energy levels

d. Avoidance of high hazard areas (e.g., areas subject to high ambient temperatures, missiles, fires, and irradiation)

e. Protection from missiles, fire, and/or irradiation, when required

f. Single failure criterion and the effects of common cause failures

g. Simplicity of layout

h. Ease of installation

i. Ease of access

Class $1 \mathrm{E}$ and Non-Class $1 \mathrm{E}$ power and control cable is sized in accordance with ICEA Publications $\mathrm{P} 46-426$ and $\mathrm{P} 54-440$ with allowance for overloads and 
undervoltage conditions. Raceway derating is in accordance with NEMA standard WC51. Medium voltage power cables are also sized for fault current flow for the interrupting time of the overcurrent protection. Fault current capability is also considered for low voltage power cables and control cables, where applicable. Instrumentation cable ratings are selected in accordance with the application.

\section{Containment Penetrations}

Power, control and instrument wire leak-tight reactor containment penetration assemblies are provided to maintain containment integrity for wiring penetrations during normal and abnormal conditions. The penetrators provide double wiring seals combined with single containment aperture seals. Power penetrators are rated at $15 \mathrm{kV}, 5 \mathrm{kV}$ and 600 volts; control penetrators are rated at 600 volts; and instrument wire penetrators are rated in accordance with service requirements. All penetrators are designed to Seismic Category I requirements. 
PWR ACCOUNT 25

ACCOUNT 25 MISCELLANEOUS PLANT EQUIPMENT

Miscellaneous plant equipment includes systems and components for maintenance, plant start-up, or general supply of plant equipment requirements. Included are the cranes and hoists; air, water and steam services; auxiliary boiler and associated equipment; plant fuel oil system; fire protection system; communications systems; and various on-site and off-site environmental monitoring systems.

Interconnecting piping systems are included with each system, as required. They comprise the piping, fittings, valves, steam traps, strainers, specialties, hangers and supports, insulation, and other components required for a complete system. The piping systems are generally designed as American Nuclear Society Non-Nuclear Safety. In some cases they may be designed as Safety Class 3, where they interface with Safety Class piping systems. Materials and wall thicknesses are chosen based on the service conditions and operational requirements of each system. The factors generally considered include: temperature, pressure, corrosion resistance, abrasion resistance, fluid purity requirements and cost. Carbon steel is used for steam, clean water, air, oil and other services without special requirements. Other materials used include: cement lined carbon steel, coated and wrapped carbon steel for buried service, galvanized carbon steel and copper.

The following paragraphs outline the contents of the detailed descriptions.

Account 251 Transportation and Lifting Equipment (major cranes and other cranes and hoists)

Account 252 Air, Water and Steam Service Systems (compressed air systems, service water system, fire protection system, potable water system, auxiliary steam system and plant fuel oil storage tank)

Account 253 Communications Systems (local communications system, fire detection system and security system)

Account 254 Furnishings and Fixtures (instrument shop apparatus, off-site radiological monitoring system, meteorological monitoring system, water quality monitoring system, seismic monitoring system and other furnishings and fixtures)

Account 255 Waste Water Treatment Equipment 
PWR ACCOUNT 25

ACCOUNT 251 Transportation and Lifting Equipment

\section{Major Cranes}

Three major cranes are provided within the plant. Servicing the reactor building is a 420 ton overhead polar gantry crane with a 50 ton auxiliary hoist and a bridge span of 103 feet. The main hoist on this crane is fully redundant and is qualified to retain load during a safe shut-down earthquake (SSE).

Within the turbine building, an overhead traveling bridge crane is used with a main hoist capacity of 210 tons and an auxiliary hook capacity of 30 tons. The bridge span is 128 feet and covers the main operating floor area.

A separate 100 ton overhead traveling bridge crane with a bridge span of 61 feet is provided for the feedwater heater area.

\section{Other Cranes and Hoists}

In addition to the above major cranes, there are two five ton overhead trave1ing bridge cranes located in the diesel-generator portion of the control room and diesel-generator building. There are also ten monorail hoists with capacities in the five to ten ton range to serve various plant areas.

ACCOUNT 252 Air, Water and Steam Service Systems

Compressed Air Systems

The compressed air system is composed of two separate subsystems; the plant compressed air system, and the containment building instrument air system.

The plant compressed air system supplies service air throughout the plant and instrument air throughout the plant, excluding the containment building. The system consists of three 50 percent capacity oil-free reciprocating compressors, complete with intake filters, aftercoolers and two 100 percent capacity air receivers and air dryers. Each compressor has an inlet air silencer and filter.

The containment building instrument air system supplies instrument air in the containment building. The system consists of two 100 percent capacity oilfree compressor packages with two 100 percent capacity air dryers. This system is designed to Seismic Category I requirements.

\section{Service Water System}

The service water system supplies cooling water from the main condenser heat rejection system to the turbine building closed cooling water system heat exchanger (refer to Account 235) and the reactor plant nuclear service water system (refer to Account 226) during normal plant operation. The system has three 50 percent capacity vertical wet pit pumps which are located in the 
circulating water pump house. Make-up water to the main condenser heat rejection system is discharged near the suction of these pumps to lower the service water average temperature. Service water returning to the cooling tower is combined with the returning (heated) circulating water to reduce the amount of piping required (refer to Account 262).

In the event that cooling water is not available from the service water system, the nuclear service water system supplies cooling water to the primary component cooling water system and the diesel-generator jacket cooling water heat exchangers utilizing the mechanical wet evaporative cooling towers (ultimate heat sink).

\section{Fire Protection System}

The fire protection system is designed to minimize the probability and effect of the occurrence of an in-plant fire by combining a fire detection system with a fire protection system. The fire detection system is described under Account 253 .

The fire protection system has four 50 percent capacity (2,000 gpm each) horizontal fire pumps, two diesel driven and two motor driven; two 100 percent capacity (300,000 gallons each) water storage tanks; one $50 \mathrm{gpm}$ jockey pump; circulating hot water freeze protection; yard fire mains; hydrants and hose houses; building and equipment sprinkler systems; building hose cabinets; and a quality assurance document storage halon system.

The jockey pump normally operates to maintain system pressure. One of the motor driven fire pumps is utilized in the event that the jockey pump cannot maintain system pressure. The second motor driven pump is started if the system pressure continues to drop, and the diesel engine driven pumps are started in sequence to maintain system pressure. All pumps take suction from the two 300,000 gallon storage tanks.

The fire protection water storage tanks are filled with river water using the screen wash pumps. A manually valved connection downstream of the screen wash strainer allows screen wash water to flow through a simplex strainer with a $60 \times 60$ mesh and a 2-1/2 inch fiberglass reinforced plastic pipe to the fire water storage tanks.

The diesel engine driven pumps are independent of plant services and are provided with separate fuel storage tanks. The hot water freeze protection system receives heat from the plant auxiliary steam system through a steam to hot water heat exchanger.

Sprinkler systems are provided in the following buildings: reactor containment building, control room and diesel-generator building, primary auxiliary building, turbine room and heater bay, administration and service building, fire pump house and selected station service equipment areas. Deluge sprinkler systems are provided for the generator step-up, unit auxiliary and reserve 
auxiliary transformers, the main turbine lube oil storage area and the dieselgenerator unit fuel storage areas.

Quality assurance document storage areas are protected with Halon fire suppression systems.

\section{Potable Water System}

Potable water is required for drinking, sanitary, and washing purposes at the plant. This water is supplied by the local municipal water supply system and distributed throughout the plant by a potable water piping system. Included in this system are outlets at wash rooms, drinking fountains, safety showers and eye wash stations, and hose bibb stations.

\section{Auxiliary Steam System}

Auxiliary steam is used for building heating, driving the steam generator feed pump turbine(s) during start up, the turbine driven emergency feedwater pump, and miscellaneous heating and freeze protection needs. When possible, this steam is supplied by pressure reduced main steam. Otherwise, it is supplied by the auxiliary boilers.

Two 100 percent capacity oil-fired auxiliary bollers with supporting auxiliary systems are provided. The boilers are shop assembled "package" type, designed for pressurized furnace operation. Normally, steam is used for atomizing the oil, but during start-up, compressed air or mechanical atomization may be used. Each boiler is sized to provide enough steam for a cold start of the main unit under the worst expected conditions.

A single forced draft $f$ an is provided for each boiler to supply the required combustion air and force the combustion gases through the ductwork and the common stack. No induced draft fans are included. The stack is a freestanding type shared and located between the two boilers.

A single deaerator and three 100 percent capacity boiler feed pumps are provided for each boller. Fuel is No. 2 fuel oil from the plant fuel oil storage tank. Three 50 percent fuel oil pumps are provided.

Hydrazine and ammonia are used to treat the auxiliary boiler feedwater, the same as for the main steam generator feedwater. A manually controlled blowdown is used to periodically remove any sediment which collects in the boiler drums.

The auxiliary boilers are manually started. They are each capable of being normally started either locally or from the control room. Each phase of the start-up procedure is separately initiated. Each auxiliary boiler is programmed to shut-down when the steam flow falls below its minimum flow capability during plant start-up. 
Plant Fuel 0il Storage Tank

The plant fuel oil storage tank has a capacity of 270,000 gallons and is 42 feet in diameter by 27 feet high. It is surrounded by a steel dike 87.5 feet in diameter by six feet high. The ground inside the dike is sealed with clay to prevent any spilled oil from contaminating ground water. This tank provides storage for fuel oil for the auxiliary bollers and diesel driven fire pumps and additional, but non-safety related, fuel ofl storage for the dieselgenerator units.

ACCOUNT 253 Communications Systems

Local Communications System

The plant communications system consists of a dial telephone system, a soundpowered telephone system and an intercommunication and paging system. These systems are designed to provide in-plant, on-site and off-site communications for all conditions of operation. The following paragraphs provide a brief description of each system.

A complete dial automatic telephone system is provided, consisting of an automatic switchboard and dial telephone handset stations.

Portable sound powered telephone handsets and jacks are located throughout the station. Interconnecting jack wiring is provided under Account 246.

A public-address/intercommunications system is provided, consisting of a control panel, amplifiers, handsets, loudspeakers and interconnecting wiring. High intensity directional double reentrant type loud speakers and handset sound booths are provided in high noise areas.

\section{Fire Detection System}

A fire detection system is provided for early warning of incipient or actual combustion. This system supplements and activates the fire protection system described under Account 252 .

Flame or smoke detection devices are located in infrequently visited or hazardous areas such as the cable tunnels or fuel storage areas. Signal devices are installed in the fire protection system to indicate initiation of operation of systems or components, such as fire pumps or deluge systems. Manual fire alarm stations and audible alarm devices are strategically located throughout the plant.

\section{Security System}

The security system is provided to control general access to the plant and to limit and control access to restricted or sensitive areas within the various buildings. 
The security system control panels and moinitoring stations are located in the security building. Various aspects of the plant security philosophy are also discussed under Account 214.

In addition to personnel check point systems and components, the security system includes closed circuit television monitors, electronic lock/card readers and perimeter fence and general area monitoring and surveillance devices. The objective of the system is to prevent industrial sabotage or theft of nuclear materials by controlling and limiting access to the plant and selected areas within the plant.

\section{ACCOUNT 254 Furnishings and Fixtures}

Instrument Shop Apparatus

Instrument shop apparatus are provided for testing, calibration, repairing, and routine maintenance of the plant instrumentation and control devices.

A typical list of instrument shop apparatus is provided below:
a. Dead weight tester
b. Pneumatic calibrator equipment
c. Decade resistance box
d. Digital volt meter
e. Variable voltage and current sources
f. Potentiometer
g. Osci1loscope
h. Electronic counter
i. Stop watch
j. Resistance and impedance bridges
k. Megger
1. Pressure gauges
m. Meters: dc (mA, Amps, Volts), ac (Amps, Volts)

Off-Site Radiological Monitoring System

The off-site radiological monitoring system consists of both preoperational and post operational programs. It provides data for individual and population 
exposure calibrations, for analysis of the possible buildup of environmental radioactivity and for public information. The post operational program, in conjunction with the radiological data management system described under Account 227, provides data required for estimation of the population dose during norma1 operation and design level releases. A rapid monitoring program provides fast and accurate data on population exposure during accident conditions.

The preoperational program is a radiation surveillance program implemented prior to plant start-up. The program identifies critical exposure pathways, defines critical population groups, selects sample media and sampling site locations, collects and analyzes environmental samples and interprets data.

The post operational program provides the necessary radiological data to demonstrate compliance with technical specification and effluent limits. The program requires measurement of gross radioactivity, specific radionuclides and other pertinent data for semi-annual reports required by the Nuclear Regulatory Commission.

The rapid monitoring program is part of the emergency procedure plan. It provides the personnel, organization and equipment necessary to enact prompt counter-measures for protection of the public in cases of reactor accidents.

Meteorological Monitoring System

The meteorological monitoring system provides all equipment essential for the monitoring and recording of the atmospheric parameters of the plant prior to construction, during construction and over the operational life of the plant. The equipment for the system consists of a meteorological tower and various meteorological monitoring instruments. Data from this system are used to determine an initial radiological site signature prior to construction and for dose calculations performed by the radiological monitoring system.

Water Quality Monitoring System

The water quality monitoring system monitors the rates and concentrations of contaminant in the plant effluent discharge. Typical variables measured are radioactivity, chlorine, suspended solids, $\mathrm{pH}$, oil and grease. Sampling techniques are established to yield representative batches or flows of the effluent discharge. Analytical data are recorded in necessary form for immediate as well as future interpretation and use.

\section{Seismic Monitoring System}

The seismic monitoring system is provided for the following purposes:

a. Furnish to the control room information on the presence of any seismic event so that immediate administrative procedures or decisions can be made. 
b. Provide basic data to determine the conservatism used in the modeling and design assumptions made for the structures, and the design input motion to the supported systems and components.

c. Provide information to determine the advisability of continuing the operation of the plant following an earthquake.

Other Furnishings and Fixtures

Among the other furnishings and fixtures provided for the plant are provisions for monitoring and recording the temperature of the plant thermal effluent, office and cafeteria equipment and furniture, chemical laboratory fixtures, machine shop equipment, change room lockers and benches and portable fire extinguishers located throughout the plant.

\section{$\underline{\text { ACCOUNT } 255 \text { Waste Water Treatment Equipment }}$}

The waste water treatment system treats normal operating wastes from the plant and rainfall runoff from contaminated areas so that they will be suitable for discharge to the North River or for reuse. The system consists of two collection basins, a clarifier, two in-depth type pressure filters, various pumps, tanks, chemical feeds and mixers, and a belt-press type sludge dewatering machine.

Plant operational waste water and runoff from contaminated areas are collected and pumped to the two main collection basins, each of approximately 530,000 gallon capacity. Runoff from the transformer area and the fuel oil handling area is held in those areas until it is determined by observation or by analysis if the water is contaminated. Contaminated water is cleaned up locally, or is pumped to one of the two main basins. Oil is removed from the water held in the basins by means of a tube type skimmer.

The plant waste water is normally pumped from the basins to a clarifier by one of the three raw waste pumps at a rate of $250 \mathrm{gpm}$. Two pumps may be used during the processing of plant waste water and precipitation runoff at a combined rate of $450 \mathrm{gpm}$. The third pump is a spare.

Lime injection and air oxidation equipment are provided upstream of the 24 feet diameter clarifier. The clarifier provides a minimum detention time of two hours at $450 \mathrm{gpm}$, which allows most of the suspended solids to settle. The settled solids are periodically removed by one of two $40 \mathrm{gpm}$ underflow pumps and stored in the underflow storage tank. It is then pumped to the twometer sludge dewatering belt press filter at a rate of up to 80 gpm.

Overflow from the clarifier is collected in a clearwell and pumped to the high rate pressure filters. Three high-rate, dual media filters are provided to remove suspended solids carried over from the clarifier. At the maximum flow rate of $450 \mathrm{gpm}$, all three filters will normally be in service. At the 
low flow rate of $250 \mathrm{gpm}$, only two filters are required at a time. Under this condition, the third filter can be kept in stand-by until an operating filter is to be backwashed, at which time the standby filter is put into service. Each filter is eight feet in diameter and contains a stratified sand and anthracite bed.

Capability is provided to add acid to the discharge from the filters to ensure that the waste water is within the acceptable pH range of six to nine before it is discharged. A backwash storage tank (which also serves as an effluent monitoring tank) provides storage capacity for backwash of all three filters $(15,000$ gallons). The waste water is monitored for total suspended solids, ofl and grease, $\mathrm{pH}$ and other parameters as required. If any of these parameters do not meet the discharge permit requirements, the water will be pumped back to the waste holding basins by the backwash/effluent pumps. These pumps are also used to discharge the treated liquid wastes to the North River or to backwash the filters. The pumps are rated at $750 \mathrm{gpm}$ based upon the filter backwash requirements. 
Mechanical key parameters related to the heat rejection system are given in Items 32 and 33 of Table 3-1. Configuration of structures related to the heat rejection system are shown on the Plot Plan given in Figure 3.1. The table and figure supplement and amplify the following discussion of Account 26.

The main condenser heat rejection system is a closed loop circulating water system. It consists of buildings, structures and mechanical equipment that serve the main condensers and service water system to reject the plant excess heat through two natural draft wet evaporative cooling towers. The circulating water is chlorinated to control biological fouling.

Make-up water from the North River Initially passes through a bar rack to remove any large debris. It then passes through traveling water screens to protect the pumps. Automatic self-cleaning strainers following the pumps further remove suspended material. After straining, most of the make-up water is discharged to the cooling tower basin to replace water lost by evaporation and blowdown. Sulfuric acid is injected into the cooling tower make-up water as required to avoid scaling. The remaining make-up water is clarified and demineralized for use as steam cycle make-up.

Interconnecting piping systems are included with the auxiliary systems. They comprise the piping, fittings, valves, hangers and supports, and other components required for a complete system. The piping systems are designed as American Nuclear Society Non-Nuclear Safety. Materials and wall thicknesses are chosen based on the service conditions and operational requirements of each system. The factors generally considered include: temperature, pressure, corrosion resistance, abrasion resistance, fluid purity requirements and cost. Carbon steel is used for clean water and other services without special requirements. Other materials used include: stainless steel, concrete, polyvinyl chloride (PVC) and fiberglass reinforced plastic (FRP). The circulating water pipes between the condensers and the cooling towers are of reinforced concrete and carbon steel.

The paragraphs given below identify the subjects covered by the detailed descriptions that follow.

Account 261 Structures (make-up water intake structure, circulating water pump house and make-up water pretreatment building)

Account 262 Mechanical Equipment (circulating water pumps, cooling towers and cooling tower basins, plant make-up and blowdown equipment and make-up water pretreatment plant) 
ACCOUNT 261 Structures

Make-up Water Intake Structure

The make-up water intake structure is Non-Seismic Catgegory I and is located along the riverbank west of the main plant structures. It is approximately 38 feet wide, 36 feet long and 30 feet deep below plant grade with the top slab located at grade. The structure is reinforced concrete with the foundation mat bearing on rock. There are two intake chambers, each ten feet wide (inside) and 36 feet long at the bottom. The reinforced concrete top slab over the two chambers supports the two make-up water pumps. A ten feet high masonry enclosure is supported above the top slab. Its roof is insulated metal deck covered with built-up roofing and supported on steel framing. A trash pit with truck access ramp is located north of the two intake chambers.

The two intakes are protected by bar racks, stop logs and traveling screens. The traveling screens are the fish collection type where any fish which become trapped on the screen are gently washed into a trough separate from the trash and returned to the river downstream of the intake. To minimize the number of $\mathrm{fish}$ which may become trapped on the screen, the approach velocity to the screens is kept below $0.5 \mathrm{feet} / \mathrm{sec}$ and the velocity through the screen is as low as possible.

A trash rake is provided to clean the bar rack. Debris from washing the screens and debris collected from the bar rack are discharged to a container in the trash pit. The container is periodically emptied by an outside contractor. Water drains from the container onto the trash pit floor. A drain in the floor of the trash pit conducts water from the floor to one intake chamber, in front of the traveling screen.

\section{Circulating Water Pump House}

The circulating water pump house is a Non-Seismic Category I reinforced concrete structure connected to the two cooling tower basins by reinforced concrete flumes and supported on a three feet thick reinforced concrete foundation. The flume bottoms slope upward from the bottom of the pump bays to the bottoms of the cooling tower water basins. The circulating water pump basin foundation is supported on rock. The circulating water basin is approximately 50 feet wide, 90 feet long and 28 feet high from the top of the bottom slab to the operating floor. Attached to the west end of the circulating water pump basin is a service water pump basin, also founded on rock. This basin is 16 feet wide, 26 feet long and 18 feet high from the top of the bottom slab to the operating floor.

The circulating water pump basin is divided into four pump bays, one for each pump. The service water basin is a single bay. Exterior walls, interior walls, base mat, operating floor slab and interior columns are reinforced concrete. Portions of the operating floor are grating. The concrete operating floor slab is supported on the walls dividing the circulating water pump basin into separate pump bays. The grating is supported on these same walls 
and on the interior columns. The circulating water pumps and service water pumps are supported from the reinforced concrete operating floor slab. All pump bays are provided with panel screens and stop logs.

A 20 feet square equipment room ten feet high is located on the solid portion of the operating floor slab. The equipment room is masonry construction with an insulated built-up roof on a metal deck supported by steel framing. The equipment room is cooled with propeller type fans. In the winter months, heating is provided by electrical space heaters. The equipment room houses the circulating water system chlorination equipment, and local instrument racks.

\section{Make-up Water Pretreatment Building}

The make-up water pretreatment building is a Non-Seismic Category I structure located west of the main plant structures and east of the intake structure. It is a two story steel framed structure 50 feet wide, 150 feet long and 30 feet high. The building volume is approximately 200,000 cubic feet. It is supported on reinforced concrete footings founded on rock. The reinforced concrete ground floor is located six feet below grade. The intermediate floor is cast-in-place concrete on metal deck supported on steel framing. The roof is concrete channel plank supported on steel framing and covered with a roofing membrane. The exterior walls are reinforced concrete to one foot above grade and insulated metal siding above that. The interior walls are concrete block.

The building has a heating and ventilating system which consists of roof ventilators for cooling and electric unit heaters for heating.

The building houses the strainers, clarifiers, chemical feeds, sludge dewatering equipment, circulating water system sulfuric acid feed equipment, and other equipment required for a complete water pretreatment system.

\section{ACCOUNT 262 Mechanica1 Equipment}

\section{Circulating Water Pumps}

There are four 25 percent capacity mixed flow, vertical wet pit type circulating water pumps provided. Each pump is designed for a flow rate of 183,100 gpm with a total dynamic head of 90 feet. The combined capacity of 732,400 gpm includes:

$691,800 \mathrm{gpm}$ for condenser cooling

$2,100 \mathrm{gpm}$ for cooling the three condenser vacuum pumps

$693,900 \mathrm{gpm}$ (d) $88^{\circ} \mathrm{F}$ (Tota1)

$3,600 \mathrm{gpm}$ for blowdown

5 percent design margin on each pump for wear and miscellaneous 
Each circulating water pump motor is rated at $5000 \mathrm{hp}$ and $300 \mathrm{r} / \mathrm{min}$. The pumps are located within a pump house well to which the water flows from the individual cooling tower basins by gravity. The pumps discharge the water through the main condensers, where heat is absorbed. The water then returns to the distribution system of the towers. Water flow is controlled by the number of pumps placed in service at a given time. Flow from each individual cooling tower is controlled by an overflow from the tower basin.

Cooling Towers and Cooling Tower Basins

There are two hyberbolic natural draft wet cooling towers each capable of cooling $358,876 \mathrm{gpm}$ of water from $110^{\circ} \mathrm{F}$ to $88^{\circ} \mathrm{F}$ when operating at a wet bulb temperature of $74^{\circ} \mathrm{F}$. The total design water flow is based on:

$695,689 \mathrm{gpm} @ 110^{\circ} \mathrm{F}$ from condenser and vacuum pump cooling $22,063 \mathrm{gpm}$ returning service water ef $113^{\circ} \mathrm{F}$

The total nominal design capacity of the two cooling towers is $718,000 \mathrm{gpm}$ or $359,000 \mathrm{gpm}$ per tower.

The design wet bulb temperature of $74^{\circ} \mathrm{F}$ is the annual maximum at the Middletown site. By designing for circulating water temperature of $88^{\circ} \mathrm{F}$ leaving the towers and $110^{\circ} \mathrm{F}$ returning, the maximum turbine exhaust pressure is estab1ished at $3.0 \mathrm{in}-\mathrm{HgA}$. It is estimated that the wet bulb temperature will be low enough to permit operation at or below turbine design exhaust pressure of 2.5 in-HgA 91 percent of the time. During the short periods of especially high wet bulb temperature (above approximately $60^{\circ} \mathrm{F}$ ) back pressure rises above $2.5 \mathrm{in}-\mathrm{HgA}$ to a maximum of $3.0 \mathrm{in-HgA}$, with a corresponding increase of less than one percent in the heat rate.

Each cooling tower is a round reinforced concrete structure with film type fill designed to expose maximum surface of the hot water to the air. Evaporation of a portion of the water is the primary cooling mode, although some sensible heat exchange also occurs. The cooled water is collected in a basin under the tower. Reinforced concrete flumes connect the two basins to the circulating and service water pump basins.

The hot water distribution system located inside the cooling tower above the fill distributes the water uniformly over the fill. The distribution system also permits increased flow to be directed to the perimeter to avoid icing in cold weather, and isolating a portion of the fill to avoid overcooling in cold weather.

Drift eliminators are chevron shaped slats located above the water distribution systems. They remove entrained liquid from the discharged air/vapor stream. Drift is limited to less than 0.01 percent of the water circulation rate.

The air flow through the waterfill is induced by the density difference between the heated (less dense) air inside the hyberbolic shell and the cooler surrounding air. 
Plant Make-up Water and Blowdown Equipment

Two 100 percent capacity vertical centrifugal pumps are installed at the intake structure to provide make-up water to the circulating water system (losses due to evaporation, drift, blowdown), steam cycle (losses due to blowdown, leaks, unrecovered auxillary steam) and general plant use. The make-up water pumps discharge to the make-up pretreatment plant, where the water is strained and/or clarified as required.

Water from the North River approaching the pumps first passes through a bar rack with 3.5 inch openings to remove large material such as 1 ogs, and then through either of two traveling water screens having $3 / 8$ inch square openings. Approach velocity to the traveling water screens is 0.5 feet per second and velocity through the screen is one foot per second. The bar rack is cleaned by a motorized rake. Debris collected on the traveling water screens is flushed into a trough by a water spray from behind the screen, collected in a bin and periodically disposed of off-site. Any fish which become trapped on the screens are washed of $f$ separately from the debris and gently returned to the river downstream of the intake. Two 100 percent capacity screen wash pumps are provided for cleaning the screens of both fish and debris.

Blowdown is used to control the concentration of dissolved solids in the circulating water. An average blowdown rate of 0.5 percent of the circulating water flow has been established for this plant, resulting in a dissolved solids concentration approximately five times that of the make-up water.

Blowdown is removed from the circulating water system at the discharge of the circulating water pumps and discharged to the river. Discharge to the river requires no treatment, except that chlorination of the circulating water must be stopped shortly before and during blowdown. A single fiberglass-reinforced plastic outfall pipe angled up to prevent scouring of the bottom is provided downstream of the make-up water intake structure.

Make-up Water Pretreatment Plant

Raw river water is fed from the make-up water pumps to the make-up water pretreatment plant. The purpose of this system is to precondition the raw river water which is used as make-up to the circulating water system, and the plant demineralizers. This equipment is located in the make-up water pretreatment bullding.

The primary objective of the system is to remove debris and suspended solids characteristically present in the river water. The amount of solids and debris contained in the raw influent is subject to wide fluctuation primarily due to seasonal changes and natural river environment.

The water first passes through two automatic self-cleaning strainers to remove debris larger than $1 / 32$ of an inch. The major portion of the water, to be used as make-up for the circulating water system, is then discharged directly to the cooling tower basin. Chlorination is applied directly to the 
circulating water on an intermittent basis to minimize biological fouling within the condenser and throughout the piping system. The circulating water system chlorination equipment is located at the circulating water pump house. Sulfuric acid is added to the make-up water to the cooling tower as needed to neutralize excess alkalinity and minimize any tendency for scaling in the cooling tower. The sulfuric acid tank and feed equipment is located at the make-up pretreatment building.

The portion to be demineralized is further treated in a pretreatment system consisting of a single clarifier and three dual media pressure filters, a backwash water storage tank, chemical feeders, as well as pumps, valves, and piping. The pretreatment system is designed to process water at a maximum rate of approximately 830,000 gallons per day.

The water that is directed to the pretreatment system is initially mixed with a coagulant chemical and is then piped to a 27 feet diameter clarifier. Should the clarifier be out of service, the influent water will bypass directly to the clearwe11. The clarifier provides for a minimum detention time of two hours in order to permit a large percentage of the influent suspended solids to settle. The solids which settle within the clarifier are periodically removed by one of the two 100 percent capacity underflow pumps provided. These pumps, which are rated at $40 \mathrm{gpm}$ each, pump the underflow solids to the station's liquid waste treatment system. Overflow from the clarifier is collected within a clearwell and then pumped by two of the three 50 percent capacity pumps to the dual media filters.

Three parallel dual media filters are provided. These filters are used to remove the small amount of suspended solids which are not removed within the clarifier. At the maximum system flow rate, all three filters will normally be in service. However, two filters are capable of treating the entire flow when one filter is removed from service for backwashing. Each filter is ten feet in diameter and contains a two feet deep bed of anthracite and a one foot deep bed of sand.

While the majority of the discharge from these filters is directed to the demineralized water make-up system, a small portion of the filtered water is directed to a 20,000 gallon backwash water storage tank. This tank provides a clean supply of water that is required for periodic filter backwashes. Spent backwash water from the filters is piped to the liquid waste treatment system. 


\subsection{ENGINEERING DRAWINGS}

The engineering drawings included in this section amplify and supplement the system design descriptions given in Section 3.3. The titles of these drawings are as follows:

Figure

Number

3.1

3.2

i

3.3

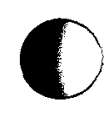

3.4

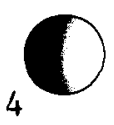

3.5

\section{Title of Drawing}

Plot Plan - 1144 MWe PWR NPGS Middletown Hypothetical Site

General Arrangement Plan at E1. 19'-0' (Ground F1.) 1144 MWe PWR NPGS Middletown Hypothetical Site

General Arrangement P1an at E1. 73'-0" (Oper.F1.) 1144 MWe PWR NPGS Middletown Hypothetical Site

General Arrangement Sections "A-A" and "B-B" Elevations 1144 MWe PWR NPGS Middletown Hypothetical Site

Steam Heat Balance Diagram 1144 MWe PWR NPGS Middlet own Hypothetical Site
Drawing Number

$7553.001-\mathrm{P}-01-\mathrm{R} 2$

$7697.703-\mathrm{P}-01-\mathrm{R} 1$

$7697.703-\mathrm{P}-02-\mathrm{R} 1$

$7697.703-P-03-R 1$

7553.001-P-02-R2 


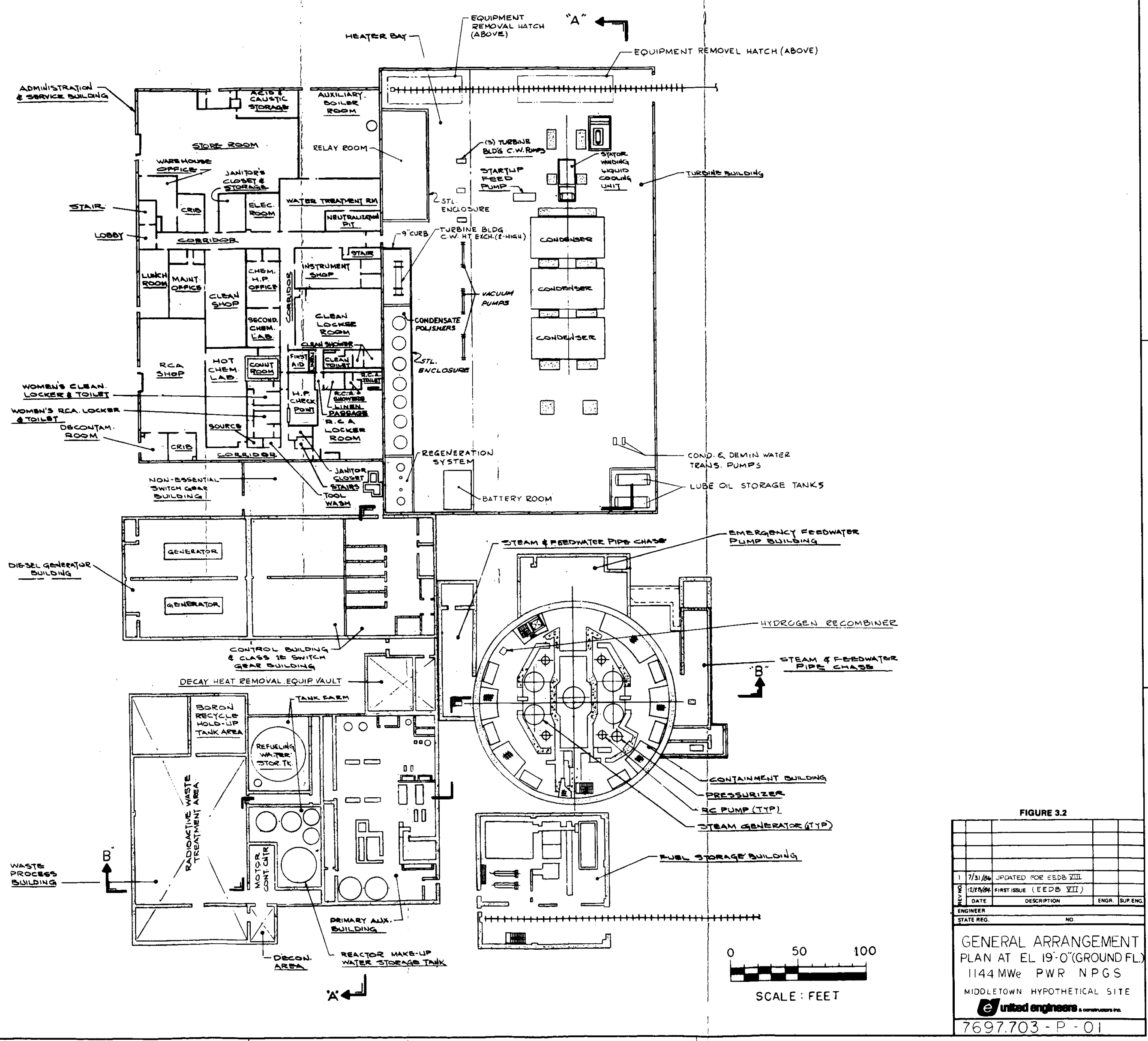




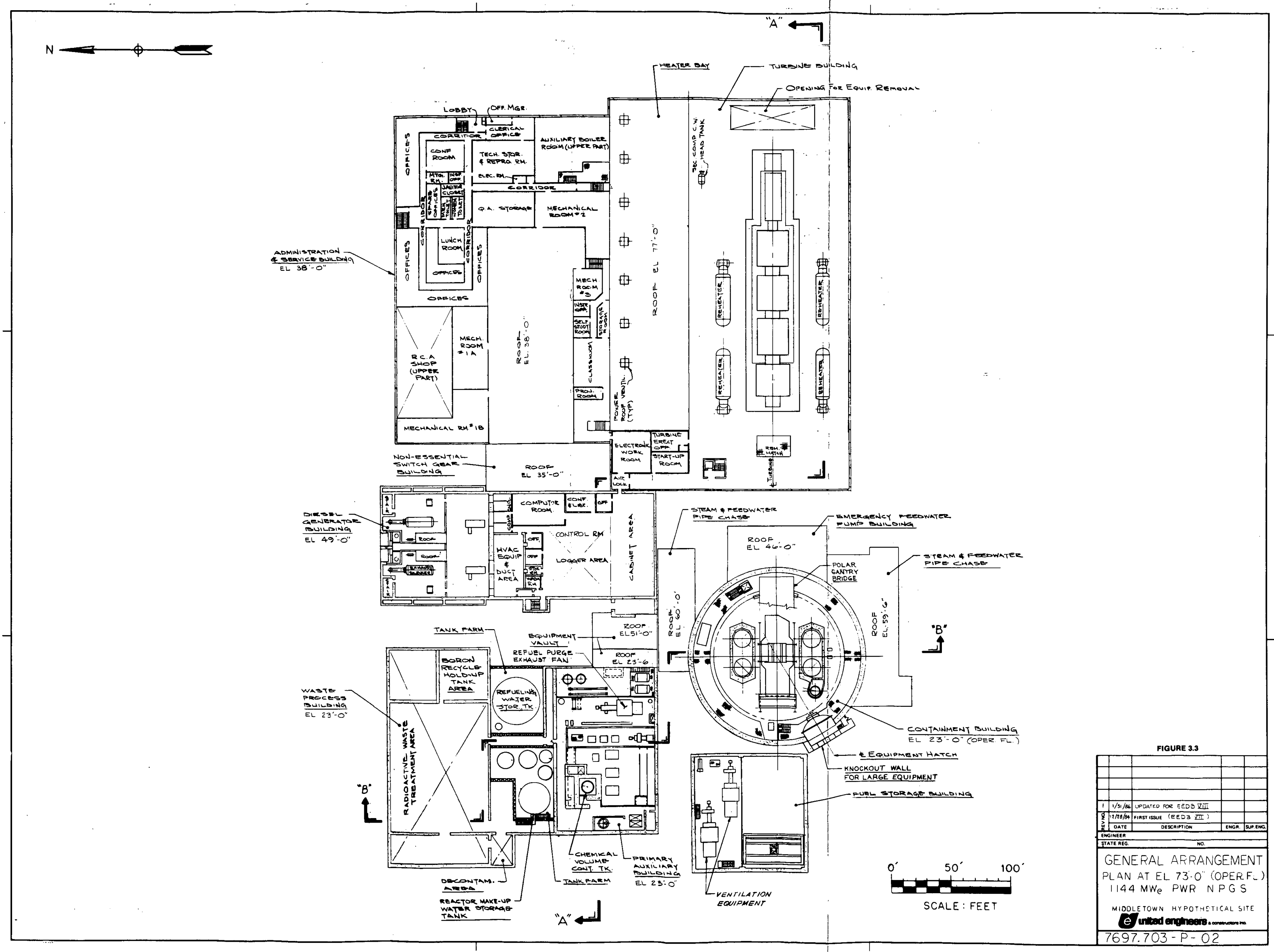




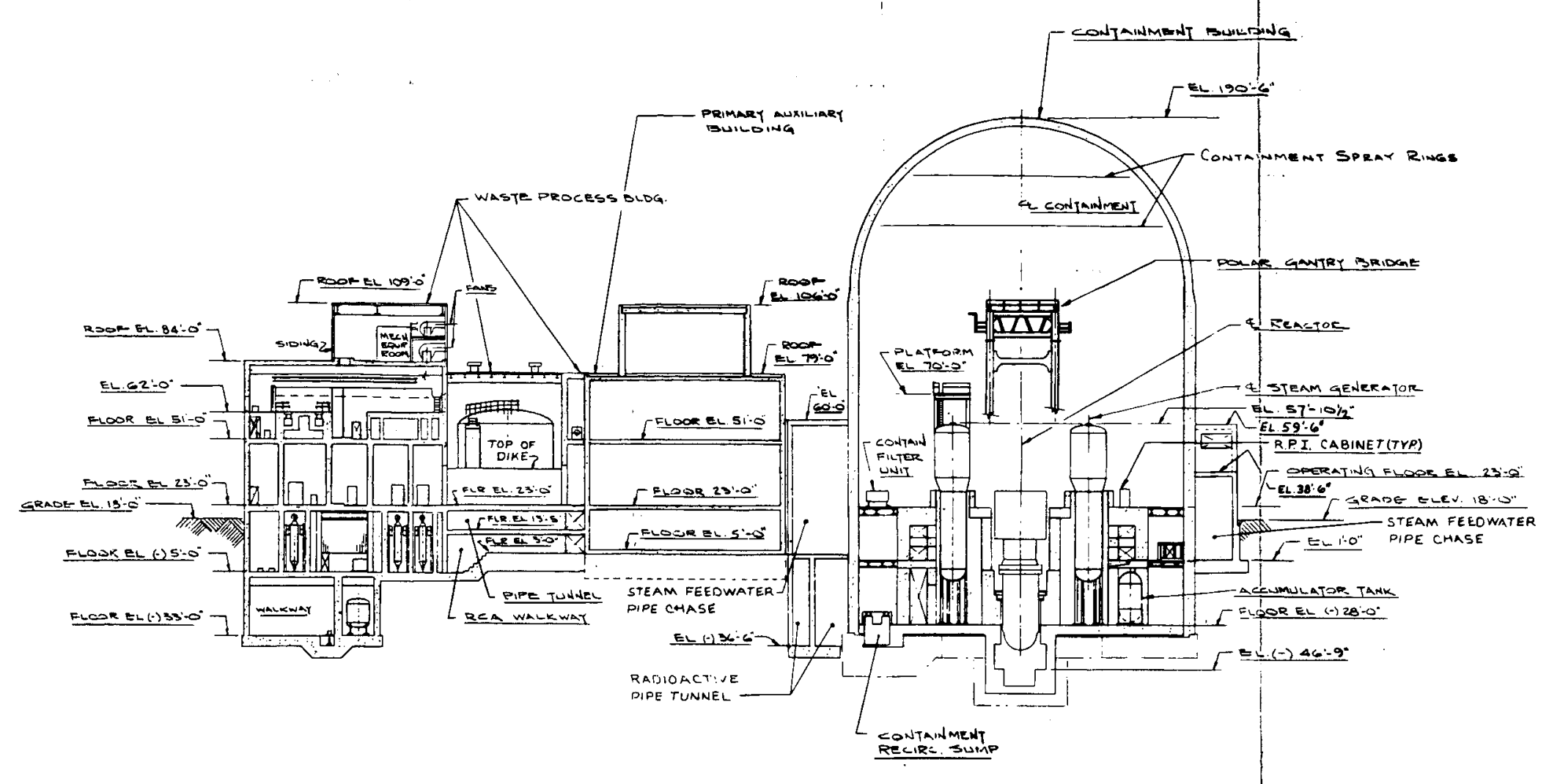

SECTION "B-B"

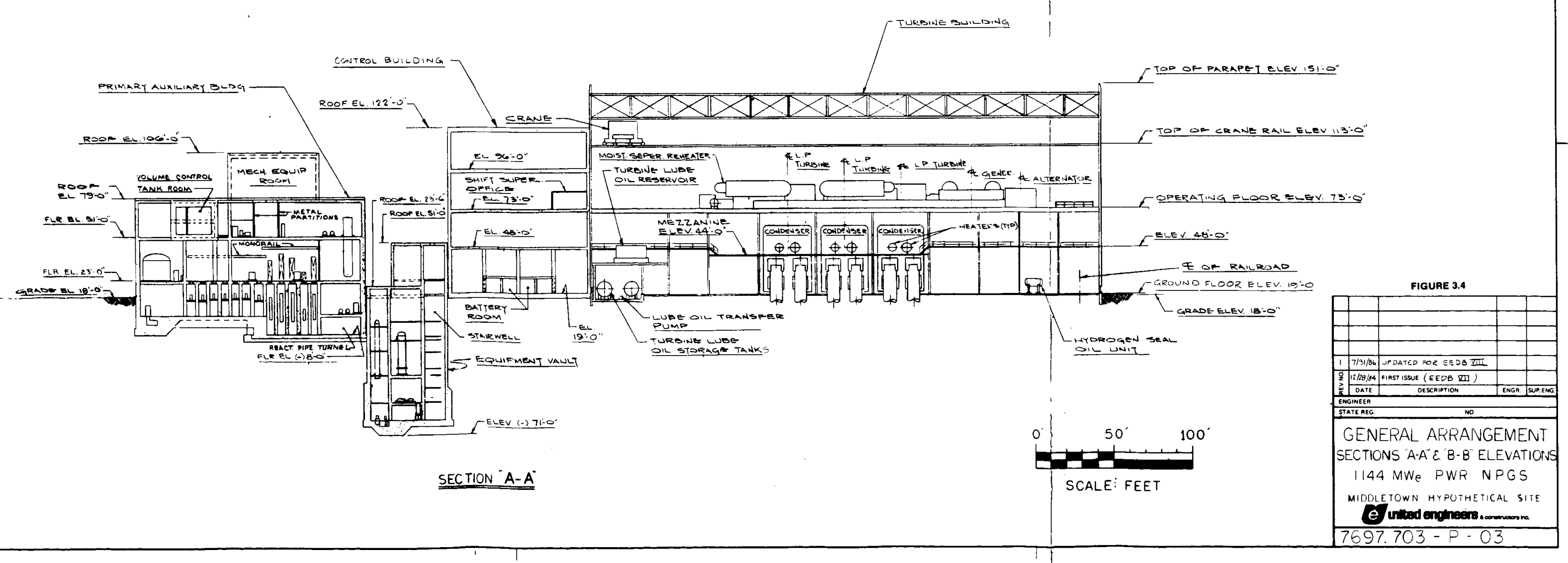




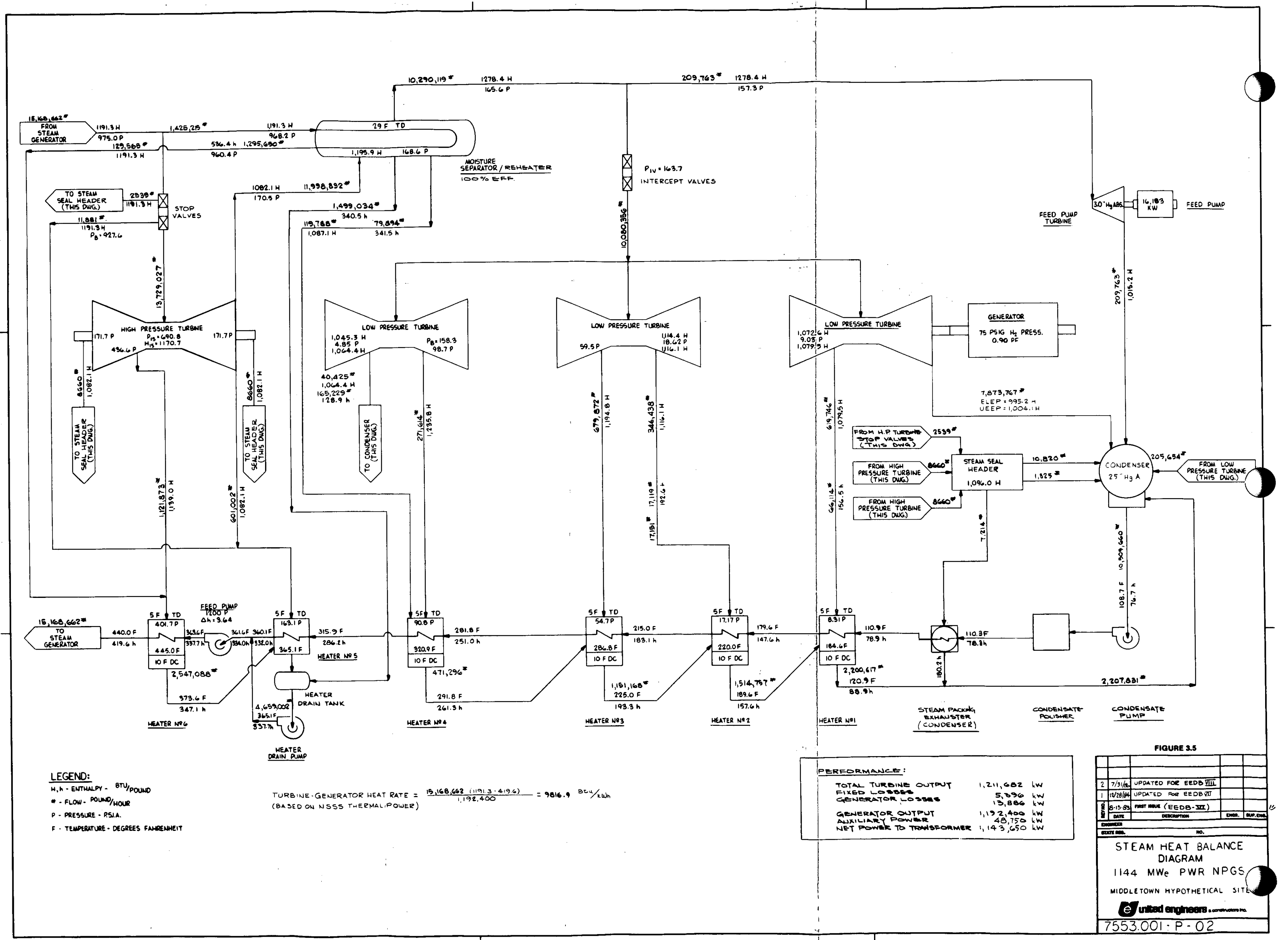




\subsection{DESIGN/CONSTRUCTION SCHEDULE}

The overall design/construction milestone schedule for the PWR technical data model is divided into two logical phases:

- Pre-construction (Licensing) activities that culminate in the award of a construction permit.

- Engineering and Construction activities which culminate in the completion and commercial operation of the unit.

These milestone schedules are discussed below.

\section{Preconstruction Licensing Activities}

The major licensing milestones that must be attained in order to begin construction activities on a nuclear power plant project are site selection and environmental and safety related regulatory requirements.

- Site Selection - Prior to U.S. Nuclear Regulatory Commission (NRC) involvement in the licensing process for a proposed nuclear unit, a utility makes an assessment of its need for power, where it is needed and the type of generation required. The utility then conducts a site selection program to determine the most cost-effective and licensable site. This effort typically requires nine months. Data gathered during site selection serves to justify the site and are later incorporated into support documents required by licensing regulations.

Site selection has recently become more complicated and time consuming because more than half of the states now require a utility to obtain state site certification and a favorable state Environmental Impact Statement for the proposed action. Acquisition time for site certification varies from state to state due to differences in regulatory requirements and stringency of review. Review periods have been known to consume from just a few months to several years. Preparation and review time for a State Environmental Impact Statement typically consumes 12 months, after all data have been submitted by the applicant to the cognizant state agency(s).

The PWR technical data model is located at the EEDB Hypothetical Middletown Site. By definition, it is representative of a Northeastern, U.S. location. Taking the hypothetical location into account, it has been determined that the PWR 1144 MWe plant would most probably be in a state having a site certification authority and requiring a state environmental review. 
- Regulatory Licensing Requirements - The NRC is the dominant regulator in the commercial nuclear power plant licensing process. The NRC is mandated under the Atomic Energy Act of 1954, as amended, to protect the public in matters of private utilization of fissionable material. To this end it must:

a. assess the potential health and safety aspects of the facility and ensure that it poses no undue risk to the health and safety of the public, and

b. assess the potential environmental effects of the facility to ensure that its existence will be consistent with the national environmental goals, as set forth by the National Environmental Policy Act of 1969 , as amended.

In addition, several other Federal Agencies, principally the Environmental Protection Agency (EPA) and the Army Corps of Engineers, have statutory authorities to regulate various non-nuclear related aspects of commercial nuclear power plants. The NRC will only issue a permit or license with concurrence of all Federal, state and local regulatory agencies.

In order to obtain the needed information to perform these assessments, the NRC requires that each applicant submit certain documents for review. The NRC review process is shown on the flow diagram presented in Figure 3.6. The required documents are as follows:

- A Preliminary Safety Analysis Report (PSAR) - This report defines the nature of the proposed nuclear station and includes preliminary plans for its use in sufficient detail to show the bases upon which the applicant concludes that it can be sited, built and operated safely.

- An Environmental Report (ER) - This report analyzes the potential environmental impact of the proposed station and its associated facilities.

- A Final Safety Analysis Report (FSAR) - This report updates and completes the information provided in the PSAR. Its acceptance is required for a commercial operation permit.

The PSAR and ER documents are typically filed and accepted for review (docketed) by the NRC at the same time. In states having utility siting legislation, this milestone occurs approximately 24 months from the start of site selection and 12 months after receiving site certification. At the same time as the NRC docketing, a public notice of document avallability is published in the Federal Register, and copies of the documents are furnished to cognizant state and local authorities. Copies are also placed in the NRC Public Document Room in Washington, D.C. and at a public facility near the proposed site. Notice of public hearings is published and an Atomic Safety 
and Licensing Board (ASLB) is appointed and convened to entertain and adjudicate petitions by interested parties.

The NRC then begins a series of reviews of the PSAR and ER. These reviews are based on criteria in the NRC's Standard Review Plan (SRP) for Light Water Reactors. When the NRC staff is satisfied that SRP criteria have been met, or that commitments have been made to meet them, it prepares a Safety Evaluation Report (SER) summarizing the results of the PSAR review. In addition, an Advisory Committee on Reactor Safeguards (ACRS) conducts an independent review on a less detailed level. At the same time, an environmental impact evaluation is performed on the applicant's Environmental Report. Based on this review, the NRC prepares an Environmental Impact Statement (EIS) which establishes the agency's environmental views on the project. Typically, the Federal EIS effort requires 18 months to complete. Initially, an EIS draft version is issued for public review and comment, with a final version following. During this same period, the NRC also conducts a site suitability analysis. Upon completion of these activities, public hearings are held, with the ASLB presiding.

Upon satisfactory responses to all outstanding safety and environmental issues, the NRC issues a construction permit (CP). The CP licensing process involves an approximate elapsed time of 48 months from the start of the project.

Under certain circumstances, the applicant may desire to begin site clearing activities prior to receiving the CP. This is possible via NRC's Limited Work Authorization (LWA) clause, which allows the applicant to begin nonsafety related activities on the site while a few issues remain open. Typically, a LWA is issued after the NRC has completed the final EIS and public hearings have been held, but prior to the award of a construction permit.

Figure 3.7 presents a typical preconstruction licensing schedule for the EEDB PWR nuclear power plant technical data model.

The last major licensing hurdle for an applicant is the operating license. Generally, the utility must allow from 24 to 36 months between filing of an application and issuance of an operating license. This application is supported by a Final Safety Analysis Report (FSAR) and an operating license stage environmental report. The FSAR reflects the as-built facility and forms the basis for the granting of an operating license. A review and public hearing process similar to that for the $\mathrm{CP}$ is then"followed.

The major unknown factor in the overall licensing schedule is the time consumed in public hearings and responses to public intervenors. This aspect of licensing alone has consumed from a few months to several years, and at times has caused the cancellation of a nuclear project.

Engineering and Construction Activities

Figure 3.8 presents a typical engineering and construction schedule for the EEDB PWR technical data model at the Middletown site. It has been developed on the basis of the median level past experience of the power industry in the 
construction of nuclear power generating units. Experience has shown that the period for construction of new nuclear power plants has increased dramatically in the past decade. This schedule expansion has come about because of developing uncertainty over the need for power, mounting financial difficulties and increasing manhour content, caused by the increase and changes in interpretation of regulations and criteria applicable to the nuclear industry as a whole. This trend may be halted or reversed in the future should proposed legislative reforms be enacted by Congress, and improvements in construction practices be initiated by industry.

The engineering and construction milestone schedule presented in Figure 3.8 indicates an expected period of 98 months from the issuance of a Construction Permit (CP) to the start of fuel loading. The schedule assumes a single eight hour daily work shift and a 40 hour work week. These assumptions translate into an average craft labor force of approximately 2000 over the 98 month construction period, and a peak force of approximately 3000 to 3500 . This labor force is based on the total site craft labor hours developed in the EEDB Phase VII Update (1986) for the median industry experience PWR ME technical data mode1.

The PWR-BE (best industry experience) technical data model was developed specifically to reflect the above mentioned necessary legislative reforms and improvements in construction practice.2,5,6 Although Figure 3.8 reflects the activities and durations for the PWR ME (median industry experience), it also reflects the activities and general duration ratios for the $P W R \cdot B E$. The equivalent construction period for the $\mathrm{PWR} \cdot \mathrm{BE}$ is 72 months from the issuance of a construction permit to the start of fuel loading. This schedule also assures a single eight hour daily work shift and a 40 hour work week. These assumptions translate into an average craft labor force of approximately 1500 over the 72 month construction period and a peak force of approximately 2300 to 2600. This labor force is based on the total site craft labor hours developed in the EEDB Phase VIII Update (1986) for the best industry experience $P W R \cdot B E$ technical data mode1.

The milestone schedule addresses, in a generalized form, the construction sequencing and interfacing of the principal structures and systems comprising the plant. Where appropriate, engineering and design, procurement, erection, and installation of equipment, components and piping are identified. In addition, the principal milestones of the project are identified and properly sequenced.

Figure 3.8 also identifies the critical activities which establish the overall project duration. The critical path is initiated at the site selection activity, moves through the licensing process leading to the the issuance of a construction permit, extends along the path for construction of the Reactor Containment Building ( $R C B)$ and installation of equipment and continues through the various test and start-up activities to commercial operation. It should be noted that the critical path is contingent upon satisfactory completion of the NRC Licensing Review as shown on the schedule. 
The engineering and construction activities for the other major structures (Primary Auxiliary Building, Control Room/Diesel-Generator Building, Fuel Storage Building, Waste Processing Building, Turbine Building, Cooling Towers, and Switchyard) can be accommodated within the 98 month overall construction schedule, and thus do not establish the critical path.

In practice, however, circumstances can arise which cause normally non-critical activities to become critical, and extend the overall duration of the construction schedule. Late delivery of major equipment as a result of unavailability of raw materials, over-extended fabrication facilities, expiration of shop labor contracts, wildcat strikes or failure of equipment under test has caused extension of construction schedules. When such delays occur for items on the critical path, schedule delays occur because no float time is provided for these items. When such delays occur for items not on the critical path, overall construction schedule delays may be avoided only to the extent that float time is provided for them. 
FIGURE 3.6

ENERGY ECONOMIC DATA BASE

PHASE VIII UPDATE (1886)

SINGLE UNIT 1144 MWE PRESSURIZED WATER REACTOR NUCLEAR POWER GENERATING STATION (PWR)

PAECONSTAUCTION PERMIT LICENSING PROCESS FLOW DIAGRAM

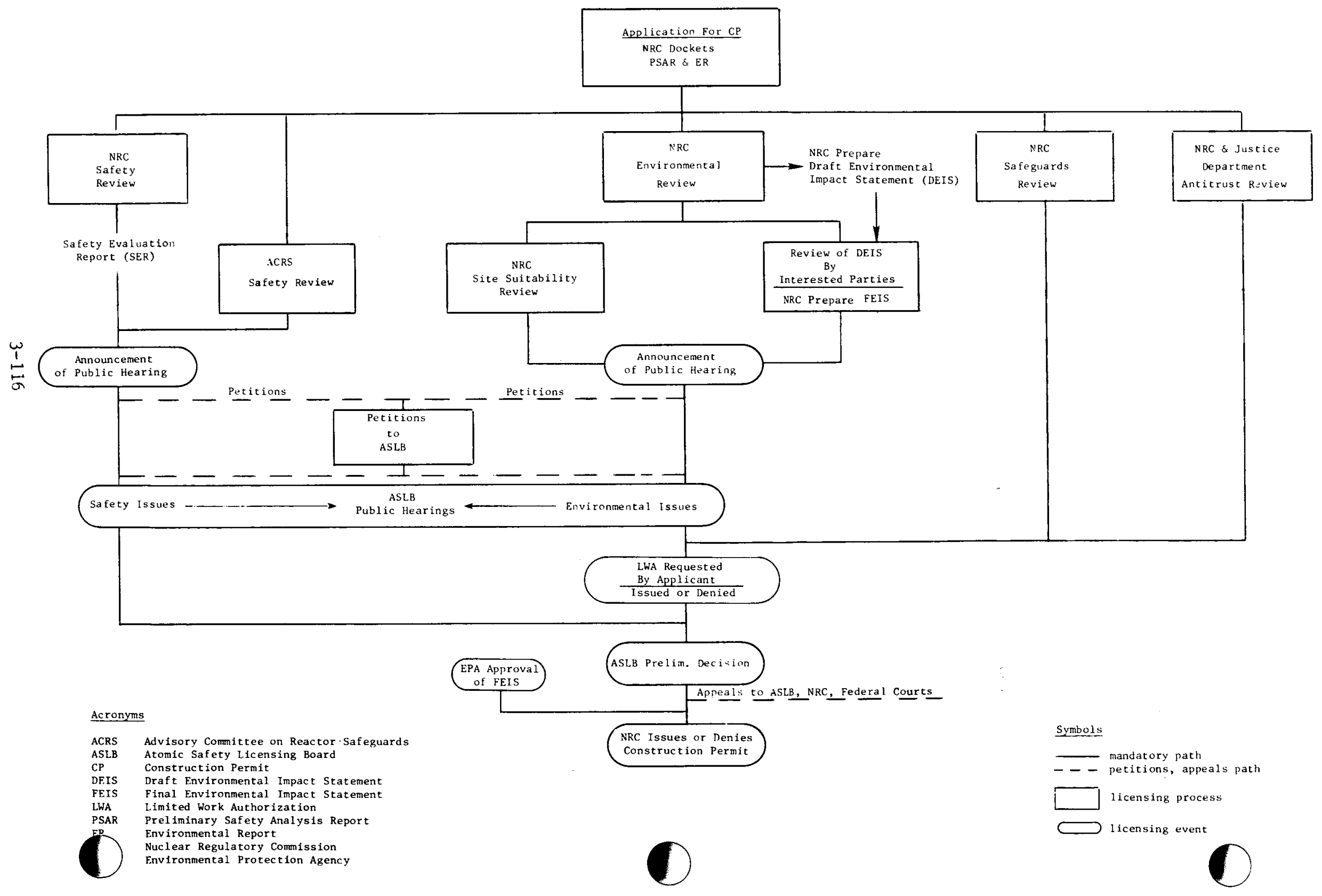


ENERGY ECONOMIC DATA BASE

PHASE VIII UPDATE (1986)

SINGLE UNIT 1144 MWE PRESSURIZED WATER REACTOR NUCLEAR POWEI GENERATING STATION (PWR)

LICENSING MILESTONE SCHEDULE

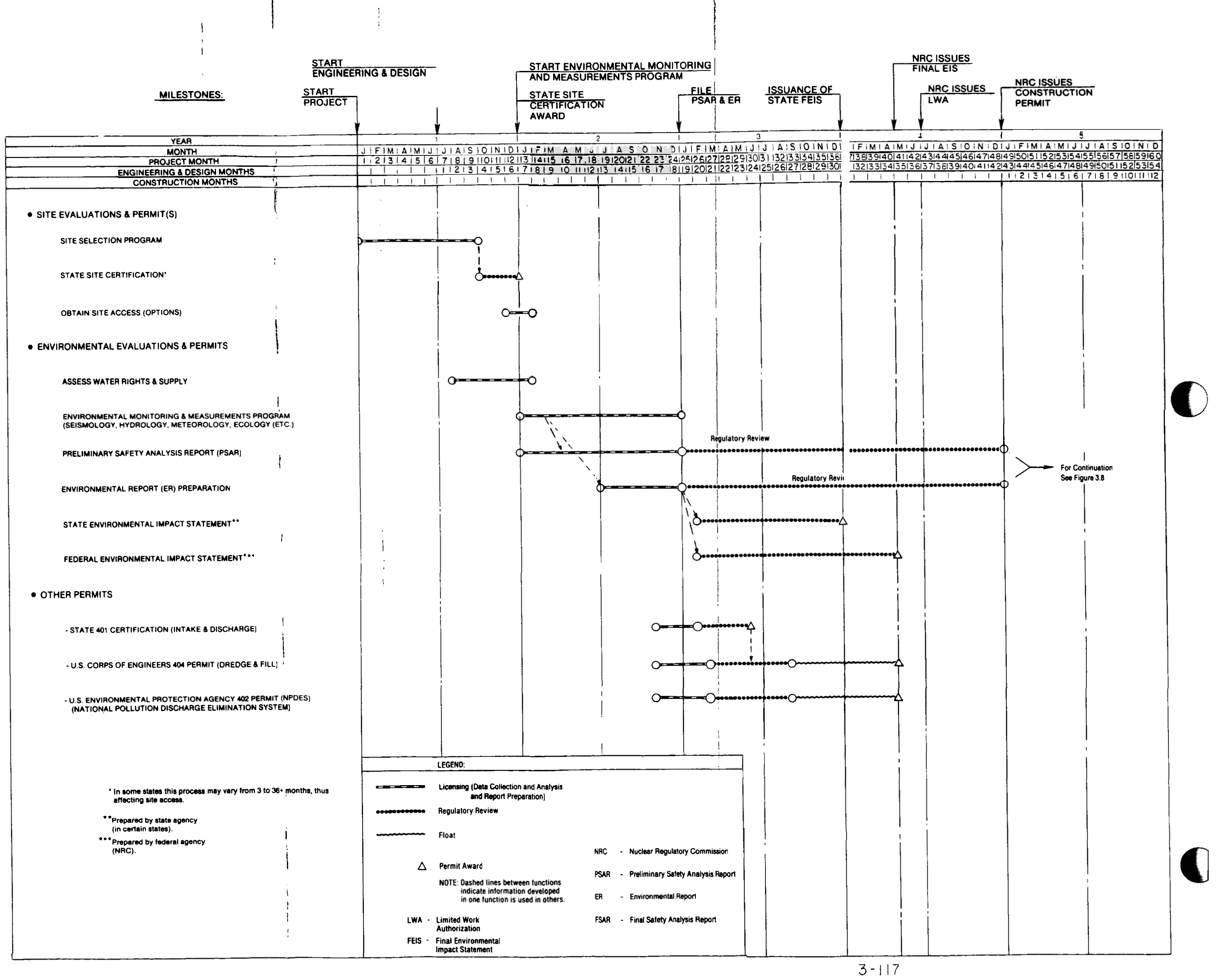




$\frac{\text { SUPPLEMENT TO FIGURE } 3.7}{\text { EXPLANATION OF ITEMS ON THE PWR }}$

1. Site Selection Program - Selection of a power plant site utilizes a screening process whereby areas are eliminated that do not conform to predetermined primary standards (e.g., cooling water, seismic zones, meteorology) until prime and alternate sites are found.

2. State Site Certification - More than half the states have siting legislation which gives a state agency(s) authority over utility siting efforts. These states each have specific requirements and time frames for obtainment of site certification.

3. Obtain Site Access - Site access is obtained by buying 1and, taking out options or eminent domain. Early site access is preferred so that environmental data collection and evaluation can be initiated.

4. Assess Water Rights and Supply - Cooling of the plant's condensers is a prime consideration. Such being the case, the amount of water for consumptive use, the utility's rights to this water and its quality must be assessed.

5. Environmenta1 Monitoring and Measurements Program - Detailed environmental monitoring and measurements programs are initiated by the utility in order to fulfill regulatory requirements. These entail studies in seismology, hydrology, meteorology, ecology and other disciplines.

6. Preliminary Safety Analysis Report (PSAR) - The PSAR defines the nature of the proposed nuclear station and includes plans for its use in sufficient detall to show the bases upon which the PSAR concludes it can be sited, built and operated safely.

7. Environmental Report (ER) Preparation - The ER analyzes the potentia1 environmental impact of the proposed station and associated facilities.

8. State Environmental Impact Statement (SEIS) - Certain states have enacted legislation which requires the preparation of a State Environmental Impact Statement in addition to one on the Federal level. The SEIS describes the environmental impacts associated with the project.

9. Federal Environmental Impact Statement (EIS) - The Federal EIS is mandated by the National Environmental Policy Act (NEPA) of 1969 for major Federal actions significantly affecting the environment. The draft EIS is prepared by a "lead" Federal agency and is typically based on the applicants Environmental Report. The draft EIS is followed by a final EIS after public and other agency comments are considered.

10. State 401 Certification (Intake and Discharge) - Section 401 of the Clean Water Act requires that, in order to obtain a Federal license or permit for an activity which may result in a discharge into navigable waters, the applicant must obtain a "certification" from the state in which the discharge originates. The discharge must comply with all 
SUPPLEMENT TO FIGURE 3.7 EXPLANATION OF ITEMS ON THE PWR LICENSING MILESTONE SCHEDULE

applicable Federal and State regulations. The certification is required as part of the Corps of Engineers 404 permit for dredge and fill operations in connection with intake and discharge structures.

11. U.S. Corps of Engineers 404 Permit (Dredge \& Fil1) - Section 404 of the Clean Water Act requires an applicant to obtain a permit for the discharge of dredge or fill material into navigable waters at specified disposal sites, as related to intake and discharge structures.

12. U.S. Environmental Protection Agency 402 Permit - National Pollution Discharge Elimination System (NPDES) - Under Section 402 of the Clean Water Act, the NPDES program, as administered by EPA, requires permits for the discharge of "pollutants" from any "point source" in the United States. The NPDES permit sets limitations on the concentrations of pollutants in the discharge and requires periodic monitoring efforts. A NPDES permit must be renewed every five years by the applicant.

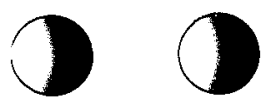




\section{O, 10}

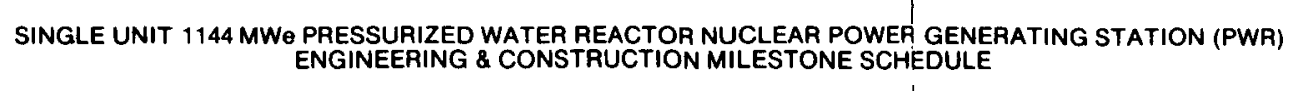

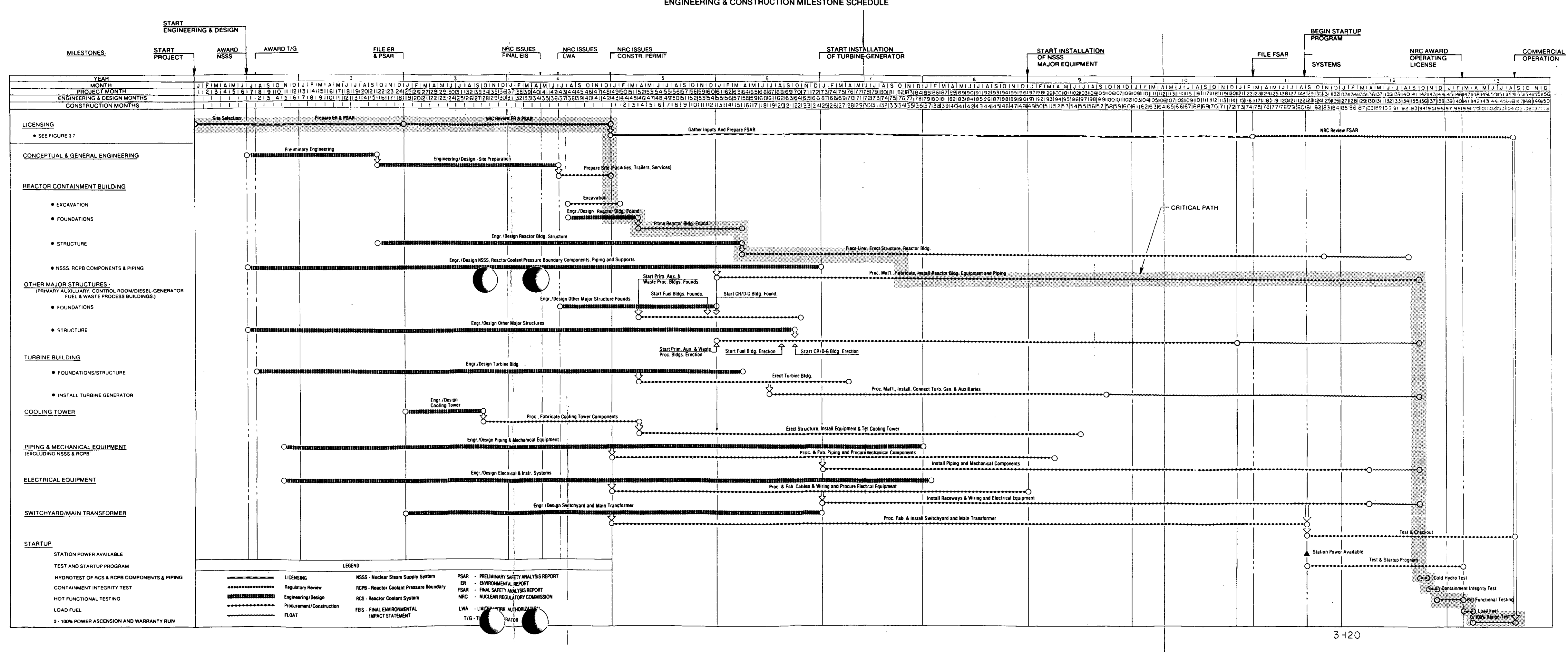


SUPPLEMENT TO FIGURE 3.8

DEFINITION OF ITEMS ON THE PWR ENGINEERING AND

CONSTRUCTION MILESTONE SCHEDULE

\section{Conceptual and General Engineering}

a. Preliminary Engineering - Project definition, conceptual design, definition of criteria, and field investigation to permit design of structures.

b. Engineering/Design - Site Preparation - Finalize foundation and structural design.

c. Prepare Site - Initiate excavation, set up temporary facilities.

2. Reactor Containment Building

a. Excavation and Foundations - Complete design of foundation, excavation, form, set reinforcing and pour concrete.

b. Structure - Complete engineering, design and erection.

c. NSSS, RCPB Components and Piping - Complete engineering, design and installation of Nuclear Steam Supply System components, Reactor Coolant Pressure Boundary components and piping inside the Reactor Containment Building. Also, procure, fabricate and install building service components and piping.

3. Other Major Structures (Primary Auxiliary, Control Room/Diese1-Generator, Fuel Storage and Waste Process Buildings)

a. Foundations - Engineering and design of foundations, excavate, form, set reinforcing and pour concrete.

b. Structure - Engineering and design of the structure and systems, erect the buildings and procure, fabricate and install building service components and piping.

4. Turbine Bullding

a. Foundations/Structure - Engineering and design of foundations, excavate, form, set reinforcing and pour concrete. Engineering and design of the structure and systems, erect the building and procure, fabricate, and install building service components and piping.

b. Install Turbine Generator - Erect T-G on pedestal, instal1 T-G auxiliaries and piping and tie-in turbine to main, extraction and auxiliary steam systems and condenser. 
SUPPLEMENT TO FIGURE 3.8

DEFINITION OF ITEMS ON THE PWR ENGINEERING AND CONSTRUCTION MILESTONE SCHEDULE

5. Cooling Tower - Engineering, design, procurement, fabrication and erection of cooling towers.

6. Piping and Mechanical Equipment (Excluding NSSS and RCPB) - Engineering, design, procurement, fabrication and installation of piping and mechanical equipment for all systems excluding the NSSS and RCPB.

7. Electrical Equipment - Engineering, design, procurement, fabrication and installation of power buses, electrical and instrumentation cables, panels, reactor control centers, distribution networks, batteries and battery systems.

8. Switchyard/Main Transformer - Engineering, design, procurement, fabrication and installation of station switchyard and main transformer.

\section{Startup}

a. Station Power Avallable - Energize Reserve Auxiliary

Transformer and station auxiliary power system.

b. Test \& Startup Program - Perform the necessary testing and inspection of system components and integrated systems to verify their operation as designed.

c. Hydrotest of the Reactor Coolant System (RCS) and the Reactor Coolant Pressure Boundary (RCPB) Components and Piping - Perform testing and inspection to verify that the RCS and $\mathrm{RCPB}$ components and piping can perform their intended safety function under actual pressure conditions.

d. Containment Integrity Test - Perform testing and inspection to verify that the containment, penetrations and isolation system can perform as designed.

e. Hot Functional Testing - Perform testing and inspection to verify that the vessel and appurtenances perform as designed.

f. Load Fuel - Put fuel into the vessel, install the head and sea1 the containment.

g. 0-100 Percent Power Ascension and Warranty Run - Conduct core physics testing to verify operation of the core as designed, increase power on a step by step basis and perform testing on the integrated RCS, Engineered Safeguard Features (ESF) and ancillary systems and conduct a 100-hour warranty run at rated power to verify reactor/turbine/generator performances. 


\section{SECTION 4}

\subsection{SYSTEM DESIGN DESCRIPTION FOR THE 1311 MWe}

LARGE SCALE PROTOTYPE BREEDER NUCLEAR POWER GENERATING STATION

(EEDB PROGRAM TECHNICAL DATA MODEL A5 - LSPB)

\subsection{INTRODUCTION}

Section 4 describes the design of the EEDB Program 1311 MWe large scale prototype breeder nuclear power plant technical data model, as of the technical and regulation date of January 1, 1986. The LSPB technical data model is based on a conceptual design, while the PWR technical data model is based on actual commercial plant designs. The LSPB data model represents the approach to 1 iquid metal reactor design taken by the DOE Large Scale Prototype Breeder (LSPB) Program.

In the 1311 MWe large scale prototype breeder nuclear power plant, the liquid sodium reactor coolant is heated at a cover gas pressure of six inches w.g. inside the nuclear react or by the fission process. The heated liquid sodium is pumped through a primary piping system or "loop" to an intermediate heat exchanger. In the intermediate heat exchanger, the thermal energy is transferred to sodium in a second or intermediate loop. This heated sodium is pumped through an intermediate piping system to a steam generator.

In the steam generators, approximately $12.6 \times 10^{6} 1 \mathrm{~b} / \mathrm{hr}$ of steam is heated to its final superheated conditions, nominally 2290 psia, $855^{\circ} \mathrm{F}$. A third independent piping loop feeds the superheated steam to the steam turbine and steam reheaters and returns feedwater to the steam generators.

Both fresh (new) and spent (used) fuel for the nuclear reactor can be stored in the ex-vessel storage tank (EVST) on-site. The EVST has the capacity to hold one annual refueling, a ful1-core unload and spares. Radioactive and other waste products are stored on-site, and treated and disposed of offsite. Special sodium handing and storage facilities are also provided.

General key parameters are given for the LSPB in Table 4-1, Items 1 through 13. Engineering drawings are presented in Figures 4.1 through 4.5 , which may be found in Section 4.4. A milestone 1icensing/design/construction schedule and discussion are given in Section 4.5 and Figures 4.6 through 4.8.

\subsection{DESIGN CRITERIA AND KEY PARAMETERS}

The plant technical design is based upon the report, Large Scale Prototype Breeder. (3) This report was developed by the Consolidated Management office for the LMFBR of the Electric Power Research Institute (EPRI/CoMO) and their industrial contractors for the U.S. Department of Energy. The design represents improvements and innovations which have evolved from the Conceptual Design Study (CDS) and the earlier Large Development Plant (LDP) Study sponsored by DOE. 
The original EPRI/CoMO design was based on different ground rules and a different classification of accounts than is used in EEDB. In order to achieve consistency with EEDB ground rules and comparability with the other EEDB data mode1s, some of the standard aspects of the EPRI/CoMO LSPB were changed; however, all of the innovative design features (primarily the NSSS and related structures) were retained.

In some cases, the EPRI/CoMO design met the plant design objectives by a different approach than is used for the other EEDB data models. Where changing to the EEDB design approach was not practical, the original design was retained. It is not believed that any inconsistency between data models thus introduced significantly affects data model comparability.

Table 4-1 summarizes the key technical parameters for the LSBP. These base parameters, together with the text, engineering drawings and milestone schedules of the following sections, provide the system design descriptions for the EEDB LSPB technical data mode1. 
TABLE $4-1$

ENERGY ECONOMIC DATA BASE

PHASE VIII UPDATE

LARGE SCALE PROTOTYPE BREEDER NUCLEAR POWER GENERATING STATION (LSPB)

TECHNICAL DATA MODEL BASE PARAMETER SUMMARY

\section{GENERAL}

\begin{tabular}{|c|c|c|}
\hline 1. & Site & Middletown, USA \\
\hline 2 . & Operation & Base Load \\
\hline 3. & Technical Data Model Reference Date & January 1,1986 \\
\hline $4 \cdot$ & Plant Life (years) & 40 \\
\hline 5 . & Number of Units & Single \\
\hline 6 . & Thermal Power (MWt) & \\
\hline & a. Rated (core) & 3,500 \\
\hline & b. Nuclear Steam Supply System (1) & 3,542 \\
\hline 7. & Net Plant Heat Rate $(B t u / k W h)(2)$ & 9,109 \\
\hline 8 . & Net Plant Efficiency $(\%)(2)$ & 37.46 \\
\hline 9. & Net Power to GSU (3) (MWe) & 1311 \\
\hline 10 . & $\begin{array}{l}\text { Water Table (Feet above mean } \\
\text { river leve } 1 \text { ) }\end{array}$ & 10 \\
\hline 11. & $\begin{array}{l}100 \text { Year Flood (Feet above mean } \\
\text { river level) }\end{array}$ & 8 \\
\hline 12 . & External Missiles & Tornadoes only \\
\hline
\end{tabular}

\section{LICENSING}

13. Codes \& Standards Reference Date January 1, 1986

(1) Includes React or Coolant Pumping Power

(2) Based on Rated Thermal Power

(3) Generator Step-up Transformer 
TABLE $4-1$

ENERGY ECONOMIC DATA BASE

PHASE VIII UPDATE

LARGE SCALE PROTOTYPE BREEDER NUCLEAR POWER GENERATING STATION (LSPB)

TECHNICAL DATA MODEL BASE PARAMETER SUMMARY

CIVIL/STRUCTURAL

14.1. Containment

a. Type

b. Overall Height ( $f t)$

c. Outside Dimensions Length $x$ Width ( $f t$ )

d. Gross Volume $\left(10^{6} \mathrm{cu} \mathrm{ft}\right)$

e. Design Pressure (psig)

1. Inerted Cel1s

2. Areas Except Inerted Cells
Reinforced Concrete with Steel Plate Liner

133.5 (Including Floor and Base Mat)

$162 \times 134$

2.3

10

3

14.2. Confinement Structure(4)
a. Type
Stee1
b. Overa11 Height ( $f t$ )
95 (Above Top of Containment)
c. Outside Dimensions -
$241 \times 200$
Length $x$ Width ( $f t$ )
d. Free Volume $\left(10^{6} \mathrm{cu} f \mathrm{t}\right)$
4.6

15. Turbine Building

Enclosed

16. Turbine Pedestal

High Tuned

17. Fuel/Blanket Storage (Number of Cores)

$1 \cdot 3$

18. Flooding Provisions

No Special Provisions

(4) The combination of the Confinement Structure, other confinement buildings (portions of nuclear island structures surrounding the containment designed for this purpose) and the nuclear island HVAC System are designed to limit radioactive release; "other confinement buildings" are not included in these parameters. 
TABLE $4-1$

\section{ENERGY ECONOMIC DATA BASE}

PHASE VIII UPDATE

LARGE SCALE PROTOTYPE BREEDER NUCLEAR POWER GENERATING STATION (LSPB)

TECHNICAL DATA MODEL BASE PARAMETER SUMMARY

CIVIL/STRUCTURAL (Cont'd)

19. Seismic SSE/OBE (g)

$0.25 / 0.125$

20. Foundations (Type)

a. Seismic Category I Mat

b. Non-Seismic Category I Spread Footings and/or Mats

21. Grade Elevation (Feet above mean 18

river leve1)

\section{MECHANICAL}

22. Reactor

a. Type

Cylindrical Stainless Steel Vessel with a Toroidal Knuckle, a Conical Frustum, a Spherical Bottom Cap and a Flat Cover Structure with Rotating Plugs

b. Vesse1 Inside Diameter/Height (in/in)

$569 / 739$

c. Number Fuel Assemblies

372 (Driver), 175 (Axial Blanket), 90 (Radial Blanket), 432 (Radial Shield), 36 (Control Assy.)/6.2 (Pitch)

d. Initial Core

e. Enrichment (\%)

f. Refueling Method
$(\mathrm{Pu}-\mathrm{U}) \mathrm{O}_{2}$

24.4 (Equilibrium Core)

- Rotating Plugs and In-Vessel Through-the-Head Refueling System

- Tilting "A"-Frame and Inclined Tube Fuel Transfer System Between EVST and React or Vessel 
TABLE $4-1$

ENERGY ECONOMIC DATA BASE

PHASE VIII UPDATE

LARGE SCALE PROTOTYPE BREEDER NUCLEAR POWER GENERATING STATION (LSPB) TECHNICAL DATA MODEL BASE PARAMETER SUMMARY

MECHANICAL (Cont'd)

23. Primary Fluid Type/Wt $\left(10^{5}\right.$ lbs at $500^{\circ} \mathrm{F}$ )

24. Moderator

25. Reactor Coolant Conditions at Reactor Outlet

a. Temperature $\left({ }^{\circ} \mathrm{F}\right)$

b. Pressure

c. F1ow $\left(10^{6} 1 \mathrm{~b} / \mathrm{h}\right)$

26. Reactor Coolant/Recirculation Loops
a. Number of Loops/Number of Pumps per Loop

b. Drive Type/hp

27a. Intermediate Heat Exchangers

a. Number per Primary Coolant Loop

b. Type

c. Classification (Section III, ASME B\&PVC)

d. Total Heat Transfer Surface (Effective) (SF)

e. Total Coolant Flow at Rated Load (Int. Loops) $\left(10^{6} \mathrm{lb} / \mathrm{h}\right)$
Liquid Sodium (Primary and Intermediate)/

52 (Primary)

32 (Intermediate)

Not Applicable

950

Near Atmospheric (6 in-w.g.)

141.2

Four (Primary)/One

Four (Intermediate)/One

Variable Speed Electric Motor (Primary and Intermediate)/ 14,000 (Primary)

7,000 (Intermediate)

1

Shell and Tube Type Heat Exchanger

Tube Side - Class 1

Shell Side - Class 2

249,200

136.4 
TABLE $4-1$

ENERGY ECONOMIC DATA BASE

PHASE VIII UPDATE

LARGE SCALE PROTOTYPE BREEDER NUCLEAR POWER GENERATING STATION (LSPB)

TECHNICAL DATA MODEL BASE PARAMETER SUMMARY

MECHANICAL (Cont'd)

27b. Steam Generators

a. Number per Intermediate Coolant 1 Loop

b. Type

Benson Cycle Once-through, Combined Evaporator/Superheater

c. Classification (Section III, ASME B\&PVC)

None (Steam generators are external to the reactor containment building and separated from the safety class portion of the intermediate sodium loop; they are designed to Section VIII of the ASME B\&PVC)

d. Tota1 Heat Transfer Surface (SF) 327,816

e. Total Steam Flow at Rated Load 12.6 $\left(10^{6} 1 \mathrm{~b} / \mathrm{h}\right)$

f. Outlet Steam Pressure at Rated 2,290 Load (psia)

28. Turbine-Generator
a. Configuration
Tandem-Compound, 6-F1 ow
b. Speed $(r / m i n)$
1,800
c. Last Stage Blade Length (in)
44

29. Main Steam Conditions at High

Pressure Turbine Inlet (Rated Load)
a. Pressure (psia)
2,215
b. Temperature $\left({ }^{\circ} \mathrm{F}\right)$
850
c. Flow $\left(10^{6} 1 \mathrm{~b} / \mathrm{hr}\right)$
12.6
30. Gross Turbine-Generator Output
at 2.5 in-HgA (MWe)
1,418 
TABLE 4-1

\section{ENERGY ECONOMIC DATA BASE \\ PHASE VIII UPDATE}

LARGE SCALE PROTOTYPE BREEDER NUCLEAR POWER GENERATING STATION (LSPB)

TECHNICAL DATA MODEL BASE PARAMETER SUMMARY

MECHANICAL (Cont'd)

31. Condensers
a. Type
Single Pressure
b. She11s/Divisions per Shell
$3 / 1$
c. Arrangement
Transverse
d. Number of Passes
Two
e. Water Box
Sp1it
f. Pressure (in-HgA)
2.5
g. Total Heat Transfer Surface (SF)
$1,165,530$

32. Cooling Tower
a. Type
Natural Draft Wet Evaporative
b. Number/Total Flow - Normal (gpm)
$2 / 711,400$

33. Cooling Tower Conditions
a. Approach $\left({ }^{\circ} \mathrm{F}\right)$
14
b. Range $\left({ }^{\circ} \mathrm{F}\right)$
22
c. Wet Bulb $\left({ }^{\circ} \mathrm{F}\right)$
74

34. U1timate Heat Sink

- 2-100\% Sodium to Air Heat Exchangers with Electric Motor Driven Fans

- 1-100\% Natural Convection Sodium to Air Heat Exchanger

35. Feedwater Pumps
a. Main (Number/Drive)
2/Turbine
b. Other (Number/Service/Drive)
- 2/Booster/Main Shaft
- 1/Start-up (5)/Motor

(5) Non-standard practice for other EEDB data models 
TABLE $4-1$

ENERGY ECONOMIC DATA BASE

PHASE VIII UPDATE

LARGE SCALE PROTOTYPE BREEDER NUCLEAR POWER GENERATING STATION (LSPB)

TECHNICAL DATA MODEL BASE PARAMETER SUMMARY

MECHANICAL (Cont'd)

36. Feedwater Heaters
a. Open Stages (Number)
One
b. High Pressure Closed Stages (Number/Number Trains)
$1 / 2$
c. Low Pressure Closed Stages (Number/Number Trains)
$3 / 3$

37. Stages of Reheat (Number/Type)

One/Steam

\section{ELECTRICAL}

38. Connection to off-site Power (Number $/ \mathrm{kV}$ )

$2 / 500,2 / 230$

39. Generator
a. Rating (MVA)
1,660
b. Voltage $(\mathrm{kV})$
25
c. Power Factor
0.9
d. $\mathrm{H}_{2}$ Pressure (psig)
75

40. Generator Disconnect
a. Type
b. Rating (kV)

Load Break Switch

36

41. Auxiliary Power System
a. Medium Voltage System A (kV)
13.8
b. Medium Voltage System B (kV)
$4 \cdot 16$
c. Low Voltage System (V)
480
d. Direct Current Systems (V)
125 and 250 
TABLE 4-1

ENERGY ECONOMIC DATA BASE

PHASE VIII UPDATE

LARGE SCALE PROTOTYPE BREEDER NUCLEAR POWER GENERATING STATION (LSPB)

TECHNICAL DATA MODEL BASE PARAMETER SUMMARY

\section{ELECTRICAL (Cont'd)}

42. Unit Auxiliary Transformer Nameplate Rating(6) (MVA)

188

43. Reserve Auxiliary Transformer

188

44. Gas-Turbine Unit (5)

a. Standby Power Supply (Class 1E)

1. Number

2. Voltage $(\mathrm{kV})$

$4 \cdot 16$

3. Rating ( $k W / P F)$

$3000 / 0.9$

b. Emergency Power Supply (Non-Class 1E)

1. Number

1

2. Voltage (V)

480

3. Rating ( $k W / p F)$

$1500 / 0.9$

45. Control Room Wiring

Wired Directly tos Panels in Control Room

46. Mu1tiplexing of Cables

Plant Wide/Distributed Control System (5)

47. Instrumentation

Independent Sensors for Computer Input

(5) Non-standard practice for other EEDB data models

(6) Total of all transformers at top class of cooling rating 


\subsection{SYSTEM DESIGN DESCRIPTIONS}

The material presented in this section is organized as follows:

Code of

Acounts

21

22

23

24

25

26
Title of Account

Page

4-12

$4-30$

4-50

4-68

4-80

4-90 
Civil/Structural key parameters are given in Items 10 through 12 and 14 through 21 of Table 4-1. Plant configuration in the form of a Plot Plan and General Arrangement drawings is given in Figures 4.1 through 4.4. The table and figures supplement and amplify the following discussion of Account 21 .

The primary structure in the plant is the reactor containment system which is composed of the reactor containment building and the confinement structure. The reactor containment building is Seismic Category $I$ and consists of a tornado-hardened reinforced concrete rectangular structure having a flat top and base. A continuous welded plate liner is attached to the inside face of the concrete to ensure a high degree of leak-tightness. The reactor containment building houses the reactor, the primary heat transport system and portions of the reactor and heat transport supporting systems. The interior concrete of the reactor containment supports the reactor plant components and equipment.

The confinement structure is a rectangular steel building located above the reactor containment building, the reactor service building, the steam generator buildings and the auxiliary buildings which surround the reactor containment building. The confinement structure is Seismic Category I but is not designed to resist tornados. This system of reinforced concrete buildings and steel confinement structure provides biological shielding and prevents significant release of radiation for abnormal events in the reactor coolant system.

The containment and other Seismic Category I structures house all safetyrelated equipment essential for safe plant operation, shut-down and control. Construction of these structures generally includes a reinforced concrete foundation mat, exterior walls, interior walls, floor slabs and roof slabs. The exterior walls are designed to resist horizontal loads and behave as shear walls. The interior slabs and roof slabs are supported on heavy structural steel framing.

The containment and the surrounding major Seismic Category I structures are located on a common ten feet thick reinforced concrete nuclear island base mat founded on rock approximately ten feet below grade.

The major Seismic Category I structures include:

Reactor Containment Building (Account 212) - Houses the reactor vessel, primary cooling system, ex-vessel fuel storage tank, and portions of the intermediate heat transport, shut-down heat removal, sodium auxiliaries, containment recirculating gas cooling and fuel transfer systems. It also provides biological shielding and prevents significant release of radiation for abnormal events in the housed systems. The interior concrete of the reactor containment supports the reactor plant components and equipment, provides biological shielding and protects the steel liner from postulated pipe break effects in the reactor coolant system. 


\section{LSPB ACCOUNT 21}

Reactor Confinement Structure (Account 212) - Houses an equipment handling bridge crane and operating space covered by this crane and provides a roof structure for the reactor contalnment building, the reactor service building, the steam generator buildings, and the north and south auxiliary buildings. The confinement structure has a low leakage "skin" and is maintained at a low negative pressure to prevent significant radioactive releases to the environment.

Reactor Service Building (Account 215) - Houses major portions of the primary sodium processing, sampling and storage, reactor refueling, and inert gas processing systems, major portions of the factlities for intermediate storage and transfer of new and spent fuel, portions of the recirculation gas cooling system, and the entire confinement filter system.

Control Building (Account 218A) - Houses the necessary instrumentation and control equipment essential for plant operation under normal and abnormal conditions. The control building also houses the technical support center.

Gas Turbine Building (Account 218C) - Houses the Class 1E gas turbine-generator units and associated equipment and fuel oil day tanks.

Steam Generator Buildings (Account 218E) - Houses the steam generators, portions of the intermediate heat transport systems (including the intermediate sodium pumps), electric power and distribution equipment and miscellaneous instrumentation, control and electric panels.

Auxiliary Buildings (Account 218I) - The north and south auxiliary buildings house the intermediate sodium expansion tanks, forced draft direct reactor auxiliary cooling system coolers, HVAC equipment for the steam generator and auxiliary buildings, auxiliary sodium equipment and miscellaneous instrumentation, control and electric panels. The west auxiliary building houses Class $I E$ and Non-Class $I E$ instrumentation, control and electric panels, decay reactor auxiliary cooling system, natural draft heat exchanger, pipeways, and HVAC unit coolers.

Intermediate Sodium Storage Vau1ts (Account 218T) - Houses the sodium/water reaction product separation tanks, the intermediate sodium drain and storage tanks and the essential chilled water systems.

The major Non-Seismic Category I structures house equipment and components not required for plant safety or safe shut-down. In general, these structures consist of structural steel framing, metal siding and concrete channel plank roofing, and are founded on reinforced concrete spread footings. The NonSeismic Category I structures are designed such that their failure will not cause loss of function of a Seismic Category I structure.

The major Non-Seismic Category I structures include:

Turbine Room and Heater/Auxiliary Bay (Account 213) - Houses the turbine generator, condensers and associated equipment, feedwater heaters, feedwater 
pumps, condensate pumps, condensate polishing and demineralizing equipment, other auxiliary equipment, and electrical switchgear rooms.

Gate House. (Account 214) - Provides a controlled means of access to the plant and houses the necessary monitoring, control and communication equipment for on-site response to emergency conditions.

Nuclear Island Maintenance Building (Account 216) - Houses the regulated maintenance shop, sodium removal area, decontamination facility, lay-down and maintenance areas, intermediate activity level liquids area, radwaste areas, and supporting systems.

Plant Service Building (Account 218B) - Houses the general of fices, conference rooms, lunch room and assembly area, operating personnel facilities, medical facility, laboratory area, on-site operating center, and security support facilities.

Electrical Equipment Building (Account 218H) - Houses non-essential switchgear, the Non-Class $1 \mathrm{E}$ gas-turbine-generator unit, and associated equipment.

Auxiliary Boiler Building (Account 218R) - Houses the auxtliary boilers and water treatment equipment.

Fire Pump House (Account 218D)

Waste Water Treatment Building (Account 218S)

The following additional major Non-Seismic Category I structures are included under Account 261 - Structures (Main Condenser Heat Rejection System):

Make-up Water Intake Structure

Circulating Water Pump House

Make-up Water Pretreatment Building

Interconnecting piping systems are provided for Building Services systems such as rainwater conductor and sewage systems. They comprise the piping, fittings, valves, hangers and supports and other components required for a complete system. Materials and wall thicknesses are chosen based on the service conditions and operational requirements of each system. The factors generally considered include: temperature, pressure, corrosion resistance, abrasion resistance, fluid purity requirements and cost. Carbon steel is used for steam (below $750^{\circ} \mathrm{F}$ ), clean water, air, of 1 , and other services without special requirements. other materials used include cast iron for sanitary drains and some below grade service, copper for potable water, galvanized steel for yard drains, and polyvinylchloride (PVC) and fiberglass reinforced plastic (FRP) for corrosive services.

The following pages provide detalled descriptions of the major and minor Seismic Category I and Non-Seismic Category I structures, ordered numerically by account number. 


\section{LSPB ACCOUNT 21}

\section{ACCOUNT 211 Yardwork}

The plant location is the hypothetical site of Middletown, USA. This site is defined in Appendix A-1 of this Technical Reference Book. The plant configuration is shown in the Plot Plan given in Figure 4.1.

The datum plane for site and yard elevations is mean river level. Main plant finish grade is 18 feet above mean river level. Soil overburden is estimated to be eight feet thick. Limestone rock with no underground cavities and satisfactory for supporting plant structures is located below the overburden.

Site preparation consists of clearing, grubbing, and stripping of top soil for all structures, roads, rallroads, parking areas, materials handling areas and construction facilities. Rough grading quantities include the general cut and fill for the main plant structures and fine grading with landscaping.

Earth excavation, rock excavation, backfill, concrete fill and dewatering for the main plant structures are included with the structure associated yardwork. This includes all excavation work for the main nuclear and turbine plant areas. Excavation work for structures not included within the main excavation are included with the structural work for each of the individual buildings. The cut and fill work also includes hauling, dumping, stockpiling, placing and compacting. For those portions of structures below rock, concrete fill is used under and adjacent to the structure. In cases where rock elevations vary or where Seismic Category I base mats or footings are above rock, concrete fill is used to assure that building loads are carried to competent rock. Earth $\mathrm{fill}$ is separated into select and Category $I$ fill adjacent to Seismic Category I structures, select and Non-Category I fill adjacent to Non-Seismic Category I structures and general area fill in the main plant area. In general, the main plant excavation is a ten feet deep open cut with deeper cuts provided to accommodate special depth requirements.

Structural and fill concrete are produced by an on-site concrete batch plant. Excavated material is used on site for general fill wherever possible. Spoil areas and storage areas are utilized for excavated material not used for fill or for top sol1. Erosion and sedimentation control of these areas is practiced in accordance with EPA requirements. Temporary settling basins are provided to collect all runoff during construction prior to discharge into the North River.

The transformer area, above ground ofl storage tanks and other of 1 or chemical storage and handling areas are designed to contain spills and collect surface water runoff. This runoff, together with the turbine building floor drains and other plant dirty drains, is routed by underground piping to the holding pond or to the waste water treatment area for treatment, as required, before discharge into the North River.

The yard drainage system consists of interceptor ditches (paved and unpaved) and storm drains with catch basins to carry of storm water from developed areas. Water courses that are intercepted near the plant are diverted by 
ditches into existing stream beds or storm drains. Culverts carry stream flow under the raflroad and roads. The yard surface water drainage is directed to the North River via the existing water courses wherever possible. Building roof drainage is directed to the yard drainage system.

The sanitary sewage system piping and toilet facilities for permanent plant requirements are designed based on permanent plant personnel requirements. This system is a package type activated sludge sewage treatment plant, including final chlorination, to meet secondary treatment effluent standards.

Highway access is provided to the site by five miles of secondary roads connecting to a state highway. These roads are in good condition and need no additional improvements. An on-site asphalt road, paved in accordance with the standard thicknesses for public highways, is provided around the main plant structures. Service roads are arranged to provide access to truck sized doors in the plant and to a11 buildings requiring servicing or maintenance by vehicles. In addition, parking areas, concrete curbs and walks are provided. Temporary construction roads with minimum thickness paving and unpaved roads for materials handling equipment are provided.

Railroad access to the site is provided by constructing a single track railroad spur which intersects the B\&M Railroad. The length of the spur from the main line to the plant is five miles. The spur approaches the site from the east. During construction, 600 to 800 cars of construction materials are delivered including the transformers and generator stator. These items are the heaviest loads anticipated to be delivered by rail and require special cars. Additional spurs are provided to the southwest. corner of the nuclear island maintenance building, the south end of the reactor service building, the northwest corner of the turbine building, and the east side of the warehouse area. All roadbed, trackage and railroad structures are designed in accordance with the latest railroad standards.

Site erection facilities for the reactor vessel and other NSSS components are provided. These facilities are multipurpose and are designed to be converted into the nuclear island maintenance building and the maintenance shop and warehouse when NSSS component site erection is completed (refer to Accounts 216 and $218 \mathrm{~N})$.

In addition to the above items, fencing, a main gate guard house and roadway and yard lighting are provided with the yardwork.

\section{ACCOUNT 212 Reactor Containment/Confinement Building}

The reactor containment building, which houses the nuclear steam supply system (NSSS) and associated equipment, is a tornado hardened Seismic Category I reinforced concrete rectangular structure with a flat roof and a flat reinforced concrete foundation. The contalnment structure is designed for a maximum calculated internal design pressure of three psig. Inerted cells within the containment are designed for a maximum calculated internal design pressure of ten psig. The reinforced concrete foundation is the central 
portion of the Selsmic Category I building common mat. This nuclear island concrete base mat is a total of 200 feet wide, 296.8 feet long and eight to ten feet thick. It is eight feet thick beneath the containment building and ten feet thick beneath the Selsmic Category I buildings surrounding the containment. The mat is founded approximately ten feet below finished grade and two feet below the top of rock. The building outside dimensions including base mat are 134 feet wide, 162 feet long and 133.5 feet high. The building walls and roof slab have a thickness of three feet.

A continuously welded steel plate liner, $1 / 4$ of an inch thick, is anchored to the Inside face of the concrete. The liner functions as a leak-tight membrane to prevent significant fission product release in the event of an accident. The bottom of the liner is set on the eight feet thick portion of the nuclear island base mat. The liner plate below the operating floor is protected by a three feet thick layer of concrete on the containment walls and a two feet thick layer on the bottom of the containment. Above the operating floor, the iner plate is exposed.

An equipment air lock is provided in the containment wall between the containment and the reactor service building. Hatches with removable sealing type covers are provided in the containment roof slab for moving components too large for the equipment air lock. These air locks and hatches are used to move equipment into the containment during construction and for removal and replacement of equipment during plant operation. Personnel air locks are provided to allow personnel entrance and egress during normal operation. Piping, electrical cable, fuel transfer and duct penetrations are provided through the containment wall at various locations below the operating floor. They are designed to remain gastight during all conditions for which the containment is designed.

The containment and interior structures are integrally attached to provide a common rigid structure. The operating floor supports the primary heat transfer system equipment. Major internal structures are the operating floor and the vertical walls which form the major equipment cells.

The major equipment cells are:

a. Reactor Vessel Cell - A three feet thick octagonal reinforced concrete steel plate 11ned cell enclosing and supporting the reactor and guard vessels.

b. Primary Loop Ce11s - Four interconnected reinforced concrete steel plate lined cells each containing a primary sodium pump, an intermediate heat exchanger, associated piping and their supports.

c. Ex-vessel Fuel Storage Cell - An Irregular shaped reinforced concrete steel plate lined cell enclosing the EVST. 
d. Recirculating Gas Cooling Ce11 - An irregular shaped reinforced concrete cell enclosing the recirculating gas cooling system fans, coolers and ducts.

e. Fuel Transfer Cells - Two reinforced concrete cells located above the operating floor housing the fuel transfer mechanisms; one connecting the react or vessel to the ex-vessel storage tank cell, and the other connecting the ex-vessel storage tank cell with the ex-containment portion of the fuel handling system.

other reinforced concrete internal structures are the operating deck and the direct reactor auxiliary cooling system cells (DRACS). Various reinforced concrete or steel shield walls are also provided at appropriate locations.

In addition to housing NSSS equipment and providing a leak tight structure, the containment also serves as a biological shield which protects the environment and adjacent structures from the effects of normal plant operation and abnormal events. It also protects the housed systems from the effects of various natural phenomena that are postulated to occur at the plant site.

The containment building heating, ventilating and air conditioning (HVAC) systems maintain a containment atmosphere suitable for equipment operation and provide a means for removing fission products prior to entry, during refueling and following a design basis accident (DBA).

During normal operation, sultable temperatures above the operating floor are maintained by the containment cooling system. This system is comprised of four fan coll units, each rated at $33-1 / 3$ percent of the maximum design heat load. Two 100 percent capacity water chillers, located in one of the auxiliary buildings, provide water at $42^{\circ} \mathrm{F}$ to the fan coil units in the containment.

The major equipment cells located below the operating floor (Items $a, b$ and $c$ above) are maintained at suitable operating temperatures by their independent cell gas systems. Each of the cell gas systems is equipped with a redundant fan, heat exchanger and filter unit. Four 100 percent capacity essential chillers, two of which are located in each (north and south) of the intermediate sodium storage vaults, provide coolant at $42^{\circ} \mathrm{F}$ to the cell gas system heat exchangers in the containment. These cells are steel lined and Insulated to prevent sodium spills from coming in contact with the concrete structures and also to limit the temperature of the concrete in the event of a sodium fire.

Prior to entry into the containment, fission products are removed by the containment HVAC System at the rate of $12,500 \mathrm{cfm}$. The contaminated air is exhausted to the confinement structure where it is processed by the confinement exhaust system filter train prior to being exhausted to the atmosphere. This filter train consists of a moderate efficiency filter, and HEPA-charcoal-HEPA filters. 
Above the reactor containment, there $1 \mathrm{~s}$ a Seismic Category I confinement structure that extends over the reactor service, steam generator and north and south auxiliary bulldings. It is a rectangular steel frame structure with metal insulated siding and a low leakage "skin" applied over the internal walls of the metal building. The roof is metal roof deck covered with insulation and built-up roofing and supported on steel framing. The structure is 200 feet wide, 241 feet long, and 95 feet high above the top of the reactor containment building. Although designed as Seismic Category I, the confinement structure is not designed to withstand tornado pressure or tornado missiles. The steel frame also supports the rails for a traveling bridge crane which services the roof hatches in the reactor containment building, and the other buildings which it covers.

The confinement, together with the nuclear 1sland HVAC system, controls the release of radioactive materials to the atmosphere by maintaining a negative pressure in the confinement structure, the reactor service building, the steam generator buildings and the north and south auxiliary buildings. Air discharged from the confinement is monitored, and filtered as required.

The gross volume of the reactor containment building 1 s $2,300,000$ cubic feet. The volume of the confinement building is approximately 4,570,000 cubic feet.

ACCOUNT 213 Turbine Room and Heater/Auxiliary Bay

The turbine building (including heater/auxiliary bay) is a Non-Seismic Category I structure, located west of the containment structure. The turbine room is a three story (elevations 19 feet, 46.5 feet and 75 feet) steel framed structure 143 feet wide, 343 feet long and 124 feet high. The heater/auxiliary bay is a 58 feet wide three step tiered structure with sections 173 feet high by 110 feet long, 87 feet high by 34 feet long, and 28 feet high by 173 feet long. The combined building volume is approximately $7,630,000$ cubic feet.

The building is supported on reinforced concrete footings on rock. The reinforced concrete ground floor is located at grade. The mezzanine and operating floors are cast-in-place concrete on metal deck supported on steel framing. The roof is concrete channel plank covered with a roofing membrane and supported on steel framing. The exterior walls are insulated metal siding, and the interior walls are concrete block or metal partitions. The turbine pedestal is described under Account 231.

The building houses the turbine-generator unit, its condensers and associated equipment, feedwater and deaerating heaters, feedwater pumps, condensate pumps, condensate polishing and demineralizing equipment, turbine lube oil equipment, other auxiliary equipment, and electrical switchgear areas. The feedwater heaters are located in the heater bay.

A rail car bay is located in the northwest corner of the building for transport of generator and turbine parts. An overhead traveling crane located at the top of the bullding serves this bay as well as the full turbine hall 
LSPB ACCOUNT 21

operating floor area. All floors are connected by several stairways and a passenger elevator.

The turbine room and heater/auxiliary bay are cooled by power roof ventilators and heated by steam unit heaters located throughout the building.

ACCOUNT 214 Gate House

The gate house is a single story concrete block Non-Seismic Category I structure located north of the turbine room and heater/auxiliary bay at the plant main entrance. The building is 56 feet wide, 60 feet long and 16 feet high (top of parapet). A covered court (15 feet by 21 feet) is provided in the northwest corner of the building. The volume of the gate house is approximately 42,600 cubic feet.

The exterior walls are constructed of 12 inch concrete block with windows supported on a continuous footing below the frost line. Interior walls are concrete block and floor slabs are reinforced concrete at grade. The roof is concrete channel plank covered with built-up roofing and supported on steel framing. Most areas are provided with suspended acoustical cellings.

The building heating, ventilating and air conditioning (HVAC) equipment is located on the roof of the building and maintains environmental conditions within prescribed comfort limits. This equipment is non-safety related.

The building houses a reception area, guard station, passage area, mechanical equipment room, and lavatories. The gate house provides space for security guards to control access to and exit from the plant protected area with appropriate security devices. The interior located guard station is constructed as a bullet resistant enclosure.

\section{ACCOUNT 215 Reactor Service Building}

The reactor service building is a multi-level reinforced concrete Selsmic Category I structure located east of the containment structure. It is supported on a portion of the ten feet thick nuclear 1sland base mat. The building is 79 feet wide, 199.3 feet long and 123.5 feet high with two elevator/stair towers on the north and south ends of the east face of the building. In addition, there is a washdown area and a below grade primary sodium storage vault at the south end of the building. The volume of the building is approximately $2,180,000$ cubic feet.

The exterior walls are reinforced concrete ( 4000 psi). The interior walls are masonry or metal partitions. The intermediate floor slabs and roof slab are cast-in-place concrete over metal deck and supported on steel framing. The west wall of the reactor service bullding is common with the east walls of the reactor containment bullding and the two eastern steam generator buildings. Building cells housing primary sodium containing components are inerted with nitrogen and lined with carbon steel plates. 


\section{LSPB ACCOUNT 21}

The building is designed as a tornado-hardened structure, except for the portion of the building above elevation 109.5 feet. This portion of the building is designed not to collapse in the event of the design basis tornado. The confinement structure (refer to Account 212) extends above the reactor service building from elevation 142 feet ( 124.5 feet above grade) and provides crane service to the reactor service building roof hatches.

The reactor service building houses the ex-containment portions of the fuel handling systems and portions of the recirculating gas systems. It also houses the EVST cooling system, cell atmosphere processing system, radioactive argon processing system, confinement air filter system, and primary sodium sampling system. Access to the containment for personnel and equipment is provided through air locks from the reactor service building.

The reactor service building is ventilated by filtered and temperature conditioned outside air supplied at $84,000 \mathrm{cfm}$. During the winter months, heating is provided by the bullding hot water heating system. Cooling is provided by the plant chilled water systems. The engineered safety features HVAC equipment area, Class $1 \mathrm{E}$ switchgear areas, and radioactive gas cooling system areas have separate safety related cooling systems supplied by the essential chilled water system. The sodium storage vault is inerted with a nitrogen atmosphere and serviced by two-100 percent gas cooling systems.

ACCOUNT 216 Nuclear Island Maintenance Building

The nuclear island maintenance bullding is a reinforced concrete and steel frame Non-Selsmic Category I structure located east of the nuclear island bulldings. This building was converted from a site fabrication shop and the high power $x$-ray facllity utilized during construction. The nuclear island maintenance bullding volume is approximately 3,750,000 cubic feet.

The converted site fabrication shop is a dual high-bay steel frame building; one bay is 151 feet wide, 155 feet long and 110 feet high, and the other bay 1830 feet wide, 155 feet long and 90 feet high. There is also a 48.5 feet wide and 49 feet long room attached to the northwest corner. The north portion of this building has a below grade reinforced concrete floor slab founded on rock, while the remainder of the retnforced concrete floor is at grade on earth. The exterior walls of th1s structure are insulated metal siding and the interior walls are masonry. The roof slabs are concrete channel plank covered with built-up roofling or a roofing membrane and supported on steel framing.

The converted high power $x$-ray facility is a four story, reinforced concrete building 75 feet wide; 114 feet long and $111: 5$ feet high, with a 23 feet wide, 114 feet long and 29. feet high extension attached to the north face of the facility. The walls, floors and roof slab are reinforced concrete. The roof slab is covered with insulation and bullt-up roofing. An elevator and stairway provide personnel/equipment access to the upper floors. 
LSPB ACCOUNT 21

The high-bay portion of the site fabrication shop section of the maintenance building houses a large equipment decontamination facility, large component maintenance facility, regulated maintenance shop, electrical and instrumentation shop, sodium removal process equipment area, intermediate activity level liquid storage area and large truck aisle. The shops within the high-bay area are single story enclosures having heights of 12 to 20 feet. The room on the northwest corner houses a health physics facility.

The high power $x$-ray facility section of the maintenance building houses the radwaste facilities. Radioactive liquid and solid waste processing and drum storage areas are provided. This section of the maintenance building is served by the truck aisle located in the site fabrication shop section.

The converted fabrication shop and high power $x$-ray facility sections of the maintenance building each have separate HVAC systems. Using chilled or hot water, these systems supply appropriately filtered and conditioned air to the various equipment areas. Potentially radioactive areas are provided with a redundant HEPA filter exhaust system.

ACCOUNT 218A Control Building

The control building is a four story reinforced concrete tornado hardened Seismic Category I structure located west of the containment building and founded on the ten feet thick common nuclear island mat. The building is 55.8 feet wide, 200 feet 1 ong and 69.8 feet high. In addition, there are two Non-Seismic Category I rooms on the roof of the control building housing non-safety related power distribution equipment. These two rooms are each 28 feet wide, 32 feet long and 15 feet high. A three foot wide annulus separates the control bullding from the reactor containment building to provide a confinement area for the west side of the reactor containment building. The total control building volume is approximately 806,000 cubic feet.

The exterior walls, floor slabs and roof slabs are reinforced concrete, interior walls are masonry. The exterior walls are a minimum of two feet thick. The west wall of the confinement annulus and the west walls of the two western steam generator buildings are common with the east walls of the control building. Intermediate floor slabs are cast-in-place concrete on metal deck supported on steel framing. The roof slabs are reinforced concrete over metal deck covered with built-up roofing and supported on steel framing. The east side of the control building roof slab serves as the bottom floor slab of the west auxiliary building (refer to Account 218I).

The first floor of the control building houses the control room, technical support center, shift supervisors' office, two auxiliary panel areas (one on either side of the control room) and lunch room. The second floor contains a cable spreading room on either side of the control room, gallery for control room observation, and chilled water pump room at each end of the building. The third floor houses the computer room, and the control room filter units and HVAC equipment. The fourth floor houses the class $1 \mathrm{E}$ power distribution equipment, and the HVAC equipment servicing the fourth floor. 
The control bullding HVAC system provides the equipment and redundancy necessary to maintain an operating environment in the bullding during all normal and emergency conditions. The control room is also provided with redundant recirculating filter units to ensure protection against airborne radioactivity during off-normal operation. These control room habitability systems are considered to be a part of the station engineered safety features (ESF) and consist of redundant Seismic Category I air intakes and recirculation charcoal filtration units. The control building is supplied with smoke vent capability for safety related equipment areas. Food supplies, water and other necessities for prolonged isolation in the control building are provided in appropriate storage areas.

ACCOUNT 218B Plant Service (Administration) Building

The plant service building is a Non-Seismic Category I structure located within the overall plant building complex. It is adjacent to the north walls of the control bullding and the heater bay. The main entrance and lobby are opposite the gate house. The building is a three story, steel framed structure 100 feet wide, 160 feet long and 51.5 feet high. It has a 20 feet wide, 80 feet long and 13.5 feet high first floor extension on the east end of the north side of the building and a below grade area 42 feet wide, 102 feet long and 20 feet deep located beneath the west portion of the main building and plant access corridor. The total building volume is approximately 931,000 cubic feet.

The building is supported by a combination of reinforced concrete spread footings and below grade walls founded on rock. The reinforced concrete ground floor is located at grade. The intermediate floors are reinforced concrete on metal deck supported on steel framing. The roof slab is concrete channel plank covered with built-up roofing and supported on steel framing. The exterior walls are insulated metal siding and the interior walls are efther concrete block or metal partitions. The south wall is common with the access corridor, the control building, and the turbine generator building heater/auxiliary bay.

The bullding houses the plant security area, operating personnel locker rooms and showers, health physics work station, turbine building chemical laboratory, medical facility, lavatorles, lunch, room and assembly area, on-site operating support center, general offices and conference rooms. The building provides controlled access to the plant access corridor and also to the third floor level of the north stairwell for the west auxiliary building.

The plant service building HVAC systems maintain environmental conditions of normally occupled spaces within the prescribed comfort zone and insure that temperatures and humidity in other areas are suitable for material storage and equipment operation. A centralized non-safety related HVAC system located on the ground floor services the entire building. 


\section{ACCOUNT 218C Gas-Turbine Building}

The gas-turbine building is a two story Seismic Category I reinforced concrete structure located just east of the reactor service building. The building is supported on a four feet thick mat which is founded at grade and is separated from the nuclear island mat. It is 45 feet wide, 155 feet long and 40 feet high. The total building volume is approximately 279,000 cubic feet.

The exterior walls, interior walls, floor slabs and roof slab are reinforced concrete. The exterior walls are a minimum of two feet thick. The building is divided into a north and south section separated by a 2.5 feet thick wall. The intermediate floors are cast-in-place concrete on metal deck supported on steel framing. The roof is covered with insulation and built-up roofing.

The gas-turbine building houses the two safety-related Class IE gas-turbine generators, day tanks, air starting equipment, supporting equipment, electrical switchgear, Class $1 \mathrm{E}$ dc equipment (batteries and battery chargers), and HVAC equipment. Two oil storage tanks are located east of the building buried below grade. Personnel access to the two sections of the building are from the north and south elevator/stairwell towers of the reactor service building.

Each gas-turbine compartment in the building is provided with its own ventilation system for use when the gas-turbines are in operation, and a standby heating system for protection under winter conditions. Elevated above the roof at the center of the east side of the structure are two missile protected air exhaust structures. Missile protected air inlets are located in the second floor walls on the north and south ends of the building.

ACCOUNT 218D Fire Pump House Including Foundations for Two Fire Protection Tanks

The fire pump house is a Non-Seismic Category I structure located southwest of the turbine building. The two Non-Seismic Category I fire protection water tanks are located south of the fire pump house.

The fire pump house is a single story steel frame structure 28 feet wide, 84 feet long and 17 feet high. Two halls eight feet wide and eight feet high enclose the piping between the main structure and the two fire protection water tanks. The building has an approximate volume of 42,000 cubic feet. The building houses the fire pumps and the distribution equipment supporting the electrical heaters used for freeze protection of the storage tanks.

The bullding is supported on reinforced concrete spread footings. The floor is reinforced concrete supported on grade, and contains trenches for some of the piping. The exterior walls are insulated metal siding. The roof is metal deck covered with insulation and bullt-up roofing supported on steel framing. 
The fire pump house is ventilated by roof fans. Heating is provided by electric unit heaters.

Each fire protection tank foundation is a reinforced concrete ring wall 18 inches thick with the mean diameter equal to the tank diameter. The top of the ring wall is six inches above grade, and the bottom is four feet below grade. Tank anchor bolts are set in the ring wall. A compacted sand bed is provided inside the ring wall to support the tank floor.

ACCOUNT 218E Steam Generator Buildings

The four steam generator buildings are multi-level tornado hardened reinforced concrete Seismic Category I structures located and adjoining the north and south face of the reactor containment building at each of the four corners. The north and south steam generator bulldings are separated by the north and south auxiliary buildings respectively. They are supported on a portion of the ten feet thick nuclear island base mat. Each building is 33 feet wide, 46 feet long and 123.5 feet high. The total volume of all four buildings is approximately 687,000 cubic feet.

The exterior walls and interior walls are reinforced concrete. The exterior walls are a minimum of 27 inches thick. The intermediate floor and roof slabs are cast-in-place concrete on metal deck supported on steel framing. Each of the walls on three sides of each steam generator building are common with one of the reactor containment, auxiliary, reactor service or control butlding walls.

The confinement structure (refer to Account 212) extends above each steam generator building from elevation 142.5 feet ( 123.5 feet above grade) and provides an enclosure for equipment mounted on the top slab of the building. It also provides crane service to this equipment and for the steam generator building top slab hatches.

The steam generator buildings house the components of the intermediate heat transport and steam generator system. The principal components are the intermediate sodium pumps and the steam generators.

The steam generator bulldings are provided with minimum outside air, HVAC systems. These systems are non-safety related and are shared with the north and south auxiliary bulldings. There are two 50 percent air conditioning units each for the north and south complex of buildings. The outside air flow is established on the basis of cell ventilation requirements. The HVAC systems are designed in conjunction with the confinement system to ensure that the steam generator buildings are maintained at a negative pressure for a11 modes of operation. The HVAC units are located in the north and south auxiliary buildings.

ACCOUNT 218H Electrical Equipment Building

The electrical equipment building is a Non-Selsmic Category I structure 
LSPB ACCOUNT 21

located south of the turbine building with which it has a common north wall. The building is a four story steel frame structure 54 feet wide, 60 feet long, and 80 feet high with an approximate volume of 229,000 cubic feet. The building is supported on reinforced concrete spread footings. The reinforced concrete ground floor is located at grade. Exterlor walls are insulated metal siding, intermediate floors are cast-1n-place concrete on metal deck supported by steel framing. The roof is metal deck covered with insulation and built-up roofing and supported on steel framing.

The ground floor houses the Non-Class IE gas-turbine-generator, gas-turbine auxiliaries and associated electrical equipment. The two floors above house the $\mathrm{ac}$ and $\mathrm{dc}$ plant distribution equipment and the station batteries. A partial fourth floor is provided to house additional station batteries and other equipment.

The electrical equipment building HVAC systems provide the heating and ventilating necessary to insure that temperature and humidity are suitable for electric equipment operation. A centralized non-safety related HVAC system located on the partial fourth floor services the entire building.

ACCOUNT 218I Auxiliary Buildings

There are three auxiliary bulldings: the Auxiliary Building North, Auxiliary Building South, and the Auxiliary Building West. Each is a multi-level, tornado-hardened, Seismic Category I, reinforced concrete structure, adjacent to the containment building, that function as a confinement area. The exterior walls, interior walls and roof slabs are relnforced concrete. The exterior walls are a minimum of two feet thick. Intermediate floor slabs are cast-inplace concrete on metal deck supported on steel framing. The west building roof slab is covered with built-up roofing.

The north and south auxiliary buildings are located to the north and south of the reactor containment bullding between the steam generator buildings and share common walls with the steam generator and reactor containment buildings. Each of the bulldings is 33 feet wide, 70 feet long and 123.5 feet high. The volume of each building is approximately 247,000 cubic feet.

The equipment arrangement of the two bulldings are virtually identical and house intermediate sodium expansion tanks, direct reactor auxiliary cooling system (DRACS) forced draft coolers, auxiliary sodium equipment, and miscellaneous electrical instrumentation and control panels. A portion of the confinement structure (refer to Account 212) extends above the north and south auxiliary buildings from elevation 142.5 feet ( 124.5 feet above grade) and provides the roof function and crane service to these buildings.

The north and south auxiliary bulldings also house both safety and non-safety related HVAC systems. The large non-safety related HVAC system consists of four 50 percent capacity units in each building. Each set of two units furnishes controlled ventilation and cooling to one-half of an auxillary building, and the adjacent steam generator bullding at a flow of $75,000 \mathrm{cfm}$. 
Four safety related cell unit coolers are provided to ensure proper cooling of the DRACS cells ( $14,000 \mathrm{cfm}$ each) and the safety related electrical equipment cells $(4,000 \mathrm{cfm}$ each) located in the north and south auxiliary buildings. A11 exhaust air is directed to the confinement system.

The west auxillary bullding is located above and supported by the east portion of the control building (refer to Account 218A). It is 24 feet wide, 200 feet long and 53.7 feet high, rising from elevation 88.8 feet $(70.8$ feet above grade) to 142.5 feet ( 124.5 feet above grade). The volume of the west auxi1lary bullding is approximately 225,000 cubic feet. The structure abuts the west wall of the reactor containment bullding. The west auxiliary building also includes stalrwell/elevator/equipment well towers located at the north and south ends, which provide access to the west auxiliary building, two of the steam generator bufldings, and the control bullding.

The west auxiliary building is composed of three floors, each of which is divided into equivalent north and south areas. It houses Class $1 \mathrm{E}$ and NonClass $1 \mathrm{E}$ instrumentation and control pane1s, DRACS natural draft heat exchanger pipeway and ductways, HVAC unit coolers and DRACS storage tank.

The first two floors contain safety related electrical equipment and are serviced by safety-related unft coolers at 2,400 $\mathrm{cfm}$ each. The top floor is serviced by two non-safety related unit coolers at $3,000 \mathrm{cfm}$ each. The unit coolers receive ventilation air from the confinement and filter the circulated air. They discharge air to the confinement system to maintain a negative air pressure during off-normal operation. Safety-related equipment areas are provided with smoke venting equipment.

ACCOUNT 218K Pipe Tunnels

The pipe tunnels are Non-Seismic Category I reinforced concrete box-type structures. The tunnels are founded at various elevations. Where they extend beneath a building, the bottom floor of the building is the roof of the tunnel. In other areas, the roof is cast-in-place concrete over metal deck and supported on steel framing. The tunnels provide protection for piping runs between various buildings.

ACCOUNT 218N Maintenance Shop and Warehouse

The maintenance shop and warehouse is a two story, ell-shaped, stee1-frame Non-Seismic Category I structure, located at the northwest corner of the turbine room and heater/auxiliary bay. This building is a conversion from the site fabrication facility structure abutting the north and west walls of the auxillary boller bullding. The 32 feet high bullding is 222 feet long on one side of the ell and 221 feet long on the other side. Building volume is approximately $1,164,000$ cubic feet.

The floor slab is reinforced concrete at grade. The mezzanine floor is cast-in-place concrete on metal deck supported by steel framing. The roof is metal deck covered with insulation and bullt-up roofing and supported on 
steel framing. Exterior walls are insulated metal siding and interior walls are concrete block or metal partitions. A 15 ton crane is provided in the machine shop/pipe fabrication area. Rolling steel doors are provided for equipment access.

The north portion of the building houses the carpenter shop, sheet metal shop, electrical and instrumentation shop, paint shop, lubrication room, sandblast room, degreasing room, tool room, pipe fabrication area and machine shop. The remalnder of the building houses a lunch and vending area, locker rooms, storage (warehouse) areas, and utility vehicle parking area. Wide access aisles are provided for utilization of all work and storage areas.

The maintenance shop and warehouse HVAC systems maintain environmental conditions of normally occupied spaces within prescribed comfort zones and ensure that temperatures and humidity in other areas are suitable for material storage and equipment operation. The HVAC equipment for the entire building is located on the mezzanine over the lunch room and locker room area.

ACCOUNT 218R Auxiliary Boller Building

The auxiliary boller building is a single story steel frame Non-Selsmic Category I structure located north of the turbine building with which it shares a common wall and adjacent to the maintenance shop and warehouse. It is 100 feet wide, 100 feet long and 38 feet high, with a deaerator room 21 feet wide, 27 feet long and 16 feet high located above the southeast corner. The building volume is approximately 390,000 cubic feet.

This building is supported on reinforced concrete footings. The reinforced concrete ground floor is located at grade. The roof is concrete channel plank covered with bullt-up roofing supported on steel framing. The exterior walls are insulated metal siding and interior walls are concrete block.

The auxiliary boller building is provided with steam coll air tempering units for boiler room ventilating air supply and for the boiler combustion air supply. Exhaust fans are provided at varlous locations around the boiler house to provide additional ventilation during the summer months. In the winter months, unit heaters furnished with steam from the auxiliary boiler provide heat.

ACCOUNT $218 \mathrm{~S}$ Waste Water Treatment Bullding

The waste water treatment building is located west of the main plant structures. It is a one story prefabricated non-Selsmic Category I steel structure 25 feet wide, 80 feet long and 20 feet high. The building volume 1s approximately 40,000 cubic feet.

The building is supported on reinforced concrete spread footings. The reinforced concrete ground floor is located at grade. The roof is standing seam metal deck supported by steel framing. The exterior walls are insulated 
metal siding. Partial interior partitions to separate various equipment are relnforced concrete.

The building houses a control area, storage area, pumps, tanks and other waste water treatment equipment. Large items, such as the batch holding tank, are located adjacent to the building.

Two waste water holding basins are located close to the waste water treatment bullding. Both are constructed of reinforced concrete, 100 feet long by 70 feet wide, with the bottoms ten feet below grade and the tops of the walls two feet above grade. The basins are side by side, with one common wall. The pumps for emptying the basins are supported on structural steel at one end of the basin. The steel also supports grating around the pumps to provide access.

Heating is provided by electric unit heaters. The building is ventilated by drawing outside air through wall louvers and exhausting through power roof ventilators.

\section{ACCOUNT 218T Intermediate Sodium Storage Vaults}

The two intermediate heat transport system storage vaults are reinforced concrete Seismic Category I structures located north and south of the nuclear island. The intermediate heat transport system sodium storage tanks, sodium water reaction products tanks and their cyclone separators are located below grade. Two essential water chillers and missile protected air inlets and outlets are located above grade on each storage vault. The base of each structure is a reinforced concrete mat founded on rock.

Each below-grade structure in 84 feet wide, 103 feet long and 33.5 feet high. The above-grade structures are 43 feet wide, 101 feet long and 22 feet high. The total volume of both buildings is approximately 603,000 cubic feet.

The exterior walls, interior walls, floor slabs and roof slab are reinforced concrete. The exterior walls are a minimum of two feet thick. The intermediate floors are cast-in-place concrete on metal deck supported on steel framing. The roof is covered with built-up roofing.

Each storage vault is provided with 1 ts own ventilation system and a standby heating system for protection under winter conditions. Cooling is provided in each structure from a $4,000 \mathrm{cfm}$ unlt cooler supplied with chilled water from the essential water chillers. 
ACCOUNT 22 REACTOR PLANT EQUIPMENT

Mechanical key parameters related to the reactor plant are given in Items 22 through 27 and 34 of Table 4-1. Reactor plant equipment configuration in the form of General Arrangement drawings is given in Figures 4.2 through 4.4. The table and figures supplement and amplify the following discussion of Account 22 .

The reactor plant equipment produces and supplies superheated steam to the turbine-generator unit, which converts the thermal energy to electric energy. The NSSS scope includes the reactor vessel and guard vessel, control system, main heat transfer/transport system, auxiliary heat transport system, the fuel handling and storage system, inert gas storage and purification system, liquid metal receiving, storage and make-up system, sodium purification system, special heating system, decontamination equipment, reactor and process monitoring systems, and associated instrumentation and controls for these systems.

The Balance of Reactor Plant (BORP) systems include the radwaste processing systems, inert gas cell cooling system, emergency cooling water system, environmental monitoring systems, and associated instrumentation and controls for these systems.

Interconnecting piping systems are included with each NSSS and balance of reactor plant auxiliary system. They comprise the piping, fittings, valves, containment piping penetrations, cold traps, steam traps, strainers, specialities, hangers and supports, pipe whip and seismic restraints, insulation and other components required for a complete system. Materials and wall thicknesses are chosen based on the service conditions and operational requirements of each system. The factors generally considered include: temperature, pressure, corrosion resistance, abrasion resistance, fluid purity requirements and cost. Thin wall stainless steel is used for primary and intermediate sodium. Carbon steel is used for steam (below $750^{\circ} \mathrm{F}$ ), clean water, air, oil, and other services without special requirements. Other materials used include stainless steel and stainless steel tubing.

The piping systems are designed for American Nuclear Society Safety Class 1 , 2 or 3 (SC1, SC2, SC3) or Non-Nuclear Safety (NNS). Safety-related piping systems that are not part of the primary coolant boundary, such as for the emergency cooling water and primary component cooling water systems, are designed for SC2 or SC3. Non-safety-related piping systems that do not interface with safety class systems are designed for NNS.

- The paragraphs given below provide brief technical descriptions of the reactor plant equipment accounts, in order to afford guidance to the more detailed descriptions of the pages that follow.

Account 221 Reactor Equipment (reactor vesse1 and closure head, reactor guard vessel, reactor core and blanket and reactor contro1) 
Account 222 Main Heat Transfer and Transport System (1iquid sodium pumps, intermediate heat exchangers, steam generators, main liquid sodium piping system and sodium loop pressure control)

Account 223 Safeguards System (shutdown heat removal system)

Account 224 Radwaste Processing System (1iquid, gas and solid radioactive waste systems)

Account 225 Fuel Handling and Storage System (new and spent fuel storage, fuel and blanket assembly transfer, and exvessel storage tank (EVST) cooling and purification systems)

Account 226 Other Reactor Plant Equipment (cell inert gas system, special heating system, liquid metal storage and processing system, emergency cooling water system, maintenance equipment and sampling system)

Account 227 Reactor Plant Instrumentation and Control (benchboard, panels and racks, process computers, multiplexing equipment, monitoring systems, plant control and protection systems and associated instruments) 
ACCOUNT 221 Reactor Equipment

The reactor equipment includes the reactor vesse1, reactor vessel closure head, react or guard vessel, core (fuel, breeding blanket, and shield), control rod clusters, control rod drives, various internal supports, piping, and flow control baffles, and closure head drive mechanisms. The reactor vessel serves to contain the liquid sodium coolant. The coolant flows up through the fuel, blanket and shield assemblies where it picks up heat and transports it to the intermediate heat exchangers. There it is transferred to an independent intermediate fluid for transport to the steam generators for the production of steam.

Reactor Vesse1 and Closure Head

The reactor vessel is a top supported, vertical, cylindrical steel vessel with a welded toroidal knuckle, a conical frustum and spherical bottom end cap, and a non-removable flat plate closure head. The flat cover structure is composed of a fixed outer ring which is sealed to the reactor vessel top flange and three eccentric inner rotating plugs. The plugs permit access to any point in the core assembly without exposing the liquid sodium to air.

The closure head also incorporates radiation shielding and reflective insulation. The vessel contains the core, core supporting structures, control rods and other parts directly associated with the core. The vessel has inlet and outlet nozzles located below the closure head but above the top of the reactor core.

The top of the reactor core is surrounded by a horizontal baffle which serves to separate the hot and cold liquid sodium. Coolant enters the reactor vesse1 through the inlet nozzles and flows downward through the inlet pipes and inlet manifold to the core inlet plenum. Then the coolant flow is directed upward through the core where the nuclear fission reaction heats the liquid sodium. The heated sodium is directed through the upper plenum to the outlet nozzles. It is then pumped through the four primary sodium loops to the intermediate heat exchangers.

Reactor Guard Vesse1

The reactor guard vessel is a bottom supported vertical cylindrical steel vessel with a bottom head whose shape matches the reactor vessel contour. The guard vessel surrounds the reactor vessel and provides a 15 inch space between the two vessels for inspection access. The guard vessel prevents the reactor core from being uncovered in the event of a reactor vessel leak.

Reactor Core and Blanket

The core is approximately hexagonal in shape and consists of four types of hexagonal assemblies. These are the fuel, breeding blanket, shield and control assemblies. The fuel is in the form of enriched plutonium/uranium oxide pellets which are enclosed in stainless steel tubes. The tubes (rods) are combined into fuel assemblies. 
The breeding blanket is in the form of depleted urantum oxide pellets which are enclosed in stainless steel tubes. These tubes (rods) are combined into radial/axial blanket assemblies which are distributed as concentric rings through the core. Axial blankets are formed in the top and bottom layers of the active core by including depleted uranium oxide pellets in the top and bottom portions of each fuel rod.

The shield is composed of stainless steel rods which are combined into shield assemblies. At the time of refueling both fuel and blanket assemblies are redistributed and/or transferred to the ex-vessel storage tank. Fresh fuel and blankets are added as required.

\section{Reactor Control}

Reactor control is provided by neutron-absorbing control rod clusters actuated by control rod drives which are mounted on the closure head of the reactor vessel. The control rod clusters are used to follow load changes, to provide reactor trip capability, and to furnish control for slight deviations in reactivity due to temperature. In the event of a reactor trip, the control rods fall into the core by gravity. Two independent and diverse means are provided to trip the reactor. The primary shut-down system employs electromagnetic release mechanisms. The secondary shut-down system employs pneumatic release mechanisms with spring assist. The trip signals are provided by the plant protection system.

\section{ACCOUNT 222 Main Heat Transfer and Transport Systems}

The main heat transfer and transport system consists of four similar heat transfer loops connected in parallel to the reactor vessel. Each loop is composed of a primary loop with a primary sodium pump, an intermediate heat exchanger ( $I H X$ ) and a check valve; an intermediate loop with an intermediate sodium pump; and a steam generation system with one Benson cycle steam generator. The utilization of two sodium heat transfer systems in series for each heat transfer loop permits the retention of all of the primary radioactive sodium within the reactor containment building. In addition, the system includes intermediate sodium expansion tanks, sodium/water $\left(\mathrm{Na} / \mathrm{H}_{2} \mathrm{O}\right)$ reaction products separation tanks, sodium drain and storage tanks, interconnecting piping and valves, and instrumentation for operational control. The primary loop and the IHX are located in the containment building. Most of the intermediate loop and all of the steam generation system are located in the steam generator buildings. The $\mathrm{Na} / \mathrm{H}_{2} \mathrm{O}$ reaction products separators and all primary and intermediate loop drain and storage tanks are located in underground vaults.

During operation, the primary sodium transports the heat generated by the reactor to the intermediate heat exchanger. The intermediate sodium transports the heat from the intermediate heat exchanger to the steam generators where superheated steam is produced to drive the turbine-generator unit. The primary heat transport system loops utilize syphon breaker lines to minimize loss of coolant from the reactor vessel, in the event of a break in the 
LSPB ACCOUNT 22

primary loop. This design feature eliminates the need for primary pump and IHX guard vessels.

\section{Liquid Sodium Pumps}

The eight primary and intermediate sodium pumps are vertical shaft, single piped suction, free surface centrifugal units equipped with variable speed synchronous motor drives. Speed control is provided by a separate variable frequency drive system for each pump. The four primary sodium pumps are two-stage pumps. The four intermediate sodium pumps are single stage pumps. The liquid sodium enters the pumps from the bottom axial inlets, passes up through the impeller(s) and is discharged through a single exit nozzle on the side of the pump casing.

In addition, each pump has a pony motor connected to the main motor shaft through a gear box. The pony motor allows pump operation at low flow requirements for normal removal of reactor shut-down heat.

Intermediate Heat Exchangers (IHX)

The IHX is a top supported vertical shell and tube counter flow heat exchanger with single wall straight tubes. Primary sodium enters the she11 above the midpoint and flows up between the shell and the tube shroud, into the tube area, down around the tubes and out the side above the tube sheet. The intermediate sodium enters the bottom tube plenum of the IHX and flows up through the tubes to the top tube plenum, exiting at the top of the IHX. Thermal expansion is accommodated by a bellows joint on the intermediate sodium outlet nozzle and a floating upper tube sheet.

\section{Steam Generators}

The four steam generators are vertical counter flow she11 and tube evaporatorsuperheaters with double wall straight tubes. The heated intermediate sodium enters the upper part of the shell and flows downward around the tubes and exits near the bottom of the she1l. Feedwater enters the bottom plenum, flows upward through the tubes, is evaporated and converted to superheated steam and exits at the top end of the steam generator. Thermal expansion is accommodated by a convoluted shell located in the lower half of the steam generator.

Main Liquid Sodium Piping System

The main liquid sodium piping is thin wall (0.5 inches) stainless steel pipe. The primary loop pipe has a 36 inch outside diameter, except for the primary pump suction line which has a 40 inch outside diameter. The intermediate loop pipe has a 36 inch outside diameter. The thin walls of the sodium pipe require specially designed pipe supports to preclude distortion of the pipe cross section. The primary sodium loops are provided with check valves to permit operation with one loop out of service. These valves are located at a high point in the cold leg piping and are designed for remote servicing. 
Main Sodium Loop Pressure Control

The pressure in both the primary and intermediate loops is maintained by the primary and intermediate loop argon cover gas systems. Intermediate sodium expansion and contraction is accounted for by flow to or from the intermediate loop expansion tanks. The pressure of the intermediate loop is maintained in the IHX at a pressure higher than the primary loop to ensure that primary sodium will not leak into the intermediate sodium loop.

Rupture discs protect the steam generators from possible overpressure due to a sodium water reaction. These discs are designed to rupture when an overpressure occurs allowing flow into the sodium/water reaction products separation tanks.

\section{ACCOUNT 223 Safeguards System}

The safeguards system is provided to mitigate the consequences of postulated accidents. The system consists of the auxiliary heat transfer system discussed under this account and other engineered safety features discussed under other accounts. The containment/confinement systems and the habitability system are discussed in Accounts 212 and $218 \mathrm{~A}$, respectively.

\section{Shutdown Heat Removal System (SHRS)}

The primary function of the shut-down heat removal system is to remove reactor decay and sensible heat following reactor shut-down when the normal (steam generator/condenser) heat sink is unavailable. The shut-down heat removal system consists of the direct reactor auxiliary cooling system (DRACS) and the ex-vessel storage tank (EVST) cooling system.

The DRACS consists of three cooling systems, each with a design capability of removing 10.75 MWt ( 0.3 percent of core operating power) from the primary sodium "coolant.

Two of the systems are identical and consist of a primary and an intermediate loop in order to restrict the radioactive primary sodium to the confines of the containment building. In each of these loops, primary sodium is extracted from the top plenum through the primary sodium piping, circulated through an intermediate sodium to sodium heat. exchanger by an electromagnetic (EM) pump and returned to the bottom of the core through the primary sodium piping. The intermediate sodium discharged from each of the heat exchangers is circulated by an EM pump through a separate air blast heat exchanger. The pumps, piping and heat exchangers of the primary and intermediate loops are designed to American Nuclear Society Safety Class 2 and Selsmic Category I requirements. Each primary loop and equipment, including the intermediate heat exchanger, is located in the containment building. The intermediate loops and equipment are located in the north and south auxiliary bays. 
The third system is a natural convection loop which transfers heat from the primary sodium to intermediate sodium using a natural convection heat exchanger located in the reactor vessel. The intermediate sodium transfers the heat by natural convection through intermediate loop piping to a sodium to air heat exchanger, located at the top of the west auxiliary bay. The primary sodium circulation is inhibited during normal operation by two redundant flow control devices (ball check valves) which are equipped with manual override capability. Dampers on the sodium to air heat exchanger also prevent natural circulation during normal operation. These dampers are operated automatically when required and are equipped with a manual override.

The secondary loop pressure in each of the three systems is controlled by means of an argon cover gas system and an expansion tank. The pressure control for the primary loop is discussed under Account 222.

The EVST cooling system is discussed under Account 225. It serves as a functional backup to the DRACS through a piping interconnection.

ACCOUNT 224 Radwaste Processing System

The concept of radioactive waste processing for the plant is based on an examination of all potential pathways of radioactive release to the environment. The transport of radioactivity from the primary coolant system to various parts of the plant during normal operation is traced and evaluated in order to determine the performance of each process interposed between the source of radioactivity and the subsequent pathways to the environment. Necessary processing and treatment equipment is provided to keep the release of radioactivity to the environment as low as is reasonably achievable.

There are three radwaste systems: the radioactive liquid waste system, the radioactive gas waste system, and the radioactive solid waste system. All potentially radioactive liquids, gases and solids are collected and processed according to physical and chemical properties, and the radioactive concentrations. Care is taken in the design to minimize the mechanical leakage paths in these systems in order to limit unprocessed leakage.

\section{Liquid Radioactive Waste System (LRWS)}

The liquid radioactive waste system consists of two processing flow circuits, namely the low activity level liquid (LALL) processing system and the intermediate activity level liquid (IALL) processing system.

Low Activity Level Liquids Processing System: Low activity level liquids are defined as radioactive liquids having an activity concentration less than $10^{-4}$ microcuries $/ \mathrm{cm}^{3}$. This category of radioactive liquids consists of low-purity wastes, chemical wastes, and detergent wastes. The LALL subsystem influents emanate from floor and equipment drains, laboratory drains, and decontamination station and personnel shower drains from various plant buildings. The LALL system is designed to collect the various low activity liquid waste streams. The liquid is then filtered, demineralized and monitored prior to discharge to the cooling tower blowdown or recycled for further processing. 
Intermediate Activity Level Liquid Processing System: The intermediate activity level liquid influents to the LRWS is generated in the sodium removal and decontamination subsystem of the maintenance system. IALL radwaste is stored in four 22,500 gallon collection tanks prior to processing. Processing is accomplished using mobile demineralizers as required to support the large component cleaning vessel (LCCV) cleaning cycles. The processed liquid is stored in four 22,500 gallon IALL storage tanks for subsequent reuse or transferred to the LALL subsystem for discharge. A truck bay is provided in the Nuclear Island Maintenance Building, for housing the mobile equipment. The vendor services will include the provision of its own operating personnel and will, if required, include the shipment of waste for off-site burial or processing. Provisions are provided in the truck bay for connection to the in-plant equipment.

\section{Gas Waste System}

The radioactive gas waste system is designed to provide storage for short-lived isotope decay and controlled release to the environment of fission product gases removed from the argon cover gas and the nitrogen cell inerting gas.

The gas waste system is composed of two systems, namely the radioactive argon processing system (RAPS) and the cell atmosphere processing system (CAPS). The RAPS continuously processes radioactive argon. It functions to separate out the noble gases, to provide holdup time to allow decay of short-lived isotopes prior to disposal, and to recycle processed argon gas to the cover gas system. The RAPS is designed to operate under conditions of 0.1 percent fuel failure. Normal RAPS flow is seven SCFM with a maximum capability of 50 SCFM. The CAPS continuously processes the cell inerting nitrogen gas. It functions to provide holdup time to allow decay of short-lived isotopes prior to disposal. Normal CAPS flow is 0.7 SCFM with a maximum capability of 400 SCFM.

A supply of make-up gas and the necessary gas distribution systems are provided to supply argon cover gas and nitrogen for inerted cells, pressurizing gas system, and other systems. Both gases are stored in cryogenic storage tanks with capacities of 6,000 gallons for argon and 18,000 gallons for liquid nitrogen.

\section{Solid Radioactive Waste System (SRWS)}

The solid radioactive waste system is designed to process and package solid wastes so that they can be shipped to a federal or state licensed burial site. The packaged shipment containers will be processed such that the surface dose rate.will be in compliance with NRC and Department of Transportation regulations.

The system is designed to process or handle the following types of radioactive wastes: 1) spent demineralizer resins, 2) compactible solids, 3) noncompactible solids (e.g., spent filter cartridges), 4) metallic sodium, and 5) sodium bearing components. The nuclear island maintenance building provides the appropriate space, crane coverage, and loadout access locations for the system components. 
Solidification of spent demineralizer resins is accomplished by providing a connection in the truck bay to a mobile solidification unit. This mobile unit will be contracted on an as needed basis to solidify spent resins and other liquid wastes which cannot be processed through the LRWS.

\section{ACCOUNT 225 Fuel Handling and Storage System}

The fuel handling and storage system is required to process and inspect new fuel, blanket, control rod and shield assemblies shipped to the site, perform refuelings of the reactor, store spent assemblies and prepare shipments for off-site processing.

New Fuel Storage

The new fuel/blanket storage facilities are located in the fuel handling cell of the reactor service building. The storage pit provides 420 dry storage tubes in a subcritical array which is sufficient to maintain $k$ eff $\leq 0.95$. The eight inch tubes are arranged in a 12 by 35 rectangular array on 14 inch centers. This capacity is equivalent to 0.62 core, excluding shield assemblies.

Spent Fuel Storage

The spent fuel storage is designed to accommodate the spent fuel, blanket and other core assemblies equivalent to one normal fuel reload (208 assemblies) and one complete core unload (673 assemblies, excluding shield assemblies) or 1.3 cores plus spare (39) positions.

The fuel and other assemblies are stored in the ex-vessel storage tank (EVST) which is a cylindrical sodium filled and cooled vessel. The capacity of this vessel is 950 assemblies. The EVST is located within the reactor containment building, adjacent to the reactor service building. The assemblies are contained in a fixed subcritical grid. Assemblies are positioned by means of a fuel transfer arm which is mounted on a rotating plug in the EVST top head.

Fuel and Blanket Assembly Transfer

Fuel and other core components are loaded and unloaded from the core by means of an "A" frame and transfer tube system. The system is composed of two inclined transfer tubes, one extending into the reactor vessel, while the other extends into the ex-vessel storage tank. At the top of the tubes in the fuel transfer cell is a fuel bucket drive and a swing mechanism.

Spent core assemblies are transferred from the reactor vessel by placing an assembly in a transfer bucket while it is inside the reactor vessel. It is then tilted and raised up the inclined tube through the reactor vessel head and into the fuel transfer cell. The transfer bucket is then tilted to align with the transfer tube which penetrates the EVST, and is lowered into the storage tank. In the EVST, the bucket is tilted up to the vertical position for assembly removal and placement in the EVST storage grid. New core assemblies are loaded into the reactor core by reversing the sequence described above. 
LSPB ACCOUNT 22

Ex-Vessel Storage Tank (EVST) Cooling and Purification System

The EVST cooling system removes decay heat generated by the assemblies stored in the EVST. There are two natural circulation loops each consisting of an in-vessel natural circulation heat exchanger, a secondary natural circulation loop consisting of a natural draft sodium to air heat exchanger, an expansion tank, and a diffusion cold trap. Each loop is designed to remove the maximum decay heat load of 950 assemblies. The normal operation is to operate both loops at very low heat loads. The EVST cooling system may serve as a functional backup to the DRACS through a piping interconnection (refer to Account 223).

The EVST sodium is purified by a clean-up system which circulates the sodium through a cold trap and the EVST. The system consists of dual EM pumps and a single cold trap rated at $120 \mathrm{gpm}$ at $625^{\circ} \mathrm{F}$. There is a normally closed connection between this system and the reactor vessel primary sodium purification system. This cross connection can be used if required during abnormal operation to either cool the EVST, or provide additional purification for the primary reactor sodium.

\section{ACCOUNT 226 Other Reactor Plant Equipment}

This account discusses the remainder of the reactor plant equipment, such as the cell inert gas system, special heating system, liquid metal storage and processing system, emergency cooling water system, primary component cooling water system, maintenance equipment, and sampling system.

\section{Ce11 Inert Gas System}

This system circulates cooled nitrogen gas to inerted cells in the containment and the reactor service building, auxiliary buildings and the primary sodium storage vault. Inerted cells serviced include the reactor vessel cavity, the primary sodium loop celis, the primary sodium cold trap cell, the auxiliary heat transfer system cells and pipeways, and the ex-vessel storage tank cavity. The cell inert gas system also circulates cooled argon gas to the fuel transfer cell in the contalnment building. Gas coolers and vaneaxial fans are located external to the inerted cells. The fans circulate the inerting gas between the cells and the coolers. The coolers exchange the heat from the inerting gas to the essential or normal chilled water systems.

\section{Special Heating System}

The special heating system is composed of the electrical heat tracing and temperature controls required for the primary, intermediate and auxiliary sodium components, piping and valves. This heating equipment is used to bring components up to specification temperatures prior to the introduction of hot sodium; to maintain component temperature above the melting point of sodium or at specification temperatures if sodium flow is insufficient; and to remelt the sodium in the event of sodium solidification in the components. 
Heater redundancy is provided where failure could cause undesirable thermal stresses, or where access for heater replacement is restricted. Reliability is improved by operating heaters at reduced voltage (less than $1 / 2$ of rating). The heaters are arranged, grouped and controlled in zones of uniform heat output.

\section{Liquid Metal Storage and Processing System}

The liquid metal storage and processing system includes the equipment for receiving," storing and distributing the liquid sodium used in the plant and maintaining it at the desired degree of purity.

Sodium is received as a solid in railroad tank cars fitted with heating pipes. A receiving station is provided with a steam to oil heat exchanger and the pumping system required to circulate the hot oil through the solidified sodium in the tank cars. Transfer facilities are provided for transferring the liquified sodium to the plant storage tanks after it has been heated.

There are three liquid metal purification systems provided for the primary, EVST, and intermediate sodium systems.

The primary sodium purification system consists of one cold trap having a capacity of 100 gallons per minute. The system is located in the reactor service building with the EVST cold trap.

The intermediate sodium purification system consists of 12 cold traps (three for each 10op) rated at $120 \mathrm{gpm}$. These cold traps; associated regenerative heat exchangers and sodium circulating pumps are located in the north and south auxiliary buildings. The system is arranged so that adjacent intermediate loops can share their six cold traps.

The EVST sodium purification system is described under Account 225. The EVST and primary purification systems are arranged so that the cold traps can be shared.

Primary/EVST sodium storage is provided by three tanks located in the primary sodium vessel vault with a total capacity of 154,000 gallons. If a complete drain of the systems were required, use of tank cars or temporary dump tanks would be required.

Intermediate sodium storage is provided by ten tanks. Five tanks are located in each of the intermediate heat transport system sodium drain and storage vaults. Total storage capacity is approximately 500,000 gallons.

\section{Emergency Cooling Water System}

The emergency cooling water system provides chilled water to all safety related buildings and equipment that require a source of cooling water during accident conditions. The system is designed and constructed as a safety-related system. The system provides chilled water to the containment, the north and 
south auxiliary buildings and the reactor service and control buildings at $42^{\circ} \mathrm{F}$ with a return temperature of $57^{\circ} \mathrm{F}$.

The water is chilled by four 50 percent capacity air cooled chillers of 300 ton capacity each. The chillers and the afrblast cooling coils are housed in missile-proof Seismic Category I structures above the two intermediate sodium storage vaults.

\section{Maintenance Equipment}

The maintenance equipment consists of the specialized equipment required for access to, removal/in-place servicing, handling and shielding required to service the NSSS equipment and includes the following items:

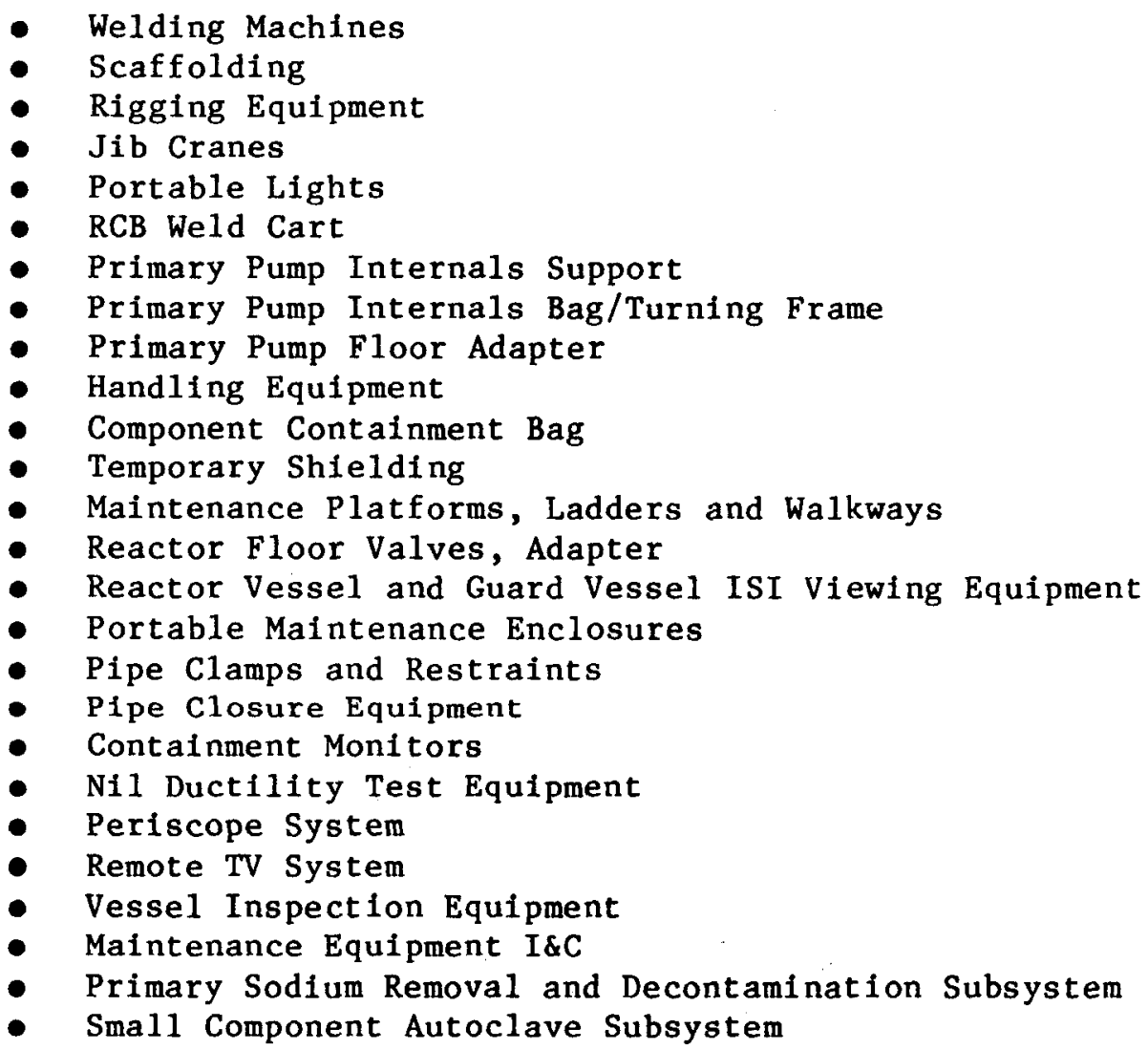

\section{Sampling System}

The sampling system provides representative sodium, gas and water samples for chemical and radioactive analyses to evaluate the chemistry of these fluids.

\section{ACCOUNT 227 Reactor Plant Instrumentation and Control}

The reactor plant instrumentation and control system provides monitoring and protection for plant, personnel and equipment and controls to enable the operator to start up, operate, and shut down the reactor. 
Main Control Board

The overall design of the main control board is primarily dictated by the requirements of the reactor plant. The main control board is composed of three control consoles arranged in a triad configuration designed in accordance with appropriate IEEE nuclear standards. They contain a combination of Class $1 \mathrm{E}$ and Non-Class $1 \mathrm{E}$ control and information devices necessary for remote operation of the plant. Digital technology is utilized for the plant control system utilizing multiplexing for the system/equipment interface, and CRT's and touch sensitive devices for the operator interface.

Overall arrangements, besides providing for physical separation requirements, are coordinated to assure safe and efficient operation. The front panels of the main control boards contain the operator interface devices for the heat transport systems, engineered safety features, reactivity control, turbine, turbine auxiliaries, cooling systems, generator, generator auxiliaries and electrical auxiliary power distribution systems. The use of combustible materials within the main control board is prohibited.

The main control board provides control and data acquisition interfaces with the NSSS, the turbine plant, and the main generator and auxiliary electric power system. The NSSS interface is discussed under this account description. The turbine plant and the main generator and auxiliary electric power system interfaces are discussed under Accounts 236 and 243 respectively.

\section{NSSS Control Board Interface}

Reactor and NSSS auxiliary process systems and components which are monitored and controlled from this board are tabulated below:

a. Safety Related Systems and Components

Primary Heat Transport System

Shutdown Heat Removal System

DRACS

EVST Cooling System

Containment Isolation System

Containment/Confinement System

Control Room Habitability System

Recirculating Gas Cooling System

Fluid Leak Detection System

Emergency Cooling Water System

b. Non-Safety Related Systems and Components

Control Rod Drives

Primary Sodium Pumps

Intermediate Sodium Pumps

Intermediate Heat Exchangers

Steam Generators 


\section{Inert Gas Storage and Purification System Sodium Purification System \\ Special Heating Systems}

Instrumentation and control systems associated with the NSSS are tabulated below:

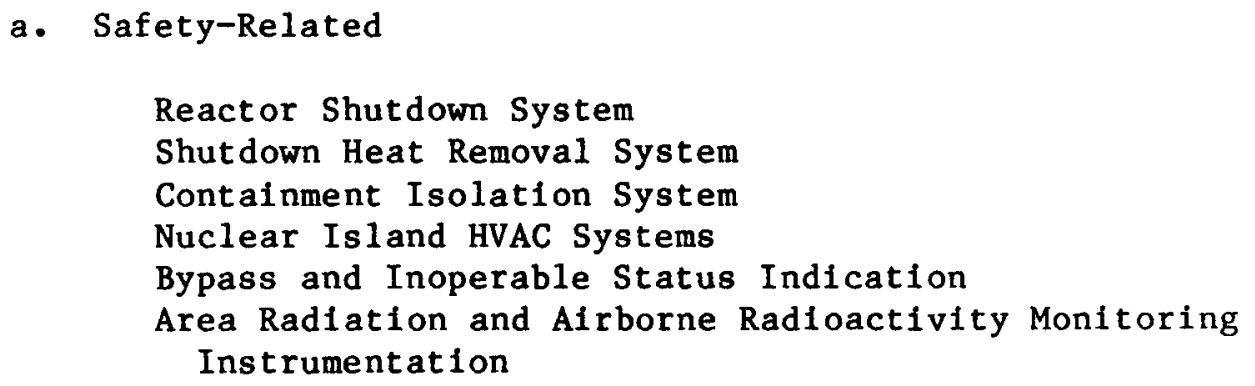

Safe Shutdown Control

The main control room is the primary station for safe shut-down control of the plant and is designed to be available at all times. Controls required for bringing the plant to hot or refueling shut-down and for maintaining the shutdown condition are located in the main control room. In the event that the main control room becomes uninhabitable, the plant may be brought to and maintained in a safe shut-down condition using alternate control provisions in the remote shut-down facility located in the reactor service building. The remote shut-down facility consists of a control. console equivalent to one wing of a main control room console (for Non-Class IE control). A panel containing four CRT's and other touch sensitive devices is provided for control of systems containing safety functions. (Class $1 \mathrm{E}$ ).

\section{Radwaste Panels and Racks}

The complete waste management system consists essentially of three subsystems: radioactive liquid waste system, radioactive gaseous waste system and radioactive solid waste system. Overall control of the complete system is exercised from radwaste panels in a local control room located near the radwaste facilities in the nuclear island maintenance building. 
Instrument Racks

Open type instrument racks are provided to mount local instruments such as pressure transmitters, manifolds, pressure switches, and other pneumatic instruments that connect directly with the process pipes. Each rack has a rigid structure, suitably braced, to withstand stress incidental to shipping, installation and operation without warping or twisting.

Plant Computer Systems

The overall architecture of the plant instrumentation and control system is based upon the concept of distributed microprocessor based control and data acquisition.

The microprocessor-based controllers and data acquisition modules are housed in process control units that are located near the process units to be controlled. Plant management functions are implemented in a process computer that carries on a data exchange with the rest of the system through a computer interface unit. Centralized operator functions are implemented through operator interface units using microprocessor-driven cathode ray tube (CRT) consoles. The distributed data base located in each process control unit (e.g., control variables, control loop status, and input data) is accessible by other process control units, CRT consoles and the process computer over the plant data buses.

The process control units contain both control and logic modules. These modules have the capability to provide a mix of both continuous and sequential control functions that can be used to implement a variety of applications. The modules take the place of conventional analog controllers, programmable logic controllers or batch controllers. The process control unit also provides operator interfacing capability at the local level with panelboard instrumentation.

Higher level operator interfacing capability is provided by CRT/keyboard based consoles to implement system-wide plant operating and engineering functions. Each console is a stand-alone device that has its own microcomputer-based drive electronics and its own interface to the plant data buses. The operator console itself includes a color character graphic CRT and various touch sensitive devices.

The functions implemented in the operator interface units will include the basic operational capabilities usually performed by conventional panelboard instrumentation: alarm annunciation, manual/automatic station operation, process variable indication, and trending graphics. Additional operation capabilities currently available only through a computer include: alarm logging and display, instrument "out-of-service" indication, numeric storage and recall of trend data, and monitoring of the operational status of a11 control hardware. The operator interface unit is also used to implement engineering functions such as control system configuration and tuning, assigning of tags to inputs and control loops, and configuration of console displays. 
The plant computers and the distributed microprocessor control and data acquisition systems support the following plant instrumentation and control systems :
a. Plant Control System
b. Plant Protection System
c. Plant Data Handling and Display System

\section{$\underline{\text { Radiological Monitoring System (RMS) }}$}

The radiological data management system is designed to assure compliance with the applicable NRC and licensing requirements, by providing information concerning the radiological environment of the plant. The system enables the health physicist and plant operating personnel to maintain complete awareness, in real-time, of plant radiation levels. Permanent records are automatically produced for regulatory requirements. The system consists of the following equipment :
a. Process Radiation Monitoring Instrumentation
b. Effluent Radiation Monitoring Instrumentation
c. Area Radiation Monitoring Instrumentation
d. Data Acquisition and Processing Instrumentation

Except for containment isolation, all data management and display functions for the RMS are provided by the plant control system and plant data handling and display system.

\section{Neutron Flux Monitoring System}

The neutron flux monitoring system provides four overlapping ranges of instrumentation: low level range, source range, wide range and power range. Within each range of instrumentation, channels are provided comprised of a detector, preamplifier (source and wide ranges), junction box (power range) and signal conditioning equipment. - The $f l u x$ monitoring system is designed to measure neutron flux proportional to reactor power from shut-down to above full power and to provide inputs for plant protection, plant control, data handling and display, accident monitoring, annunciation, and diagnostics.

The low level range equipment monitors neutron flux during the initial fuel loading when the flux is below the source range sensitivity. The equipment consists of detectors, electronic and acoustic transmitters sealed in a core special assembly, and receiving and decoding equipment which outputs to the plant control system and data handling and transmission system. 
The source range equipment monitors neutron flux at shut-down, including all phases of shut-down maintenance of the reactor core, through criticality and into low power operation. Each source range channel consists of a fission chamber, pulse counting electronics and a timer-scaler which provide outputs to the control console and the data handling and display system.

The wide range monitors connect to the plant protection system and operate from low power to above full power conditions. Each wide range nuclear channel consists of a fission counter and electronics containing a log counting portion, a log mean square voltage portion and a d-c linear power portion covering the reactor power range from 0-150 percent. This wide range channel provides outputs to the secondary shut-down system of the plant protection system to initiate protective trips. The plant protection system provides buffered outputs for indication, annunciation, diagnostics, and data logging.

The power range inputs to plant protection system equipment which monitor neutron flux in the high flux range produced during reactor power operation. Each redundant power range channel will consist of a compensated ion chamber and signal conditioning electronics providing a linear d-c output covering a 0-150 percent reactor power range. This instrument range, by diverse means, monitors the same reactor power range as the wide range $d-c$ linear power channels and provides outputs to the plant protection system to initiate protective trips. The plant protection system provides buffered outputs for the plant control system, indications, annunciation, diagnostics, and data logging.

\section{Instrumentation for Following the Course of an Accident}

Instrumentation to assess plant and environs conditions during and following an accident are provided to give indications of critical plant variables. Necessary indications are those required by the plant operator during accident conditions to:

a. Determine the overall status of the plant

b. Initiate and accomplish safe plant shut-down

c. Determine whether reactor trip, engineered safety features and manually initiated safety systems are functioning proper1y

d. Determine the potential for causing a gross breach of the barriers to radioactivity release

e: Assess the operation of plant systems

f. Provide information regarding the release of radioactive materia1 
These indications also provide material evidence for post-accident investigation into the causes and consequences of the event. The required instrumentation is selected or designed to be capable of surveying postulated accident environments in which they are located for the time their function is required.

The following variables are monitored in the control room or at remote locations, as necessary:

a. Type B Variables

Reactivity Control

Core Cooling Parameters

Maintaining Heat Transport System Integrity

Maintaining Containment Integrity

b. Type C Variables

Fuel Cladding Parameters

Heat Transport System Boundary Parameters

Containment Parameters

c. Type D Variables

Shut-Down Heat Removal System Parameters

Primary Sodium System Parameters

Steam Generator Parameters

Containment Cooling System Parameters

Radwaste System Parameters

Ventilation System Status

Power Supply Parameters

d. Type E Variables

Containment Radiation Leve1

Area Radiation Level

Airborne Radioactive Materials Released from Plant

Environs Radiation and Radioactivity

Meteorology

Accident Sampling Capability

\section{Reactor Instrumentation System}

The Reactor Instrumentation System provides those elements which are used to supply information on the level of the liquid sodium in the reactor vessel, the temperature of the primary sodium coolant exiting the reactor core, vibration of upper internals structure, reactor and primary heat transport system loose parts monitoring, and internals in-service inspection. This information is supplied to the plant control system, the plant protection system and the data handling and transmission system for the functions of control, protection and diagnostics. Temperature monitoring is done by an 
array of thermocouples located above the reactor core which measure the temperature of the core outlet liquid sodium. Sodium level monitoring is done by a series of dry-well induction-coil type level probes penetrating several locations of the fixed deck of the vessel. Vessel upper internals vibration monitoring uses a number of accelerometers mounted on the upper internal structure of the reactor vessel for diagnostics during initial reactor start-up. The reactor and primary heat transport system loose parts monitors provide continuous monitoring for impact noises indicative of loose parts. In-vessel inspection consists of under sodium viewing equipment and gauges to meet in-service inspection requirements.

\section{Failed Fuel Detection System}

The failed element detection and location system provides the instrumentation and equipment to detect, characterize, and locate fuel and blanket assemblies with failed pins. This instrumentation supplies signals to the data handling and transmission system and the plant control system for surveillance, display and alarm and diagnostics purposes. The system is composed of the following subsystems :

$$
\begin{aligned}
& \text { a. Reactor Cover Gas Monitoring Subsystem } \\
& \text { b. Delayed Neutron Monitoring Subsystem } \\
& \text { c. Sipper (Sodium Sampling Tube) Subsystem }
\end{aligned}
$$

\section{P1ant Control System}

The plant control system provides overall control and coordination for the automatic and manual control of the reactor, heat transport system, turbine, and auxiliary systems during plant start-up, operating and shut-down modes. The plant control system includes the plant supervisory control systems, the reactor control systems and the heat transport control systems.

The plant supervisory control system is a real-time digital computer based system which integrates overall automatic and manual control of the plant power generation equipment. Continuous control system actions are taken to maintain appropriate conditions among the plant heat transport loops and power generation equipment. Control actions include demands for plant trips to limit potential damage to major plant equipment.

The reactor control system directs and monitors the position and motion of the control rods for all modes of reactor operation. The reactor control system generates signals to appropriate control rod drive mechanisms to direct control rod motion and position.

The heat transport control system provides local automatic and manual controls and monitoring for the primary heat transport system, the intermediate heat transport system, and the steam generator system for all plant operations 
including start-up, power range, shut-down, normal heat removal, and maintenance. The heat transport control system provides the interlocks and permissives associated with heat transport control system operations.

\section{P1ant Protection System}

The plant protection system functions to limit consequences of initiating faults in the LSPB so that radioactivity release guidelines are not exceeded and the public is protected. The plant protection system includes the reactor shut-down system and the containment isolation system. The reactor shut-down system shuts the reactor down, trips the heat transport system pumps and activates the shut-down heat removal systems. The containment isolation system acts to prevent or to 1 mit radioactive material release to the outside environment.

Plant protection system design requirements include: on-line test capability, calibration and maintenance capabiality, non-susceptibility to single failures, physical and electrical separation of redundant instrument channels, automatically safe conditions upon failure of any instrument channel, and a design life of 40 years. It is a fully digital multiplexed system with a quadriplexed level of redundancy. The digital systems have the ability to automatically test and calibrate the whole trip channel.

The plant protection system has safety-related (Class 1E) interfaces with the following plant systems:

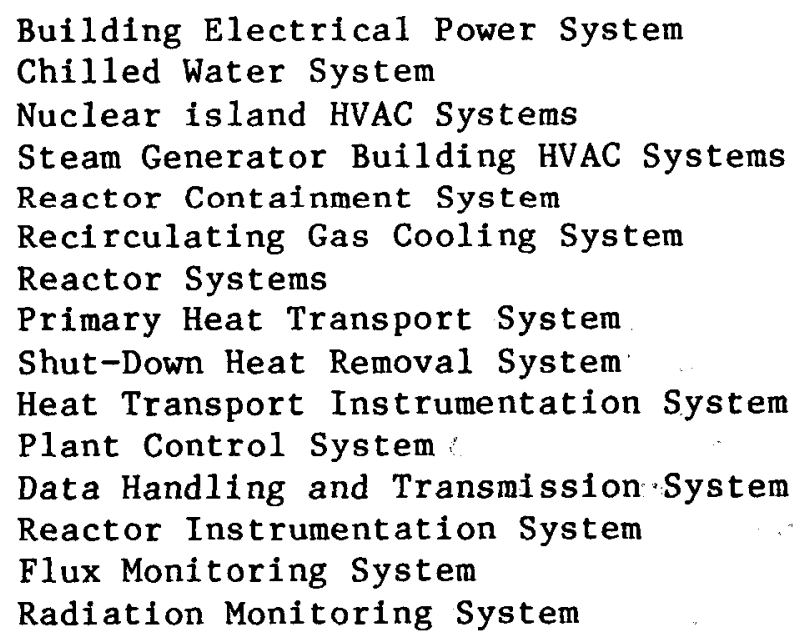

Reactor Plant Instrument Tubing and Fittings

The scope of supply of instrument tubing begins at the first accessible root valve at the piping and extends to the instrument shutoff valve. Materials and certification of instrument lines which are part of the pressure boundary are in accordance with Instrument Soclety of America Standards. 


\section{ACCOUNT 23 TURBINE PLANT EQUIPMENT}

Mechanical key parameters related to the turbine plant are given in Items 28 through 31 and 35 through 37 of Table 4-1. A steam heat balance is given in Figure 4.5. The table and figure supplement and amplify the following discussion of Account 23.

The turbine plant equipment includes the steam handling, power conversion and condensate/feedwater machinery of the steam cycle. All turbine plant equipment includes margin in the design to compensate for some wear and performance degradation during the life of the plant.

The thermal energy from the reactor intermediate heat transport loop generates superheated steam at 2290 psia within the steam generator. The main steam piping supplies this steam to the throttle/control valves of the turbinegenerator unit. The steam turbine is a tandem-compound six-flow machine which develops the mechanical energy to drive the electric generator at 1800 $\mathrm{r} / \mathrm{min}$. Normally, 56 percent of the steam generator outlet flow passes through the turbine and exhausts into the condenser. The remaining 44 percent of the flow is either directed to the steam reheaters, or extracted at various stages from the turbine for the five stages of feedwater heating and the auxiliary steam turbine drives for the steam generator feedwater pumps.

Essentially all of the main steam entering the high pressure turbine flows completely through to the exhaust. Approximately 94 percent of the high pressure exhaust flow is directed to the inlet of the double flow intermediate pressure turbine. The remaining six percent flows through the tube side of the moisture separator/reheaters.

Approximately eight percent of the steam entering the intermediate pressure turbine is extracted after partial expansion and directed to the shell side of the highest pressure feedwater heater. The remaining 92 percent flows completely through the intermediate pressure turbine. Of the steam exiting this turbine, approximately eight percent is directed to the deaerator. The balance flows through the shell side of the moisture separator/reheaters. The separator/reheaters remove water droplets and reheat the steam before it enters the three low pressure turbines. This provides a two-fold benefit; excessive water induced erosion of the low pressure turbines is avoided and the turbine cycle efficiency is improved.

A turbine bypass system is provided to pass up to 50 percent of inlet steam flow directly to the condenser. This is necessary if heat must be rejected during start-up, shut-down, or other normal transient conditions.

Condensate is pumped from the condenser hot-wells by three 50 percent capacity condensate pumps through 100 percent flow deep bed polishing demineralizers, the steam packing exhauster condenser, and through the three stages of low pressure heaters to the deaerator. Two 50 percent capacity turbine driven feedwater pumps supply water from the deaerator storage tank to the high 
pressure feedwater heater to raise the feedwater temperature to $420^{\circ} \mathrm{F}$ before entering the steam generators. One motor driven start-up feedwater pump is provided.

Interconnecting piping systems are included with each turbine plant auxiliary system at the three-digit or lower order code-of-accounts level of detail. They comprise the piping, fittings, valves, steam traps, strainers, specialties, hangers and supports, insulation and other components required for a complete system. The piping systems are generally designed as American Nuclear Society Non-Nuclear Safety. In some cases they may be designed as Safety Class 2 or 3, where they interface with Safety Class piping systems. Materials and wall thicknesses are chosen based on the service conditions and operational requirements of each system. The factors generally considered include: temperature, pressure, corrosion resistance, abrasion resistance, fluid purity requirements and cost. Carbon steel is used for steam (below $\left.775^{\circ} \mathrm{F}\right)$, clean water, air, oil and other services without special requirements. other materials used include: chrome-molybdenum steel, stainless steel and stainless steel tubing.

The paragraphs given below provide brief technical descriptions that preview the more detailed descriptions given in the pages that follow.

Account 231 Turbine-Generator (turbomachinery, generator, exciter, stator cooling water system, gas systems, hydrogen seal oil system, electro-hydraulic control system, turbine gland steam sealing system, moisture separator/ reheater, moisture separator/reheater drain system, lubricating oil system and turbine oil storage and conditioning system)

Account 232 Not used

Account 233 Condensing System (condensers, condensate system, condenser gas removal system, turbine bypass system and condensate polishing system)

Account 234 Feedheating System (feedwater heaters, feedwater system and extraction steam system)

Account 235 Other Turbine Plant Equipment (main vapor piping system, turbine bullding closed cooling water system, demineralized water make-up system, chemical treatment system and neutralization system)

Account 236 Turbine Plant Instrumentation and Control (turbine plant control board, panels, cabinets and racks, and process computer) 


\section{ACCOUNT 231 Turbine-Generator}

The turbine-generator produces 1418 MWe at the generator terminals with rated load throttle steam conditions of $2215 \mathrm{psia} / 850^{\circ} \mathrm{F}, 124 \mathrm{psia} / 457^{\circ} \mathrm{F}$ reheat, zero percent make-up, 2.5 in-HgA back pressure, turbine driven feedwater pumps, and five stages of feedwater heating. With an estimated 107 MWe station auxiliary load, 1311 MWe is delivered to the generator step-up transformer for off-site transmission.

For brief periods during the summer, when the ambient wet bulb temperature approaches the site maximum of $74^{\circ} \mathrm{F}$, the condenser pressure may rise above 2.5 in-HgA, limiting the turbine-generator performance. During the worst condition, the condenser pressure will not exceed 3.0 in-HgA which causes a reduction in generator capability of less than one percent and a corresponding increase in heat rate. The cumulative total of these periods during which performance is limited is estimated as 800 hours per year.

The turbine is an $1800 \mathrm{r} / \mathrm{min}$ tandem-compound machine with six-flow exhaust and 44 inch last stage blades. It consists of a single flow high pressure section, a double flow intermediate pressure section and three double flow low pressure sections. The throttle flow at rated load is $12,552,383$ pounds of steam per hour.

The cold reheat steam exhausts from the intermediate pressure turbine and passes in parallel through two moisture separator/reheaters which are horizontal shell and tube heat exchangers with a high efficiency separator incorporated in the design. High pressure section exhaust steam is supplied to the tube side for reheating the steam flow before being admitted through the intercept valves to the low pressure machines. The high pressure condensate from the tube side is piped to the highest pressure feedwater heater, while the drains from the moisture separator are directed to the third stage feedwater heater.

The turbine is provided with a low speed turning gear for rotating the turbine spindle after shut-down. Low speed rotation is required for uniform cooling and thermal contraction of the rotating parts.

The "high-tuned" turbine pedestal is reinforced concrete and is supported on a thick reinforced concrete foundation mat bearing on rock. The turbine pedestal is isolated from the remaining building support loads.

\section{Generator}

The generator has a rating of 1660 MVA with $0.90 \mathrm{PF}, 25,000 \mathrm{~V}, 3$ phase, 60 $\mathrm{Hz}$. It is a totally enclosed $1800 \mathrm{r} / \mathrm{min}$ machine utilizing hydrogen at 75 psig to cool the rotor and stator end turns. The stator is a conductor-cooled type with deionized water as the liquid coolant.

The generator is furnished with the following equipment: cooling system, including hydrogen coolers; terminal bushings; instruments; grounding pads; 
bearing seals; housing insulation; foundation plates and shims; and special tools.

The generator stator is serviced by the following external equipment: a deionized water circulating and cooling unit assembled on a skid, including storage tank, pumps, coolers, deionizer, flow meter, conductivity cells, gauges, piping, valves, filters, instruments, and regulating equipment; and a stator winding cooling control cabinet assembled and combined with the hydrogen cooling control cabinet, including annunciator, generator automatic runback logic and all necessary control devices.

\section{Exciter}

The exciter is of the direct driven alternator and rotating silicon diode rectifier type. It has a 2.5 response ratio and is designed for $1800 \mathrm{r} / \mathrm{min}$. The alternator bearings, the silicon diode rectifier assemblies, and the main generator collector and brush rigging are all enclosed within the exciter housing. The housing is furnished with suitable water-to-air heat exchangers and a closed ventilation circuit for circulating the cooling air.

The excitation switchgear is a metal enclosed integrated unit of standard low voltage design that is located indoors. The function of the excitation switchgear is to connect, rectify and control excitation to the ac alternator exciter from the alternator stator, and to provide voltage regulation by adjustment of the generator field voltage (dc regulator) or the generator terminal voltage (ac regulator). The excitation switchgear houses the exciter field breaker, the thyristor regulator bridge and the ac and dc regulator $\operatorname{logic}$.

\section{Stator Cooling Water System}

The stator cooling water system provides deionized cooling water to the windings of the generator stator. Coolant deionization reduces electrical conduction losses and ensures.good dielectric behavior. Pipes and fittings in contact with deionized water are stainless steel, brass and copper.

The deionized water is pumped from a storage tank by an exciter shaft or motor driven circulating pump through a heat exchanger and filters into the cooling circuit inside the stator conductors and back to the storage tank. If the conductivity of the cooling water exceeds a preset value at the outlet of the first filter, some of the flow is diverted through a mixed bed demineralizer which discharges into the storage tank.

\section{Gas Systems}

Hydrogen and carbon dioxide gas systems are provided for controlling the atmosphere within the main generator housing.

Hydrogen gas is utilized to cool the generator rotor and the stator end turns and to reduce rotor windage losses. The hydrogen is calculated within the 
generator housing under pressure. The heat from electrical and mechanical losses is removed by two she11 and tube type coolers located at each end of the generator housing.

The hydrogen is supplied from a series of hydrogen storage containers which are individually connected to a manifold. The manifold is equipped with a relief valve, generator pressure and bottle pressure regulators with isolation valves, high and low pressure gauges, a pressure switch for hydrogen supply pressure "low" alarm and bottle connectors. A hydrogen control cabinet is provided on which are mounted hydrogen purity gauges, temperature detectors and other devices required to ensure safe and effective operation of the hydrogen control system.

The carbon dioxide system consists of a liquid carbon dioxide storage unit with refrigeration system, vaporizer, relief valves and two pressure reducing valves. Carbon dioxide is used for purging hydrogen from the generator housing during shut-down, an for purging air from the housing before being filled with hydrogen during start-up.

\section{Hydrogen Seal Oil System}

The hydrogen seal oil system provides oil to the generator hydrogen seal assemblies to prevent the escape of hydrogen to the outside atmosphere from inside the generator housing.

Oil is pumped from a gas detraining tank, through a filter, to a hydrogen seal assembly located at each end of the generator shaft. Some of the oil passes through the two seal assemblies towards the hydrogen side and comes in contact with the hydrogen inside the generator. This oil absorbs bubbles of hydrogen and is collected in an oil manifold which is connected to the gas detraining tank by piping. Hydrogen diffuses towards the surface of the oil inside the tank. Vacuum pumps dispose of the hydrogen by transferring it to the outside atmosphere.

\section{Electro-Hydraulic Control (EHC) System}

The electro-hydraulic control system consists of the speed control unit, the load control unit and the flow control units for the turbine machinery. The speed control unit compares actual turbine speed with a speed reference, or actual acceleration with an acceleration reference, and provides a speed error signal for the load control unit. The load control unit combines the speed error signal with the load reference signal to determine the desired steam flow signals for the stop valves, control valves and intercept valves. Finally, the valve flow control units accurately position the appropriate turbine valves to obtain the desired steam flows through the turbine.

A high pressure fluid system is provided to convert the low power level signals from the EHC circuits to high power level mechanical outputs for positioning the large steam valves. This system consists of a fluid reservoir, two independent pumping systems, fluid coolers, accumulators, a fluid transfer unit and a filter unit. 
The EHC includes a backup mechanical-hydraulic control system which takes over in case of a failure of the EHC. A turbine stress evaluator is also included as part of the system to protect the turbine against excessive thermal stresses by influencing the EHC operation.

\section{Turbine Gland Steam Sealing System}

The turbine gland steam sealing system seals the turbine shaft at turbine shell penetrations under all conditions of turbine loading. The sealing system prevents air in-leakage along the shaft (high pressure and intermediate pressure turbines during start-up and low pressure turbines at all load conditions) and steam outleakage from the high pressure and intermediate pressure turbines during partial load and full load operation. In addition to sealing the main turbine, the gland steam sealing system seals the steam generator and feed pump turbines and the main turbine main steam and intercept valves.

Another function of this system is to provide steam for prewarming the turbine Internals and rotor while on turning gear, prior to start-up.

Each turbine shaft end is provided with a series of labyrinth packings and two (low and intermediate pressure turbines) or three (high pressure turbine) glands. The outer glands of each shaft are piped to, and maintained at, a pressure slightly below atmospheric by the steam packing exhauster. Steam leaking outward through the packings and air leaking inward are collected in the outer gland and drawn off to the steam packing exhauster.

The steam packing exhauster consists of a shell and tube type service condenser with two motor driven air removal blowers. The blowers create a vacuum of three to five inches of water which draws steam and air from the outer gland of each turbine shaft seal into the condenser shell. With condensate as a coolant, the steam is condensed and drained into the main condenser, while the air is removed by blowers to atmosphere.

The inner (10w and intermediate pressure turbines) or middle (high pressure turbine) glands of each shaft are connected by pipes to the seal steam header. The header is maintained at an acceptable pressure by a group of control valves and safety valves which admit supplemental steam when needed from the main steam piping, or auxiliary steam piping, and "spill" excess steam to the main condenser. The inner glands of the high pressure turbine are also vented to the intermediate pressure turbine exhaust, ahead of the moisture separator reheater.

During start-up, steam from the auxiliary steam system or main steam systems is supplied to the seal steam header and from there to the inner glands of the low and intermediate pressure turbines and the middle gland of the high pressure turbine. This steam flows through the labyrinth packings inward toward the turbines and outward to the outer glands. As load increases with a corresponding pressure increase inside the high pressure and intermediate pressure turbines, flow direction through the inner (intermediate pressure 
turbine) and middle (high pressure turbine) glands reverses. Steam from inside the turbines flows outward to the seal steam header. (This does not occur with the low pressure turbines which always require external steam to be supplied.) As steam from the high pressure and intermediate pressure turbines is supplied to the seal steam header, the amount of supplemental steam required decreases.

As the load continues to increase, the quantity of steam being supplied by the high pressure and intermediate pressure turbines exceeds the quantity required for sealing the low pressure turbines, steam generator feed pump turbines and the high and intermediate pressure turbine valve stems. The excess is "spilled" to the main condenser.

The sealing system operates automatically at a11 load conditions.

\section{Moisture Separator/Reheater}

Two moisture separator/reheaters are utilized to recondition the wet steam exhausted from the intermediate pressure turbine, prior to its passage to the low pressure turbines. The moisture is removed and then the steam is reheated to a superheated state.

Each moisture separator/reheater is a horizontal she11 and tube type heat exchanger. Steam from the high pressure turbine section exhaust flows through the tubes. Intermediate pressure turbine exhaust steam flows through the she 11 .

Intermediate pressure turbine exhaust steam enters the bottom of the reheater she11 and passes through stainless steel chevron plate type moisture separators. The steam flows upward through the "U"-shaped reheater tube bundle, where it is reheated to superheat conditions. Exiting from the top, the steam flows to the low pressure turbines.

Moisture Separator/Reheater Drain System

The thermal energy required for reheating is supplied by extraction from the high pressure to intermediate pressure crossover lines to the tube side of the reheater bundle. The bundle drains to the No. 5 feedwater heater.

Each moisture separator drains to the No. 3 feedwater heater.

\section{Lubricating 011 System}

The lubricating oil system supplies oil to the main turbine-generator bearings, the thrust bearing wear detector, the overspeed trip device, the turning gear oil turbine and the oil trip. The system equipment includes pumps, oil coolers, a lube oil reservoir, and necessary interconnecting piping and controls. 
LSPB ACCOUNT 23

A main turbine shaft driven centrifugal pump normally supplies the required bearing lubricating oil. During start-up and shut-down, this shaft driven pump is primed by an ac motor driven suction pump. When the unit approaches rated speed, an oil tank booster pump takes over for the motor suction pump. This booster pump is driven by an ofl turbine utilizing the discharge from the shaft driven centrifugal pump.

Additional pumps include the ac turning gear oil pump and the dc emergency bearing oil pump. Both the ac motor driven suction pump and the ac motor driven turning gear oil pump start automatically on low oil pressure. The dc emergency bearing oil pump is powered by the station batteries and is used as a final back-up source for lubricating oil.

The lubricating oil system reservoir contains a screen for removing foreign materials from the oil drained into the reservoir and the following additional equipment: vapor extractor, air ejector, pressure control orifices and flow check valves, two oil coolers, float-type oil level indicator with high and low level alarms, and pressure switches with test valves for automatic starting of the turning gear and emergency (ac and dc) motor driven oil pumps.

Turbine 0i1 Storage and Conditioning System

The turbine oil storage and conditioning system provides storage for new and used turbine lubricating oil, continuous on line purification of the oil in the main turbine reservoir and in the steam generator feed pump turbine reservoirs, and transfer between the reservoirs, storage tanks and trucks. It can also be used for batch cleanup of contaminated oil during a unit outage.

The system consists of a lube oil conditioning unit, one clean and one dirty oil storage tank, a transfer pump and interconnecting pipe, fittings and valves.

During normal plant operation, lube oil from the main turbine reservoir and from the steam generator feed pump turbine reservoirs overflows to the lube oil conditioning unit where water and solids are removed by a combination of precipitation and filtration. The cleaned oil is returned to the reservoirs. This continuous bypass method of operation provides maximum protection against turbine damage due to contaminated oil.

Each of the storage tanks can hold a full inventory of oil to permit batch replacement or batch cleaning of the full inventory during a plant outage.

New oil received by truck can be pumped by the truck's onboard pumps to either the clean or dirty oil storage tank or to the lube oil conditioner, but not directly to the turbine reservoirs. By making all oil to the reservoirs go through the lube oil conditioner, risk of contamination is minimized. Discharge of used oil to trucks is done with the lube oil transfer pump. 
During a plant shut-down, it is possible to batch purify oil held in any of the reservoirs, the clean oil storage tank or the dirty oil storage tank and return the purified oil to any of these locations.

The lube oil conditioning unit is capable of removing all free water and reducing solids contamination to an acceptable level without removing additives or increasing the oil acidity.

\section{ACCOUNT 233 Condensing System}

The three surface condensers are single stage, two-pass design with divided fabricated steel water boxes and shell. The condensers are designed to handle the total heat rejection from the main turbine and the two auxiliary turbine drives for the feedwater pumps. Each condenser has a condensing surface of 388,510 square feet composed of 28,741 one inch diameter, 22 BWG (Birmingham) Wire Gage), SS-304 tubes, 52 feet long. Cooling water flow in each condenser is $219,400 \mathrm{gpm}$ resulting in a tube velocity of seven feet per second and a temperature rise at ful1 load of $22^{\circ} \mathrm{F}$.

Each condenser shell is floor mounted and connected to the turbine exhaust flange by means of a stainless steel expansion joint to accommodate thermal expansion. The three shells are interconnected by means of a pressure equalizing duct.

The tube sheets are bolted to the shell with provisions for thermal expansion of the tubes. The tubes are rolled into the holes in the tube sheets with flared ends to reduce entrance and exit losses.

The shell is carbon steel welded construction with $1 / 16$ inch corrosion allowance. The water boxes are fabricated steel construction and are bolted to the condenser shel1s. They are designed for easy removal without disturbing the tube sheets. The total hotwell capacity of the three she11s is 66,000 gallons at normal water level.

The hotwell is designed to deaerate the condensate to.limit dissolved oxygen to a maximum of five parts per million at the outlet during normal steadystate operation.

\section{Condensate System}

The condensate pumps are of the vertical "can" type, suitable for the net positive suction head requirements of condenser hotwell service. The pumps develop sufficient head to ensure adequate delivery to the deaerator after overcoming the pressure drop in the condensate piping, steam packing exhauster condenser, the condensate polishing demineralizers and the low pressure feedwater heaters.

Three half-size motor driven pumps are supplied. The third pump is on standby service or is isolated for maintenance. In addition to the main flow, the condensate pumps supply seal water to various equipment such as the condensate 
pump seals, heater drain pump seals, and steam generator feedwater pump glands. The condensate pumps also discharge excess condensate to the condensate storage tank and supply water to the turbine exhaust hood sprays and turbine bypass desuperheaters.

The condensate storage tank is a field erected tank made of carbon steel. Its foundation is a reinforced concrete ring wall 18 inches thick with the mean diameter equal to the tank diameter. The top of the ring wall is six inches above grade, and the bottom is four feet below grade. Tank anchor bolts are set in the ring wall. A compacted sand bed is provided inside the ring wall to support the tank floor.

\section{Condenser Gas Removal System}

Three half-size mechanical vacuum pumps are supplied for removing non-condensible gases from the three condenser shells. During start-up, all three pumps are operating, to minimize the evacuation time. When an acceptable vacuum is reached, one pump is placed in the standby mode. Normally, two pumps are required to maintain the condenser vacuum. If the condenser pressure rises, the standby pump starts automatically. To avoid cycling, the standby pump is manually stopped.

The vacuum pumps are motor driven rotary two-stage units. The seals for the pumps utilize demineralized water and a closed cooling system integrated with each pump assembly. Circulating water is used for cooling.

\section{Turbine Bypass System}

The turbine bypass system:

- provides a means of controlled heat release from the reactor through the steam generators and main condenser during start-up, hot shut-down, cool-down and reactor physics testing;

- provides a means of limiting the inflow transients to prevent reactor trips during rapid load reductions including load rejections, of up to 100 percent electric power;

- provides a bypass of superheated steam to the condenser during transients; and

- provides capability for testing the turbine cycle.

The condensing system is designed to accept up to 50 percent of the main steam flow bypassing the turbine during start-up and transient conditions. For this purpose, a single main steam header is provided with six pipelines, block valves, dump valves and desuperheaters, which discharge into the main condensers. Each valve is rated to pass approximately eight percent of the 
rated main steam flow. The control of the turbine bypass valves is coordinated with the turbine controls such that minimum transient disturbance is experienced by the nuclear steam supply system. One of the steam dump control valves can be modulated manually from the control room to provide load follow capability.

The control valves and desuperheaters are designed to reduce the steam pressure downstream of the valves to a maximum of 250 psia and to reduce the temperature to a maximum of $450^{\circ} \mathrm{F}$. Piping upstream of the desuperheater is ASTM A335 P22 chrome-molybdenum steel. Downstream of the desuperheater the piping is carbon steel ASTM A53B or Al06B.

\section{Condensate Polishing System}

One complete condensate polishing system is provided that is capable of treating 100 percent of the condensate flow. The condensate polishing system removes both dissolved and suspended impurities from the condensate stream by a combination of filtration and ion exchange. The system consists of six parallel mixed bed ion exchange vessels. At maximum flow conditions, five of the vessels are in service with the sixth being regenerated or on standby.

A mixed bed polishing vessel will normally remain in service until its cycle is terminated, due to either a high accumulation of solids, indicated by excessive pressure drop, or exhaustion of its ion exchange capability, indicated by high effluent conductivity. At the termination of a service cycle, the exhausted resin is sluiced hydraulically from the polishing vessel to the resin separation/cation regeneration vesse1. Within this vessel, the resin charge is separated into cation and anion portions. The anion resin is then sluiced to the anion regeneration vessel before chemical regeneration is commenced. Cation resin is regenerated with a dilute solution of sulfuric acid; anion resin is regenerated with a warm dilute solution of sodium hydroxide. To lengthen the service cycle of the resin charge, the system has the optional capability to recycle a dilute ammonia solution between the resin contained in the two external regeneration vessels. Following regeneration, the resins are sluiced to the resin storage vessel where they are remixed and stored.

Provided as part of the condensate polishing system are chemical storage tanks and pumps for acid, caustic and ammonia, a caustic dilution water heater, an air blower, condensate pumps, piping, valves, instrumentation and a control panel.

\section{ACCOUNT 234 Feedheating System}

Five stages of feedwater heaters are utilized to heat the feedwater returning to the steam generators. Heaters are placed in series with each stage operating at increasing extraction pressure along the feedwater heater train. Pressures are maintained by various stages of extraction steam from the intermediate pressure and the low pressure turbines. Heating the boiler feedwater in this manner improves the overall cycle efficiency. 
Heaters 1 through 3 and 5 are closed type heaters having a horizontal "U"tube arrangement, using stainless steel tubes. The high pressure heater (Heater No. 5) is provided with a desuperheating section. Heater 4 is a horizontal tray type deaerator with a storage tank sized for seven minutes operation at turbine guaranteed load. The deaerator and storage tank are elevated to provide adequate NPSH for the steam generator feedwater booster pumps. The condensate and heating steam are intimately mixed in the deaerator such that the condensate is brought to saturation temperature. This liberates any remaining dissolved gases which are vented to atmosphere. If not removed, these dissolved gases could damage the steam generator tubes. Each closed heater has an integral drain-cooler section with the exception of the first stage heater. The drains from Heaters 3 and 5 cascade to the next lower pressure heater through a control valve that maintains water level within the she11. The drain from Heater 2 is pumped into the condensate line between the polishing demineralizers and the steam packing exhauster. Drains from Heater 1 cascade to the condenser. The deaerator storage tank discharges to the suction of the feedwater booster pumps.

Due to the physical size of the heaters required for each stage of feedwater heating, three parallel trains of heaters are utilized for the first three stages, with each individual heater being sized for one-third capacity. The highest stage feedwater heater is in two trains with each heater sized for 50 percent of the flow. The two lowest stage feedwater heaters are installed in the condenser necks below the three low pressure turbines. One of the three trains of both the first and second stage heaters is located in each of the three condenser necks. The individual trains of the remaining two stages of feedwater heaters and the deaerating heater and its storage tank are located in the heater/auxiliary bay.

Only the highest heater stage is in the discharge of the feedwater pump and subject to full system pressure. The three low pressure heaters are subject only to the discharge pressure: of the condensate pumps.

\section{Feedwater System}

Feedwater leaving the deaerator storage tank flows to the suction of the booster feedwater pumps, where its pressure is increased to provide adequate NPSH for the steam generator feed pumps, which are in series with the booster feedwater pumps. At the discharge of the steam generator feed pumps, the pressure is sufficient to deliver the water through the high pressure feedwater heater to the steam generator inlet, and maintain the required main steam pressure.

The booster feedwater pumps are single stage horizontal centrifugal pumps mounted on the same shaft as the feed pumps.. Each pump is sized to deliver the necessary flow at rated load to the suction of one steam generator feed pump.

The two steam generator feed pumps are multi-stage barrel type centrifugal pumps each driven by a steam turbine to provide water to the high pressure 
feedwater heater. Each 50 percent feed pump is designed for a flow rate of $13,750 \mathrm{gpm}$.

The steam generator feed pump drives are each multi-stage, non-extraction, condensing turbines.

Steam for the feed pump turbines is supplied by extraction from the reheaters to low pressure turbines cross-over pipes during normal operation and from the main steam system during low load operation. The turbines exhaust through ducts to the main condenser. To account for pressure drop through the ducts, these auxiliary turbines are designed for a backpressure of 0.5 in-HgA higher than the main turbine.

A 30 percent capacity motor driven feed pump is used for start-up and standby. It is a multi-stage horizontal centrifugal pump rated to deliver $8,000 \mathrm{gpm}$.

Extraction Steam System

The extraction steam system conveys steam extracted from selected stages of the turbines to:

a. The she11 side of the closed feedwater heaters where it condenses heating the feedwater which is in the tubes.

b. The deaerator where it mixes with and heats the feedwater.

c. The steam generator feedwater pump drive turbines.

d. The plant auxiliary steam system.

A11 extraction lines except the four lowest pressure extractions are provided with motorized shut-off valves and non-return valves to prevent any back flow to the turbine. The lowest pressure extraction is for moisture removal, and discharges directly to the condenser. The second and fourth lowest pressure extractions supply steam to the two lowest pressure feedwater heaters which are mounted in the condenser necks. The third lowest pressure extraction is for moisture removal and discharges to the lowest pressure feedwater heater. Since, in all four cases, the extraction steam pipe never exits from the condenser, installation of any valves is physically impractical.

Extraction flow to the feedwater heaters is controlled only by the rate at which it condenses in the heater shell. When the steam condenses in the feedwater heaters, the drains are normally cascaded to the shell side of the next lowest pressure heater. A level control valve on the drain line keeps the drain cooler tubes submerged. An alternate drain on each heater shell bypasses the drain cooler section and drains directly to the condenser. These drains are automatically opened in response to a high liquid level in the shell. The lowest pressure heater drains to the condenser. Drains from the next lowest pressure heater are pumped into the condensate line between the gland steam condenser and the polishing demineralizers. The moisture 
separator/reheater tube bundle drains into the shell side of the highest pressure feedwater heater.

Extraction flow to the steam generator feedwater pump turbines is controlled by the feed pump turbine inlet valves.

Extraction steam from the intermediate pressure turbine is supplied to the low pressure portion of the auxiliary steam system when it is available in preference to producing it in the auxiliary boilers.

ACCOUNT 235 other Turbine Plant Equipment

This section discusses the remainder of the turbine plant equipment, such as the turbine building closed cooling water system, demineralized water make-up system, chemical treatment system and neutralization system.

\section{Main Vapor Piping System}

The main vapor piping system consists of the main steam and hot and cold reheat systems.

The main steam system conveys high pressure superheated steam from the steam generators to the high pressure turbine. Chromium-molybdenum steel pipe is used in the main steam system. The hot and cold reheat steam system conveys exhaust steam from the intermediate pressure turbine to the moisture separator/reheaters and returns it to the low pressure turbines. Carbon steel pipe is used for both the hot and cold reheat.

Each system comprises the main steam or reheat piping, auxiliary piping, fittings, necessary välves, steam traps and strainers, specialities, hangers, supports and insulation. Also included in the main steam system are the main steam isolation and relief valves and the steam generator building piping penetrations.

When it is available, steam extracted from the main steam system is supplied to the high pressure portion of the auxiliary steam system in preference to producing it in the auxiliary boilers.

\section{Turbine Building Closed Cooling Water System}

Cooling of turbine plant and miscellaneous plant auxiliary equipment in the turbine building is accomplished with a closed recirculating cooling water system. Heat is rejected from this system to the main cooling towers through the service water system (refer to Account 252). The cooling water is circulated through the closed system by two 50 percent capacity motor driven pumps. A third pump is provided as a spare. A head/surge tank assures adequate net positive suction head at the pump suction, and automatic replenishment of any water lost to leaks. It also provides an expansion volume to account for the varying volume of the water between cold fill and full load. 
The heat absorbed by the cooling water is transferred to the service water in two 50 percent capacity she11 and tube heat exchangers. A third heat exchanger is provided as a spare. Cooling water is on the shell side and service water is in the tubes.

\section{Demineralized Water Make-up System}

The demineralized water make-up system provides treatment to the effluent water from the make-up water pretreatment system. This system produces a high quality demineralized water supply that is utilized as make-up to the steam cycle.

The system provides a maximum of 480,000 net gallons of demineralized water per day to storage. It consists of two trains of treatment equipment which utilize a common forced draft degasifier. Each train contains an activated carbon filter, a strong acid cation exchanger, a strong base anion exchanger and a mixed bed polishing vessel. Additional equipment provided as part of the demineralizer system includes bulk acid and caustic storage tanks, day tanks, regenerant pumps, a caustic dilution water heater, pumps, blowers, piping, valves and instrumentation.

Water directed to the demineralizer system is initially treated by the activated carbon filters. These filters are each eight feet in diameter and contain a medium bed depth of 2.5 feet. The filters protect the downstream ion exchange resin by removing any chlorine or organics from the water.

Following activated carbon filtration, the water is treated by strong acid cation exchangers. These vessels are each 8.5 feet in diameter and contain a resin charge of 142 cubic feet. The resin within these vessels is regenerated by a dilute solution of sulfuric acid. Following the strong acid cation exchangers, the water is combined and treated by a single forced draft degasifier 5.5 feet in diameter. The degasifier removes carbon dioxide from the water in order to reduce the anion loading on the downstream strong base anion exchangers.

The water is pumped from the degasifier to the strong base anion exchangers. These vessels are also 8.5 feet in diameter and contain 112 cubic feet of resin. The anion resin is regenerated with a warm dilute solution of sodium hydroxide. Following these vessels are the mixed bed polishing vessels. These vessels are each 7.5 feet in diameter and contain 53 cubic feet of cation resin and 80 cubic feet of anion resin. After treatment by the demineralized water make-up system, the product water is discharged to the demineralized water tank.

All of the pressure vessels of the demineralized water make-up system are rubber-1ined and are designed with 100 percent freeboard. Additionally, the system is designed so that each cation and anion exchange vessel is regenerated once per day at maximum flow. The activated carbon filters and the mixed bed exchangers require weekly backwashing and regeneration at maximum flow. 


\section{LSPB ACCOUNT 23}

Chemical Treatment System

The chemical treatment system injects hydrazine and ammonia into the condensate/feedwater system downstream of the condensate polishing unit and/or at the deaerator storage tank outlet. The hydrazine chemically scavanges any oxygen not removed in the condenser/deaerator. The ammonia maintains the condensate in an acceptable alkaline range by increasing its $\mathrm{pH}$ as required.

The hydrazine is received and stored in 55 gallon drums and transferred by drum pump to the hydrazine storage tank. Two positive displacement metering pumps (one spare) inject the solution into the condensate/feedwater piping at a rate determined by a control signal.

Aqueous ammonia is received by truck and placed in a storage tank (included as part of the condensate polishing system). Two positive displacement metering pumps (one spare) transfer the ammonia directly from the bulk storage tank into the condensate/feedwater piping at a rate determined by a control signal. The ammonia is also used in the regeneration of the condensate polishing demineralizer.

\section{Neutralization System}

The neutralization system is designed to receive and neutralize the waste water from a complete regeneration cycle of either a condensate polisher or a make-up demineralizer train. The system consists of two sumps, each able to contain up to 60,000 gallons of waste water, which is equivalent to the volume of waste from one condensate polisher regeneration. Consequently, when the waste in one sump is being neutralized, the other is available to collect waste. Additional equipment provided are an air grid mixer in each sump, two 100 percent capacity $1250 \mathrm{cfm}$ air blowers, and four $1000 \mathrm{gpm}$ acid/caustic resistant vertical sump pumps. Two of these pumps are provided per sump so that one pump per sump is considered to be a 100 percent spare. These pumps are used to recirculate the waste in the sump to enhance mixing and to transfer the neutralized waste to the waste water treatment equipment (refer to Account 255) for additional treatment and discharge.

The required acid and/or caustic for neutralization is supplied from the bulk storage tanks in the water treatment area. Positive displacement acid and caustic chemical pumps, identical to the pumps provided for regeneration of the resin of the make-up water treatment system, are provided for delivering chemicals to the neutralization system. Chemical addition is automatically controlled based on pH. Self-neutralization based on mixing of the spent acid and caustic regenerants is utilized to the maximum possible extent.

\section{ACCOUNT 236 Turbine Plant Instrumentation and Control}

The turbine plant instrumentation and control system provides monitoring and protection for plant, personnel and equipment. It enables the operator to start up, operate and shut down the turbine plant in conjunction with the reactor plant. 
Turbine Plant Control Board Interface

The turbine plant is controlled from the main control board described under Account 227. Turbine and auxiliary process systems and components which are monitored and controlled from the main control board are tabulated below:

Feedwater System

Heater Vents and Drains

Main Steam System

Turbine

Extraction Steam System
Condensate System

Circulating Water system

Service Water System

Turbine Supervisory and Control System Instrument and Service Air System

\section{Turbine Supervisory Instrumentation}

The turbine supervisory instrumentation system continuously monitors turbine speed, control valve position, vibration, eccentricity, expansion and temperature. Recorders provided with the turbine include: vibration, eccentricity, expansion, turbine metal temperatures, and bearing metal temperatures.

\section{Electro-Hydrau1ic Contro1 Cabinet}

The electro-hydratilic control cabinet contains the control and indicating equipment required for the start-up, normal operation and testing of the turbine. These cabinets are furnished with the turbine-generator unit.

Typical control functions provided are:

Selection of starting rates: slow, medium or fast

Setting of turbine speed at start-up

Setting of load limit, and loading rate limit

Chest/she11 warming

Turbine trip

Selection of operating mode: standby, manual or remote

Selection of load: increase or decrease

Typical indicating functions provided are:

Turbine speed

Percentage of warming rate

Throttle steam pressure, first stage pressure, intermediate pressure

Generator output, MWe

Acceleration, $\mathrm{r} / \mathrm{min} / \mathrm{min}$

Valve positions for main stop valves, control valves and intermediate valves.

Typical testing functions are provided for:

Thrust bearing wear detector

Backup overspeed trip 
Electrical trip

Mechanical overspeed and piston trip

Main stop valves, control valves and intermediate valves.

\section{Automatic Turbine Tester}

The automatic turbine tester provides on-line automatic, sequential functional testing of turbine stop and control valves, remote trip of solenoids and mechanical protective devices. Improper functioning of the devices or systems tested is indicated on the automatic turbine tester control panel in the control room. The control panel is provided with the turbine.

Turbine Stress Evaluator

The turbine stress evaluator continuously monitors temperatures and differential temperatures in designated turbine components and automatically computes and provides operating limits through the electro-hydraulic control system for safe speed and load operation from the standpoint of thermal stress.

\section{Turbine Accessory Panels}

Turbine accessory panels contain the instrumentation and control devices for various turbine auxiliary systems. These panels are field mounted or control room mounted. Control panels located in the field are furnished for such typical auxiliary systems as generator hydrogen and cooling water control, turning gear motor control, excitation control and reheater protection piping control. These panels are furnished with the main turbine-generator unit.

Instrument Racks

These racks are similar in construction to those described previously under the same heading in the reactor plant instrumentation and control section under Account 227.

\section{Process Computer Systems}

The computer systems for the turbine plant are the same computer systems used for the reactor plant. Refer to the reactor plant instrumentation and control section under Account 227.

Turbine Plant Instrument Tubing and Fittings

The material requirements of the turbine plant instrument tubing and fittings are similar to those for the reactor plant, as described in the reactor plant instrumentation and control section under Account 227. 
Electrical key parameters related to the electrical plant are given in Items 38 through 47 of Table 4-1. The table supplements and amplifies the following discussion of Account 24.

The electric plant equipment conveys the electric power generated in the plant to the low voltage bushings of the generator step-up transformers (GSU), controls and meters the electric energy, and protects the components through which the power flows. It also conveys electric power from the electric generator, the off-site power system, or the emergency generators to the plant auxiliaries and the plant control, protection and surveillance systems during normal operation, and to the plant protection system and engineered safety features during normal operation, abnormal conditions, and accident conditions.

Continuous ratings of equipment serving plant auxiliaries and systems, as well as interrupting ratings of their protective and disconnecting devices, are based on equipment load tabulations, fault studies and voltage regulation studies. Equipment continuous current ratings are based on the maximum continuous load plus the largest spare auxiliary, and the effects of diversity. Short time intermittent loads are not included.

The electric plant design features are as follows:

a. The plant auxiliary distribution system design is based on a source voltage variation of plus or minus ten percent.

b. The main generator, the two half-size, three phase generator step-up transformers (GSU) and the two three phase unit auxiliary transformers (UAT) are interconnected with isolated phase bus.

c. The generator is provided with a load break switch in the mains between the generator and the UAT tap to disconnect the generator from the off-site power system.

d. Two three-winding unit auxiliary transformers (UAT), each $25 \mathrm{kV}$ to $13.8-4.16 \mathrm{kV}$, are connected to the generator main leads between the generator load break switch and the GSU.

e. Two three-winding reserve auxiliary transformers (RAT), each $230 \mathrm{kV}$ to $13.8-4.16 \mathrm{kV}$, are connected to an off-site transmission system.

$\mathrm{f}$. The Non-Class $1 \mathrm{E}$ medium voltage ac distribution system is nominally $13.8 \mathrm{kV}$ and $4.16 \mathrm{kV}$. Eight $13.8 \mathrm{kV}$ balance-ofplant (BOP) buses and four $4.16 \mathrm{kV}$ BOP buses are provided. The $13.8 \mathrm{kV}$ buses are fed from the " $\mathrm{X}$ " windings and the $4.16 \mathrm{kV}$ buses are fed from the " $\mathrm{Y}$ " windings of the UAT's and RAT's. 
g. The Class $1 \mathrm{E}$ medium voltage ac distribution system is a nominal $4.16 \mathrm{kV}$. Two separate and independent Class $\mathrm{lE}$ buses are provided. Each Class $\mathrm{IE}$ bus is fed from the " $Y$ " windings of the UAT's and RAT's through a tap in the $4.16 \mathrm{kV}$ buses.

h. The low voltage ac distribution systems are a nominal 480 volts. Twenty-five load center transformer/distribution buses are provided for the BOP systems and eight buses are provided for the Class $1 \mathrm{E}$ systems. The low voltage ac distribution system is divided into two separate and independent groups of buses.

i. Four separate and independent Class 1E, 208/120 volt nominal, three-phase, four-wire uninterruptible ac instrumentation and control power supplies and distribution buses fed from the Class $1 \mathrm{E} 480$ volt buses are provided.

j. Five separate and independent Non-Class $1 \mathrm{E}, 208 / 120$ volt nominal, three-phase, four-wire uninterruptible ac power supplies and distribution buses fed from the BOP 480 volt buses are provided. They supply power to BOP instrumentation and control and standby lighting panels.

k. The Class $1 \mathrm{E}$ dc distribution and supply systems are nominally 125 volts. Four separate and independent station batteries and distribution buses are provided.

1. The Non-Class $1 \mathrm{E}$ dc distribution and supply system is nominally $125 / 250$ volts ungrounded. One 250 volt and four 125 volt batteries and distribution buses are provided.

m. Two Class 1E 125 volt battery chargers are provided for each Class $1 \mathrm{E}$ battery. Two Non-Class $1 \mathrm{E} 125$ volt battery chargers are provided for each of the four 125 volt NonClass $1 \mathrm{E}$ batteries. Two Non-Class lE 250 volt battery chargers are provided for the 250 volt Non-Class $1 \mathrm{E}$ battery.

n. Two redundant Class $1 \mathrm{E}, 100$ percent, $4.16 \mathrm{kV}, 3000 \mathrm{kWe}$ gas turbine-generator units are provided as the standby power supply for the Class IE buses, and are automatically connected to their respective buses when the normal and preferred power supplies are not available.

o. One Non-Class $1 \mathrm{E}, 480 \mathrm{~V}, 1500 \mathrm{kWe}$ gas turbine-generator unit is provided as the emergency power supply for certain BOP buses, and are automatically connected to these buses when the normal and reserve power supplies are not avai1able. 
Motor starting voltage and frequency and allowable operational variations, at which the required starting and operating torques are developed, are as follows:

a. Continuous operation of ac motors

1) Voltage: \pm 10 percent of rated

2) Frequency: $\mp 5$ percent of rated

b. Starting and short time (approximately 30 seconds) operation of ac motors:

1) Class 1E (Voltage): 75 percent of rated

2) Non-C1ass 1E (Voltage): 80 percent of rated

c. dc Motors (Voltage): 210 to 280 volts

All Class lE loads (those loads essential to prevent significant release of radioactivity to the environment) are furnished with ac or dc power from one of the following: the Class $1 \mathrm{E}$ ac buses, the Class $1 \mathrm{E}$ uninterruptible instrumentation and control ac power supplies or the Class $1 \mathrm{E}$ dc buses.

The normal power supply for the plant electric auxiliaries is from the main generator through the unit auxiliary transformers. The preferred emergency power supply is from the $230 \mathrm{kV}$ off-site power supply via the reserve auxiliary transformers. The alternate access power supply is from the $500 \mathrm{kV}$ off-site power supply via the generator step-up transformers and the unit auxiliary transformers, when the generator load break switch is open. The standby power supply is from the two Class $1 \mathrm{E}$ gas turbine-generator units to the corresponding Class $1 \mathrm{E}$ medium voltage ac buses.

The power and control circuits, including circuit breakers and cabling, to all Class lE loads are qualified, channeled and separated to meet Class lE requirements. Protective devices are coordinated on the basis that protection of the Class $1 \mathrm{E}$ systems is the primary goal.

Table 4-2 (refer to page 4-72) presents allowable ranges of temperature and limits for exposure to radiation for electric equipment. Design ambient conditions for spaces housing electric equipment are based on these ranges and limits plus margin.

Physical and electrical separation of equipment and systems is provided to assure the availability of the minimum required equipment during any design basis event. Physical separation of equipment and circuits is done in such a way that the single failure and fire protection criteria are met and that the independence achieved cannot be compromised by adjacent or supporting mechanical and structural systems.

The paragraphs given below provide brief technical descriptions that provide guidance to the more detailed descriptions that follow: 


\section{LSPB ACCOUNT 24}

Account 241 Switchgear (generator load break switch and station service switchgear)

Account 242 Station Service Equipment (station service and start-up transformers, unit substations and auxiliary power sources)

Account 243 Switchboards (control boards and panels and auxiliary power and signal boards)

Account 244 Protective Equipment (general station grounding, lightning protection, cathodic protection, and heat tracing and freeze protection systems)

Account 245 Electric Structures and Wiring Containers (underground duct runs and conduit and cable tray raceways)

Account 246 Power and Control Wiring (main generator bus duct, power wiring, control cable and instrument wire, and containment penetrations) 
TABLE 4-2

\section{ENERGY ECONOMIC DATA BASE}

PHASE VIII UPDATE (1986)

1311 MWe LARGE SCALE PROTOTYPE BREEDER NUCLEAR POWER GENERATING STATION (LSPB) DESIGN AMBIENT CONDITIONS FOR ELECTRIC EQUIPMENT

\begin{tabular}{|c|c|c|c|c|c|c|}
\hline & & & $\begin{array}{r}\text { Amb } \\
\text { Tempe } \\
\text { Li } \\
\left(^{\circ}\right.\end{array}$ & $\begin{array}{l}\text { ient } \\
\text { rature } \\
\text { mit } \\
\text { F) }\end{array}$ & $\begin{array}{r}\mathrm{Aml} \\
\mathrm{Rad} \\
\mathrm{L} \\
(\mathrm{l}\end{array}$ & \\
\hline $\begin{array}{l}\text { Type } \\
\text { Equi }\end{array}$ & of & Limit & Equi pment & $\begin{array}{c}\begin{array}{c}\text { Equi pment } \\
\text { Space }\end{array} \\
\end{array}$ & Equipment & $\begin{array}{c}\text { Equi pment } \\
\text { Space }\end{array}$ \\
\hline & & Maximum & 90 & N/A & $\mathrm{N} / \mathrm{A}$ & $\mathrm{N} / \mathrm{A}$ \\
\hline & & Minimum & 77 & 80 & N/A & N/A \\
\hline & & Maximum & 104 & 100 & $1 \times 10^{8}$ & $1 \times 10^{7}$ \\
\hline & & Minimum & $\mathrm{N} / \mathrm{A}$ & N/A & $\mathrm{N} / \mathrm{A}$ & N/A \\
\hline & & Maximum & 104 & 100 & $\mathrm{~N} / \mathrm{A}$ & N/A \\
\hline & & Minimum & $40 *$ & $50 *$ & $\mathrm{~N} / \mathrm{A}$ & N/A \\
\hline $\begin{array}{l}* \\
* *\end{array}$ & $\begin{array}{l}\text { Or abo } \\
\text { Sensit } \\
\text { contro } \\
\text { electr } \\
\text { as app }\end{array}$ & $\begin{array}{l}\text { wpoint ten } \\
\text { elays and } \\
\text { environmer } \\
\text { equipment } \\
\text { le. }\end{array}$ & $\begin{array}{l}\text { erature, wh } \\
\text { ther electr } \\
\text { spaces sucl } \\
\text { oom, comput }\end{array}$ & $\begin{array}{l}\text { ichever is } \\
\text { ical devic } \\
\text { h as the c } \\
\text { er room, o }\end{array}$ & $\begin{array}{l}\text { higher } \\
\text { s are placed } \\
\text { ntrol room, } \\
\text { battery roc }\end{array}$ & \\
\hline
\end{tabular}


ACCOUNT 241 Switchgear

Generator Load Break Switch

A load break switch is provided in the main generator isolated phase bus to disconnect the generator rapidly from the off-site system when no fault is present. This allows quick connection to the alternate access power supply (GSU and UAT). The switch comprises three single-pole, water cooled, gangoperated, load break switches with a spare single pole and an independent cooling system. The cooling system has redundant active components.

\section{Station Service Switchgear}

The medium voltage metal-clad switchgear includes Non-Class $1 \mathrm{E} 13.8 \mathrm{kV}$ buses, Non-Class 1E $4.16 \mathrm{kV}$ buses and Class $1 \mathrm{E} 4.16 \mathrm{kV}$ buses. These buses are divided into two load groups or trains. Each train is supplied by an independent secondary winding of a three winding UAT or a three winding RAT. Motors rated $2500 \mathrm{hp}$ and above are rated $13.2 \mathrm{kV}$ and motors rated $250 \mathrm{hp}$ to $2250 \mathrm{hp}$ are rated $4.0 \mathrm{kV}$.

Transfer schemes are provided for automatically and manually transferring each train between the preferred emergency power supply and the normal power supply. Load shedding schedules are provided for automatically stripping all Class $1 \mathrm{E}$ buses whenever there is an off-site power failure. Sequential loading schemes are provided for the Class $1 \mathrm{E}$ buses to automatically connect selected engineered safety features to those buses after load shedding, and to re-energize the buses from the gas turbine-generator units.

Overcurrent and differential protection are provided for each incoming feeder circuit. Overcurrent protection is provided for all feeder circuits. Differential protection, overload protection and zero sequence overcurrent ground protection are provided for all medium voltage motor circuits.

Non-Class $1 E$ and Class $1 E 480$ volt motor control centers are provided for power distribution to motors $100 \mathrm{hp}$ and below, lighting loads and miscellaneous loads such as motor-operated valves, resistance heaters, heat tracing and motor space heaters. These motors are rated at 460 volts. Overcurrent protection is provided for all incoming and feeder circuits. Overload protection is provided for all motor circuits.

\section{ACCOUNT 242 Station Service Equipment}

\section{Station Service and Start-up Transformers}

Two half-size unit auxiliary transformers (UAT) and two half-size reserve auxiliary transformers (RAT) are provided to furnish power to the plant auxiliary power system. Each pair of transformers is sized with sufficient margin to carry the plant auxiliary load under the heaviest load conditions. Transformer impedances are based on limiting fault current availability to switchgear capability considering the required range for voltage regulation. 
Each transformer is protected with overcurrent and differential protection schemes and sudden internal overpressure devices.

Unit Substations

Unit substations are provided to transform the medium distribution voltages to the distribution voltage of 480 volts for Non-Class $\mathrm{lE}$ and Class lE low voltage loads. Motors rated $125 \mathrm{hp}$ through $200 \mathrm{hp}$ are connected to the unit substation buses. These motors are rated at 460 volts.

Unit substation transformer impedances are based on matching switchgear capability to fault current availability considering voltage regulation. overcurrent protection is provided for all feeder circuits. Overload protection is provided for all motor circuits.

\section{Auxiliary Power Sources}

The battery systems comprise the Non-Class $1 \mathrm{E}$ and $\mathrm{Class} 1 \mathrm{E}$ batteries and battery chargers. Each Class IE 125 volt dc bus is supplied from a Class $1 \mathrm{E}$ 125 volt battery and two Class $1 \mathrm{E} 125$ volt battery chargers. Each Non-Class $1 \mathrm{E} 125$ volt dC bus is supplied from a Non-Class $1 \mathrm{E} 125$ volt battery and two Non-Class $1 E 125$ volt battery chargers. The Non-Class $1 \mathrm{E} 250$ volt de bus is supplied from one Non-Class 1 E 250 volt battery and two Non-Class 1E 250 volt battery chargers. During normal operation, dc power is supplied from the battery chargers. During emergency operation, dc power is supplied from the batteries. During start-up and shut-down, dc power is supplied from whichever source is available.

Two redundant Class $1 \mathrm{E}$ gas turbine-generator sets are provided as the on-site source of emergency ac power to the Class $1 \mathrm{E} 4.16 \mathrm{kV}$ buses. Each gas turbinegenerator set is provided with a system of controls designed to manually or automatically start and load the unit. Stopping the sets can only be done manual1y. Each gas turbine-generator has a fuel oil day tank and two fuel oil transfer pumps which are capable of restoring the day tank to its normal level within 20 minutes upon receiving a low level signal. Each gas turbinegenerator set is physically and electrically independent and is capable of providing the minimum power with margin required to shut down and maintain the LSPB unit in a safe condition following a design basis accident. Rating, configuration and switching of the gas turbine-generator sets are designed to prevent their use for any purpose other than that of standby power supply in accordance with preferred practice. Each is capable of operating as a single independent power source during a design basis event and in parallel with the reserve, preferred and plant power supply during testing. Each set can be tested during LSPB operation and/or plant shut-down independently of its redundant unit.

A single Non-Class lE gas turbine-generator set is provided as the on-site source of emergency power to specific 480 volt ac loads which are not safety related, but if lost, could result in a significant danger to plant operating personnel or large economic loss. This gas turbine-generator set is started in the event of loss of off-site power. 
Four Class $1 \mathrm{E}$ and five Non-Class $\mathrm{IE}$ dual input solid state inverters are provided to serve as uninterruptible power sources for miscellaneous vital and non-vital ac and plant instrumentation loads. The Class $1 \mathrm{E}$ and NonClass lE inverters are supplied with power from their respective Class $\mathrm{IE}$ and Non-Class IE ac buses through regulating transformers or directly from their respective Class $1 E$ and Non-Class $1 \mathrm{E}$ station batteries.

ACCOUNT 243. Switchboards

Contro1 Boards

The electric plant is controlled from the main control board described under Account 227. Electric plant systems and components which are monitored and controlled from the main control board are tabulated below:

a. Main Generator

GSU Circuit Breaker

Generator Load Break Switch

Grid/Generator Synchronizing

Excitation (Watts/Vars)

Auxiliary Systems

b. Auxiliary Power Distribution System (Class $1 \mathrm{E}$ and NonC1ass 1E)

RAT Primary Switch

$13.8 \mathrm{kV}$ and $4.16 \mathrm{kV}$ Incoming Feeder Circuit Breakers

Batteries

Battery/dc switchgear Main C1rcuit Breakers

Gas Turbine-Generat or Units

Gas Turbine-Generator Units Remote/Manual Control

Gas Turbine-Generator Units Circuit Breakers

One electrical system relay panel lineup is provided in the main control room for protection and metering of the main generator, the generator step-up transformers and the unit and reserve auxiliary transformers. The main generator protection includes high speed differential, ground overcurrent, loss-of-field, negative sequence overcurrent, and distance relays. The generator step-up transformers and the unit auxiliary transformers are protected by individual and overall differential relays, as well as overcurrent relays. The reserve auxiliary transformer is also protected by differential relays.

Technical Support Center and Emergency Operations Facility System Control Pane1s

Separate operator interface units from the Plant Computer Systems under Account 227 are provided for on-site technical support and interfacing with the Emergency Operations Facility systems during emergencies. The Technical 
Support Center system control console provides monitoring, data acquisition and communications links with the main control room that are necessary for centralized management and control of an on-site emergency. The Emergency Operations Facility system control console provides essential communications and data links with regulatory, state and local agencies having support or decision making responsibilities relative to the off-site impact of on-site emergencies.

\section{Auxiliary Power and Signal Boards}

Four Class $1 E$ and five Non-Class $1 \mathrm{E}$ ac power distribution buses are provided to distribute ac power from the inverters to the 120 volt or $208 / 120$ volt uninterruptible loads. They are configured as one bus per inverter for both Class $1 \mathrm{E}$ and Non-Class $1 \mathrm{E}$ equipment. Overcurrent protection is provided for all circuits.

Four Class $1 \mathrm{E}$ and five Non-Class $1 \mathrm{E}$ dc power panels are provided to distribute dc power from the station batteries and their associated chargers. There is one panel per station battery/charger combination. Overcurrent protection is provided for all feeder circuits. A ground detection scheme is provided for each dc bus.

ACCOUNT 244 Protective Equipment

\section{General Station Grounding System}

The station grounding system provides the means for maintaining an effective ground at equipment and metal structures and for protecting personnel from dangerous potentials.

A complete grounding system is provided for equipment and raceways, consisting of jumpers from each cable tray and conduit to the ground grid, a bare copper wire run in and bonded to each cable tray, a ground bus mounted in each metal enclosure and connected to the ground grid, pigtails from equipment frames to the ground grid and a dedicated instrument grounding system.

A complete yard grounding system is provided as the plant grounding grid, consisting of building ground grids, unit ground grid and interconnections. Materials used include bare stranded copper conductors, copper clad steel ground rods, silicon-bronze connectors for above-ground connections and thermite process welds for below-grade connections.

\section{Lightning Protection System}

Underwriters laboratories approved lightning protection schemes are provided for all buildings and structures. 


\section{Cathodic Protection System}

Cathodic protection is provided to minimize galvanic corrosion of selected buried metal structures and pipes. A complete integrated system is provided, including transformers, rectifiers, sacrificial anodes, coke breeze anode beds, special wire and terminations.

\section{Heat Tracing and Freeze Protection System}

Electric heat tracing freeze protection is provided for gas turbine-generator unit fuel oil piping and selected water piping located outdoors and aboveground.

A complete system is provided consisting of heat tracing wire, thermal cement, insulation, thermostats, control and alarm panels and interconnecting power and control wire and raceways.

(Refer also to "Special Heating System" under Account 226.)

ACCOUNT 245 Electric Structures and Wiring Containers

\section{Underground Duct Runs}

The Class $1 \mathrm{E}$ and Non-Class $1 \mathrm{E}$ underground duct runs provide physical and environmental protection and physical separation for wire and cable routed between buildings. The duct runs' metallic and non-metallic ducts are encased in reinforced and non-reinforced concrete. Reinforced concrete manholes are provided at appropriate places in long duct runs to facilitate cable pulling. Class $1 E$ duct runs are designed to Seismic Category I requirements and consist of ducts of rigid steel conduit encased in reinforced concrete. Non-Class $1 \mathrm{E}$ duct runs passing under roadways or railroads are encased in reinforced concrete.

\section{Conduit and Cable Tray Raceways}

The Class $1 \mathrm{E}$ and Non-Class $1 \mathrm{E}$ conduit and cable trays provide mechanical protection and physical separation and support for wire and cable routed from point to point within structures. The bulk of the raceway capacity is provided by cable trays of various sizes. Raceways are routed in accordance with the same criteria as for cable routing described under Account 246. Fire stops are placed in cable trays wherever they penetrate floors or firewalls, and in other areas where their installation will reduce the hazard of fire propagation. Class $1 \mathrm{E}$ raceway supports are designed in accordance with Seismic Category I requirements.

Account 246 Power and Control Wiring

Main Generator Bus Duct

Isolated phase bus is provided to interconnect generator terminals, GSU 
low voltage terminals and UAT high voltage terminals. This bus is rated at $25 \mathrm{kV}, 45,000$ amperes and is forced-cooled. Tap buses to the UAT and to the potential transformers are self-cooled.

\section{Power Wiring, Control Cable and Instrument Wire}

The plant wire and cable consists of single and multi-conductor power cable; multi-conductor control cable; coaxial, triaxial, shielded twisted pair, multi-shielded twisted pair and shielded quadruplex instrument wire; and containment electrical penetrations. Materials for insulation systems are selected to provide optimum system performance in the areas of physical stability; tensile strength; flexibility; aging characteristics; resistance to abrasion, ozone (where required), water absorption, heat distortion, and solvent extraction; irradiation; self-extinguishing and non-propagating fire characteristics; and resistance to corona effects (where required).

Wire and cable routing is governed by the following:

a. Requirements for the power supply, control network and/or instrumentation signals

b. Requirements for loading

c. Requirements for physical separation of redundant circuits and circuits having different voltage and energy levels

d. Avoidance of high hazard areas (e.g., areas subject to high ambient temperatures, missiles, fires, and irradiation)

e. Protection from missiles, fire, and/or irradiation, when required

f. Single failure criterion and the effects of common cause failures

g. Simplicity of layout

h. Ease of insta1lation

i. Ease of access

Class $1 \mathrm{E}$ and Non-Class $1 \mathrm{E}$ power and control cable is sized in accordance with ICEA Publications P46-426 and P54-440 with allowance for overloads and undervoltage conditions. Medium voltage power cables are also sized for fault current flow for the interrupting time of the overcurrent protection. Fault current capability is also considered for low voltage power cables and control cables, where applicable. Instrumentation cable ratings are selected in accordance with the application. 


\section{Containment Penetrations}

Power, control and instrument wire leak-tight reactor containment penetration assemblies are provided to maintain containment integrity for wiring penetrations during normal and abnormal conditions. The penetrators provide double wiring seals combined with single containment aperture seals. Power penetrators are rated at $15 \mathrm{kV}, 5 \mathrm{kV}$ and 600 volts; control penetrators are rated at 600 volts; and instrument wire and fiber optics penetrators are rated in accordance with service requirements. All penetrators are designed to Seismic Category I requirements. 


\section{ACCOUNT 25 MISCELLANEOUS PLANT EQUIPMENT}

Miscellaneous plant equipment includes systems and components for maintenance, plant start-up, or general supply of plant equipment requirements. Included are the cranes and hoists; air, water and steam services; auxiliary boiler and associated equipment; plant fuel oil system; fire protection system; communications systems; and various on-site and off-site environmental monitoring systems.

Interconnecting piping systems are included with each system, as required. They comprise the piping, fittings, valves, steam traps, strainers, specia1ties, hangers and supports, insulation, and other components required for a complete system. The piping systems are generally designed as American Nuclear Society Non-Nuclear Safety. In some cases they may be designed as Safety Class 3, where they interface with Safety Class piping systems. Materials and wall thicknesses are chosen based on the service conditions and operational requirements of each system. The factors generally considered include: temperature, pressure, corrosion resistance, abrasion resistance, fluid purity requirements and cost. Carbon steel is used for steam, clean water, air, oil and other services without special requirements. Other materials used include: cement 1 ined carbon steel, coated and wrapped carbon steel for buried service, galvanized carbon steel and copper.

The following paragraphs outline the contents of the detailed descriptions.

Account 251 Transportation and Lifting Equipment (major cranes and other cranes and hoists)

Account 252 Air, Water and Steam Service Systems (compressed air systems, service water system, fire protection system, potable water system, auxiliary steam system, normal chilled water system and plant fuel oil storage tank)

Account 253 Communications Systems (local communications system, fire detection system and security system)

Account 254 Furnishings and Fixtures (instrument shop apparatus, off-site radiological monitoring system, meteorological monitoring system, water quality monitoring system, seismic monitoring system and other furnishings and fixtures)

Account 255 Waste Water Treatment Equipment 


\section{ACCOUNT 251 Transportation and Lifting Equipment}

\section{Major Cranes}

Four major cranes are provided within the plant. The reactor service building, reactor containment bullding, steam generator buildings and reactor auxiliary bulldings are all served by a traveling bridge crane in the confinement structure. This crane has a main hook capacity of 150 tons, an auxiliary hook capacity of 20 tons and a span of 188 feet. The confinement structure crane is qualified for Seismic Category I service.

The reactor service building has an additional traveling bridge crane with a main hoist capacity of 50 tons, an auxiliary hook capacity of ten tons, and a bridge span of 21 feet.

Within the turbine building, an overhead traveling bridge crane is used with a main hoist capacity of 200 tons and an auxiliary hook capacity of 25 tons. The bridge span is 134 feet and covers the main operating floor area.

The nuclear island maintenance building nuclear maintenance area is served by a traveling bridge crane having a main hoist capacity of 200 tons and a bridge span of 95 feet.

Other Cranes and Hoists

In addition to the above major cranes, a 20 ton circular monorall with spurs serves the reactor and containment building. There are also 11 other traveling bridge cranes and monorall hoists with capacities in the five to 30 ton range to serve varlous plant areas.

\section{ACCOUNT 252 Air, Water and Steam Service Systems}

\section{Compressed Air Systems}

The compressed air system is composed of two separate subsystems: the plant instrument air system, and the service air system.

The instrument air system provides clean, oil-free dry air for operation of instruments, controls, pneumatic valve operators and air locks in all areas of the plant except in the inerted cells. The system consists of three air compressor units, two refrigerant type air dryers, two dessicant type air dryers, prefilters and after-filters, and interconnecting piping and valves.

Each air compressor unit consists of an intake filter silencer, a two stage compressor rated to deliver 750 SCFM at 124.7 psig, an aftercooler and a receiver.

The service air system is supplied with air from the instrument air system through a connection on the header between the compressor units and the refrigerant type dryers. The service air system is a distribution system of 
piping and valves. The service air system provides compressed air throughout the plant for maintenance systems, unloading devices, tools, miscellaneous cleaning and inspection services. The system also delivers breathable air to required stations.

\section{$\underline{\text { Service Water System }}$}

The service water system supplies cooling water from the main condenser heat rejection system to:

- the turbine building closed cooling water heat exchanger (refer to Account 235);

- the normal chilled water mechanical refrigeration units condensers (refer to Account 252);

- the radioactive waste system evaporator condensers (refer to Account 224).

The system has three 50 percent capacity vertical wet pit pumps which are located in the circulating water pump house, automatic self-cleaning pump discharge strainers, two horizontal centrifugal normal chilled water refrigeration unit recirculation pumps, and interconnecting piping and valves.

Make-up water to the main condenser heat rejection system is discharged near the suction of these pumps to lower the service water average temperature. Service water returning to the cooling tower is combined with the returning (heated) circulating water to reduce the amount of piping required (refer to Account 262).

\section{Fire Protection System}

The fire protection system is designed to minimize the probability and effect of the occurrence of an in-plant fire by combining a fire detection system with a fire protection system. The fire detection system is described under Account 253. The fire protection system described in this account is composed of two subsystems: the normal (non-sodium) fire protection system; and the sodium fire protection system.

Normal Fire Protection System: The normal fire protection system utilizes water, carbon dioxide, halon and portable extinguishers to suppress fires in areas of the plant not containing sodium.

Water fire suppression systems are used in most areas of the plant. The water system consists of sprinklers, deluge and water sprays, wet and dry standpipes, and yard hydrants. The water supply consists of one electric motor driven fire pump, one diesel engine driven fire pump and one electric motor driven jockey pump, which can take water from either of two 300,000 gallon capactty storage tanks. The storage tanks, pumps, yard piping and hydrants are all Non-Seismic Category $I$. Electric immersion heaters are 
installed to provide freeze protection for the storage tanks. One Seismic Category I pump, taking its suction from two Seismic Category I storage tanks, provides water at design pressure and quantity to special service wet and dry standpipes located in buildings and areas of the plant containing systems, equipment and components essential for reactor safe shut-down.

Carbon dioxide systems provide automatic total flooding and manual application by $\mathrm{CO}_{2}$ hose reels in normally unoccupied areas of the plant containing gas turbine-generators, electrical cabling and electrical equipinent. These systems consist of low pressure, refrigerated, insulated storage units, piping, valves, other necessary components, and necessary instrumentation and controls. Automatic local application of $\mathrm{CO}_{2}$ is also provided for steam turbine-generator bearing protection, in addition to steam turbine-generator purging •

Halon 1301 systems provide automatic total flooding in areas of the plant containing electronic equipment and components where the protected areas or contiguous areas are normally occupied. These systems consist of pressurized storage cylinders, piping, valves, other necessary components, and instrumentation and controls. Automatic total flooding of Halon 1301 is also provided in plant record areas located in, adjacent to, and above areas containing systems, equipment, and components essential for reactor safe shut-down.

Sodium Fire Protection System: The sodium fire protection system is designed to suppress the effects of sodium fires resulting from sodium spills or leaks from liquid metal equipment located outside of the reactor containment building. The system is composed of both passive and inerted cell suppression means. Passive fire suppression systems include the employment of sodium catch pans and fire sippression decks.

A nitrogen inerting system is provided to maintain an oxygen and water deficient atmosphere in cells containing radioactive sodium. These cells are inerted with nitrogen in order to maintain the oxygen and water concentrations at less than two percent and $1,000 \mathrm{ppm}$, respectively.

The fuel transfer cell is inerted with argon to maintain oxygen and water below $100 \mathrm{ppm}$. This cell has more stringent requirements because radioactive sodium, adhering to spent fuel elements, will be exposed to the cell atmosphere during fuel handling operations.

The inert cell atmospheres are provided by the inert gas receiving and processing system (refer to Account 224) and are cooled by the recirculating gas cooling system (refer to Account 226).

\section{Potable Water System}

Potable water is required for drinking, sanitary, and washing purposes at the plant. This water is supplied by the local municipal water supply system and distributed throughout the plant by a potable water piping system. Included in this system are outlets at wash rooms, drinking fountains, safety showers and eye wash stations, and hose bibb stations. 


\section{Auxiliary Steam System}

Auxiliary steam is used for building heating, driving the steam generator feed pump turbine(s) during start up, and miscellaneous heating and freeze protection needs. When possible, this steam is supplied by extraction from the main cycle. Otherwise, it is supplied by the auxiliary boiler.

The auxiliary steam system is divided into a high pressure-temperature portion and a low pressure-temperature portion. The high pressure-temperature portion operates at $405 \mathrm{psig}$ and $450^{\circ} \mathrm{F}$. Steam is supplied to this portion by main steam extraction (through a pressure reducing valve and desuperheater) or from the auxiliary bofler. High pressure-temperature auxiliary steam is provided to the highest pressure feedwater heater during plant start-up for condensate and feedwater system flush and heating.

The low pressure-temperature portion of the auxiliary steam system operates at 155 to $160 \mathrm{psig}$ and $385^{\circ} \mathrm{F}$. Steam is supplied from the high pressuretemperature portion of the system through a pressure reducing valve and desuperheater, or from the extraction steam system through a pressure reducing valve and a desuperheater. All auxiliary steam users other than the highest pressure feedwater heater are supplied from the low pressure-temperature portion of this system.

A single oil-fired auxiliary boiler with supporting auxiliary systems is provided. The boiler is a shop assembled "package" type, designed for natural circulation operation. Normally, steam is used for atomizing the oil, but during start-up, compressed air or mechanical atomization may be used. The boiler is sized to provide 125,000 pounds per hour of saturated steam at 405 psig.

A single deaerator and two 100 percent capacity boiler feed pumps are provided. Fuel is No. 2 fuel oil from the plant fuel oil storage tank.

Hydrazine and ammonia are used to treat the auxiliary boiler feedwater, the same as for the main steam generator feedwater. A manually controlled blowdown is used to periodically remove any sediment which collects in the boller drums.

The auxiliary steam system is not safety related.

Norma1 Chilled Water System

The process chilled water system is designed to transfer heat from the cell inert gas system nitrogen/argon coolers to the plant service water system. The cell inert gas system is described under Account 226. In addition, chilled water is provided to the nuclear island HVAC and balance of plant HVAC systems and for intermittent process cooling in the nuclear island maintenance building.

The system is composed of three 50 percent chillers, pumps, compression tanks and air separators. The chillers produce chilled water which is circulated 
by the pumps to the cell inert nitrogen/argon coolers. The chillers are cooled by plant service water. A refrigerant pump-out and storage system is also provided for maintenance.

Plant Fuel Oil Storage Tank

The plant fuel oil storage tank is surrounded by a six feet high dike. The ground inside the dike is sealed with clay to prevent any spilled oil from contaminating ground water. This tank provides storage for fuel oil for the auxiliary boilers and diesel driven fire pumps and additional, but non-safety related, fuel oil storage for the gas turbine-generator units.

ACCOUNT 253 Communications Systems

Local Communications System

The plant communications system consists of a private automatic telephone system, a sound-powered telephone system, and an intercommunication and paging system. These systems are designed to provide in-plant, on-site and off-site communications for all conditions of operation. The following paragraphs provide a brief description of each system.

A complete touchtone automatic telephone system is provided consisting of automatic switching equipment, touchtone type handset stations located throughout the plant, connections to the commercial telephone system and interfaces with the inter-plant communications systems.

Portable sound-powered telephone handsets and jacks are located throughout the station. Interconnecting jack wiring is provided under Account 246.

An intra-plant public address/intercommunications system with party lines is provided, consisting of a control panel, amplifiers, handsets, loudspeakers and interconnecting wiring.

\section{Fire Detection System}

A fire detection system is provided for early warning of incipient or actual combustion. This system supplements and activates the fire protection system described under Account 252.

Flame or smoke detection devices are located in infrequently visited or hazardous areas such as the cable tunnels or fuel storage areas. Signal devices are installed in the fire protection system to indicate initiation of operation of systems or components, such as fire pumps or deluge systems. Manual fire alarm stations and audible alarm devices are strategically located throughout the plant.

A central station including a primary and a standby computer and supporting peripherals is provided. The central station's prime function is to collate and present to the operators the status of all fire, smoke, heat and gas 
detectors, the $\mathrm{CO}_{2}$ systems, and the Halon 1301 systems; the operating status of the water spray (deluge) systems, sprinkler systems and fire pumps; and the position status of the fire protection water control valves in the supply piping to the water-supplied extinguishing systems.

\section{Security System}

The security system is provided to control general access to the plant and to limit and control access to restricted or sensitive areas within the various buildings. The objective is to prevent industrial sabotage or theft of nuclear materials which could damage the plant or threaten the health and safety of the public. Specific consideration is given to potential threats posed by a determined violent external assault, attack by stealth or deceptive actions by several persons with or without inside assistance and to an internal threat by an insider, including an employee in any position.

Security measures include a perimeter physical security fence (seven feet high with barbed wire on "Y" outriggers) provided with intrusion detection devices, a 20 feet wide isolation zone on each side of the fence, lighting systems for effective night time surveillance, patrol roads, buildings designed to resist forced entry and fire bombing, an electronic card-key system for access control to certain sensitive and vital areas within the plant, a personnel access control station and an armed security force.

ACCOUNT 254 Furnishings and Fixtures

Instrument Shop Apparatus

Instrument shop apparatus are provided for testing, calibration, repairing, and routine maintenance of the plant instrumentation and control devices.

A typical list of instrument shop apparatus is provided below:

a. Dead weight tester

b. Pneumatic calibrator equipment

c. Decade resistance box

d. Digital volt meter

e. Variable voltage and current sources

f. Potentiometer

g. Oscilloscope

h. Electronic counter

i. Stop watch 
j. Resistance and impedance bridges

k. Megger

1. Pressure gauges

m. Meters: dc (mA, Amps, Volts), ac (Amps, Volts)

\section{Off-Site Radiological Monitoring System}

The off-site radiological monitoring system consists of both preoperational and post operational programs. It provides data for individual and population exposure calibrations, for analysis of the possible buildup of environmental radioactivity and for public information. The post operational program, in conjunction with the radiological data management system described under Account 227, provides data required for estimation of the population dose during normal operation and design level releases. A rapid monitoring program provides fast and accurate data on population exposure during accident conditions.

The preoperational program is a radiation survelllance program implemented prior to plant start-up. The program identifies critical exposure pathways, defines critical population groups, selects sample media and sampling site locations, collects and analyzes environmental samples and interprets data.

The post operational program provides the necessary radiological data to demonstrate compliance with technical specification and effluent limits. The program requires measurement of gross radioactivity, specific radionuclides and other pertinent data for semi-annual reports required by the Nuclear Regulatory Commission.

The rapid monitoring program is part of the emergency procedure plan. It provides the personnel, organization and equipment necessary to enact prompt counter-measures for protection of the public in cases of reactor accidents.

Meteorological Monitoring System

The meteorological monitoring system provides all equipment essential for the monitoring and recording of the atmospheric parameters of the plant prior to construction, during construction and over the operational life of the plant. The equipment for the system consists of a meteorological tower and various meteorological monitoring instruments. Data from this system are used to determine an initial radiological site signature prior to construction and for dose calculations performed by the radiological monitoring system.

Water Quality Monitoring System

The water quality monftoring system monitors the rates and concentrations of contaminant in the plant effluent discharge. Typical variables measured are radioactivity, chlorine, suspended solids, $\mathrm{pH}$, oil and grease. Sampling 
techniques are established to yield representative batches or flows of the effluent discharge. Analytical data are recorded in necessary form for immediate as well as future interpretation and use.

\section{Seismic Monitoring System}

The seismic monitoring system is provided for the following purposes:

a. Furnish to the control room information on the presence of any seismic event so that immediate administrative procedures or decisions can be made.

b. Provide basic data to determine the conservatism used in the modeling and design assumptions made for the structures, and the design input motion to the supported systems and components.

c. Provide information to determine the advisability of continuing the operation of the plant following an earthquake.

\section{Other Furnishings and Fixtures}

Among the other furnishings and fixtures provided for the plant are provisions for monitoring and recording the temperature of the plant thermal effluent, office and cafeteria equipment and furniture, chemical laboratory fixtures, machine shop equipment, change room lockers and benches and portable fire extinguishers located throughout the plant.

\section{ACCOUNT 255 Waste Water Treatment Equipment}

The waste water treatment system treats normal operating wastes from the plant and rainfall runoff from contaminated areas so that they will be suitable for discharge to the North River or for reuse. The system consists of two collection basins, a clarifier, two in-depth type pressure filters, various pumps, tanks, chemical feeds and mixers, and a belt-press type sludge dewatering machine.

Plant operational waste water and runoff from contaminated areas are collected and pumped to the two main collection basins, each of approximately 530,000 gallon capacity. Runoff from the transformer area and the fuel oil handling area is held in those areas until it is determined by observation or by analysis if the water is contaminated. Contaminated water is cleaned up locally, or is pumped to one of the two main basins. Oil is removed from the water held in the basins by means of a tube type skimmer.

The plant waste water is normally pumped from the basins to a clarifier by one of the three raw waste pumps at a rate of $250 \mathrm{gpm}$. Two pumps may be used during the processing of plant waste water and precipitation runoff at a combined rate of $450 \mathrm{gpm}$. The third pump is a spare. 
Lime injection and air oxidation equipment are provided upstream of the 24 feet diameter clarifier. The clarifier provides a minimum detention time of two hours at $450 \mathrm{gpm}$, which allows most of the suspended solids to settle. The settled solids are periodically removed by one of two $40 \mathrm{gpm}$ underflow pumps and stored in the underflow storage tank. It is then pumped to the twometer sludge dewatering belt press filter at a rate of up to $80 \mathrm{gpm}$.

Overflow from the clarifier is collected in a clearwell and pumped to the high rate pressure filters. Three high-rate, dual media filters are provided to remove suspended solids carried over from the clarifier. At the maximum flow rate of $450 \mathrm{gpm}$, all three filters will normally be in service. At the low flow rate of $250 \mathrm{gpm}$, only two filters are required at a time. Under this condition, the third filter can be kept in stand-by until an operating filter is to be backwashed, at which time the standby filter is put into service. Each filter is eight feet in diameter and contains a stratified sand and anthracite bed.

Capability is provided to add acid to the discharge from the filters to ensure that the waste water is within the acceptable $\mathrm{pH}$ range of six to nine before it is discharged. A backwash storage tank (which also serves as an effluent monitoring tank) provides storage capacity for backwash of all three filters ( 15,000 gallons). The waste water is monitored for total suspended solids, oil and grease, $\mathrm{pH}$ and other parameters as required. If any of these parameters do not meet the discharge permit requirements, the water will be pumped back to the waste holding basins by the backwash/effluent pumps . These pumps are also used to discharge the treated liquid wastes to the North River or to backwash the filters. The pumps are rated at $750 \mathrm{gpm}$ based upon the filter backwash requirements. 
Mechanical key parameters related to the heat rejection system are given in Items 32 and 33 of Table 4-1. Configuration of structures related to the heat rejection system are shown on the Plot Plan given in Figure 4.1. The table and figure supplement and amplify the following discussion of Account 26 .

The main condenser heat rejection system is a closed loop circulating water system. It consists of buildings, structures and mechanical equipment that serve the main condensers and service water system to reject the plant excess heat through two natural draft wet evaporative cooling towers. The circulating water is chlorinated to control biological fouling.

Make-up water from the North River initially passes through a bar rack to remove any large debris. It then passes through traveling water screens to protect the pumps. Automatic self-cleaning strainers following the pumps further remove suspended material. After straining, most of the make-up water is discharged to the cooling tower basin to replace water lost by evaporation and blowdown. Sulfuric acid is injected into the cooling tower make-up water as required to avoid scaling. The remaining make-up water is clarified and demineralized for use as steam cycle make-up.

Interconnecting piping systems are included with the auxiliary systems. They comprise the piping, fittings, valves, hangers and supports, and other components required for a complete system. The piping systems are designed as American Nuclear Society Non-Nuclear Safety. Materials and wall thicknesses are chosen based on the service conditions and operational requirements of each system. The factors generally considered include: temperature, pressure, corrosion resistance, abrasion resistance, fluid purity requirements and cost. Carbon steel is used for clean water and other services without special requirements. Other materials include: stainless steel, concrete, polyvinyl chloride (PVC) and fiberglass reinforced plastic (FRP). The circulating water pipes betwe n the condensers and the cooling towers are of reinforced concrete and carbon steel.

The paragraphs given below identify the subjects covered by the detailed descriptions that follow.

Account 261 Structures (make-up water intake structure, circulating water pump house and make-up water pretreatment building)

Account 262 Mechantcal Equipment (circulating water pumps, cooling towers and cooling tower basins, plant make-up water and blowdown equipment and make-up water pretreatment plant) 
ACCOUNT 261 Structures

Make-up Water Intake Structure

The make-up water intake structure is Non-Seismic Catgegory I and is located along the riverbank west of the main plant structures. It is approximately 38 feet wide, 36 feet long and 30 feet deep below plant grade with the top slab located at grade. The structure is reinforced concrete with the foundation mat bearing on rock. There are two intake chambers, each 10 feet wide (inside) and 36 feet long at the bottom. The reinforced concrete top slab over the two chambers supports the two make-up water pumps. A ten feet high masonry enclosure is supported above the top slab. Its roof is insulated metal deck covered with built-up roofing and supported on steel framing. A trash pit with truck access ramp is located north of the two intake chambers.

The two intakes are protected by bar racks, stop logs and traveling screens. The traveling screens are the fish collection type where any fish which become trapped on the screen are gently washed into a trough separate from the trash and returned to the river downstream of the intake. To minimize the number of fish which may become trapped on the screen, the approach velocity to the screens is kept below $0.5 \mathrm{feet} / \mathrm{sec}$ and the velocity through the screen is as low as possible.

A trash rake is provided to clean the bar rack. Debris from washing the screens and debris collected from the bar rack are discharged to a container in the trash pit. The container is perlodically emptied by an outside contractor. Water drains from the container onto the trash pit floor. A drain in the floor of the trash pit conducts water from the floor to one intake chamber, in front of the traveling screen.

\section{Circulating Water Pump House}

The circulating water pump house is a Non-Seismic Category I reinforced concrete structure connected to the two cooling tower basins by reinforced concrete flumes and supported on a three feet thick reinforced concrete foundation. The flume bottoms slope upward from the bottom of the pump bays to the bottoms of the cooling tower water basins. The circulating water pump basin foundation is supported on rock. The circulating water pump basin is approximately 50 feet wide, $90^{\circ}$ feet long, and 28 feet high from the top of the bottom slab to the operating floor. Attached to the west end of the circulating water pump basin is a service water pump basin, also founded on rock. This basin is 16 feet wide, 26 feet long, and 18 feet high from the top of the bottom slab to the operating floor.

The circulating water pump basin is divided into four pump bays, one for each pump. The service water basin is a single bay. Exterior walls, interior walls, base mat, operating floor slab and interior columns are reinforced concrete. Portions of the operating floor are grating. The concrete operating floor slab is supported on the walls dividing the circulating water pump basin into separate pump bays. The grating is supported on these same walls 
and on the interior columns. The circulating water pumps and service water pumps are supported from the reinforced concrete operating floor slab. All pump bays are provided with panel screens and stop logs.

A 20 feet square equipment room ten feet high is located on the solid portion of the operating floor slab. The equipment room is masonry construction with an insulated built-up roof on a metal deck supported by steel framing. The equipment room is cooled with propeller type fans. In the winter months, heating is provided by electric space heaters. The equipment room houses the circulating water system chlorination equipment, and local instrument racks.

\section{Make-up Water Pretreatment Building}

The make-up water pretreatment building is a. Non-Seismic Category I structure located west of the main plant structures and east of the intake structure. It is a two story steel framed structure 50 feet wide, 150 feet long and 30 feet high. The building volume is approximately 200,000 cubic feet. It is supported on reinforced concrete footings founded on rock. The reinforced concrete ground floor is located six feet below grade. The intermediate floor is cast-in-place concrete on metal deck supported on steel framing. The roof is concrete channel plank supported on steel framing and covered with a roofing membrane. The exterior walls are reinforced concrete to one foot above grade and insulated metal siding above that. The interior wa11s are concrete block.

The building has a heating and ventilating system which consists of roof ventilators for cooling and electric unit heaters for heating.

The building houses the strainers, clarifiers, chemical feeds, sludge dewatering equipment circulating water system sulfuric acid feed equipment, and other equipment required for a complete water pretreatment system.

ACCOUNT 262 Mechanical Equipment

\section{Circulating Water Pumps}

There are four 25 percent capacity mixed flow, vertical wet pit type circulating water pumps provided. Each pump is designed for a flow rate of 174,200 gpm with a total dynamic head of 90 feet. The combined capacity of 696,800 gpm includes:

$658,200 \mathrm{gpm}$ for condenser cooling

$2,100 \mathrm{gpm}$ for cooling the three condenser vacuum pumps

$660,300 \mathrm{gpm}$ @ $88^{\circ} \mathrm{F}$ (Total)

$3,300 \mathrm{gpm}$ for blowdown

5 percent design margin on each pump for wear and miscellaneous 
Each circulating water pump motor is rated at $5000 \mathrm{hp}$ and $360 \mathrm{r} / \mathrm{min}$. The pumps are located within a pump house well to which the water flows from the individual cooling tower basins by gravity. The pumps discharge the water through the main condensers, where heat is absorbed. The water then returns to the distribution system of the towers. Water flow is controlled by the number of pumps placed in service at a given time. Flow from each individual cooling tower is controlled by an overflow from the tower basin.

\section{Cooling Towers and Cooling Tower Basins}

There are two hyperbolic natural draft wet cooling towers each capable of cooling $355,653 \mathrm{gpm}$ of water from $110^{\circ} \mathrm{F}$ to $88^{\circ} \mathrm{F}$ when operating at a wet bulb temperature of $74^{\circ} \mathrm{F}$. The total design water flow is based on:

$663,206 \mathrm{gpm} \& 110^{\circ} \mathrm{F}$ from condenser and vacuum pump cooling $48,100 \mathrm{gpm}$ returning service water a $98^{\circ} \mathrm{F}(30,060 \mathrm{gpm}$ from the normal chilled water system chiller condensers)

The total nominal design capacity of the two cooling towers is $711,400 \mathrm{gpm}$ or $355,700 \mathrm{gpm}$ per tower.

The design wet bulb temperature of $74^{\circ} \mathrm{F}$ is the annual maximum at the Middletown site. By designing for circulating water temperatures of $88^{\circ} \mathrm{F}$ leaving the towers and $110^{\circ} \mathrm{F}$ returning, the maximum turbine exhaust pressure is established at $3.0 \mathrm{in}-\mathrm{HgA}$. It is estimated that the wet bulb temperature will be low enough to permit operation at or below turbine design exhaust pressure of 2.5 in-HgA 91 percent of the time. During the short periods of especially high wet bulb temperature (above approximately $60^{\circ} \mathrm{F}$ ), back pressure rises above 2.5 in-HgA to a maximaum of 3.0 in- HgA, with a corresponding increase of less than one percent in the heat rate.

Each cooling tower is a round reinforced concrete structure with film type f111 designed to expose maximum surface of the hot water to the air. Evaporation of a portion of the water is the primary cooling mode, although some sensible heat exchange also occurs. The cooled water is collected in a basin under the tower. Reinforced concrete flumes connect the two basins to the circulating and service water pump basins.

The hot water distribution system located inside the cooling tower above the fill distributes the water uniformly over the fill. The distribution system also permits increased flow to be directed to the perimeter to avoid icing in cold weather, and isolating a portion of the fill to avoid overcooling in cold weather.

Drift eliminators are chevron shaped slats located above the water distribution systems. They remove entrained liquid from the discharged air/vapor stream. Drift is limited to less than 0.01 percent of the water circulation rate. 
The air flow through the waterfill is induced by the density difference between the heated (less dense) air inside the hyperbolic shell and the cooler surrounding air.

Plant Make-up Water and Blowdown Equipment

Two 100 percent capacity vertical centrifugal pumps are installed at the intake structure to provide make-up water to the circulating water system (losses due to evaporation, drift, blowdown), steam cycle (losses due to blowdown, leaks, unrecovered auxiliary steam) and general plant use. The make-up water pumps discharge to the make-up pretreatment plant, where the water is strained and/or clarified as required.

Water from the North River approaching the pumps first passes through a bar rack with 3.5 inch openings to remove large material such as logs, and then through either of two traveling water screens having $3 / 8$ inch square openings. Approach velocity to the traveling water screens is 0.5 feet per second and velocity through the screen is one foot per second. The bar rack is cleaned by a motorized rake. Debris collected on the traveling water screens is flushed into a trough by a water spray from behind the screen, collected in a bin and periodically disposed of off-site. Any fish which become trapped on the screens are washed off separately from the debris and gently returned to the river downstream of the intake. Two 100 percent capacity screen wash pumps are provided for cleaning the screens of both fish and debris.

Blowdown is used to control the concentration of dissolved solids in the circulating water. An average blowdown rate of 0.5 percent of the circulating water flow has been established for this plant, resulting in a dissolved solids concentration approximately five times that of the make-up water.

Blowdown is removed from the circulating water system at the discharge of the circulating water pumps and discharged to the river. Discharge to the river requires no treatment, except that chlorination of the circulating water must be stopped shortly before and during blowdown. A single fiberglass-reinforced plastic outfall pipe angled up to prevent scouring of the bottom is provided downstream of the make-up water intake structure.

Make-up Water Pretreatment P1ant

Raw river water is fed from the make-up water pumps to the make-up water pretreatment plant. The purpose of this system is to precondition the raw river water which is used as make-up to the circulating water system, and the plant demineralizers. This equipment is located in the make-up water pretreatment building.

The primary objective of the system is to remove debris and suspended solids characteristically present in the river water. The amount of solids and debris contained in the raw influent is subject to wide fluctuation primarily due to seasonal changes and natural river environment. 
LSPB ACCOUNT 26

The water first passes through two automatic self-cleaning strainers to remove debris larger than $1 / 32$ of an inch. The major portion of the water, to be used as make-up for the circulating water system, is then discharged directly to the cooling tower basin. Chlorination is applied directly to the circulating water on an intermittent basis to minimize biological fouling within the condenser and throughout the piping system. The circulating water system chlorination equipment is located at the circulating water pump house. Sulfuric acid is added to the make-up water to the cooling tower as needed to neutralize excess alkalinity and minimize any tendency for scaling in the cooling tower. The sulfuric acid tank and feed equipment is located at the make-up pretreatment building.

The portion to be demineralized is further treated in a pretreatment system consisting of a single clarifier and three dual media pressure filters, a backwash water storage tank, chemical feeders, as well as pumps, valves, and piping.

The water that is directed to the pretreatment system is initially mixed with a coagulant chemical and is then plped to a clarifier. Should the clarifier be out of service, the influent water will bypass directly to the clearwell. The clarifier provides for a minimum detention time of two hours in order to permit a large percentage of the influent suspended solids to settle. The solids which settle within the clarifier are periodically removed by one of the two 100 percent capacity underflow pumps provided. The underflow solids are pumped to the station's liquid waste treatment system. Overflow from the clarifier is collected within a clearwell and then pumped by two of the three 50 percent capacity pumps to the dual media filters.

Three parallel dual media filters are provided. These filters are used to remove the small amount of suspended solids which are not removed within the clarifier. At the maximum system flow rate, all three filters will normally be in service. However, two filters are capable of treating the entire flow when one filter is removed from service for backwashing. Each filter contains $a$ bed of anthracite and a bed of sand.

While the majority of the discharge from these filters is directed to the demineralized water make-up system, a small portion of the filtered water is directed to a 20,000 gallon backwash water storage tank. This tank provides a clean supply of water that is required for periodic filter backwashes. Spent backwash water from the filters is piped to the liquid waste treatment system. 


\subsection{ENGINEERING DRAWINGS}

The engineering drawings included in this section amplify and supplement the system design descriptions given in Section 4.3. The titles of these drawings are as follows:

Figure

Number

Title of Drawing

$4 \cdot 1$

$4 \cdot 2$

$4 \cdot 4$

$4 \cdot 5$
Plot P1an - 1311 MWe LSPB NPGS Middletown Hypothetical Site

General Arrangement Plan at E1. 19'-0" (Ground F1.) 1311 MWe LSPB NPGS

Middletown Hypothetical Site

Genera1 Arrangement Plan at E1. 88'-9" (Oper. F1.)1311 MWe LSPB NPGS Middletown Hypothetical Site

General Arrangement Section "A-A" Elevation 1311 MWe LSPB NPGS Middletown Hypothetical Site

Steam Heat Balance Diagram 1311 MWe LSPB NPGS Middletown Hypothetical Site
Drawing Number

$7697.703-L R-01-R 1$

7697.802-LSPB-01

$7697.803-L S P B-02$

7697.803-LSPB-03

$7697.803-L S P B-04$ 


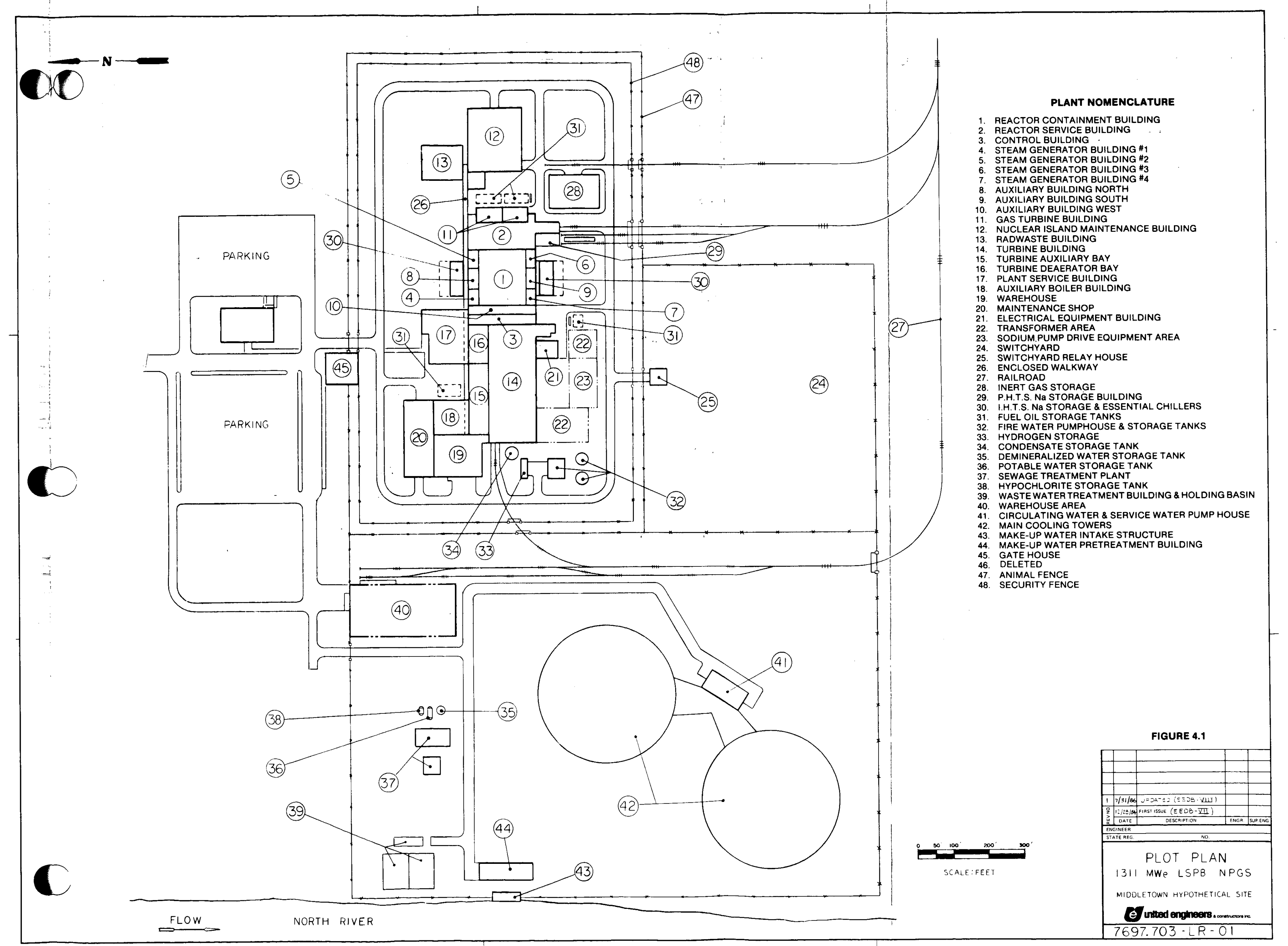




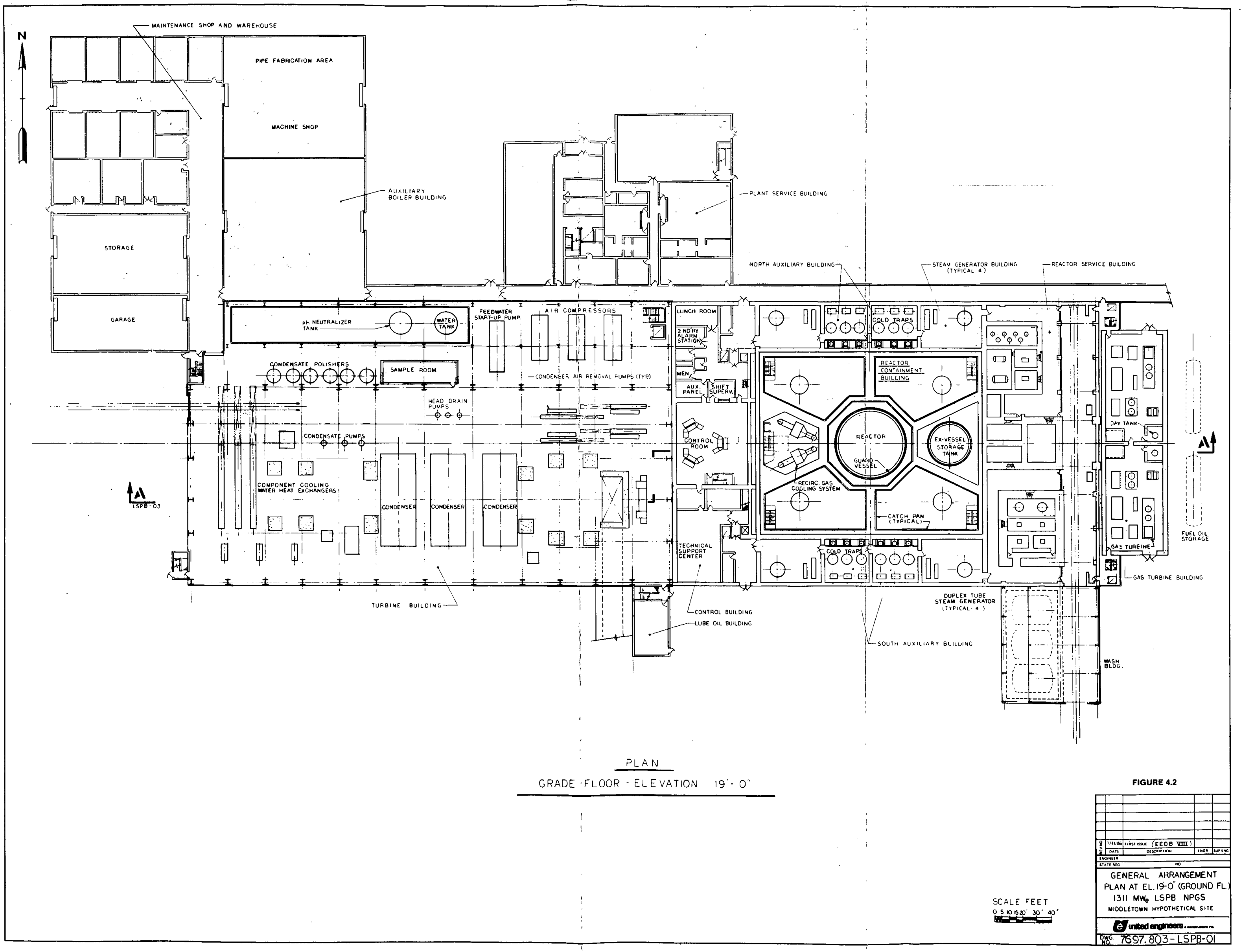




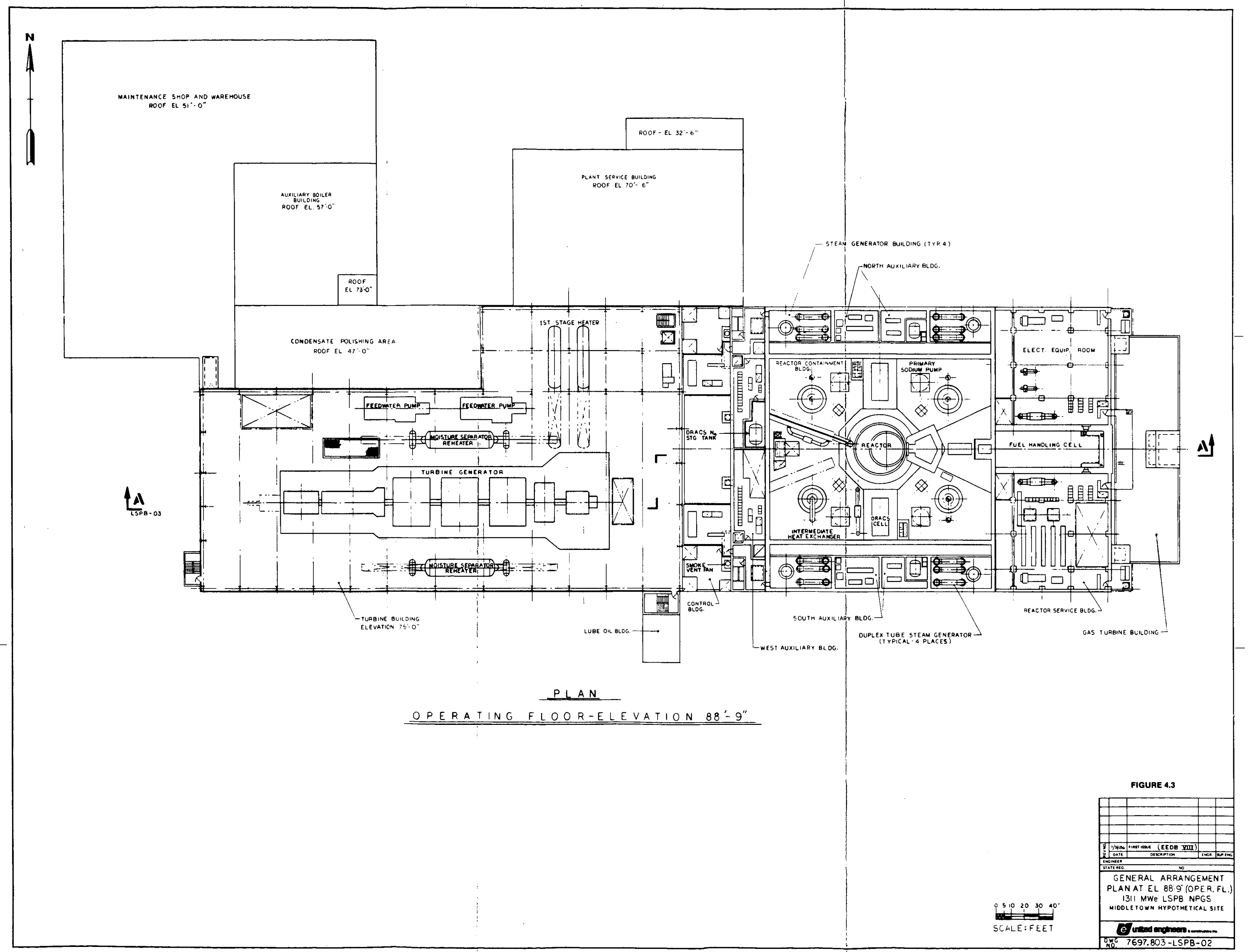




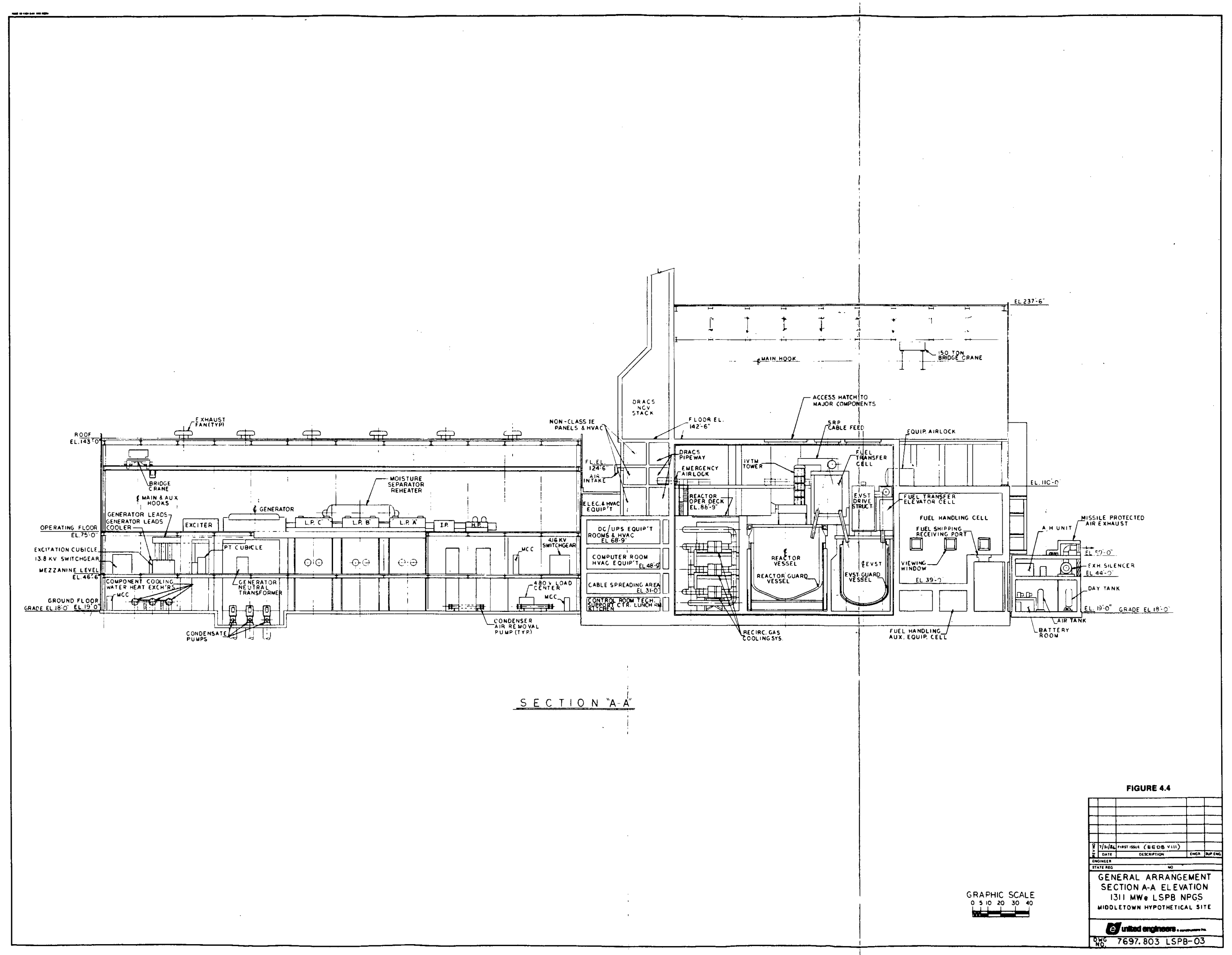




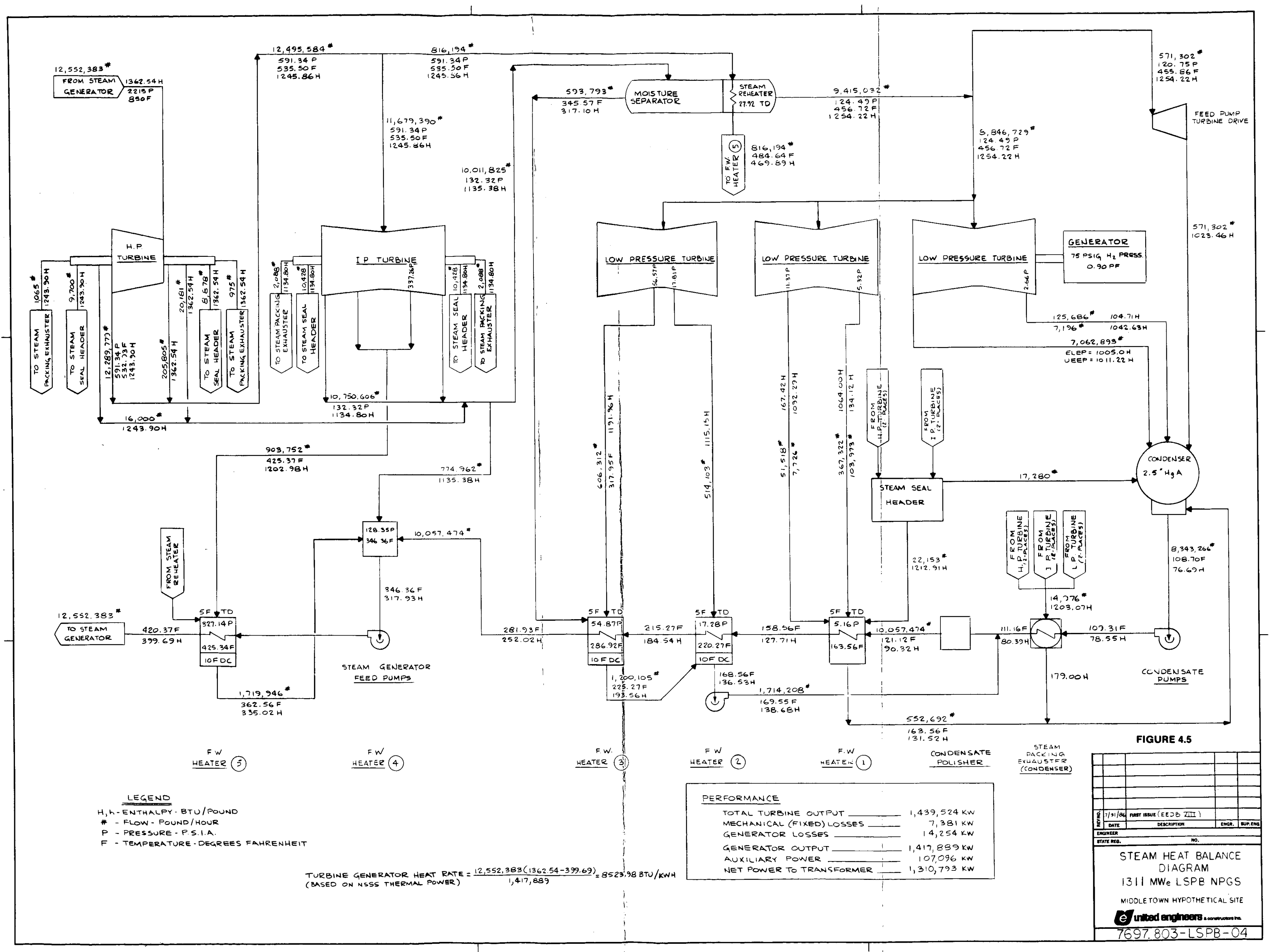




\subsection{DESIGN/CONSTRUCTION SCHEDULE}

The overall design/construction milestone schedule for the LSPB technical data model is divided into two logical phases:

- Pre-construction (Licensing) activities that culminate in the award of a construction permit.

- Engineering and Construction activities which culminate in the completion and commercial operation of the unit.

These milestone schedules are discussed below. The discussion and schedules are based on the assumption that the LSPB is a viable nth-of-a-kind nuclear power plant design which reflects best industry nuclear power plant construction experience. It is also assumed that the Nuclear Regulatory Commission has developed a set of regulations and review plans specific to liquid metal fast breeder reactor nuclear power plants.

\section{Preconstruction Licensing Activities}

The major licensing milestones that must be attained in order to begin construction activities on a nuclear power plant project are site selection and environmental and safety related regulatory requirements.

- Site Selection - Prior to U.S. Nuclear Regulatory Commission (NRC) involvement in the licensing process for a proposed nuclear unit, a utility makes an assessment of its need for power, where it is needed and the type of generation required. The utility then conducts a site selection program to determine the most cost-effective and licensable site. This effort typically requires nine months. Data gathered during site selection serves to justify the site and are later incorporated into support documents required by licensing regulations.

Site selection has recently become more complicated and time consuming because more than half of the states now require a utility to obtain state site certification and a favorable state Environmental Impact Statement for the proposed action. Acquisition time for site certification varies from state to state due to differences in regulatory requirements and stringency of review. Review periods have been known to consume from just a few months to several years. Preparation and review time for a State Environmental Impact Statement typically consumes 12 months, after all data have been submitted by the applicant to the cognizant state agency(s).

The LSPB technical data model is located at the EEDB Hypothetical Middletown Site. By definition, it is 
representative of a Northeastern, U.S. location. Taking the hypothetical location into account, it has been determined that the LSPB 1311 MWe plant would most probably be in a state having a site certification authority and requiring a state environmental review.

- Regulatory Licensing Requirements - The NRC is the dominant regulator in the commercial nuclear power plant licensing process. The NRC is mandated under the Atomic Energy Act of 1954, as amended, to protect the public in matters of private utilization of fissionable material. To this end it must:

a. assess the potential health and safety aspects of the facility and ensure that it poses no undue risk to the health and safety of the public, and

b. assess the potential environmental effects of the facility to ensure that its existence will be consistent with the national environmental goals, as set forth by the National Environmental Policy Act of 1969 , as amended.

In addition, several other Federal Agencies, principally the Environmental Protection Agency (EPA) and the Army Corps of Engineers, have statutory authorities to regulate various non-nuclear related aspects of commercial nuclear power plants. The NRC will only issue a permit or license with concurrence of all Federal, state and local regulatory agencies.

In order to obtain the needed information to perform these assessments, the NRC requires that each applicant submit certain documents for review. The NRC review process is shown on the flow diagram presented in Figure 4.6. The required documents are as follows:

- A Preliminary Safety Analysis Report (PSAR) - This report defines the nature of the proposed nuclear station and includes preliminary plans for its use in sufficient detail to show the bases upon which the applicant concludes that it can be sited, built and operated safely.

- An Environmental Report (ER) - This report analyzes the potential environmental impact of the proposed station and its associated facilities.

- A Final Safety Analysis Report (FSAR) - This report updates and completes the information provided in the PSAR. Its acceptance is required for a commercial operation permit.

The PSAR and ER documents are typically filed and accepted for review (docketed) by the NRC at the same time. In states having utility siting 
legislation, this milestone occurs approximately 24 months from the start of site selection and 12 months after receiving site certification. At the same time as the NRC docketing, a public notice of document availability is published in the Federal Register, and copies of the documents are furnished to cognizant state and local authorities. Copies are also placed in the NRC Public Document Room in Washington, D.C. and at a public facility near the proposed site. Notice of public hearings is published and an Atomic Safety and Licensing Board (ASLB) is appointed and convened to entertain and adjudicate petitions by interested parties.

The NRC then begins a series of reviews of the PSAR and ER. These reviews are based on criteria in the NRC's Standard Review Plan (SRP) for Liquid Metal Fast Breeder Reactors (refer to assumptions at the beginning of Section 4.5). When the NRC staff is satisfied that SRP criteria have been met, or that commitments have been made to meet them, it prepares a Safety Evaluation Report (SER) summarizing the results of the PSAR review. In addition, an Advisory Committee on Reactor Safeguards (ACRS) conducts an independent review on a less detailed level. At the same time, an environmental impact evaluation is performed on the applicant's Environmental Report. Based on this review, the NRC prepares an Environmental Impact Statement (EIS) which establishes the agency's environmental views on the project. Typically, the Federal EIS effort requires 18 months to complete. Initially, an EIS draft version is issued for public review and comment, with a final version following. During this same period, the NRC also conducts a site suitability analysis. Upon completion of these activities, public hearings are held, with the ASLB presiding.

Upon satisfactory responses to a11 outstanding safety and environmental issues, the NRC issues a construction permit (CP). The CP licensing process involves an approximate elapsed time of 48 months from the start of the project.

Under certain circumstances, the applicant may desire to begin site clearing activities prior to receiving the $C P$. This is possible via NRC's Limited Work Authorization (LWA) clause, which allows the applicant to begin nonsafety related activities on the site while a few issues remain open. Typically, a LWA is issued after the NRC has completed the final EIS and public hearings have been held, but prior to the award of a construction permit.

Figure 4.7 presents a preconstruction licensing schedule for the EEDB LSPB nuclear power plant technical data model.

The last major licensing hurdle for an applicant is the operating license. Generally, the utility must allow from 24 to 36 months between filing of an application and issuance of an operating license. This application is supported by a Final Safety Analysis Report (FSAR) and an operating 1icense stage environmental report. The FSAR reflects the as-built facility and forms the basis for the granting of an operating license. A review and public hearing process similar to that for the $\mathrm{CP}$ is then followed. 
The major unknown factor in the overall licensing schedule is the time consumed in public hearings and responses to public intervenors. This aspect of 1icensing alone has consumed from a few months to several years, and at times has caused the cancellation of a nuclear project.

\section{Engineering and Construction Activities}

Figure 4.8 presents an engineering and construction schedule for the EEDB LSPB technical data model at the Middletown site. It has been developed on the basis of the best past experience of the power industry in the construction of nuclear power generating units. It is also based on the assumptions that legislative regulatory reforms have been enacted by Congress and improvements in construction practices have been initiated by industry.

The engineering and construction milestone schedule presented in Figure 4.8 indicates an expected period of 81 months from the issuance of a Construction Permit (CP) to the start of fuel loading. The schedule assumes a single eight hour daily work shift and a 40 hour work week. These assumptions translate into an average craft labor force of approximately 1800 over the 81 month construction period, and a peak force of approximately 2700 to 3200 . This labor force is based on the total site craft labor hours developed in the EEDB Phase VIII Update (1986) for the best industry experience LSPB technical data model.

As discussed in Section 4.2, the EEDB LSPB technical data model is based on the EPRI/COMO LSPB design modified to meet EEDB ground rules. Likewise, the EEDB LSPB construction schedule is based on the CoMO LSPB construction schedule modified to meet EEDB ground rules. Differences in CoMO construction schedule bases and EEDB ground rules have led to the following major differences in overall schedule durations:

Activity

"Limited Work Authorization

(LWA)" to "Start Construction"

"Start Construction" to "End Construction"

"End Construction" to "Fuel Load"

"Fuel Load" to "0-100\% Range Tests"

TOTAL

\begin{tabular}{cr} 
Duration (months) \\
\hline EPRI/CoMO & EEDB \\
LSPB & $\underline{\text { LSPB }}$ \\
\hline
\end{tabular}

\begin{tabular}{lr}
3 & 6 \\
52.5 & 77 \\
11 & 4 \\
\hline 66.5 & 7 \\
\hline
\end{tabular}

The difference in duration of the pre-construction permit activities is caused by a difference in CoMO and EEDB, ground rules. The more significant difference in the combined durations of "LWA". to "Start Construction" plus "Start Construction" to "End Construction" is caused by two factors. First, EEDB utilizes a single shift, 40 hour work week for construction, while CoMO utilizes a "rolling 4-10" schedule arrangement (single shift, 70 hour work week arranged in consecutive sets of four ten hour workdays). 
According to the CoMO Constructability Report (part of reference 3) the "rolling 4-10" decreases the construction schedule (start of pre-construction activities to end of construction activities) to roughly 75 percent of what would accrue for the straight shift, 40 hour work week of the EEDB LSPB schedule. The second factor is related to differences in craft labor productivities utilized in the two schedules. Although the EEDB LSPB has similar quantities of commodities and equipment to those of the CoMO LSPB, the CoMO LSPB has approximately 25 percent lower direct craft manhours than the EEDB LSPB. The manhours per unit of commodity and equipment used in the EEDB LSPB, however, are consistent with those used for the other technical data models updated in the EEDB Phase VIII Update (1986). The lower total direct manhours for the COMO LSPB, relative to those for the EEDB LSPB, decrease the construction schedule to rough1y 90 percent of what would accrue for the EEDB LSPB direct craft labor level. When these two factors are applied to the EEDB LSPB construction schedule, the duration is reduced from 83 ("LWA" to "End Construction") months to approximately 55.5 months. Therefore, the CoMO LSPB and EEDB LSPB construction durations are generally compatible when these two differences in approach are taken into consideration.

The milestone schedule addresses, in a generalized form, the construction sequencing and interfacing of the principal structures and systems comprising the plant. Where appropriate, engineering and design, procurement, erection, and installation of equipment, components and piping are identified. In addition, the principal milestones of the project are identified and properly sequenced.

Figure 4.8 also identifies the critical activities which establish the overall project duration. The critical path is initiated at the site selection activity, moves through the licensing process leading to the the issuance of a construction permit, extends along the path for construction of the Nuclear Island Building Foundation/Reactor Building and installation of equipment, and continues through the various test and start-up activities to commercial operation. It should be noted that the critical path is contingent upon satisfactory completion of the NRC Licensing Review as shown on the schedule.

The engineering and construction activities for the other major structures (Steam Generator Buildings, Auxiliary Buildings, Control Building, Reactor Service Building, IHTS Na Storage and Essential Chillers, Turbine Building, Cooling Towers, and Switchyard) can be accommodated within the 81 month overa11 construction schedule, and thus do not establish the critical path.

In practice, however, circumstances can arise which cause normally non-critical activities to become critical, and extend the overall duration of the construction schedule. Late delivery of major equipment as a result of unavailability of raw materials, over-extended fabrication facilities, expiration of shop labor contracts, wildcat strikes or failure of equipment under test has caused extension of construction schedules. When such delays occur for items on the critical path, schedule delays occur because no float time is provided for these items. When such delays occur for items not on the critical path, overall construction schedule delays may be avoided only to the extent that float time is provided for them. 
FIGURE 4.6

ENEAGY ECONOMIC DATA BASE PHASE VIII UPDATE (1986) LSPB SUPPLEMENT

SINGLE UNIT 1311 MWe LARGE SCALE PROTOTYPE BAEEDER NUCLEAR POWER GENERATING STATION (LSPB)

PRECONSTRUCTION PERMIT LICENSING PROCESS FLOW DIAGRAM

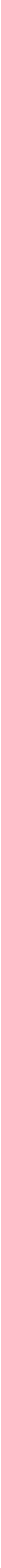


ENERGY ECONOMIC DATA BASE PHASE VIII UPDATE (1986)

SINGLE UNIT 1311 MWE LARGE SCALE PROTOTYPE BREEDER NUCLEAR POWER GENERATING STATION (LSPB)

LICENSING MILESTONE SCHEDULE

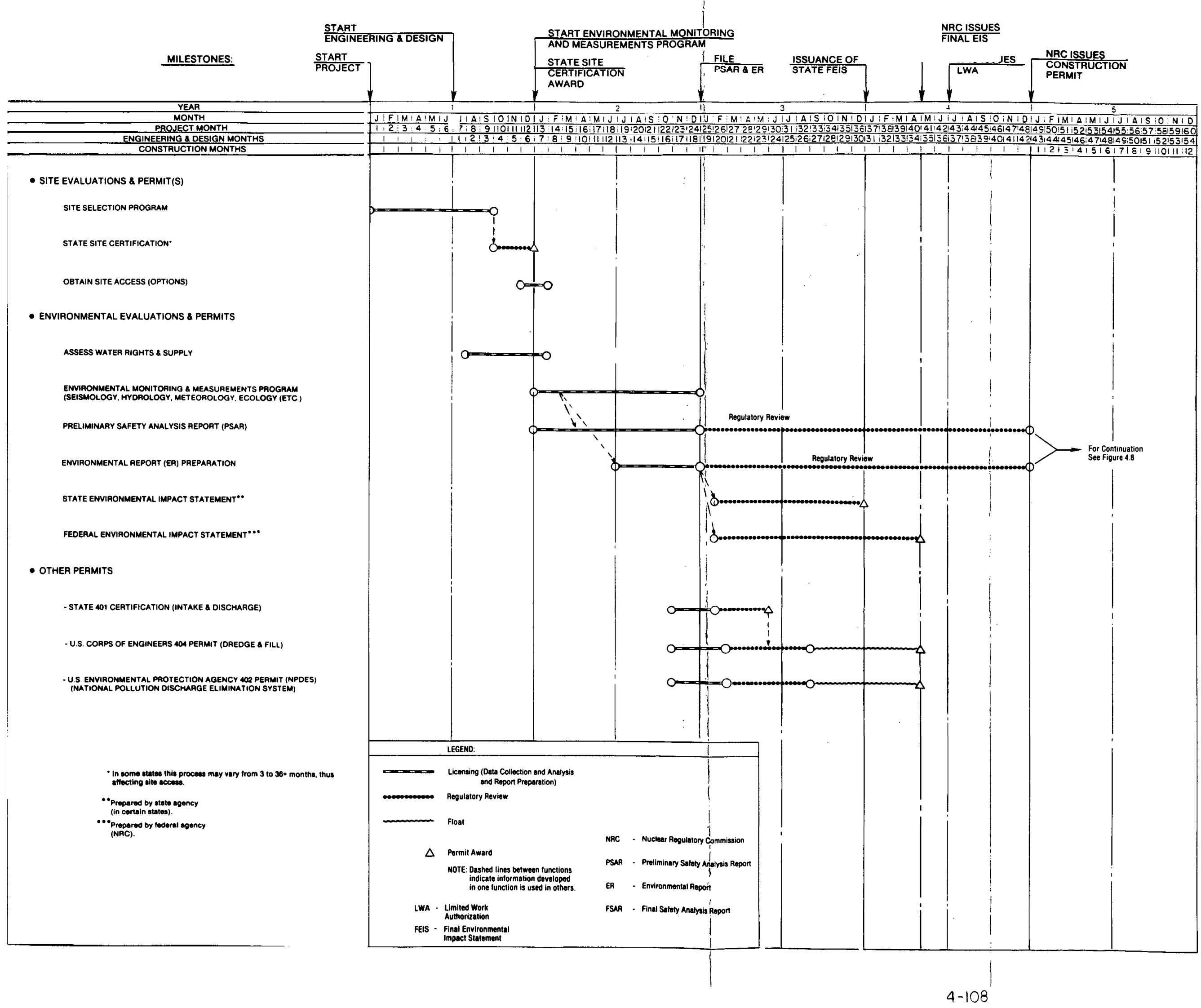


SUPPLEMENT TO FIGURE 4.7 EXPLANATION OF ITEMS ON THE LSPB LICENSING MILESTONE SCHEDULE

1. Site Selection Program - Selection of a power plant site utilizes a screening process whereby areas are eliminated that do not conform to predetermined primary standards (e.g., cooling water, seismic zones, meteorology) until prime and alternate sites are found.

2. State Site Certification - More than half the states have siting legislation which gives a state agency(s) authority over utility siting efforts. These states each have specific requirements and time frames for obtainment of site certification.

3. Obtain Site Access - Site access is obtained by buying land, taking out options or eminent domain. Early site access is preferred so that environmental data collection and evaluation can be initiated.

4. Assess Water Rights and Supply - Cooling of the plant's condensers is a prime consideration. Such being the case, the amount of water for consumptive use, the utility's rights to this water and its quality must be assessed.

5. Environmental Monitoring and Measurements Program - Detailed environmental monitoring and measurements programs are initiated by the utility in order to fulfill regulatory requirements. These entail studies in seismology, hydrology, meteorology, ecology and other disciplines.

6. Preliminary Safety Analysis Report (PSAR) - The PSAR defines the nature of the proposed nuclear station and includes plans for its use in sufficient detail to show the bases upon which the PSAR concludes it can be sited, built and operated safely.

7. Environmenta1 Report (ER) Preparation - The ER analyzes the potential environmental impact of the proposed station and associated facilities.

8. State Environmental Impact Statement (SEIS) - Certain states have enacted legislation which requires the preparation of a State Environmental Impact Statement in addition to one on the Federal level. The SEIS describes the environmental impacts associated with the project.

9. Federal Environmental Impact Statement (EIS) - The Federal EIS is mandated by the National Environmental Policy Act (NEPA) of 1969 for major Federal actions significantly affecting the environment. The draft EIS is prepared by a "lead" Federal agency and is typically based on the applicants Environmental Report. The draft EIS is followed by a final EIS after public and other agency comments are considered.

10. State 401 Certification (Intake and Discharge) - Section 401 of the Clean Water Act requires that, in order to obtain a Federal license or permit for an activity which may result in a discharge into navigable waters, the applicant must obtain a "certification" from the state in which the discharge originates. The discharge must comply with all 
SUPPLEMENT TO FIGURE 4.7

EXPLANATION OF ITEMS ON THE LSPB

LICENSING MILESTONE SCHEDULE

applicable Federal and State regulations. The certification is required as part of the Corps of Engineers 404 permit for dredge and fill operations in connection with intake and discharge structures.

11. U.S. Corps of Engineers 404 Permit (Dredge \& Fi11) - Section 404 of the Clean Water Act requires an applicant to obtain a permit for the discharge of dredge or fill material into navigable waters at specified disposal sites, as related to intake and discharge structures.

12. U.S. Environmental Protection Agency 402 Permit - National Pollution Discharge Elimination System (NPDES) - Under Section 402 of the Clean Water Act, the NPDES program, as administered by EPA, requires permits for the discharge of "pollutants" from any "point source" in the United States. The NPDES permit sets limitations on the concentrations of pollutants in the discharge and requires periodic monitoring efforts. A NPDES permit must be renewed every five years by the applicant. 


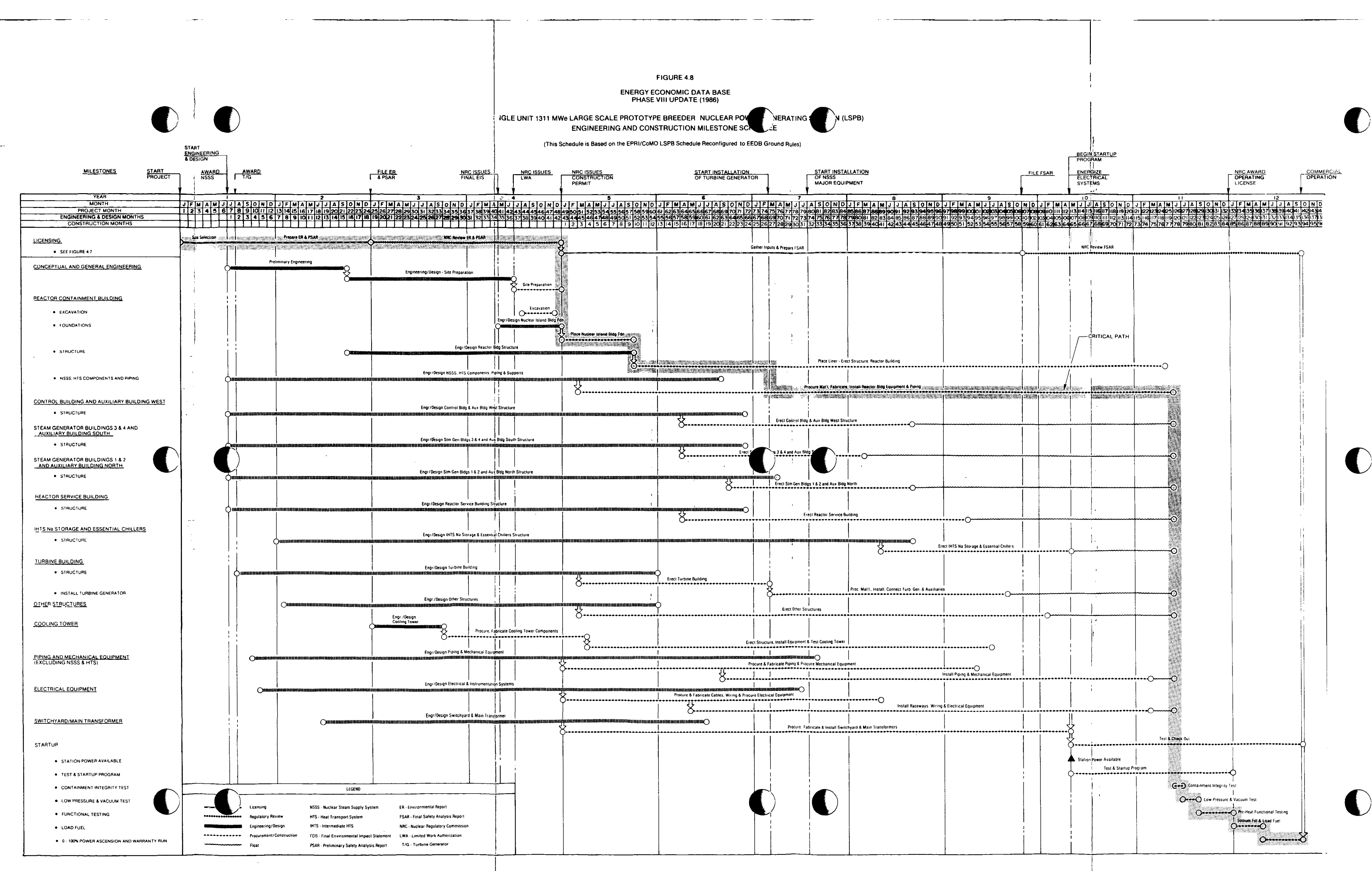


SUPPLEMENT TO FIGURE 4.8

DEFINITION OF ITEMS ON THE LSPB ENGINEERING AND CONSTRUCTION MILESTONE SCHEDULE

1. Conceptual and General Engineering

a. Preliminary Engineering - Project definition, conceptual design, definition of criteria, and field investigation to permit design of structures.

b. Engineering/Design - Site Preparation - Finalize foundation and structural design.

c. Prepare Site - Initiate excavation, set up temporary facilities.

2. Reactor Containment Building and Nuclear Island Building Foundation

a. Excavation and Foundations - Complete design of nuclear island building foundation, excavation, form, set reinforcing and pour concrete.

b. Structure - Complete engineering, design and erection of reactor building.

c. NSSS, HTS Components and Piping - Complete engineering, design and installation of Nuclear Steam Supply System components, Heat Transport System components and piping inside the Reactor Containment Building and other nuclear island buildings. Also, procure, fabricate and install building service components and piping.

3. Control Building and Auxiliary Building West

a. Structure - Engineering and design of the structure and systems, erect the buildings, and procure, fabricate and install building service components and piping.

4. Steam Generator Buildings 3 and 4 and Auxillary Building South

a. Structure - Engineering and design of the structure and systems, erect the buildings, and procure, fabricate and install building service components and piping.

5. Steam Generator Buildings 1 and 2 and Auxillary Building North

a. Structure - Engineering and design of the structure and systems, erect the buildings, and procure, fabricate and install building service components and piping. 
SUPPLEMENT TO FIGURE 4.8

DEFINITION OF ITEMS ON THE LSPB ENGINEERING AND

CONSTRUCTION MILESTONE SCHEDULE

6. Reactor Service Building

a. Structure - Engineering and design of the structure and systems, erect the buildings, and procure, fabricate and install building service components and piping.

7. IHTS Na Storage and Essential Chillers

a. Structure - Engineering and design of the structure and systems, erect the buildings, and procure, fabricate and install building service components and piping.

8. Turbine Building

a. Foundations/Structure - Engineering and design of foundations, excavate, form, set reinforcing and pour concrete. Engineering and design of the structure and systems, erect the building and procure, fabricate, and install building service components and piping.

b. Insta11 Turbine Generator - Erect $T-G$ on pedestal, install T-G auxiliaries and piping and tie-in turbine to main, extraction and auxiliary steam systems and condenser.

9. Other Structures - Engineering and design of foundations, excavate, form, set reinforcing and pour concrete. Engineering and design of the structure and systems, erect the buildings and procure, fabricate and install building service components and piping.

10. Cooling Tower - Engineering, design, procurement, fabrication and erection of cooling towers.

11. Piping and Mechanical Equipment (Excluding NSSS and HTS) - Engineering, design, procurement, fabrication and installation of piping and mechanical equipment for all systems excluding the NSSS and HTS.

12. Electrical Equipment - Engineering, design, procurement, fabrication and installation of power buses, electrical and instrumentation cables, panels, reactor control centers, distribution networks, batteries and battery systems.

13. Switchyard/Main Transformer - Engineering, design, procurement, fabrication and installation of station switchyard and main transformer. 
SUPPLEMENT TO FIGURE 4.8

DEFINITION OF ITEMS ON THE LSPB ENGINEERING AND

CONSTRUCTION MILESTONE SCHEDULE

\section{Startup}

a. Station Power Available - Energize Reserve Auxiliary

Transformer and station auxiliary power system.

b. Test \& Startup Program - Perform the necessary testing and inspection of system components and integrated systems to verify their operation as designed.

c. Containment Integrity Test - Perform testing and inspection to verify that the containment, penetrations and isolation system can perform as designed.

d. Low Pressure and Vacuum Test - Perform testing and inspection to verify that reactor vessel and HTS leakage rates are within allowable limits and to precondition the system with argon.

e. Functional Testing - Perform testing and inspection to verify that reactor, HTS, inert gas system and preheat system components perform as designed.

f. Sodium Fill and Load Fue1 - Fill vessel and HTS components with sodium, preheat to refueling temperature, put fuel into the vessel and seal the containment.

g. 0-100 Percent Power Ascension and Warranty Run - Conduct core physics testing to verify operation of the core as designed, increase power on a step by step basis and perform testing on the integrated HTS, Engineered Safeguard Features (ESF) and ancillary systems and conduct a 100-hour warranty run at rated power to verify reactor/turbine/generator performances. 


\section{SECTION 5}

\subsection{SYSTEM DESIGN DESCRIPTION FOR THE 488 MWe}

HIGH SULFUR COAL FOSSIL POWER GENERATING STATION

(EEDB PROGRAM TECHNICAL DATA MODEL C5 - HS5)

\subsection{INTRODUCTION}

Section 5 describes the design of the EEDB Program 488 MWe high sulfur coalfired power plant technical data model, as of the technical and regulation date of January 1, 1986.

In the 488 MWe high sulfur coal-fired power plant, the boiler feedwater is heated and boiled by the combustion of pulverized coal. Motor-driven fans supply the required air for the combustion process, which takes place at a pressure slightly below atmospheric in the balanced draft boiler. Before the gaseous combustion byproducts are discharged through a stack, the particulate ash and sulfur dioxide are reduced to acceptable levels by precipitators and wet lime scrubbers.

In the boiler, approximately $3.5 \times 10^{6} 1 \mathrm{~b} / \mathrm{hr}$ of steam is heated to its final superheated conditions, nominally $2515 \mathrm{psig}, 1000^{\circ} \mathrm{F}$. The superheated steam is fed to a high pressure steam turbine, returned to the boiler for reheating, fed to intermediate and low pressure turbines, condensed and returned to the boiler as feedwater.

Unit trains deliver the eastern, high sulfur, bituminous coal several times weekly. Coal is stored at the plant site in an above-ground pile. Ash and other waste products are temporarily stored in silos, tanks or shallow ponds, and disposed of off-site.

General key parameters are given for the HS5 in Table 5-1, Items 1 through 11 . Engineering drawings are presented in Figures 5.1 through 5.8 , which may be found in Section 5.4. A milestone licensing/design/construction schedule and discussion are given in Section 5.5 and Figures 5.9 through 5.13.

\subsection{DESIGN CRITERIA AND KEY PARAMETERS}

The plant technical design is based upon power industry experience and the following criteria:

a. A single drum, subcritical pressure, single reheat type steam generator is selected to supply steam to a tandemcompound four-flow turbine.

b. The steam generator is designed to burn a high sulfur eastern bituminous coal. 
TABLE 5-1

\section{ENERGY ECONOMIC DATA BASE}

PHASE VIII UPDATE

488 MWe HIGH SULFUR COAL FOSSIL POWER GENERATING STATION (HS5)

COMPARISON PLANT TECHNICAL DATA MODEL BASE PARAMETER SUMMARY

\section{GENERAL}
1. Site
Middletown, USA
2. Operation
Base Load
3. Technical Data Mode1 Reference Date
January 1, 1986
4. Plant Life (years)
30
5. Number of Units
Single
6. Rated Thermal Power (MWt)
1,377
7. Net Plant Heat Rate (Btu/kWh)
9,628
8. Net Plant Efficiency (\%)
35.44
9. Net Power to GSU(1) (MWe)
488
10. Water Table (Feet above mean river level)
11. 100 Year Maximum Water Level (Feet above mean river leve1)
10

\section{CIVIL/STRUCTURAL}

12. Boiler House

13. Turbine Building

14. Turbine Pedestal

15. Flooding Provisions

16. Seismic

17. Foundations

18. Grade Elevation (Feet above mean river leve1)
Enclosed

Enclosed

High Tuned

No Special Provisions

Uniform Building Code Zone 1

Spread Footings

18

(1) Generator Step-Up Transformer 
TABLE $5-1$

ENERGY ECONOMIC DATA BASE

PHASE VIII UPDATE

488 MWe HIGH SULFUR COAL FOSSIL POWER GENERATING STATION (HS5)

COMPARISON PLANT TECHNICAL DATA MODEL BASE PARAMETER SUMMARY

MECHANICAL

19. Steam Generator Type

Pulverized Coal Balanced

Draft Furnace

20. Steam Generator Outlet Conditions

a. Superheater Outlet at Maximum $\quad 3.97 / 2640 / 1010$ Continuous Rating (MCR) $\left(10^{6} \mathrm{lb} / \mathrm{h} / \mathrm{psig} /{ }^{\circ} \mathrm{F}\right)$

b. Superheater Outlet at Rated Load 3.5/2515/1010 $\left(10^{6} \mathrm{lb} / \mathrm{h} / \mathrm{psig} /{ }^{\circ} \mathrm{F}\right)$

c. Reheater Outlet at Rated Load 3.2/530/1005

21. Forced Draft Fan
a. Number
2
b. Drive
Motor
c. Capacity (acfm@ boiler MCR)
489,000

22. Induced Draft Fan
a. Number
2
b. Drive
Motor
c. Capacity (acfm @ boller MCR)
867,000

23. Fue1 Type

Eastern Coal
a. Moisture (\% by wt)
b. Ultimate Analysis (\% by dry wt)

11.3

$\begin{array}{lrll}\text { Carbon } & 69.34 & \text { Chlorine } & 0.04 \\ \text { Hydrogen } & 4.90 & \text { Sulfur } & 3.61 \\ \text { Nitrogen } & 0.86 & \text { Oxygen } & 9.65 \\ & & \\ 11.6 & \\ \text { As Received } 11,026 \\ \text { Dry } & 12,432\end{array}$


TABLE 5-1

ENERGY ECONOMIC DATA BASE

PHASE VIII UPDATE

488 MWe HIGH SULFUR COAL FOSSIL POWER GENERATING STATION (HS5)

COMPARISON PLANT TECHNICAL DATA MODEL BASE PARAMETER SUMMARY

MECHANICAL (Cont' 'd)

24. Coal Delivery

100 Car Unit Train at

5 hour Nominal Turnaround

25. Coa1 Storage

60 Days at Rated Load,

8 hours in Silos

26. Coal Firing Rate at

5,112

Rated Load (tons/day)

27. Coal Handling System

Rotary Car Dumper, Coal Breaker, Stacker/Reclaimer Transfer Tower Stacker/Reclaimer, Crusher, Boiler House Transfer Tower, Trippers

28. Number of Pulverizers/Spares

$5 / 1$

29. Stack
a. Height ( $f t$ )
650
b. Gas Velocity (fps)
$40 \max$.

30. $\mathrm{SO}_{2}$ Scrubber
a. Type
Lime (Wet) Preceded by
Electrostatic Precipitator
b. Number of Modules/
Number of Spares
$4 / 1$

31. Sludge Fixation

On-Site

32. Waste Disposal

Trucked off-Site

33. Turbine-Generator
a. Configuration
Tandem-Compound 4-F1 ow
b. Speed ( $r / m i n)$
3600
c. Last Stage Blade Length (in)
30 
TABLE 5-1

ENERGY ECONOMIC DATA BASE

PHASE VIII UPDATE

488 MWe HIGH SULFUR COAL FOSSIL POWER GENERATING STATION (HS5)

COMPARISON PLANT TECHNICAL DATA MODEL BASE PARAMETER SUMMARY

MECHANICAL (Cont'd)

34. Main Steam Conditions at High

Pressure Turbine Inlet (Rated Load)
a. Pressure, psia
2415
b. Temperature ${ }^{\circ} \mathrm{F}$
1000
c. Throttle Flow $\left(10^{6} \mathrm{lb} / \mathrm{hr}\right)$
3.5

35. Gross Turbine-Generator Output

at 2.5 in-HgA (MWe)

36. Condensers
a. Type
Single Pressure
b. She11/Divisions per Shell
$1 / 1$
c. Arrangement
Longi tudinal
d. Number of Passes
1
e. Water Box
Split
f. Pressure (in-HgA)
2.5
g. Total Heat Transfer Surface (SF)
332,600

37. Cooling Tower
a. Type
Natura1 Draft Wet Evaporative
b. Number/Total Flow-Normal (gpm)
$1 / 239,000$

38. Cooling Tower Conditions (Design)
a. Approach $\left({ }^{\circ} \mathrm{F}\right)$
14
b. Range $\left({ }^{\circ} \mathrm{F}\right)$
22
c. Wet Bulb $\left({ }^{\circ} \mathrm{F}\right)$
74 
TABLE 5-1

\section{ENERGY ECONOMIC DATA BASE}

PHASE VIII UPDATE

488 MWe HIGH SULFUR COAL FOSSIL POWER GENERATING STATION (HS5)

COMPARISON PLANT TECHNICAL DATA MODEL BASE PARAMETER SUMMARY

MECHANICAL (Cont'd)

39. Feedwater Pumps
a. Main (Number/Drive)
2/Turbine
b. Other (Number/Service/Drive)
2/Booster/Motor

40. Feedwater Heaters
a. Open Stages (Number)
One
b. High Pressure Closed Stages
$2 / 1$
(Number/Number Trains)
c. Low Pressure Closed Stages
(Number/Number Trains)
41. Stages of Reheat (Number/Type)
One/Boiler

\section{ELECTRICAL}

42. Connection to off-site Power (Number $/ \mathrm{kV}$ )

$2 / 230,2 / 115$

43. Generator
a. Rating (MVA)
610
b. Voltage (kV)
25
c. Power Factor
0.9
d. $\mathrm{H}_{2}$ Pressure (psig)
75

44. Generator Disconnect

Bolted Links

45. Auxiliary Power System
a Medium Voltage System A(kV)
None
b. Medium Voltage System B (kV)
$4 \cdot 16$ 
TABLE 5-1

\section{ENERGY ECONOMIC DATA BASE}

PHASE VIII UPDATE

488 MWe HIGH SULFUR COAL FOSSIL POWER GENERATING STATION (HS5) COMPARISON PLANT TECHNICAL DATA MODEL BASE PARAMETER SUMMARY

ELECTRICAL (Cont'd)
c. Low Voltage System (V)
480
d. Direct Current Systems (V)
$250 / 125$

46. Unit Auxiliary Transformer

44

Nameplate Rating (2) (MVA)

47. Reserve Auxiliary Transformer

Nameplate Rating(2) (MVA)

48. Diese1-Generat or Unit
a. Type/Number.
b. Voltage (V)
480
c. Rating (kW/PF)
$400 / 0.8$

High Speed/2

49. Control Room Wiring

Wired Directly to Panels

in Control Room

50. Multiplexing of Cables

None

51. Instrumentation

Independent Sensors for

Computer Input

(2) Total of all transformers at top class of cooling rating 
c. The coal handling system is designed to unload a 100-car unit train in approximately five hours. The design provides indoor coal storage silos with a capacity sufficient for eight hours consumption at rated load, and an outdoor storage area with a capacity sufficient for 60 days consumption at rated load.

d. The plant design includes a wet lime scrubber system for removal of sulfur-dioxide $\left(\mathrm{SO}_{2}\right)$ from the flue gas, preceeded by an electrostatic precipitator for removal of particulates.

This design basis reflects current industry practice, experience, and response to regulations as of January $1,1986$.

Table 5-1 summarizes the key technical parameters for the HS5. These base parameters, together with the text, engineering drawings and milestone schedules of the following sections, provide the system design descriptions for the HS5 technical data model.

\subsection{SYSTEM DESIGN DESCRIPTIONS}

The material presented in this section is organized as follows:

Code of

Accounts

Title of Account

Page

21

Structures and Improvements

22

Boiler Plant Equipment

23

Turbine Plant Equipment

$5-48$

24

Electric Plant Equipment

$5-65$

25

Miscellaneous Plant Equipment

$5-74$

26

Main Condenser Heat Rejection System

$5-82$ 


\section{ACCOUNT 21 STRUCTURES AND IMPROVEMENTS}

Civil/Structural key parameters are given in Items 12 through 18 of Table 5-1. Plant configuration in the form of a Plot Plan and General Arrangement drawings is given in Figures 5.1 through 5.4. The table and figures supplement and amplify the following discussion of Account 21 .

The primary structure in the plant is the steam generator building, otherwise referred to as the boiler house. This is a rectangular structural steel building that is sectioned into a number of specific rooms or functional areas.

The steam generator building and other plant structures that house the plant equipment are fully enclosed buildings. The superstructures have braced steel frames, metal siding and concrete channel plank roofing. They bear on reinforced concrete spread footings or reinforced concrete footings founded on the rock underlying the site. Grating floors are used whenever possible to allow maximum air circulation within the building. The siding for the buildings is generally insulated metal panels with interior liner panels. The plant stack is a reinforced concrete structure with a lined steel flue.

The major plant structures include:

Steam Generator Building (Account 212) - Houses and supports the main plant boiler, auxiliary boiler, air compressors, emergency diesel-generator units and forced and induced draft fans and draft systems.

Turbine, Heater and Control Building (Account 213) - Houses the turbine-generator, condensers and associated equipment, condensate pumps, condensate booster pumps, condensate polishing and demineralizing equipment, feedwater heaters, feedwater pumps and other auxiliary equipment.

The control and switchgear area, located in this building, houses the main control room and the auxiliary power distribution system switchgear area.

Administration and Service Building (Account 218B) - Houses the general offices, conference rooms, storage areas and various laboratories and shops.

Coal Handling System Structures (Accounts 218L through 218R, 218T and 218W These structures are the Stacker/Reclaimer Transfer Tower, Coal Car Thaw Shed, Rotary Car Dumper Building and Tunnel, Coal Breaker House, Coal Crusher House, Boiler House Transfer Tower, and various other facilities.

Electrical Switchgear Building (Account 218I)

Waste Water Treatment Building (Account 218S)

Materials Handling and Service Building (Account 218U)

Stack Structure (Account 219) 
HS5 ACCOUNT 21

The following additional major structures are included under Account 225 Flue Gas Desulfurization Structures:

Lime Unloading Building

Lime Feed Preparation and Storage Facilities

Lime Preparation Electrical and Control Building

Lime Feed Slurry Building

Absorber Island Enclosure

Absorber Island Electrical and Control Building

Thickener Equipment Building

Process and Seal Water Pump House

Sludge Stabilization Building and Stackout Area

The following additional major structures are included under Account 261 Main Condenser Heat Rejection System, Structures:

Make-up Water Intake Structure (Including Fire Pump House)

Circulating Water Pump House

Make-up Water Pretreatment Building

Interconnecting piping systems are provided for Building Services systems, such as rainwater conductor and sewage systems. They comprise the piping, fittings, valves, hangers and supports and other components required for a complete system. Materials and wall thicknesses are chosen based on the service conditions and operational requirements of each system. The factors genera1ly considered include: temperature, pressure, corrosion resistance, abrasion resistance, fluid purity requirements and cost. Carbon steel is used for steam (below $750^{\circ} \mathrm{F}$ ), clean water, air, oil and other services without special requirements. Other materials used include cast iron for sanitary drains and some below grade service, copper for potable water, galvanized steel for yard drains, and polyvinyl chloride (PVC) and fiberglass reinforced plastic (FRP) for the coal pile runoff control system and other corrosive services.

The following pages provide detailed descriptions of the major and minor structures, ordered numerically by account number. 
ACCOUNT 211 Yardwork

The plant location is the hypothetical site of Middletown, USA. This site is defined in Appendix A-2 of this Technical Reference Book. The plant configuration is shown in the Plot Plan given in Figure 5.1 .

The datum plane for site and yard elevations is mean river level. Main plant finish grade is 18 feet above mean river level. Soil overburden is estimated to be eight feet thick. Limestone rock with no underground cavities and satisfactory for supporting plant structures is located below the overburden.

Site preparation consists of clearing, grubbing, and stripping of top soil for all structures, roads, railroads, parking areas, materials handling areas and construction facilities. Rough grading quantities include the general cut and fill for the main plant structures and fine grading with 1andscaping.

Earth excavation, rock excavation, backfi11, concrete fill and dewatering for the main plant structures are included with the structure associated yardwork. This includes all excavation work for the steam generator building and the turbine, service, heater and control building areas. Excavation work for structures not included within the main excavation are included with the structural work for each of the individual buildings. The cut and fill work also includes hauling, dumping, stockpiling, placing and compacting. For those portions of the structure below rock, concrete fill is used under and adjacent to the structure. In cases where rock elevations vary, concrete fill is used to assure that building loads are carried to competent rock.

Excavated material is used on site for general fill whenever possible. Spoil areas and storage areas are utilized for excavated material not used for fill or for top soll. Erosion and sedimentation control of those areas is practiced in accordance with EPA requirements. Temporary settling basins are provided to collect all runoff during construction prior to discharge into the North River.

The transformer area, above ground oil storage tanks, coal storage area and other ofl or chemical storage and handling areas are designed to contain spills and collect surface water runoff. Selected coal handling, flue gas desulfurization, precipitator and ash handling areas are also designed to collect surface water runoff. This runoff, together with the steam generator and turbine building floor drains and other plant dirty drains, is routed by underground piping to the holding pond or to the waste water treatment building for treatment, as required, before discharge into the North River.

The yard drainage system consists of interceptor ditches (paved and unpaved) and storm drains with catch basins to carry off storm water from developed areas. Water courses that are intercepted near the plant or coal storage pile, are diverted by ditches into existing stream beds or storm drains. Culverts carry stream flow under the railroad, rallroad car storage yard and roads. The yard surface water drainage is directed to the North River via the existing water courses wherever possible. Building roof drainage is directed to the yard drainage system. 
$\underline{\text { HS5 ACCOUNT } 21}$

The sanitary sewage system, piping and toilet facilities for permanent plant requirements are provided based on 35 gallons per day per person and a permanent work force of 155 people, for a capacity of 5500 gallons per day. This system is a package type activated sludge sewage treatment plant, including final chlorination, to meet secondary treatment effluent standards.

Highway access is provided to the site by five miles of secondary roads connecting to a state highway. These roads are in good condition and need no additional improvements. An on-site asphalt road, paved in accordance with the standard thicknesses for public highways, is provided around the main plant structures. Service roads are arranged to provide access to truck sized doors in the plant and to all buildings and auxiliary structures requiring servicing or maintenance by vehicles. Paved roads for washing and refueling locomotives and mobile equipment are also provided. In addition, parking areas, concrete curbs and walks are provided. Temporary construction roads with minimum thickness paving and unpaved roads for material handling equipment are provided.

Railroad access to the site is provided by constructing a single track railroad spur which intersects the B\&M Railroad. The length of the spur from the main line to the plant site is five miles. The spur approaches the site from the east. Anticipated railroad traffic is up to 400 cars per week in 100 car unit coal trains plus the required number of lime cars. During construction, 400 to 500 cars of construction materials are delivered including the boiler components, transformers, and generator stator. These items are the heaviest loads anticipated and require special cars. A yard locomotive is provided to handle on-site car movements.

In addition to the coal delivery loop track, there are spur tracks into the northeast end of the turbine hal1, the fuel oil tank area, the locomotive repair shop and the lime unloading area. A temporary spur is installed to the construction yard storage area and to the boiler area for delivery and installation of the boiler headers, boiler panels and subassemblies. All roadbed, trackage and railroad structures are designed in accordance with the latest railroad standards.

In addition to the above items, fencing, a main gate guard house, and roadway and yard lighting are provided with the yardwork.

ACCOUNT 212 Steam Generator Building

The steam generator building consists of the boiler house, auxiliary boiler room, air compressor room, diesel-generator room, and forced draft fan room. The building is 160 feet wide, 175 feet long and 260 feet high above the top of the boiler. It has an overall volume of approximately 7,141,000 cubic feet. A description of each of these building areas is given below. 
Boiler House

The boiler house is a steel framed structure 160 feet wide and 145 feet long with two main roof heights of 140 feet above grade for the coal silos and conveyors and 261 feet above grade over the top ( 245 feet) of the boiler. The building volume is approximately 5,760,000 cubic feet.

The building is supported on reinforced concrete footings on rock. The reinforced concrete ground floor is located at grade. The roof is cast-inplace concrete over metal deck covered with insulation and built-up roofing supported on steel framing. The exterior walls are insulated metal siding and the interior walls are either concrete block or metal partitions. Access platforms are steel grating supported by steel framing. A11 floors and platforms are connected by several stairways. Each floor and major platform elevation are served by a passenger elevator.

The building houses the steam generator, coal silos and pulverizers, coal conveyors, and the fire protection booster pump.

Ventilation for the boiler house is provided by power roof ventilators and heating is provided by steam unit heaters located throughout the building.

Auxiliary Boiler Room

The auxiliary boller room is located north of the boiler house. It is a one story steel frame structure 40 feet wide, 55 feet long and 40 feet high. The building volume is approximately 88,000 cubic feet. The building substructure and superstructure are identical to that described for the boiler house. The south and east walls are common with the boller house and the air compressor room respectively. The auxiliary bofler room houses the auxiliary boiler and its accessory equipment.

Ventilation is provided by wall exhaust fans and heating is provided by steam unit heaters.

\section{Air Compressor Room}

The air compressor room is located north of the boiler house. It is a one story steel frame structure 40 feet wide, 90 feet long and 40 feet high. The building volume is approximately 144,000 cubic feet. The bullding substructure and superstructure are identical to that described for the boiler house. The south and west walls are common with the boiler house and the auxiliary boiler room respectively. "The air compressor room houses the soot blowing air compressors, recelvers and accessories; and the station air compressors, receivers, air dryers and accessories.

Ventilation is provided by wall exhaust fans and heating is provided by steam unit heaters. 
HS5 ACCOUNT 21

\section{Diese1-Generator Room}

The diesel-generator room is located on the west side of the boiler house south of the forced draft fan room. It is a one story steel framed structure 30 feet wide, 30 feet long and 40 feet high. The building volume is approximately 36,000 cubic feet. The diesel-generator room substructure is common with that of the boiler house. The superstructure is identical to that described for the boiler house. The north wall is common with the forced draft fan room.

The diesel-generator room houses the two emergency diesel-generator units, air intakes for the diesel-generator units, and auxiliary equipment. The exhaust silencers are mounted on the roof. A monorail hoist is installed for equipment maintenance and removal.

Ventilation is provided by wall exhaust $f$ ans and heating is provided by steam unit heaters.

Forced Draft Fan Room

The forced draft $f$ an room is located on the west side of the boiler house. It is a one story steel framed structure 30 feet wide, 125 feet long and 40 feet high. The building volume is approximately 150,000 cubic feet. The fan room is part of the boiler house and has a common substructure. The roof slab is cast-in-place concrete over acoustically treated metal deck supported on steel framing. The exterior walls are acoustical masonry block. The walls and roof are designed to resist the differential pressure caused by the fans. Sound attenuators are installed at the air inlets in the walls, and personnel doors are pressure tight and arranged to provide an air lock. A lintel is installed in the west wall to allow for future equipment removal.

The fan room houses the forced draft fans, primary air fans, inlet silencers, combustion air steam coils and accessories. A monorail hoist is installed for equipment maintenance and removal. (Refer to Figure 5.6)

\section{ACCOUNT 213 Turbine, Heater and Control Building}

The building consists of the turbine hall, auxiliary (heater) bay, and control and switchgear building, as described below.

Turbine Hall and Heater Bay

The turbine hall and heater bay are located east of the boiler house. The turbine hall is a three story (elevations 19 feet, 41 feet and 64 feet) steel framed structure 110 feet wide, 250 feet long and 110 feet high. The heater bay is a five story (elevations 19 feet, 41 feet, 64 feet, 84 feet and 104 feet) steel framed structure 30 feet wide, 225 feet. long and 109 feet high. The building volume is approximately $3,760,000$ cubic feet. 
The building is supported on reinforced concrete footings on rock. The reinforced concrete ground floor is located at grade. The mezzanine, operating and deaerator floors are cast-in-place concrete on metal deck supported on steel framing. The roof is cast-in-place concrete over metal deck covered with insulation and built-up roofing supported on steel framing. The exterior walls are insulated metal siding, and the interior walls are either concrete block or metal partitions. The turbine pedestal is described under Account 231 .

The building houses the turbine-generator unit, its condensers and associated equipment, feedwater heaters and deaerator, boiler feedwater pumps, boiler feedwater booster pumps, condensate pumps, condensate polishing and demineralizing equipment, turbine lube ofl equipment, and other auxiliary equipment. The feedwater heaters and deaerator are located in the heater bay.

A rail car bay is located at the north end of the turbine hall for transport of generator and turbine parts. An overhead traveling crane located at the top of the bullding serves this bay as well as the full turbine hall operating floor area. All floors are connected by several stairways.

The turbine hall and heater bay are cooled by power roof ventilators and heated by steam unit heaters located throughout the building.

\section{Control and Switchgear Building}

The control and switchgear building, located northwest of the turbine hall, is a four story steel framed structure 75 feet wide, 90 feet long and 65 feet high. The building volume is approximately 439,000 cubic feet. The building substructure and superstructure are identical to that described for the turbine hall and heater bay. The east wall of the control and switchgear building is common with the turbine hall and heater bay.

Most areas that have control or office functions are provided with acoustical suspended cellings. In addition, the computer room is provided with a raised f1oor system.

The control and switchgear building houses the control room, instrumentation and control cabinet room, relay room, communications room, computer room, cable spreading room, $13.8 \mathrm{kV}$ and $4.16 \mathrm{kV}$ switchgear, battery rooms, dc auxiliary rooms, and coal sampling and water analysis laboratories.

The control and switchgear building HVAC system provides filtered and conditioned air for ventilation to the various rooms listed above. Supply air to these rooms is provided by a multi-zone air handling unit and a heating and ventilating unit. Supply air to the building is heated as necessary by steam preheaters in the air handling units. Steam for preheating the air is supplied by the auxiliary steam system. A centrifugal water chiller supplies chilled water for air conditioning and cooling requirements to the main control room, instrumentation and control cabinet room, relay room, communications room, computer room and the laboratories. Local wall or ceiling fans exhaust air as required from the toilet and battery rooms. 


\section{ACCOUNT 218B Administration and Service Building}

The administration and service building is located south of the turbine hall and heater bay. The building is a one and two story steel framed structure 140 feet wide and 150 feet long. The one story portion is 85 feet long and 20 feet high. The two story portion is 65 feet long and 40 feet high. The building volume is approximately 602,000 cubic feet.

The building is supported on reinforced concrete footings on rock. The reinforced concrete ground floor is located at grade. The intermediate floor is cast-in-place concrete on metal deck supported on steel framing. The roof is concrete channel plank covered with insulation and built-up roofing supported on steel framing. The exterior walls are insulated metal siding and the interior walls are either concrete block or metal partitions. Most areas are provided with suspended acoustical cellings.

The building houses the machine shop, equipment rooms, service shops, storage areas, locker and change rooms, showers, toilet rooms, lunch room, laboratories, general offices and conference rooms. The building also houses an on-site emergency vehicle. The machine shop is located in the two story portion of the bullding.

The administration and service building HVAC systems maintain environmental conditions of normally occupied spaces within the prescribed comfort zone and ensure that temperatures and humidity in other areas are suitable for material storage and equipment operation. Heating and air conditioning is provided by fan cooler/heating units located throughout the bullding. Supply air. is provided by a multi-zone air handling unit and the fan cooler/heating units. Return air fans exhaust air to the air handling unit or to atmosphere, as required. Supply air to the building is heated as necessary by steam preheaters in the air handling units and hot water colls in the fan cooler/heating units. Hot water and chilled water for the fan cooler/heating units are supplied from a central hot water heating system and a central chilled water system. Steam for preheating supply air to the air handling unit is supplied by the auxiliary steam system. Local wall or ceiling fans exhaust air as required from tollet rooms, locker rooms and laboratory fume hoods.

ACCOUNT 218I Electrical Switchgear Building (Coal Handling)

The coal handling electrical switchgear building is located southwest of the main plant structures and adjacent to the coal breaker house. The building is a single story prefabricated steel structure 25 feet wide, 45 feet long and 16 feet high with an approximate volume of 18,000 cubic feet. It is supported on reinforced concrete spread footings and the reinforced concrete ground floor is located at grade.

The electrical switchgear building houses auxiliary power distribution system equipment for distributing power to the coal handling equipment located in the various coal handling system structures. 
HS5 ACCOUNT 21

Supply air is provided by ventilating units consisting of roughing filters and supply air fans. The building is pressurized by the fans to protect equipment from coal dust, and heated by electric unit heaters.

ACCOUNT 218L Stacker/Reclaimer Transfer Tower

The stacker/reclaimer transfer tower is located east of the coal breaker house and south of the main plant structures. The tower is a two story steel framed structure 45 feet wide, 50 feet long and 80 feet high. The building volume is approximately 180,000 cubic feet.

The building is supported on reinforced concrete footings on rock. The reinforced concrete ground floor is located at grade. The intermediate floor is cast-in-place concrete on metal deck supported on steel framing. The roof is standing seam metal deck supported on steel framing.

The bullding houses the head pulleys and drives for the coal-breaker-house to transfer-tower conveyor and the dead-storage-reclaim to transfer-tower conveyor, the tall pulleys for the transfer-tower to crusher-house conveyor, and the transfer-tower to stacker/reclaimer-yard conveyor, a motorized flop gate and a 500 ton surge bin. (Refer to Figure 5.7.)

ACCOUNT 218M Coal Car Thaw Shed

The coal car thaw shed is located southwest of the main plant structures and immediately south of the car dumper. It is a one story steel framed structure 20 feet wide, 390 feet 1 ong and 24 feet high. The building volume is approximately 187,000 cubic feet. The shed is located on the track approaching the rotary car dumper.

The shed is supported on reinforced concrete spread footings. The reinforced concrete ground floor is located at grade. The exterior walls are metal siding and the roof is metal deck covered with built-up roofing. The shed has six heating bays and one soaking bay and is furnished with the coal car thawing equipment.

ACCOUNT 218N Rotary Car Dumper Building and Tunnel

The rotary car dumper building, is located southwest of the main plant structures and west of the coal breaker house. It is a one story steel framed structure 52 feet wide, 66 feet long and $26^{\prime \prime}$ feet high. The building volume is approximately 89,000 cubic feet. The underground dump pit floor is 58 feet below grade, with a sump three feet deeper and a volume of 203,000 cubic feet.

The foundation and pit floor slab are reinforced concrete founded on rock. The dump pit, hoppers, ground floor slab and conveyor tunnels are reinforced concrete. The building roof is insulated metal roof deck covered with built-up roofing and supported on steel framing. The exterior walls are insulated and uninsulated metal siding and the interior walls are masonry block. 
The building houses the rotary car dumper, platen scale, traveling hammermill lump breaker, receiving hoppers, vibrating feeders, transfer chutes, dust suppression system, control room, toilet facilities, and equipment rooms. (Refer to Figure 5.7.)

Heating is provided by electric unit heaters. Supply air to the electrical equipment rooms is provided by a ventilating unit consisting of a roughing filter and supply air fan. Excess air is exhausted through wall louvers. These rooms are pressurized by the fans to protect equipment from coal dust. A packaged air cooled air conditioning unit maintains the control room at required ambient conditions. The substructure and tunnels are supplied with air through a ventilating fan.

\section{ACCOUNT 2180 Coal Breaker House}

The coal breaker house is located east of the car dumper and southwest of the main plant structures. It is a four story steel framed structure 58 feet wide, 62 feet long and 144 feet high. The bullding volume is approximately 518,000 cubic feet.

The building is supported on reinforced concrete footings on rock. The reinforced concrete ground floor is located at grade. The three intermediate floors are cast-in-place concrete on metal deck supported on steel framing. The roof is standing seam metal deck supported on steel framing. The exterior walls are insulated and uninsulated metal siding and the interior walls are masonry block.

The building houses the head pulley and drive for the car-dumper to coalbreaker-house conveyor; two coal breakers, magnetic separators, distribution hoppers, slide gates and belt feeders; the tail pulley of the coal-breakerhouse to stacker/reclaimer-transfer-tower conveyor; an "as-received" sampler; and an elevator. (Refer to Figure 5.7.)

Heating is provided for the coal breaker house by electric unit heaters. Supply air to electrical equipment rooms is provided by a ventilating unit consisting of a roughing filter and supply air fan. Excess air is exhausted through wall louvers. These rooms are pressurized by the fans to protect equipment from coal dust.

\section{ACCOUNT 218P Coal Crusher House}

The coal crusher house is located north of the stacker/reclaimer transfer tower and south of the main plant structures. It is a four story steel framed structure 40 feet wide, 40 feet long and 100 feet high. The building volume is approximately 160,000 cubic feet.

The building is supported on reinforced concrete footings on rock. The reinforced concrete ground floor is located at grade. The three intermediate floors are cast-in-place concrete on metal deck supported on steel framing. The roof is standing seam metal deck supported on steel framing. The exterior walls are uninsulated metal siding, and the interior walls are masonry block. 
The bullding houses the head pulleys and drives for the two stacker/reclaimertransfer-tower to crusher-house conveyors, two magnetic separators, a surge bin, two vibrating feeders, and two crushers. (Refer to Figure 5.7.)

Heating is provided for the coal crusher house by electric unit heaters. Supply air to electrical equipment rooms is provided by a ventilating unit consisting of roughing filters and supply air fans. Excess air is exhausted through wall louvers. These rooms are pressurized by the fans to protect equipment from coal dust.

\section{ACCOUNT 2180 Boller House Transfer Tower}

The boiler house transfer tower is located at the south end of the heater bay. It is a three story steel frame structure 23 feet wide, 30 feet 1 ong and 200 feet high. The tower volume is approximately 138,000 cubic feet.

The tower is supported on reinforced concrete footings on rock. The reinforced concrete ground floor, which is integral with the boiler house ground floor, is located at grade. The two intermediate floors are cast-in-place concrete on metal deck supported on steel framing. The roof is standing seam metal deck on steel framing. The exterior walls, from elevation 19 feet (boiler house ground floor) to 110 feet and 140 feet, are common with the turbine hall, heater bay and the boiler house on three side and insulated metal siding on the other side. From elevation 140 feet to $200 \mathrm{feet}$, the exterior walls are uninsulated metal siding.

The tower houses the head pulleys and drives for the crusher-house to boilerhouse-transfer-tower conveyors and transfer-chutes to tripper conveyors, and the as-fired sampling system. (Refer to Figure 5.7.)

Heating is provided to the electrical equipment room by electric unit heaters. Supply air is provided by a ventilating unit consisting of a roughing filter and supply air fan. Excess air is exhausted through wall louvers. This room is pressurized by the fans to protect equipment from coal dust.

\section{ACCOUNT 218R Dead Storage Transfer Tunne1}

The dead storage transfer tunnel is an underground reinforced concrete and steel conveyor gallery founded on rock. The tunnel houses the dead storage reclaim conveyors that transfer coal from the dead storage reclaim hoppers to the stacker/reclaimer transfer tower via the reclaim transfer tunnel. The tunnel is 10 feet wide, 10 feet high and approximately 500 feet long. (Refer to Figure 5.7.)

Ventilation for the dead storage transfer tunnel is provided by a fan house located south of the dead storage reclaim hoppers. 
ACCOUNT 218S Waste-Water Treatment Building

The waste water treatment building is located west of the main plant structures. It is a two story steel frame structure 30 feet wide, 60 feet long and 40 feet high. The building volume is approximately 72,000 cubic feet.

The bullding is supported on reinforced concrete spread footings. The reinforced concrete ground floor is located at grade. The roof is standing seam metal deck supported by steel framing. The exterior walls are insulated metal siding. Partial interior partitions to separate various equipment are reinforced concrete.

The building houses a control area, storage area, pumps, tanks and other waste water treatment equipment. Large 1tems of the pretreatment equipment, such as the batch holding tank, are located adjacent to the building.

Three waste water holding basins are located close to the waste water treatment building. All are constructed of reinforced concrete. The bottoms are ten feet below grade and the tops of the walls are two feet above grade. The basin for metal cleaning wastes is 70 feet wide by 125 feet long. The two basins for general plant waste are 65 feet wide by 125 feet long. All three basins are side by side with common walls between them. The pumps for emptying the basins are supported on structural steel at one end of the basin. The steel also supports grating around the pumps to provide access.

Heating is provided by electric unit heaters. The building is ventilated by drawing outside air through wall louvers and exhausting through power roof ventilators.

\section{ACCOUNT 218T Locomotive Repair Shop and Garage Facilities}

The locomotive repair shop and garage is located north of the rotary car dumper. It is a one story steel framed structure 65 feet wide, 65 feet long and 30 feet high. The building volume is approximately 126,800 cubic feet.

The bullding is supported on reinforced concrete spread footings. The reinforced concrete ground floor is located at grade. The roof is standing seam metal deck on steel framing. The exterior walls are metal siding.

The building houses a locomotive repair area and four-bay garage facility for the on-site diesel operated heavy equipment and service vehicles. Pits are provided for servicing under the locomotive and under the bulldozer.

Heating is provided by electric unit heaters. The area is ventilated by drawing outside air through wall louvers and exhausting through power roof ventilators. 
HS5 ACCOUNT 21

ACCOUNT 218U Materials Handling and Service Building

The materials handling and service building is located north of the locomotive repair shop and garage facilities. It is a one story steel framed structure 50 feet wide, 60 feet 1 ong and 20 feet high. The building volume is approximately 60,000 cubic feet.

The building is supported on reinforced concrete spread footings. The reinforced concrete ground floor is located at grade. The roof is insulated metal deck covered with built-up roofing supported on steel framing. The exterior walls are insulated metal siding and the interior walls are masonry block. Most areas are provided with suspended acoustical cellings.

The building houses service shops, offices, storage areas, lunch room, toilet rooms and shower rooms.

The HVAC system provides filtered and conditioned air to the of fices, lunch rooms, electrical and mechanical rooms, toilet rooms and shower rooms. Supply air to the rooms is provided by a multi-zone air handling unit and a heating and ventflating unit. The multi-zone air handing unit consists of a roughing filter, heating and cooling coils, and supply air fan.

\section{ACCOUNT 218W Miscellaneous Coal Handling Structures}

\section{Coal Conveyor Galleries}

The yard coal conveyor galleries include all overhead conveyor supporting structures and their associated foundations. The conveyor galleries consist of a conveyor support frame, expanded metal walkways and an open truss on each side of the conveyor/walkway support framing. The trusses are connected at the top and bottom by steel framing. The walkways are 30 inches wide on one side and 18 inches wide on the other. The galleries are supported on steel frame bents and relnforced concrete spread footings. A removable sheet metal hood over the conveyor protects it from the weather and minimizes fugitive dust. Lighting and service power is provided along the walkways.

\section{Coal Storage Pile Liner}

An Impervious clay liner is placed under the live and dead coal storage piles to prevent contamination of ground water by coal pile runof $f$ or seepage. The clay is tapered from two feet thick near the edge of the piles to three feet thick in the center so that it slopes to the perimeter. To minimize excavation, the liner is placed directly on the cleared and compacted grade. The perimeter of the liner is formed into a ditch which collects the runoff and channels it to the inlet to the coal pile runoff basin. The outside edge of the ditch is three feet above grade to preclude overflowing. The ditch is sloped 0.002 feet/foot toward the runoff basin.

Underneath the clay liner, a drainage system consisting of four inch perforated polyvinyl-chloride pipes approximately 75 feet on centers collects ground 
HS5 ACCOUNT 21

water and diverts it to sampling storage basins outside the lined area. The pipes are set two to three feet below grade level and are expected to be normally dry. The sampling basins are periodically inspected and any water which is collected is analyzed to verify that it did not result from a break in the clay liner.

\section{Coal Pile Runoff Basin}

The runoff basin is constructed of reinforced concrete. It is 200 feet wide and 250 feet long with a sloped bottom. The inside bottom of the basin varies from six feet to seven feet below grade. The walls extend three feet above grade to be even with the outside top of the liner ditch and to act as a fence. The volume to grade level is adequate to contain all of the water collected from a ten year 24 hour storm ( 4.9 inches). Thus, the walls provide three feet of freeboard.

The runoff basin is periodically emptied by three 50 percent capacity pumps and discharged through the waste water treatment system to the North River.

\section{ACCOUNT 219 Stack Structure}

The stack structure is 650 feet high ( 250 percent of the boiler house height) with a 27.5 foot inside flue diameter. These dimensions provide a gas velocity of less than 40 feet per second at valves wide open, five percent overpressure turbine operation. This velocity minimizes entrainment of condensed acid droplets into the gas stream.

The flue is a free-standing steel structure lined with an asphaltic urethane membrane/adhesive coating and 1-1/2 inch thick borosilicate blocks, to provide protection from acid which condenses from the flue gas. A drain system is provided at the bottom of the flue to remove and transfer any liquid which is collected to the waste water treatment area.

A tapered reinforced concrete shell surrounds and supports the flue, providing structural integrity. Shell diameters at the bottom are 59.5 feet inside and 63 feet outside. Shel1 diameters at the top are 35.5 feet inside and 37 feet outside.

A ladder with safety climb device and an electric man/material lift provide access in the stack annulus for testing, inspection and maintenance. Other accessories include sampling ports, smoke density and temperature probes, lightning protection/grounding and aircraft warning lights. The annulus is covered at the top with a rain cap.

The foundation is an octagonal reinforced concrete mat keyed two feet into the rock underlying the site. It is 10 feet thick and 94.5 feet across the flats. 
HS5 ACCOUNT 22

ACCOUNT 22 BOILER PLANT EQUIPMENT

Mechanical key parameters related to the boiler plant equipment are given in Items 19 through 32 of Table 5-1. Boiler Plant equipment configuration in the form of General Arrangement drawings is given in Figures 5.2 through 5.4. The table and figures supplement and amplify the following discussion of Account 22 .

The steam generating system supplies superheated steam to the turbine-generator unit, which converts the thermal energy to electrical energy. The steam generating system includes the steam generator; soot blowers; pulverizers; coal feeders and coal feed piping; fuel firing equipment; primary air, forced draft and induced draft fans; primary and secondary regenerative air preheaters; associated ductwork; associated instrumentation and controls; and supporting structural steel. Major auxiliary systems are the ash and dust handling system, the fuel handling system and the lime flue gas desulfurization system.

Interconnecting piping systems are included with each plant system as required. They comprise the piping, fittings, valves, steam traps, strainers, specialties, hangers and supports, insulation and other components required for a complete system. Materials and wall thicknesses are chosen based on the service conditions and operational requirements of each system. The factors generally considered include: temperature, pressure, corrosion resistance, abrasion resistance, fluid purity requirements and cost. Carbon steel is used for steam (below $750^{\circ} \mathrm{F}$ ), clean water, air, oil and other services without special requirements. Other materials used include: rubber lined carbon steel, fiberglass reinforced plastic (FRP), basalt lined carbon steel, abrasion resistant cast iron alloy, stainless steel tubing and carbon steel duct lined with an acid resistant membrane and a potassium based monolithic material coating.

The paragraphs given below provide brief technical descriptions of the boiler plant equipment accounts, in order to afford guidance to the more detailed descriptions of the pages which follow.

Account 221 Steam Generating System (boiler, burners, soot blowing system, vent and drain system and boiler blowdown equipment)

Account 222 Draft System (forced draft and primary air fans, air preheating steam coils, electrostatic precipitators, and induced draft fans)

Account 223 Ash and Dust Handling System (fly ash system and bottom ash and pyrites system)

Account 224 Fuel Handling System (coal handling and storage system, fuel feed to boiler, and ignition and plant fuel oil system) 
Account 225 Flue Gas Desulfurization Structures (lime unloading building, lime feed preparation and storage facilities, lime preparation electrical and control building, lime feed slurry building, absorber island enclosure, absorber island electrical and control building, thickener equipment building, process and seal water pump house, and sludge stabilization building and stackout area)

Account 226 Desulfurization Equipment (lime unloading/storage facility, lime slurry preparation system, sulfur dioxide absorber system, waste slurry thickening system, waste stabilization system and miscellaneous desulfurization equipment)

Account 227 Steam Generator Plant Instrumentation and Control (bench-board, panels and racks, process computer, monitoring systems, plant control systems and associated instruments) 


\section{ACCOUNT 221 Steam Generating System}

The steam generator is designed for a maximum continuous rating of $3.97 \times 10^{6}$ $1 \mathrm{~b} / \mathrm{hr}$ of steam at $2,640 \mathrm{psig}$ and $1,010^{\circ} \mathrm{F}$ at the superheater outlet and $1005^{\circ} \mathrm{F}$ steam at the reheater outlet, when $475^{\circ} \mathrm{F}$ feedwater is delivered to the economizer. This provides a three percent margin above the calculated turbine steam flow at the valves wide open, five percent overpressure condition. The furnace is designed for firing eastern high sulfur bituminous coal. Ignitors fired with No. 2 fuel oil are utilized during start-up and low load operation.

The overall dimensions of the steam generator are approximately 70 feet wide, 100 feet long and 245 feet above the ground floor elevation. The single furnace is designed for balanced draft operation.

\section{Burners}

Five rows of burners are located in the front ( 3 rows) and rear (2 rows) walls of the furnace. Each row of burners is supplied with pulverized coal from a separate pulverizer. Four rows of burners and pulverizers are required to maintain steam temperature at the boller maximum continuous rating. The fifth burner row and pulverizer are spares to facilitate maintenance and extend burner and pulverizer 1 ife.

\section{Soot Blowing System}

The steam generator is equipped with an automatic sequential soot blowing system. The system is designed to remove soot and ash from the boiler surfaces to maintain effective heat transfer. The soot blowers utilize compressed air at 300 psig as the blowing medium. The soot blower lances are rotated and traversed by means of electric motors. Two 5,000 SCFM centrifugal air compressors supply the necessary compressed air.

Vent and Drain System

The steam generator is equipped with a vent and drain system which provides a means of removing air, steam and accumulated water from the boiler and piping systems during start-up and shut-down. The system also is used for filling and draining the steam generator during chemical cleaning and hydrostatic testing. The system drains to the waste water treatment system.

\section{Boiler Blowdown Equipment}

Solids which tend to concentrate in the boller drum are removed by intermittent blowdown at a rate of 0.1 percent of the main steam flow. The blowdown is taken from the lower (1iquid) portion of the steam drum. It flows through a heavy wall carbon steel pipe to a flash tank where the pressure is dropped to approximately atmospheric, and the temperature decreases accordingly. Steam from the flash tank is vented to the atmosphere, and the water is discharged to the waste water holding basins. 


\section{ACCOUNT 222 Draft System}

A draft system flow diagram is given in Figure 5.6. The figure supplements and amplifies the following discussion of Account 222.

A balanced draft arrangement is used for the steam generator. In this arrangement, fans are used both to supply the combustion air and to exhaust the combustion gases. The supply (primary air and forced draft) and exhaust (induced draft) fans are designed to maintain the furnace pressure at slightly (approximately 0.1 in. w.g.) below atmospheric.

Air from the primary air fans is used to dry and transport the pulverized coal to the burners. The balance and major portion of the combustion air (secondary air) is supplied by the forced draft fans. Both primary air and forced draft fans are located in and draw air from a fan room at the rear of the boiler house.

Combustion gases are removed from the furnace by the induced $d r a f t$ fans and discharged to the flue gas desulfurization system.

Instrumentation for the boiler air and gas system monitors significant air and gas pressures, differential pressures, flows and temperatures from the furnace air inlet (wind box) to the furnace gas outlet.

\section{Primary Air Fans}

Two half-size primary air fans are provided. Each fan is directly coupled to a single speed drive motor. Capacity is controlled by inlet air vanes.

The primary air fans take suction from inside the fan room and discharge through the regenerative primary air heaters, where the air is heated by the flue gas. From the air heaters, the air goes to the pulverizers, where the pulverized coal is entrained, and through the burners into the furnace. This primary air is the minor portion of the combustion air.

Temperature of the air to the pulverizers is controlled by introducing tempering air into the heated primary air. The tempering air is a portion of the primary air that has been bypassed around the air heaters.

The boiler can be operated at a reduced load with a single primary air fan in service.

\section{Forced Draft Fans}

Two half-size forced draft fans are provided. Each fan is directly coupled to a single speed drive motor. Capacity is controlled by inlet air vanes.

The forced draft fans take suction from inside the fan room and discharge through the regenerative secondary air heaters where the air is heated by the flue gas. From the air heaters, the air goes to the burner windboxes and 
into the furnace. This secondary air is the major portion of the combustion air.

A single forced draft fan can be used to operate the boiler at a reduced capacity.

Air Preheating Steam Coils

Steam coils are provided at the air inlets to the fan room. They are designed to maintain the air to the forced draft and primary air fans at $80^{\circ} \mathrm{F}$. This avoids significant air density variations due to seasonal temperature ranges. The coils are self draining when not in use to avoid freezing.

A second set of steam coils are in the outlet ducts of the forced draft and primary air fans. These coils preheat the air as required to maintain the temperature of the primary and secondary regenerative air heaters' cold end above the acid precipitation point. The air heater cold end is the end through which the air to be heated enters and the cooled flue gas exits.

\section{Electrostatic Precipitators}

Two half-size electrostatic precipitators are located between the regenerative air heaters and the induced draft fans. They are provided to reduce the particulate emissione of the flue gas to the 1979 New Source Performance Standards (NSPS) level of 0.03 pounds per million Btu heat input. Each precipitator has a design efficiency of 99.64 percent and is sufficiently sectionalized to assure continued operation at guaranteed efficiency with one isolated section out of service. Provisions are made to isolate each regenerative air heater, precipitator, and induced draft fan train.

\section{Induced Draft Fans}

Two half-size induced draft fans are provided, one at the outlet of each precipitator. They maintain the furnace pressure slightly below atmospheric and increase the flue gas pressure sufficiently to provide a positive flue gas pressure at the inlets of the flue gas booster fans (refer to Account 226). The induced draft fans discharge into a plenum from which the booster fans take suction. The fans are driven by direct coupled two speed motors.

One induced draft $f a n$ is capable of sustaining boiler operation at reduced load.

\section{ACCOUNT 223 Ash Handling System}

\section{Fly Ash System}

The fly ash handling system removes fly ash from the precipitator, air heater and gas duct hoppers, and transports it to the fly ash storage silo located at the flue gas desulfurization sludge stablization area (refer to Account 
226). The fly ash system consists of two full-size subsystems for valve wide open, five percent overpressure turbine operation. For design purposes, 90 percent of the total ash is assumed to be fly ash. To meet this assumption, each subsystem is rated at 24 tons of ash per hour.

A positive pressure pneumatic system is utilized because of the required transport distance. An air lock tank is located under each dust collection hopper. These tanks are sequentially vented, filled, pressurized and discharged to feed the ash from the hoppers into the pressurized transport lines. System capacity allows intermittent operation with automatic actuation of the cycle by a timer.

Each fly ash hopper is furnished with a heater and is insulated to avoid condensation or other moisture which might cause the ash to cake. A pair of porous stone fluidizing pads in each hopper aids in removing the ash from the hopper by minimizing arching and other blockages.

An enclosed, weather-resistant control panel, located near the precipitator, contains all alarms, controllers, indicating, lights and switches required for automatic or manual operation of the fly ash system. Primary devices, located at the signal source, provide signals to receiver type indicators and controllers located in the control pane1. An annunciator in this control panel alarms various system malfunctions and transmits a common trouble alarm to the main control room.

Fly ash from the silos is utilized as a stabilizing medium for the flue gas desulfurization system sludge and is processed through the sludge stablization system for disposal.

\section{Bottom Ash and Pyrites System}

The bottom ash and pyrites handling system removes bottom ash from the boiler ash hoppers and pyrites from the pulverizer hoppers, and sluices them to dewatering bins for storage and discharge to trucks for off-site disposal. Economizer ash, which is actually $\mathrm{fly}$ ash, is also handled by the bottom ash system because it tends to be large coarse particles which resemble bottom ash more than $f 1 y$ ash. The system consists of one 100 percent capacity transport system and two 100 percent capacity dewatering bins for valves wide open, five percent overpressure turbine operation. For design purposes, 30 percent of the total ash is assumed to be bottom ash, including pyrites and economizer coarse fly ash. To meet this assumption, the transport system is rated for ten tons of ash/pyrites per hour and each dewatering bin is sized for 45 hours of storage.

The bottom ash system is designed for intermittent operation. When operating, collected ash is sequentially sluiced from each boiler hopper section to either of two dewatering bins. The small quantities of the collected ash and pyrites from the economizer ash collection tanks and the pulverizer hoppers are sluiced to a transfer collection tank where they are combined prior to being sluiced to either of the two dewatering bins. When a dewatering bin is 
full, the operator initiates the dewatering cycle, to drain the sluice water to a settling tank, where fines carried with the water are settled. Water in the settling tank is decanted into a recirculation tank, where additional settling occurs. Water in the recirculation tank is reused for sluicing.

The bottom ash hopper is furnished as part of the bottom ash system. It is rectangular in shape, with a triple vee shaped bottom which forms three outlets and sectionalizes the interior volume. It is refractory lined and filled with water to the approximate top of the vees. Hot ash from the furnace falls into the water where it is suddenly cooled and shatters. The ash then settles to the bottom of the hopper until it is removed. Each outlet includes a pneumatically opened and closed door, a clinker grinder to reduce large lumps of ash to an acceptable size, and a jet pump to entrain the ash and water into the sluice line.

The top edge of the bottom ash hopper has a continuous water trough into which the boiler seal plate projects, sealing the furnace bottom. The seal trough is designed to provide an adequate seal whether the boiler is cold or hot. In addition, it provides pressure/vacuum relief to protect the furnace sides from rupture or collapse. Water continuously overflows the inside edge of the trough to cool the refractory which is above the water level and to replace water lost by evaporation.

Each economizer ash collection tank is a water filled rectangular steel vessel with a sloped bottom in which there is a single outlet protected by an internal grate. Water level is automatically maintained by a level control valve. Ash from the economizer duct hopper falls into the ash collection tank by gravity, through pipes at the bottom of the economizer hoppers. The bottoms of these pipes are below the water level in the collection tank in order to provide a seal for the economizer duct. When large pieces of ash are collected on the grate, they must be manually broken by use of rods or other devices. The single outlet discharges directly to a jet pump which delivers the economizer ash to the bottom ash handling system. The water in the tank cools the hot ash and prevents the pieces, from sintering together into large lumps.

One pyrites hopper is provided at each pulverizer. Each hopper is a closed cylindrical steel tank with a conical bottom and a single outlet with a jet pump. It is connected to the pulverizer rejects chute through a seal which maintains the pulverizer internal pressure. An internal grid retains any large pieces which might. block the jet pump. These must be manually removed.

The pumps include:

a) High pressure and low pressure sluice pumps which pump the sluice water through the jet pumps to entrain the ashes and pyrites and transport them to the dewatering bins.

b) Seal water pumps which provide a continuous supply of water to the seal trough. 
c) Sludge return pumps which pump the sediment from the bottom of the settling and recirculation tanks to the dewatering bins.

d) Bottom ash hopper sump pumps which transfer any hopper area spills to the dewatering bins.

e) Ash storage area sump pumps to transfer any spills or collected rain water or wash water to the dewatering bins.

The dewatering bins are vertical cylindrical vessels with conical bottoms and screens for draining the water while retaining the ash. A hydraulically operated door at the bottom of each bin controls the ash discharge to trucks. Two dewatering bins are provided so that one will be available to receive ashes and pyrites, while the other is being dewatered or emptied. The settling tank is a conical vessel intended to still the water drained from the dewatering bins and allow fines to settle at the bottom. The recirculation tank provides additional settling of the water, and also provides a surge volume for sluicing until water returns via the dewatering bins.

In order to provide economic service life, sluice piping is basalt lined carbon steel. This material is more resistant to abrasion and to attack by acidic water than carbon steel or hardened steel. Other bottom ash system piping is ordinary carbon steel.

An enclosed, free-standing control panel, located in the back of the boiler house, includes all alarms, controllers, indicating, lights and switches required for automatic or manual operation of the bottom ash system. Primary devices located at the signal source provide signals to receiver type indicators and controllers located in the control panel. An annunicator in this control panel alarms various system malfunctions and transmits a common trouble alarm to the main control room.

\section{ACCOUNT 224 Fuel Handling. System}

Coal Handling and Storage System

A coal handling system flow diagram is given in Figure 5.7. The figure supplements and amplifies the following discussion of Account 224.

The design basis for the coal handling system is to support a coal firing rate of up to 233 tons per hour (valves wide open, five percent overpressure turbine operation) on demand.

The basic functions of the coal handling system are to unload the coal, convey it to storage, provide storage, reclaim it from storage and convey it to the silos in the boiler house. Subordinate functions include thawing frozen cars, moving the cars through the dumper, size reduction and minimizing fugitive dust (dust suppression). The buildings and structures supporting this system are located in the yard of the power plant southwest of the boiler house and turbine hal1 (refer to Accounts 218L, 218M, 218N,2180,218P, 218Q and 218R). 
Coal is delivered in unit trains of 100 cars each containing a nominal 100 tons of coal. The cars are leased to provide assurance that coal transportation will always be available. The cars each have one swivel coupling and one flxed coupling so they can be emptied by a rotary car dumper without uncoupling.

Unloading: An arriving train follows the track loop around the south side of the coal pile and enters the thaw shed and rotary car dumper from the south end. The over-the-road locomotives do not need to be uncoupled from the cars because clearances are maintained at the thaw shed and the car dumper to allow them to pass through.

During the winter, the coal cars are heated by electric heaters in the thaw shed. The heating is sufficient to melt any ice securing the coal to the car walls and to weaken any internal ice bonding the coal into large lumps or a solid mass. It will not be sufficient to completely melt all ice, particularly in the center of the car.

When the first car reaches the rotary car dumper, the locomotive is idled and the train is advanced by a hydraulic car indexer as each car is emptied. The indexer precisely locates each car in the dumper. Due to the swivel couplings on the cars, it is not necessary to uncouple them for dumping.

The rotary dumper overturns one car at a time, spilling the contents (coal) onto a "grisly" bar grate with ten inch square openings. The grisly retains any lumps too large to pass through. A traveling hammermill lump breaker reduces the size of the retained lumps so that they also will fall through.

Under the grisly, the coal is collected in two hoppers from which it is discharged via vibrating feeders to the single take-away conveyor belt.

Design unloading rate is 2000 tons per hour. This enables a unit train of 100 cars to be unloaded in about five hours of an eight hour shift. The remaining time provides margin for unanticipated delays or inclement weather. Approximately one unit train every two days is required to provide sufficient coal for continuous plant operation at rated load.

The take-away belts deliver the coal to the breaker house where either of two 100 percent capacity breakers reduce the size to approximately three inch lumps. After the coal passes through the breakers, a small sample is removed for "as received" testing. A single belt conveyor transfers the coal from the breakers to the stacker/reclaimer transfer tower. In the transfer tower, the coal can be sent to either the storage pile via the stacker/reclaimer or to the boiler house silos via the crusher house.

Storage: A total of 307,000 tons of coal is stored at the plant site in the form of active or dead storage. The active (short term) storage pile provides a three day supply of coal, or approximately 15,000 tons, for operation at rated load. This coal pile is continuously cycled and completely turned over for each cycle. The dead storage (long term) coal pile provides a 57 day 
supply of coal, or approximately 292,000 tons. This pile provides coal to the plant boiler only if normal rail delivery of coal is interrupted for extended periods of time. Since the Illinois No. 6 bituminous coal used by the plant has a relatively low moisture content (up to 11.3 percent), long term storage poses no severe spontaneous ignition or coal property degradation problems. Bulldozers and front-end loaders are utilized to compact the dead storage pile and to trim and maintain the active and dead storage piles.

Coal Stacking/Reclaiming: In those cases when coal is sent to active storage, the stacker/reclaimer transfer tower feeds the stacker/reclaimer conveyor. This conveyor is reversible and extends the length of the active coal pile. The stacker/reclaimer conveyor is sized to stack at a rate of 2,000 tons per hour, or reclaim at a rate of 550 tons per hour. If the average reclaim rate is 85 percent of the design rate, a 550 tons per hour design permits reclaiming at approximately twice the burn rate at valves wide open, five percent overpressure turbine operation. This provides sufficient capacity to concurrentiy fill the boiler house silos in a single shift.

Normally, coal is stacked on one end of the active coal pile and reclaimed from the other. Coal is discharged and stacked from the stacker/reclaimer boom conveyor. Coal is reclaimed by the stacker/reclaimer bucket wheel from which it is transferred to the boom conveyor, and then to the stacker/reclaimer conveyor. This conveyor transfers reclaimed coal to the 500 ton surge bin in the stacker/reclaimer transfer tower.

Bulldozers stack out and reclaim coal from the dead storage pile. During stacking out, coal is pushed from the active pile area to the dead pile area. During reclaiming, coal is pushed into ground level reclaim hoppers. These hoppers discharge through vibrating feeders to an underground conveyor system that also terminates (via reclaim transfer tunnel) at the stacker/reclaimer transfer tower surge bin.

From the transfer tower surge bin, the coal is carried by two 100 percent capacity conveyor belts to the crusher house. The conveyors discharge the coal into a crusher house surge bin. Vibrating feeders in the bottom of the surge bin feed either or both of two 100 percent capacity coal crushers. The crushers reduce the coal to approximately $1-1 / 2$ inch size. The crushed coal is transferred from either crusher to either of two 100 percent capacity ( 550 tons per hour) conveyor belts and trippers that feed the five pulverizer silos in the boiler house.

Each silo holds approximately 375 tons (total of 1875 tons) which is the estimated use in eight hours at valves wide open, five percent overpressure turbine operation. Silos are mounted on load cells to provide an indication of the amount of coal that each contains.

Weighing and Sampling: Coal is weighed and totalized at two locations in the coal handling system; 1) at the rotary-car-dumper to breaker-house conveyor belt scale, and 2) at the crusher-house to boiler-house conveyors load indicators. As-fired coal is sampled in the boiler house transfer tower, prior to 
delivery to the coal silos. As-recelved coal is sampled in the breaker house after discharge from the coal breakers.

Auxiliary Equipment: Magnetic separators remove miscellaneous iron from the coal at the top of the breaker house, the stacker/reclaimer transfer house and the crusher house. Each coal conveyor is equipped with wire-reinforced fabric/rubber belt material and self-aligning troughing (angled side) idlers. The conveyors, and adjacent walkways, are supported by the yard conveyor galleries (refer to Account 218W). A solvent/water spray dust suppression system prevents excessive dusting at the discharge of each conveyor.

\section{Fuel Feed to Boiler}

Each coal silo is dedicated to a specific pulverizer. Coal is discharged from the silo through a feeder into the pulverizer raw coal inlet. The coal is both reduced in size to approximately 80 percent minus 200 mesh and dried in the pulverizer. Drying is accomplished by the hot primary air which also transports the pulverized coal to the burners through the coal pipes.

Pulverization is accomplished by grinding the coal between stationary rollers and a rotating race which are forced into contact by heavy springs. As the coal is reduced in size, the primary air carries it to the classifier where coal of the desired fineness is separated and carried out with the air to the burners and the furnace. Oversize material is returned to the grinding zone. A high rate of recirculation of partially ground coal lowers the average moisture content in the grinding zone and also promotes better classification.

The pulverizer also separates pyrites, metal and other foreign material from the coal. These materials are generally harder and denser than the coal. As a result they do not crush as easily, and tend to migrate to a discharge chute which drops them into a hopper beside the pulverizer, from which they are periodically flushed by the bottom ash system.

Equipment from the silo discharge to the burners is furnished as part of the steam generator package.

\section{Ignition and Plant Fuel 011 System}

The fuel oil system supplies No. 2 fuel oil to the main boiler ignitors for start-up and low-load operation. This fuel oil is also used for the auxiliary boiler and miscellaneous diesel driven equipment, such as the emergency diesel-generator unit, the yard locomotive, the diesel-driven fire pump and the auxiliary coal moving equipment. The plant fuel oil systems are located in the plant yard, boiler room, auxiliary boiler room and at the make-up water intake and discharge structure.

An above ground fuel oil tank provides storage for a 30 day supply of oil. A dike surrounding the tank contains the oil in the event of a spill or tank failure. Separate pumps, which take suction directly from the fuel oil storage tank, supply the fuel oil to the main and auxiliary boilers and other plant fuel oil system day tanks. 
Oil delivery for the above ground tank is made by either rail or truck. An unloading pump is provided for vehicles not having unloading equipment.

Instrumentation for the fuel oil system monitors and controls the unloading, storage and transfer of fuel oil to points of use. It also provides information both locally and to the main control room as required for controls, displays, alarms and logs.

\section{ACCOUNT 225 Flue Gas Desulfurization Structures}

These structures are designed to segregate, enclose, support, protect, ventilate and heat the various active and passive equipment comprising the subsystems of the Lime Flue Gas Desulfurization System. A plot plan showing the location of these structures is given in Figure 5.1 .

ACCOUNT 225.1 Lime Unloading Building

The lime unloading building is a steel frame structure located southwest of the main plant structures. It consists of a railcar unloading shed attached to an equipment and control building. The shed is 26 feet wide, 100 feet long and 48 feet high; the attached service building is 27 feet wide, 160 feet long and 31 feet high, including a parapet that is three feet high. The total building volume is approximately 258,700 cubic feet.

The building is supported on reinforced concrete footings founded on rock. The reinforced concrete ground floor is located at grade. The reinforced concrete unloading pit extends approximately 40 feet below grade. The shed roof is standing seam metal deck supported on steel framing. Its exterior walls are uninsulated metal siding. The service building roof is concrete channel plank covered with insulation and built-up roofing supported on steel framing. Its exterior walls are insulated metal siding, and the interior walls are masonry block.

The building is heated by electric unit heaters and is ventilated by drawing outside air through wall louvers and exhausting through roof ventilators. Supply air to the electrical equipment room is provided by a ventilating unit consisting of a roughing filter and a supply air fan. Excess air is exhausted through wall louvers. This room is pressurized by the fan to protect equipment from lime dust.

\section{ACCOUNT 225.2 Lime Feed Preparation and Storage Facilities}

The lime feed preparation and storage facilities are located southwest of the main plant structures and adjacent to the lime unloading building. The lime slaking equipment and slurry storage tanks are housed beneath the lime storage silos, providing integral storage and slaking facilities. There are two separate facilities, each 65 feet in diameter by 160 feet in overall height reinforced concrete structures. The silos are supported on reinforced concrete footings on rock. 
HS5 ACCOUNT 22

The silos have two operating levels, the ground floor and the slaker floor, approximately 40 feet above grade. The ground floor houses the slurry storage tanks and transfer pumps. The slaker floor houses the slakers and classifiers. Intermediate platforming provides access for maintenance to the bin bottoms, feeders, conveyors and classifiers.

The ground floors are reinforced concrete located at grade. The slaker floors are cast-in-place concrete on metal deck supported on steel framing. The silo roofs are insulated metal deck covered with built-up roofing and supported on steel framing. Parts of the exterior walls are insulated metal siding.

The slaking and storage areas are heated by electric unit heaters, and ventilated by wall fans and louvers.

ACCOUNT 225.3 Lime Preparation Electrical and Control Building

The lime preparation electrical and control building is a four story steel frame structure, located between the lime storage silos. The building is 25 feet wide, 60 feet long and 60 feet high with a volume of approximately 90,000 cubic feet. It houses the control room, electrical equipment room, mechanical service room, lavatory, personnel facilities, and HVAC equipment for both the silos and the electrical and control building.

The building is supported on reinforced concrete footings on rock. The reinforced concrete ground floor is located at grade. The intermediate floors are cast-in-place concrete on metal deck supported on steel framing. The exterior walls are insulated metal siding and the roof is concrete channel plank covered with insulation and built-up roofing supported on steel framing.

The HVAC system in the lime preparation electrical and control building maintains environmental conditions of normally occupied spaces within prescribed comfort zones and ensures that temperatures and humidity in other areas are suitable for equipment operation. Supply air is provided by a multi-zone air handiing unit and a heating and ventilating unit. Supply air is filtered and the building is pressurized by the supply fan to protect personnel and equipment from lime dust. A centrifugal compressor supplies chilled water for air conditioning the control room and other selected areas.

ACCOUNT 225.4 Lime Feed Slurry Bullding

The lime feed slurry building is located south of the absorber island area. It is a one story prefabricated steel structure 20 feet wide, 20 feet 1 ong and 20 feet high. The building volume is approximately 8000 cubic feet.

The building is supported on reinforced concrete spread footings. The reinforced concrete ground floor is located at grade. The exterior walls are insulated metal siding. The roof is concrete channel plank covered with insulation and built-up roofing. 
HS5 ACCOUNT 22

The building is located between the two lime slurry feed tanks and houses the pumps for feeding lime slurry to the absorber modules. Heating is provided by electric unit heaters. The building is ventilated by drawing outside air through wall louvers and exhausting through wall fans.

ACCOUNT 225.5 Absorber Island Enclosure

The absorber island enclosure is located in the flue gas desulfurization area north of the absorbers. It consists of a single story steel frame structure 50 feet wide, 140 feet 1 ong and 28 feet high. The building volume is approximately 196,000 cubic feet. The columns and foundations of the enclosure also partly support the inlet and outlet flue gas ducts located above the enclosure.

The structure is supported on reinforced concrete spread footings. The reinforced concrete ground floor is located at grade. The building has a concrete channel plank roof covered with insulation and built-up roofing supported on steel framing and insulated metal siding.

The enclosure houses pumps and other absorber auxiliary equipment. The building is heated by electric unit heaters and is ventilated by drawing outside air through wall louvers and exhausting through roof ventilators.

ACCOUNT 225.6 Absorber Island Electrical and Control Building

The absorber island electrical and control building is located north of the absorber island area. It is a two story steel frame structure 60 feet wide, 90 feet long and 40 feet high. The building volume is approximately 216,000 cubic feet.

The building is supported on reinforced concrete spread footings. The reinforced concrete ground floor is located at grade. The intermediate floor is cast-in-place concrete on metal deck supported on steel framing. The roof is concrete channel plank covered with insulation and built-up roofing supported on steel framing. The exterior walls are insulated metal siding, and the interior walls are masonry block.

The building houses the absorber island control room, office, toilet rooms and switchgear area. The control room is heated by electric baseboard radiators and cooled by a window type air conditioner. The switchgear room is heated by electric unit heaters. Supply air is provided by a ventilating unit consisting of a roughing filter and supply air fan. Excess air is exhausted through a wall louver. The electric equipment rooms are pressurized by the fan to protect equipment from lime dust.

ACCOUNT 225.7 Thickener Equipment Building

The thickener equipment building is located northwest of the main plant structures. It is a one story prefabricated steel structure, 50 feet wide, 80 feet 1 ong and 20 feet high. The building volume is approximately 80,000 cubic feet. 
The building is supported on reinforced concrete spread footings. The reinforced concrete ground floor is located at grade. The siding is uninsulated metal and the roof is standing seam metal.

The building houses the process liquor pumps, polymer feed skids, electrical equipment and local control and instrumentation. Heating is provided by electric unit heaters. The building is ventilated by drawing outside air through wall louvers and exhausting through wall fans.

ACCOUNT 225.8 Sludge Stabilization Building and Stackout Area

The sludge stabilization building is located northwest of the main plant structures. It is a three story steel frame structure averaging 80 feet wide, 155 feet long and 75 feet high, with a total volume of approximately 930,000 cubic feet.

The building is supported on reinforced concrete footings on rock. The reinforced concrete ground floor is located at grade. The intermediate floors are cast-in-place concrete on metal deck supported on steel framing. The roof is cast-in-place concrete over metal deck, covered with insulation and built-up roofing supported on steel framing. The roof has raised removable sections located to provide crane access for removing filters. The exterior walls are insulated metal siding and the interior walls are masonry or metal partitions.

The buflding houses the flue gas desulfurization waste processing equipment (filters, pumps, filtrate tanks, mixers, feeders, conveyors and supporting equipment), electrical and HVAC equipment, control room, offices, maintenance facilities and personnel facilities. It also encloses the bottom portions of the fly ash and lime storage silos.

The building is heated by electric unit heaters and is ventilated by drawing outside air through wall louvers and exhausting through roof ventilators. The HVAC system also provides filtered and conditioned air to the personnel, control, electrical and service areas. These areas are pressurized by the HVAC system to prevent infiltration of lime or ash dust.

The sludge stabilization system stackout area is a paved area approximately 250 feet wide and 350 feet long located along the exit road from the sludge stabilization building. This area can be used for temporary storage of flue gas desulfurization system/fly ash/sludge in case of a transportation interruption or other emergency. The area is curbed and sloped so that any runof $f$ is collected by drains and transferred to the liquid waste treatment system. Front end loaders are used to transfer material into this area and to load the stored material into trucks for disposal.

ACCOUNT 225.9 Process and Seal Water Pump House

The process and seal water pump house is located west of the main plant structures. It is a one story prefabricated steel structure 20 feet wide, 40 feet long and $16 \mathrm{feet}$ high. The building volume is approximately 12,800 cubic feet. 
The building is supported on reinforced concrete spread footings. The rein-forced concrete ground floor is located at grade. The exterior walls are insulated metal siding, and the roof is insulated standing seam metal.

The building houses the process and seal water pumps, tanks, filters and associated equipment. Heating is provided by electric unit heaters. The building is ventilated by drawing outside air through wall louvers and exhausting through wall fans.

ACCOUNT 226 Desulfurization Equipment

The flue gas desulfurization (FGD) system is designed to remove sulfur dioxide $\left(\mathrm{SO}_{2}\right)$ from the essentially particulate free flue gas exiting the electrostatic precipitator and produce a comixed fly ash/FGD waste product suitable for landfill disposal. The system design is a non-recovery wet lime process consisting of: a lime unloading and storage facility; a lime slurry preparation system; an $\mathrm{SO}_{2}$ absorber system; a waste slurry thickening system; a waste stabilization system; and a water distribution system.

The performance criteria for this design is the 1979 New Source Performance Standards for $\mathrm{SO}_{2}$ emissions. In addition to this performance requirement, the system design provides a zero liquid discharge capability and incorporates many reliability features.

A simplified flow diagram for the process is given in Figure 5.8 and Table 5-3. The figure and table supplement and amplify the following discussion of Account 226 .

ACCOUNT 226.1 Lime Unloading/Storage Facility

Lime for the FGD system and FGD liquid waste treatment system is delivered in raflroad hopper cars. The lime unloading/storage facility is designed to receive the lime shipments and to convey the lime to the storage silos for lime slurry preparation. The system consists of rail unloading hoppers, crushers, blowers, silos, dust collection equipment, piping, valves, instrumentation and controls.

Rail cars containing lime are brought to the lime unloading shed which houses the unloading hoppers. Two unloading hoppers are provided, each with a capacity of 100 tons. Lime from the hoppers is crushed by two 70 ton per hour, roller type crushers. Following crushing, the lime is pneumatically conveyed to the two main lime storage silos. Three positive displacement blowers, each $6500 \mathrm{cfm}$, are provided for transporting the lime to the silos.

Lime is pneumatically transferred from the main storage silos to the two waste stabilization storage silos (refer to Account 226.5). Two feeders and two positive displacement blowers are provided for this purpose.

Lime storage is provided for a nominal 30 days of operation at valves wide open, five percent overpressure turbine operation (approximately 14.5 tons 
per hour of lime). The two lime silos each provide a 15 day storage capacity of approximately 5,200 tons of lime.

ACCOUNT 226.2 Lime S1urry Preparation System

The lime slurry preparation system receives dry lime from the storage silos of the lime unloading/storage facility, slakes the lime, removes the inert material, and stores the resultant slurry. The slurry produced is primarily used within the $\mathrm{SO}_{2}$ absorber system; however, a small portion of this slurry is also directed to the plant liquid waste treatment system for use in neutralization.

The lime slurry preparation system consists of two trains. The major equipment associated with each train is housed directly beneath the lime storage area of each silo and includes the following: two ten ton per hour slakers with dedicated lime feed assemblies, a common spiral classifier serving both slakers, a slurry storage tank, two slurry transfer pumps and the required piping, valves, instruments and controls.

The design lime demand of 350 tons per day is met by operating two slakers (one train at design capacity or both trains at 50 percent capacity) for approximately 18 hours per day or three slakers ( $1-1 / 2$ trains) for 12 hours per day.

Lime is discharged from the silo bin bottom at a controlled rate by rotary feeders and is transferred by screw conveyors to the first cell of the four cell attrition slakers. Make-up water is also fed to this first cell and the combined water-1ime mixture cascades through the remaining cells to provide sufficient residence time for the slaking reaction to take place. The resultant lime slurry flows by gravity from the slaker to the common spiral classifier where a large portion of the grit is removed. The grit is conveyed to an outdoor dumpster for subsequent disposal. The final lime slurry product drains from the classifier to the two lime slurry storage tanks which are located directly beneath the classifier.

Each storage tank has a capacity of 350,000 gallons. This volume is equivalent to the amount of lime slurry ( 15 percent solids) required for 12 hours of absorber operation at unit rated load with the design coal and an $\mathrm{SO}_{2}$ removal efficiency of 90 percent. Each tank, which is 45 feet in diameter and 32 feet high, is an epoxy-phenolic lined carbon steel vessel with an acid brick bottom. A single, 40 horsepower top entry agitator is provided with each tank to keep the contents in suspension. The 100 percent capacity lime slurry transfer pumps are sized to transfer lime slurry to the feed tanks in the absorber island and to the liquid waste treatment system.

ACCOUNT 226.3 Sulfur Dioxide Absorber System

The sulfur dioxide absorber system brings the flue gas into intimate contact with a recirculating slurry within an absorber vessel in order to remove $\mathrm{SO}_{2}$ from the flue gas stream. The $\mathrm{SO}_{2}$ absorber system is sized to treat 100 
percent of the flue gas flow at valves wide open, five percent overpressure turbine operation with a design removal efficiency of 94 percent of the $\mathrm{SO}_{2}$ contained in the entering flue gas. However, under full load operation with design coal, the $\mathrm{SO}_{2}$ absorber system operates at a nominal removal efficiency of 90 percent in order to comply with the 1979 New Source Performance Standard $\mathrm{SO}_{2}$ emission standard of 0.6 pounds of $\mathrm{SO}_{2}$ per million Btu of heat input. The four percent margin in removal efficiency is provided to allow $f$ or variations from the design coal and for age related decreases in removal ef ficiency over the life of the unit.

The major components of the $\mathrm{SO}_{2}$ absorber system include: spray tower type absorber modules fabricated of $317 \mathrm{~L}$ stainless steel, recirculation pumps, mist eliminator wash pumps and blend tank, lime feed pumps and storage tanks, dampers, agitators, piping, valves, instrumentation and controls. Additionally, a bypass duct around the absorber modules, sized to handle 100 percent of the flue gas at the boiler maximum continuous rating, is provided in case of operating problems with the absorber system and for use during start-up.

Four identical vertical spray absorber modules are provided. At valves wide open, five percent overpressure turbine operation with design coal, three modules treating 100 percent of the flue gas are required. Each module is 35 feet in diameter and is sized for a maximum flue gas velocity of nine feet per second. Each absorber module contains four banks of sprays and a distribution plate at the inlet to the tower. Flue gas enters the absorber modules with a slight downward direction and turns up through a bank of sprays where the gas is initially quenched. The gas then passes through a flooded distribution plate, followed by three more banks of sprays. Only three banks of sprays (the initial quench spray and two banks above the plate) are required to operate to achieve 90 percent removal efficiency at design conditions. The fourth spray bank is a spare which can be used for $\mathrm{SO}_{2}$ removal "catch-up" following upset operations.

Four rubber lined centrifugal recirculation pumps are provided per absorber module, each pump associated with one spray header. The pumps are each designed to discharge $10,000 \mathrm{gpm}$ to produce a liquid to gas ratio $(\mathrm{L} / \mathrm{G})$ of 60 gallons/1000 acfm with three of the four pumps in operation. These pumps take suction from the recirculation tank that is provided as an integral component of each absorber module. The recirculation tanks are conservatively sized to provide a mean residence time of six minutes at the design L/G of 60 gallons/1000 acfm. Each recirculation tank has three side entry agitators.

Lime slurry, as required to maintain the alkalinity within the absorber system, is added to each recirculation tank. The lime, which is prepared within the lime slurry preparation system, is pumped to the absorbers from the lime feed tanks via a recirculating lime slurry feed 10op. Two, 100,000gallon lime feed tanks are provided, each sized to contain four hours of 15 weight percent slurry at the maximum expected demand rate of the absorbers. Three rubber-lined lime feed pumps, each sized for approximately $900 \mathrm{gpm}$, or 150 percent of the maximum absorber slurry demand rate, are provided. The sizing of these pumps ensures that the slurry velocity in both the feed and return lines is sufficient to prevent the solids from settling. 
The outlet from each absorber is provided with a two-stage, chevron-type mist eliminator. These remove liquid droplets and particulates contained in the scrubbed flue gas flow. The bottom of the first demister stage is washed from the bottom in a continuous sequential fashion with a combination of process liquor and fresh water that is supplied from the mist eliminator wash blend water tank via the mist eliminator wash pumps. The top of the first demister stage is washed at regular, but infrequent intervals (e.g., once per shift). A single mist eliminator wash blend water tank is provided. The tank has a storage capacity of approximately 24,000 gallons which is equivalent to 60 minutes of washing at the maximum expected system wash rate of 390 gallons per minute. Two 100 percent capacity mist eliminator wash pumps take suction from this tank. Each pump has a capacity of 450 gallons per minute.

The absorber system waste products are discharged via a bleed stream from the recirculating slurry. This bleed stream, which contains 8-15 weight percent of solids, is directed to a two compartment agitated waste slurry sump. Each sump compartment has a storage capacity of 9,000 gallons which is equivalent to a ten minute retention of a 12 weight percent bleed stream at design conditions from four absorber modules. (Normally, each compartment handles the bleed stream from two operating absorber modules; however, each is also capable of handling the bleed stream from four modules.) From this sump, the bleed stream is pumped to the waste slurry thickening system by the waste slurry pumps. Three rubber-lined centrifugal pumps are provided, one designated for each compartment and a common spare. Each pump has a capacity of 1000 gallons per minute.

\section{ACCOUNT 226.4 Waste Slurry Thickening System}

The waste slurry thickening system dewaters the bleed slurry from the absorber modules to produce a concentrated underflow slurry and a high quality (low suspended solids) overflow. The waste slurry thickening system consists of thickeners, a polymer feeder, a process liquor (thickener overflow) tank, process liquor pumps, underflow transfer pumps, agitators, miscellaneous pumps, piping, valves, instruments and controls. The underflow slurry, which contains a minimum of 25 weight percent solids, is pumped to the sludge stabilization system for treatment prior to disposal. The overflow is returned for reuse within the FGD system. Additionally, the waste slurry thickening system serves as the point for adding to the FGD process a portion of the precipitation runoff collected within the waste stabilization area of the station.

The waste slurry thickening system is designed to process 160 percent of the maximum waste solids produced by the absorbers or 200 percent of the expected typical solids production. As such, the waste slurry thickening system is capable of operating with one of the two thickeners out of service. The system design also includes provisions for discharging the contents of a thickener to the temporary FGD waste storage basin should it be necessary to empty a thickener for inspection or repairs. 
HS5 ACCOUNT 22

Two 150 foot diameter, center feed, peripheral overflow type thickeners arranged in a parallel flow configuration are provided. The thickener sizing criteria is 30 square feet per ton per day of dry solids'in the absorber bleed stream. The thickener sizing permits either thickener to process all of the typical bleed flow from the absorbers ( 24 tons per hour of dry solids) or 80 percent of the design maximum absorber bleed $f l o w$ ( 30 tons per hour of dry solids). Each thickener has a concrete conical bottom, with 15 feet high side walls constructed of coated carbon steel.

The side wall height includes an allowance of two feet for water storage during periods of water imbalance within the FGD system. The major mechanical components within each thickener include a four paddle-wheel type flocculator and a rake with an electric drive and lift mechanism. The rake mechanism is center column supported.

A polymer feed system is provided to prepare and feed a polymer solution to the thickeners. The polymer solution enhances settling within the thickeners. The polymer feed system is capable of mixing and aging either a dry polymer (powder) or a liquid polymer. The system consists of two vertical cylindrical 1600 gallon tanks, two tank agitators, two feed pumps and other miscellaneous equipment. The polymer system is sized to prepare and feed approximately 150 pounds of dry polymer per day based upon a feed rate of 0.2 pounds of polymer per ton of dry solids contained in the bleed stream to the thickeners.

Overflow from the thickeners is piped to the two thickener overflow tanks. These tanks are constructed of epoxy-1ined carbon steel and are each designed for a working volume of approximately 130,000 gallons. This volume provides sufficient surge capacity for typical daily water imbalances resulting from the intermittent operation of FGD subsystems. Thickener overflow (process 11quor) is pumped from these tanks for various uses within the FGD system, including lime slaking, mist eliminator washing, make-up to the absorber recirculation tanks, polymer dilution, level control within the waste slurry sump, blended seal water and line flushing. Each of the overflow tanks are provided with two process 1iquor pumps. Each of these pumps is capable of pumping $1500 \mathrm{gpm}$, which is equivalent to 50 percent of the maximum anticipated system demand for process 1iquor.

Underflow from the thickeners is pumped by the underflow transfer pumps to the two interconnected thickener underflow transfer tanks. These tanks are part of the waste stabllization system. Four-100 percent capacity underflow transfer pumps, are provided, two per thickener. Each pump has a capacity of $425 \mathrm{gpm}$ which is equivalent to the design underflow solids production rate and a 25 weight percent solids slurry.

ACCOUNT 226.5 Waste Stabilization System

The waste stabilization system is provided to process fly ash and FGD sludge for codisposal within a solid waste landfill. While the waste stabilization system normally treats a combination of FGD sludge and fly ash, it is also 
able to process fly ash alone. The primary influents to the waste stabilization system are thickener underflow (from the waste slurry thickening system) and $f l y$ ash (from the fly ash system).

The waste stabilization system is designed to operate 14 hours per day to process the fly ash and FGD wastes produced by the unit (approximately 2000 tons per day of comixed waste). The waste stabilization system consists of underflow transfer tanks, filter feed pumps, filtrate tanks, lime and fly ash storage silos and feeders, vacuum filters, pug mill mixers, conveyors, pumps, piping valves, instruments and controls.

Sludge from the waste slurry thickening system is pumped to the agitated thickener underflow transfer tanks. Two lined carbon steel tanks are provided, each sized to hold approximately 275,000 gallons of slurry. Each tank's capacity is equivalent to 12 hours of thickener underflow containing 25 percent solids. Each tank is provided with two fllter feed pumps. These pumps discharge to a common header which normally feeds the agitated vats of the vacuum filters. As an alternate, these pumps can also discharge to the pug mills or simultaneously to both locations.

Three 50 percent capacity vacuum filters are provided. Each filter has a 12 foot diameter drum that is twenty-four feet long. The filter sizing is based upon a dry solids loading of 60 pounds of dry solids per square foot per hour and the production of a filter cake that contains 50 percent solids. The filter cake discharged from the vacuum filters is conveyed by belt conveyors to the pug mill mixers, while the filtrate is returned to the waste slurry thickeners via the filtrate tanks and pumps.

Two 100 percent pug mill mixers are furnished. Each mixer has a 175 ton per hour processing rate. As chosen by the equipment operator, the pug mill mixers combine lime with fly ash and filter cake from the vacuum filters or with thickener underflow slurry, or with both. Alternatively, the equipment operator can choose to have the pug mill mixers combine fly ash with either make-up water or with process liquor if FGD sludge is unavailable. Fly ash for feed to the pug mil1 mixers is stored in two 600 ton capacity silos. The combined storage capacity of these silos represents approximately 50 hours of fly ash production by the station. Lime, which is added to the pug mill mixers when FGD sludge and $f l y$ ash are mixed to enhance the stabilization process is stored in two 150 ton capacity storage silos. Based upon a maximum lime addition rate of 0.05 pounds of lime per pound of dry solids, a five day supply of lime is available.

Wastes discharged from the pug mill mixers are conveyed by a series of belt conveyors to truck loading stations or to a final stackout conveyor. The stackout conveyor is rated at 175 tons per hour. The waste is normally loaded directly onto trucks for transport to the disposal areas. However, if truck service is interrupted, the waste can be conveyed to the stackout area, which provides storage for up to four days of material. 
ACCOUNT 226.6 Miscellaneous Desulfurization Equipment

Included in this account are the FGD make-up water and seal water systems, and the flue gas booster fans. The make-up water system receives water from the plant intake water system and provides limited storage prior to distributing to the FGD subsystems. The seal water system receives water from the plant's intake water system and process liquor from the FGD waste thickening system in order to provide a process liquor/make-up water mixture for equipment seals in the absorber system. This blending capability is provided to reduce FGD system make-up water requirements, if necessary, in order to achieve closed-loop operation. The make-up water system includes: a 100,000 gallon tank; three $1000 \mathrm{gpm}$ pumps; piping, valves, instrumentation and controls. The seal water system includes: a 35,000 gallon blending tank; two $250 \mathrm{gpm}$ pumps; two 100 percent self cleaning strainers; piping, valves, instrumentation and controls.

Two half-size flue gas booster fans are provided to increase the flue gas pressure sufficiently to overcome the pressure drop through the sulfur dioxide absorber modules and downstream ductwork. The booster fans take suction from the induced draft fan discharge plenum (refer to Account 222) and discharge into the absorber module ductwork. The fans are driven by direct coupled single speed motors.

\section{ACCOUNT 227 Steam Generator Plant Instrumentation and Control}

The steam generator plant instrumentation and control system provides monitoring and protection for plant, personnel and equipment and it enables the operator to start up, operate and shut down the boiler. Monitors are provided for $\mathrm{SO}_{2}, \mathrm{NO}_{\mathrm{x}}$, particulates and oxygen to insure compliance with federal emission standards and other applicable regulations.

\section{Boiler-Turbine-Generator Control Board (BTG)}

The boiler-turbine-generator control board is a hard-wired, walk-in, "L"shaped, duplex control board, designed in accordance with appropriate IEEE standards. It contains the control and information devices necessary for remote operation of the unit. Arrangement of the controls within the BTG control board is system oriented. Within systems it is train and/or loop oriented. Instrument configurations and arrangements follow human enginneering factors principles.

Overall arrangements are coordinated to assure safe and efficient operation. The front panels of the BTG control board contain the controls and information displays for the coordinated control system, boiler control system, boiler auxiliaries, turbine, turbine auxiliaries cooling water systems, generator, generator auxiliaries, and electrical auxiliary power distribution system. The rear panels of the BTG control board contain controls and instrumentation for miscellaneous support systems, that do not require continuous operator attention. 
Space is provided on the BTG control board for inserts of the following items: electro-hydraulic control insert, load/frequency control equipment insert, burner control insert, and computer CRT with keyboard. Computer console, printers and trend recorders are mounted separately from the BTG board. The coal handling, ash handling, flue gas desulfurization and other auxiliary systems are also controlled from the BTG control board.

The use of combustible materials within the BTG control board is prohibited. Each component is clearly identified with a distinctively colored permanent tag. Colored nameplates are employed on exterior surfaces of the BTG control pane1 to identify component function.

The BTG control board is composed of three sections: the boiler control board, the turbine plant control board and the main generator and auxiliary electric power system control board. The boiler control board is discussed under this account description. The turbine plant control board is discussed under Account 236. The main generator and auxiliary electric power system control board is discussed under Account 243.

\section{Boiler Control Board}

The boiler control board is a part of the BTG control board described above. Necessary devices and control logic for remote operation of the steam generating unit and its auxiliaries are mounted on and in this control board. In addition to these controls, the boiler control board houses the coordinated control system and the burner control system.

Coordinated Control System: The coordinated control system operates the boiler and turbine-generator as an integrated unit. This system coordinates the regulation of the following:

- feedwater flow,

- fuel feed,

- air flow,

- main steam temperature control,

- reheat steam temperature control, and

- turbine servo (load reference motor).

The system is designed to minimize interactions between the values to be controlled (the unit generation, steam pressure and steam temperature) by proper adjustment of feedwater, fuel, air, turbine control valve and steam temperature regulating equipment. The system has the flexibility of operating in one of three modes: coordinated mode, boiler follow mode, or turbine follow mode. 
Burner Control System: The burner control system is designed to prevent continued operation of the steam generator where a hazardous furnace condition could exist, and to assist the operator in starting and stopping of the burners and fuel feed equipment.

The control system consists of four major subsystems:

- furnace purge system,

- burner/pulverizer mill control system,

- boiler fuel safety system, and

- alarm system.

The furnace purge system insures that the boiler is adequately purged under the conditions and in the proper sequence prior to igniting the first fire in the boiler. The burner/mill control system allows remote operation of the ignitors and burners. The subsystem is designed to follow a predetermined set program in safely placing ignitors and burners in and out of service. The boiler fuel safety system is designed to shut off all fuel to the furnace in the event that predetermined potentially hazardous conditions should deve1op during operation. Examples of these conditions are loss of flame, excessively high or low furnace pressure, or loss of primary air. The alarm system alerts the operator to the existence of certain equipment malfunctions such as mill trip, main flame fallure and detector failure.

Heating, Ventilating and Air Conditioning (HVAC) Panels

These panels provide monitoring and control of the HVAC systems for the steam generator building.

Logic Panels and Cabinets

These panels and cabinets furnish mounting space for analog devices, such as function generators, summers, dividers, analog controllers and selectors. Typical process control loops which have analog devices in these panels and cabinets are: feedwater turbine speed control, soot blowing, coal handling, ash handling, and compressed air supply.

\section{Instrument Racks}

Open type instrument racks are provided to mount local instruments such as pressure transmitters, manifolds, pressure switches, and other pneumatic instruments that connect directly with the process pipes. Each rack has a rigid structure, suitably braced, to withstand stress incidental to shipping, installation and operation without warping or twisting. Instruments, electrical devices and conduits on the racks are placed out of the paths of condensation or water drains from testing or calibrating instruments. Sufficient clearance is provided for maintenance or replacement of the instrumentation 
without interruption of service to adjacent devices. There is provision to collect the drains when an instrument is removed. Suitable engraved plastic nameplates are provided for each instrument.

\section{Process Computer}

The process computer system is designed to provide real time, on-line data acquisition, alarm monitoring, data manipulation, and performance calculation functions while providing data display to the plant operators. Sequence of events and post trip review functions, as well as normal alarm recording data, group logs and periodic logs provide additional historical recording functions.

The system combines state-of-the-art computer hardware with color CRTs to assemble and display plant performance data and plant status information.

Normal operation of the plant is not dependent on the availability of the process computer system. The design objectives of the computer are summarized below:

a. Reduce the amount of information that an operator must monitor.

b. Reduce the size of the BTG control board.

c. Improve the operator's perception, decision making, and response time.

d. Provide dynamic alarm indications.

e. Provide graphic display of system parameters and process trends.

f. Provide graphic comparison of design limits and actual performance.

g. Provide boiler performance and fuel management data.

h. Provide turbine plant performance calculations and displays.

\section{Boiler Plant Instrument Tubing and Fittings}

The scope of supply of instrument tubing begins at the first accessible root valve at the piping and extends to the instrument shut of $f$ valve. Materials and certification of instrument lines which are part of the pressure boundary are in accordance with Instrument Society of American Standards. 
Mechanical key parameters related to the turbine plant are given in Items 33 through 36 and 39 through 41 of Table 5-1. A steam heat balance is given in Figure 5.5. The table and figure supplement and amplify the following discussion of Account 23.

The turbine plant equipment includes the steam handling, power conversion and condensate/feedwater machinery of the steam cycle. A11 turbine plant equipment is designed to support turbine operation at the valves wide open, five percent overpressure point (VWO, $5 \%$ OP).

The thermal energy from the combustion of coal generates superheated steam in the boiler. The main steam piping supplies this steam to the throttle/ control valves of the turbine-generator unit. The steam turbine is a tandemcompound four-flow machine which develops the mechanical energy to drive the electric generator at $3600 \mathrm{r} / \mathrm{min}$. Normally, 64 percent of the steam generator outlet flow passes through the turbine and exhausts into the condenser. The remaining 36 percent of the flow is extracted at various stages from the turbine for the seven stages of feedwater heating and the auxiliary steam turbine drives for the boiler feedwater pumps.

Cold reheat pipes carry approximately 90 percent of main steam inlet flow from the high pressure turbine exhaust to the reheater section of the boiler. Hot reheat piping supplies reheated steam to interceptor valves that control steam flow to the intermediate pressure turbine.

Condensate is pumped from the condenser hot-wells by three 50 percent capacity condensate pumps through 100 percent flow deep bed polishing deminera1izers, the steam packing exhauster condenser, and through the four stages of low pressure heaters to the deaerator. Two 50 percent capacity turbine driven feedwater pumps supply water from the deaerator storage tank to the high pressure feedwater heaters to raise the feedwater temperature to $475^{\circ} \mathrm{F}$ before entering the economizer inlet of the boiler.

Interconnecting piping systems are included with each turbine plant auxiliary system, either at the three-digit or lower order code-of-accounts leve1 of detail. They comprise the piping, fittings, valves, steam traps, strainers, specialties, hangers and supports, insulation and other components required for a complete system. Materials and wall thicknesses are chosen based on the service conditions and operational requirements of each system. The factors generally considered include: temperature, pressure, corrosion resistance, abrasion resistance, fluid purity requirements and cost. Carbon steel is used for steam (below $750^{\circ} \mathrm{F}$ ), clean water, air, oil and other services without special requirements. Other materials used include: chromiummolybdenum alloy steel, stainless steel and stainless steel tubing.

The paragraphs given below provide brief technical descriptions that preview the more detailed descriptions given in the pages that follow. 
Account 231 Turbine-Generator (turbomachinery, generator, exciter, stator cooling water system, gas systems, hydrogen seal oil system, electro-hydraulic control system, turbine gland steam sealing system, lubricating oil system and turbine oil storage and conditioning system)

Account 232 Not used

Account 233 Condensing System (condensers, condensate system, condenser gas removal system, and condensate polishing system)

Account 234 Feedheating System (feedwater heaters, feedwater system, and extraction steam system)

Account 235 Other Turbine Plant Equipment (main vapor piping system, turbine building closed cooling water system, demineralized water make-up system, chemical treatment system and neutralization system)

Account 236 Turbine Plant Instrumentation and Control (turbine plant control board, panels, cabinets and racks, and process computer) 


\section{ACCOUNT 231 Turbine-Generator}

The turbine-generator produces 523 MWe at the generator terminals with rated load throttle steam conditions of $24.15 \mathrm{psia} / 1000^{\circ} \mathrm{F}, 531 \mathrm{psia} / 1000^{\circ} \mathrm{F}$ reheat, zero percent make-up, 2.5 in-HgA back pressure, turbine driven feedwater pumps, and seven stages of feedwater heating. With an estimated 35 MWe station auxiliary load, 488 MWe is delivered to the generator step-up transformer for off-site transmission.

For brief periods during the summer, when the ambient wet bulb temperature approaches the site maximum of $74^{\circ} \mathrm{F}$, the condenser pressure may rise above 2.5 in-HgA, limiting turbine-generator performance. During the worst condition, the condenser pressure will not exceed $3.0 \mathrm{in}-\mathrm{HgA}$ which causes a reduction in generating capability and a corresponding increase in heat rate. The cumulative total of these periods during which performance is limited by the ambient temperature is estimated as 800 hours per year.

The turbine is a $3600 \mathrm{r} / \mathrm{min}$ tandem-compound machine with four-flow exhaust and 30 inch last stage blades. It consists of a single flow high pressure section, a single flow intermediate pressure section and two double flow low pressure sections. The throttle flow at rated load is 3,500,000 pounds of steam per hour.

The cold reheat steam exhausts from the high pressure turbine and passes through the reheater section of the boiler. Hot reheat steam at $1000^{\circ} \mathrm{F}$ returns and passes through four interceptor valves to the intermediate pressure turbine. Exhaust from the intermediate pressure turbine passes to the low pressure turbines.

The turbine is provided with a low speed turning gear for rotating the turbine spindle after shut-down. Low speed rotation is required for uniform cooling and thermal contraction of the rotating parts.

The "high-tuned" turbine pedestal is reinforced concrete and is supported on a thick reinforced concrete foundation mat bearing on rock. The turbine pedestal is isolated from the remaining building support loads.

\section{Generator}

The generator has a rating of 610 MVA with $0.90 \mathrm{PF}, 25,000 \mathrm{~V}, 3$ phase, $60 \mathrm{~Hz}$. It is a totally enclosed $3600 \mathrm{r} / \mathrm{min}$ machine utilizing hydrogen at 75 psig to cool the rotor and stator end turns. The stator is a liquid conductor-cooled type with deionized water as the liquid coolant.

The generator is furnished with the following equipment: cooling system, including hydrogen coolers; terminal bushings; instruments; grounding pads; bearing seals; housing insulation; foundation plates and shims; and special tools. 
The generator stator is serviced by the following external equipment: a deionized water circulating and cooling unit assembled on a skid, including storage tank, pumps, coolers, deionizer, flow meter, conductivity cells, gauges, piping, valves, filters, instruments, and regulating equipment; and a stator winding cooling control cabinet assembled and combined with the hydrogen cooling control cabinet, including annunciator, generator automatic runback logic and all necessary control devices.

\section{Exciter}

The exciter is of the direct driven alternator and rotating silicon diode rectifier type. It has a 2.5 response ratio and is designed for $3600 \mathrm{r} / \mathrm{min}$. The alternator bearings, the silicon diode rectifier assemblies, and the main generator collector and brush rigging are all enclosed within the exciter housing. The housing is furnished with suitable water-to-air heat exchangers and a closed ventilation circuit for circulating the cooling air.

The excitation switchgear is a metal enclosed integrated unit of standard low voltage design that is located indoors. The function of the excitation switchgear is to connect, rectify and control excitation to the ac alternator exciter from the alternator stator, and to provide voltage regulation by adjustment of the generator field voltage (dc regulator) or the generator terminal voltage (ac regulator). The excitation switchgear houses the exciter fleld breaker, the thyristor regulator bridge and the ac and $d c$ regulator $\log 1 \mathrm{c}$.

\section{Stator Cooling Water System}

The stator cooling water system provides deionized cooling water to the windings of the generator stator. Coolant deionization reduces electrical conduction losses and ensures good dielectric behavior. Pipes and fittings in contact with deionized water are stainless steel, brass and copper.

The deionized water is pumped from a storage tank by an exciter shaft or motor driven circulating pump through a heat exchanger and filters into the cooling circuit inside the stator conductors and back to the storage tank. If the conductivity of the cooling water exceeds a preset value at the outlet of the first filter, some of the flow is diverted through a mixed bed demineralizer which discharges into the storage tank.

\section{Gas Systems}

Hydrogen and carbon dioxide gas systems are provided for controlling the atmosphere within the main generator housing.

Hydrogen gas is utilized to cool the generator rotor and the stator end turns and to reduce rotor windage losses. The hydrogen is circulated within the generator housing under pressure. The heat from electrical and mechanical losses is removed by two she11 and tube type coolers located at each end of the generator housing. 
The hydrogen is supplied from a series of hydrogen storage containers which are individually connected to a manifold. The manifold is equipped with a relief valve, generator pressure and bottle pressure regulators with isolation valves, high and low pressure gauges, a pressure switch for hydrogen supply pressure "low" alarm and bottle connectors. A hydrogen control cabinet is provided on which are mounted hydrogen purity gauges, temperature detectors and other devices required to ensure safe and effective operation of the hydrogen control system. Enough hydrogen supply is provided to fill and pressurize the generator once and supply the required make-up for a nominal operating period.

The carbon dioxide system consists of a liquid carbon dioxide storage unit with refrigeration system, vaporizer, relief valves and two pressure reducing valves. Carbon dioxide is used for purging hydrogen from the generator housing during shut-down, and for purging air from the housing before being filled with hydrogen during start-up. Sufficient capacity is provided to purge the system of air twice and of hydrogen once.

\section{Hydrogen Sea1 0i1 System}

The hydrogen seal oil system provides oil to the generator hydrogen seal assemblies to prevent the escape of hydrogen into the outside atmosphere from the inside of the generator housing.

oil is pumped from a gas detraining tank, through a filter, to a hydrogen seal assembly located at each end of the generator shaft. Some of the oil passes through the two seal assemblies towards the hydrogen side and comes in contact with the hydrogen inside the generator. This ofl absorbs bubbles of hydrogen and is collected in an oil manifold which is connected to the gas detraining tank by piping. Hydrogen diffuses towards the surface of the oil inside the tank. Vacuum pumps dispose of the hydrogen by transferring it to the outside atmosphere.

\section{Electro-Hydraulic Control (EHC) System}

The electro-hydraulic control system consists of the speed control unit, the load control unit and the flow control units for the turbine machinery. The speed control unit compares actual turbine speed with a speed reference, or actual acceleration with an acceleration reference, and provides a speed error signal for the load control unit. The load control unit combines the speed error signal with the load reference signal to determine the desired steam flow signals for the stop valves, control valves and intercept valves. Finally, the valve flow control units accurately position the appropriate turbine valves to obtain the desired steam flows through the turbine.

A high pressure fluid system is provided to convert the low power level signals from the EHC circuits to high power level mechanical outputs for positioning the large steam valves. This system consists of a fluid reservoir, two independent pumping systems, fluid coolers, accumulators, a fluid transfer unit and a filter unit. 
HS5 ACCOUNT 23

\section{Turbine Gland Steam Sealing System}

The turbine gland steam sealing system seals the turbine shaft at turbine shell penetrations under all conditions of turbine loading. The sealing system prevents alr in-leakage along the shaft (high pressure and intermediate pressure turbines during start up and low pressure turbines at all load conditions) and steam outleakage from the high pressure and intermediate pressure turbines during partial load and full load operation. In addition to sealing the main turbine, the gland steam sealing system seals the boiler feed pump turbines and the main turbine main steam and intercept valves.

Another function of this system is to provide steam for prewarming the turbine internals and rotor while on turning gear prior to start-up.

Each turbine shaft end is provided with a series of labyrinth packings and two glands. The outer glands of each shaft are piped to, and maintained at a pressure slightly below atmospheric by, the steam packing exhauster. Steam leaking outward through the packings and air leaking inward are collected in the outer gland and drawn of $f$ to the steam packing exhauster.

The steam packing exhauster consists of a shell and tube type service condenser with two motor driven air removal blowers. The blowers create a vacuum of three to five inches of water which draws steam and air from the outer gland of each turbine shaft seal into the condenser shell. With condensate as a coolant, the steam is condensed and drained into the main condenser, while the air is removed by the blowers to atmosphere.

The inner glands of each shaft are connected by pipes to the seal steam header. The header is maintained at an acceptable pressure by a group of control valves and safety valves which admit supplemental steam when needed from the main steam piping, cold reheat piping or auxiliary steam piping, and "spi11" excess steam when needed to the main condenser.

During start up, steam from the auxiliary steam system or main steam system is supplied to the seal steam header and from there to all the inner glands. This steam flows through the labyrinth packings inward toward the turbines and outward to the outer glands. As load increases with a corresponding pressure increase inside the high pressure and intermediate pressure turbines, flow direction through the inner glands of these turbines reverses. Stean from inside the turbines flows outward to the seal steam header. (This does not occur with the low pressure turbines, which always require external steam to be supplied.) As steam from the high pressure and interemediate pressure turbines is supplied to the seal steam header, the amount of supplemental steam required decreases.

As the load continues to increase, the quantity of steam being supplied by the high pressure and intermediate pressure turbines exceeds the quantity required for sealing the low pressure turbines, boiler feed pump turbines and main turbine valve stems. The excess is "spilled" to the main condenser. 
The sealing system operates automatically at all load conditions.

\section{Lubricating OiI System}

The lubricating oil system supplies oil to the main turbine-generator bearings, the thrust bearing wear detector, the overspeed trip reset, and the oil trip. The system equipment includes pumps, oil coolers, a lube oil reservoir, and necessary interconnecting piping and controls.

A main turbine shaft driven centrifugal pump normally supplies the required bearing lubricating oil. During start-up and shut-down, this shaft driven pump is primed by an ac motor driven suction pump. When the unit reaches 95 percent of rated speed, an oil tank booster pump takes over for the motor suction pump. This booster pump is driven by an oil turbine utilizing the discharge from the shaft driven centrifugal pump.

Additional pumps include the ac turning gear oil pump and the dc emergency bearing oil pump. Both the ac motor driven suction pump and the ac motor driven turning gear oil pump start automatically on low oil pressure. The dc emergency bearing oil pump is powered by the station batteries and is used as a final back-up source for lubricating oil.

The lubricating oil system reservoir contains a screen for removing foreign materials from the oil drained into the reservoir and the following additional equipment: vapor extractor, air ejector, pressure control orifices and flow check valves, two oil coolers, float-type oil level indicator with high and low level alarms, and pressure switches with test valves for automatic starting of the turning gear and emergency (ac and dc) motor driven oil pumps.

\section{Turbine 0i1 Storage and Conditioning System}

The turbine oil storage and conditioning system provides storage for new and used turbine lubricating oil, continuous on line purffication of the oil in the main turbine reservolr and in the steam generator feed pump turbines reservoirs, and transfer between the reservoirs, storage tanks and trucks. It can also be used for batch cleanup of contaminated oil during a unit outage.

The storage and transfer portions of this system are common to the main turbine and the steam generator feed pump turbines, but separate purification equipment is provided. The storage and transfer portions of this system include: one clean and one dirty oil storage tank, a transfer pump and interconnecting pipe, fittings and valves. Purification equipment includes: an ac motor driven centrifuge, positive displacement inlet and discharge pumps, electric heater, necessary instruments, transfer switch, feed/stop valve and electric controller with safety interlocks. The purification system for the main turbine has a capacity of 1050 gallons per hour of 150 SSU lubricating oil at $100^{\circ} \mathrm{F}$. The electric heater is $60 \mathrm{~kW}$. Equipment for the feed pump turbine drives is proportionately smaller. 
HS5 ACCOUNT 23

During normal plant operation, lube oil from the main turbine reservoir and from the steam generator feed pump turbines reservoirs overflows to the lube oil conditioning unit where water and solids are removed by the centrifuge. The cleaned oil is returned to the reservoirs. This continuous bypass method of operation provides maximum protection against turbine damage due to contaminated oil.

Each of the storage tanks can hold a full inventory of oil to permit batch replacement or batch cleaning of the full inventory during a plant outage.

New oil received by truck can be pumped by the truck's onboard pumps to either the clean or dirty oil storage tank or the lube oil conditioner, but not directly to the turbine reservoirs. By making all oil to the reservoirs go through the lube oil conditioner, risk of contamination is minimized. Discharge of used oil to trucks is done with the lube oil transfer pump.

During a plant shut-down, it is possible to batch purify oil held in any of the reservoirs, the clean oil storage tank or the dirty oil storage tank and return the purified oil to any of these locations.

The lube oil conditioning unit is capable of reducing the moisture to 0.1 percent by volume and reducing solids contamination to 0.02 percent by volume without removing additives or increasing the oil acidity.

ACCOUNT 233 Condensing System

The 1ongitudinal mounted single shell surface condenser is a single pressure, single pass design with divided fabricated steel water boxes. The condenser is designed to handle the total heat rejection from the main turbine and the two auxiliary turbine drives for the feedwater pumps. The condenser has a condensing surface of 332,600 square feet composed of $31,2603 / 4$ inch diameter, 18 BWG (Birmingham Wire Gage), 90-10 CuNi tubes, 55 feet 1ong. Cooling water flow is $227,700 \mathrm{gpm}$ resulting in a tube velocity of seven feet per second and a temperature rise at full load of $22^{\circ} \mathrm{F}$.

The condenser shell is floor mounted and connected to the turbine exhaust flange by means of a rubber expansion joint to accommodate thermal expansion. The tube sheets are bolted to the shell with provisions for thermal expansion of the tubes. The tubes are rolled into the holes in the tube sheets with flared ends to reduce entrance and exit losses.

The shell is carbon steel welded construction with $1 / 16$ inch corrosion allowance. The water boxes are fabricated steel construction and are bolted to the condenser she11. They are designed for easy removal without disturbing the tube sheets. The hotwell capacity of the she11 is 33,000 gallons at normal water level.

The hotwell is designed to deaerate the condensate to limit dissolved oxygen to a maximum of five parts per million at the outlet during normal steadystate operation. 
HS5 ACCOUNT 23

\section{Condensate System}

The condensate pumps are of the vertical "can" type, suitable for the net positive suction head requirements of condenser hotwell service. The pumps develop sufficient head to ensure adequate delivery of the condensate to the deaerator after overcoming the pressure drop in the condensate piping, steam packing exhauster condenser, condensate polishing demineralizers and the four low pressure stages of feedwater heaters.

Three half-size motor driven pumps are supplied. The third pump is on standby service or is isolated for maintenance. In addition to the main flow, the condensate pumps supply seal water to various equipment such as the condensate pump seals and steam generator feedwater pump glands. The condensate pumps also discharge excess condensate to the condensate storage tanks and supply water to the turbine exhaust hood sprays.

The condensate storage tank is a field erected tank made of carbon steel. Its foundation is a reinforced concrete ring wall 18 inches thick with the mean diameter equal to the tank diameter. The top of the ring wall is six inches above grade, and the bottom is four feet below grade. Tank anchor bolts are set in the ring wall. A compacted sand bed is provided inside the ring wall to support the tank floor.

Condenser Gas Removal System

Two full-size mechanical vacuum pumps are supplied for removing non-condensible gases from the condenser shell. During start-up, both pumps operate to minimize the evacuation time. When an acceptable vacuum is reached, one pump is placed in the standby mode. Normally, one pump is adequate to maintain the condenser vacuum. If the condenser pressure rises, the standby pump starts automatically. To avoid cycling, the standby pump is manually stopped.

The vacuum pumps are motor driven rotary two-stage units. The seals for the pumps utilize demineralized water and a closed cooling system integrated with each pump assembly. Circulating water is used for cooling.

\section{Condensate Polishing System}

One complete condensate polishing system is provided that is capable of treating 100 percent of the condensate flow. The condensate polishing system removes both dissolved and suspended impurities from the condensate stream by a combination of filtration and ion exchange. The system consists of four individual high flow rate, deep bed type demineralizers operating in parallel. At maximum flow conditions, three of the demineralizers are in service with the fourth acting as a standby. Each demineralizer has a resin charge of 135 cubic feet, consisting of 90 cubic feet of cation resin and 45 cubic feet of anion resin. Each demineralizer is seven feet in diameter, and has a flow rate of $2,000 \mathrm{gpm}$ ( $50 \mathrm{gpm}$ per square foot of flow area). The vessels are steel, lined with rubber, and have stainless steel internals. The vessels are designed for operating conditions of 500 psig at $130^{\circ} \mathrm{F}$. 
A mixed bed polishing vessel will normally remain in service until its cycle is terminated due to either a high accumulation of solids, indicated by excessive pressure drop, or exhaustion of its ion exchange capability, indicated by high effluent conductivity. At the termination of a service cycle, the exhausted resin is sluiced hydraulically from the polishing vessel to the resin separation/cation regeneration vesse1. Within this vessel, the resin charge is separated into cation and anion portions. The anion resin is then sluiced to the anion regeneration vessel before chemical regeneration is commenced. Cation resin is regenerated with a dilute solution of sulfuric acid; anion resin is regenerated with a warm dilute solution of sodium hydroxide. To lengthen the service cycle of the resin charge, the system has the optional capability to recycle a dilute ammonia solution between the resin contained in the two external regeneration vessels. Following regeneration, the resins are sluiced to the resin storage vessel where they are remixed and stored.

Provided as part of the condensate polishing system are chemical storage tanks and pumps for acid, caustic and ammonia, a caustic dilution water heater, an air blower, condensate pumps, piping, valves, instrumentation and a control panel designed for semi-automatic operation.

\section{ACCOUNT 234 Feedheating System}

Seven stages of feedwater heaters are utilized to heat the feedwater returning to the boiler. Heaters are placed in series with each stage operating at increasing extraction pressure along the feedwater heater train. Pressures are maintained by various stages of extraction steam from the high pressure, intermediate pressure and low pressure turbines. Heating the boiler feedwater in this manner improves the overall cycle efficiency.

Heaters 1 through 4 and 6 and 7 are closed type heaters having a horizontal "U"-tube arrangement, using stainless steel tubes. Heater 5 is a horizontal tray type deaerator with a storage tank sized for five minutes operation at valves wide open, five percent overpressure turbine operation. The deaerator and storage tank are elevated to provide adequate NPSH for the steam generator feedwater booster pumps. The condensate and heating steam are intimately mixed in the deaerator such that the condensate is brought to saturation temperature. This 1 iberates any remaining dissolved gases which are vented to atmosphere. If not removed, these dissolved gases could damage the steam generator tubes. Each closed heater has an integral drain-cooler section. The drains from Heaters 2 through 4 and Heater 7 cascade to the next lower pressure heater through a control valve that maintains water level within the she11: The drain from Heater 6 cascades to the deaerator. Drains from Heater 1 cascade to the condenser. The deaerator storage tank discharges to the suction of the feedwater booster pumps.

Due to the physical size of the heaters required for the first stage of feedwater heating, two parallel trains of heaters are utilized for this stage, with each individual heater being sized for one-half capacity. These heaters are installed in the condenser necks below the two low pressure turbines. 
Heaters $2,3,4,6$ and 7 are each single she1l 100 percent capacity heaters and are located in the heater/auxiliary bay, together with the deaerating heater and its storage tank. Only the two highest heater stages are in the discharge of the feedwater pump and subject to full system pressure. The four low pressure heaters are subject only to the discharge pressure of the condensate pumps.

To allow for maintenance, a bypass 1 ine and valve are provided for each closed heater stage. Although the first stage may be bypassed, maintenance cannot be performed until the unit is shut down (due to its location in the condenser neck).

\section{Feedwater System}

Feedwater leaving the deaerator storage tank flows to the suction of the booster feedwater pumps, where its pressure is increased to provide adequate NPSH for the boiler feed pumps which are in series with the booster feedwater pumps. At the discharge of the boiler feed pumps, the pressure is sufficient to deliver the water through the two high pressure feedwater heaters to the boiler economizer inlet, and maintain the required main steam pressure.

The booster feedwater pumps are single stage horizontal centrifugal pumps directly driven by nominal $1800 \mathrm{r} / \mathrm{min}$ motors. Each pump is sized to deliver 52 percent of the flow at valves wide open, five percent overpressure turbine operation to the suction of one boiler feed pump. The booster pump total dynamic head of 416 feet provides a sufficient margin above the NPSH required for the boiler feed pump.

The two boiler feed pumps are multi-stage barrel type centrifugal pumps each driven by a stean turbine to provide water at 1200 psia to the high pressure feedwater heater. Each pump is designed for 52 percent of the flow required at valves wide open, five percent overpressure turbine operation. This provides a margin for seal leakage and/or wear.

The boiler feed pump drives are each dual-admission, multi-stage, non-extraction condensing turbines. Normally extraction steam from the main turbine is used to drive this turbine. During low load operation, the dual-admission inlet allows use of main steam when the pressure of the extraction steam is too low. For start-up, auxiliary boiler steam is supplied through the low pressure inlet. The turbines exhaust through ducts to the main condenser. To account for pressure drop through the ducts, these auxiliary turbines are designed for a backpressure of $0.5 \mathrm{in}$-HgA higher than the main turbine.

\section{Extraction Steam System}

The extraction steam system conveys steam extracted from selected stages of the turbines to:

a. The shell side of the closed feedwater heaters where it condenses heating the feedwater which is in the tubes. 


\section{HS5 ACCOUNT 23}

b. The deaerator where it mixes with and heats the feedwater.

c. The boiler feed pump drive turbines.

d. The combustion air preheating coils.

e. The plant auxiliary steam system.

All extraction lines, except the lowest pressure extraction are provided with motorized shut-of $f$ valves and non-return valves to prevent any back flow to the turbine. The lowest pressure extraction supplies steam only to the first stage feedwater heaters which are located in the condenser necks. Since this extraction steam pipe never exits the condenser, installation of any valves is physically impractical.

Extraction flow to the feedwater heaters is controlled only by the rate at which it condenses in the heater shell. When the steam condenses in the closed feedwater heaters $(1,2,3,4,6 \& 7)$, the drains are normally cascaded to the shell side of the next lowest pressure heater. A level control valve on the drain line keeps the drain cooler tubes submerged. An alternate drain on each heater shell bypasses the drain cooler section and drains directly to the condenser. These drains are automatically opened in response to a high liquid leve1 in the she11. The lowest pressure heater drains to the condenser. Heater 6 normally drains to the deaerator.

Extraction flow to the boiler feed pump turbines is controlled by the feed pump turbine inlet valves as discussed above.

Extraction flow to the air preheating coils is controlled by the air temperature control system and by a freeze protection system for the coils. Condensed drains are returned to the main condenser.

Extraction steam is supplied to the auxiliary steam system when it is available, in preference to producing it in the auxiliary boilers. Drains from users on this system are not normally returned to the main cycle.

ACCOUNT 235 Other Turbine Plant Equipment

This section discusses the remainder of the turbine plant equipment, such as the turbine building closed cooling water system, demineralized water make-up system, chemical treatment system and neutralization system.

\section{Main Vapor Piping System}

The main vapor piping system consists of the main steam and hot and cold reheat systems.

The main steam system conveys high pressure superheated steam from the boiler to the high pressure turbine. Chrome-molybdenum and stainless steel pipe is used in the main steam system. The main steam line is chrome-molybdenum alloy steel specially made in a non-scheduled size/wall thickness. 
The hot and cold reheat steam system conveys exhaust steam from the high pressure turbine to the boiler reheater and returns it to the intermediate pressure turbine. Chrome-molybdenum pipe is used for the hot reheat. Carbon steel is used for the cold reheat.

Each system comprises the main steam or reheat piping, auxiliary piping, fittings, necessary valves, steam traps and strainers, specialties, hangers, supports and insulation required for a complete system.

\section{Turbine Building Closed Cooling Water System}

Cooling of turbine plant and miscellaneous plant auxiliary equipment in the turbine building is accomplished with a closed recirculating cooling water system. Heat is rejected from this system to the main cooling towers through the service water system (refer to Account 252). The cooling water is circulated through the closed system by two 50 percent capacity motor driven pumps. A third pump is provided as a spare. A head/expansion tank assures adequate net positive suction head at the pump suction, and automatic replenishment of any water lost to leaks. It also provides an expansion volume to account for the varying volume of the water between cold fill and full load.

The heat absorbed by the cooling water is transferred to the service water in two 50 percent capacity shell and tube heat exchangers. Counter-flow exchangers are used, with the cooling water exiting the heat exchangers approximately $10^{\circ} \mathrm{F}$ warmer than the entering service water. Cooling water is on the shell side and service water is in the tubes.

Demineralized Water Make-up System

The demineralized water make-up system treats effluent water from the make-up water pretreatment system. This system produces a high quality demineralized water supply that is utilized as make-up to the steam cycle.

The system provides a maximum of 200,000 net gallons of demineralized water per day to storage. It consists of two trains of treatment equipment which utilize a common forced draft degasifier. Each train contains an activated carbon filter, a strong acid cation exchanger, a strong base anion exchanger and a mixed bed polishing vessel. Additional equipment provided as part of the demineralizer system includes bulk acid and caustic storage tanks, day tanks, regenerant pumps, a caustic dilution water heater, pumps, blowers, piping, valves and instrumentation.

Water directed to the demineralizer system is initially treated by the activated carbon filters. These filters are each four feet in diameter and contain a median bed depth of 2.5 feet. The filters protect the downstream ion exchange resin by removing any chlorine or organics from the water.

Following activated carbon filtration, the water is treated by strong acid cation exchangers. These vessels are each 4.5 feet in diameter and contain a resin charge of 40 cubic feet. The resin within these vessels is regenerated 
by a dilute solution of sulfuric acid. Following the strong acid cation exchangers, the water is combined and treated by a single forced draft degasifier four feet in diameter. The degasifier removes carbon dioxide from the water in order to reduce the anion loading on the downstream strong base anion exchangers.

The water is pumped from the degasifier to the strong base anion exchangers. These vessels are also 4.5 feet in diameter and contain 40 cubic feet of resin. The anion resin is regenerated with a warm dilute solution of sodium hydroxide. Following these vessels are the mixed bed polishing vessels. These vessels are each four feet in diameter and contain 20 cubic feet of cation resin and 30 cubic feet of anion resin. After treatment by the demineralized water make-up system, the product water is discharged to the demineralized water storage tank.

Al1 of the pressure vessels of the demineralized water make-up system are rubber-lined and are designed with 100 percent freeboard. Additionally, the system is designed so that each cation and anion exchange vessel is regenerated once per day at maximum flow. The activated carbon filters and the mixed bed exchangers require week $1 \mathrm{y}$ backwashing and regeneration when operated at maximum flow.

\section{Chemical Treatment System}

The chemical treatment system injects hydrazine and ammonia into the condensate/feedwater system downstream of the condensate polishing unit. The hydrazine chemically scavanges any oxygen not removed in the condenser. The ammonia maintains the condensate in an acceptable alkaline range by increasing its $\mathrm{pH}$ as required.

The hydrazine is received and stored as a 35 percent solution in 55 gallon drums and transferred to the solution tank where it is mixed with condensate to form a five percent solution. Filling the solution tank and making the proper solution is controlled manually. Two positive displacement metering pumps (one spare) inject the solution into the condensate piping, at a rate of up to five gallons per hour. Injection rate is automatically varied in proportion to condensate flow. The proportionality ratio is manually adjusted.

Aqueous ammonia is received by truck and stored in a 7000 gallon storage tank (included as part of the condensate polishing system). Two positive displacement metering pumps (one spare) transfer the ammonia directly from the bulk storage tank into the condensate piping, downstream of the condensate polishing unit, at a rate of up to five gallons per hour. Injection rate is automatically controlled in proportion to condensate conductivity. The ammonia is also used in the regeneration of the condensate polishing demineralizer.

\section{Neutralization System}

The neutralization system is designed to receive and neutralize the waste water from a complete regeneration cycle of either a condensate polisher or a 
make-up demineralizer train. The system consists of two sumps, each able to contain up to 26,500 gallons of waste water, which is equivalent to the volume of waste from one condensate polisher regeneration. Consequently, when the waste in one sump is being neutralized, the other is available to collect waste. Additional equipment provided are an air grid mixer in each sump, two 100 percent capacity $1000 \mathrm{cfm}$ air blowers, and four $500 \mathrm{gpm}$ acid/caustic resistant vertical sump pumps. Two of these pumps are provided per sump so that one pump per sump is considered to be a 100 percent spare. These pumps are used to recirculate the waste in the sump to enhance mixing and to transfer the neutralized waste to the waste water treatment equipment (refer to Account 255) for additional treatment and discharge.

The required acid and/or caustic for neutralization is supplied from the bulk storage tanks in the make-up water treatment area. Positive displacement acid and caustic chemical pumps, identical to the pumps provided for regeneration of the resin of the make-up water treatment system, are provided for delivering chemicals to the neutralization system. Chemical addition is automatically controlled based on $\mathrm{pH}$. Self-neutralization, based on mixing of the spent acid and caustic regenerants, is utilized to the maximum possible extent.

\section{ACCOUNT 236 Turbine P1ant Instrumentation and Control}

The turbine plant instrumentation and control system provides monitoring and protection for plant, personnel and equipment. It enables the operator to start up, operate and shut down the turbine plant in conjunction with the boiler plant.

\section{Turbine Plant Control Board}

The turbine plant control board is a part of the boiler-turbine-generator (BTG) control board described under Account 227. This portion of the BTG control board provides monitoring and control of the turbine and auxiliary process systems and components tabulated below:

\author{
Feedwater System \\ Heater Vents and Drains \\ Main Steam System \\ Turbine \\ Extraction Steam System
}

\author{
Condensate System \\ Circulating Water System \\ Service Water System \\ Turbine Supervisory and Control System \\ Instrument and Service Air Systems
}

Turbine Supervisory Pane1

The turbine supervisory panel is furnished with the main turbine-generator unit and is mounted on the turbine plant section of the BTG control board. The panel contains the multi-point vibration recorder for shaft vibration, the eccentricity, speed and position recorder, and the multipoint expansion and temperature recorder. An indicator is also provided for turbine shaft vibration phase angle. 
Electro-Hydraulic Control Cabinet

The electro-hydraulic control cabinet contains the control and indicating equipment required for the start-up, normal operation and testing of the turbine. This cabinet is furnished with the turbine-generator unit and is mounted as a subpanel on the turbine plant section of the BTG control board.

Typical control functions provided are:

Selection of starting rates: slow, medium or fast

Setting of turbine speed at start-up

Setting of load limit, and loading rate limit

Chest/she11 warming

Turbine trip

Selection of operating mode: standby, manual or remote

Selection of load: increase or decrease

Typical indicating functions provided are:

Turbine speed

Percentage of warming rate

Throttle steam pressure, first stage pressure, intermediate pressure

Generator output, MWe

Acceleration, $\mathrm{r} / \mathrm{min} / \mathrm{min}$

Valve positions for main stop valves, control valves and

intermediate valves.

Typical testing functions are provided for:

Thrust bearing wear detector

Backup overspeed trip

Electrical trip

Mechanical overspeed and piston trip

Main stop valves, control valves and intermediate valves.

Turbine Accessory Panels

Turbine accessory panels contain the instrumentation and control devices for various turbine auxiliary systems. These panels are field mounted or control room mounted. Control panels located in the field are furnished for such typical auxiliary systems as generator hydrogen and cooling water control, turning gear motor control, excitation control and reheater protection piping control. These panels are furnished with the main turbine-generator unit.

Heating, Ventilating and Air Conditioning Pane1s

These panels provide monitoring and control of the HVAC systems for the turbine, heater and control building. Typical HVAC systems controlled from these panels are the various turbine building and control building air handling systems. 


\section{Logic Panels and Cabinets}

These panels and cabinets provide mounting space for analog devices, such as function generators, summers, dividers, analog controllers and selectors. Typical turbine plant systems which have analog devices in these panels and cabinets are the condensate and feedwater systems, circulating water system, heater vents and drain system and main steam system.

\section{Instrument Racks}

These racks are similar in construction to those described previously under the same heading in the boiler plant instrumentation and control section under Account 227.

\section{Process Computer}

The computer for the turbine plant is the same computer used for the boiler plant. Refer to the boiler plant instrumentation and control section under Account 227.

\section{Turbine Plant Instrument Tubing and Fittings}

The material requirements of the turbine plant instrument tubing and fittings are similar to those for the boiler plant, as described in the boller plant instrumentation and control section under Account 227. 
Electrical key parameters related to the electrical plant are given in Items 42 through 51 of Table 5-1. The table supplements and amplifies the following discussion of Account 24.

The electric plant equipment conveys the electric power generated in the plant to the low voltage bushings of the generator step-up transformer (GSU), controls and meters the electric energy, and protects the components through which the power flows. It also conveys electric power from the electric generator, the off-site power system, or the emergency generators to the plant auxiliaries and the plant control, protection and surveillance systems during normal operation and emergency conditions.

Continuous ratings of equipment conveying power from the main generator to the GSU are based on valves wide open, five percent overpressure turbine operation and generator voltage variation of plus or minus five percent.

Continuous ratings of equipment serving plant auxiliaries and systems, as well as interrupting ratings of their protective and disconnecting devices, are based on equipment load tabulations, fault studies and voltage regulation studies. Equipment continuous current ratings are based on the maximum continuous load plus the largest spare auxiliary, and the effects of diversity. Short time intermittent loads are not included.

The electric plant design features are as follows:

a. The plant auxiliary distribution system design is based on a source voltage variation of plus or minus five percent.

b. The main generator, the three phase generator step-up transformers and the four three phase unit auxiliary transformers (UAT) are interconnected with isolated phase bus.

c. Four two- and three-winding unit auxiliary transformers (UAT), are connected to the generator main leads. Two are two-winding transformers rated at $24.5 \mathrm{kV}$ to $13.8 \mathrm{kV}$ and two are three-winding transformers rated at $24.5 \mathrm{kV}$ to $4.16-4.16 \mathrm{kV}$.

d. Two reserve auxiliary transformers (RAT), are connected to an off-site transmission system. One is a two winding transformer rated at $115 \mathrm{kV}$ to $13.8 \mathrm{kV}$ and the other is a three-winding transformer rated at $115 \mathrm{kV}$ to $4.16-4.16 \mathrm{kV}$.

e. The medium voltage ac distribution system is nominal1y $13.8 \mathrm{kV}$ and $4.16 \mathrm{kV}$. Two buses are provided for the 13.8 $\mathrm{kV}$ voltage level. Two $4.16 \mathrm{kV}$ buses each are provided for the boiler/turbine plant and the $\mathrm{SO}_{2}$ removal system. One $4.16 \mathrm{kV}$ bus is provided for the coal handling system. 
f. The low voltage ac distribution systems are a nominal 480 volts. Load center transformer/distribution buses are provided for the plant process systems; two for the precipitators, five for the coal handling system (two with the coal car thaw shed equipment) and six for the $\mathrm{SO}_{2}$ removal systems.

g. Two separate 120 volt nominal, uninterruptible power supplies/distribution buses fed from the 480 volt buses are provided. One supplies power to the instrumentation and control systems, while the other provides power to the plant computer.

h. The dc distribution and supply system is nominally $125 / 250$ volts. One center-tapped station battery and distribution system is provided.

i. One 125 volt battery charger is provided for each of the two 125 volt sections of the $125 / 250$ volt center-tapped battery.

j. Two 100 percent, $400 \mathrm{kWe}$ diesel-generator units are provided as the power supply for the emergency buses, and are automatically connected to their respective buses when the unit and reserve auxiliary transformer power sources are not available.

Motor starting voltage and frequency and allowable operational variations, at which the required starting and operating torques are developed, are as fo11ows :

a. Continuous operation of a-c motors

1) Voltage: \pm 10 percent of rated

2) Frequency: $\mp 5$ percent of rated

b. Starting and short time (approximately 30 seconds)

operation of ac motors (Voltage): 80 percent of rated

c. dc Motors (Voltage): 210 to 280 volts

Emergency loads are furnished with ac or dc power from one of the following: the ac emergency buses, the uninterruptible ac power supplies or the dc buses.

The unit power supply for the plant electric auxiliaries is from the main generator through the unit auxiliary transformers. The reserve power supply is from the $115 \mathrm{kV}$ off-site power supply via the reserve auxiliary transformers. The emergency power supply is from one of the two diesel-generator units to the corresponding emergency ac bus. 
Table 5-2 (refer to page 5-68) presents allowable ranges of temperature for electric equipment. Design ambient conditions for spaces housing electric equipment are based on these ranges and limits plus a minimum of five percent for margin.

The paragraphs given below provide brief technical descriptions that provide guidance to the more detailed descriptions that follow:

Account 241 Switchgear (station service switchgear)

Account 242 Station Service Equipment (station service and startup transformers, unit substations and auxiliary power sources)

Account 243 Switchboards (control boards and panels and auxiliary power and signal boards)

Account 244 Protective Equipment (general station grounding, lightning protection, cathodic protection, and heat tracing and freeze protection systems)

Account 245 Elecric Structures and Wiring Containers (underground duct runs and conduit and cable tray raceways)

Account 246 Power and Control Wiring (main generator bus duct and power wiring, control cable and instrument wire) 
TABLE 5-2

ENERGY ECONOMIC DATA BASE

PHASE VIII UPDATE (1986)

488 MWe HIGH SULFUR COAL FOSSIL POWER GENERATING STATION (HS5)

DESIGN AMBIENT CONDITIONS FOR ELECTRIC EQUIPMENT

\begin{tabular}{|c|c|c|c|c|}
\hline \multicolumn{3}{|c|}{ Limits } & \multicolumn{2}{|c|}{$\begin{array}{l}\text { Ambient } \\
\text { Temperature } \\
\text { Limit } \\
\left({ }^{\circ} \mathrm{F}\right)\end{array}$} \\
\hline \multicolumn{2}{|c|}{$\begin{array}{c}\text { Type of } \\
\text { Equipment }\end{array}$} & Limit & Equi pment & $\begin{array}{c}\text { Equipment } \\
\text { Space }\end{array}$ \\
\hline \multirow{2}{*}{\multicolumn{2}{|c|}{ Battery }} & Maximum & 90 & N/A \\
\hline & & Minimum & 77 & 80 \\
\hline \multirow{2}{*}{\multicolumn{2}{|c|}{ Cable }} & Maximum & 104 & 100 \\
\hline & & Minimum & N/A & N/A \\
\hline \multirow{2}{*}{\multicolumn{2}{|c|}{ 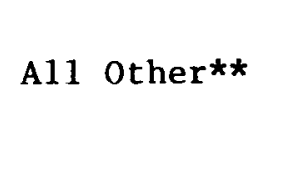 }} & Maximum & 104 & 100 \\
\hline & & Minimum & $40 *$ & $50 *$ \\
\hline \multicolumn{5}{|c|}{$\begin{array}{l}\text { * Or above dewpoint temperature, whichever is higher } \\
\text { ** Sensitive relays and other electrical devices are placed in } \\
\text { controlled environment spaces such as the control room, electronic } \\
\text { equipment room, computer room, or battery room, as applicable. }\end{array}$} \\
\hline
\end{tabular}


ACCOUNT 241 Switchgear

\section{Station Service Switchgear}

The medium voltage metal-clad switchgear comprises two $13.8 \mathrm{kV}$ buses and four $4.16 \mathrm{kV}$ buses. Each bus is supplied by an independent or shared winding of a UAT or by a shared winding of a RAT. Motors rated $2500 \mathrm{hp}$ and above are rated $13.2 \mathrm{kV}$ and motors rated $250 \mathrm{hp}$ to $2250 \mathrm{hp}$ are rated $4.0 \mathrm{kV}$.

Transfer schemes are provided for automatically and manually transferring each medium voltage bus between the reserve power supply and the unit power supply. Overcurrent and differential protection are provided for each incoming feeder circuit. Overcurrent protection is provided for all feeder circuits. Differential protection, overload protection and zero sequence overcurrent ground protection is provided for all medium voltage motor circuits.

Low voltage ( 480 volt) motor control centers are provided for power distribution to motors $100 \mathrm{hp}$ and below, lighting loads and miscellaneous loads such as motor-operated valves, resistance heaters, heat tracing and motor space heaters. These motors are rated at 460 volts. Overcurrent protection is provided for all incoming and feeder circuits. Overload protection is provided for all motor circuits.

ACCOUNT 242 Station Service Equipment

Station Service and Start-up Transformers

Four unit auxiliary transformers (UAT) and two reserve auxiliary transformers (RAT) are provided to furnish power to the plant auxiliary power system. Each UAT winding is sized with sufficient margin to carry the plant auxiliary load of its connected bus under the heaviest load conditions. Each RAT winding is sized to cover either the start-up load of its two or three connected buses or the plant auxiliary load of either one of its connected buses at the heaviest load conditions.

Transformer impedances are based on limiting fault current availability to switchgear capability considering the required range for voltage regulation. Each transformer is protected with overcurrent and differential protection schemes and sudden internal overpressure devices.

Unit Substations

Unit substations are provided to transform the medium distribution voltages to the distribution voltage of 480 volts for low voltage loads. Motors rated $125 \mathrm{hp}$ through $200 \mathrm{hp}$ are connected to the unit substation buses. These motors are rated at 460 volts.

Unit substation transformer impedances are based on matching switchgear capability to fault current availability considering voltage regulation. 
Overcurrent protection is provided for all feeder circuits. Overload protection is provided for all motor circuits. The distribution buses for the precipitators are fed from a loop feeder with a primary disconnect switch in each tap.

\section{Auxiliary Power Sources}

The battery systems comprise the plant batteries and battery chargers. The plant $125 / 250$ volt dc bus is supplied from a $125 / 250$ volt center-tapped battery and two 125 volt battery chargers, one for each 125 volt section of the $125 / 250$ volt battery. During normal operation, dc power is supplied from the battery chargers. During emergency operation, dc power is supplied from the batteries. During start-up and shut-down, dc power is supplied from whichever source is available.

Two diese1-generator units are provided as the on-site source of emergency ac power to the emergency buses. Each diesel-generator unit is a skidmounted unit complete with necessary auxiliary systems and controls. Minimum voltage that can be experienced at the diesel-generator units' terminals during motor starting is 85 percent.

Two dual input solid state inverters are provided to serve as uninterruptible power sources for miscellaneous ac and plant instrumentation loads. The inverters are supplied with power from the ac buses through regulating transformers or directly from the station batteries.

ACCOUNT $243 \quad$ Switchboards

Control Boards

Twelve feet of control benchboard are provided in the boiler-turbine-generator (BTG) control board described under Account 227, for control, monitoring and data acquisition of the main generator and the auxiliary electric power system functions tabulated below:

a. Main Generator

GSU Circuit Breaker

Grid/Generator Synchronizing

Excitation (Watts/Vars)

Auxiliary Systems

b. Auxiliary Power Distribution System

RAT Primary Switch

$13.8 \mathrm{kV}$ and $4.16 \mathrm{kV}$ Incoming Feeder Circuit Breakers

Load Center Incoming Feeder Circuit Breakers

Battery

Battery/dc Switchgear Main Circuit Breakers

Diesel-Generat or Units

Diesel-Generator Units Circuit Breaker 
One electric system relay panel lineup is provided in the main control room for protection and metering of the main generator, the generator step-up transformers and the unit and reserve auxiliary transformers. The main generator protection includes high speed differential, ground overcurrent, loss-of-field, negative sequence overcurrent, and distance relays. The generator step-up transformers and the unit auxiliary transformers are protected by individual and overall differential relays as well as overcurrent relays. The reserve auxiliary transformer is also protected by differential relays.

\section{Auxiliary Power and Signal Boards}

Two ac power distribution panels are provided to distribute ac power from the inverters to the 120 volt or $120 / 240$ volt uninterruptible loads. They are configured as one panel per inverter. Overcurrent protection is provided for all circuits.

One dc power distribution switchgear lineup is provided to distribute de power from the station batteries and their associated chargers. Overcurrent protection is provided for all feeder circuits. A ground detection scheme is provided for the dc bus.

\section{ACCOUNT $244 \quad$ Protective Equipment}

\section{General Station Grounding System}

The station grounding system provides the means for maintaining an effective ground at equipment and metal structures and for protecting personnel from dangerous potentials.

A complete grounding system is provided for equipment and raceways. It consists of jumpers from each cable tray and conduit to the ground grid, a bare copper ground wire run in and bonded to each cable tray, a ground bus mounted in each metal enclosure and connected to the ground grid, pigtails from equipment frames to the ground grid and a dedicated instrument grounding system.

A complete yard grounding system is provided as the plant grounding grid. It consists of building ground grids, unit ground grid and interconnections. Materials used include bare stranded copper conductors, copper clad steel ground rods, silicon-bronze connectors for above-ground connections and thermite process welds for below-grade connections.

\section{Lightning Protection System}

Underwriters Laboratories approved lightning protection schemes are provided for the steam generator building, the turbine hall and selected tall structures, such as coal conveyor towers and the plant stack. 
Cathodic Protection System

Cathodic protection is provided to minimize galvanic corrosion of selected buried metal structures and pipes. A complete integrated system is provided, including transformers, rectifiers, sacrificial anodes, coke breeze anode beds, special wire and terminations.

Heat Tracing and Freeze Protection System

Electric heat tracing freeze protection is provided for diesel-generator unit fuel oil piping and selected water piping located outdoors and above-ground.

A complete system is provided consisting of heat tracing wire, thermal cement, insulation, thermostats, control and alarm panels, and interconnecting power and control wire and raceways.

\section{ACCOUNT 245 Electric Structures and Wiring Containers}

\section{Underground Duct Runs}

The underground duct runs provide physical and environmental protection for wire and cable routed between buildings. The duct runs' non-metallic ducts are encased in reinforced and non-reinforced concrete. Reinforced concrete manholes are provided at appropriate places in long duct runs to facilitate cable pulling. Duct runs passing under roadways or railroads are encased in reinforced concrete.

\section{Conduit and Cable Tray Raceways}

The conduit and cable trays provide mechanical protection and physical support for wire and cable routed from point to point within structures. The bulk of the raceways consist of cable trays of various sizes. Raceways are routed in accordance with the same criteria as for cable routing described under Account 246. Fire stops are placed in cable trays wherever they penetrate floors or firewalls, and in other areas where their installation will reduce the hazard of fire propagation.

ACCOUNT 246 Power and Control Wiring

Main Generator Bus Duct

Isolated phase bus is provided to interconnect generator terminals, GSU low voltage terminals and UAT high voltage terminals. This bus is rated at 25 $\mathrm{kV}, 15,000$ amperes and is force-cooled with duplicate active components in the cooling unit. Tap buses to the UAT and to the potential transformers are self-cooled. 
HS5 ACCOUNT 24

Power Wiring, Control Cable and Instrument Wire

The plant wire and cable consists of three-conductor and triplexed singleconductor power cable; multi-conductor control cable; coaxial, triaxial, shielded twisted pair, multi-shielded twisted pair, and shielded quadruplex instrument wire. Materials for insulation systems (ethylene-propylene rubber insulation with chloro-sulfonated polyethylene jacket) are selected to provide optimum system performance in the areas of physical stability; tensile strength; flexibility; aging characteristics; resistance to abrasion, ozone (where required), water absorption, heat distortion, and solvent extraction; self-extinguishing and non-propagating fire characteristics; and resistance to corona effects (where required). Wire and cable are separated by energy level to reduce heating and arcing fault problems.

Wire and cable routing is governed by the following:

a. Requirements for the power supply, control network and/or instrumentation signals

b. Requi rements for loading

c. Requi rements for physical separation of circuits having different voltage and energy levels

d. Avoidance of high hazard areas (e.g., areas subject to high ambient temperatures and fires)

e. Simplicity of layout

f. Ease of installation

g. Ease of access

Power and control cable is sized in accordance with ICEA Publications P46-426 and P54-440, with allowance for overloads and undervoltage conditions. Raceway derating is in accordance with NEMA Standard WC51. Medium voltage power cables are also sized for fault current flow for the interrupting time of the overcurrent protection. Fault current capability is also considered for low voltage power cables and control cables, where applicable. Instrumentation cable ratings are selected in accordance with the application. 


\section{ACCOUNT 25 MISCELLANEOUS PLANT EQUIPMENT}

Miscellaneous plant equipment includes systems and components for maintenance, plant start-up, or general supply of plant equipment requirements. Included are the cranes and hoists; air, water and steam services; auxiliary boiler and associated equipment; plant fuel oil system; fire protection system; communications systems; and various on-site and off-site environmental monitoring systems.

Interconnecting piping systems are included with each system, as required. They comprise the piping, fittings, valves, steam traps, strainers, specialties, hangers and supports, insulation and other components required for a complete system. Materials and wall thicknesses are chosen based on the service conditions and operational requirements of each system. The factors generally considered include: temperature, pressure, corrosion resistance, abrasion resistance, fluid purity requirements and cost. Carbon steel is used for steam, clean water, air, oil and other services without special requirements. Other materials used include: cement lined carbon steel, coated and wrapped carbon steel for buried service, galvanized carbon steel and copper.

The following paragraphs outline the contents of the detailed descriptions

Account 251 Transportation and Lifting Equipment (major cranes, other cranes and hoists, railway equipment and roadway equipment)

Account 252 Air, Water and Steam Service Systems (compressed air systems, service water system, fire protection system, potable water system, auxiliary steam system and plant fuel oil storage tank)

Account 253 Communications Systems (local communications system, and fire detection system)

Account 254 Furnishings and Fixtures (instrument shop apparatus, meteorological monitoring system, water quality monitoring system, stack gas monitoring system and other furnishings and fixtures)

Account 255 Waste Water Treatment Equipment 
HS5 ACCOUNT 25

\section{ACCOUNT 251 Transportation and Lifting Equipment}

\section{Major Cranes}

Within the turbine building, an overhead traveling bridge crane is used with main hoist capacity of 70 tons and an auxiliary hook capacity of 20 tons. The bridge span is 100 feet and covers the main operating f1oor area.

Other Cranes and Hoists

In addition to the above major cranes, there are also seven monorail hoists with capacities in the five to ten ton range to serve various plant areas.

\section{Rai1way Equipment}

One diesel locomotive is provided for on-site movement of lime hopper cars and other rail cars. It is a $550 \mathrm{hp}$ diesel electric switch engine which develops $61,000 \mathrm{lb}$ of continuous tractive effort at $5.5 \mathrm{mph}$.

\section{Roadway Equipment}

Two bulldozers are provided for use with the coal handling system. Two front end loaders are provided for cleanup at the coal piles and at the sludge stabilization area.

\section{ACCOUNT 252 Air, Water and Steam Service Systems}

\section{Compressed Air Systems}

The plant compressed air system supplies service and instrument air throughout the plant. The system consists of three 50 percent capacity oi1-free reciprocating compressors, complete with intake filters, aftercoolers and two 100 percent capacity air receivers and air dryers. Each compressor has an inlet air silencer and filter. To provide for an additional source of service air, an interconnection is made with the soot blower air compressor system.

\section{Service Water System}

The service water system supplies cooling water from the main condenser heat rejection system to the turbine building closed cooling water system heat exchanger (refer to Account 235). The system has three 50 percent capacity vertical wet pit pumps which are located in the circulating water pump house. Make-up water to the main condenser heat rejection system is discharged near the suction of these pumps to lower the service water average temperature. Service water returning to the cooling tower is combined with the returning (heated) circulating water, to reduce the amount of piping required (refer to Account 262). 


\section{Fire Protection System}

The fire protection system is designed to minimize the probability and effect of the occurrence of an in-plant fire by combining a fire detection system with a fire protection system. The fire detection system is described under Account 253 .

The fire protection system has three 50 percent capacity $(1,300 \mathrm{gpm}$ each) vertical wet pit fire pumps, two motor driven and one diesel driven; one 50 gpm vertical wet pit jockey pump; yard fire mains; hydrants and hose houses; building and equipment sprinkler systems; and building hose cabinets.

The jockey pump normally operates to maintain system pressure. One of the motor driven fire pumps is utilized in the event that the jockey pump cannot maintain system pressure. The second motor driven pump is started if the system pressure continues to drop, and the diesel engine driven pump is started if necessary to maintain system pressure. The diesel engine driven pump is independent of plant services and is provided with a separate fuel storage tank. A booster pump is provided in the steam generator building to supply water to the top elevations.

The pumps are located in the fire pump house part of the make-up water intake structure. Discharge from the pumps passes through an Underwriters Laboratory accepted duplex strainer with a 60 x 60 mesh to remove any debris which could potentially clog sprinkler heads or similar small passages.

Sprinkler systems are provided in the following buildings: steam generator building (including the diesel-generator room and machine shop); turbine, heater and control building; administration and service building; material handling and service building; and selected station service equipment areas. Deluge sprinkler systems are provided for the generator step-up, unit auxiliary and reserve auxiliary transformers, the main turbine lube oil storage area, and the diesel-generator unit and other fuel storage areas.

\section{Potable Water System}

Potable water is required for drinking, sanitary, and washing purposes at the plant. This water is supplied by the local municipal water supply system and distributed throughout the plant by a potable water piping system. Included in this system are outlets at wash rooms, drinking fountains, safety showers and eye wash stations, and hose bibb stations.

\section{Auxiliary Steam System}

Auxiliary steam is used for building heating, driving the boiler feed pump turbine(s) during start up, deaerator pegging (maintaining deaerator above atmospheric pressure), and miscellaneous heating and freeze protection needs. When possible, this steam is supplied by extraction from the main cycle. otherwise, it is supplied by the auxiliary boilers. 
One 100 percent capacity oil-fired auxiliary boiler with supporting auxiliary systems is provided. The boiler is a shop assembled "package" type, designed for pressurized furnace operation. Normally, steam is used for atomizing the oil, but during start-up, compressed air or mechanical atomization may be used. Each boiler is sized to provide enough steam for a cold start of the main unit under the worst expected conditions.

A single forced draft $f$ an is provided to supply the required combustion air and force the combustion gases through the ductwork and the stack. No induced draft fans are included. The stack is braced along the outside wall of the steam generator building and projects 15 feet above the boiler house roof.

A single deaerator and three 100 percent capacity boiler feed pumps are provided. Fuel is No. 2 fuel oil from the plant fuel oil storage tank. Three 50 percent fuel oil pumps are provided.

Hydrazine and ammonia are used to treat the auxiliary boller feedwater, the same as for the main boiler feedwater. A manually controlled blowdown is used to periodically remove any sediment which collects in the boiler drum.

The boiler package includes complete combustion and feedwater controls.

The auxiliary boiler is manually started. It is capable of being normally started either locally or from the control room. Each phase of the start-up procedure is separately initiated. The auxiliary boiler is programmed to shut-down when the steam flow falls below its minimum flow capability during plant start-up.

\section{Plant Fuel Oil Storage Tank}

The plant fuel oil storage tank has a capacity of 125,000 gallons and is 38 feet in diameter by 15 feet high. It is surrounded by. a steel dike 70 feet in diameter by six feet high. The ground inside the dike is sealed with clay to prevent any spilled oil from contaminating ground water. This tank provides storage for fuel oil for the auxiliary boller, diesel driven fire pumps, diesel-generator units and other diesel engine users.

\section{ACCOUNT 253 Communications Systems.}

\section{Local Communications System}

The plant communications system consists of a dial telephone system, a soundpowered telephone system and an intercommunication and paging system. These systems are designed to provide in-plant, on-site and off-site communications for all conditions of operation. The following paragraphs provide a brief description of each system.

A complete dial automatic telephone system is provided, consisting of an automatic switchboard and dial telephone handset stations. 
Portable sound powered telephone handsets and jacks are located throughout the station. Interconnecting jack wiring is provided under Account 246.

A public-address/intercommunications system is provided, consisting of a control panel, amplifiers, handsets, loudspeakers and interconnecting wiring. High intensity directional double reentrant type loud speakers and handset sound booths are provided in high noise areas.

\section{Fire Detection System}

A fire detection system is provided for early warning of incipient or actual combustion. This system supplements and activates the fire protection system described under Account 252.

Flame or smoke detection devices are located in infrequently visited or hazardous areas such as the cable tunnels or fuel storage areas. Signal devices are installed in the fire protection system to indicate initiation of operation of systems or components, such as fire pumps or deluge systems. Manual fire alarm stations and audible alarm devices are strategically located throughout the plant.

\section{ACCOUNT 254 Furnishings and Fixtures}

\section{Instrument Shop Apparatus}

Instrument shop apparatus are provided for testing, calibration, repairing, and routine maintenance of the plant instrumentation and control devices.

A typical 1ist of instrument shop apparatus is provided below:
a. Dead weight tester
b. Pneumatic calibrator equipment
c. Decade resistance box
d. Digital volt meter
e. Variable voltage and current sources
f. Potentiometer
g. Osci1loscope
h. Electronic counter
1. Stop watch
j. Resistance and impedance bridges 


\section{k. Megger \\ 1. Pressure gages \\ m. Meters: dc (mA, Amps, Volts), ac (Amps, Volts)}

\section{Meteorological Monitoring System}

The meteorological monitoring system provides all equipment essential for the monitoring and recording of the atmospheric parameters of the plant prior to construction, during construction and over the operational $11 \mathrm{fe}$ of the plant. The equipment for the system consists of a meteorological tower and various meteorological monitoring instruments. Data from this system are used to determine an inftial air quality site signature prior to construction and for periodic reevaluation during construction and plant operation.

\section{Water Ouality Monitoring System}

The water quality monitoring system monitors the rates and concentrations of contaminant in the plant effluent discharge. Typical variables measured are chlorine, suspended solids, $\mathrm{pH}$, oil and grease. Sampling techniques are established to yield representative batches or flows of the effluent discharge. Analytical data are recorded in necessary form for immediate as well as future interpretation and use.

\section{Stack Gas Monitoring System}

The stack gas monitoring system provides for the measurement and recording of pollutants contalned in the stack gas. Measurements are made of concentrations of criteria pollutants $\left(\mathrm{SO}_{2}, \mathrm{NO}_{\mathrm{x}}, \mathrm{CO}, \mathrm{Pb}\right.$, oxidants and particulates). Concentration measurements are corrected for diluting air by measuring oxygen concentration in the stack gas.

Plant emission standards for criteria pollutants are in accordance with the 1979 New Source Performance Standards in conjunction with local and state regulations at the Middletown site.

The detecting instruments are of the in-situ type, having their sensing devices located in the stack. Withdrawal and conditioning of stack gas samples are not required. Sulfur dioxide and nitrogen oxide are reported in terms of concentration (i.e., parts per mililon). Particulate emission is reported in mass flow units, ( $1 . e ., 1 \mathrm{bs} / \mathrm{hr}$ ) by combining measurements of particulate concentration and the mass flow rate of the stack gas. Emission rate is integrated and logged daily. Sampling ports are provided in the stack for comformance testing.

\section{Other Furnishings and Fixtures}

Among the other furnishings and fixtures provided for the plant are provisions for monitoring and recording the temperature of the plant thermal effluent, 
office and cafeteria equipment and furniture, chemical laboratory fixtures, machine shop equipment, change room lockers and benches, and portable fire extinguishers located throughout the plant.

ACCOUNT 255 Waste Water Treatment Equipment

The waste water treatment system treats normal operating wastes from the plant, rainfall runoff from contaminated areas, metal cleaning wastes, and emergency Elue gas desulfurization system blowdown so that they will be suitable for discharge to the North River or for reuse. The system consists of three collection basins, a clarifier, three in-depth type pressure filters, various pumps, tanks, chemical feeds and mixers, and a belt-press type sludge dewatering machine.

Plant operational waste water and runoff from contaminated areas are collected and pumped to the two main collection basins, each of approximately 600,000 gallon capacity. Runoff from the coal pile is contained within the coal pile runoff basin until there is capacity available in one of the two main basins. Runoff from the transformer area and the fuel oil handling area is held in those areas until it is determined by observation or by analysis if the water is contaminated. Contaminated water is cleaned up locally, or is pumped to one of the two main basins. The third basin, of approximately 650,000 gallon capacity, is dedicated to the collection and storage of metal cleaning wastes. 0il is removed from the water held in the basins by means of a tube type skimmer.

The plant waste water is normally pumped from the basins to a clarifier by one of the three raw waste pumps at a rate of $500 \mathrm{gpm}$. Two pumps may be used during the processing of plant waste water and precipitation runof $f$ at a combined rate of $800 \mathrm{gpm}$. The third pump is a spare. Water is pumped from either one of the main basins or the basin holding metal cleaning wastes, so that no combination of waste streams occurs.

Lime injection and air oxidation equipment are provided upstream of the 38 feet diameter clarifier. The clarifier provides a minimum detention time of two hours at $800 \mathrm{gpm}$, which allows most of the suspended solids to settle. The settled solids are periodically removed by one of two $50 \mathrm{gpm}$ underflow pumps and stored in the underflow storage tank. It is then pumped to the two-meter sludge dewatering belt press filter at a rate of up to $80 \mathrm{gpm}$.

Overflow from the clarifier is collected in a clearwell and pumped to the high rate pressure filters. During metal cleaning operations, clarifier overflow may be returned to cleaning operations for reuse. Three high-rate, dual media filters are provided to remove suspended solids carried over from the clarifier. At the maximum flow rate of $800 \mathrm{gpm}$, all three filters will normally be in service. At the low flow rate of $500 \mathrm{gpm}$, only two filters are required at a time. Under this condition, the third filter can be kept in stand-by until an operating filter is to be backwashed, at which time the standby filter is put into service. Each filter is 8.5 feet in diameter and contains a stratified sand and anthracite bed. 
Capability is included to add acid to the discharge from the filters to ensure that the waste water is within the acceptable $\mathrm{pH}$ range of six to nine before it is discharged. A backwash storage tank (which also serves as an effluent monitoring tank) provides storage capacity for backwash of all three filters (15,000 gallons). The waste water is monitored for total suspended solids, oil and grease, $\mathrm{pH}$ and other parameters as required. If any of these parameters do not meet the discharge permit requirements, the water will be pumped back to the waste holding basins by the backwash/effluent pumps. These pumps are also used to discharge the treated 1iquid wastes to the North River or to backwash the filters. The pumps are rated at $850 \mathrm{gpm}$ based upon the filter backwash requirements. 
ACCOUNT 26 MAIN CONDENSER HEAT REJECTION SYSTEM

Mechanical key parameters related to the heat rejection system are given in Items 37 and 38 of Table 5-1. Configuration of structures related to the heat rejection system are shown on the Plot Plan given in Figure 5.1. The table and figure supplement and amplify the following discussion of Account 26.

The main condenser heat rejection system is a closed loop circulating water system. It consists of buildings, structures and mechanical equipment that serve the main condensers and service water system to reject the plant excess heat through one natural draft wet evaporative cooling tower. The circulating water is chlorinated to control biological fouling.

Make-up water from the North River initially passes through a bar rack to remove any large debris. It then passes through traveling water screens, to protect the pumps. Automatic self-cleaning strainers following the pumps further remove suspended material. After straining, most of the make-up water is discharged to the cooling tower basin to replace water lost by evaporation and blowdown. Sulfuric acid is also injected into the cooling tower make-up water as required to avoid scaling. The remaining make-up water is clarified and used as make-up to the flue gas desulfurization system or demineralized for use as steam cycle make-up.

Interconnecting piping systems are included with the auxiliary systems. They comprise the piping, fittings, valves, hangers and supports, and other components required for a complete system. Materials and wall thicknesses are chosen based on the service conditions and operational requirements of each system. The factors generally considered include: temperature pressure, corrosion resistance, abrasion resistance, fluid purity requirements and cost. Carbon steel is used for clean water and other services without special requirements. Other materials used include: stainless steel, concrete, polyvinyl chloride (PVC) and fiberglass reinforced plastic (FRP). The circulating water pipes between the condensers and the cooling towers are of reinforced concrete.

The paragraphs given below identify the subjects covered by the detailed descriptions that follow.

Account 261 Structures (make-up water intake structure, circulating water pump house and make-up water pretreatment building)

Account 262 Mechanical Equipment (circulating water pumps, cooling tower and cooling tower basins, plant make-up and blowdown equipment and make-up water pretreatment plant) 
HS5 ACCOUNT 26

$\underline{\text { ACCOUNT } 261 \quad \text { Structures }}$

Make-up Water Intake Structure (including Fire Pump House)

The make-up water intake and fire pump structure is located along the riverbank west of the main plant structures. It is approximately 36 feet wide, 29 feet long and 30 feet deep below plant grade with the top slab located at grade. The structure is reinforced concrete with the foundation mat bearing on rock. There are two intake chambers, each nine feet wide (inside) and 29 feet long at the bottom. The reinforced concrete top slab over the two chambers supports the two make-up water pumps and fire pumps with the two make-up pumps in one chamber and the fire pumps in the other. A ten feet high masonry enclosure is supported above the top slab. Its roof is insulated metal deck covered with built-up roofing and supported on steel framing. A trash pit with truck access ramp is located north of the two intake chambers.

The two intakes are protected by bar racks, stop logs and traveling screens. The traveling screens are the fish collection type where any fish which become trapped on the screen are gently washed into a trough separate from the trash and returned to the river downstream of the intake. To minimize the number of $f$ ish which may become trapped on the screen, the approach velocity to the screens is kept below $0.5 \mathrm{feet} / \mathrm{sec}$ and the velocity through the screen is as low as possible.

A trash rake is provided to clean the bar rack. Debris from washing the screens and debris collected from the bar rack are discharged to a container in the trash pit. The container is periodically emptied by an outside contractor. Water drains from the container onto the trash pit floor. A drain in the floor of the trash pit conducts water from the floor to one intake chamber, in front of the traveling screen.

\section{Circulating Water Pump House}

The circulating water pump house is a reinforced concrete structure connected to the cooling tower basin by a reinforced concrete flume and supported on a three feet thick reinforced concrete foundation. The flume bottom slopes upward from the bottom of the pump bays to the bottom of the cooling tower water basin. The circulating water pump basin foundation is supported on rock. The circulating water basin is approximately 40 feet wide, 29 feet long and 26 feet high from the top of the bottom slab to the operating floor. Attached to the west end of the circulating water pump basin is a service water pump basin, also founded on rock. This basin is ten feet wide, 12 feet long and 12 feet high from the top of the bottom slab to the operating floor.

The circulating water pump basin is divided into two bays, one for each pump. The service water basin is a single bay. Exterior walls, interior walls, base mat, operating floor slab and interior columns are reinforced concrete. Portions of the operating floor are grating. The concrete operating floor slab is supported on the walls dividing the circulating water pump basin into separate pump bays. The grating is supported on these same walls and on the 
interior columns. The circulating water pumps and service water pumps are supported from the reinforced concrete operating floor slab. All pump bays are provided with panel screens and stop logs.

A 16 feet square equipment room ten feet high is located on the solid portion of the operating floor slab. The equipment room is masonry construction with an insulated built-up roof on a metal deck supported by steel framing. The equipment room is cooled with propeller type fans. In the winter months, heating is provided by electrical space heaters. The equipment room houses the circulating water system chlorination equipment and local instrument racks.

\section{Make-up Water Pretreatment Building}

The make-up water pretreatment building is located northwest of the main plant structures and east of the intake structure. It is a two story steel framed structure 50 feet wide, 100 feet long and 30 feet high. The building volume is approximately 150,000 cubic feet. It is supported on reinforced concrete footings founded on rock. The reinforced concrete ground floor is located six feet below grade. The intermediate floor is cast-in-place concrete on metal deck supported on steel framing. The roof is concrete channel plank supported on steel framing and covered with a roofing membrane. The exterior walls are reinforced concrete to one foot above grade and insulated metal siding above that. The interior walls are concrete block.

The building has a heating and ventilating system which consists of roof ventilators for cooling and three electric unit heaters for heating.

The building houses the strainers, clarifiers, chemical feeds, sludge dewatering equipment, circulating water system sulfuric acid feed equipment and other equipment required for a complete water pretreatment system.

ACCOUNT 262 Mechanical Equipment

\section{Circulating Water Pumps}

There are two 50 percent capacity mixed flow, vertical wet pit type circulating water pumps provided. Each pump is designed for a flow rate of 120,900 gpm with a total dynamic head of 80 feet. The combined capacity of 241,800 gpm includes:

$227,700 \mathrm{gpm}$ for condenser cooling

$1,400 \mathrm{gpm}$ for cooling the two condenser vacuum pumps

\section{$229,100 \mathrm{gpm} @ 88^{\circ} \mathrm{F}$ (Total)}

$1,200 \mathrm{gpm}$ for blowdown

5 percent design margin on each pump for wear and miscellaneous

Each circulating water pump motor is rated at $3500 \mathrm{hp}$ and $360 \mathrm{r} / \mathrm{min}$. The pumps are located within a pump house well to which the water flows from the cooling tower basin by gravity. The pumps discharge the water through the 
main condensers, where heat is absorbed. The water then returns to the distribution system of the tower. Water flow is controlled by the number of pumps placed in service at a given time. Flow from the cooling tower is controlled by an overflow from the tower basin.

Cooling Tower and Cooling Tower Basin

There is a single hyperbolic natural draft wet cooling tower capable of cooling $238,485 \mathrm{gpm}$ of water from $110^{\circ} \mathrm{F}$ to $88^{\circ} \mathrm{F}$ with an ambient wet bulb temperature of $74^{\circ} \mathrm{F}$. The design water flow is based on:

$229,675 \mathrm{gpm}$ @ $110^{\circ} \mathrm{F}$ from condenser and vacuum pump cooling

$8,810 \mathrm{gpm}$ returning service water @ $98^{\circ} \mathrm{F}$

The nominal design capacity of the cooling tower is $239,000 \mathrm{gpm}$.

The design wet bulb temperature of $74^{\circ} \mathrm{F}$ is the annual maximum at the Middletown site. By designing for circulating water temperatures of $88^{\circ} \mathrm{F}$ leaving the tower and $110^{\circ} \mathrm{F}$ returning, the maximum turbine exhaust pressure is established as $3.0 \mathrm{In}-\mathrm{HgA}$. It is estimated that the wet bulb temperature will be low enough to permit operation at or below the turbine design exhaust pressure of 2.5 in-HgA for 91 percent of the time. During the short periods of especially high wet bulb temperature (above approximately $60^{\circ} \mathrm{F}$ ) back pressure rises above 2.5 in-HgA to a maximum of $3.0 \mathrm{in}-\mathrm{HgA}$, with a corresponding increase of less than one percent in the heat rate.

The cooling tower is a round reinforced concrete structure with film type fill designed to expose maximum surface of the hot water to the air. Evaporation of a portion of the water is the primary cooling mode, although some sensible heat exchange also occurs. The cooled water is collected in a basin under the tower. A reinforced concrete flume connects the basin to the circulating and service water pump basin.

The hot water distribution system located inside the cooling tower above the fill distributes the water uniformly over the fill. The distribution system also permits increased. flow to be directed to the perimeter to avoid icing in cold weather, and isolating a portion of the fill to avoid overcooling in cold weather.

Drift eliminators are chevron shaped slats located above the water distribution systems. They remove, entrained liquid from the discharged air/vapor stream. Drift is limited to less than 0:01 percent of the water circulation rate.

The air flow through the waterfill is induced by the density difference between the heated (less dense) air inside the hyperbolic shell and the cooler surrounding air. 
Plant Make-up Water and Blowdown Equipment

Two 100 percent capacity vertical centrifugal pumps are installed at the intake structure to provide make-up water to the circulating water system (losses due to evaporation, drift, blowdown), steam cycle (losses due to blowdown, leaks, unrecovered auxiliary steam), flue gas desulfurization system and general plant use. The make-up water pumps discharge to the make-up pretreatment plant, where the water is strained and/or clarified as required.

Water from the North River approaching the pumps first passes through a bar rack with 3.5 inch openings to remove large material such as logs, and then through either of two traveling water screens having $3 / 8$ inch square openings. Approach velocity to the traveling water screens is 0.5 feet per second and velocity through the screen is one foot per second. The bar rack is cleaned by a motorized rake. Debris collected on the traveling water screens is flushed into a trough by a water spray from behind the screen, collected in a bin and periodically disposed of of $f-s i t e$. Any fish which become trapped on the screens are washed of $f$ separately from the debris and gently returned to the river downstream of the intake. Two 100 percent capacity screen wash pumps are provided for cleaning the screens of both fish and debris.

Blowdown is used to control the concentration of dissolved solids in the circulating water. An average blowdown rate of 0.5 percent of the circulating water flow has been established for this plant, resulting in a dissolved solids concentration approximately five times that of the make-up water.

Blowdown is removed from the circulating water system at the discharge of the circulating water pumps. Whenever possible, it is discharged to the bottom ash recirculation tank to replace water lost from that system by evaporation and with the ash. When necessary, excess cooling tower blowdown can be discharged to the river. Discharge to the river requires no treatment, except that chlorination of the circulating water must be stopped shortly before and during blowdown. A single fiberglass-reinforced plastic outfall pipe angled up to prevent scouring of the river bottom is provided downstream of the make-up water intake structure.

Make-up Water Pretreatment Plant

Raw river water is fed from the make-up water pumps to the make-up water pretreatment plant. The purpose of this system is to precondition the raw river water which is used as make-up to the circulating water system, the plant demineralizers and the FGD system. This equipment is located in the make-up water pretreatment building.

The primary objective of the system is to remove debris and suspended solids characteristically present in the river water. The amount of solids and debris contained in the raw influent is subject to wide fluctuation primarily due to seasonal changes and natural river environment. 
The water first passes through two automatic self-cleaning strainers to remove debris larger than $1 / 32$ of an inch. The major portion of the water, to be used as make-up for the circulating water system, is then discharged directly to the cooling tower basin. Chlorination is applied directly to the circulating water on an intermittent basis to minimize biological fouling within the condenser and throughout the piping system. The circulating water system chlorination equipment is located at the circulating water pump house. Sulfuric acid is added to the make-up water to the cooling tower as needed to neutralize excess alkalinity and minimize any tendency for scaling in the cooling tower. The sulfuric acid tank and feed equipment is located at the make-up pretreatment building.

The portion to be demineralized is further treated in a pretreatment system consisting of a single clarifier and two dual media pressure filters, a backwash water storage tank, chemical feeders, as well as pumps, valves, and piping. The pretreatment system is designed to process water at a maximum rate of approximately 232,500 gallons per day.

The water that is directed to the pretreatment system is initially mixed with a coagulant chemical and is then piped to a 15 feet diameter clarifier. Should the clarifier be out of service, the influent water will bypass directly to the clearwel1. The clarifier provides for a minimum detention time of two hours in order to permit a large percentage of the influent suspended solids to settle. The solids which settle within the clarifier are periodically removed by one of the two 100 percent capacity underflow pumps provided. These pumps, which are rated at $20 \mathrm{gpm}$ each, pump the underflow solids to the station's liquid waste treatment system. Overflow from the clarifier is collected within a clearwe 11 and then pumped by two of the three 50 percent capacity pumps to the dual media filters.

Two parallel dual media filters are provided. These filters are used to remove the small amount of suspended solids which are not removed within the clarifier. At the maximum system flow rate, both filters will normally be in service. However, a single filter is capable of treating the entire flow when one filter is removed from service for backwashing. Each filter is seven feet in diameter and contains a two feet deep bed of anthracite and a one foot deep bed of sand.

While the majority of the discharge from these filters is directed to the demineralized water make-up system, a small portion of the filtered water is directed to a 10,000 gallon backwash water storage tank. This tank provides a clean supply of water that is required for periodic filter backwashes. Spent backwash water from the filters is piped to the liquid waste treatment system. 


\subsection{ENGINEERING DRAWINGS}

The engineering drawings included in this section amplify and supplement the system design descriptions given in Section 5.3. The titles of these drawings are as follows:

Figure

Number

5.1

5.2

5.3

5.4

5.5

5.6

5.7

5.8

\section{Title of Drawing}

Plot Plan - 488 MWe HSC FPGS -

Middletown Hypothetical Site

General Arrangement -

Plan at E1. 19'-0" (Ground F1.) -

Boiler and Turbine Area -

488 MWe HSC FPGS -

Middletown Hypothetical Site

General Arrangement -

Plan at El. 64'-0" (Oper.F1.) -

Boiler and Turbine Area -

488 MWe HSC FPGS -

Middletown Hypothetical Site

General Arrangement -

Section "A-A" - Elevation -

488 MWe HSC FPGS -

Middletown Hypothetical Site

Steam Heat Balance Diagram -

488 MWe HSC FPGS -

Middletown Hypothetical Site

Flow Diagram - Balanced Draft System 488 MWe HSC FPGS -

Middletown Hypothetical Site

Flow Diagram - Coal Handling System 488 MWe HSC FPGS -

Middletown Hypothetical Site

Flow Diagram - Flue Gas Desulfurization

System - 488 MWe HSC FPGS -

Middletown Hypothetical Site
Drawing Number

$7553.001-\mathrm{HSC} 5-01-\mathrm{R} 2$

7697.703-HSC5-01-R1

$7697.703-\mathrm{HSC5}-02-\mathrm{R} 1$

7697.703-HSC5-03-Rl

$7553.001-\mathrm{HSC5}-02-\mathrm{R} 2$

7697.703-HSC5-04-R1

7697.703-HSC5-05-R1

7697.703-HSC5-06-R1 
PLANT NOMENCLATURE

1. STEAM GENERATOR BUILDING

3. CONTROL AND SWITCHGEAR BUILDING

. ADMINISTRATION/SERVICE BUILDING

FGD ABSORBER MODULES

. STACK

FUEL OLL STORAGE TANK
CONDENSATE STORAGE TANK

13. LOCOMOTIVE REPAIR SHOP
14. WASTE WATER TREATMENT BUILDING

15. PROCESS AND SEAL WATER PUMPHOUSE
16. TEMPORARY FGD WASTE STORAGE AREA

T. COOLING TOWER

THICKENERS

THICKENER EQUIPMENT BUILDING

SLUDGE STABILIZATION BUILDIN

UNDERFLOW SURGE TAN

BREAKER HOUSE

CAUSHER HOUS

RECLAIM TRANSFER TUNNEL

COLPILE RUNOFF BASIN

INTAKE STRUCTURE

MAKE-UP WATER PRETREATMENT BUILOING

BUCKET WHEEL STACKER/RECLAIMER

DEAD STORAGE COAL PILE

ACTIVE STORAGE COAL PILE

ABSORBER ISLAND ENCLOSURE

PROCESS WATER SURC

DEWATERING TANKS

LIME FEED S TAPAY QUIDOI

AESORBERA

SECURITY FENCE

BOILER HOUSE TRANSFER TOWE

作

54. TEMPORARY WASTE STORAGE AREA

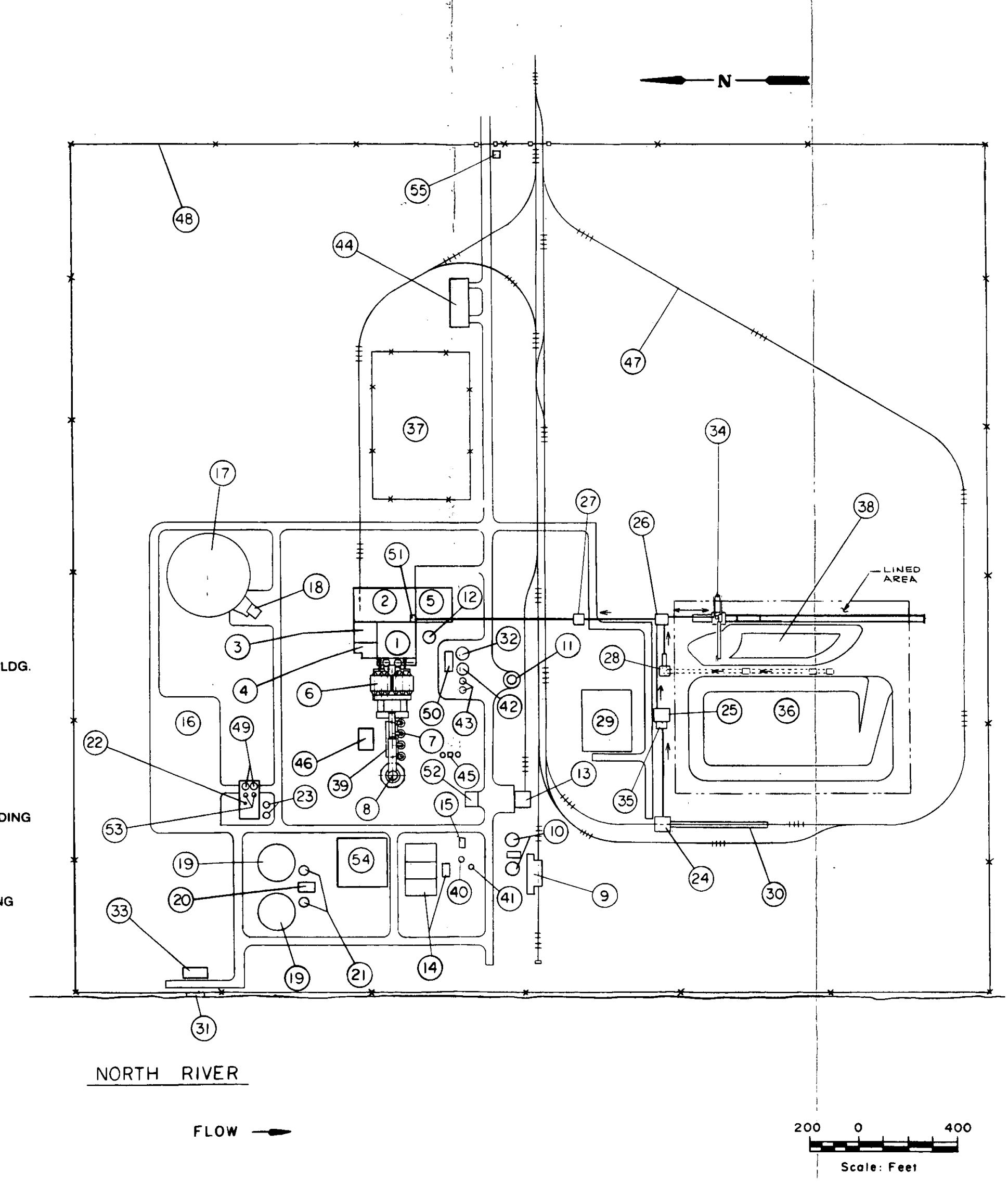

FIQURE 5,

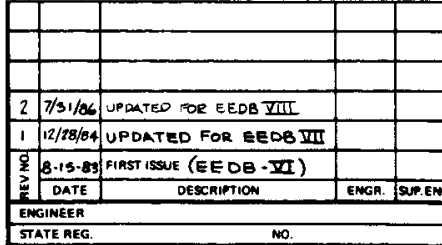

PLOT PLAN

$488 M W_{\text {E HSC FPGS }}$

MOOLE TOWN HYPOTHETICAL SIT

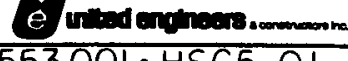




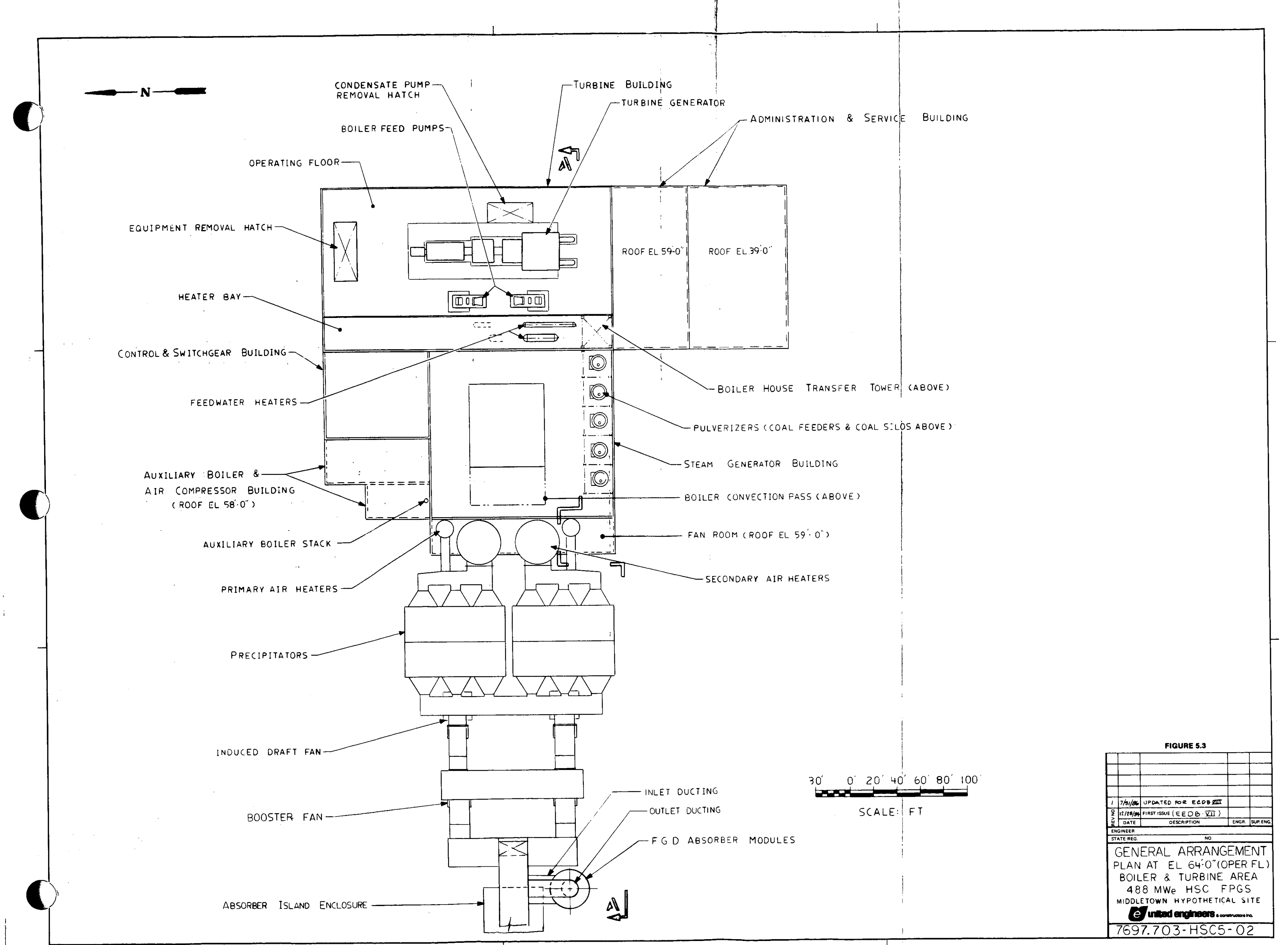



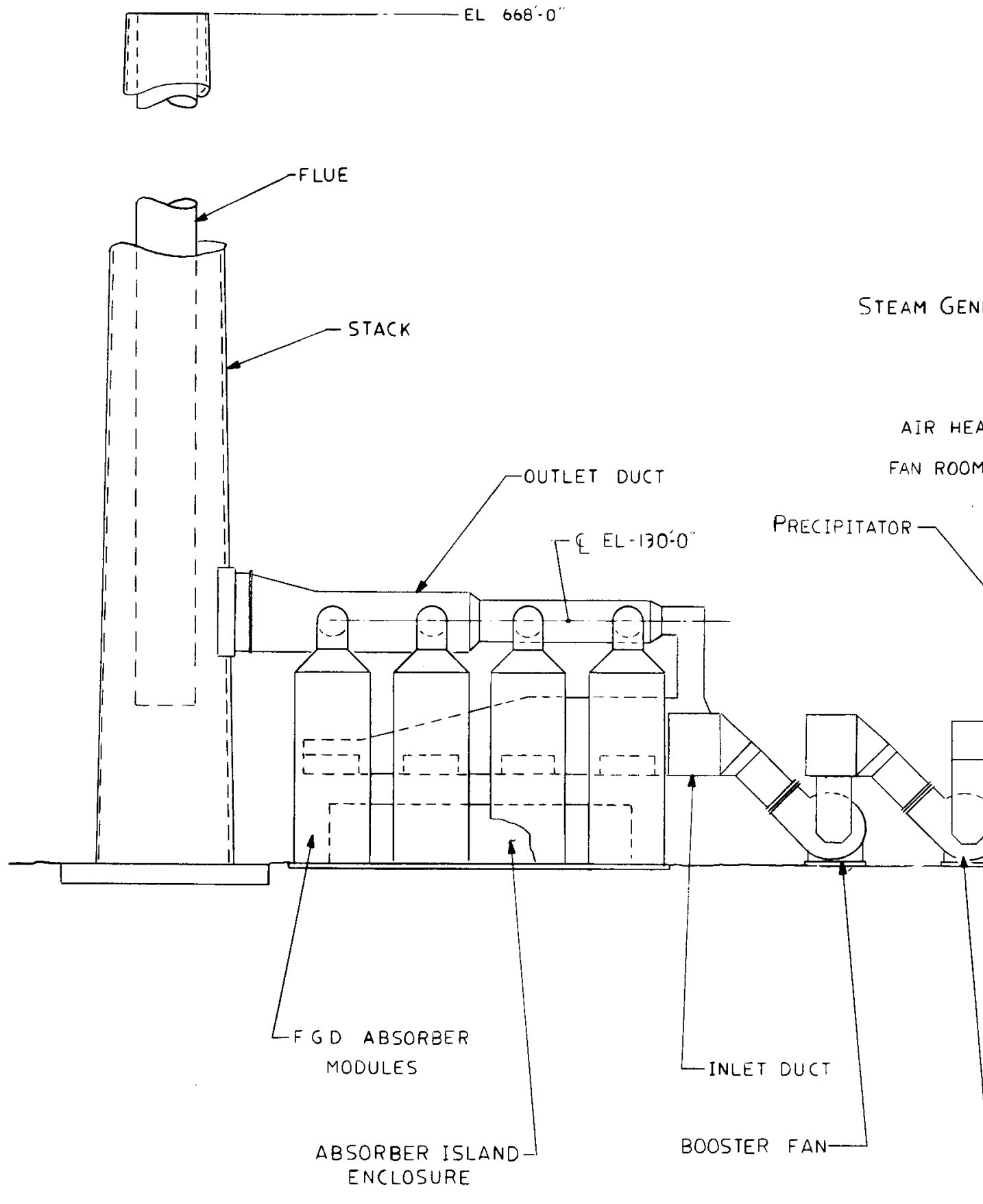

EXHAUST FAN

(TYPICAL)
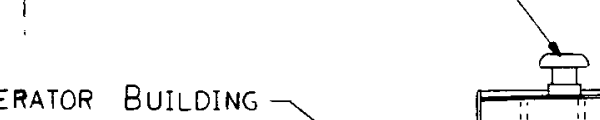

TERS -

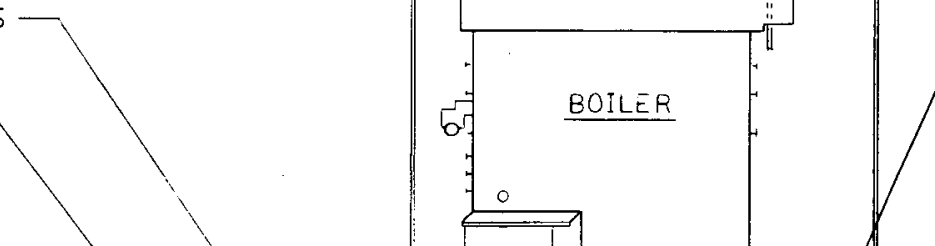

HEATER BAY
BOILER FEED PUMP

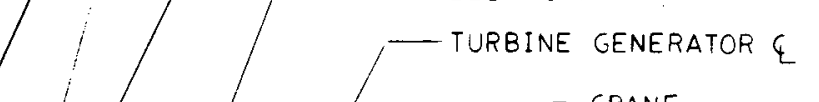
- CRANE
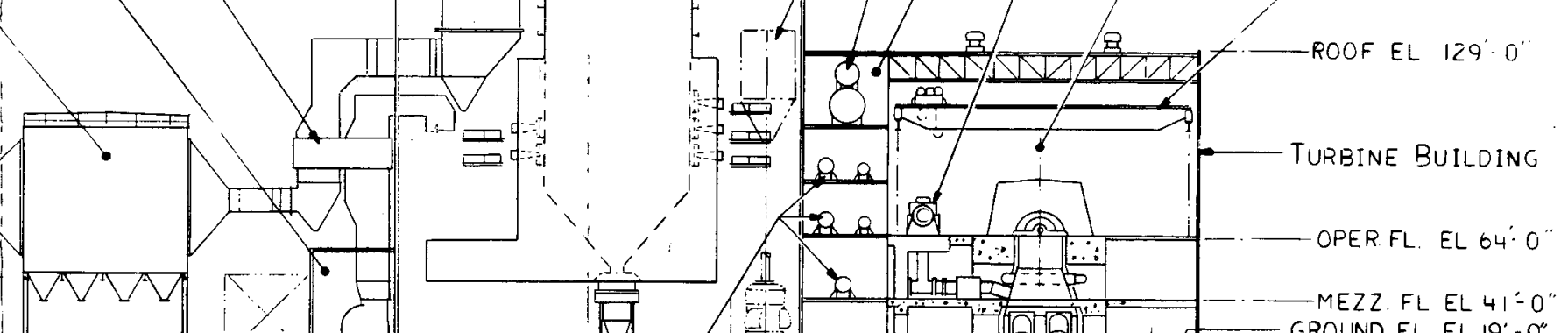
10 MVM
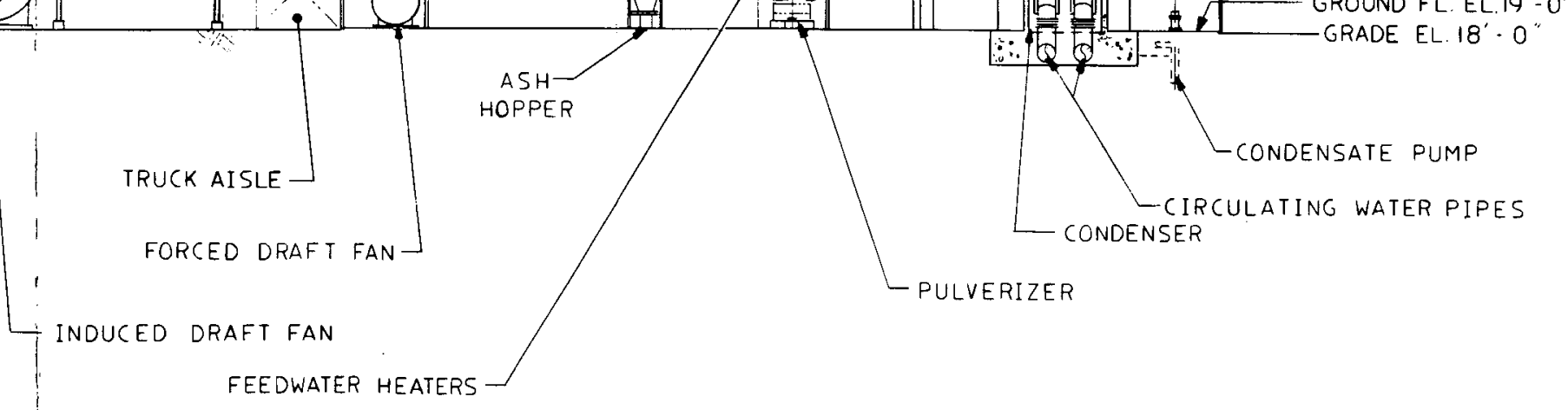

FIGURE 5.4

$\begin{array}{lllllll}30^{\circ} & 0^{\prime} & 20^{\prime} & 40^{\prime} & 60^{\prime} & 80^{\prime} & 100^{\circ}\end{array}$ SCALE: FT

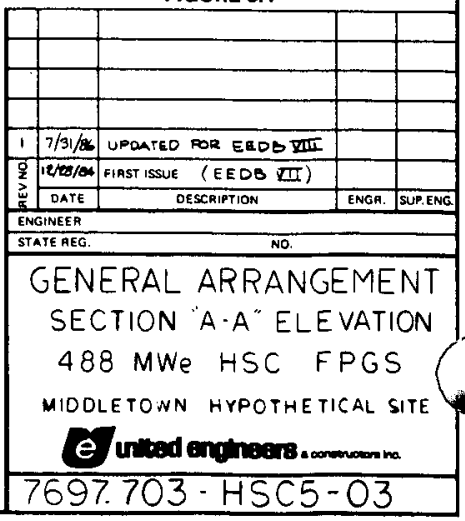




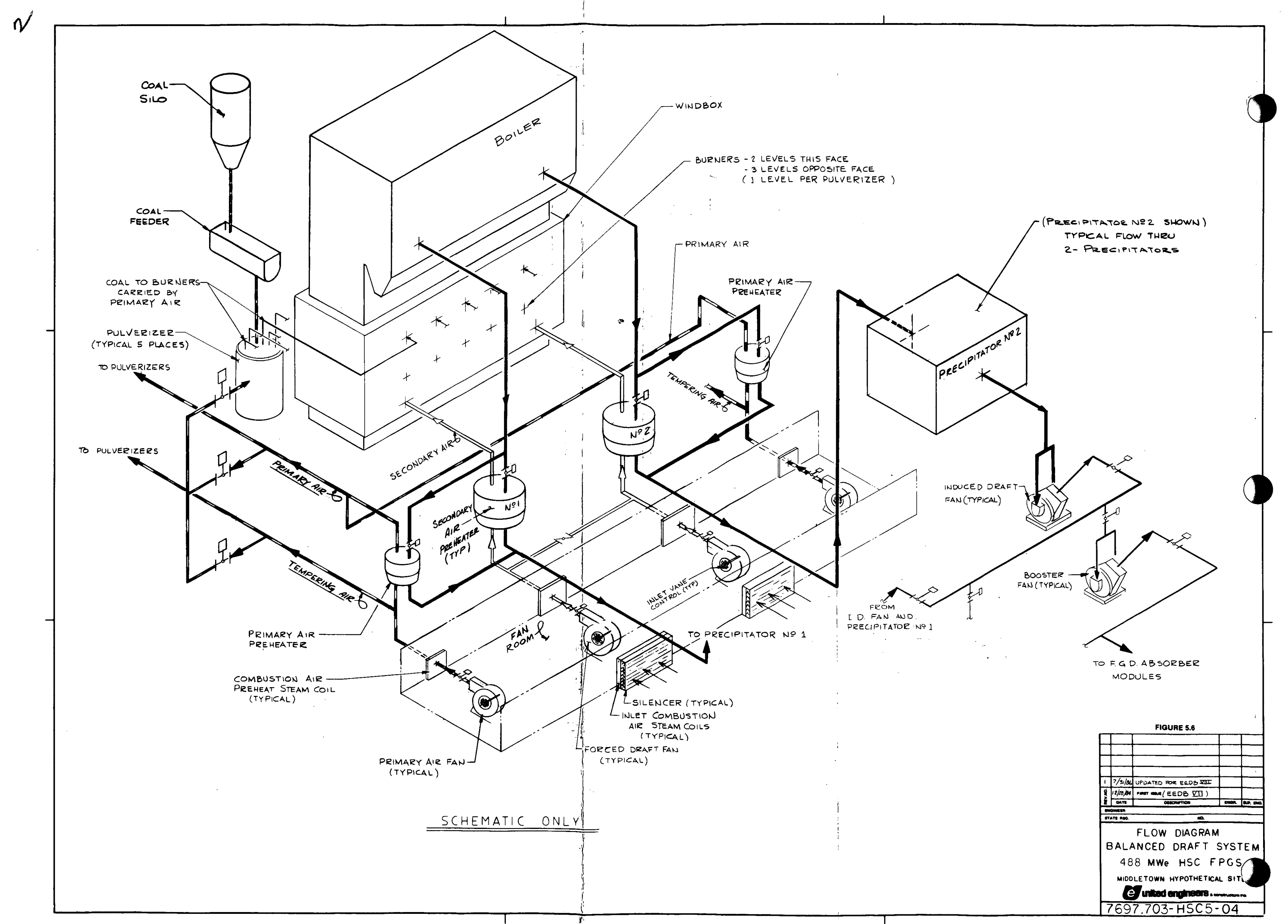




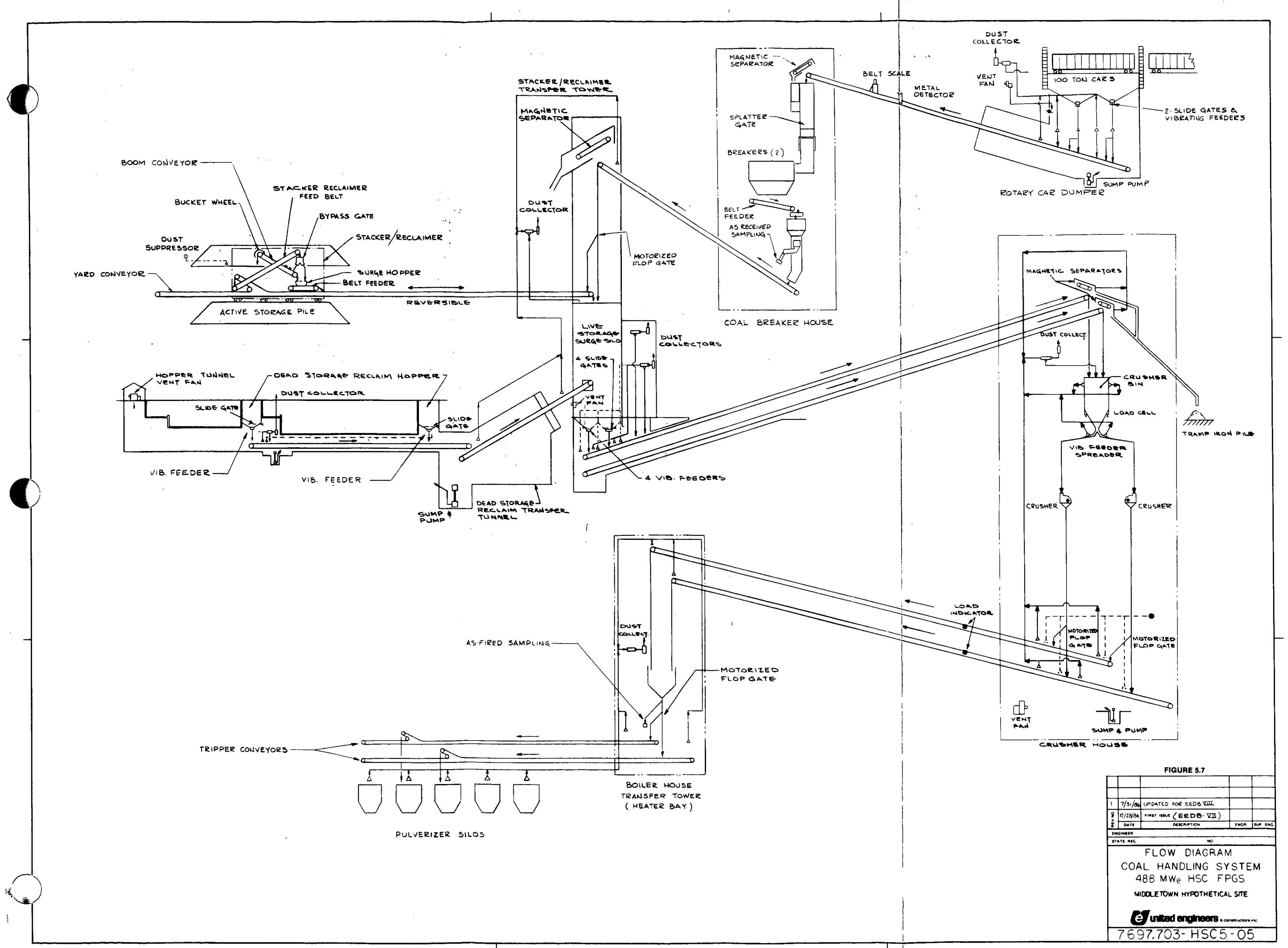




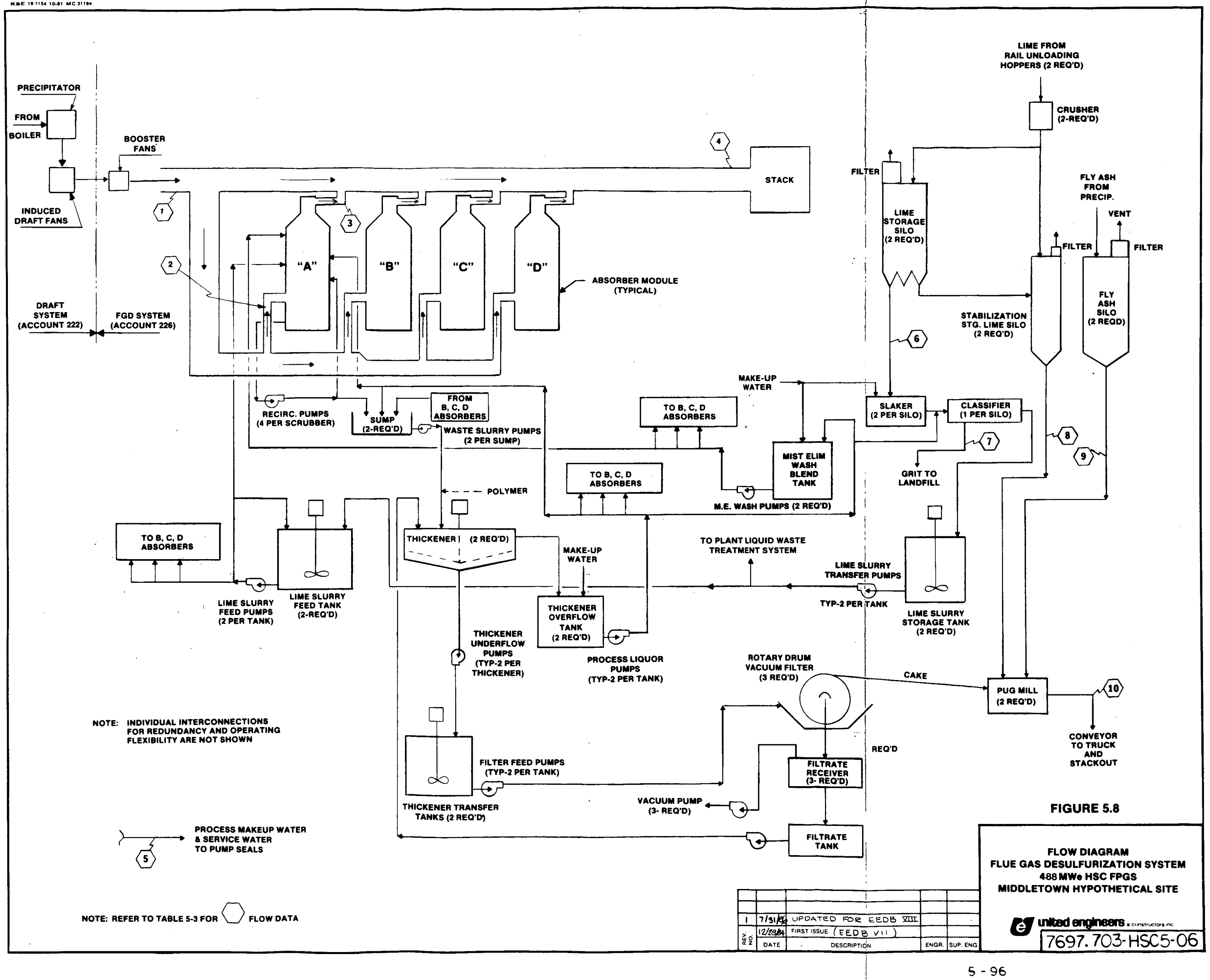


TABLE $5-3$

ENERGY ECONOMIC DATA BASE

PHASE VIII UPDATE (1986)

488 MWe HIGH SULFUR COAL FOSSIL POWER GENERATING STATION (HS5)

FLUE GAS DESULFURIZATION SYSTEM FLOWS

(Reference Figure 5.8 - Drawing Number 7697.703-HSC5-06)

\begin{tabular}{|c|c|c|c|c|c|}
\hline STREAM & $\underline{1}$ & $\underline{2}$ & $\underline{3}$ & $\underline{4}$ & $\underline{5}$ \\
\hline \multicolumn{6}{|l|}{ F1ow $(1 \mathrm{bs} / \mathrm{hr})$} \\
\hline Dry Gas & $5,519,721$ & $1,839,907$ & $1,839,198$ & $5,517,595$ & - \\
\hline $\mathrm{H}_{2} \mathrm{O}$ (Vapor) & 311,436 & 103,812 & 180,851 & 542,554 & - \\
\hline $\mathrm{SO}_{2}$ & 30,669 & 10,223 & 1,022 & 3,067 & - \\
\hline Steam & - & - & - & - & - \\
\hline $\mathrm{H}_{2} \mathrm{O}$ (Liquid) & - & - & - & - & 301,741 \\
\hline Solids (Including Hydration) & - & - & - & - & - \\
\hline Lime & - & - & - & - & - \\
\hline Grit & - & - & - & - & - \\
\hline Fly Ash & 158 & 53 & 53 & 158 & - \\
\hline TOTAL ... & $5,861,984$ & $1,953,995$ & $2,021,124$ & $6,063,374$ & 301,741 \\
\hline TEMPERATURE $\left({ }^{\circ} \mathrm{F}\right)$ & 290 & 290 & 127 & 127 & - \\
\hline STREAM & $\underline{6}$ & $\underline{7}$ & $\underline{8}$ & $\underline{9}$ & $\underline{10}$ \\
\hline \multicolumn{6}{|l|}{ Flow $(1 \mathrm{bs} / \mathrm{hr})$} \\
\hline Dry Gas & - & - & - & - & - \\
\hline $\mathrm{H}_{2} \mathrm{O}$ (Vapor) & - & - & - & - & - \\
\hline $\mathrm{SO}_{2}$ & - & - & - & - & - \\
\hline Steam & - & - & - & - & - \\
\hline $\mathrm{H}_{2} \mathrm{O}$ (Liquid) & - & 991 & - & - & 60,209 \\
\hline Solids (Including Hydration) & - & - & - & - & 59,631 \\
\hline Lime & 26,017 & - & 4,481 & - & 4,481 \\
\hline Grit & 2,891 & 2,313 & 498 & - & 1,076 \\
\hline Fly Ash & - & - & - & 39,366 & 39,366 \\
\hline TOTAL & 28,908 & 3,304 & 4,979 & 39,366 & 164,763 \\
\hline
\end{tabular}




\subsection{DESIGN/CONSTRUCTION SCHEDULE}

The overall design/construction milestone schedule for the HS5 technical data model is divided into two logical phases:

- Preconstruction (Licensing) activities that culminate in the award of a construction permit.

- Engineering and Construction activities which culminate in the completion and commercial operation of the plant.

These milestone schedules are discussed below.

Preconstruction Licensing Activities

Certain licensing requirements at the Federal and state levels must be satisfied before a utility can initiate construction of a new coal-fired power plant. The principal regulatory program at the Federal level is a requirement for an Environmental Impact Statement (EIS) in compliance with provisions of the National Environmental Policy Act (NEPA) of 1969. The Act requires that an EIS must be prepared for a major Federal action significantly affecting the environment. Such actions include issuance of permits for air or liquid effluent discharges or work in navigable waters. Generally, issuance of a favorable EIS is a precursor to obtaining other necessary permits. Failure to obtain any one of the mandated Federal or state permits may preclude the start of construction activities at the site.

Major regulatory programs other than the EIS at the Federal and/or state levels which can have significant schedule impact include:

- Prevention of Significant Deterioration (PSD) and New Source Performance Standards (NSPS) regulating air quality impacts.

- State 401 Certification (water intake and discharge) and Corps of Engineers 404 permit (dredge and fill operation in navigable waterway) for impact to water and navigation.

- National (or State) Pollution Discharge Elimination System (NPDES/SPDES) permit for discharging of a liquid effluent into surface waters.

A number of states have been granted NPDES and PSD granting authority by the U.S. Environmental Protection Agency.

A majority of states now have site certification authorities and environmental review requirements, either established by statute or executive/administrative directive. The major interest of state governments is focused upon the issuance of a certificate of need for a generating facility and/or the protection of the environment from the potential impacts of construction and operation. 
In this respect states fall into four categories. First, there are those states that require a site certification for energy facilities. Second, there are states that require a site certification and also a state environmental review process, ranging from preparation of a comprehensive state Environmental Impact Statement/Environmental Assessment (EIS/EA) to a discretionary (case by case basis) environmental impact report. Third, there are those states that do not require a site certification but do require an environmental review; and fourth, there are those states having no certification requirement, nor do they require environmental reviews. These site licensing actions for the 50 United States and Puerto Rico are depicted on Figure 5.9 .

The presence of a state licensing authority and/or a requirement for a state EIS/EA impacts the preconstruction licensing schedule by adding another regulatory layer to the licensing process. In general, the impact is most significant where both requirements exist.

Where a state has an agency with primary responsibility for power plant site certification, the utility may have to satisfy one or more of the following conditions before it can commence any site related construction activity.

- Compatibility with the state's master plan for the development of energy resources.

- A demonstration that the power plant will be needed.

- A study showing that the power plant site selected is preferable to other sites considered.

- Field monitoring and sampling data characterizing the environmental conditions at the site.

Figures 5.10 and 5.11 diagram the activities necessary for a site certification stage and a power plant permitting stage in the licensing process. The site cetification stage activities are representative of a state with site certification and/or environmental review requirements. The plant permitting stage activities are representative of Federa1 requirements, imposed on power plants built in any state. In those states requiring site certification and/or environmental reviews, the preconstruction licensing schedule has been extended from a few months to several years. Regulatory requirements which must be satisfied in order to commence construction of a new coal-fired power plant show a wide diversity from one state to another. This has resulted in a preconstruction licensing process for fossil-fired thermal power plants that can vary from approximately 30 to over 60 months in duration, depending upon the location of the plant.

The HS5 technical data model is located at the Hypothetical Middletown (refer to Appendix A-2) Site. By definition, it is representative of a Northeastern U.S. location. Taking the hypothetical location into account it has been determined that the HS5 would most probably be in a Group 1 state having a 
site certification authority and requiring a state environmental review. A preconstruction licensing milestone schedule of 42 months for the HS5, as shown in Figure 5.12 , is considered typical for this set of conditions. However, this schedule may be extended considerably and the issue of a construction permit delayed in a state having more stringent site certification conditions than those assumed.

Figure 5.12 identifies the major licensing requirements that must be initiated, and in certain cases completed prior to proceeding to a following action in the process of obtaining a construction permit.

\section{Engineering and Construction Activities}

The engineering and construction phase of a coal-fired power plant is somewhat more predictable than the preconstruction licensing phase. This is the result of decades of past experience by the power industry in the construction of fossil-fired power plants. Factors such as climate, geology and fuel, however, can affect the time required for construction. For a given plant size, the variation in schedule typically may vary by up to six months.

An engineering and construction milestone schedule for the EEDB HS5 technical data model at the Middletown site is presented in Figure 5.13. It indicates an expected construction duration of 46 months from issuance of a construction permit to commercial operation. The schedule assumes a single eight hour daily work shift and a 40-hour week. These assumptions translate into an average craft labor work force of approximately 1000 over the 46 month construction period, and a peak force of approximately 1500 to 1800 . This labor force is based upon the total site craft labor hours developed in the EEDB Phase VIII Update (1986).

The milestone schedule addresses, in a generalized form, the construction sequencing and interfacing of the principal structures and systems comprising the plant. Where appropriate, engineering and design, procurement, erection, and installation of equipment, components and piping are identified and properly sequenced.

Figure 5.13 also identifies the critical activities which establish the overall project duration. The critical path is initiated at the site selection activity, moves through the licensing process and site preparation, extends along the path for construction of the Steam Generator Building and installation of equipment and continues through the various test and start-up activities to commercial operation.

The engineering and construction activities for the other major structures (Turbine, Heater and Control Building, FGD Structure, Coal Handling system Structures, Cooling Towers and Switchyard) can be accommodated within the 46 month overa11 construction schedule, and thus do not establish the critical path. 
In practice, however, circumstances can arise which cause normally non-critical activities to become critical and extend the overall duration of the construction schedule. Late delivery of major equipment as a result of unavallability of raw materials, over-extended fabrication facilities, expiration of shop labor contracts, wildcat strikes, or failure of equipment under test has caused extension of construction schedules. When such delays occur for items on the critical path, schedule delays occur because no float time is provided for these items. When such delays occur for items not on the critical path, overall construction schedule delays may be avoided only to the extent that float time is provided for them. 


\section{ENERGY ECONOMIC DATA BASE} PHASE VIII UPDATE (1986)

\section{STATES WITH POWER PLANT SITE CERTIFICATION AUTHORITIES} AND/OR THOSE REQUIRING A STATE EIS/EA

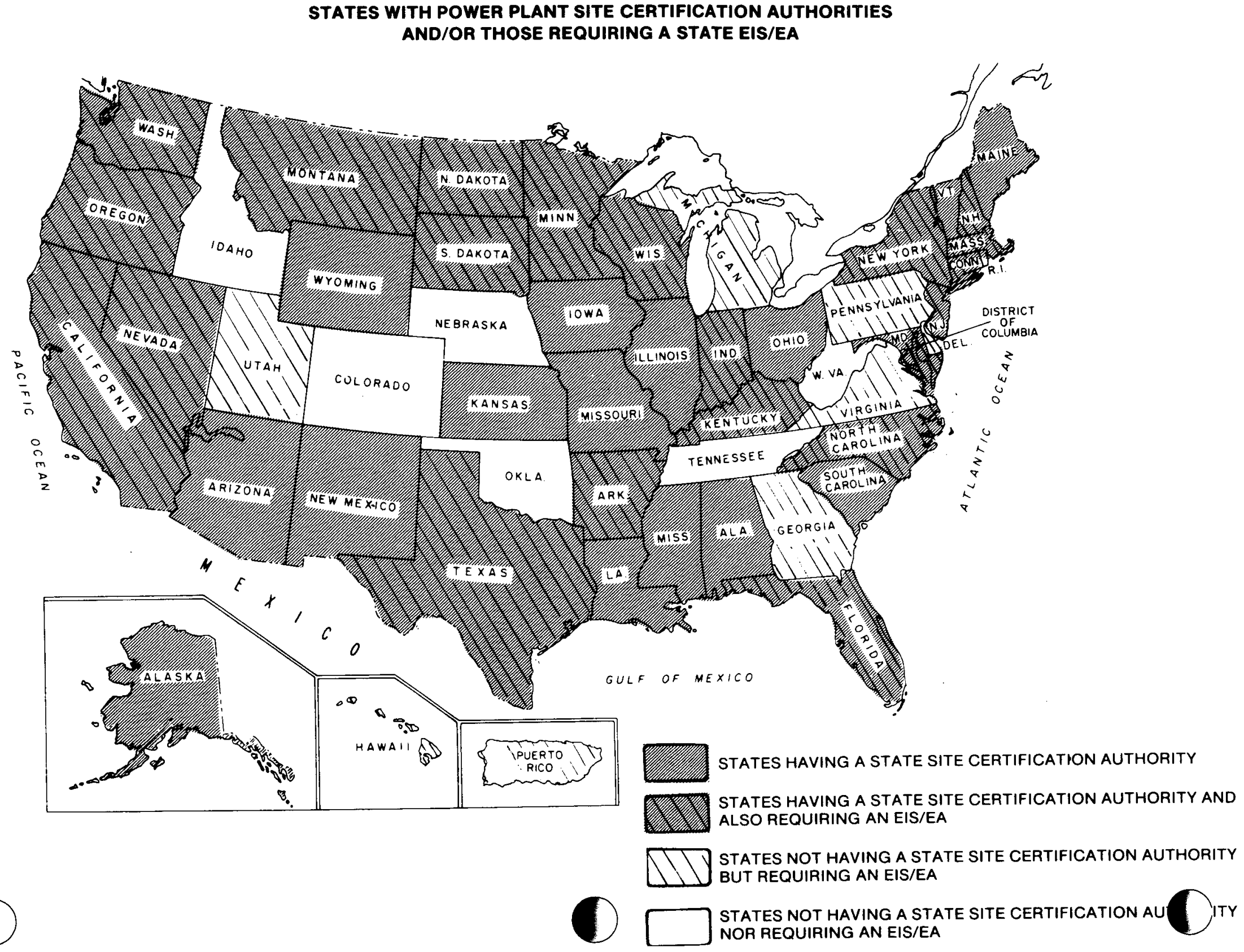


FIGURE 5.10

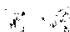

ENERGY ECONOMIC DATA BASE

PHASE VIII UPDATE (1986)

488 MWE HIGH SULFUA COAL-FIRED POWER GENERATING STATION (HS5) LICENSING ACTIVITY AND CHRONOLOGY DIAGRAM SITE CERTIFICATION STAGE (GROUP 1 STATES)

UTILITY INITIATION

OF PROJECT
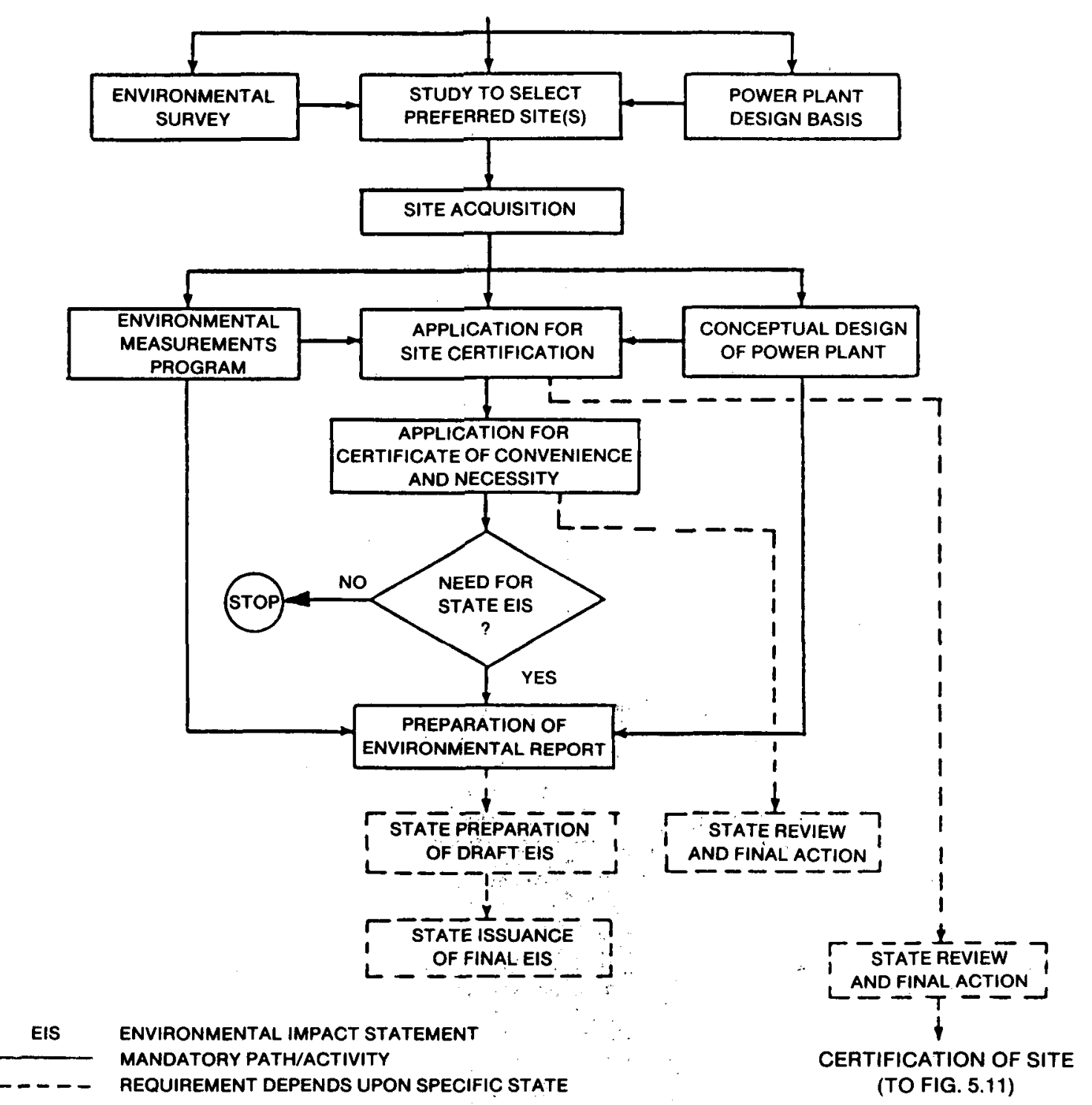
FIGURE 5.11

ENERGY ECONOMIC DATA BASE

PHASE VIII UPDATE (1986)

488 MWe HIGH SULFUR COAL-FIRED POWER GENERATING STATION (HS5)

LICENSING ACTIVITY AND CHAONOLOGY DIAGRAM

POWER PLANT PERMITTING STAGE (GROUP 1 AND 2 STATES)

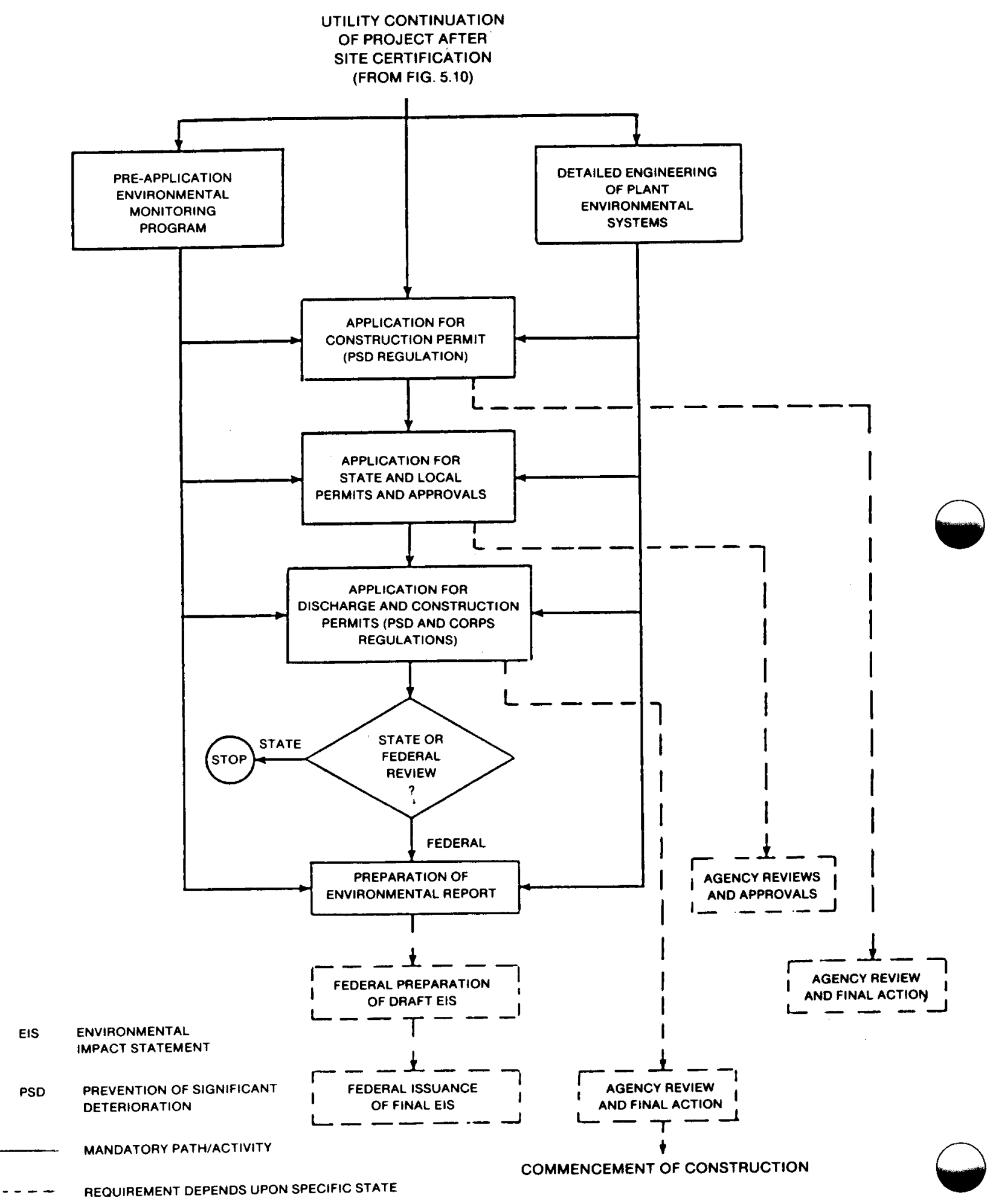


SINGLE UNIT 488 MWe HIGH SULFUR, COAL-FIRED POWER GENERATING STATION (HS5)

LICENSING MILESTONE SCHEDULE

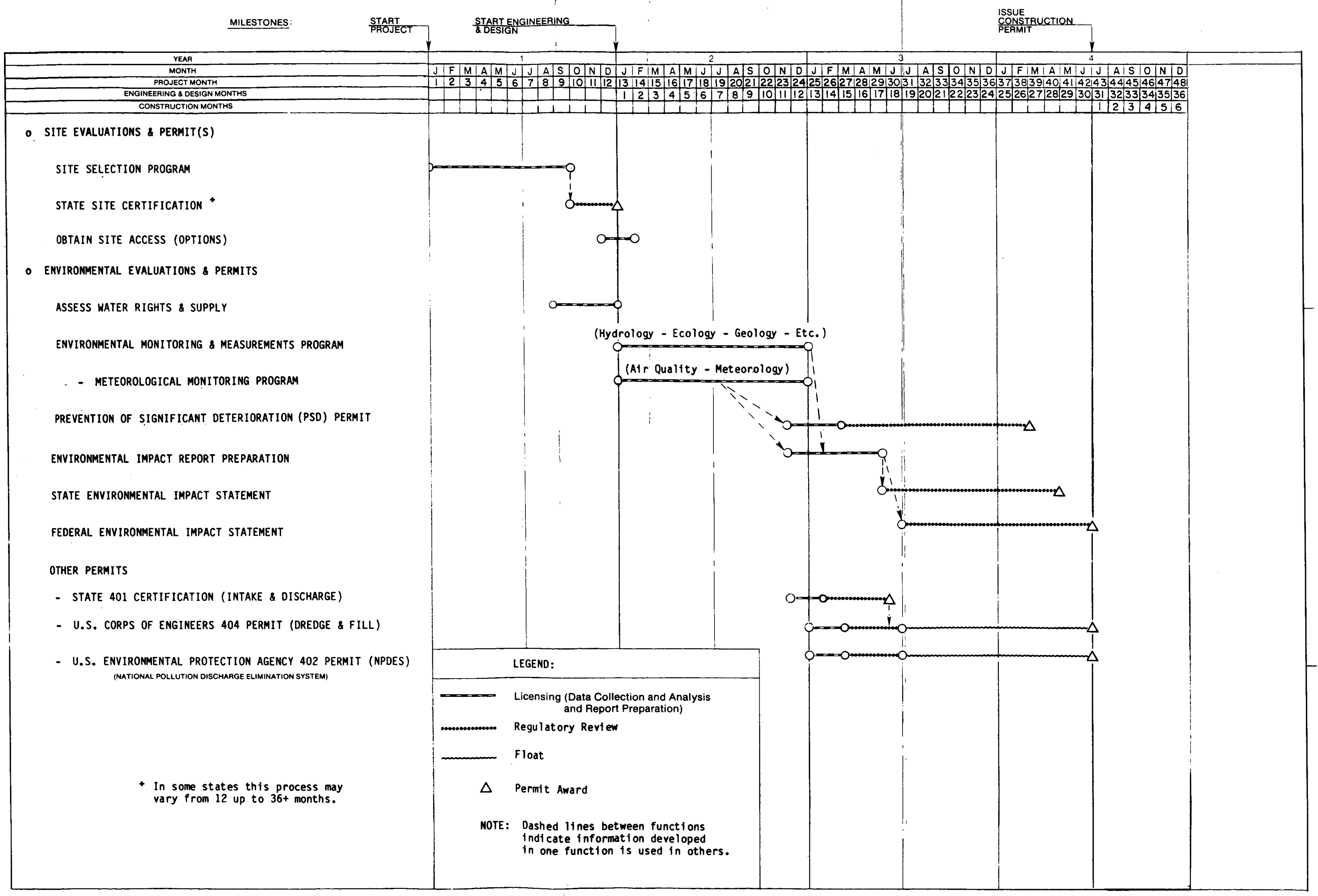


SUPPLEMENT TO FIGURE 5.12

EXPLANATION OF ITEMS ON THE HS5

LICENSING MILESTONE SCHEDULE

1. Site Selection Program - Selection of a power plant site utilizes a screening process whereby. areas are eliminated that do not conform to predetermined primary standards (e.g., cooling water, meteorology) until prime and alternate sites are found.

2. State Site Certification - More than half the states have siting legislation which gives a state agency(s) authority over utility siting efforts. These states each have specific requirements and time frames for obtainment of site certification (refer to Figure 5.9).

3. Obtain Site Access - Site access is obtained by buying land, taking out options or eminent domain. Early site access is preferred so that environmental data collection and evaluation can be initiated.

4. Assess Water Rights and Supply - Cooling of the plant's condensers is a prime consideration. Such being the case, the amount of water for consumptive use, the utility's rights to this water and its quality must be assessed.

5. Environmental Monitoring and Measurements Program - Detailed environmental monitoring and measurements programs are initiated by the utility in order to fulfill regulatory requirements. These entail studies in hydrology, meteorology, ecology and other disciplines.

6. Prevention of Significant Deterioration (Air Quality) Permit - The Prevention of Significant Deterioration permit is based on engineering analyses performed by the applicant. In addition to analysis for each pollutant emitted in significant quantities ( $>100$ tpy), analyses for Best Achievable Control Technology, Air Quality Impacts and Additional Impacts Analyses (on soil, vegetation and visibility) are required.

7. Environmental Impact Report Preparation - An Environmental Impact Report is prepared by the applicant to supply information to a federal agency for their preparation of an Environmental Impact Statement (EIS). The report generally includes a description of the proposed facility, an analysis of the affected environment, the impact of construction and operation of the facility on that environment and alternatives to the proposed action.

8. State Environmental Impact Statement (SEIS) - Certain states have enacted legislation which requires the preparation of a State Environmental Impact Statement in addition to one on the Federal level (refer to Figure 5.9). The SEIS describes the environmental impacts associated with the project. 


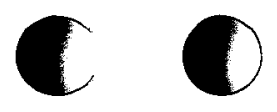

SUPPLEMENT TO FIGURE 5.12

EXPLANATION OF ITEMS ON THE HS5

LICENSING MILESTONE SCHEDULE

9. Federa1 Environmental Impact Statement (EIS) - The Federal EIS is mandated by the National Environmental Policy Act (NEPA) of 1969 for major Federal actions significantly affecting the environment. The draft EIS is prepared by a "lead" Federal agency and is typically based on the applicants Environmental Report. The draft EIS is followed by a final EIS after public and other agency comments are considered.

10. State 401 Certification (Intake and Discharge) - Section 401 of the Clean Water Act requires that, in order to obtain a Federal license or permit for an activity which may result in a discharge into navigable waters, the applicant must obtain a "certification" from the state in which the discharge originates. The discharge must comply with all applicable Federal and State regulations. The certification is required as part of the Corps of Engineers 404 permit for dredge and fill operations in connection with intake and discharge structures.

11. U.S. Corps of Engineers 404 Permit (Dredge \& Fil1) - Section 404 of the Clean Water Act requires an applicant to obtain a permit for the discharge of dredge or fill material into navigable waters at specified disposal sites, as related to intake and discharge structures.

12 . Vischarge Enmental Protection Agency 402 Permit. - National Pollution Water Act, the NPDES program, as administered by EPA, requires permits for the discharge of "pollutants" from any "point source" in the United States. The NPDES permit sets limitations on the concentrations of pollutants in the discharge and requires periodic monitoring efforts. A NPDES permit must be renewed every five years by the applicant.

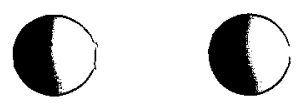




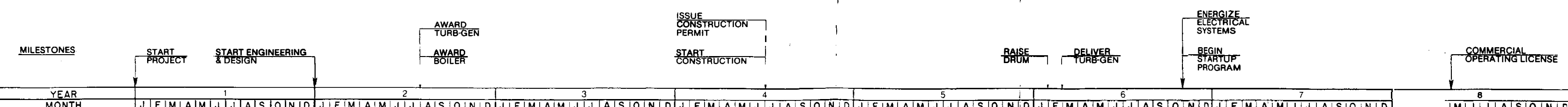

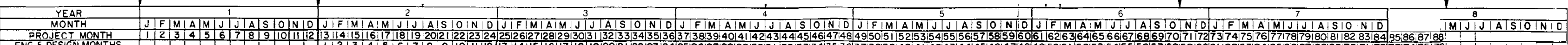

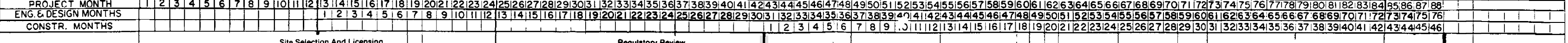
LICENSING

ENGINEERING

SITE PREPARATION

BOILER HOUSE

- structure

- Boller

IURBINE BUILDING

- foundation

- TURBINE-

COOLING TOWER

PIPING \& MECHANICAL
EQUIPMENT

ELECTRICAL
EOUIPMENT

DRAFT PLANT

- SO, REMOVAL
SYSTEMS

$\underset{\substack{\text { PARTICULATE } \\ \text { REMOVAL SYSTEM }}}{\text { STS }}$

COAL HANOLING SYSTEM

SWITCHYARD

START-UP

- STATION POWER
AVALLABLE

- Boller hyoro

- boller boll-out

\begin{tabular}{l}
- COMMECTIAL \\
OPEAATIOA \\
\hline
\end{tabular}

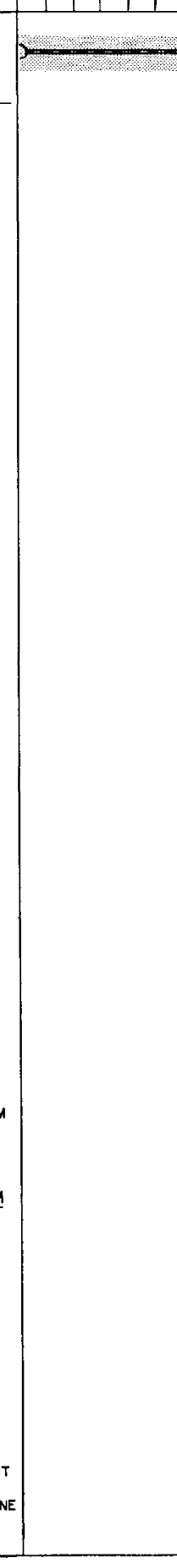

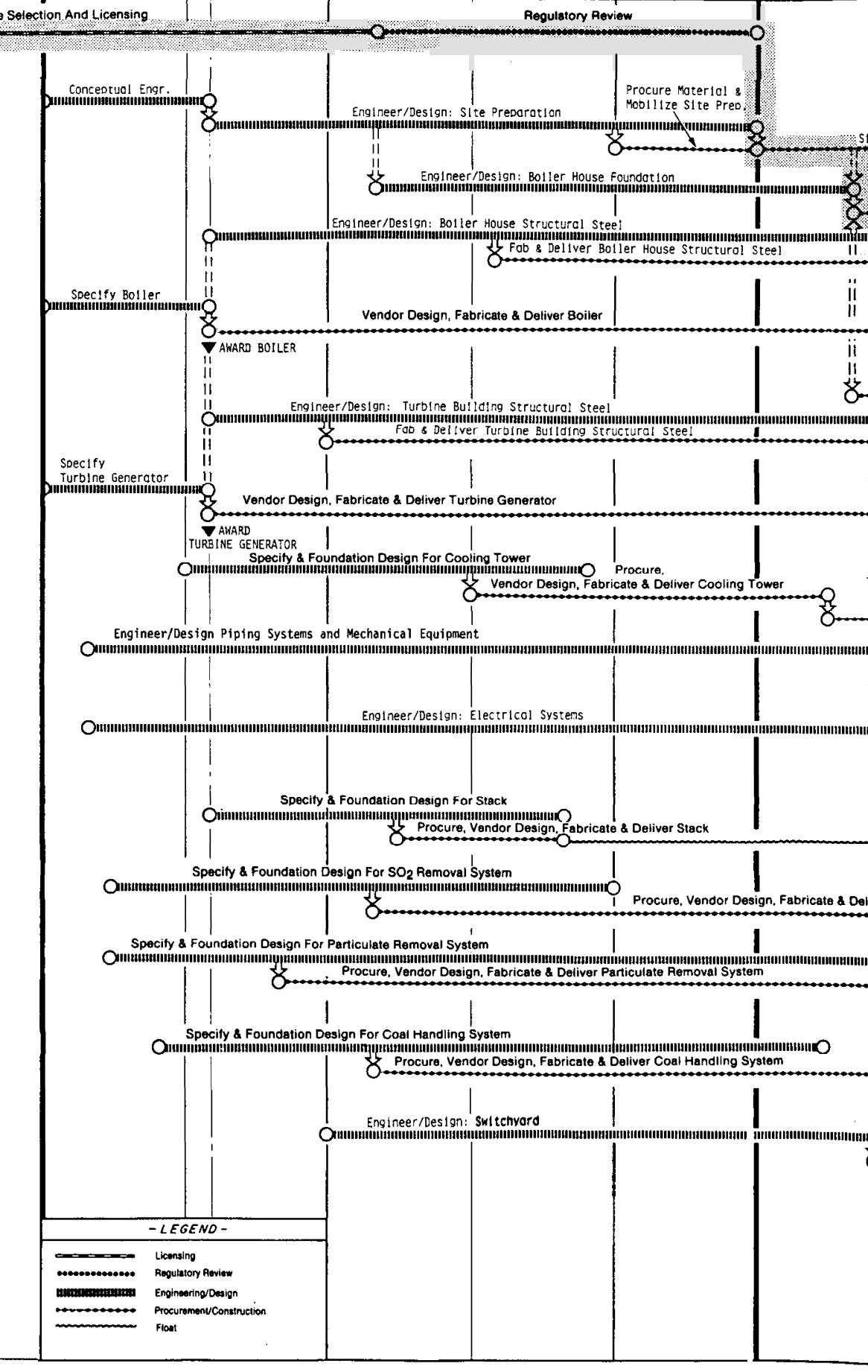

(1)

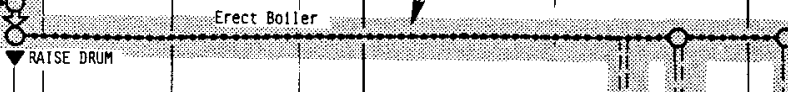

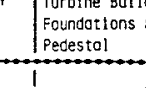

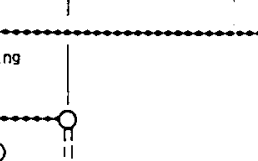

$\left.\left|\frac{x+1}{\mid}\right|\right|_{\mid}$
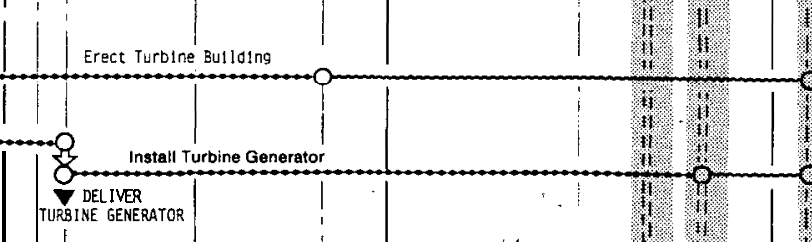

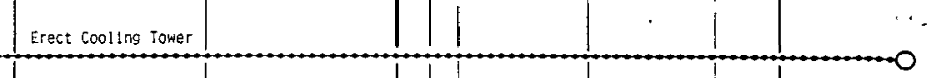
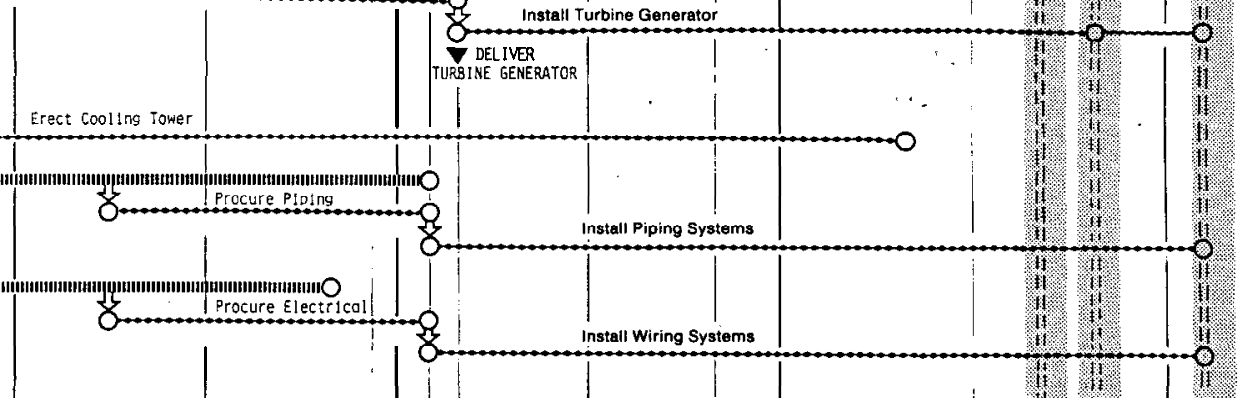

instal piping systems

Install Wiring Systems

ier so2 Removal System

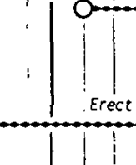

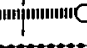

$: 8$. Erect s.52 Remonvol system
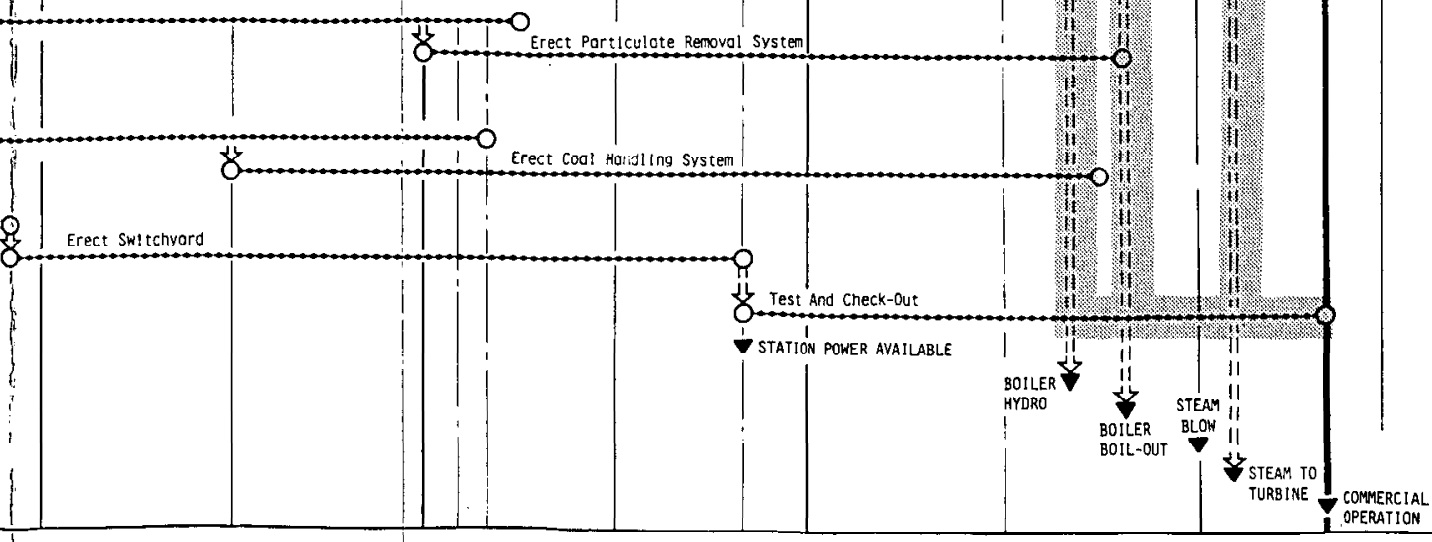
SUPPLEMENT TO FIGURE 5.13

DEFINITION OF ITEMS ON THE HS5 ENGINEERING AND

CONSTRUCTION MILESTONE SCHEDULE

1. Engineering

a. Conceptual Engineering-Engineering/Design - Project definition, conceptual design, definition of criteria, and field investigation to permit design of structures. Finalize foundation and structural design.

b. Site Preparation - Initiate excavation, set up temporary facilities.

2. Boiler House (Steam Generator Building)

a. Foundations - Complete design of foundation, excavate, form, set reinforcing and pour concrete.

b. Structure - Complete engineering, design and erection.

c. Boiler - Complete engineering, design and installation of Boiler and Draft System components inside the Steam Generator Building. Also, procure, fabricate and install building service components and piping.

3. Turbine Building (Turbine, Heater and Control Building)

a. Foundations - Engineering and design of foundations, excavate, form, set reinforcing and pour concrete. Engineering and design of the structure and systems, erect the building and procure, fabricate, and install building service components and piping.

b. Turbine Generator - Erect T-G on pedestal, install T-G auxiliaries and piping and tie-in turbine to main, extraction and auxiliary steam systems and condenser.

4. Cooling Tower - Engineering, design, procurement, fabrication and erection of cooling towers.

5. Piping and Mechanical Equipment - Engineering, design, procurement, fabrication and installation of piping and mechanical equipment for all systems.

6. Electrical Equipment - Engineering, design, procurement, fabrication and installation of power buses, electrical and instrumentation cables, panels, reactor control centers, distribution networks, batteries and battery systems. 
SUPPLEMENT TO FIGURE 5.13

DEFINITION OF ITEMS ON THE HS5 ENGINEERING AND

CONSTRUCTION MILESTONE SCHEDULE

7. Draft Plant

a. Stack - Engineering, design, procurement, fabrication and erection of the unit chimney.

b. $\mathrm{SO}_{2}$ Removal Systems - Analysis, engineering, design, procurement, fabrication, erection and installation of the FGD structures, equipment and ducts.

c. Particulate Removal System - Engineering, design, procurement, fabrication and erection of the electrostatic precipitators.

8. Coal Handling System - Engineering, design, procurement, fabrication, erection and installation of the coal receiving, storage and reclaiming structures, conveyors and equipment.

9. Switchyard - Engineering, design, procurement, fabrication and installation of the station switchyard and main transformer.

\section{Startup}

a. Station Power Available - Energize Reserve Auxiliary

Transformer and station auxiliary power system.

b. Boiler Hydro - Perform testing and inspection to verify

that the steam generation components and piping can perform their intended function under actual pressure conditions.

c. Boiler Boil-0ut - Perform caustic and phosphate boil-out of the boiler pressure parts, followed by an acid wash.

d. Steam to Turbine - Perform steam cleaning of steam lines. Perform testing and inspection of turbine system and auxiliaries prior to introduction of steam to turbine.

e. Commercial Operation 


\section{SECTION 6}

6.0 REFERENCES, DEFINITIONS AND GLOSSARY

\subsection{REFERENCES AND BIBLIOGRAPHY}

1. DOE/NE-0052 "Program Reference Book for the Energy Economic Data Base Program - EEDB," prepared for the U.S. Department of Energy by United Engineers \& Constructors Inc., Philadelphia, PA 19101, under Contract No. CHENG-38-6818; Ju1y, 1983 .

2. "Energy Economic Data Base (EEDB) Program, Phase VIII Update (1986) Report" United Engineers \& Constructors Inc., Philadelphia, PA 19101, UE\&C/ORNL$860930 / 6$, Martin Marietta Sub-Contract No. 43X-86004V, September, 1986.

3. "Large Scale Prototype Breeder," prepared for the U.S. Department of Energy by Consolidated Management office for the LMFBR of the Electric Power Research Institute, September, 1984.

4. DOE/NE-0059/1 "Technical Reference Book for the Energy Economic Data Base Program - EEDB," prepared for the U.S. Department of Energy by United Engineers \& Constructors Inc., Philadelphia, PA 19101, under Contract No. DE-AC05840R21400; August, 1985.

5. DOE/NE-0051/2 "Phase VII Update (1984) Report for the Energy Economic Data Base Program EEDB-VII," prepared for the U.S. Department of Energy by United Engineers \& Constructors Inc., Philadelphia, PA 19101, under Contract No. DE-AC05-840R21400, August 1985 .

6. DOE/NE-0051/1 "Phase VI Update (1983) Report for the Energy Economic Data Base Program - EEDB-VI," prepared for the U.S. Department of Energy by United Engineers \& Constructors Inc., Philadelphia, PA 19101, under Contract No. DE-AC05-840R21400: September, 1984.

7. DOE/NE-0051 "Phase V Update (1982) Report for the Energy Economic Data Base Program EEDB-V," prepared for the U.S. Department of Energy by United Engineers \& Constructors Inc., Philadelphia, PA 19101, under Contract No. CH-ENG-38-6818; Ju1y, 1983.

8. "Phase IV Final Report and Fourth Update of the Energy Economic Data Base (EEDB) Program," United Engineers \& Constructors Inc., Philadelphia, PA 19101, UE\&C/DOE-810930, U.S. Department of Energy Contract (Argonne Nat1onal Laboratory) 31-109-38-6411, September, 1981; and Supplement, November, 1981 .

9. "Phase III Final Report and Third Update of the Energy Economic Data Base (EEDB) Program," United Engineers \& Constructors Inc., Philadelphia, PA 19101, UE\&C/DOE-810731, U.S. Department of Energy Contract DE-AC02-78ET33020, (formerly EN-78-C-02-4954), July, 1981 . 
$6.1($ Cont'd)

10. "Phase II Final Report and Second Update of the Energy Economic Data Base (EEDB) Program," United Engineers \& Constructors Inc., Philadelphia, PA 19101, UE\&C/DOE-810430, U.S. Department of Energy Contract DE-AC02-78ET33020, (former1y EN-78-C-02-4954), Apri1, 1981 .

11. "Final Report and Initial Update of the Energy Economic Data Base (EEDB) Program - Phase I," United Engineers \& Constructors Inc., Philadelphia, PA 19101, UE\&C/DOE-790930, U.S. Department of Energy Contract EN-78-C-02-4954, December, 1979.

12. "Commercial Electric Power Cost Studies," United Engineers \& Constructors Inc., NUREG: U.S. Nuclear Regulatory Commission and/or COO: U.S. Energy Research and Development Administration.

a. "Capital Cost: Boiling Water Reactor Plant," Volumes 1 and 2, NUREG-0242, COO-2477-6, June 1977 .

b. "Capital Cost: Pressurized Water Reactor Plant," Volumes 1 and 2 , NUREG-0241, COO-2477-5, June 1977.

c. "Capital Cost: High and Low Sulfur Coal Plants - 1200 MWe (Nominal)," Volumes 1, 2 and 3, NUREG-0243, COO-2477-7, June 1977.

d. "Capital Cost: Low and High Sulfur Coal Plants - 800 MWe (Nomina1)," Volumes 1, 2 and 3, NUREG-0244, COO-2477-8, June 1977

13. "The HTGR for Electric Power Generation - Design and Cost Evaluation," United Engineers \& Constructors Inc., Philadelphia, PA 19101, Gas Cooled Reactor Associates Contract GCRA/AE/78-1 Proprietary, September, 1980 .

14. "Conceptual Design of a large HWR for U.S. Siting," CEND-379; Combustion Engineering, Inc., Windsor, CT 06905 and United Engineers \& Constructors Inc., Philadelphia, PA 19101, U.S. Department of Energy Contract EN-77-C-015068, September, 1979.

15. "NSSS Capital Costs for a Mature LMFBR Industry for Energy Economic Data Base Program - Phase I," Combustion Engineering, Inc., Windsor, CT 06095, CE-FBR78-532, United Engineers \& Constructors Inc. Subcontract, October, 1978.

16. "NSSS Capital Costs for a Mature LMFBR Industry for Energy Economic Data Base Program - Phase I: Addendum," Combustion Engineering, Inc., Windsor, CT 06095, CE-ADD-80-310, United Engineers \& Constructors Inc. Subcontract, September 25, 1980 (Addendum to Reference 15). 
$6.1\left(\right.$ Cont' $\left.^{d}\right)$

17. "1170 MWt, HTGR Steamer Cogeneration Plant - Design and Cost Study," UE\&C/DOE 800716; United Engineers \& Constructors Inc., Philadelphia, PA 19101 and General Atomic Company, La Jolla, CA, U.S. Department of Energy Contract DE-AC02-78ET34222, August 1980.

18. "Study of Electric Plant Applications for Low Btu Gasification of Coal for Electric Power Generation," Combustion Engineering, Inc. Windsor, CT 06905, U.S. Department of Energy Contract FE-1545-TK59.

19. "An Assessment of New Coal-Fueled, Cogeneration Power Plants for Electricity Production and Hot Water District Heating," Oak Ridge National Laboratory, ORNL/TM-6830/P8 (unpub1ished).

20. "Reference Safety Analysis Report," Nuclear Energy Systems Division, Westinghouse Electric Corporation, Pittsburgh, PA 15230, RESAR-3S, July, 1975. 


\subsection{DEFINITIONS}

The following commonly used terms are specifically defined as they are used in the Energy Economic Data Base Program.

\subsubsection{Rated Load (Unit or Equipment)}

The operating condition that exists when the unit steam turbine-generator is operating at that load for which the turbine-generator performance is guaranteed by the manufacturer.

\subsubsection{Rated Thermal Power (Nuclear Power Generating Stations)}

The rated load heat input to the reactor coolant from the reactor core expressed as thermal megawatts (MWt).

\subsubsection{Rated Thermal Power (Fossil Power Generating Stations)}

The rated load heat input to the boiler in the form of. fuel, expressed as thermal megawatts (MWt).

\subsubsection{Net Power to GSU (Generator Step-up Transformer)}

The generator output at rated load and voltage reduced by the plant auxiliary power load at these conditions, expressed as electric megawatts (MWe).

\subsubsection{Net Plant Heat Rate}

The figure of merit obtained by dividing the product of the "Thermal Power" and the constant 3412.14 (British thermal units per hour per electric kilowatt) by the "Net Power to GSU," expressed as British thermal units/kilowatt-hour $(\mathrm{Btu} / \mathrm{kWh})$.

\subsubsection{Net Plant Efficiency}

The figure of merit obtained by dividing the "Net Power to GSU" by the "Thermal Power," expressed as a percentage.

\subsubsection{Maximum Continuous Rating (Fossil Boiler)}

The boiler design condition which corresponds to a main and reheat steam pressure of five percent above that for rated load conditions, and a flow rate in excess of that predicted by the turbine manufacturer at the valves wide open, five percent overpressure condition.

\subsubsection{Valves Wide Open, Five Percent Overpressure Condition (VWO, 5\% OP)}

The operating condition that exists when the turbine is operated with the main throttle valve(s) fully opened and the main steam pressure at the throttle valve inlet five percent greater than that at rated load. Typically, this is 
the maximum load condition for which the turbine manufacturer predicts (but does not guarantee) performance. 
6.3 GLOSSARY OF ACRONYMS AND ABBREVIATIONS

6.3.1 Governmental Organizations

AEC

- Atomic Energy Commission, Predecessor to ERDA and NRC

ANL

- Argonne National Laboratory

DOE (DOE)

- Department of Energy

(Successor to ERDA and AEC)

EPA

- Environmenta1 Protection Agency

ERDA

- Energy Research and Development Administration, (Predecessor to DOE)

NRC

- Nuclear Regulatory Commission (Successor to AEC)

ORNL

- Oak Ridge Nationa1 Laboratory

US

- United States

6.3.2 Other Organizations

$\begin{array}{ll}\text { AIChE } & - \text { American Institute of Chemical Engineers } \\ \text { ANS } & - \text { American Nuclear Society } \\ \text { API } & - \text { American Petroleum Institute } \\ \text { ASCE } & - \text { American Society of Civil Engineers } \\ \text { ASME } & - \text { American Society of Mechanical Engineers } \\ \text { CE } & - \text { Combustion Engineering, Inc. } \\ \text { EPRI/CoMO } & - \text { Electric Power Research Institute/Consolidated } \\ & - \text { Management Organization } \\ \text { GE } & - \text { General Electric Company } \\ \text { ICEA } & - \text { Insulated Cable Engineers Association, Inc. } \\ \text { IEEE } & - \text { Institute of Electrical and Electronics } \\ \text { ISA } & - \text { Instrument Society of America }\end{array}$




\subsection{2 (Cont'd)}

$\begin{array}{ll}\text { NFPA } & - \text { National Fire Protection Association } \\ \text { UE\&C } & -\quad \begin{array}{l}\text { United Engineers \& Constructors Inc. } \\ \text { (A Raytheon Subsidiary) }\end{array} \\ \text { UL } & - \text { Underwriters' Laboratories, Inc. } \\ \text { WE } & - \text { Westinghouse Electric Corporation } \\ \text { WEC } & \end{array}$

6.3.3 Technical Identification and Programs

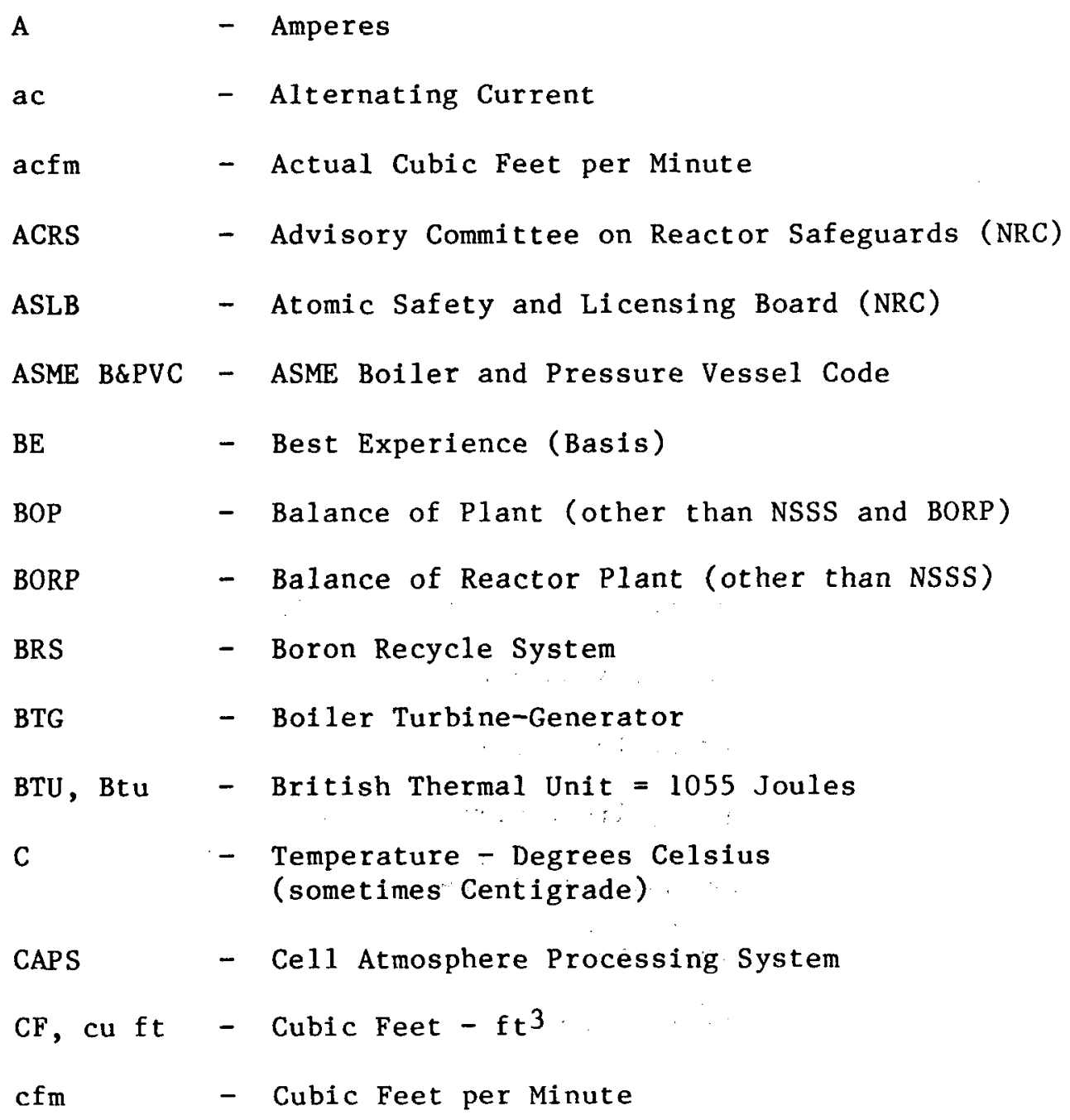




\subsection{3 (Cont'd)}

CFR

CGC

CGCC

co

CP

CRT

CSS

CuNi

cves

CY, cu yd

DBA

dc

DF

DNA

DRACS

EA

EEDB

EHC

EIS

EM

ER

ESF

EVST
- Code of Federal Regulations (usually preceded by a Title number and followed by a Part number as 10CFR50)

- Combustible Gas Control (System)

- Coal Gasification Combined Cycle Plant

- Carbon Monoxide

- Construction Permit

- Cathode Ray Tube

- Containment Spray System

- Copper Nickle

- Chemical and Volume Control System

- Cubic Yard - yd $\mathrm{d}^{3}$

- Design Basis Accident

- Direct Current

- Decontamination Factor

- Data Not Available

- Direct Reactor Auxiliary Cooling System

- Environmental Assessment

- Energy Economic Data Base

- Electrohydraulic Control

- Environmental Impact Statement

- Electromagnetic

- Environmental Report

- Engineered Safeguard Features or Engineered Safety Features

- Ex-Vessel Storage Tank 
6.3 .3 (Cont'd)

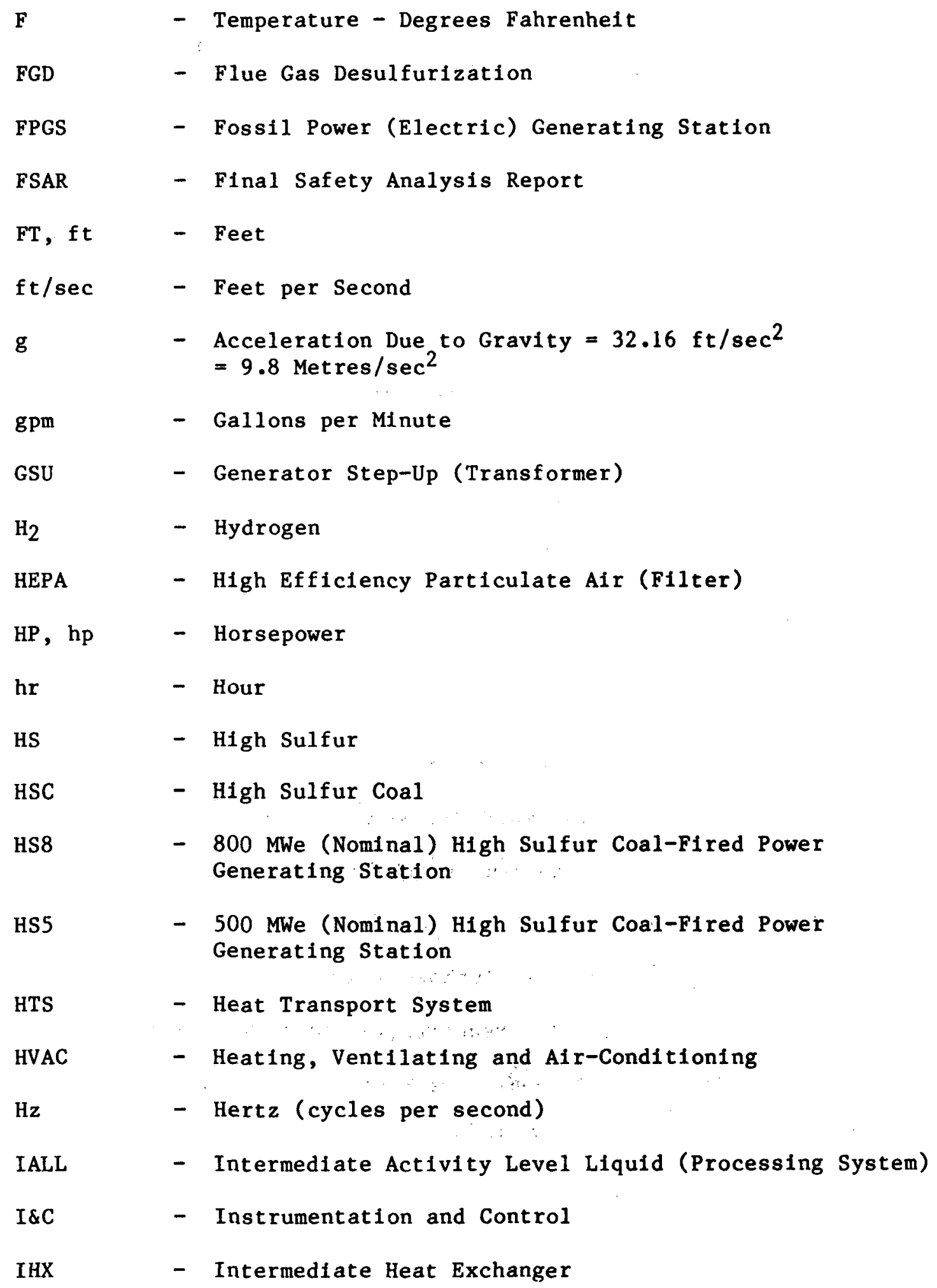


6.3 .3 (Cont'd)

$$
\begin{aligned}
& \text { In, in - Inches } \\
& \text { in-Hg - Inches of Mercury ( } 1 \text { in-Hg = 25.4 Torr) } \\
& \text { in-HgA - Inches of Mercury - Absolute } \\
& k_{\text {eff }} \text { - Effective Multiplication Factor (The require- } \\
& \text { ment for criticality in a finite system is } \\
& k_{\text {eff }}=1 \text { ) } \\
& \mathrm{kV} \quad-\text { Volts } \times 10^{3}-\text { Kilovolts } \\
& \text { kVA - Volt-Amperes } \times 10^{3} \text { - Kilovolt-Amperes } \\
& \mathrm{kW} \quad-\text { Watts } \times 10^{3}-\mathrm{Kil} \text { owatt }=3412.9 \mathrm{Btu} / \mathrm{hr} \\
& \text { kWh - Kilowatt-Hour - } 3412.9 \text { Btu } \\
& \text { LALL - Low Activity Leve1 Liquid (Processing System) } \\
& \text { LB, 1b - - Pound or Pounds (depending on context) } \\
& \text { lb/hr } \quad-\text { Pounds per Hour } \\
& \text { LCCV - Large Component Cleaning Vessel } \\
& \text { LMFBR - Liquid Metal Fast Breeder Reactor } \\
& \text { LOCA - Loss-of-Coolant-Accident } \\
& \text { LRWS - Liquid Radioactive Waste System } \\
& \text { LSPB - Large Scale Prototype Breeder Reactor } \\
& \text { LT } \quad-\text { Lot } \\
& \text { LWA - Limited Work Authorization (NRC) } \\
& \text { LWR - Light Water Reactor (includes BWR and PWR) } \\
& \text { MCR - Maximum Continuous Rating (Fossil Boilers) } \\
& \text { ME - Median Experience (Basis) } \\
& \text { min } \quad-\text { Minute }
\end{aligned}
$$


6.3 .3 (Cont'd)

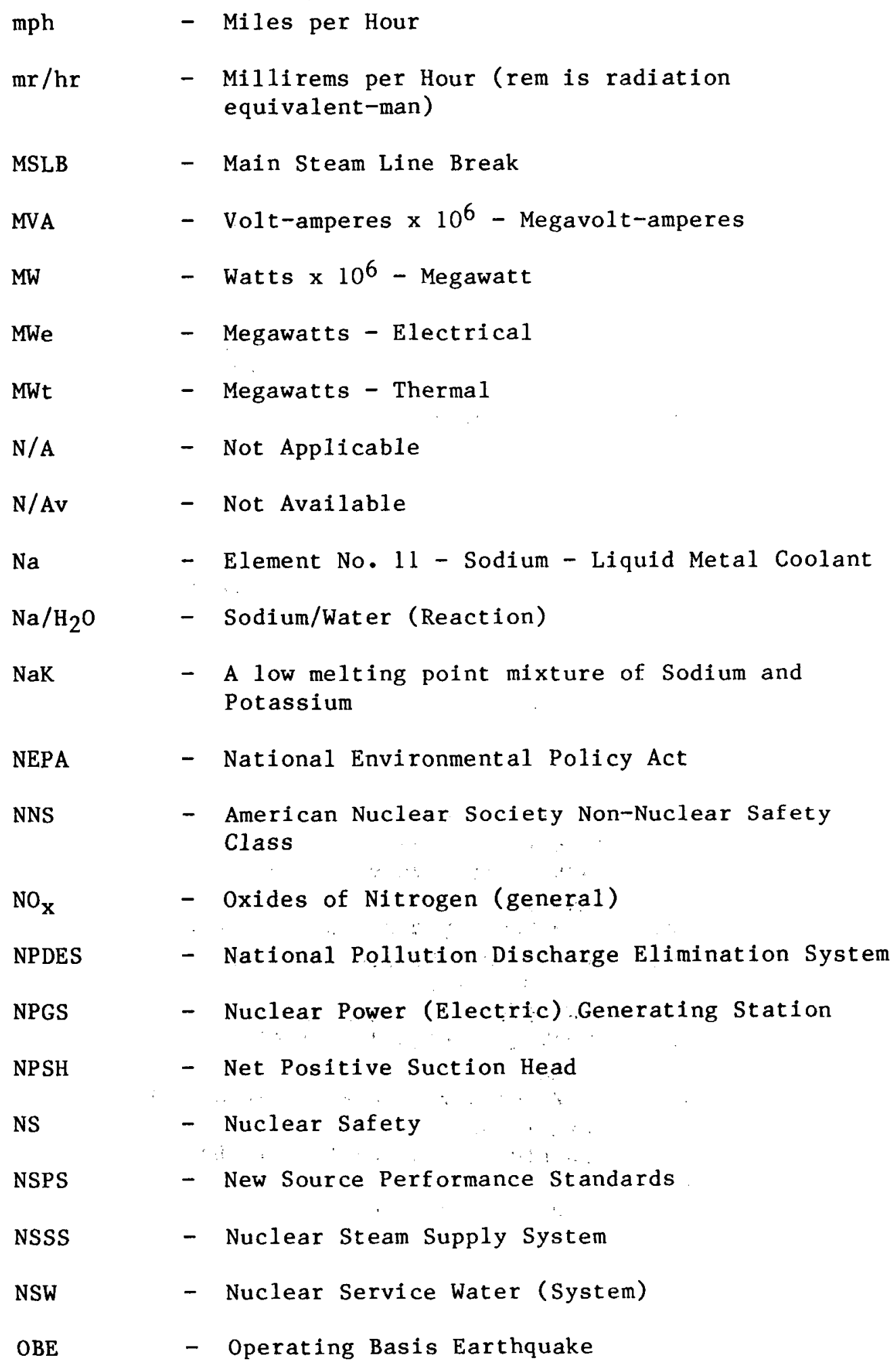


6.3 .3 (Cont'd)

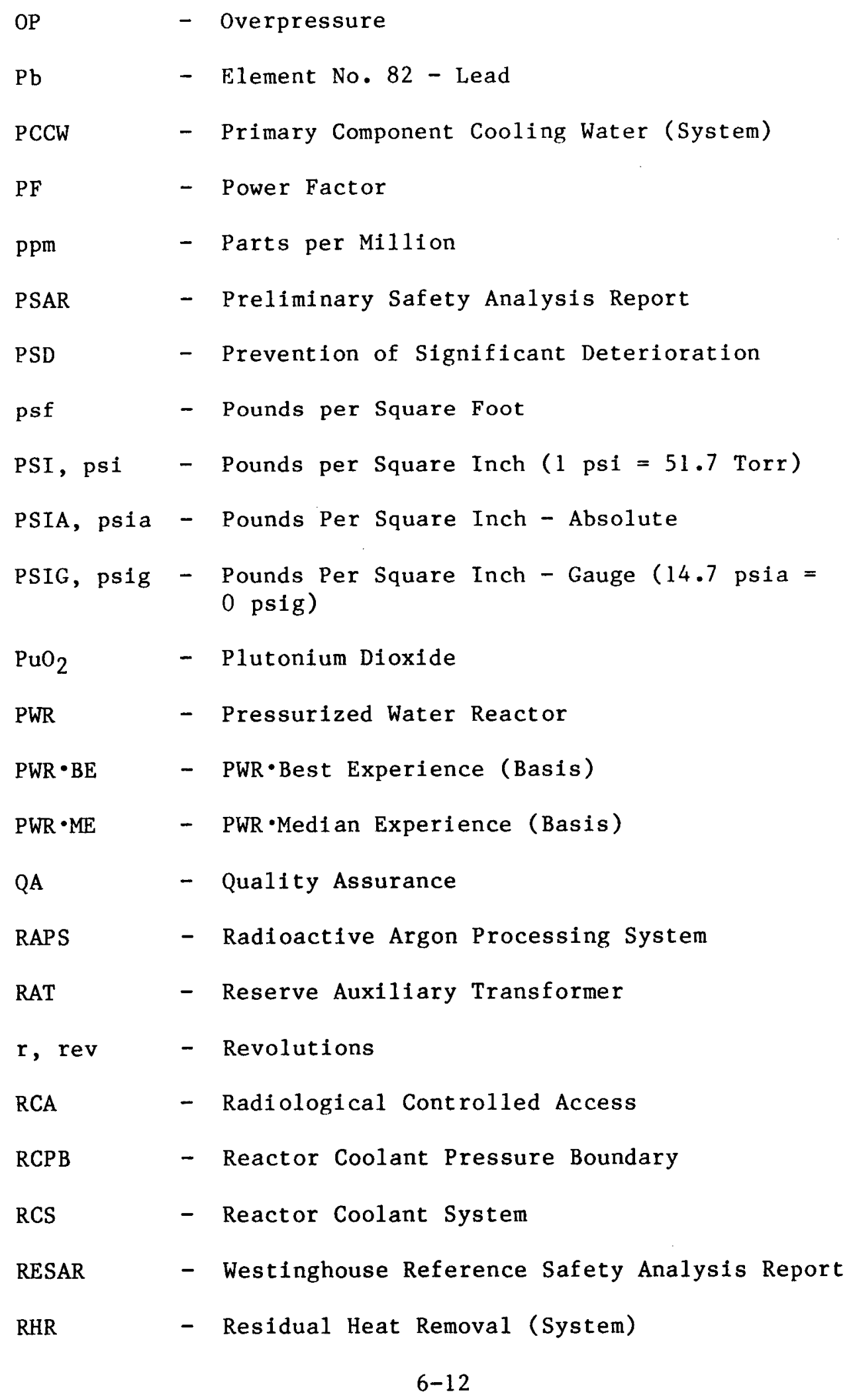


6.3 .3 (Cont'd)

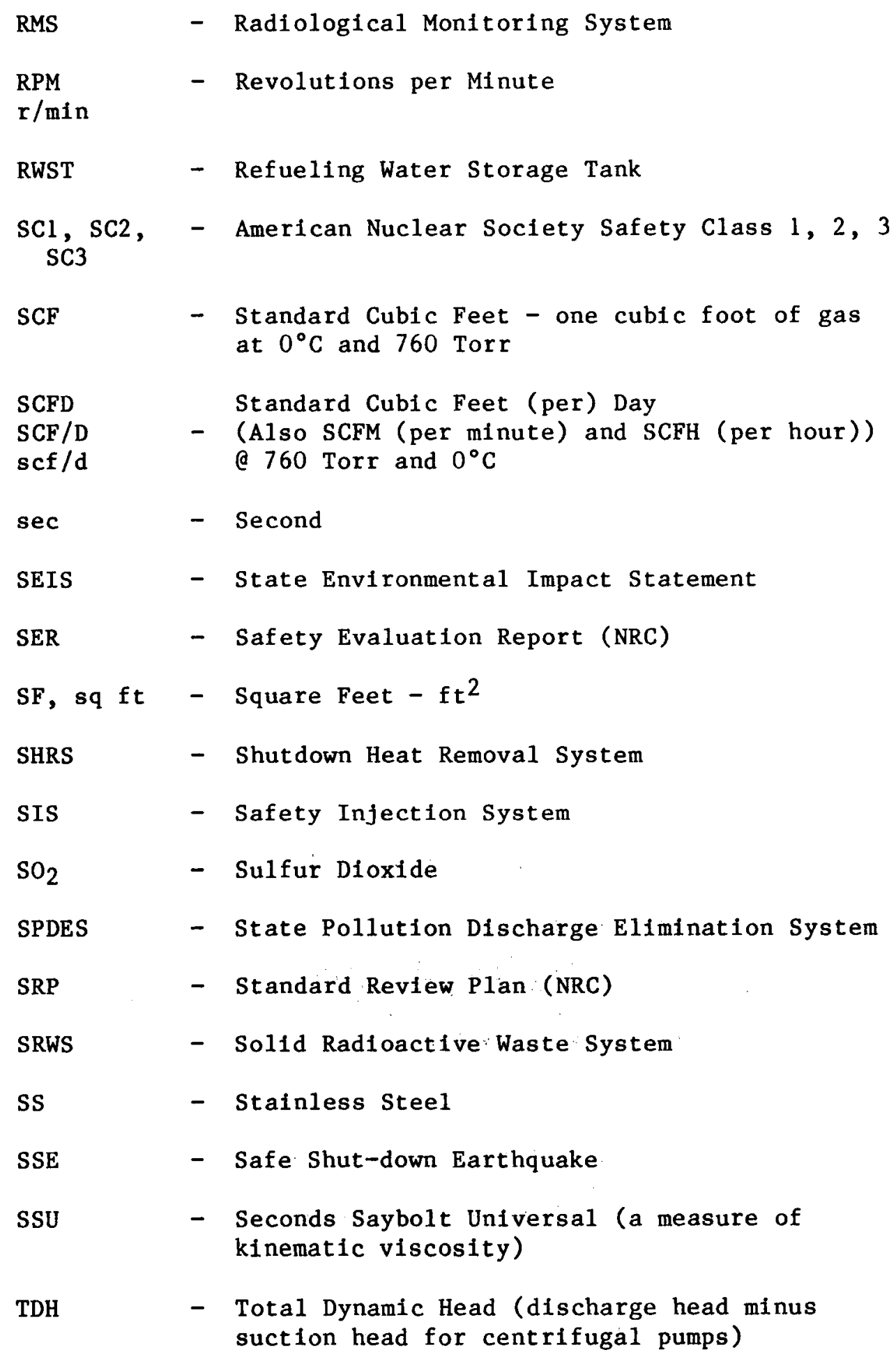


6.3.3 (Cont'd)

$\begin{array}{ll}\text { tph } & - \text { Tons per Hour } \\ \text { tpy } & - \text { Tons per Year } \\ \text { UAT } & - \text { Unit Auxiliary Transformer } \\ \text { UHS } & - \text { Ultimate Heat Sink } \\ \mathrm{UO}_{2} & - \text { Uranium Dioxide } \\ \text { V } & - \text { Volts } \\ \text { VWO } & - \text { Valves Wide Open } \\ \text { We } & - \text { Water Gage (usually inches of water, } 1 \text { in. W.G. } \\ \text { w.g. } & =1.87 \text { Torr) } \\ & - \text { Watts - Thermal } \\ \text { Wt } & - \text { year }=8760 \text { Hours }=3.154 \times 10^{7} \text { Seconds } \\ \begin{array}{l}\text { Y } \\ \text { yr }\end{array}\end{array}$


APPENDIX - A-1

ENERGY ECONOMIC DATA BASE (EEDB) PROGRAM

DESCRIPTION OF STANDARD HYPOTHETICAL MIDDLETOWN SITE

FOR NUCLEAR POWER PLANTS

The material in this Appendix was developed during the Initial Update (1978) of the EEDB Program. It is reviewed during each succeeding update and revised for current practice and regulations as required. The material presented in this Appendix is current through January 1, 1986.

$$
\text { A-1-1 }
$$


ENERGY ECONOMIC DATA BASE (EEDB) PROGRAM

DESCRIPTION OF A STANDARD HYPOTHETICAL MIDDLETOWN SITE

FOR NUCLEAR POWER PLANTS

\section{Al.1 GENERAL}

This site description provides the site and environmental data, derived from Appendix A of "Guide for Economic Evaluation of Nuclear Reactor Plant Designs", USAEC Report NUS-531, modified to reflect current nuclear power plant siting requirements. These data form the site-related bases of the criteria used to develop the conceptual designs of the nuclear power plant technical data models for the EEDB Program, including evaluation of the routine and accidental release of radioactive and other liquids and gases to the environment. The site is representative of locales found in the northeastern United States.

\section{Al.2 TOPOGRAPHY AND GENERAL SITE CHARACTERISTICS}

The site is located on the east bank of the North River at a distance of twenty-five miles south of Middletown, the nearest large city. The North River flows from north to south and is approximately one-half mile ( $2600 \mathrm{ft})$ wide adjacent to the plant site. A flood plain extends from both river banks an average distance of one-half mile, ending with hilltops generally 150 to 250 feet above the river level. Beyond this area, the topography is gently rolling, with no major critical topographical features. The plant site itself extends from river level to elevations of 50 feet above river level. The containment building, other Seismic Category I structures, primary nonSeismic Category I structures and the switchyard are located on level ground at an elevation of 18 feet above the mean river level. This elevation is ten feet above the 100-year maximum river level, according to U.S. Army Corps of Engineers' studies of the area.

In order to optimize land area requirements for the nuclear power plant site, maximum use of the river location is employed. The containment structure is located approximately 400 feet from the east bank of the river. The site land area is taken as approximately 500 acres.

\section{Al.3 SITE ACCESS}

Highway access is provided to the hypothetical site by five miles of secondary road connecting to a state highway; this road is in good condition and needs no additional improvements. Railroad access is provided by constructing a spur which intersects the $B \& M$ Railroad. The length of the required spur from the main line to the plant site is assumed to be five miles in length. The North River is navigable throughout the year with a 40 feet wide by 12 feet deep channel. The distance from the shoreline to the center of the ship channel is 2,000 feet. All plant shipments are assumed to be made overland except that heavy equipment (such as the reactor vessel and the generator stator) may be transported by barge. The Middletown Municipal Airport is located three miles west of the State highway, 15 miles south of Middletown, and ten miles north of the site. 


\section{Al.4 POPULATION DENSITY AND LAND USE}

The hypothetical site is near a large city (Middletown) of 250,000 population, but in an area of low population density. Variation in population with distance from the site boundary is:

\begin{tabular}{rr} 
Miles & $\begin{array}{r}\text { Cumulative } \\
\text { Population }\end{array}$ \\
\hline 0.5 & 0 \\
1.0 & 310 \\
2.0 & 1,370 \\
5.0 & 5,020 \\
10.0 & 28,600 \\
20.0 & 133,000 \\
30.0 & $1,010,000$
\end{tabular}

There are five industrial manufacturing plants within 15 miles of the hypothetical site. Four are small plants, employing less than 100 people each. The fifth, near the airport, employs 2,500 people. Closely populated areas are found only in the centers of the small towns so that the local land area used for housing is small. The remaining land, including that across the river, is used as forest or cultivated crop land, except for railroads and highways.

\section{A1.5 NEARBY FACILITIES}

Utilities are available as follows:

- Natural gas service is available two miles from the site boundary on the same side of the river.

- Communication lines are furnished to the project boundaries at no cost.

- Power and water for construction activities are available at the southwest corner of the site boundary.

- Two independent of $\mathrm{f}$-site power sources (one at $500 \mathrm{kV}$ or $230 \mathrm{kV}$ for the generator connection and one at $230 \mathrm{kV}$ or $115 \mathrm{kV}$ for the reserve auxiliary transformer connection) are available at the switchyard..

\section{Al.6 METEOROLOGY AND CLIMATOLOGY}

\section{Al.6.1 Ambient Temperatures}

The winters in the Middletown area are moderately cold, with average temperatures in the low $30 \mathrm{~s}$. The summers are fairly humid with average temperatures in the low $70 \mathrm{~s}$, and with high temperatures averaging around $82^{\circ} \mathrm{F}$. The 
historic maximum wet bulb and dry bulb temperatures are $78^{\circ} \mathrm{F}$ and $99^{\circ} \mathrm{F}$ respectively.

The year-round temperature duration curves for the dry bulb temperatures and coincident wet bulb temperatures are shown in Figure Al.1.

\section{A1.6.2 Prevailing Wind}

According to Weather Bureau records at the Middletown Airport, located ten miles north of the site on a low plateau just east of the North River, surface winds are predominantly southwesterly 4-10 knots during the warm months of the year, and westerly 6-13 knots during the cool months.

There are no large diurnal variations in wind speed or direction. Observations of wind velocities at altitudes indicate a gradual increase in mean velocity and a gradual veering of the prevailing wind direction from southwest and west near the surface to westerly and northwesterly aloft.

In addition to the above, studies of the area indicate that there is a significant channeling of the winds below the surrounding hills into the northsouth orientation of the North River. It is estimated that winds within the river valley blow approximately parallel to the valley orientation in excess of 50 percent of the time.

\section{A1.6.3 Atmospheric Diffusion Properties}

During the warm months of the year, according to analysis of Weather Bureau records, the atmospheric conditions near the surface are 25 percent unstable (Pasquil1 A, B and $\mathrm{C}$ ), 40 percent neutral (Pasquill D), and 35 percent stable (Pasquill E and $F$ ). Average wind speeds are approximately six miles per hour during unstable conditions, ten miles per hour during neutral conditions, and four miles per hour during stable conditions.

During the cool months of the year, atmospheric conditions are 15 percent unstable, 50 percent neutral, and 35 percent stable. Average wind speeds are six miles per hour during unstable conditions, 12 miles per hour during neutral conditions, and four miles per hour during stable conditions.

\section{Al.6.4 Severe Meteorological Phenomena}

A maximum instantaneous wind velocity of $100 \mathrm{mph}$ has been recorded at the site. During the past 50 years, three tropical storms, all of them in the final dissipation stages, have passed within 50 miles of the site. Some heavy precipitation and winds in excess of $40 \mathrm{mph}$ were recorded, but no significant damage other than to crops resulted.

The area near the site experiences an average of 35 thunderstorms a year, with maximum frequency in early summer. High winds near $60 \mathrm{mph}$, heavy precipitation, and hail are recorded about once every four years. The ten year, 24 hour rainfall for the site is defined as 4.9 inches. 
In forty years of record keeping, there have been twenty tornadoes reported within fifty miles of the site. This moderately high frequency of tornado activity indicates a need to design Seismic Category I structures at the site for the possibility of an on-site tornado occurrence. Maximum tornado frequency occurs during the months of May and June.

During the past forty years, there have been ten storms in which freezing rain has caused power transmission line disruptions. Most of these storms have occurred in early December.

\section{Al.6.5 Potential Accident Release Meteorology}

A review of Weather Bureau records taken at the Middletown Municipal Airport over the past ten years indicates that the poorest atmospheric diffusion conditions occur in the autumn. The following conditions were noted:

- Nocturnal inversions occur on four of five nights.

- Stagnating high pressure systems have occurred each year for the past ten years during the fall, causing a persistent subsidence inversion over the entire area. Average duration of these stagnating anticyclones have been five days, with the longest occurrence being nine days.

- The longest wind persistence (duration of time winds blew continuously from one $22-1 / 2^{\circ}$ sector) during the period of record was for 96 hours from the south, along the river valley. During this time, stabilities were 20 percent unstable (Pasquill $B$ and $C$ ), 30 percent neutral (Pasquil1 $D$ ), and 50 percent stable (Pasquill E and F). This occurred during a stagnation period, so that there was also a persistent subsidence inversion aloft at an average height of 3,000 feet.

From these data, 30 day accident meteorological regimes are assumed to be as given in Tables $\mathrm{Al}-1$ and $\mathrm{Al}-2$ for a ground level release and an elevated release.

\section{Al.7 HYDROLOGY}

The North River provides an adequate source of raw make-up water for the station. The average maximum temperature is $75^{\circ} \mathrm{F}$, and the average minimum is $39^{\circ} \mathrm{F}$. The mean annual temperature is $57^{\circ} \mathrm{F}$.

U.S. Army Corps of Engineers' studies indicate that the 100 year maximum flood level rose to eight feet above the mean river level. There are no dams near the site whose failure could cause the river to rise above the eight foot level. 


\section{Al.8 GEOLOGY AND SEISMOLOGY}

\section{Al.8.1 Soil Profiles and Load Bearing Characteristics}

Soil profiles for the site show alluvial soil and rock fill to a depth of eight feet; Brassfield limestone to a depth of 30 feet; blue weathered shale and fossiliferous Richmond limestone to a depth of $50 \mathrm{feet}$; and bedrock over a depth of 50 feet. Allowable soil bearing is 6,000 psf and rock bearing characteristics are 18,000 psf and 15,000 psf for Brassfield and Richmond strata, respectively. No underground cavities exist in the limestone.

\section{A1.8.2 Seismology}

The site is located in a generally seismically inactive region. Historical records show three earthquakes have occurred in the region between 1870 and 1984. A safe shut-down earthquake (SSE) with a horizontal ground acceleration of $0.25 \mathrm{~g}$ provides conservative design margin. For design purposes, the horizontal and vertical component Design Response Spectra given in NRC Regulatory Guide 1.60, are linearly scaled to a horizontal ground acceleration of $0.25 \mathrm{~g}$.

\section{A1.9 SEWAGE AND RADIOACTIVE WASTE DISPOSAL}

\section{Al.9.1 Sewage}

Sewage generated on-site must receive primary and secondary treatment prior to discharge into the North River. Non-radioactive wastewater must be discharged in compliance with EPA effluent standards as promulgated in 40 CFR423.

\section{A1.9.2 Gaseous and Liquid Radioactive Wastes}

Gaseous and liquid effluent releases at the site must comply with 10CFR20 and the intent of Appendix I of 10CFR50.

\section{Al.9.3 Solid Radioactive Wastes}

On-site storage of solid radioactive wastes to permit radioactive decay is permissible, but ultimate disposal on site is not planned. 
$\underline{\text { TABLE A1 }-1}$

ACCIDENT METEOROLOGY FOR A GROUND LEVEL RELEASE

\begin{tabular}{|c|c|c|c|c|c|}
\hline $\begin{array}{c}\text { Time } \\
\text { Period } \\
\end{array}$ & $\begin{array}{l}\text { Pasquill } \\
\text { Stability } \\
\text { Category } \\
\end{array}$ & $\begin{array}{l}\text { Stability } \\
\text { Frequency }\end{array}$ & $\begin{array}{l}\text { Direction } \\
\text { Frequency } \\
\end{array}$ & $\begin{array}{l}\text { Wind } \\
\text { Speed } \\
\text { (m/sec) } \\
\end{array}$ & $\begin{array}{l}\text { Wind Direction } \\
\text { Type(1) } \\
\end{array}$ \\
\hline $0-2$ hrs & F & 1.0 & 1.0 & 1.0 & Invariant \\
\hline $2-24 \mathrm{hrs}$ & $F$ & 1.0 & 1.0 & 2.0 & Invariant \\
\hline \multirow[t]{3}{*}{ days } & B & 0.2 & 1.0 & 2.0 & Variant \\
\hline & D & 0.3 & 1.0 & 4.0 & Variant \\
\hline & $\mathrm{F}$ & 0.5 & 1.0 & 2.0 & Variant \\
\hline \multirow[t]{3}{*}{ 5-30 days } & B & 0.15 & 0.5 & 3.0 & Variant \\
\hline & D & 0.50 & 0.5 & 5.0 & Variant \\
\hline & $\mathrm{F}$ & 0.35 & 0.5 & 2.0 & Variant \\
\hline
\end{tabular}

(1) Lateral dispersion restricted to 1200 meters from center 1 ine for all time periods. 
$\underline{\text { TABLE Al-2 }}$

ACCIDENT METEOROLOGY FOR AN ELEVATED RELEASE

\begin{tabular}{cccccc}
$\begin{array}{c}\text { Time } \\
\text { Period }\end{array}$ & $\begin{array}{c}\text { Pasquil1 } \\
\text { Stability } \\
\text { Category }\end{array}$ & $\begin{array}{c}\text { Stability } \\
\text { Frequency }\end{array}$ & $\begin{array}{c}\text { Direction } \\
\text { Frequency }\end{array}$ & $\begin{array}{c}\text { Wind } \\
\text { Speed } \\
\text { (m/sec) }\end{array}$ & $\begin{array}{c}\text { Wind Direction } \\
\text { Type(1) }\end{array}$ \\
\cline { 3 - 3 } & B(2) & 1.0 & 1.0 & 1 & Invariant \\
$2-24$ hrs & B & 1.0 & 1.0 & 2 & Invariant \\
$1-5$ days & B & 0.33 & 0.75 & 3 & Variant \\
& D & 0.33 & 0.75 & 5 & Variant \\
$5-30$ days & F & 0.33 & 0.75 & 2 & Variant \\
& B & 0.15 & 0.5 & 4 & Variant \\
& D & 0.15 & 0.5 & 6 & Variant \\
& F & 0.35 & 0.5 & 3 & Variant
\end{tabular}

(1) Lateral dispersion restricted to 1200 meters from center 1 ine for all time periods.

(2) Inversion cap at release height. 
FIGURE A1.1

TEMPERATURE DURATION CURVES; MIDDLETOWN, U.S.A.

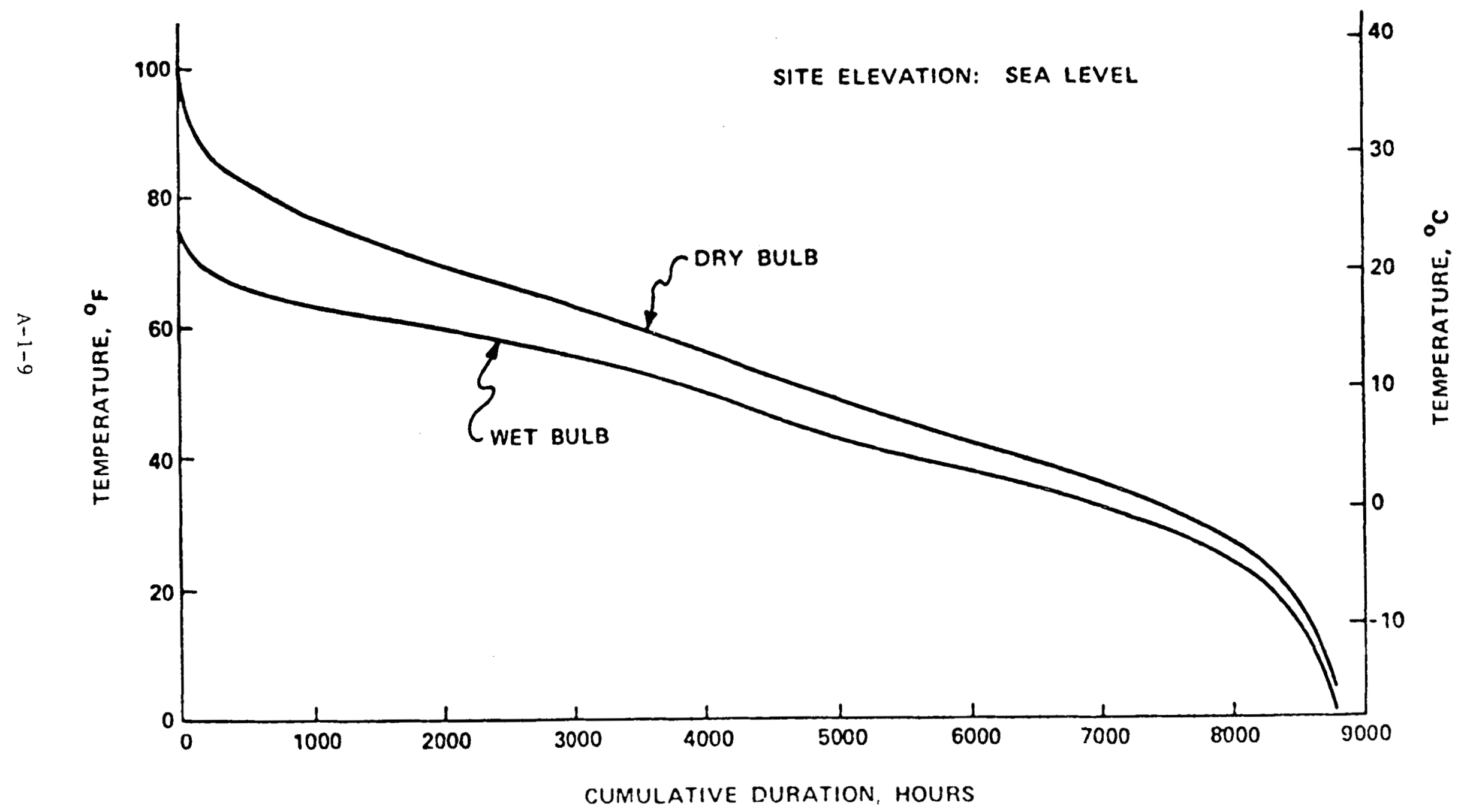



this Appendix is current through January 1, 1986. 


\author{
APPENDIX A-2 \\ ENERGY ECONOMIC DATA BASE (EEDB) PROGRAM \\ DESCRIPTION OF A STANDARD HYPOTHETICAL MIDDLETOWN SITE \\ FOR COAL-FIRED POWER PLANTS
}

\title{
A2.1 GENERAL
}

This site description provides the site and environmental data as derived from Appendix A of "Guide for Economic Evaluation of Nuclear Reactor Plant Designs," USAEC Report NUS-531, and modified to reflect current coal-fired power plant siting requirements. These data form the site-related bases of the criteria used to develop the conceptual designs of the coal-fired power plant technical data models for the EEDB Program, including evaluation of the release of effluent liquids and gases to the environment. The site is representative of locales found in the northeastern United States.

\section{A2.2 TOPOGRAPHY AND GENERAL SITE CHARACTERISTICS}

The site is located on the east bank of the North River at a distance of twenty-five miles south of Middletown, the nearest large city. The North River flows from north to south and is approximately one-half mile (2600 $\mathrm{ft}$ ) wide adjacent to the plant site. A flood plain extends from both river banks an average distance of one-half mile, ending with hilltops generally 150 to 250 feet above the river level. Beyond this area, the topography is gently rolling, with no major critical topographical features. The plant site itself extends from river level to elevations of 50 feet above river level. The primary structures and the switchyard are located on level ground at an elevation of 18 feet above the mean river level. This elevation is ten feet above the 100-year maximum river level, according to U.S. Army Corps of Engineers' studies of the area.

In order to optimize land area requirements for the coal-fired power plant site, maximum use of the river location is employed. The boiler house is located 1400 feet from the east bank of the river. The site land area is approximately 500 acres. An additional 2,000 acres, approximately six miles from the plant site, are available for solid waste disposal.

\section{A2.3 SITE ACCESS}

Highway access is provided to the hypothetical site by five miles of secondary road connecting to a state highway. This road is in good condition and needs no additional improvements. Railroad access is provided by constructing a railroad spur which intersects the B\&M Railroad. The length of the required spur from the main line to the plant site is assumed to be five miles in length. The North River is navigable throughout the year with a 40 feet wide by 12 feet deep channel. The distance from the shoreline to the center of the ship channel is 2,000 feet. All plant shipments are assumed to be made overland except that heavy equipment (such as the generator stator) may be transported by barge. The Middletown Municipal Airport is located three miles west of the State highway, 15 miles south of Middletown, and ten miles north of the site. 


\section{A2.4 POPULATION DENSITY AND LAND USE}

The hypothetical site is near a large city (Middletown) of 250,000 population, but in an area of low population density. Variation in population with distance from the site boundary is:

\begin{tabular}{rr} 
Miles & $\begin{array}{r}\text { Cumulative } \\
\text { Population }\end{array}$ \\
\hline 0.5 & 0 \\
1.0 & 310 \\
2.0 & 1,370 \\
5.0 & 5,020 \\
10.0 & 28,600 \\
20.0 & 133,000 \\
30.0 & $1,010,000$
\end{tabular}

There are five industrial manufacturing plants within 15 miles of the hypothetical site. Four are small plants, employing less than 100 people each. The fifth, near the airport, employs 2,500 people. Closely populated areas are found only in the centers of the small towns, so that the land area used for housing is small. The remaining land, including that across the river, is used as forest or cultivated crop land, except for railroads and highways.

\section{A2.5 NEARBY FACILITIES}

Utilities are available as follows:

- Natural gas service is available two miles from the site, boundary on the same side of the river.

- Communication 1 ines are furnished to the project boundaries at no cost.

- Power and water for construction activities are available at the southwest corner of the site boundary.

- Two connections to the utility grid (one at $500 \mathrm{kV}$ or 230 $\mathrm{kV}$ for the generator connection and one at $230 \mathrm{kV}$ or $115 \mathrm{kV}$ for the reserve auxiliary transformer connection) are available at the switchyard.

\section{A2.6 METEOROLOGY AND CLIMATOLOGY.}

\section{A2.6.1 Ambient Temperatures}

The winters in the Middletown area are moderately cold, with average temperatures in the low $30 \mathrm{~s}$. The summers are fairly humid with average temperatures in the low $70 \mathrm{~s}$, and with high temperatures averaging around $82^{\circ} \mathrm{F}$. The historic maximum wet bulb and dry bulb temperatures are $78^{\circ} \mathrm{F}$ and $99^{\circ} \mathrm{F}$ respectively. 
The year-round temperature duration curves for the dry bulb temperatures and coincident wet bulb temperatures are shown in Figure A2.1.

\section{A2.6.2 Prevailing Wind}

According to Weather Bureau records at the Middletown Airport, located ten miles north of the site on a low plateau just east of the North River, surface winds are predominantly southwesterly. 4-10 knots during the warm months of the year, and westerly 6-13 knots during the cool months.

There are no large diurnal variations in wind speed or direction. Observations of wind velocities at altitudes indicate a gradual increase in mean velocity and a gradual veering of the prevailing wind direction from southwest and west near the surface to westerly and northwesterly aloft.

In addition to the above, studies of the area indicate that there is a significant channeling of the winds below the surrounding hills into the northsouth orientation of the North River. It is estimated that these winds within the river valley blow approximately parallel to the valley orientation in excess of 50 percent of the time.

\section{A2.6.3 Atmospheric Diffusion Properties}

The transport and dilution of materials in the form of aerosols or gases released into the atmosphere from the Middletown coal-fired power station are a function of the state of the atmosphere along the plume path, the topography of the region, and the characteristics of the pollutants themselves. For stack emissions, the concentration of materials at ground-level in the surrounding region depends on the amount of pollutant emitted, height of the emission, windspeed, atmospheric stability, airflow patterns of the site, and various pollutant removal mechanisms. Topographic features such as hills and valleys influence diffusion and airflow patterns.

Due to the lack of complicated or severe terrain conditions and the northeastern U.S. location of the site, atmospheric diffusion properties for pollutant emissions from relatively tall stacks are estimated to be average to better than average.

\section{A2.6.4 Severe Meteorological Phenomena}

A maximum instantaneous wind velocity of $100 \mathrm{mph}$ has been recorded at the site. During the past 50 years, three tropical storms, all of them in the final dissipation stages, have passed within 50 miles of the site. Some heavy precipitation and winds in excess of $40 \mathrm{mph}$ were recorded, but no significant damage other than to crops resulted.

The area near the site experiences an average of 35 thunderstorms a year, with maximum frequency in early summer. High winds near $60 \mathrm{mph}$, heavy precipitation, and hail are recorded about once every four years. The ten year, 24 hour rainfall for the site is defined as 4.9 inches. 
In forty years of record keeping, there have been twenty tornadoes reported within fifty miles of the site. Maximum tornado frequency occurs during the months of May and June.

During the past forty years, there have been ten storms in which freezing rain has caused power transmission line disruptions. Most of these storms have occurred in early December.

\section{A2 6.5 Ambient Air Quality Concentrations}

Background concentrations of all criteria pollutants ( $\mathrm{SO}_{2}, \mathrm{NO}_{\mathrm{x}}, \mathrm{CO}, \mathrm{Pb}$, oxidants and particulates) are typical of a rural area approximately 30 miles from a major industrial metropolitan center. They are considered when determining the plant's adherence to the National Ambient Air Quality Standards. The site is located in a Class II area for Prevention of Significant Deterioration. The entire Class II increments for $\mathrm{SO}_{2}$ and particulates are assumed to be available.

\section{A2.6.6 Air Quality Estimation}

Ambient pollutant levels are estimated through the application of atmospheric diffusion models. Of the various diffusion models that have been developed, the Gaussian diffusion model is appropriate to calculate the atmospheric diffusion of stack emissions from the Middletown coal-fired station because of the relatively flat and uncomplicated topography as well as the tall stack.

This model assumes that the airflow transports and diffuses pollutants along a straight line through the entire region of interest in the airflow direction at the stack. The windspeed and atmospheric stability at the meteorological measurement location are assumed to determine the atmospheric diffusion characteristics in the entire region of interest. The EPA benchmark model for rural, single-source applications, "CRSTER" is the particular Gaussian model used to estimate the effect of plant emissions on regional air quality.*

\section{A2.7 HYDROLOGY}

The North River provides an adequate source of raw make-up water for the station. The average maximum temperature is $75^{\circ} \mathrm{F}$, and the average minimum is $39^{\circ} \mathrm{F}$. The mean annual temperature is $57^{\circ} \mathrm{F}$.

U.S. Army Corps of Engineers' studies indicate that the 100 year maximum flood level rose to eight feet above the mean river level. There are no dams near the site whose failure could cause the river to rise above the eight foot level.

* "User's Manual for Single-Source (CRSTER) Model",

U.S. Environmental Protection Agency

Office of Air Quality Planning and Standards, Research Triangle Park, NC July 1977 , EPA-450/2-77-013 


\section{A2.8.1 Soil Profiles and Load Bearing Characteristics}

Soil profiles for the site show alluvial soil and rock fill to a depth of eight feet; Brassfield limestone to a depth of $30 \mathrm{feet}$; blue weathered shale and fossiliferous Richmond limestone to a depth of $50 \mathrm{feet}$; and bedrock over a depth of 50 feet. Allowable soil bearing is 6,000 psf and rock bearing characteristics are 18,000 psf and 15,000 psf for Brassfield and Richmond strata, respectively. No underground cavities exist in the limestone.

\section{A2.8.2 Seismology}

The site is located in a generally seismically inactive region. Historical records show three earthquakes have occurred in the region between 1870 and 1984 .

\section{A2.9 SEWAGE AND LIQUID EFFLUENTS}

Sewage generated on-site must receive primary and secondary treatment prior to discharge into the North River. Other wastewater must be discharged in compliance with EPA effluent standards as promulgated in 40CFR423. 


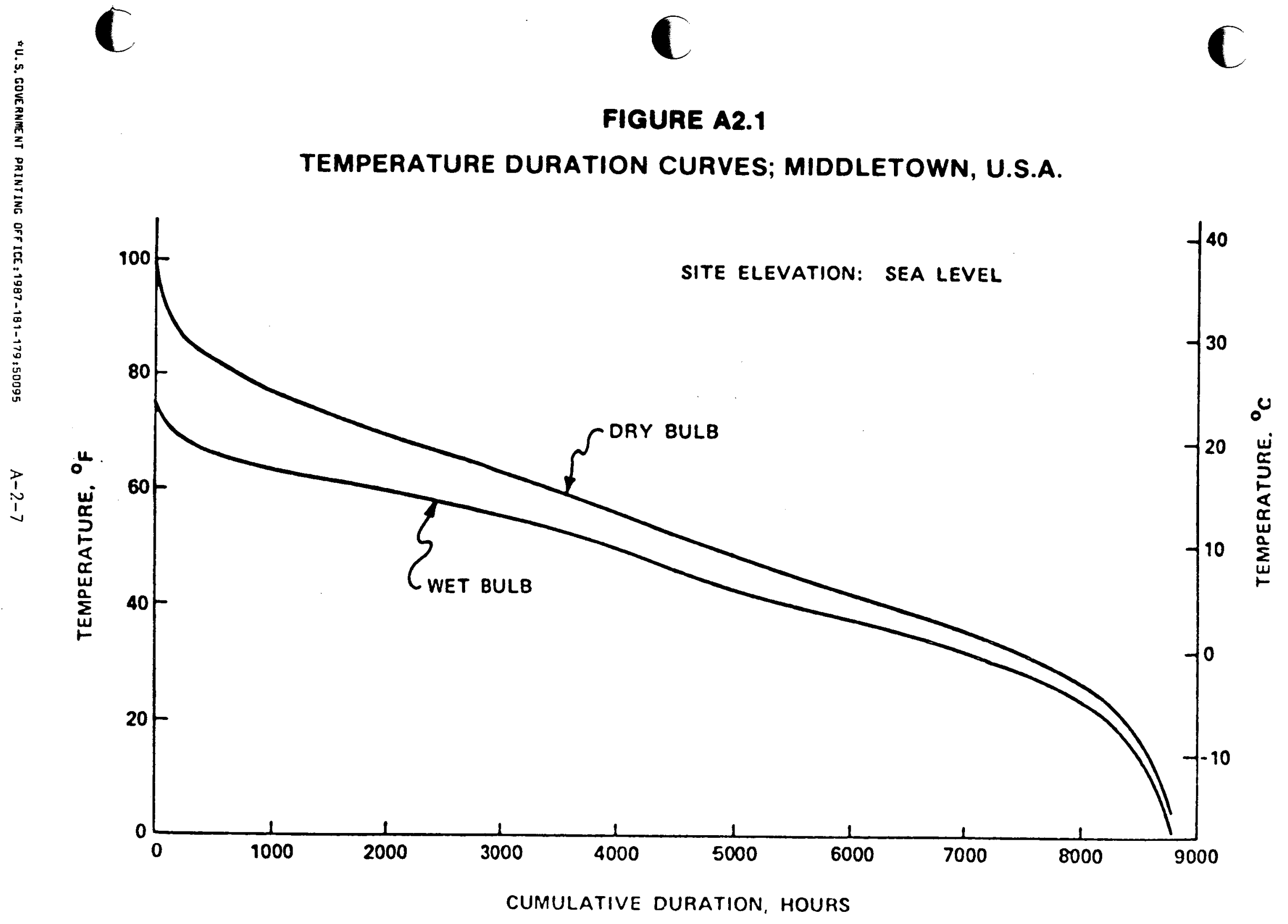

